\title{
Naturalis
}

Sistemática, filogenia e historia evolutiva de roedores Octodontoidea (Caviomorpha, Hystricognathi) del Oligoceno tardío - Mioceno Medio, vinculados al origen de la Familia Octodontidae

\section{Arnal, Michelle}

Doctor en Ciencias Naturales

Dirección: Kramarz, Alejandro Gustavo Co-dirección: Vucetich, María Guiomar

Facultad de Ciencias Naturales y Museo 2012

Acceso en:

http://naturalis.fenym.unlp.edu.ar/id/20120426001230

\section{(c) (i) () ()}


Facultad de Ciencias Naturales y Museo

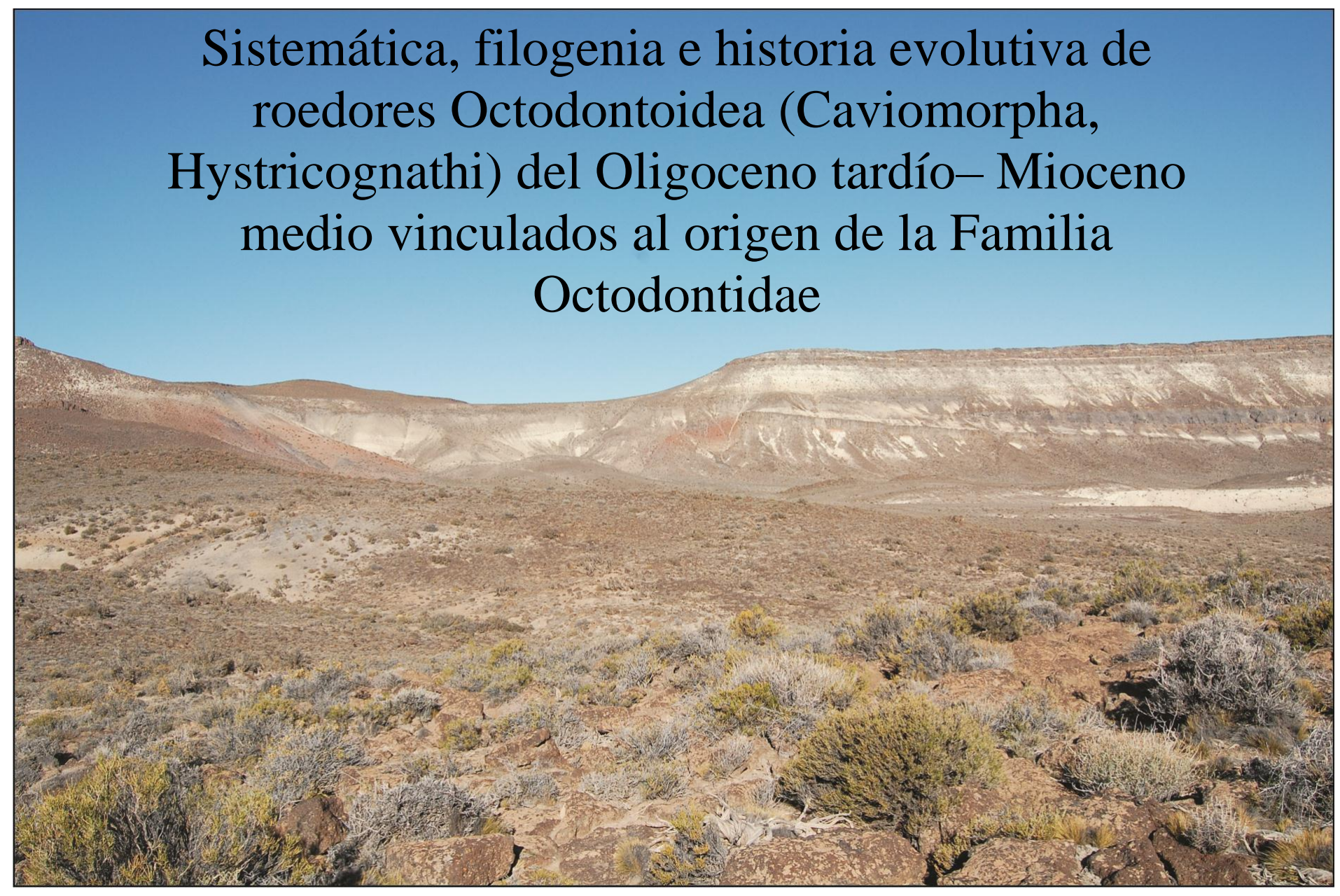

Scarrit Pocket

Tesis Doctoral - 2011

Michelle Arnal

Director: Dr. Alejandro Gustavo Kramarz

Codirectora: Dra. María Guiomar Vucetich 
A mis padres y a Andrés, por todo... 


\section{AGRADECIMIENTOS}

En primer lugar quiero agradecer de todo corazón a mis directores Alejandro Kramarz y M. Guiomar Vucetich; por muchas cosas: por dirigirme, enseñarme, escucharme y fundamentalmente por confiar en mí y apoyarme en los momentos difíciles. A Ale por la confianza, el apoyo, los consejos y aunque no lo crea por todas las discusiones ¡fueron enormemente productivas! A Guio por abrirme las puertas al mundo de los roedores fósiles, por estar siempre, por los consejos, la paciencia y las charlas inmensamente enriquecedoras. iiiLos admiro, respecto y estoy enormemente agradecida!!!

A Ceci Deschamps por su ayuda desinteresada, las charlas en su laboratorio y porque su sonrisa me ha alegrado más veces de las que se imagina.

Quiero agradecer especialmente a Guille López porque gracias a su constante y desinteresada ayuda hoy soy paleontóloga y docente. ¡Gracias Guille!

A todos los que hicieron posible que aprenda acerca de una de las cosas más lindas que tiene nuestra carrera: las campañas de campo. A Alejandro Kramarz, Analía Forasiepi, Guillermo Aguirrezabala, Alberto Garrido, Guillermo López, Laura Nicoli, Maxi Iberlucea, Pablo Puerta y Leonardo Filippi por la buena onda y por enseñarme a trabajar en el campo. Especialmente a Lau Nicoli, Ale Kramarz y Guille López porque pensaron y confiaron en mí.

A mis amigos del MACN. Especialmente a Lau Cruz, Lau Chorno y Julia por estar siempre, por aguantarme y por ser mis amigas. ¡Las quiero! A Stella Alvarez por su alegría, desde que esta en paleo la sección no es lo mismo. A Maxi Iberlucea, Martín Ezcurra, Ale Kramarz, Tano Fernícola, Ana Baez, Jere Taborda y Fer Chavez por las charlas y almuerzos diarios, compañerismo y por su apoyo. Al colo Martínez, Caro Panti y Bari por su amistad y por enseñarme que hay algo más que vertebrados en el mundo. A Pancho Prevosti y Laura Nicoli por su ayuda y las charlas compartidas.

A Pati Pérez, Alicia Álvarez, Caro Vieytes y Ceci Morgan por las charlas, almuerzos y amistad. A Ali por acompañarme en esto loco e imprevisible que se llama “estado de ánimo durante la tesis” ¡no hubiese podido sola!

A Diego Verzi por guiarme en los primeros pasos de la tesis, enseñándome y explicándome acerca de los roedores octodontoideos.

A todos los que con todo tipo de discusiones aportaron a mi formación: Tano Fernicola, Julia Desojo, Laura Cruz, Laura Chornogubsky, Martín Ezcurra, Mariano 
Bond, Ana Baez, Pancho Prevosti, Laura Nicoli, Pati Pérez, Caro Vieytes, Itatí Olivares, Diego Verzi, Javier Gelfo, Analía Forasiepi, Agus Lecuona, Mariano Donato, Ignacio Escapa, Jimena Trotteyn y Ceci Apaldetti.

A la gente de Matozoología del MLP; a Diego Verzi, Cecilia Morgan, Carolina Vieytes, Alicia Alvarez, Itatí Olivares, Belén y Mariano Merino por recibirme siempre de manera cordial.

Muchas gracias a todos los encargados de las colecciones visitadas: a Marcelo Reguero (Museo de La Plata), Eduardo Ruigómez (Museo Paleontológico Egidio Feruglio, Trelew), Jin Meng (American Museum of Natural History, USA), Chris Norris (Yale Peabody Museum, USA), Kate Wellspring (Amherst College Museum) y David Flores (MACN mastozoología) por la buena predisposición y principalmente por la paciencia.

Una mención especial a todos los que hicieron que mi visita a USA fuese perfecta: en primer lugar a Pati por las interminables charlas, cervezas compartidas, confidencialidad, alegría y por el increíble viaje que hicimos juntas...que se repita amiga!! A Anne Walton (Amherst), Dan Brinkman (Yale Peabody Museum, USA), Judy Galkyn (American Museum of Natural History, USA), Bruce Shockey (American Museum of Natural History, USA) y Marcelo Weksler (American Museum of Natural History, USA) por la ayuda, paciencia y por hacernos la estadía en USA inolvidable. A Andrés Gialombardo y la divina de su esposa Jime (para mi "anita") por recibirnos tan bien. Un agradecimiento enorme a Anne Walton y su familia, en especial a su suegro, una persona sorprendente.

El mayor de los reconocimientos para mi familia, ya que constantemente me alentaron a seguir en este camino. Sepan que lo que escriba va a ser poco. A mi papá y a mi mamá quienes me inculcaron los valores con los que me guío en la vida y de los cuales estoy completamente orgullosa. A mis hermanos Pablo, Mari y mi mitad Tati que me ayudan, apoyan y acompañan. A Andrés, la persona más especial en mi vida, por su amor, compañerismo, incondicionalidad y sobre todo paciencia. A mis sobrinos Mica, Magui, Juan Andrés, Clarita y Agustín, quienes siempre me sacan una sonrisa.

A Lai, porque su partida me enseñó mucho. Fuiste y vas a ser siempre un ejemplo para mí...

Esta tesis fue financiada a través de los proyectos CONICET PIP 5242, ANPCyT PICT- 2007- 01744, ANPCyT PICT- 2007- 01744, UNLP 11/N442 y UNLP 11/N568 de mi codirectora y el Dr. Diego Verzi. 


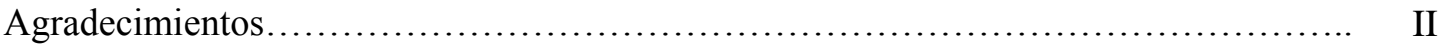

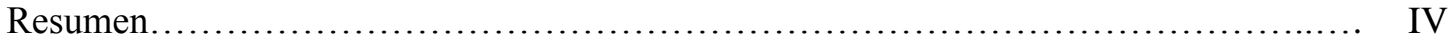

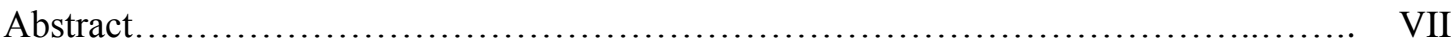

Capítulo 1: Introducción..................................................... 1

1.1 Objetivo general............................................................... 5

1.2 Objetivos particulares............................................................ 6

1.3 Hipótesis................................................................. 6

Capítulo 2: Materiales y Métodos............................................ 7

2.1 Abreviaturas institucionales................................................. 7

Abreviaturas geológicas.................................................. 7

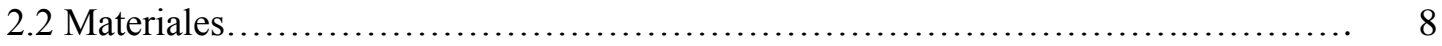

2.3 Nomenclatura utilizada y medidas tomadas................................. 8

2.3.1 Propuesta nomenclatural para las estructuras craneanas y mandibulares............ 8

2.3.2 Propuesta nomenclatural para las estructuras dentarias.......................... 9

2.3.3 Homología de las estructuras oclusales de los molariformes superiores............ 10

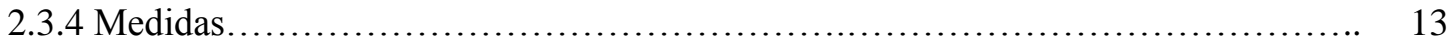

2.4 Análisis Filogenético.......................................................... 17

Capítulo 3: Contexto Geocronológico........................................... 18

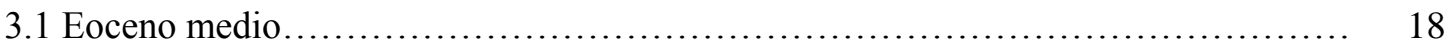

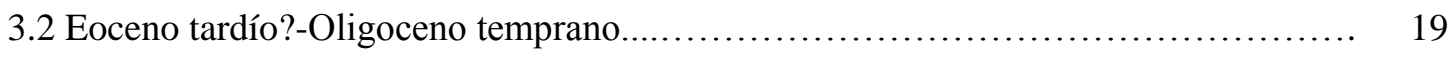

3.2.1 Santa Rosa................................................................ 19

3.3 Oligoceno temprano................................................... 19

3.3.1 La Cantera.................................................................. 19

3.4 Oligoceno tardío.......................................................... 21

3.4.1 “Edad Mamífero" Deseadense.............................................. 21

3.5 Mioceno temprano...................................................... 22

3.5.1 "Edad Mamífero" Colhuehuapense......................................... 22

3.5.2 "Edad Pinturense" ..................................................... 25

3.5.3 "Edad Mamífero" Santacrucense sensu stricto............................... 27

3.6 Mioceno medio.......................................................... 31

3.6.1 Faunas "Colloncurense" sensu stricto...................................... 31

3.6.2 "Edad Mamífero" Laventense................................................... 32

Capítulo 4: Revisión Sistemática............................................ 34

4.1 Cronología del conocimiento y taxonomía de los Octodontoidea del Oligoceno tardío- Mioceno medio....................................................... 34

4.2 Revisión sistemática..................................................... 39 
4.2 .1 Acarechimys minutus.................................................. 40

4.2.2 Acarechimys constans ....................................................................................... 48

4.2 .3 Acarechimys minutissimus............................................. 53

4.2 .4 Acarechimys pulchellus................................................ 59

4.2.5 Acaremys murinus....................................................... 64

4.2.6 Acaremys major .............................................................. 74

4.2.7 “Acaremys" sp. nov ...................................................... 77

4.2 .8 “Acaremys" tricarinatus............................................... 82

4.2.9 Caviocricetus lucasi....................................................... 86

4.2.10 Galileomys antelucanus.............................................. 92

4.2.11 Galileomys? colloncurensis............................................ 96

4.2 .12 Galileomys eurygnathus.............................................. 98

4.2.13 Migraveramus beautus y Migraveramus cf. M. beatus................................... 102

4.2.14 Platypittamys brachyodon .................................................. 107

4.2.15 Plesiacarechimys koenigswaldi ............................................. 114

4.2.16 Prospaniomys priscus .................................................... 118

4.2.17 Protacaremys prior.................................................... 130

4.2.18 Protacaremys avunculus .................................................. 137

4.2 .19 Protacaremys denisae .................................................... 140

4.2.20 "Protacaremys" sp. nov ............................................. 142

4.2 .21 Sciamys principalis ................................................... 145

4.2.22 Sciamys latidens ......................................................... 156

Capítulo 5: Análisis Filogenético.................................................. 160

5.1 Antecedentes........................................................... 160

5.2 Análisis filogenético........................................................ 166

5.2.1 Taxones incluidos en el análisis............................................. 167

5.2.2 Descripción de los caracteres incluidos en el análisis............................ 168

5.2 .3 Tratamiento de caracteres.............................................. 187

5.2.3.1 Ordenamiento de caracteres.......................................... 187

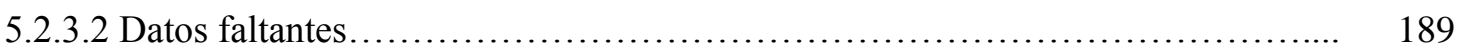

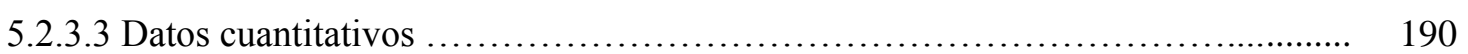

5.2.4 Análisis cladístico........................................................... 190

5.2.5 Soporte de ramas ........................................................ 197

5.2.5.1 Soporte de Bremer.................................................. 197

5.2.5.2 Boostrap standart..................................................... 198

5.2.5.3 Remuestreo simétrico.............................................. 200 
5.2.6 Clasificación.

5.2.7 Evolución de los caracteres tradicionalmente utilizados para diferenciar

Octodontidae y Echimyidae....

Capítulo 6: Diversificación temprana de Octodontoidea.

6.1 Origen y Diversificación de Octodontoidea basales................................. 211

6.2 La evolución dentaria de Acaremyidae ........................................... 216

6.3 La evolución dentaria de los Acarechimyidae..................................... 218

6.4 La evolución dentaria de "Adelphominae"....................................... 219

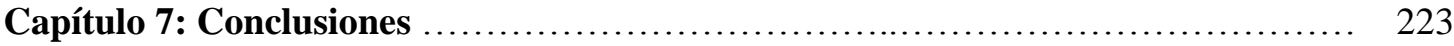

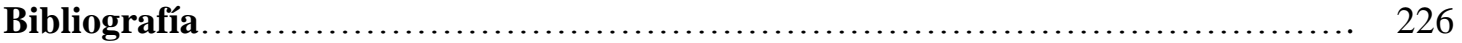

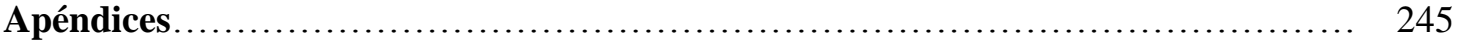

Apéndice 1- Listado de octodontoideos fósilesvinculados al origen de los

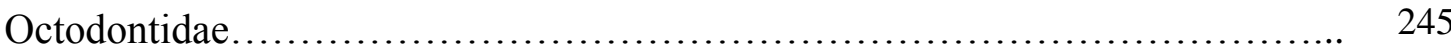

Apéndice 2- Listado de roedores fósiles incluidos en el análisis cladístico .............. 278

Apéndice 3- Listado de roedores vivientes incluidos en este trabajo.............. 281

Apéndice 4- Matriz de caracteres.................................................. 282

Apéndice 5- Sinapomorfías de los nodos del consenso............................... 286

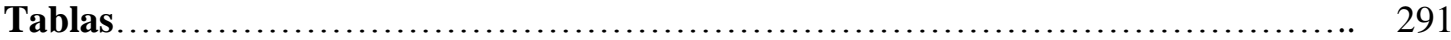

Tabla 5.1- Índices de hipsodoncia........................................... 291

Tabla 5.2- Tamaño relativo de las hileras dentarias en relación a la porción anterior del cráneo.

Tabla 5.3- Incisivos superiores..................................................... 294

Tabla 5.4- Incisivos inferiores.................................................... 295

Tabla 5.5- Relación largo/ancho del rostro........................................... 296

Tabla 5.6- Largo del diastema mandibular...................................... 297 


\section{RESUMEN}

Dentro de Caviomorpha se incluyen a los roedores histricognatos e histricomorfos endémicos de América Neotropical, los cuales se clasifican en cuatro superfamilias: Octodontoidea, Cavioidea, Chinchilloidea y Erethizontoidea. De ellas, los Octodontoidea representan la superfamilia de más alta riqueza específica y diversidad adaptativa y su monofilia está sustentada por la microestructura del esmalte de los incisivos. Las formas vivientes de Octodontoidea se agrupan en las familias Octodontidae, Echimyidae, Abrocomidae y Capromyidae, abarcando las dos primeras la mayor cantidad de especies. Los octodontoideos se encuentran ampliamente representados en el registro fósil desde al menos el Oligoceno temprano. Sin embargo, y a diferencia de lo que ocurre con las formas más modernas, los arreglos sistemáticos y las relaciones filogenéticas de estos roedores no son claras, a pesar de haber sido intensamente estudiadas. Clásicamente se ha postulado que la historia evolutiva temprana de la superfamilia había estado caracterizada por un evento simple de diferenciación muy basal de las familias Echimyidae y Octodontidae. Con el descubrimiento de una mayor cantidad de taxones fósiles se estableció la idea de una evolución temprana mucho más compleja, aunque se mantenía el concepto de una dicotomía Octodontidae-Echimyidae.

En este contexto, el objetivo general de este trabajo es revisar la sistemática y estudiar las relaciones filogenéticas, y evaluar los patrones evolutivos de taxones basales de Octodontoidea potencialmente vinculados a los representantes modernos de la familia Octodontidae.

Para cumplir con este objetivo, se revisó la sistemática de todos aquellos octodontoideos conocidos para el lapso temporal Oligoceno tardío-Mioceno medio que han sido interpretados por distintos autores como relacionados al origen de los Octodontidae modernos. En las revisiones se estudiaron los holotipos de todas las especies, ejemplares previamente estudiados y numerosos materiales inéditos. Como resultados se reconocieron como válidas las siguientes especies: Acarechimys minutus, A. minutissimus, A. constans, A. pulchellus, Acaremys murinus, A. major, "A". tricarinatus, Caviocricetus lucasi, Galileomys antelucanus, G.? colloncurensis, G. eurygnathus, Migraveramus beatus, Platypittamys brachyodon, Plesiacarechimys koenigswaldi, Prospaniomys priscus, Protacaremys prior, P. avunculus, P. denisae, 
Sciamys principalis y $S$. latidens) y 2 nuevas especies (“Acaremys" sp. nov. y "Protacaremys" sp. nov.). Las especies Sciamys varians, S. rostratus, S. robustus y Acaremys messor se reconocieron como sinónimos de Sciamys principalis; la especie Acaremys karaikensis se reconoció como sinónimo de Acaremys murinus; las especies Eoctodon crassiusculus y Protacaremys amplus se reconocieron como sinónimos de Prospaniomys priscus y por último las especies Acaremys preminutus, Archaeocardia mustersiana, Eoctodon securiclatus y Palaeocardia mater se reconocieron como sinónimos de Protacaremys prior.

Se realizó un análisis cladístico con el fin de poner a prueba hipótesis previas de las relaciones filogenéticas de estos taxones con los modernos Octodontidae. Para ello, en el análisis se incluyeron 39 especies, 26 corresponden a octodontoideos del Oligoceno tardío-Mioceno medio, 3 son octodóntidos del Mioceno tardío-Plioceno y 5 taxones vivientes. Como outgroup se incluyeron dos especies de "Phiomorpha" fósiles (considerados previamente como el grupo hermano o como stem group de Caviomorpha), y tres especies de Erethizontoidea (considerados como el grupo hermano del resto de los caviomorfos). Se analizaron 55 caracteres dentarios, 20 mandibulares y 41 caracteres craneanos. Se realizó una búsqueda heurística utilizando el algoritmo TBR con 1000 replicaciones y salvando 10 árboles por replicación. Se encontraron 360 árboles más parsimoniosos de 484 pasos cada uno. El cladograma consenso de estos árboles más parsimoniosos mostró que los octodontoideos del Oligoceno tardíoMioceno medio tradicionalmente vinculados a los modernos Octodontidae (Platypittamys, Migraveramus, Acaremys, Sciamys, Acarechimys) no tienen relación directa con los representantes actuales de la familia Octodontidae. Por el contrario, los resultados sugieren que estos taxones conforman, junto con otros octodontoideos del Oligoceno tardío-Mioceno medio, un extenso stem group del clado constituido por los octodóntidos del Mioceno tardío-reciente, los equímidos vivientes incluidos en este análisis y los taxones fósiles tradicionalmente asignados a la familia Echimyidae. Además, se comprobó que Migraveramus beatus y Deseadomys arambourgi representan las líneas evolutivas más tempranamente divergentes dentro de la superfamilia. Por otro lado, se confirmó la monofilia de la familia Acaremyidae, se comprobó la parafilia de "Adelphomyinae" y se reconoció la familia Acarechimyidae fam. nov., grupo hermano de los Acaremyidae.

La filogenia calibrada geocronológicamente, junto con la información cronoestratigráfica, de los taxones fósiles, sugiere una historia evolutiva temprana 
compleja de la superfamilia que dio origen a sucesivos linajes de octodontoideos que no dejaron descendientes modernos. A través de este estudio se detectaron al menos 3 pulsos de diversificación taxonómica. El primero de ellos ocurrió en tiempos preDeseadenses (Oligoceno temprano?), ya que en el Oligoceno tardío están establecidos los principales linajes de Octodontoidea que dominaron durante el Mioceno temprano y medio. El segundo evento de diversificación ocurrió en tiempos pre-Colhuehuapenses, e implicó la diferenciación de Acarechimyidae y los Acaremyidae más derivados. Como consecuencia, en el Colhuehuapense se registran taxones que aparecen como sobrevivientes de linajes diferenciados en tiempos pre-Deseadenses junto con representantes de nuevos linajes diferenciados en épocas pre-Colhuehuapenses. Hacia la "Edad Mamífero" Santacrucense se observa la supervivencia de algunas especies colhuehuapenses junto con la aparición de nuevos taxones que testimonian un recambio de tipos morfológicos dentarios hacia dientes de coronas más altas y superficies oclusales simplificadas, hecho que coincide con la incipiente aridización patagónica inferida para esta época. El tercer evento de diversificación ocurrió en tiempos preChasiquenses, suceso que queda evidenciado ya por la aparición en el Mioceno tardío (Chasiquense-Huayqueriense) de los primeros octodontoideos incuestionablemente asignables a la familia Octodontidae, junto con la desaparición de los restantes linajes de octodontoideos aquí analizados.

Por último, se estudió la evolución de los caracteres dentarios dentro de Acaremyidae, Acarechimyidae, "Adelphomyinae", Octodontidae. Como resultado se observa que una gran cantidad de ellos pueden entenderse evolutivamente como producto de reversiones y paralelismos entre los distintos linajes de octodontoideos, resultando en un patrón en forma de mosaico que ha dificultado históricamente la compresión de las relaciones filogenéticas entre estos roedores. 


\section{ABSTRACT}

The hystricognathous and hystricomorphous rodents endemic to Neotropical America are included within Caviomorpha. They are classified in four superfamilies: Octodontoidea, Cavioidea, Chinchilloidea and Erethizontoidea. Octodontoidea represents the superfamily with the highest specific richness and adaptive diversity, and their monophyly is supported by the incisors enamel microstructure. The living Octodontoidea are grouped into the families Octodontodae, Echimyidae, Abrocomidae and Capromyidae -the first two comprise most of the species. The octodontoids are widely represented in the fossil record since the early Oligocene. However, opposite to what happens with modern forms, the systematic arrangements and phylogenetic relationships of these rodents are not clear, even when they have been thoroughly analyzed. It has been traditionally postulated that the superfamily early evolutionary history had been characterized by a simple basal differentiation event into Echimyidae and Octodontidae. With the discovery of a greater quantity of fossil taxa, the idea of a much more complex early evolution was established, although the concept of an early Octodontidae-Echimyidae dichotomy was maintained.

In this context, the overall aim of this thesis is to revise the systematics, and to study the phylogenetic relationships and the evolutionary patterns of basal Octodontoidea that are potentially related to modern representatives of the family Octodontidae.

In order to achieve this aim, the systematics of all octodontoids known for the late Oligocene-middle Miocene lapse which have been interpreted by different authors as related to the origin of modern Octodontidae was revised. In the analysis, the holotypes of all species, previously studied specimens, and numerous new materials were studied. The results show that there following species are recognized as valid: Acarechimys minutus, A. minutissimus, A. constans, A. pulchellus, Acaremys murinus, A. major, "A". tricarinatus, Caviocricetus lucasi, Galileomys antelucanus, G.? colloncurensis, G. eurygnathus, Migraveramus beatus, Platypittamys brachyodon, Plesiacarechimys koenigswaldi, Prospaniomys priscus, Protacaremys prior, $P$. avunculus, $P$. denisae, Sciamys principalis, S. latidens, and two (2) new species ("Acaremys" sp. nov. and "Protacaremys" sp. nov.). The species Sciamys varians, S. rostratus, S. robustus and Acaremys messor were recognized as junior synonyms of 
Sciamys principalis; Acaremys karaikensis was recognized as junior synonym of Acaremys murinus; Eoctodon crassiusculus and Protacaremys amplus were recognized as junior synonyms of Prospaniomys priscus and finally Acaremys preminutus, Archaeocardia mustersiana, Eoctodon securiclatus and Palaeocardia mater were recognized as junior synonyms of Protacaremys prior. Some of these synonymies are in accordance with previous proposals.

A cladistic analysis was carried out with the aim of testing previous hypothesis of the philogenetic relationships of these taxa with modern Octodontidae. In order to achieve this, 39 species, were included in the analysis: 26 corresponding to late Oligocene-middle Miocene octodontoids, 3 to late Miocene-Pliocene octodontids, and 5 to extant taxa. As outgroups, two species of fossil "Phiomorpha" were included (which were previously considered as the stem group or as the sister group of Caviomorpha), and three species of Erethizontoidea (which are considered as the stem group of the rest of the caviomorphs). 55 dental characters, 20 mandibular and 41 cranial characters were analyzed. A heuristic search was carried out, using TBR algorithm with 1,000 replications and saving 10 trees per replication. 360 most parsimonious trees of 484 steps each were found. The consensus cladogram of the most parsimonious trees shows that the late Oligocene-middle Miocene octodontoids, traditionally related to modern Octodontidae (Platypittamys, Migraveramus, Acaremys, Sciamys, Acarechimys) do not have a direct relation with extant representatives of the family Octodontidae. On the contrary, the results suggest that these taxa form, together with other late Oligocenemiddle Miocene octodontoids, a vast stem group of the clade composed by the late Miocene-Recent octodontids, the living Echimyidae included in this analysis, and the fossil taxa traditionally assigned to the Echimyidae. Also, it was proved that Migraveramus beatus and Deseadomys arambourgi represent earlier divergent evolutionary lines within the superfamily. On the other hand, the monophyly of Acaremyidae was confirmed, the paraphyly of "Adelphomyinae" was proved, and the family Acarechimyidae fam. nov. was recognized, as sister group of Acaremyidae.

Geochronologically calibrated phylogenetics, together with chronostratigraphic information of the fossil taxa, suggests a complex early evolutionary history for the superfamily that gave rise to octodontoids successive linages with no modern descendant. This work show that at least three pulses of diversification were detected. The first one occurred in pre-Deseadan times (early Oligocene?), since in late Oligocene the main Octodontoidea linages are established, which prevailed during early and 
middle Miocene. The second event of diversification occurred in pre-Colhuehuapian times, and implied the Acarechimyidae and the more derived Acaremyidae diversification. As a consequence, in the Colhuehuapian period, taxa which appear as survivors of differentiated linages in pre-Deseadan times are registered, together with representatives of new differentiated linages in pre-Colhuehuapian periods. Towards the Santacrucian "Mammal Age" the survival of some Colhuehuapian species is observed, together with the appearance of new taxa indicating a transformation of dental morphological types into higher crown teeth and simplified oclusal surfaces, a fact that coincides with the incipient Patagonian desertification. The third event of diversification occurred in pre-Chasicoan times, an event that is demonstrated by the appearance of the first undeniable Octodontidae in the late Miocene (Chasicoan-Huayquerian), together with the disappearance of most of the octodontoids linages herein analyzed.

Finally, the evolution of dental characteristics within Acaremyidae, Acarechimyidae, "Adelphomyinae", Octodontidae and Echimyidae were studied. The results show that a great quantity of them could be understood as reversals and parallelisms within octodontoids linages. This fact resulted in a mosaic pattern that classically hindered the relationships of these rodents. 
CAPÍTULO 1

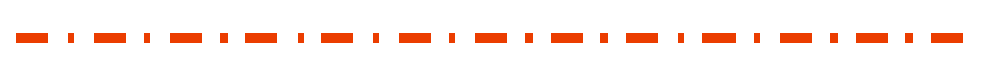

INTRODUCCIÓN 
Caviomorpha incluye a los roedores histricognatos e histricomorfos endémicos de América Neotropical (Wood, 1955). Los mismos se encuentran incluidos dentro del suborden Hystricognathi junto con los "Phiomorpha" del Viejo Mundo (Landry, 1957; Hoffstetter y Lavocat, 1970; Lavocat, 1980; Reig, 1981; Woods y Hermanson, 1985; Martin, 1994; Woods y Kilpatrick, 2005 en Wilson y Reeder). Hay un acuerdo general que propone que caviomorfos y fiomorfos se encuentran estrechamente relacionados a un grupo de roedores "ctenodactiloideos" de Asia (Flynn et al., 1986; Bryant y McKenna, 1995; Marivaux et al., 2001, 2004), conformando los Ctenohystrica (Martin, 1994; Huchon et al., 2000; Marivaux et al., 2004; Antoine et al., 2011).

Las relaciones filogenéticas y sistemáticas entre los caviomorfos no son claras, aunque en líneas generales se reconocen cuatro superfamilias (Simpson, 1945; McKenna y Bell, 1997; Woods y Kilpatrick, 2005 en Wilson y Reeder). Erethizontoidea comprende a los puerco-espines americanos o coendúes; son roedores que habitan gran parte de América desde Canadá, el oeste de los Estados Unidos, Méjico, Centroamérica y la porción tropical de Sudamérica. Anatómicamente se caracterizan por estar adaptados a la vida arbórea y por presentar la totalidad, o parte, de los pelos transformados en espinas (Voss y Angermann, 1997; Emmons, 1997); además, son de hábitos nocturnos y solitarios. La superfamilia Caviodea incluye a los cuises, maras, carpinchos, agutíes y pacas. Se distribuyen a los largo de todo el continente sudamericano. Se caracterizan por ser los caviomorfos más derivados ya que poseen una gran cantidad de caracteres apomórficos exclusivos (Kraglievich, 1930a; Landry, 1957, 1999; Reig, 1981). En este grupo se incluyen formas desde muy pequeñas (200 gr) hasta los gigantescos carpinchos (más de $60 \mathrm{Kg}$ ) y presentan hábitos de vida diversos [epígeos, semi-acuáticos, etc. (Mares y Ojeda, 1982; Woods, 1984)]. Dentro de la superfamilia Chinchilloidea se incluyen las chinchillas y chinchillones de distribución restringida a la cordillera andina y las vizcachas de amplia distribución en el continente sudamericano; habitan ambientes principalmente abiertos. Algunos autores ubican dentro de esta superfamilia a los dinómidos (Huchon y Douzery, 2001; Spotorno et al., 2004; Blanga-Kanfi et al., 2009).

La superfamilia Octodontoidea representa el grupo de roedores caviomorfos de más alta riqueza específica y diversidad adaptativa (Reig, 1989). Su monofilia está sustentada en las características derivadas de la microestructura del esmalte de los incisivos (Martin, 1992). Dentro de esta superfamilia se reconocen tradicionalmente distintas agrupaciones: Echimyidae, Octodontidae, Abrocomidae y Capromyidae (Reig, 
1981; Woods y Kilpatrick, 2005 en Wilson y Reeder), siendo las dos primeras familias las más diversas y numerosas en cuanto a número de especies. Los Echimyidae son conocidos como ratas espinosas y habitan desde las pluviselvas hasta la caatinga, desde Nicaragua hasta Paraguay y el sur de Brasil (Ellerman, 1940) (Fig. 1.1). Las formas modernas de Echimyidae se caracterizan por presentar dientes con raíces, coronas con superficies oclusales planas y flexos/idos que se introducen desde los bordes labiales y linguales de los dientes y determinan morfologías dentarias complejas; además, muestran una tendencia al desarrollo de pelos en forma de espinas (e.g. Echimys, Proechimys, Hoplomys) (Ellerman, 1940). Presentan hábitos de vida variados, ya que están adaptados a la vida arbórea, terrestre o subterránea (Ellerman, 1940; Reig, 1989). Tradicionalmente se consideró que los Echimyidae aparecen en el registro fósil en el Oligoceno tardío (Wood y Patterson, 1959; Patterson y Pascual, 1968; Patterson y Wood, 1982; Vucetich y Ribeiro, 2003). Los representantes fósiles de esta familia fueron muy diversos hasta el Mioceno medio y posteriormente, a partir del deterioro climático del Mioceno tardío, su registro se hace escaso para Patagonia. Como consecuencia de este registro, Pascual (1967) propuso que los Echimyidae se desplazaron al norte del continente en busca de climas más cálidos y húmedos mientras que los Octodontidae se establecieron en el sur de Sudamérica diversificándose en zonas más templadas y áridas. Dentro de Echimyidae se incluye tradicionalmente a la subfamilia Myocastorinae (Nedbal et al., 1994; Honeycutt et al., 2003), o coipos, que se distribuyen en el sur de Sudamérica (Fig. 1.1). Son roedores comparativamente robustos y pesados, con adaptaciones a la vida acuática (Parera, 2002). Presentan dientes protohipsodontes con valles entrantes que se retienen durante la vida del animal. Los Octodontidae (tuco tuco, degos, ratas vizcachas, ratas de las rocas, coruros, etc.) comprenden un grupo de roedores de tamaño pequeño a mediano, endémicos del sur de América del Sur (Reig, 1981; Mares y Ojeda, 1982). Las formas vivientes se caracterizan morfológicamente por tener dientes de crecimiento continuo o euhipsodontes (Mones, 1982) con la superficie oclusal simplificada en forma de 8 o arriñonada y por presentar bulas timpánicas muy desarrolladas (Ellerman, 1940). A nivel subfamiliar se reconocen 2 líneas evolutivas: los Octodontinae y los Ctenomyinae. Los Octodontinae habitan regiones áridas y abiertas desde Perú y Bolivia hasta el sur de Patagonia (Fig. 1.1). Se reconocen en el registro fósil desde el Mioceno tardío (Reig, 1989; Verzi y Carrin Iglesias, 1999; Verzi et al., 1999). En la actualidad representan la subfamilia de octodóntidos más diversa desde un punto de vista eco-morfológico 
(Contreras et al., 1993, 1994), ya que están representadas por formas generalizadas (Octodon y Octodontomys), formas de hábitos semisubterráneos (Aconaemys), subterráneos (Spalacopus) y formas adaptadas a vivir en desiertos (Octomys y Tympanoctomys). En contraposición a esta variabilidad eco-morfológica, los octodóntinos presentan una baja riqueza específica con sólo 6 géneros y 11 especies. Los Ctenomyinae tienen una distribución más amplia, desde los $15^{\circ}$ latitud Sur hasta el sur del continente. Se reconocen en el registro fósil desde el Mioceno tardío con la línea anagenética Chasichimys- Xenodontomys y por el género Palaeoctodon (Reig, 1989; Verzi, 1999, 2002). Son un grupo de roedores especializados, de hábitos exclusivamente subterráneos; en la actualidad se encuentran representados por el politípico género Ctenomys (Reig, 1986; Verzi, 1999). Los Abrocomidae representan un grupo de caviomorfos de relaciones inciertas, aunque, estudios moleculares y morfológicos los ubican dentro de los Octodontoidea siendo más afines a los Octodontidae (Reig, 1981, 1986; Huchon y Douzery, 2001; Galewski et al., 2005). Los representantes del género Abrocoma presentan hábitos de vida terrestres, viviendo en ambientes rocosos (Nowak, 1991), mientras que Cuscomys presenta es de hábitos arborícolas (Emmons, 1999) y son de tamaños medianos (Reig, 1981). En la actualidad los abrocómidos presentan una distribución andina (Glanz y Anderson, 1990; Emmons, 1999). A pesar de ello, desde el Mioceno tardío al Pleistoceno temprano presentaban una distribución más amplia, entre los Andes y la región pampeana (Rovereto, 1914; Montalvo et al., 1996; Candela, 2005). La familia Capromyidae también presenta relaciones inciertas, pero habitualmente se los relaciona con Echimyidae (Reig, 1981; Leite y Patton, 2002; Honeycutt et al., 2003; Galewski et al., 2005). En la actualidad se distribuyen en las Antillas. 


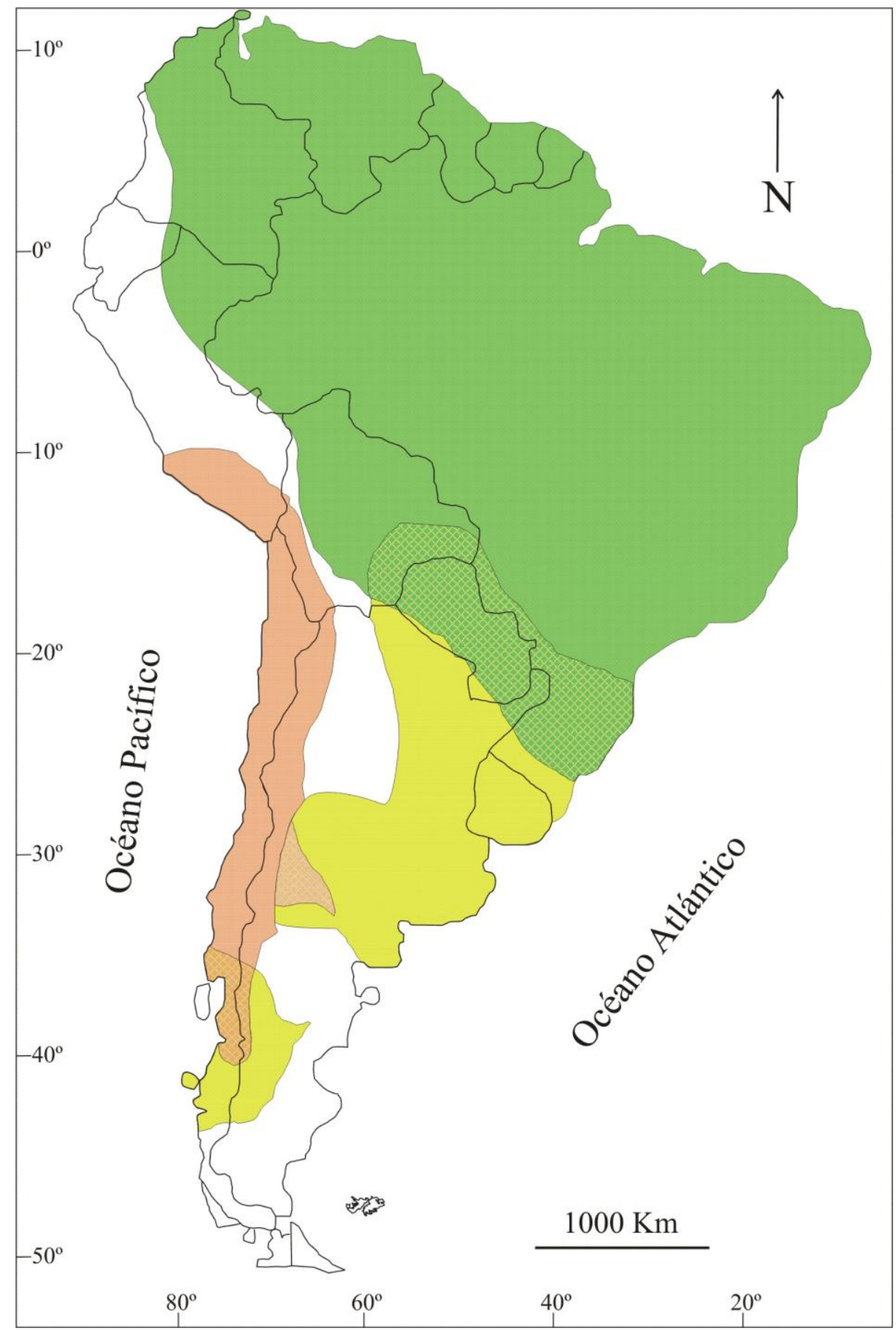

Figura 1.1. Mapa de América del Sur mostrando la distribución actual de Octodontinae (naranja), Echimyinae (verde), Myocastorinae (amarillo). Las áreas donde se superponen distribuciones se muestran en cuadrillé

Existe un aceptable grado de consenso respecto de las propuestas sistemáticas y relaciones filogenéticas de los roedores octodontoideos modernos con los del Mioceno tardío y Plioceno. Sin embargo, los arreglos sistemáticos y relaciones filogenéticas de los roedores octodontoideos más antiguos (i.e. Eoceno tardío? hasta el Mioceno medio) no son claras a pesar de haber sido intensamente exploradas. Existe una gran cantidad 
de propuestas sistemáticas, pero en general no incluyen análisis filogenéticos exhaustivos (Wood y Patterson, 1959; Patterson y Pascual, 1972; Patterson y Wood, 1982; Vucetich y Verzi, 1991; Vucetich et al., 1999; Vucetich y Vieytes, 2006; Vucetich et al. 2010a y b, Antoine et al., 2011).

Wood (1949, 1955), Wood y Patterson (1959) y Patterson y Wood (1982) propusieron que algunos de los octodontoideos más antiguos (e.g. Platypittamys, Migraveramus) constituyen el grupo de roedores caviomorfos ancestral al resto de los caviomorfos, excepto a los Erethizontoidea (Candela, 1999), por presentar características generalizadas del esqueleto y principalmente de los dientes. Sobre la base de morfología dentaria Wood (1949), Wood y Patterson (1959), Patterson y Wood (1982) incluyeron a las especies fósiles de octodontoideos dentro de las familias Octodontidae o Echimyidae. Sin embargo, en la actualidad se considera que los octodontoideos del Oligoceno-Mioceno medio conforman un conjunto heterogéneos de roedores que pueden o no estar relacionados con los modernos Octodontidae y Echimyidae (Vucetich y Kramarz, 2003; Carvalho y Salles, 2004).

En este contexto queda claro que los Octodontoidea, tanto fósiles como vivientes, constituyen un conjunto enormemente diverso y de extrema complejidad. El estudio de sus arreglos sistemáticos exceden las posibilidades de esta tesis doctoral. Por ello, en esta tesis se hará hincapié en indagar la diversidad y las relaciones filogenéticas de aquellos octodontoideos del lapso Oligoceno tardío-Mioceno medio que han sido propuestos como relacionados con el origen de los modernos Octodontidae. También se analizan otros octodontoideos basales dada su relevancia para la comprensión de esta problemática. Las relaciones de los restantes grupos de octodontoideos modernos (i.e. Echimyidae, Abrocomidae y Capromyidae), como así de otros octodontoideos fósiles que no han sido explicitamente propuestos como relacionados a los Octodontidae (e.g. Eosallamys Frailey y Campbell, 2004) serán exploradas en futuras contribuciones.

\subsection{Objetivo General}

El objetivo general de este trabajo es revisar la sistemática, analizar las relaciones filogenéticas y los patrones evolutivos de taxones fósiles de Octodontoidea potencialmente vinculados a los representantes modernos de la familia Octodontidae. 


\subsection{Objetivos Particulares}

1. Revisar la taxonomía y diversidad de los octodontoideos del Oligoceno tardíoMioceno medio que, de acuerdo a evidencias previas (e.g. Wood, 1949; Wood y Patterson, 1959; Verzi, 2002) y observaciones preliminares, estarían vinculados a la moderna familia Octodontidae.

2. Analizar las relaciones filogenéticas entre estos taxones y con los modernos Octodontidae.

3. Sobre la base de los resultados obtenidos en 1 y 2 , aportar al esclarecimiento de patrones evolutivos tempranos de los octodontoideos, así como al origen y antigüedad de la familia Octodontidae.

\subsection{Hipótesis}

1. Los taxones incluidos dentro de la familia Acaremyidae se encuentran estrechamente relacionados al origen de los Octodontidae modernos.

2. Las especies de Acarechimys se encuentran estrechamente relacionados al origen de los Octodontidae modernos.

3. Las especies del género Protacaremys se encuentran estrechamente relacionados al origen de los Octodontidae modernos.

4. Las especies del género Prospaniomys se encuentran estrechamente relacionados al origen de los Octodontidae modernos

5. Los Octodontidae modernos están más cercanamente emparentados con los Echimyidae modernos que con cualquier otro octodontoideo conocido para el lapso Oligoceno tardío- Mioceno medio. 
CAPÍTULO 2

\section{MATERIALES Y MÉTODOS}




\subsection{Abreviaturas}

\section{Institucionales}

Los ejemplares fósiles y actuales estudiados pertenecen a las siguientes colecciones:

-ACM, Amherst College Museum of Natural History, Amherst, USA.

-AMNH, American Museum of Natural History, New York, USA.

-DPC, Duke Primate Center, Duke University, USA.

-MACN A, Museo Argentino de Ciencias Naturales "Bernardino Rivadavia", Buenos Aires, Argentina; Colección Nacional Ameghino.

-MACN PV, Museo Argentino de Ciencias Naturales "Bernardino Rivadavia", Buenos Aires, Argentina; Colección Nacional de Paleovertebrados.

-MACN PV CH, Museo Argentino de Ciencias Naturales "Bernardino Rivadavia", Buenos Aires, Argentina; Colección Nacional de Paleovertebrados, colección Chubut.

-MACN PV SC, Museo Argentino de Ciencias Naturales "Bernardino Rivadavia", Buenos Aires, Argentina; Colección Nacional de Paleovertebrados, colección Santa Cruz.

-MACN Ma, Museo Argentino de Ciencias Naturales "Bernardino Rivadavia", Buenos Aires, Argentina; Colección Nacional de Mastozoología.

-MLP, Museo de La Plata, Buenos Aires, Argentina.

-MMP, Museo Municipal de Ciencias Naturales de Mar del Plata, Buenos Aires, Argentina.

-MNHN, Muséum National d'Historie Naturelle, París, Francia.

-MPEF, Museo Paleontológico Egidio Feruglio, Chubut, Argentina.

-UF, University of Florida, Florida State Museum, Florida, USA.

-YPM, Yale Peabody Museum of Natural History, New Haven, USA.

\section{Geológicas}

- Fm, Formación.

- Ma, millones de años.

-Mb, Miembro.

- SALMA, South American Land Mammal Age. 


\subsection{Materiales}

Se estudiaron 585 ejemplares correspondientes a las especies fósiles de octodontoideos vinculados de algún modo al origen de los Octodontidae (Ver Apéndice 1). Por otra parte, se estudiaron una gran cantidad de ejemplares de otros octodontoideos y caviomorfos fósiles depositados en el MACN, MLP, MMP, MPEF y ACM (Ver Apéndice 2) y ejemplares de fiomorfos fósiles depositados en las colecciones del AMNH y YPM (Ver Apéndice 2) que fueron incluidos en el análisis filogenético.

Los ejemplares de roedores vivientes incluidos en este trabajo pertenecen a la colección de Mastozoología del MACN (Ver Apéndice 3).

\subsection{Nomenclatura utilizada y medidas tomadas}

\subsubsection{Propuesta nomenclatural para las estructuras craneanas y} mandibulares

La terminología de los huesos (Fig. 2.1 y Fig. 2.2) y estructuras craneanas se tomó de Van der Klaauw (1931), Woods (1972), Woods y Howland (1976), Patterson y Wood (1982) y Wible et al. (2005), a no ser que se especifique otro autor. La nomenclatura de la musculatura se tomó de Woods (1972), Woods y Howland (1976).

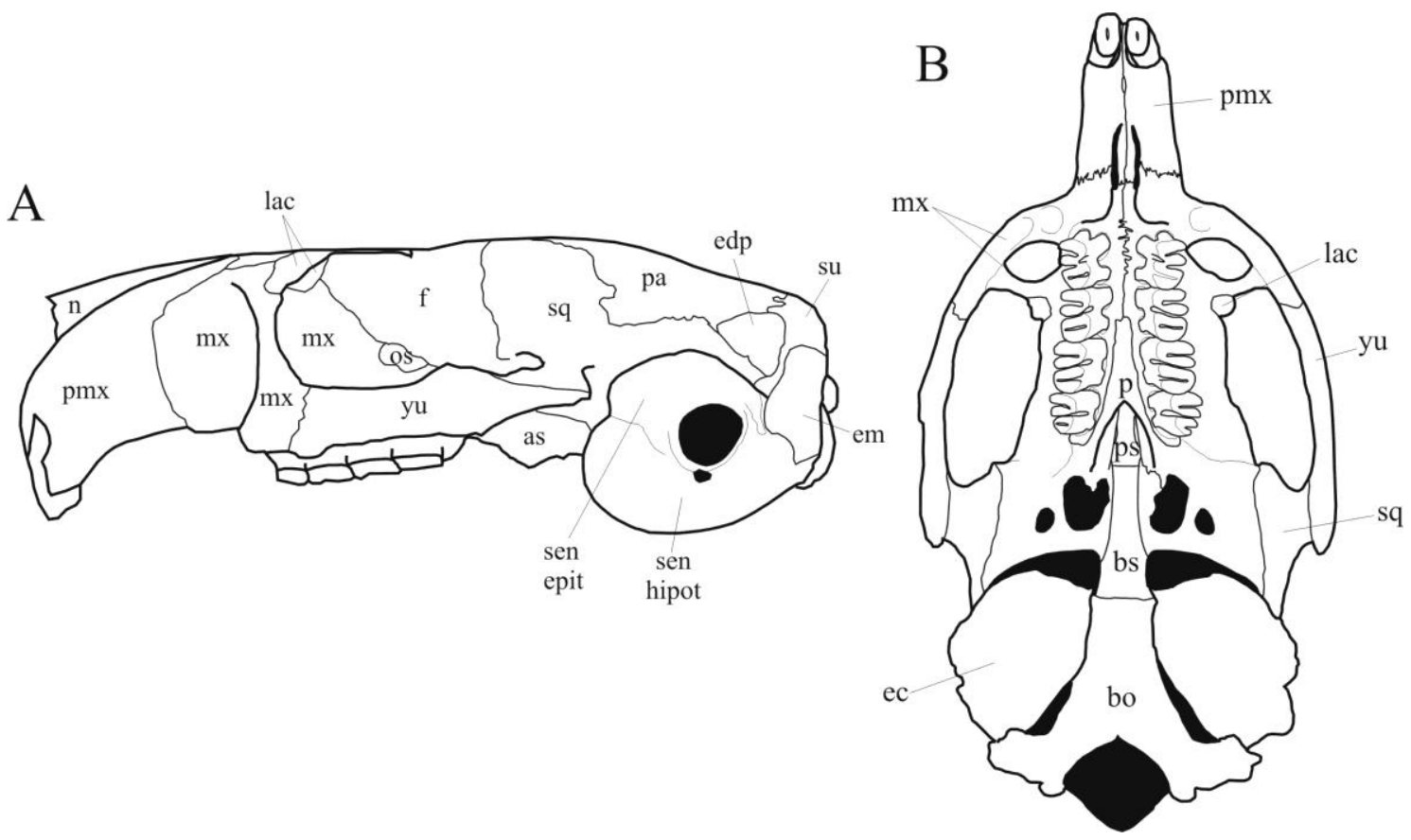

Fig. 2.1. Nomenclatura de los huesos craneanos: (A) vista lateral; (B) vista ventral. Abreviaturas: $a s$, aliesfenoides; bo, basioccipital; bs, basiesfenoides; $e c$, ectotimpánico; $e d p$, exposición dorsal del petroso; $e m$, exposición mastoidea; $f$, frontal; $y u$, yugal; lac, lagrimal; $m x$, maxilar; $n$, nasal; $o s$, orbitoesfenoides; $p$, palatino; $p a$, parietal; $p m x$, premaxilar; $p s$, preesfenoides; sen epit, seno epitimpánico; sen hipot, seno hipotimpánico; sq, escamoso; $s u$, supraoccipital 


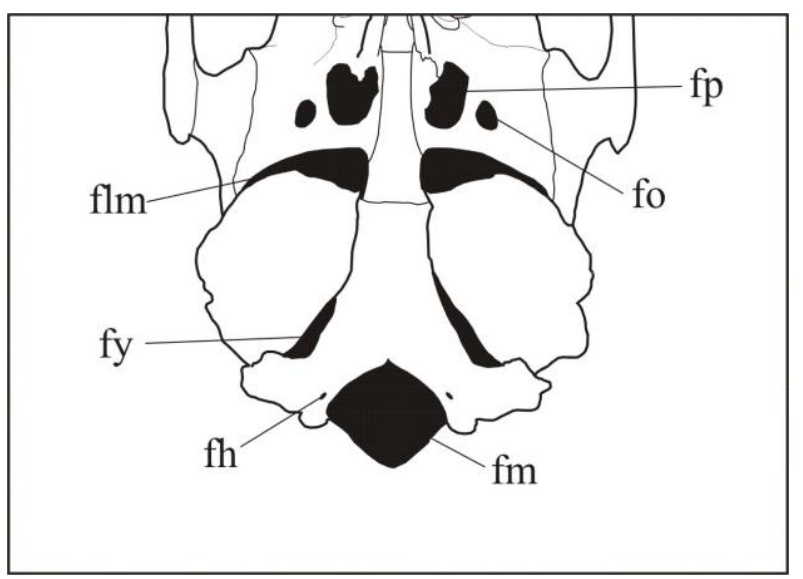

Fig. 2.2. Nomenclatura de los forámenes de la base del cráneo. Abreviaturas: $f \boldsymbol{h}$, foramen hipogloso; $f l m$, foramen lacerado medio; $f m$, foramen magnum; fo, foramen oval; $f p$, fosa pterigoidea; $f y$, fisura yugular

La terminología de las estructuras mandibulares (Fig. 2.3) se tomó de Woods (1972), Woods y Howland (1979) y Wible et al. (2005), a no ser que se especifique otro autor.

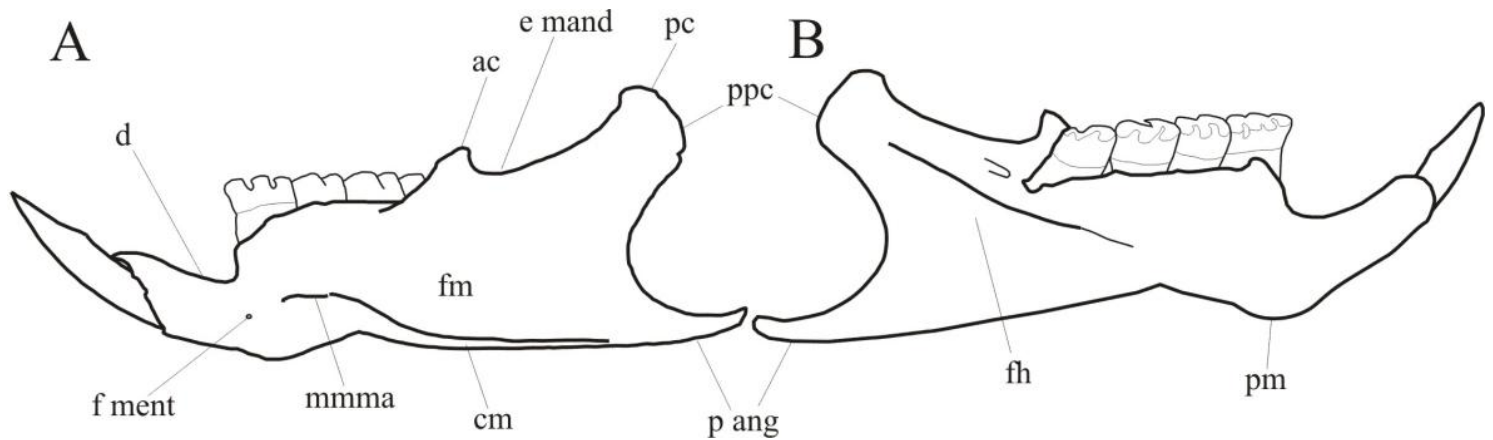

Fig. 2.3. Nomenclatura de los huesos mandibulares: (A) vista externa; (B) vista interna. Abreviaturas: $a c$, apófisis coronoides; $c m$, cresta masetérica; $d$, diastema; $e$ mand, escotadura mandibular; $f h$, fosa histricognata; $f m$, fosa masetérica; $f$ ment, foramen mentoniano; $m m m a$, muesca para inserción del músculo masetérico medial, pars anterior; $p$ ang, proceso angular; $p c$, proceso condilar; $p m$, proceso mentoniano; $p p c$, proceso post- condilar

\subsubsection{Propuesta nomenclatural para las estructuras dentarias}

La terminología de las estructuras dentarias se basó en las propuestas de Flynn et al. (1986) y Marivaux et al. (2001, 2003, 2004). A su vez, la terminología de las estructuras de los premolares de leche inferiores se basó en Candela (2002), mientras que la de los premolares inferiores definitivos se basó en Vucetich y Ribeiro (2003). La terminología de las estructuras de los premolares superiores de leche y definitivos se 
basó en la identificación de homologías primarias (topología y conectividad de las estructuras dentarias) (de Pinna 1991; Rieppel, 1994). Ver figuras 2.4 y 2.5.

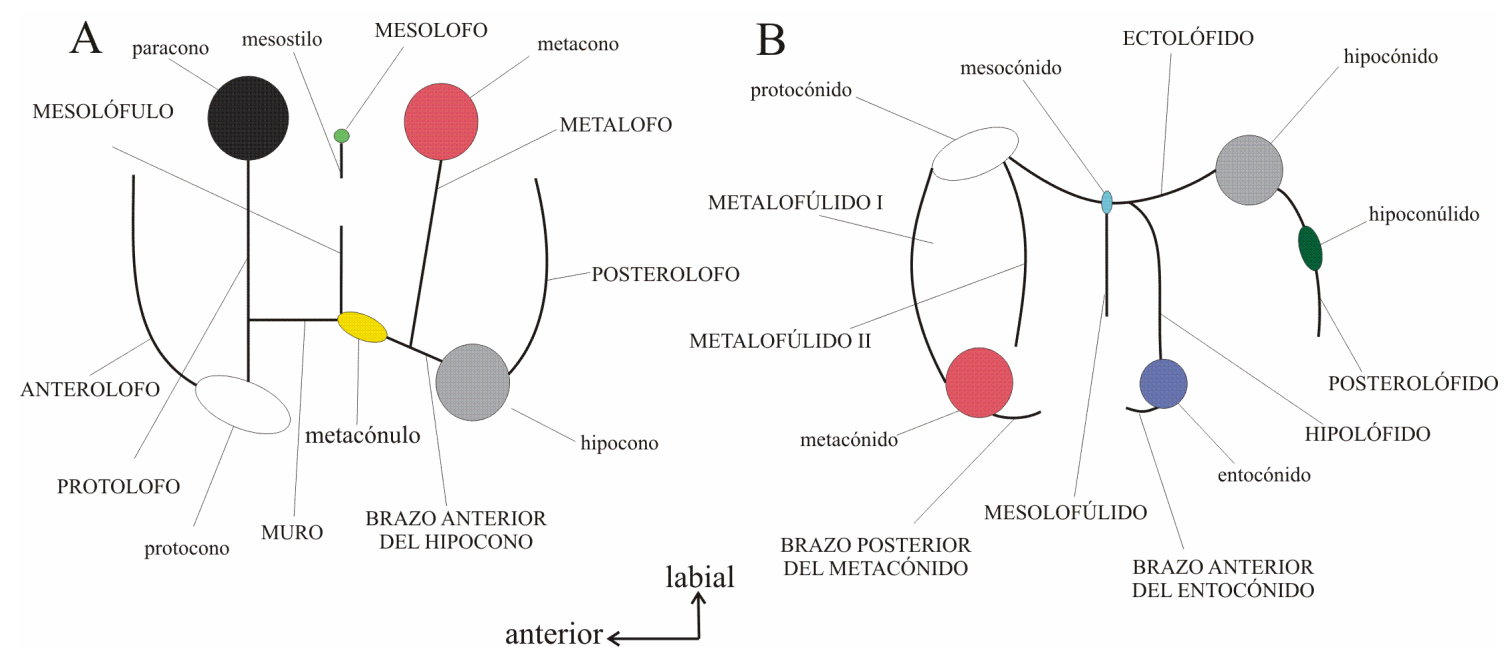

Fig. 2.4. Nomenclatura de las crestas en (A) molariformes superiores y (B) inferiores, de roedores histricognatos (modificado de Marivaux et al., 2004). Las letras mayúsculas hacen referencia a crestas, mientras que las minúsculas a cúspides

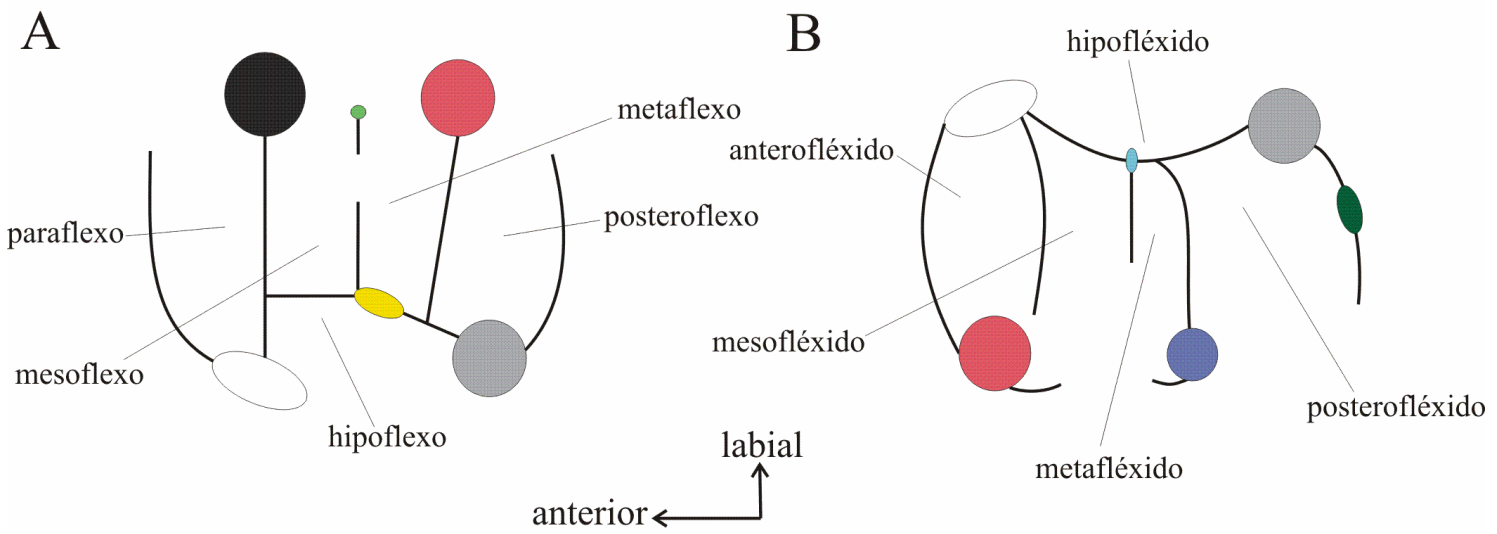

Fig. 2.5. Nomenclatura de los flexos/idos en (A) molariformes superiores y (B) inferiores de roedores histricognatos

- Abreviaturas dentarias: I, incisivo superior; i, incisivo inferior; PM, premolar superior; pm, premolar inferior; $\mathbf{M}_{\mathbf{x}}$, molar superior; $\mathbf{m}_{\mathbf{x}}$, molar inferior.

\subsubsection{Homología de las estructuras oclusales de los molariformes superiores}

La condición primitiva para los molares superiores de Rodentia es la tetralofodoncia, donde las crestas se denominan desde adelante hacia atrás anterolofo, protolofo, metalofo y posterolofo (Marivaux, 2001). Los "baluchímidos" (Ctenohystrica, Hystricognathi) son un grupo de roedores del Oligoceno- Mioceno 
temprano de Asia, cuyos integrantes desarrollaron un nuevo lofo en los dientes superiores, tercero en posición, que recibe el nombre de mesolófulo (Fig. 2.6). El mesolófulo nace de una cúspide, el metacónulo que se extiende en dirección labial y no es homólogo a ninguna otra estructura presente en roedores no-histricognatos (Flynn et al., 1986) (Fig. 2.6). El mesolofo, presente en algunos roedores (Theridomorpha, Eomyidae, Anomaluroidea, Eutypomyidae, Dipodoidea y cricétidos basales) es una cresta que nace del mesocono (ubicado en el muro), del mesostilo (ubicado en el margen labial) o de ambas estructuras. El mesolófulo ocupa una posición análoga al mesolofo, pero por su distinto origen no son estructuras homólogas. Como consecuencia, se considera que los Hystricognathi adquieren como condición derivada la pentalofodoncia cuyas crestas desde adelante hacia atrás corresponden al anterolofo, protolofo, mesolófulo, metalofo y posterolofo (Marivaux, 2001) (Fig. 2.6).

En este contexto, la identificación de un mesocono o mesocónulo es fundamental para el reconocimiento de las homologías de las estructuras oclusales de los roedores (Candela, 1999) y por lo tanto para el establecimiento de sus relaciones filogenéticas. Patterson y Wood (1982 y bibliografía allí citada) plantearon que la tercera cresta en posición en los Caviomorpha corresponde al metalofo y no existía ninguna estructura homologable al mesolófulo/mesolofo. Lavocat (1976), en cambio, interpretó a la tercera cresta en posición de los Caviomorpha como el mesolofo. Sin embargo, Candela (1999) comprobó que al menos algunos taxones fósiles de la superfamilia Erethizontoidea presentan un metacónulo y un mesolófulo; éste último puede tomar contacto con el mesostilo, o con una derivación lingual de éste (mesolofo vestigial?), formando una cresta transversal completa (Candela, 1999). Posteriormente, Marivaux et al. (2001, 2004) extendieron esta interpretación para los restantes caviomorfos y propusieron que la cresta usualmente reducida en las formas con molares tetralofodontes corresponde al metalofo, apoyando en este sentido las propuestas previas de Lavocat (1976), Hoffstetter (1975), Vucetich y Verzi (1992) y Bryant y McKenna (1995). 


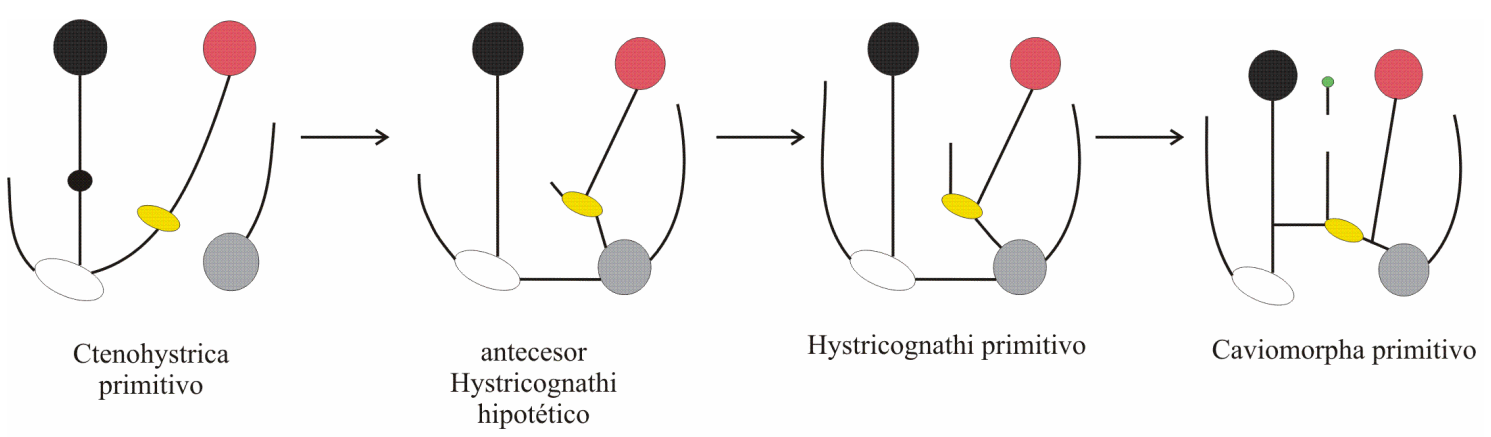

Fig. 2.6. Esquema donde se ejemplifica la evolución del patrón dentario pentalofodonte. Modificado de Flynn et al. (1986) y Candela (1999)

- El caso particular de los Octodontoidea: la evolución temprana de los octodontoideos fue muy compleja. Esta complejidad puede ser apreciada en la cantidad de patrones evolutivos que se identifican dentro de la superfamilia.

En este trabajo se propone que el patrón tetralofodonte que caracteriza a la mayoría de los octodontoideos evolucionó de un patrón pentalofodonte (Marivaux et al., 2004). Este patrón dentario primitivo evolucionó de diferentes maneras originando distintos patrones oclusales (Ver capítulo 5). Sin embargo, en algunos taxones aquí analizados resulta difícil individualizar las cúspides, y por lo tanto determinar las homologías de sus crestas asociadas.

1- Plesiacarechimys koenigswaldi es el único octodontoideo del OligocenoMioceno medio pentalofodonte. Dentro del esquema evolutivo de la superfamilia el antecesor de Plesiacarechimys adquirió secundariamente un patrón dentario pentalofodonte (Ver capítulo 5), que obviamente no es homólogo al del resto de los caviomorfos pentalofodontes. En el ejemplar tipo de Plesiacarechimys se observa que el metalofo es muy pequeño, mientras que en MLP 92-V-10-1 y MLP 92-V-10-17 esta cresta desapareció, adquiriendo nuevamente un patrón tetralofodonte.

2- En Caviocricetus lucasi las crestas desde adelante hacia atrás corresponden al anterolofo, protolofo, mesolófulo y metalofo+posterolofo. Al igual que Plesiacarechimys este patrón dentario evolucionó originariamente de un patrón tetralofodonte (Ver capítulo 5). Del análisis se desprende que el antecesor común de Plesiacarechimys y Caviocricetus era pentalofodonte y que a partir de él se diferenciaron dos líneas evolutivas que reflejan dos formas de reducción dentaria. En Caviocricetus el metalofo se fusionó al posterolofo y forma la porción labial de la cuarta 
cresta en posición. Además, se revalida la idea de Vucetich y Verzi (1996) quienes propusieron que esta morfología se adquirió por un corrimiento posterior del metalofo acompañado de una reducción del posterolofo. Aquí se concluye que este patrón tetralofodonte no es homólogo al que se observa en los restantes octodontoideos tetralofodontes (Ver capítulo 5).

3- Los acarémidos (Platypittamys, Acaremys, Sciamys y Galileomys), las especies de Acarechimys, las especies de Protacaremys y Prospaniomys priscus presentan un patrón dentario superior tetralofodonte donde no es posible identificar ningún patrón en particular de reducción de crestas ni en la ontogenia de cada diente ni a lo largo de la hilera dentaria (a excepción del DP4 de A. murinus). Dado que en los molares el extremo labial de la tercera cresta en posición se une directamente metacono, se considera que ésta corresponde al metalofo, estando el mesolófulo ausente (hasta que no haya otro tipo de evidencia). Esta morfología dentaria es considerada primitiva para los octodontoideos incluidos en este análisis (Ver capítulo 5).

4- $\quad$ Sallamys pascuali presenta molares superiores tetralofodontes, donde la tercera cresta en posición presenta una disposición variable: su extremo lingual está unido a la cresta posterior en el M1 y unido al muro en M2 y M3. Este patrón de reducción de crestas se observa también en los taxones colhuehuapenses Willidevu esteparius y Protadelphomys latus de Patagonia, que han sido tradicionalmente vinculados a Sallamys (Vucetich y Verzi, 1991). Estos taxones no fueron incluidos dentro del análisis filogenético, razón por la cual no se puede corroborar desde un punto de vista cladístico que los mismos representen un linaje de octodontoideos independiente.

5- En Prostichomys y las especies de Deseadomys, Adelphomys, Spaniomys y Stichomys no se individualizan las cúspides, sin embargo, las crestas se homologan de igual manera que sus antecesores (Protacaremys, Prospaniomys).

\subsubsection{Medidas}

Las medidas craneanas están expresadas en $\mathrm{cm}$, mientras que las medidas dentarias están expresadas en $\mathrm{mm}$ (excepto que se especifique lo contrario). Las medidas dentarias se tomaron con un ocular micrométrico de una lupa Nikon SMZ-10, con un calibre mecánico con una aproximación de 0,02 mm. Las medidas craneanas y 
mandibulares se tomaron con un calibre mecánico con una aproximación de 0,02 mm. Las medidas, sus correspondientes abreviaturas y descripción se detallan en la tabla 1 y las figuras 2.7 y 2.8 .

Si bien de varias de las especies analizadas se conocen gran cantidad de ejemplares, las medidas provistas en las tablas del capítulo 4 corresponden sólo a los ejemplares que han sido más relevantes en las revisiones taxonómicas.

Tabla 1. Descripción y abreviaturas de las medidas craneanas, mandibulares y dentarias

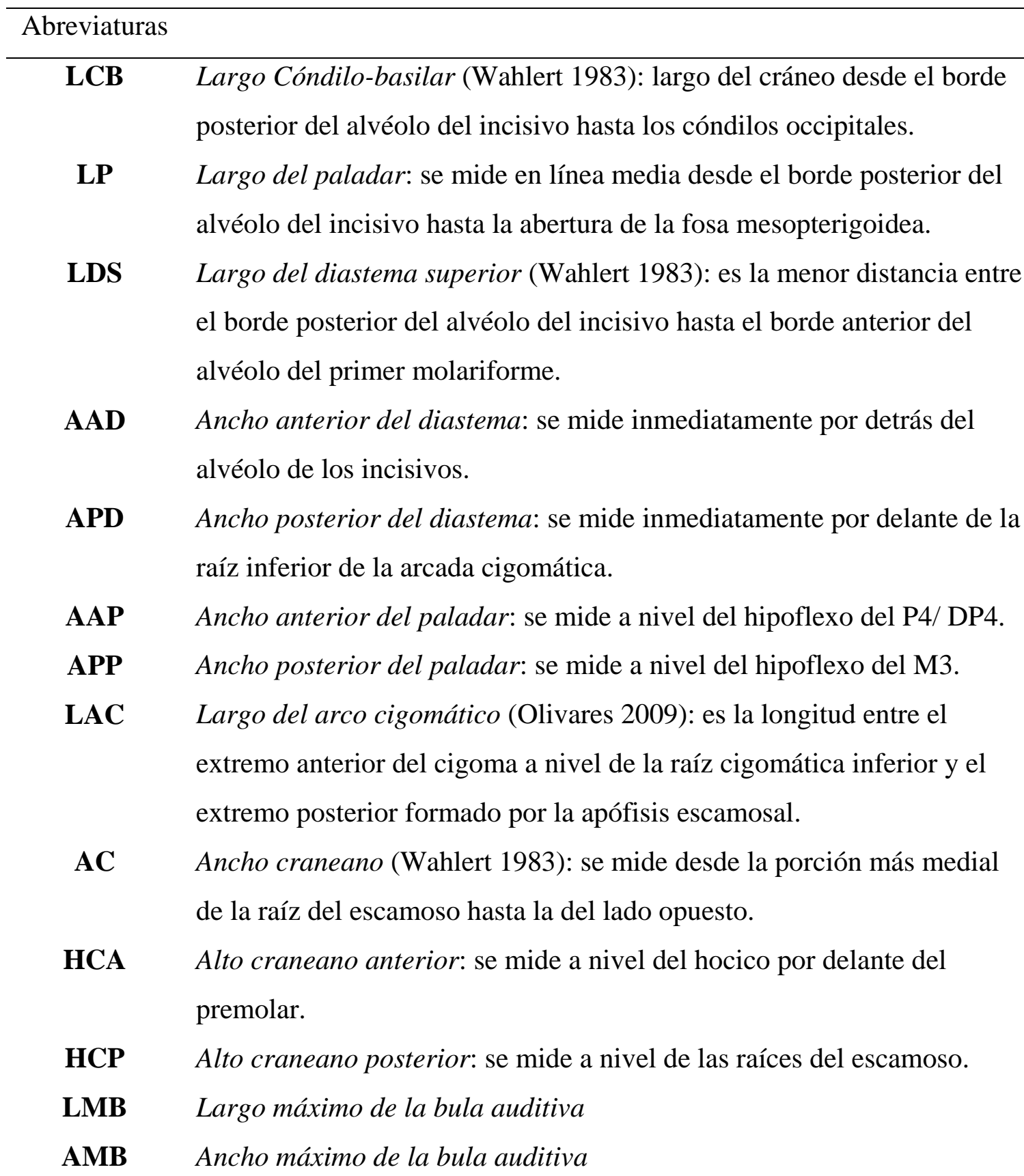


LHD Largo de la hilera dentaria superior desde el I hasta el M3

P4(DP4)/M3 Largo de la hilera dentaria superior P4/ DP4-M3

LAP Largo antero-posterior: el largo de los dientes se mide en la superficie oclusal.

Aa Ancho anterior: el ancho anterior de los dientes se mide en la base de los mismos a nivel del protocono.

Ap Ancho posterior: el ancho posterior de los dientes se mide en la base de los mismos a nivel del hipocono.

LCM Largo del cuerpo mandibular: se mide en vista lingual. Es la distancia entre el extremo del incisivo inferior y el borde posterior de la fosa retromolar. La mandíbula se orienta de forma que la hilera dentaria se encuentre horizontal.

LDi Largo del diastema inferior: longitud desde el borde posterior del alvéolo del incisivo hasta el borde anterior del alvéolo del p4/ dp4. La mandíbula se orienta de forma que la hilera dentaria se encuentre horizontal.

AM1 Altura de la mandíbula a nivel del punto más bajo del diastema: La mandíbula se orienta de forma que la hilera dentaria se encuentre horizontal.

AM2 Altura de la mandíbula a nivel del hipofléxido del p4/ dp4: La mandíbula se orienta de forma que la hilera dentaria se encuentre horizontal.

AM3 Altura de la mandíbula a nivel del borde posterior del m3: esta medida se toma desde la cara lingual de la mandíbula. La mandíbula se orienta de forma que la hilera dentaria se encuentre horizontal. 


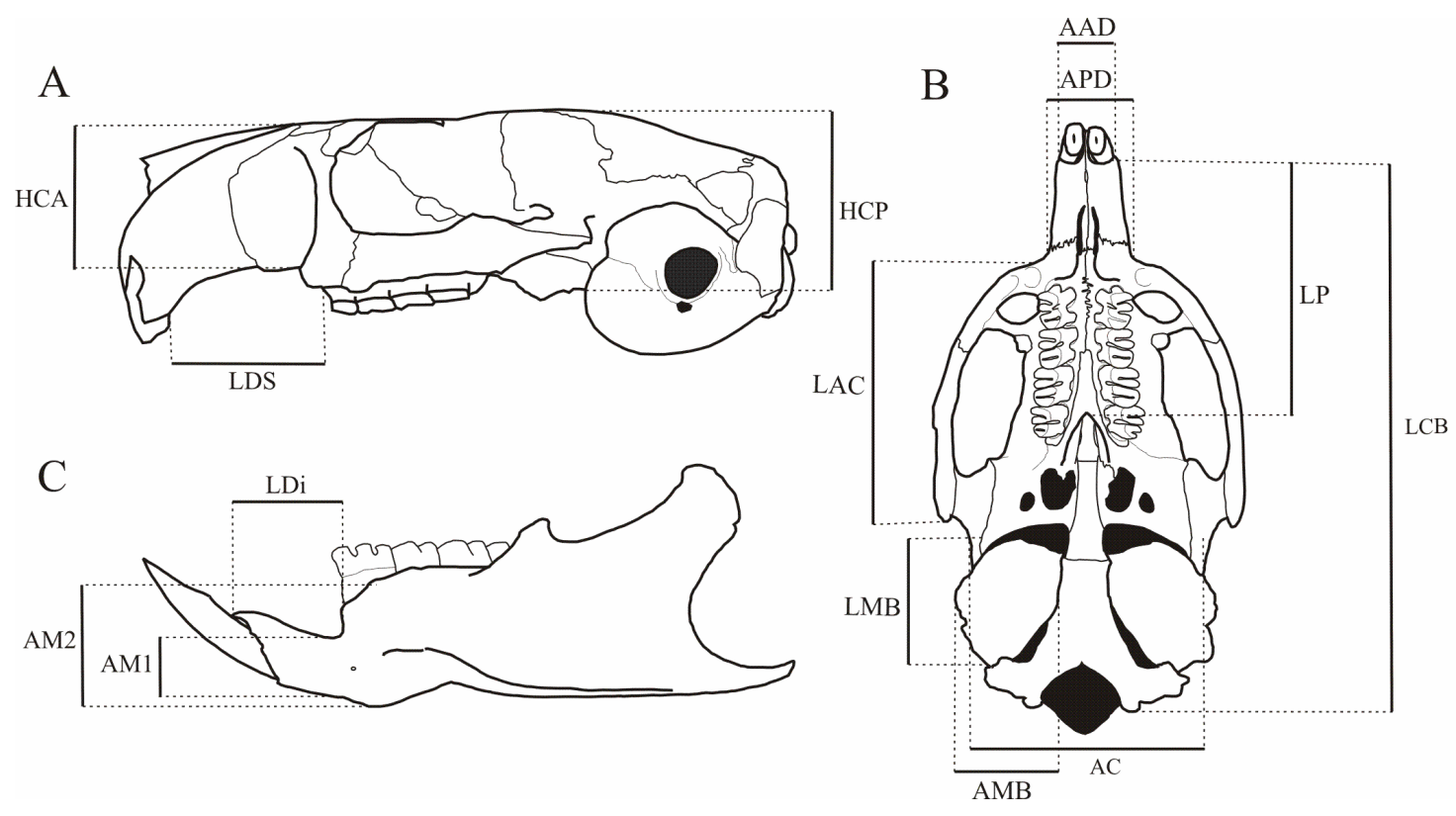

Fig. 2.7. Medidas craneanas y mandibulares. (A) Cráneo en vista lateral; (B), cráneo en vista ventral; (C), mandíbula en vista externa. Ver abreviaturas en tabla 1

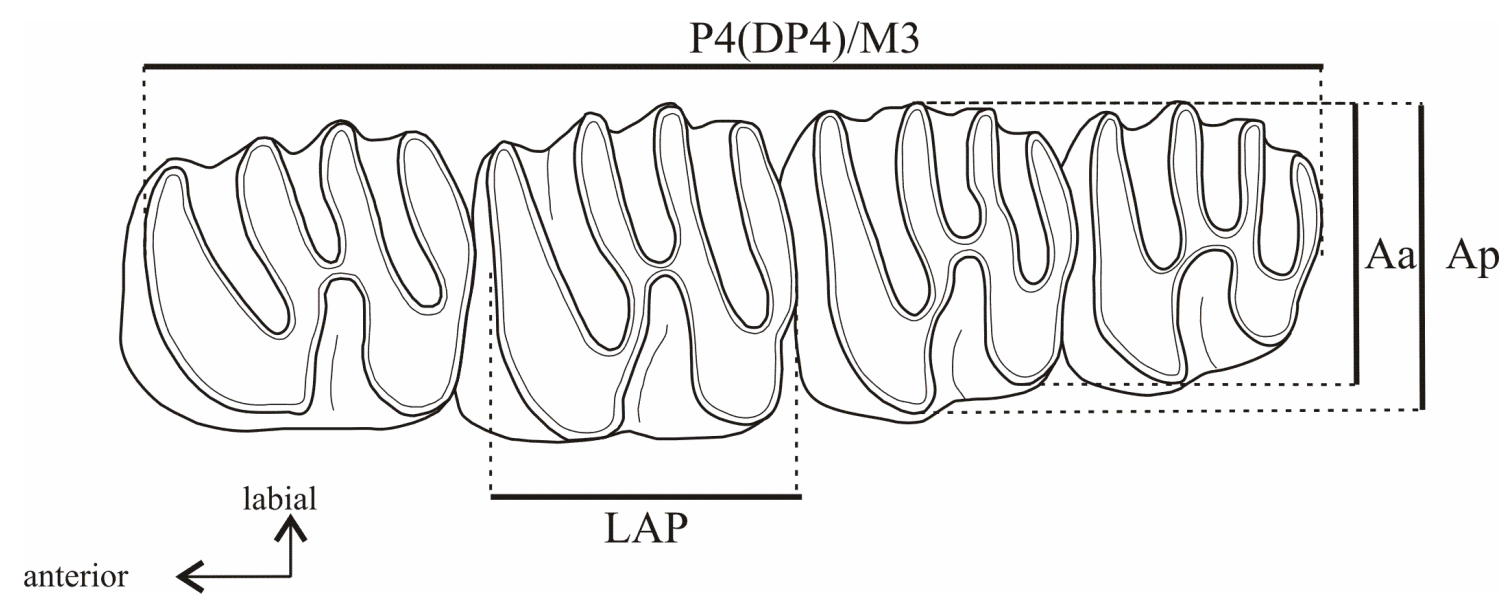

Fig. 2.8. Medidas dentarias. Ver abreviaturas en tabla 1

Los dibujos se realizaron con el programa Corel, versión 12.0. Las fotos se tomaron con una cámara digital (Cyber-shot, DSC-H3) perteneciente a la Sección de Paleontología de Vertebrados del MACN, y una cámara digital perteneciente al Dto. Científico de Paleontología de Vertebrados del MLP y el Departamento Científico Zoología de Vertebrados del MLP. Las fotografías con mayor aumento y mejor resolución se tomaron en el microscopio electrónico de barrido del MACN. 


\subsection{Análisis Filogenético}

Con el fin de analizar las relaciones entre los taxones incluidos en esta tesis, así como las relaciones de éstos con otros octodontoideos fósiles y con los modernos Octodontidae, se realizó un análisis filogenético siguiendo los principios metodológicos del cladismo o sistemática filogenética (Hennig, 1968; Farris, 1983). Esta metodología utiliza el criterio de Parsimonia para establecer las homologías entre los distintos taxones (Farris, 1983; Kitching et al., 1998), el cual permite escoger el árbol (o hipótesis filogenética) más simple y con menos inferencias ad hoc. Para la determinación de la polaridad de los caracteres se utilizó el principio de grupo externo.

Para realizar los análisis filogenéticos se utilizaron caracteres craneanos, mandibulares y dentarios, ya que son estas estructuras las que forman principalmente el registro fósil de caviomorfos hasta el Mioceno medio. Los caracteres fueron obtenidos de la bibliografía, o propuestos por primera vez para los Octodontoidea en este análisis (Ver Capítulo 5, "Descripción de los caracteres").

Para realizar los análisis filogenéticos se utilizó el software TNT (Tree Analysis Using New Technology), en su versión 1.1 (Goloboff et al., 2008). Adicionalmente se realizó la búsqueda de los taxones y caracteres más conflictivos con el fin de poder evaluar los resultados teniendo en cuenta esta información. El soporte de ramas de los nodos del consenso fue evaluado mediante el soporte Bremer, el Bootstrap y el remuestreo simétrico.

El desarrollo de la metodología cladística y del análisis filogenético realizado se encuentra en el capítulo 5: Análisis Filogenético. 
CAPÍTULO 3

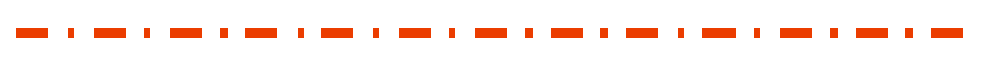

CONTEXTO

GEOCRONOLÓGICO 
Las edades basadas en mamíferos terrestres o "Edades Mamífero" de América del Sur (SALMA por su nombre en inglés: South American Land Mammal Age) son unidades biocronológicas definidas sobre la base de la asociación de mamíferos en unidades estratigráficas continentales y el "estado evolutivo" de estas comunidades (Pascual y Odreman-Rivas, 1971). Las "Edades Mamífero" fueron propuestas con el objetivo de ordenar cronológicamente el Cenozoico y parte del Cretácico de Europa, América del Norte, América del Sur y más recientemente de Australia. Sobre la base de trabajos previos (Ameghino, 1889, 1906; L. Kraglievich, 1930b, 1934; Frenguelli, 1930; Castellanos, 1937), Simpson (1940) propuso el concepto moderno de "Edades Mamífero" con el fin de agrupar en categorías jerárquicas las sucesivas faunas de mamíferos de América del Sur. Estas "Edades Mamífero" se definen sobre la base de fósiles guía y sobre primeras o últimas apariciones de determinados taxones en el registro, y se caracterizan por estar representadas por una asociación faunística determinada (Marshall et al., 1983; Madden et al., 1997). En este trabajo el término "Edad Mamífero" se escribe entre comillas debido a que en muchos casos no se han cumplido con las exigencias del Código Argentino de Estratigrafía (CAE, 1992).

Con el objetivo de explicar el marco temporal y estratigráfico en el que se encontraron los especímenes estudiados en esta tesis, se expone una breve introducción de las "Edades Mamíferos" y otras unidades faunísticas (que representarían lapsos temporales no incluidos en las "Edades Mamífero" clásicas o dudosamente incluidos en ellas) que abarcan desde el Eoceno medio-Oligoceno temprano hasta el Mioceno medio. Adicionalmente se listan las localidades donde se han encontrado roedores octodontoideos para este lapso.

\subsection{Eoceno medio}

\subsubsection{Fauna de Contamana}

La localidad de Contamana se encuentra en el centro-este de Perú, en el amazonas peruano. Dataciones radimétricas indican una antigüedad más temprana que 40,94 Ma. Se reconocieron cinco taxones, tres de los cuales se mencionarán a continuación debido a que un análisis cladístico (Antoine et al., 2011) reveló que se tratan de caviomorfos basales, cercanamente emparentados con los Octodontoidea.

- Contamana: Fm Yahuarango, Departamento de Loreto, Perú (Antoine et al., 2011):

Cachiyacui contamanensis, C. kummeli y Canaanimys maquiensis (Antoine et al., 2011). 


\subsection{Eoceno tardío?- Oligoceno temprano}

\subsubsection{Santa Rosa}

La localidad de Santa Rosa se encuentra en la provincia de Atalaya, Departamento de Ucayali, en el este de Perú (Campbell et al., 2004). La edad de la fauna de Santa Rosa es controvertida ya que no se han podido realizar dataciones absolutas, sino que dicha edad se estimó sobre la base de la asociación faunística encontrada y su estado evolutivo (Campbell et al., 2004). La fauna proveniente de la localidad de Santa Rosa no se asignó a ninguna SALMA en particular debido a que esta asociación faunística no puede ser ubicada con exactitud en el contexto estratigráfico sudamericano (Campbell, 2004). Frailey y Campbell (2004) y Goin y Candela (2004) propusieron que esta fauna tiene una edad Eoceno tardío- Oligoceno temprano. Sin embargo, Shockey et al. (2004) indicaron que los notoungulados hallados en Santa Rosa son comparables con los que se registran en el Tinguiririquense (Oligoceno temprano) y el Deseadense (Oligoceno tardío). Coincidiendo con esta última idea, Vucetich et al. (2010a) propusieron que las semejanzas presentes entre los géneros hallados en Santa Rosa con aquellos hallados en Salla (Oligoceno tardío), la hipsodoncia y el grado de laminación presente en Eodelphomys almeidacamposi, indicarían que la fauna de Santa Rosa no es tan antigua como se creía hasta ese momento.

Localidades fosilíferas donde se hallaron roedores octodontoideos:

- Santa Rosa Fm Yahuarango?, provincia de Atalaya, Departamento de Ucayali, Perú (Campbell et al., 2004) (Fig. 3.2): Eosallamys paulacoutoi, E. simpsoni, Eospina woodi, Eosachacui lavocati, Eodelphomys almeidacomposi, Echimyidae gen. y sp. indet. A, Echimyidae gén. y sp. indet. B, Echimyidae gén. y sp. indet. C (Frailey y Campbell, 2004).

\subsection{Oligoceno temprano}

\subsubsection{La Cantera (Fig. 3.1)}

En la Fm Sarmiento, Mb Puesto Almendra Superior, se reconocen dos niveles fosilíferos. Al nivel inferior GBV-19 se lo ha denominado La Cantera, cuya fauna presenta taxones que caracterizan la "Edad Mamífero" Deseadense y taxones semejantes a aquellos que se encuentran en la "Edad Mamífero" Tinguiririquense (Ré et al., 2010).

Las dataciones basadas en datos radioisotópicos indican edades de entre 31,1-29,5 Ma para el nivel inferior GBV-19 del Mb Puesto Almendra Superior (Ré et al., 2010). 
Localidades fosilíferas donde se hallaron roedores octodontoideos:

- La Cantera Fm Sarmiento, Mb Puesto Almendra Superior (Unidad 3), provincia del Chubut, Argentina (Bellosi, 2010): Draconomys verae, Vallehermosomys mazzonii, Vallehermosomys? merlinae (Vucetich et al., 2010a).

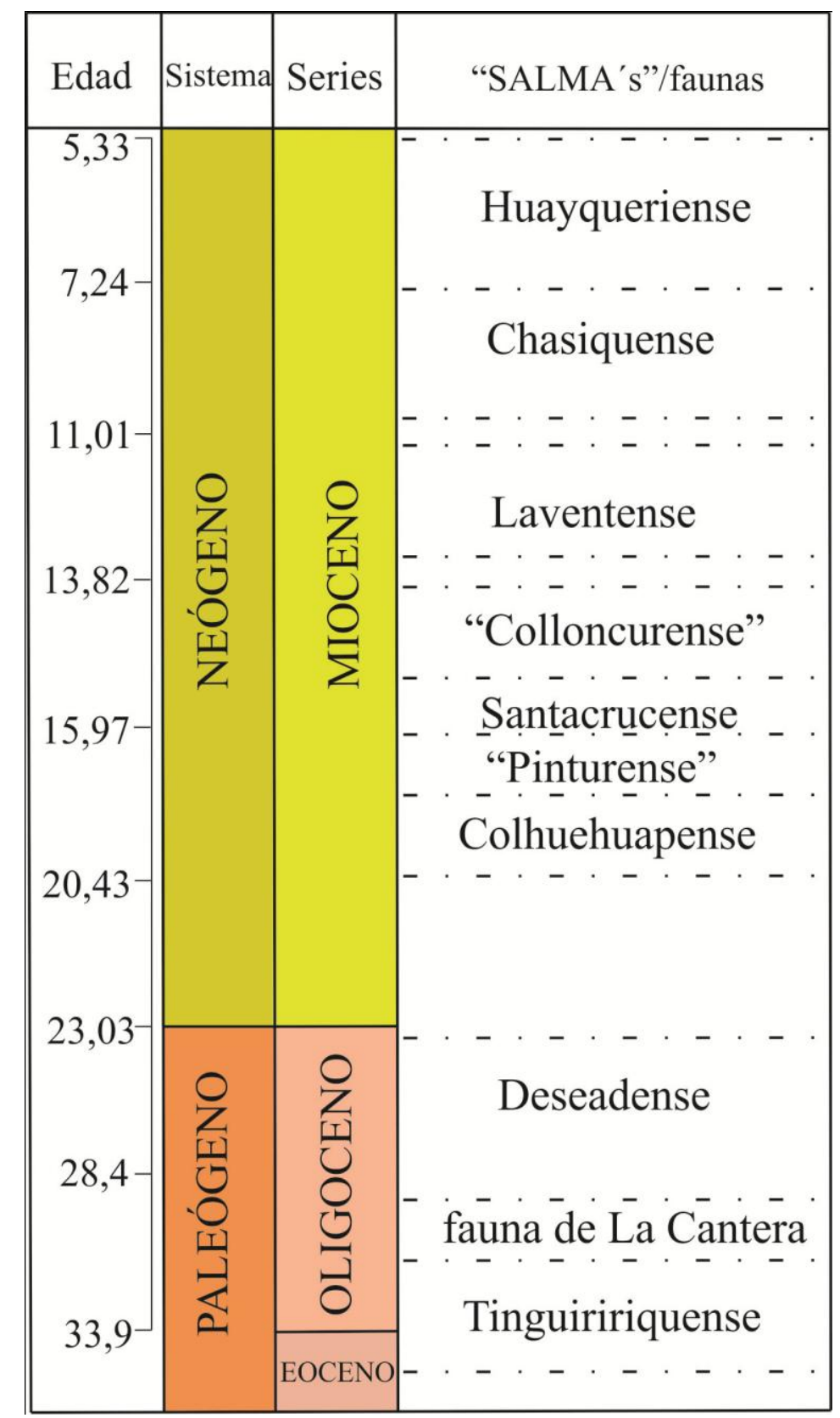

Figura 3.1. Esquema geocronológico y distribución temporal de las "Edades Mamífero" sudamericanas (SALMA). Entre comillas se denotan aquellas Edades que no son consideradas "Edades Mamífero". Esquema modificado de la ISChart (2009) y Flynn y Swisher (1995) 


\subsection{Oligoceno tardío}

\subsection{1 "Edad Mamífero" Deseadense (Fig. 3.1)}

Simpson (1940) reconoció como "Edad Mamífero" Deseadense a aquella caracterizada por la asociación de mamíferos que Ameghino (1895) llamó "fauna du Pyrotherium", ya que en ella el género Pyrotherium se destaca por ser uno de los fósiles guía más abundante y fácilmente reconocible. La localidad tipo del Deseadense es La Flecha (Wood y Patterson, 1959; Patterson y Marshall, 1978), ubicada al noreste de la provincia de Santa Cruz, unos kilómetros al sur de la desembocadura del río Deseado (Fig. 3.3). Se reconocieron numerosas localidades que fueron asignadas al Deseadense (Reguero, 1998 y bibliografía allí citada).

Las dataciones indican distintas edades para el Deseadense: Marshall et al. (1986a) realizaron estudios de $\mathrm{K}^{40} / \mathrm{Ar}^{40}$ en la localidad de Scarrit Pocket (Chubut, Argentina) que indicaron edades de entre 23,4 y $21 \mathrm{Ma}$, mientras que en la localidad de Gran Barranca (Chubut, Argentina) las dataciones indicaron una antigüedad de $29 \mathrm{Ma}$ [los mamíferos fósiles registrados en los niveles por encima de la Fauna de La Cantera guardan semejanzas con aquellos asignados a la "Edad Mamífero" Deseadense (Ré et al., 2010)]. Sobre la base del primer registro de Pyrotherium y distintas dataciones, Marshall et al. (1986a) propusieron un piso para el Deseadense de 34 Ma y un techo de 21 Ma. Flynn y Swisher (1995) asignaron el Deseadense al Oligoceno tardío y propusieron que esta edad se extendía entre los 27-29 Ma. Para los estratos de Salla, MacFadden et al. (1985) determinaron una edad de entre 28,5 y 24 Ma sobre la base de la polaridad magnética, mientras que Kay et al. (1998) determinaron una edad de entre 29-25,7 Ma sobre la base de estudios de $\mathrm{Ar}^{40} / \mathrm{Ar}^{39}$.

Localidades fosilíferas Deseadenses donde se hallaron roedores octodontoideos:

- La Flecha Fm Sarmiento, provincia de Santa Cruz, Argentina (Wood y Patterson, 1959) (Fig. 3.3): Deseadomys arambourgi (Wood y Patterson, 1959).

- Scarrit Pocket Fm Sarmiento, Rinconada de los López, provincia del Chubut, Argentina (Simpson, 1941; Chaffee, 1952) (Fig. 3.3): Platypittamys brachyodon (Wood, 1949).

- Cabeza blanca Fm Sarmiento, provincia del Chubut, Argentina (Loomis, 1914; Wood y Patterson, 1959): Deseadomys arambourgi, D. loomisi (Wood y Patterson, 1959).

- Laguna de los Machos Fm Sarmiento, Departamento de Paso de los Indios, provincia del Chubut, Argentina (Patterson y Pascual, 1968; Reguero y Prevosti, 2010): Xylechimys obliquus (Patterson y Pascual, 1968). 
- Salla parte baja de los estratos del Salla y Tapial Pampa East, cuenca de SallaLuribay, Bolivia (Hoffstetter, 1968) (Fig. 3.2): Sallamys pascuali (Hoffstetter y Lavocat, 1970) y Migraveramus beatus (Patterson y Wood, 1982).

- Cuenca de Taubaté Fm Tremembé, cuenca de Taubaté, Fazenda Santa Fé, Estado de San Pablo, Brasil (Soria y Alvarenga, 1989) (Fig. 3.2): Paulacoutomys paulista (Vucetich et al., 1993); Sallamys? minutus (Vucetich y Ribeiro, 2003).

-Nueva Palmira Fm Fray Bentos, Uruguay (Mones y Ubilla, 1978): Palmiramys waltheri (Kraglievich, 1932).

Comentarios: Kraglievich (1932) describió a Palmiramys waltheri como un representante de la familia Acaremyidae, mientras que Mones y Castiglioni (1979) la incluyeron con dudas dentro de la familia Dasyproctidae.

\subsection{Mioceno temprano}

\subsection{1 “Edad Mamífero" Colhuehuapense (Fig. 3.1)}

La localidad tipo del Colhuehuapense es Gran Barranca (Simpson, 1940; Vucetich et al., 2010b) (Barranca sur del Lago Colhue-Huapi) en la provincia del Chubut. En esta localidad aflora la Fm Sarmiento, y los fósiles de edad colhuehuapense provienen del Miembro Colhue-Huapi (Spalleti y Mazzoni, 1979; Bellosi, 2010) (Fig. 3.3) y se asigna al Mioceno temprano (Ré et al., 2010). Dentro del Mb Colhue-Huapi se reconocieron numerosos niveles portadores de mamíferos. Los niveles inferiores donde se encontraron mamíferos colhuehuapenses se agrupan en lo que se llama Lower Fossil Zone, mientras que los niveles superiores se conocen como Upper Fossil Zone y son portadores de mamíferos "Pinturenses" (Ré et al., 2010; Kramarz et al., 2010).

La fauna sobre la que está definida el Colhuehuapense se corresponde con la “faune du Colpodon" de Ameghino (1902) y se han reconocido numerosas localidades que fueron asignadas a esta edad por su contenido faunístico (Roth, 1908; Rusconi, 1933; Fleagle y Bown, 1983; Barrio et al., 1989; Leanza y Hugo, 1997).

Marshall et al. (1986a) indicaron que el Colhuehuapense se extendió entre los 19-18 Ma. Ré et al. (2010) determinaron para el intervalo estratigráfico del Mb ColhueHuapi, portador de mamíferos colhuehuapenses (Lower Fossil Zone), una edad de 2020,2 Ma. 


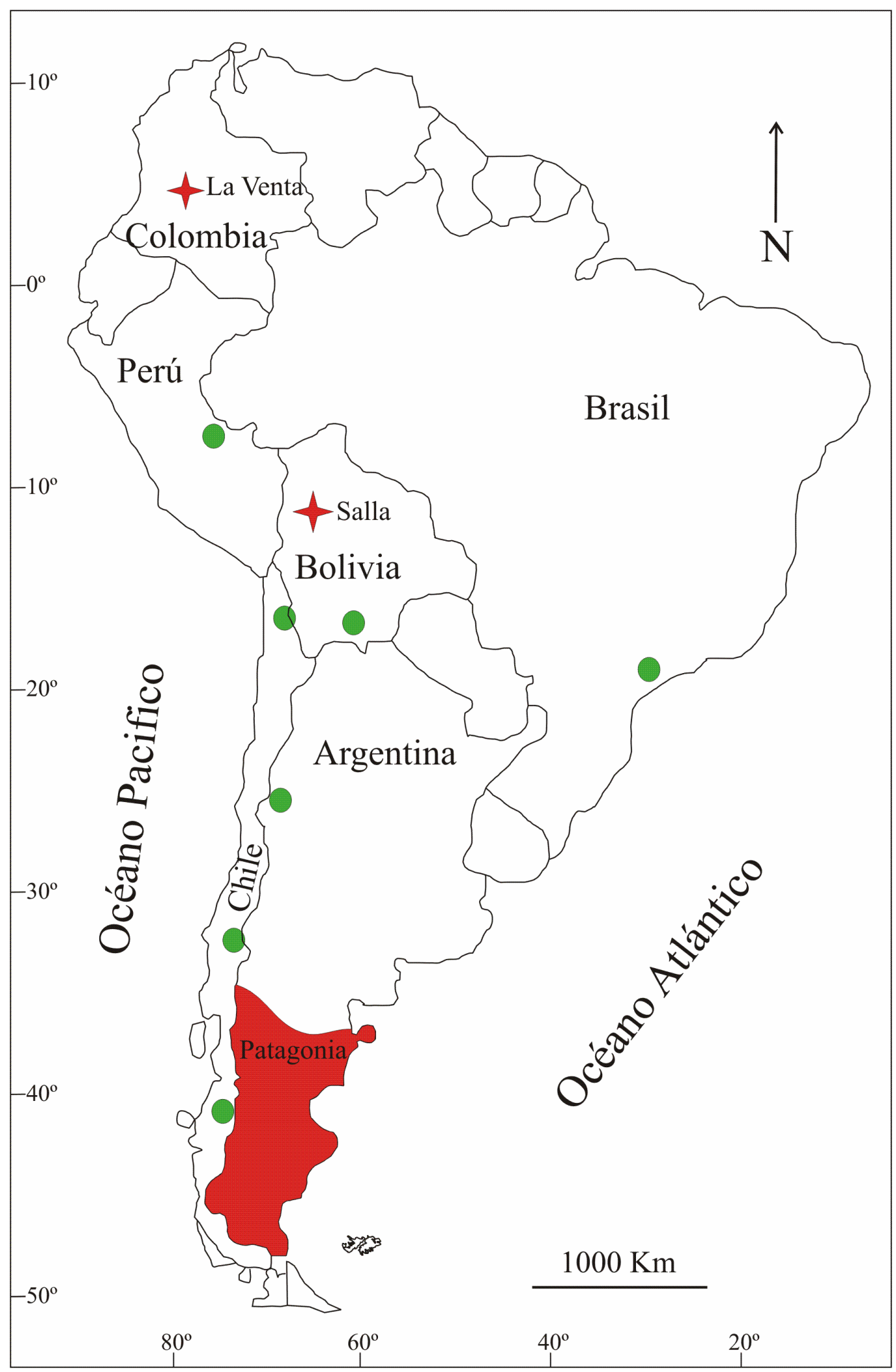

Fig. 3.2. Mapa de Sudamérica indicando las principales áreas donde se hallaron octodontoideos fósiles (Oligoceno tardío-Mioceno medio). En rojo se indican las áreas donde se encontraron los octodontoideos estudiados en esta tesis (Patagonia, Salla y La Venta) y en verde otras localidades cuyos roedores octodontoideos no fueron estudiados pero se mencionan en este capítulo 


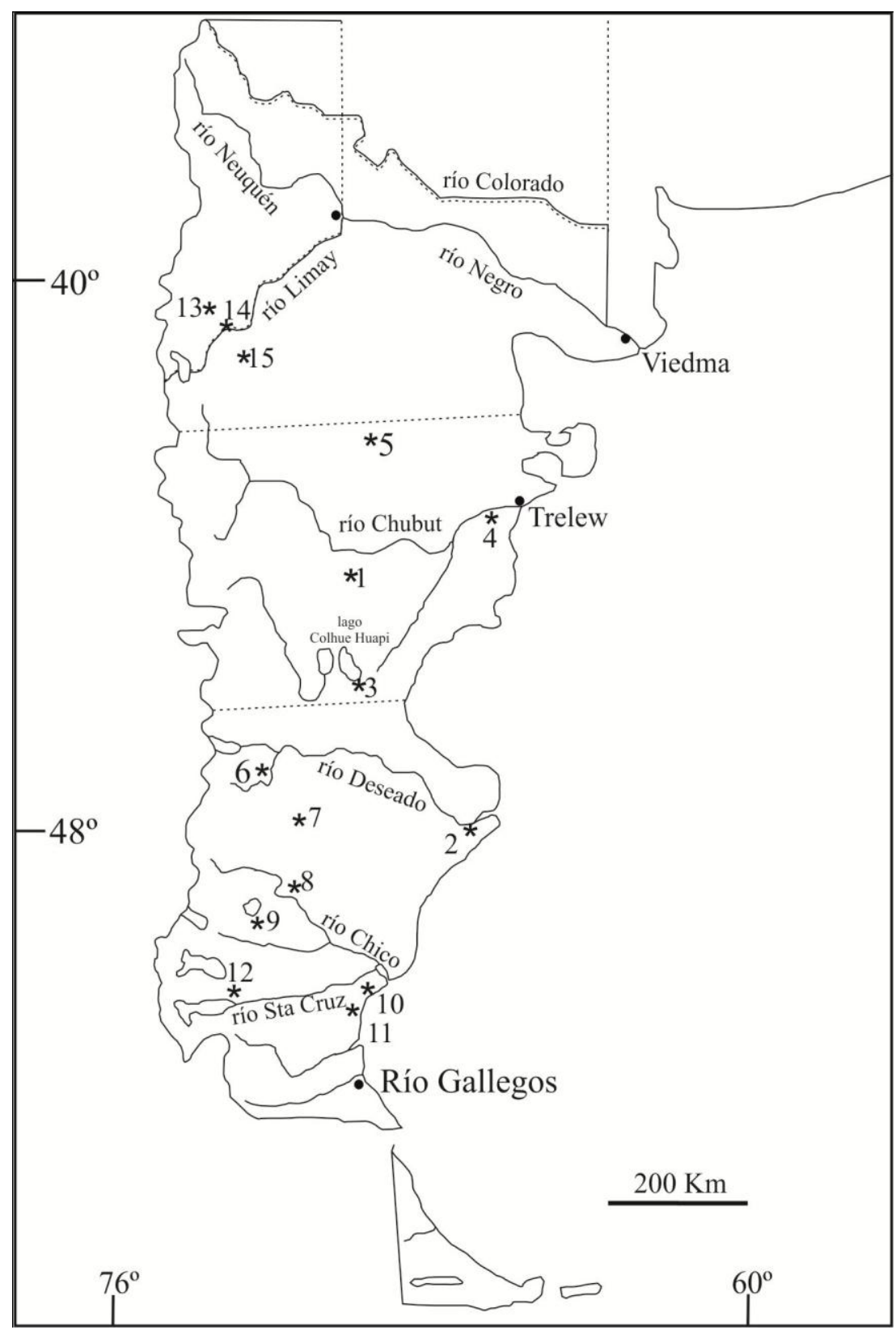

Fig. 3.3. Mapa de Patagonia Argentina indicando la distribución de las principales localidades donde se hallaron octodontoideos fósiles (Oligoceno tardío-Mioceno medio). Localidades: 1. Rinconada de los López, 2. La Flecha, 3. Gran Barranca, 4. Bryn Gwyn, 5. Sacanana, 6. río Pinturas, 7. Estancia La Cañada, 8. Gobernador Gregores, 9. Lago Cardiel, 10. Monte León, 11. Monte Observación, 12. Karaiken, 13. río Collón Curá, 14. Cañadón del Tordillo, 15. Pilcaniyeu Viejo

Localidades fosilíferas Colhuehuapenses donde se encontraron roedores octodontoideos:

- Gran Barranca Fm Sarmiento, Mb Colhue-Huapi, Lower Fossil Zone, provincia del Chubut, Argentina (Ré et al., 2010) (Fig. 3.3): Paradelphomys fissus (Patterson y Pascual, 1968); Protadelphomys sp. (Vucetich y Verzi, 1994); Galileomys antelucanus, Acaremys cf. murinus (Vucetich y Kramarz, 2003); Acarechimys minutissimus, 
Caviocricetus sp., Protacaremys? sp. nov., Prospaniomys sp. 1, Protadelphomys morfotipo A, Octodontoidea gen. et sp. nov. (Vucetich et al., 2010b).

- "Interior del territorio de Chubut" (Ameghino, 1902): Protacaremys prior, $P$. avunculus, $P$. pulchellus (=Acarechimys pulchellus Vucetich et al., 2010b),

Prospaniomys priscus, Protadelphomys latus (Ameghino, 1902). Muy probablemente esta localidad corresponda a Gran Barranca.

- Bryn Gwyn Fm Sarmiento, Mb Trelew, barranca sur del río Chubut en cercanías de la localidad de Gaiman, provincia del Chubut, Argentina (Roth, 1908; Simpson, 1935; Mendía y Bayarsky, 1981) (Fig. 3.3): Acaremys preminutus (=Protacaremys prior) (Bordas, 1939); Protadelphomys latus (Vucetich y Bond, 1984); Willidevu esteparius (Vucetich y Verzi, 1991); Caviocricetus lucasi (Vucetich y Verzi, 1996); Protadelphomys morfotipo B, Prospaniomys sp. 2, sp. nov. grande, sp. nov. chica (Vucetich et al., 2010b).

- Sacanana Fm Sarmiento, Pampa de Gan Gan, provincia del Chubut, Argentina (Rusconi, 1933; Fleage y Bown, 1983) (Fig. 3.3): Prospaniomys cf. P. priscus (Arnal y Kramarz, 2010); Protadelphomys morfotipo B (Vucetich et al., 2010b).

- Paso Córdova Fm Chichinales, margen sur del Río Negro, provincia de Río Negro, Argentina (Barrio et al., 1989): Willidevu esteparius (Vucetich y Verzi, 1991); Caviocricetus lucasi (Barrio et al., 1989; Vucetich et al., 2010b).

- Sierra del Portezuelo Norte Fm Cerro Bandera, provincia del Neuquén, Argentina (Leanza y Hugo, 1997): Caviocricetus lucasi (Kramarz et al., 2005).

\subsection{2 "Edad Pinturense" (Fig. 3.1)}

La Fm Pinturas aflora en diversas zonas aisladas en el oeste de la provincia de Santa Cruz (Bown et al., 1988; Bown y Larriestra, 1990) (Fig. 3.3). Se corresponde en parte con las "couches á Astrapothericulus" de Ameghino (1906). La localidad tipo del "Pinturense" no esta definida. La sección tipo de la Fm Pinturas se divide en tres secuencias deposicionales separadas unas de otras por superficies erosivas intraformacionales: secuencias baja, media y alta (Bown y Larriestra, 1990; Fleagle et al., 1995). Siguiendo la evidencia paleoambiental, la secuencia baja se depositó bajo condiciones de bosques húmedos y cálidos, mientras que las secuencias más altas se depositaron bajo condiciones de climas más secos y ambientes más abiertos (Bown y Larriestra, 1990). 
Kramarz y Bellosi (2005) reconocieron dos asociaciones de roedores histricognatos para la Formación Pinturas: las secuencias deposicionales baja y media presentan una asociación de roedores particular: géneros colhuehuapenses representados por especies más derivadas, géneros santacrucenses representados por especies más primitivas y especies no halladas en otras unidades faunísticas. A esta asociación de roedores Kramarz y Bellosi (2005) la denominaron “asociación Pinturense”. Mientras que en la secuencia deposicional alta se recolectaron roedores que también se registran en los niveles más bajos de la Fm Santa Cruz en Monte León y Monte Observación y en la localidad de Karaiken (Spaniomys modestus, Phanomys mixtus).

Kramarz et al. (2010) concluyeron que los niveles del Upper Fossil Zone del Mb Colhue-Huapi de la Fm Sarmiento en Gran Barranca son también portadores de fauna Pinturense, extendiendo estratigráficamente y temporalmente el concepto de esta unidad faunística.

Dataciones para el "Pinturense": Fleagle et al. (1995) dataron rocas mediante $\mathrm{Ar}^{40} / \mathrm{Ar}^{39} \mathrm{e}$ indicaron edades de 17,76 y 17,67 Ma para niveles cercanos a la base de esta formación en la localidad de estancia El Carmen, mientras que para la parte más alta de la secuencia media, en la localidad de Portezuelo Sumich Norte, las edades son de 16,58 y 16,43 Ma. Ré et al. (2010) dataron el Upper Fossil Zone de la Formación Sarmiento en Gran Barranca entre 19,7-18,7 Ma. Por lo tanto, el "Pinturense" se extendería desde los 19,7 a los 16,43 Ma (Kramarz et al., 2010).

Localidades fosilíferas "Pinturenses" donde se encontraron octodontoideos:

- estancia Ana María (= Loma de las Ranas) Fm Pinturas, provincia de Santa Cruz, Argentina (Bown y Larriestra, 1990): Galileomys eurygnathus y Prostichomys bowni (Kramarz, 2004).

- Portezuelo Sumich Sur Fm Pinturas, provincia de Santa Cruz, Argentina (Bown y Larriestra, 1990): Prostichomys bowni (Kramarz, 2001a); Galileomys eurygnathus (Kramarz, 2004).

- Carmen bajo Fm Pinturas, provincia de Santa Cruz, Argentina (Bown y Larriestra, 1990): Prostichomys bowni (Kramarz, 2001a); Galileomys eurygnathus (Kramarz, 2004).

- Carmen alto Fm Pinturas, provincia de Santa Cruz, Argentina (Bown y Larriestra, 1990): Prostichomys bowni (Kramarz, 2001a). 
- Portezuelo Sumich Norte Fm Pinturas, provincia de Santa Cruz, Argentina (Bown y Larriestra, 1990): Prostichomys bowni (Kramarz, 2001a); Acarechimys sp., Galileomys eurygnathus (Kramarz, 2004).

- Cerro Los Monos Fm Pinturas, provincia de Santa Cruz, Argentina (Bown y Larriestra, 1990): Prostichomys bowni (Kramarz, 2001a); Galileomys eurygnathus (Kramarz, 2004).

- estancia los Toldos Norte Fm Pinturas, provincia de Santa Cruz, Argentina (Bown y Larriestra, 1990): Prostichomys bowni (Kramarz, 2001a); Galileomys eurygnathus (Kramarz, 2004).

- Loma de la Lluvia Fm Pinturas, provincia de Santa Cruz, Argentina (Bown y Larriestra, 1990): Prostichomys bowni (Kramarz, 2001a); Galileomys eurygnathus (Kramarz, 2004).

- Gran Barranca Fm Sarmiento, Mb Colhue-Huapi, Upper Fossil Zone, provincia del Chubut, Argentina (Ré et al., 2010): Acarechimys sp., Acaremys sp., Prostichomys bowni, Prostichomys cf. P. bowni (Kramarz et al., 2010).

\subsection{3 "Edad Mamífero" Santacrucense sensu stricto (Fig. 3.1)}

La "Edad Mamífero" Santacrucense está definida sobre la base de una asociación de mamíferos provenientes de la Fm Santa Cruz (Pascual et al., 1965). La Fm Santa Cruz aflora en numerosas localidades de Patagonia, entre el Golfo San Jorge y el norte de Tierra del Fuego, y es una de las formaciones de Sudamérica de la cual se recobraron mayor cantidad de especímenes fósiles (Marshall et al., 1983) (Fig. 3.3). La localidad tipo de la Fm Santa Cruz es Monte León (Marshall et al., 1983) y se ubica al sur de la desembocadura del río Santa Cruz, en la provincia homónima de Santa Cruz (Fig. 3.3).

Las dataciones indican distintas edades para el Santacrucense; sobre la base de estudios realizados en Monte León y Rincón del Buque Marshal et al. (1986b) indicaron que el Santacrucense se extendió entre los 17,6-16 Ma, correspondiéndose con el Mioceno inferior tardío. Fleagle et al. (1995) realizaron estudios de $\mathrm{Ar}^{40} / \mathrm{Ar}^{39}$ que indicaron edades de 16,42, 16,16 y 16,18 Ma en la sección más baja en Monte Observación, mientras que en Monte León las dataciones arrojaron una edad de 16,5616,28 Ma.

La mayoría de los especímenes estudiados por Ameghino en 1887 y 1889 no presentan datos de procedencia exactos; en muchos casos sólo se sabe que proceden de 
la provincia de Santa Cruz o de las "barrancas del Río Santa Cruz", sin que se haya anotado otro tipo de información.

A continuación se detallan las localidades fosilíferas Santacrucenses y localidades fosilíferas asignadas tentativamente a esta edad:

\section{Localidades fosilíferas santacrucenses donde se encontraron roedores} octodontoideos:

- Monte León Fm Santa Cruz, Departamento de Corpen Aike, provincia de Santa Cruz, Argentina (Marshall, 1976) (Fig. 3.3): Adelphomys sp., Sciamys principalis, Sciamys sp., Spaniomys sp., Stichomys sp. (Ameghino, 1894).

- Monte Observación (=Cerro Observatorio) Fm Santa Cruz, Departamento de Corpen Aike, provincia de Santa Cruz, Argentina (Marshall, 1976) (Fig. 3.3): Stichomys planus (Ameghino, 1891); Acarechimys minutus, A. minutissimus, A. constans, Acarechimys sp., Acaremys murinus, Sciamys principalis, Sciamys sp., Adelphomys sp., Stichomys arenarius, S. regularis, Stichomys sp., Spaniomys modestus, S. riparius, Spaniomys sp. (Ameghino, 1894).

- Corriguen Aike Fm Santa Cruz, Departamento de Güer Aike, provincia de Santa Cruz, Argentina (Marshall, 1976): Acaremys murinus, A. tricarinatus, Sciamys principalis, Sciamys sp., Stichomys regularis, S. regius (Ameghino, 1894).

- estancia La Angelina Fm Santa Cruz, Departamento de Güer Aike, provincia de Santa Cruz, Argentina (Marshall, 1976): Sciamys sp. (Ameghino, 1894).

- Barrancas del río Santa Cruz Fm Santa Cruz, provincia de Santa Cruz, Argentina (Marshall, 1976): Sciamys principalis, S. varians, Sciamys sp., Adelphomys candidus, Spaniomys sp. (Ameghino, 1887).

- Shehuén (=río Sehuén o río Chalia) Fm Santa Cruz, provincia de Santa Cruz, Argentina (Marshall, 1976): Stichomys regularis, S. gracilis, (Ameghino, 1891); Acarechimys minutus, Spaniomys riparius, Stichomys regius (Ameghino, 1894); Acarechimys minutus, Adelphomys eximius (Scott, 1905).

- estancia Killik Aike (=Felton's estancia) Fm Santa Cruz, Departamento de Güer Aike, provincia de Santa Cruz, Argentina (Marshall, 1976): Acaremys murinus, A. major, Acarechimys minutus, Sciamys latidens, S. principalis, S. varians (Scott, 1905).

- Estancia Halliday (=Estancia Los Pozos) Fm Santa Cruz, Departamento de Güer Aike, provincia de Santa Cruz, Argentina (Marshall, 1976): Acaremys karaikensis (Ameghino, 1891); Acaremys karaikensis (Scott, 1905). 
- La Cueva Fm Santa Cruz, Departamento de Corpen Aike, provincia de Santa Cruz, Argentina (Marshall, 1976): Acaremys murinus, Acarechimys minutissimus (Ameghino, 1894).

- 10 millas al sur de Coy Inlet Fm Santa Cruz, Departamento de Güer Aike, provincia de Santa Cruz, Argentina (Marshall, 1976): Acarechimys minutissimus, Sciamys rostratus, S. varians, S. robustus (Scott, 1905).

- estancia La Costa Fm Santa Cruz, Departamento de Güer Aike, provincia de Santa Cruz, Argentina (Marshall, 1976): Acarechimys minutus, A. minutissimus, Spaniomys riparius (Tauber, 1994).

-Cañadón Silva (5109'58', S y 69 08'13', O) (Tauber, 1997): Spaniomys riparius, Stichomys regularis (Tauber, 1997).

\section{Localidades fosilíferas asignadas tentativamente al Santacrucense sensu} stricto donde se encontraron octodontoideos:

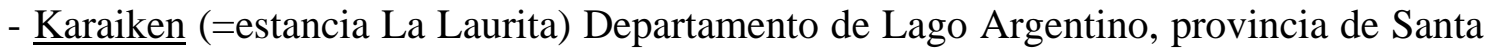
Cruz, Argentina (Marshall, 1976) (Fig. 3.3): Adelphomys sp., Sciamys principalis, Spaniomys modestus, Stichomys? (Ameghino 1902); Acaremys?, Adelphomys sp., Stichomys sp. (Kramarz, 2004).

Karaiken es la localidad tipo del horizonte Notohippidiense de Ameghino (1902), cuya fauna se asignó a la "Edad Mamífero" Santacrucense (Simpson, 1940; Marshall, 1976). Sin embargo, Marshall y Pascual (1977) consideraron que en la secuencia continental de los alrededores del Lago Argentino los fósiles provienen tanto del "piso" Notohippidiense como del Santacrucense de Ameghino, los cuales se corresponden a dos faunas distintas que se suceden temporalmente; el Notohippidiense correspondería a la parte más antigua de la "Edad Mamífero" Santacrucense (Marshall y Pascual, 1977).

- Cerro Boleadoras Fm Cerro Boleadoras, noroeste de la provincia de Santa Cruz, Argentina (Ugarte, 1956): Acarechimys sp., Stichomys sp., gen. et sp. indent. A, gen. et sp. indent. B y gen. et sp. indent. C (Vucetich, 1994).

Esta localidad fue asignada originariamente a la edad Friaseana en el sentido de Kraglievich (1930) por Ugarte (1956) sobre la base de los escasos restos de mamíferos colectados hasta ese momento. Carlini et al. (1993) sugirieron una edad Santacrucense para esta formación sobre la base del estudio de un Myrmecophagidae (Mammalia, Xenarthra). Sin embargo Scillato-Yané et al. (1993) propusieron que los xenartros 
provenientes de estos niveles son más modernos que los de la Fm Santa Cruz en sus típicas localidades costeras (Santacrucense s.s.) y más antiguos que los taxones provenientes de la Fm Collón Curá (Mioceno medio). Posteriormente, Vucetich (1994) indicó una edad Santacrucense para esta formación sobre la base del estudio de los roedores.

- estancia los Toldos Sur Fm Pinturas, secuencia superior?, provincia de Santa Cruz, Argentina (Bown y Larriestra, 1990; Kramarz y Bellosi, 2005): Spaniomys modestus (Ameghino, 1891); Acarechimys minutissimus, Acaremys sp., Spaniomys modestus, Stichomys spp. (Kramarz, 2004).

- estancia La Cañada Fm Pinturas, secuencia superior?, provincia de Santa Cruz, Argentina (Bown y Fleagle, 1993; Kramarz y Bellosi, 2005): Stichomys spp. (Kramarz, 2004).

- Gobernador Gregores Fm Pinturas?, provincia de Santa Cruz, Argentina (Bown y Fleagle, 1993; Kramarz y Bellosi, 2005) (Fig. 3.3): Acarechimys minutissimus, Acaremys sp., Adelphomys candidus, Spaniomys modestus (Kramarz, 2004).

- Lago Cardiel: Fm Pinturas?, provincia de Santa Cruz, Argentina (Bown y Fleagle, 1993; Kramarz y Bellosi, 2005) (Fig. 3.1): Acarechimys minutissimus, Acaremys sp., Adelphomys candidus, Spaniomys modestus, Stichomys spp. (Kramarz, 2004).

La correlación de las faunas provenientes de las localidades estancia La Cañada, Gobernador Gregores y Lago Cardiel con alguna de las "Edades Mamífero" es controvertida. Bown y Fleagle (1993) propusieron que estas localidades albergaban fauna asignable a las que caracterizan el "Astrapothericulense" de Ameghino (1906). Sin embargo, al menos los taxones de roedores que se encontraron en estas localidades se encuentran representados en el Santacrucense típico (Kramarz y Bellosi, 2005), y no en las secuencias bajas y medias de la Fm Pinturas.

-Las Hornillas Fm Chinches, Cordillera Frontal, provincia de San Juan, Argentina (López et al., 2010) (Fig. 3.2): Octodontoidea gen. et sp. indet. 1, gen. et sp. indet. 2 (López et al., 2010).

-Pampa Castillo Fm Río Zeballos?, provincia de Aisén, sur de Chile (Flynn et al., 2002) (Fig. 3.2): Stichomys sp.?, Spaniomys riparius, Acarechimys cf. A. minutus, Acarechimys sp. nov., Sciamys principalis (Flynn et al., 2002).

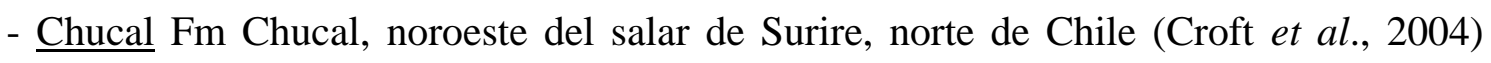

(Fig. 3.2): un octodontoideo no descripto (Croft et al., 2004). 
La fauna proveniente de Chucal se asigna a la "Edad Mamífero" Santacrucense sobre la base de la correlación bioestratigráfica y dataciones radioisotópicas (Croft et al., 2004).

La siguiente localidad presenta un caso especial y se la refiere en un apartado separado ya que sobre la base de la información bioestratigráfica, Flynn et al. (2008) consideraron que la Fm Cura-Mallín se extiende temporalmente en un lapso que abarca cuatro o cinco SALMA's (Colhuehuapense al Colloncurense/ Laventense). Las distintas faunas que se superponen en esta localidad, junto con las dataciones realizadas, indican que se trata de una de las mejores secuencias de SALMA's de Sudamérica (a excepción de Gran Barranca).

-Laguna del Laja Fm Cura-Mallín, Laguna del Laja, centro-este de Chile (Flynn et al., 2008) (Fig. 3.2): Gen. et sp. nov. (aff. Acarechimys), Gen. et sp. nov. cf. Maruchito, Maruchito sp. nov., Protacaremys sp. nov., cf. Protacaremys sp. nov., Prostichomys sp. nov. I, Prostichomys sp. nov. II, Acarechimys sp. nov., gen. et sp. nov. (aff. Prostichomys), gen. et sp. nov (aff. Protacaremys), gen. et sp. nov (aff. Prospaniomys) (Flynn et al., 2008).

\subsection{Mioceno medio}

\subsubsection{Faunas "Colloncurense" sensu stricto (Fig. 3.1)}

La "Edad Mamífero" Friasense sensu lato abarca parte del lapso temporal entre el Santacrucense y el Chasiquense (Bondesio et al., 1980; Marshall, 1983). Sobre la base de los mamíferos recolectados en diversas localidades de las provincias del Neuquén, Río Negro y Chubut, Roth (1898, 1908, 1920), Ameghino (1906) y Kraglievich (1930) reconocieron los horizontes "Colloncurense", "Friasense" y "Mayoense" (Bondesio et al., 1980). En este trabajo no se incluyeron roedores provenientes de los horizontes "Friasense" y "Mayoense", razón por la cual los mismos no se detallan a continuación. Sin embargo, se estudió una gran cantidad de ejemplares provenientes de yacimientos con sedimentos asignados a la Fm Collón Curá. La fauna proveniente de la Fm Collón Curá asociada a la Ignimbrita Pilcaniyeu caracteriza el “Colloncurense" sensu stricto (Vucetich et al., 1993). La localidad tipo de la Fm Collón Curá se encuentra en el valle inferior del río Collón Curá, provincia del Neuquén (Roth, 1898; Bondesio et al., 1980) (Fig. 3.3). Sobre la base de la fauna de roedores Vucetich et al. (1993) propusieron la siguiente secuencia faunística: santacrucense-"Friasense" 
s.s., "Colloncurense" s.s. y "Mayoense", presentando las faunas "Friasense" s.s. y "Colloncurense" s.s. afinidades con las Santacrucenses, mientras que la fauna "Mayoense" estaría más relacionada a la fauna Chasiquense (Mioceno tardío).

La definición de "Colloncurense" es motivo de controversia constante ya que las relaciones estratigráficas y cronológicas de los yacimientos asignados a dicha edad no son claras.

Dataciones radimétricas de la Ignimbrita Pilcaniyeu (Mb medio de la Fm Collón Curá) dieron distintos valores que varían entre 14,0 y 15,4 Ma (Bondesio et al., 1980) y 15,7 Ma (Flynn y Swisher, 1995), por lo cual se correlaciona el "Colloncurense" al Mioceno medio basal.

A continuación se detallan las localidades fosilíferas "Colloncurenses" y localidades fosilíferas asignadas tentativamente al "Colloncurense":

\section{Localidades fosilíferas asignadas al "Colloncurense" donde se encontraron} roedores octodontoideos:

- Río Senguer Fm Collón Curá, provincia del Neuquén (Fig. 3.3): Stichomys? (Vucetich, 1984).

- Cañadón del Tordillo Fm Collón Curá, provincia del Neuquén (Vucetich et al., 1993) (Fig. 3.3): Maruchito trilofodonte, Protacaremys denisae, Acarechimys sp. (Vucetich et al., 1993).

- Pilcaniyeu Viejo Fm Collón Curá, provincia de Río Negro (Bondesio et al., 1980) (Fig. 3.3): Plesiacarechimys koenigswaldi (Vucetich y Vieytes, 2006).

Localidades fosilíferas asignadas tentativamente al "Colloncurense" donde se encontraron roedores octodontoideos:

- Estancia Los Sauces Fm Collón Curá, Ingeniero Jacobacci, provincia de Río Negro, Argentina: Massoiamys obliquus (Vucetich, 1978).

- Río Senguer provincia del Chubut: Stichomys sp., Stichomys cf. regularis (Vucetich, 1984).

\subsection{2 “Edad Mamífero" Laventense (Fig. 3.1)}

La fauna de mamíferos proveniente del Grupo Honda en el área de La Venta (Colombia) muestra pocas semejanzas con las faunas de mamíferos colhuehuapenses, santacrucenses, colloncurenses y friasenses, aunque presenta menos semejanzas en 
comparación con las faunas de mamíferos más modernas, por lo que resulta complicado realizar correlaciones precisas con éstas. Sin embargo, en el Laventense se encuentran algunos taxones previamente considerados como fósiles guía de las edades Santacrucense y "Friasense" (Madden et al., 1997). Estos autores propusieron que la edad Laventense se ubica temporalmente entre el "Colloncurense" y el Chasiquense.

La edad Laventense se extiende desde los 11,8 hasta los 13,5 Ma. (Madden et al., 1997); la Fm Villavieja, de donde se extrajeron los roedores laventenses, se dató entre 12,9 a 11,5 Ma (Guerrero, 1997).

Localidades fosilíferas laventenses donde se encontraron roedores octodontoideos:

- La Venta Fm Villavieja, Grupo Honda, Valle superior del río Magdalena en La Venta, Colombia (Guerrero, 1997) (Fig. 3.2): Ricardomys longidens, Acarechimys cf. A. minutissimus, Echimyidae gen. et sp. indet. 1, Echimyidae? incertae sedis (Walton, 1997).

- Quebrada Honda Fm innominada, sudoeste de la localidad de Tarija, Bolivia (Croft, 2007) (Fig. 3.2): Acaremyinae sp. indet., Spaniomys sp. (Croft, 2007). 
CAPÍTULO 4

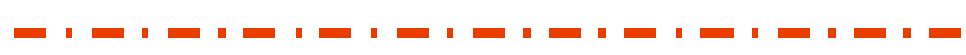

REVISIÓN

SISTEMÁTICA 


\subsection{Cronología del conocimiento y taxonomía de los Octodontoidea del Oligoceno tardío-Mioceno medio}

En el año 1887 Florentino Ameghino erigió el género Acaremys al que ubicó dentro de la familia Cercolabidae. Asignó tres especies a este género, las cuales se distinguían por sus tamaños: Acaremys murinus que es la especie tipo y la más grande de las tres, $A$. minutus y $A$. minutissimus, que es la más pequeña. De igual manera, Ameghino reconoció el género Sciamys, al cual también ubicó dentro de la familia Cercolabidae, junto con Acaremys. Para este género erigió dos especies que también se diferenciaban entre sí por su tamaño: Sciamys principalis (especie tipo y la más grande de las dos) y S. varians. Ese mismo año Ameghino describió las especies Adelphomys candidus, Stichomys regularis, S. constans, Spaniomys riparius y S. modentus las cuales incluyó dentro de la familia Echinomyidae. Un año más tarde, Ameghino realizó un estudio detallado con el objetivo de exhibir los resultados en la Exposición Universal que se llevaría a cabo en París el año siguiente. En 1889 presentó esta obra, que incluyó descripciones ampliadas de las especies creadas en 1887 y la descripción de nuevas especies; entre ellas erigió la especie Acaremys messor, que se caracterizaba por ser la especie más robusta del género hasta ese momento. Años más tarde, Ameghino (1891) reconoció la especie Acaremys karaikensis, que se caracterizaba por ser de mayor tamaño que A. messor; al mismo tiempo describió las especies Stichomys planus, $S$. gracilis y S. diminutus. Posteriormente, en el año 1894 erigió la especie Acaremys tricarinatus, que se caracterizaba por la particular morfología del p4, las especies Sciamys robustus y S. tenuissimus, que se distinguían entre sí por ser respectivamente la mayor y la menor de las especies del género Sciamys. Adicionalmente describió las especies Adelphomys eximius, Stichomys arenarius, S. regius y Spaniomys biplicatus. En el año 1902 Ameghino realizó cambios sistemáticos: Coendidae reemplazó a Cercolabidae; dentro de esta familia el autor estableció formalmente las agrupaciones Steiromyinae (Steiromys Ameghino, 1887 y géneros relacionados) y Acaremyinae (Acaremys, Sciamys y el nuevo género Protacaremys). Para Protacaremys reconoció tres especies que se diferenciaban entre sí por su tamaño y por características morfológicas: Protacaremys prior (especie tipo), P. avunculus y P. pulchellus. En este mismo trabajo erigió el género Prospaniomys que ubicó dentro de la familia Echinomyidae y para el cual reconoció una sola especie, P. priscus. A pesar de las semejanzas observables en la morfología dentaria entre Prospaniomys y los Acaremyinae, el autor ubicó a este nuevo género dentro de la familia Echinomyidae, 
sobre la base de características mandibulares y del incisivo. Ese mismo año, el autor erigió el género Eoctodon para el cual reconoció una especie, E. securiclatus, a la que ubicó dentro de la familia Octodontidae sobre la base de la morfología mandibular; Eoctodon era considerado como un integrante del tronco que dio origen a los “verdaderos octodóntidos”. Además, el autor describió la especie Protadelphomys latus y dentro de la familia Eocardidae reconoció un género y especie nueva: Palaeocardia mater.

En el año 1904 Ameghino reconoció la especie Protacaremys amplus, a la que ubicó dentro de la familia Coendidae. Adicionalmente asignó una especie nueva para género Eoctodon: E. crassiusculus, que se distingue de la especie tipo por ser de mayor tamaño y por la morfología oclusal.

Sobre la base de una gran cantidad de restos dentarios, craneanos, mandibulares y post craneanos, Scott (1905) realizó una revisión taxonómica de roedores santacrucense y reconoció nuevas especies. Observó que la mayoría de los roedores presentes en capas de esa edad presentaban semejanzas con los actuales. Dentro de la familia Erethizontidae reconoció la subfamilia Acaremyinae, donde incluyó a los géneros Acaremys y Sciamys. Asimismo, observó que este taxón debía ser elevado a rango familiar, ya que a pesar de presentar un patrón dentario comparable con los Erethizontinae, presentaban una morfología craneana y post-craneana distinta. Para el género Sciamys reconoció dos especies nuevas: $S$. rostratus (que presentaba características morfológicas intermedias entre $S$. principalis y $S$. varians) y S. latidens que presentaba características morfológicas semejantes a Acaremys. Al mismo tiempo, reconoció una nueva especie para el género Acaremys: A. major, que se caracterizaba por ser la especie de mayor tamaño. Por otro lado, Scott agrupó dentro de la subfamilia Loncherinae (Octodontidae) a Stichomys, Adelphomys, Spaniomys y las formas vivientes de Echimyidae (Kannabateomys, Echimys, Loncheres, etc.).

Bordas (1939) describió la especie Acaremys preminutus, proveniente de las “capas con Colpodon” de Patagonia, que representaba el registro más antiguo del género hasta ese momento (“Edad Mamífero” Colhuehuapense (Fig. 3.1, Capítulo 3). Por otro lado, el autor describió un ejemplar que refirió a la especie Stichomys regius con dudas (este ejemplar también representaría el registro más antiguo del género Stichomys). Siguiendo la propuesta Scott, el autor ubicó a Acaremys preminutus dentro de la familia Erethizontidae, subfamilia Acaremyinae y a la especie Stichomys regius dentro de la familia Octodontidae, subfamilia Loncherinae. 
En el año 1949 Wood describió el género Platypittamys, proveniente de sedimentos asignables a la "Edad Mamífero" Deseadense en la provincia del Chubut, Argentina. Para este género reconoció una sola especie, P. brachyodon, que incluyó dentro de la familia Acaremyidae Wood, 1949. Dentro de esta familia incluyó a Asteromys Ameghino, 1897 y Palmiramys Kraglievich, 1932 (de Patagonia y Uruguay respectivamente) de la "Edad Mamífero" Deseadense (Fig. 3.1, Capítulo 3), Protacaremys, Acaremys y Sciamys. Sobre la base de la morfología dentaria generalizada (en especial la del P4) y el tamaño del foramen infraorbitario, el autor propuso que Platypittamys podría ser el antecesor estructural del resto de los miembros de la Familia. Por otro lado, la morfología dentaria, craneana y post-craneana también generalizadas de Platypittamys indicaba que los Acaremyidae no estarían incluidos dentro de ninguna de las superfamilias de caviomorfos, sino que representarían el stock basal de Octodontoidea, Cavioidea y Chinchilloidea.

En el año 1959 Wood y Patterson estudiaron en profundidad los roedores deseadenses de Patagonia. Allí los autores sinonimizaron el término Acaremyinae de Ameghino (1902) y Acaremyidae de Wood (1949) con el término Octodontidae de Waterhouse (1839) e incluyeron dentro de esta familia a Platypittamys brachyodon. Además, erigieron el género Deseadomys para el cual reconocieron dos especies, $D$. arambourgi (especie tipo) y D. loomisi, y al cual incluyeron dentro de la familia Echimyidae junto con los géneros Protacaremys, Protadelphomys, Prospaniomys, Eoctodon, Spaniomys, Adelphomys y Stichomys y las formas vivientes de equímidos.

Patterson y Pascual (1968) describieron las especies Xylechimys obliquus del Deseadense de Patagonia y Paradelphomys fissus del Colhuehuapense de Patagonia. Adicionalmente, los autores realizaron una breve revisión sistemática de los Echimyidae actuales y fósiles donde erigieron la subfamilia Adelphomyinae, e incluyeron a Xylechimys, Deseadomys, Paradelphomys, Adelphomys y Stichomys.

En el año 1970 Hoffstetter y Lavocat describieron Sallamys pascuali del Deseadense de Salla, Bolivia. Los autores no lo incluyeron dentro de ninguna familia, aunque lo describieron como con una morfología dentaria similar a la de Platypittamys brachyodon.

En el año 1982 Patterson y Wood estudiaron la fauna de roedores deseadenses de Bolivia. En este trabajo erigieron el género Migraveramus, con una única especie: Migraveramus beatus; ésta fue incluida dentro de la familia Octodontidae, junto con Platypittamys. Además, los autores realizaron una revisión de Sallamys pascuali a quien 
ubicaron dentro de los Echimyidae, subfamilia Heteropsomyinae. Por otro lado, en este trabajo Patterson validó el género Acarechimys, el cual había sido nombrado por J. L. Kraglievich (1965: 258), pero no había sido publicado con las formalidades necesarias para que fuera considerado un nombre válido. Como especie tipo del género se estableció a Acaremys minutus (sinónimo: Stichomys gracilis Ameghino, 1891), mientras que las especies referidas fueron A. minutissimus (sinónimos: Stichomys diminutus Ameghino, 1891 y Sciamys tenuissimus Ameghino, 1894) y A. constans (sinónimo: Stichomys constans Ameghino, 1887). El género Acarechimys fue comparado por los autores con Protacaremys e incluido dentro de la familia Echimyidae.

En el año 1984 Vucetich y Bond describieron un nuevo octodontoideo que incluyeron dentro de la familia Echimyidae: Gaimanomys alwinea proveniente de Gaiman, Chubut (“Edad Mamífero” Colhuehuapense). Sin embargo, Vucetich et al., (1992) sobre la base de una mayor cantidad de restos dentarios determinaron que Protadelphomys latus y Gaimanomys alwinea representaban una misma especie.

Vucetich et al. (1993) describieron dos nuevos taxones que incluyeron dentro de la familia Echimyidae: una especie nueva del género Protacaremys, $P$. denisae y un nuevo taxón: Maruchito trilofodonte, ambos provenientes de sedimentos asignados a la “Edad Colloncurense” (Fig. 3.1, Capítulo 3) del Neuquén. En este mismo trabajo los autores reconocieron un ejemplar de los mismos niveles que asignaron a Acarechimys sp. extendiendo el biocrón de ambos géneros hasta el Mioceno medio.

Vucetich y Verzi (1996) describieron Caviocricetus lucasi, un roedor muy pequeño proveniente de terrenos asignados a la "Edad Mamífero" Colhuehuapense del Chubut, Argentina. Este roedor se caracteriza por presentar una morfología dentaria particular, única hasta el momento, para los roedores caviomorfos.

Kramarz en el año 2001 describió una nueva especie de equímido que denominó Prostichomys bowni para los niveles “Astrapothericulenses” de la Fm Pinturas (Mioceno temprano). Como lo indica su nombre, el autor relacionó esta especie con Stichomys y revalidó la subfamilia de equímidos Adelphomyinae.

En el año 2003 Vucetich y Kramarz describieron el género Galileomys, para el cual reconocieron dos especies: Galileomys antelucanus (especie tipo) recolectada en terrenos de la "Edad Mamífero" Colhuehuapense del Chubut y G.? colloncurensis proveniente de terrenos asignados a la "Edad Colloncurense" del Neuquén. En este mismo trabajo dieron a conocer el primer ejemplar de Acaremys murinus proveniente de 
terrenos asignados a la "Edad Mamífero” Colhuehuapense. Sobre la base de un análisis filogenético, los autores revalidaron y delimitaron sistemáticamente la Familia Acaremyidae.

Kramarz (2004) estudió en detalle la fauna de roedores provenientes de la Fm Pinturas, "Edad Pinturense” (Fig. 3.1, Capítulo 3) de la Provincia de Santa Cruz, Argentina. En este trabajo el autor describió la especie Galileomys eurygnathus, que se caracterizaba por ser más robusta que la especie tipo del género, G. antelucanus.

Posteriormente Frailey y Campbell (2004) dieron a conocer una de las faunas de roedores más antiguas de Sudamérica donde describieron Eosallamys paulacoutoi, E. simpsoni, Eospina woodi, Eosachacui lavocati y Eodelphomys almeidacomposi quienes fueron asignados a la familia Echimyidae. Adicionalmente, los autores reconocieron 3 especímenes referidos como Octodontoidea indet. A, B y C.

Vucetich y Vieytes (2006) describieron la especie Plesiacarechimys koenigswaldi proveniente de sedimentos de la Formación Collón Curá (“Edad Colloncurense”), en la provincia de Río Negro. Sobre la base de la microestructura del esmalte del incisivo, las homologías de la segunda cresta en los dientes inferiores y la retención del DP4/dp4 ubicaron a este taxón dentro de la superfamilia Octodontoidea.

En suma, en la actualidad se reconocen 49 especies de octodontoideos para el lapso Oligoceno-Mioceno medio, grupadas en 22 géneros. De éstas, 24 se clasifican dentro de la familia Echimyidae, 3 en la familia Acaremyidae, y 22 se consideran de posición sistemática incierta. A continuación, se re-describen y se revisan los status sistemáticos de aquellas especies que tradicionalmente han sido propuestas como relacionadas con el origen de los modernos Octodontidae.

Por último cabe aclarar que las revisiones sistemáticas de los octodontoideos se ordenaron siguiendo el orden alfabético de los géneros en cuestión. Dentro de cada género se describió en primer lugar la especie tipo. 


\title{
4.2 Revisión Sistemática
}

\author{
Orden RODENTIA Bodwich, 1821 \\ Suborden HYSTRICOGNATHI Tullberg, 1899 \\ Superfamilia OCTODONTOIDEA Waterhouse, 1839 \\ Género Acarechimys Patterson 1965 (en J. L. Kraglievich, 1965)
}

Especie tipo: Acaremys minutus Ameghino, 1887

Distribución geográfica y temporal: provincia del Chubut, Mioceno temprano "Edad Mamífero" Colhuehuapense; provincia de Santa Cruz, Mioceno temprano "Edad Pinturense”; provincia de Santa Cruz, Mioceno temprano cuspidal "Edad Mamífero” Santacrucense; provincia del Neuquén, Mioceno medio “Edad Colloncurense”; La Venta, Colombia, Mioceno medio “Edad Mamífero” Laventense.

Diagnosis enmendada y ampliada: octodontoideo de tamaño pequeño a muy pequeño. Molariformes de coronas más altas que en Protacaremys, de paredes convexas en vista lateral; las cúspides se distinguen de sus respectivas crestas y las crestas son delgadas y se encuentran separadas por valles amplios. Retención de los premolares de leche. Molares superiores tetralofodontes, con lofos transversos y ángulo antero-lingual redondeado; el anterolofo y el posterolofo se unen a las extremidades labiales del protolofo y metalofo en individuos juveniles delimitando las parafoseta y posterofoseta respectivamente. Molares inferiores con el metalofúlido II de desarrollo variable: interrumpido o ausente en m1-m2, ausente o interrumpido en el m3. dp4 con metalofúlido II de desarrollo variable y mesolófido unido al metacónido, o a veces cerca de él. Mandíbula con la muesca para la inserción del tendón del M. masseter medialis pars anterior (mmma) ubicada en la mitad superior de la mandíbula; cresta masetérica bien desarrollada y fosa masetérica moderadamente profunda o muy profunda anteriormente.

Comentarios: en la descripción original Patterson (en Patterson y Wood, 1982) describieron que el DP4 de Acarechimys presentaba la tendencia a la reducción y pérdida del metalofo. Sin embargo, esta característica no se observó en ninguno de los ejemplares estudiados. Por otro lado, Patterson describió que el anterolofo y el 
posterolofo del M1-M2 se acercan a las extremidades labiales del protolofo y metalofo respectivamente, uniéndose con poco desgaste; como esta característica es observable también en el M3, se reemplazó “M1-M2” por “molares” en la diagnosis. Además, se mencionó una característica del M3 y otra del m3 como diagnósticas del género (posterolofo reducido y metafléxido más profundo que mesofléxido respectivamente) que en esta diagnosis no fueron tenidas en cuenta ya que las mismas se encuentran ampliamente distribuidas dentro de los octodontoideos.

Scott (1905) realizó descripciones de A. minutus y A. minutissimus más extensas y detalladas que las realizadas por Ameghino. Sin embargo, las mismas presentan un nivel de detalle bajo. En esta revisión se intentó describir de forma completa estas dos especies, así como también las especies A. constans y A. pulchellus teniendo en cuenta un contexto sistemático y evolutivo distinto del de principios de siglo XX.

Historia y status sistemático del género Acarechimys: El nombre Acarechimys fue mencionado por J. L. Kraglievich (1965) en un pie de página y acreditado a Patterson. Este nombre fue formalizado en el año 1982 en un apéndice, supuestamente de la autoría de Bryan Patterson, del trabajo sobre los roedores Deseadense de Bolivia (Patterson y Wood, 1982, Apéndice 2). La especie tipo es Acaremys minutus Ameghino, 1887 (sinónimo senior de Stichomys gracilis Ameghino, 1891). Adicionalmente se refirieron al género otras dos especies A. minutissimus (sinónimo Stichomys diminutus Ameghino, 1891 y Sciamys tenuissimus Ameghino, 1894) y A. constans (sinónimo Stichomys constans Ameghino, 1887). En el año 2010 Vucetich et al. incluyeron en Acarechimys a A. pulchellus (originalmente descripta como Protacaremys pulchellus Ameghino, 1902).

Acarechimys minutus (Ameghino, 1887)

Sinónimos: Stichomys gracilis Ameghino, 1891. Esta sinonimia fue propuesta por Patterson, en Patterson y Wood (1982).

Sintipo: MLP 15-410a, fragmento mandibular izquierdo con m1-m3; MLP 15-410b, fragmento de paladar con M1-M3 de ambos lados; MACN A 238, mandíbula derecha con dp4-m3 e incisivo partido en el alvéolo. 
Tipo del sinónimo: MACN A 4263, fragmento mandibular izquierdo con dp4-m2.

Material referido: (Ver Apéndice 1)

Distribución geográfica, estratigráfica y edad: Niveles indeterminados de la Formación Santa Cruz aflorantes en las barrancas del río Santa Cruz, Monte Observación, Sehuen, Killik Aike, provincia de Santa Cruz; Fm Santa Cruz, Mioceno temprano cuspidal, “Edad Mamífero” Santacrucense.

Diagnosis modificada: especie aproximadamente $27 \%$ más pequeña que $A$. constans, $34 \%$ más pequeña que $A$. pulchellus y $13 \%$ mayor que $A$. minutissimus. Premolares deciduos inferiores con metalofúlido II y mesolófido de desarrollo variable. Molares inferiores con el metalofúlido II reducido en m1-m2 y ausente en m3; presencia de cúspide accesoria en la antero+mesofléxido de m1-m2 y extensión posterior del metacónido. Mandíbula con la mmma ubicada a nivel posterior del dp4.

Comentarios: la identificación del holotipo de A. minutus se presta a confusión, ya que no se ha realizado hasta el momento una asignación de los ejemplares que siga los requerimientos impuestos por el Código de Nomenclatura Zoológico que acepte como válida a esta especie (lo mismo ocurre con todas las especies del género). Estudiando esta problemática se reconocieron numerosos ejemplares que corresponderían al sintipo con el cual Ameghino realizó la descripción original y en la cual brinda detalles de dientes inferiores, mandíbula y paladar. En el MLP se encuentra depositado un fragmento mandibular con m1-m3 y un fragmento maxilar (MLP 15-410a y MLP 15410b) que fueron recolectados por Carlos Ameghino en las barrancas del río Santa Cruz. El paladar coincide con el de la descripción original; sin embargo la mandíbula no, ya que en ella sólo hay tres dientes, mientras que Ameghino da la medida de los 4 molariformes inferiores; esto puede haber ocurrido como consecuencia de una rotura del material a posteriori de la descripción original, o simplemente porque no fue con él con el que se realizó la descripción. Por otro lado, MACN A 238 (fragmento mandibular derecho con dp4-m3) se encuentra dibujado en el atlas de 1889 y coincide con la descripción original (figura 22, Lámina IV); se supone que los materiales figurados en el atlas tienen que ser los que estaban depositados en el MLP, ya que Ameghino hizo los dibujos entre los años 1888 y 1889 (en 1889 fue echado del MLP). Por lo expuesto 
anteriormente se concluye que los materiales con los que Ameghino realizó la descripción original de Acarechimys minutus se encuentran depositados en las colecciones de Paleontología del MACN y del MLP y se opta por no elegir un lectotipo.

Descripción: - Cráneo. Esta descripción se basa en un cráneo parcialmente completo (Fig. 4.1A-B) (YPM PU 15806) y en el fragmento maxilar que forma parte del sintipo (Fig. 4.1C) (MLP 15-410b); en el cráneo los nasales ocupan casi toda la porción dorsal del rostro y se extienden hasta el nivel de las raíces superiores de la arcada cigomática. Los procesos laterales del premaxilar se ensanchan en su porción posterior y terminan poco por detrás de los nasales (Fig. 4.1A). Los premaxilares ocupan la mitad anterior de la pared lateral del rostro. La porción vertical de la sutura premaxilar-maxilar es crenulada en su porción ventral, mientras que dorsalmente es recta y de disposición algo oblicua hacia delante; poco por debajo del límite dorsal del rostro, la sutura se dirige posteriormente. La fosa masetérica (sensu Patterson y Wood, 1982) está formada principalmente por el maxilar y secundariamente por el premaxilar; es poco profunda, de forma subtriangular y ventralmente está limitada por la tuberosidad del incisivo. Los frontales presentan sus márgenes laterales cóncavos y en su tercio posterior se hacen más anchos (Fig. 4.1A). La sutura con los premaxilares y con los nasales es crenulada. La raíz dorsal de la arcada cigomática se encuentra alineada con el borde posterior de los premaxilares. Ventralmente se continúa con la rama vertical de la arcada cigomática, que es poco oblicua en dirección posterior. La raíz ventral de la arcada cigomática nace poco por delante del DP4 (Fig. 4.1B); es casi tan alta dorso-ventralmente como ancha antero-posteriormente. En vista ventral, esta raíz se proyecta lateralmente, formando un arco que se continúa con la rama horizontal de la arcada cigomática (Fig. 4.1B). La tuberosidad masetérica se encuentra bien desarrollada y lateralmente se continúa con una depresión para la inserción del músculo masetero lateral (sensu Patterson y Wood, 1982), que es poco profunda. Posteriormente a la tuberosidad masetérica se observa un foramen bien desarrollado de homologías inciertas. En la cara dorsal de la raíz ventral de la arcada cigomática hay un surco para el pasaje del nervio infraorbitario muy poco desarrollado. La rama horizontal del cigoma es recta y poco divergente en vista ventral, mientras que en vista lateral es alta; la misma esta formada principalmente por el hueso yugal, el cual se extiende anteriormente hasta la base de la rama vertical de la arcada cigomática. La sutura yugal- maxilar es recta y oblicua postero-ventralmente anterodorsalmente. El proceso paraorbitario (sensu Verzi, 2001) se encuentra bien 
desarrollado y está formado por el yugal y una pequeña porción del escamoso. La fosa yugal se encuentra muy bien desarrollada; es larga, alta dorso-ventralmente y muy profunda. Ningún ejemplar preserva la porción posterior del cráneo.

El diastema es más largo que la serie premolo-molar y en vista ventral se ensancha posteriormente (Fig. 4.1B). Los forámenes incisivos se encuentran bien desarrollados; no se puede determinar el largo total, pero sí se observa que son anchos. Los forámenes incisivos se continúan posteriormente con los surcos diastemales, que se encuentran bien desarrollados y se extienden por el paladar hasta el nivel del DP4 (Fig. 4.1B-C). Las fosas maxilares son profundas. Los forámenes palatinos posteriores se encuentran bien desarrollados y se ubican a nivel del M1. Las narinas posteriores abren al nivel de la mitad posterior de los M2 (Fig. 4.1B-C).

- Dientes superiores. Las hileras dentarias superiores se disponen de forma paralela y se encuentran inclinadas labialmente respecto al plano horizontal del cráneo (Fig. 4.1B-C). La superficie oclusal presenta un aterrazamiento atenuado.

El DP4 es tetralofodonte y de contorno redondeado (Fig. 4.1E). El anterolofo es cóncavo hacia atrás y no alcanza el borde labial del diente. El protolofo se extiende desde el punto donde se une el brazo posterior del protocono y el muro; también es cóncavo, de disposición algo oblicua anteriormente y en su extremo labial se encuentra el paracono. El muro es corto y se encuentra dirigido postero-lingualmente. El metalofo se extiende desde el punto donde se une el muro con el brazo anterior del hipocono y se extiende labialmente hasta el metacono; al igual que las crestas anteriores es cóncavo posteriormente, y su porción más labial se encuentra algo orientada en dirección posterior. El posterolofo es cóncavo anteriormente y se une al extremo labial del metalofo delimitando la posterofoseta (Fig. 4.1E). El paraflexo y la posterofoseta son igualmente profundos y más penetrantes en la superficie oclusal que el mesoflexo, mientras que el mesoflexo es el más profundo de los flexos labiales. El hipoflexo es el flexo menos penetrante en la superficie oclusal, pero es el más profundo de todos; es oblicuo anteriormente.

Los molares son semejantes al premolar. Se diferencian en que en individuos juveniles el anterolofo se une al extremo labial del protolofo delimitando la parafoseta (Fig. 4.1D-E). Además, el área del protocono es más grande. El M3 se diferencia de los restantes molares por presentar el hipocono de posición labial respecto al protocono, y como consecuencia la porción posterior del diente se encuentra acortada labiolingualmente (Fig. 4.1D-E); en este diente el hipolofo y el posterolofo se unen en 
estados de desgaste muy tempranos. En lo concerniente a los flexos, la diferencia con el premolar radica en que el hipoflexo es más oblicuo anteriormente.

Los incisivos superiores son de sección oval. La cara esmaltada anterior es lisa; el borde lingual es recto, mientras que el labial es curvo. El extremo de ataque del diente se encuentra dirigido postero-ventralmente.

- Mandíbula. En la mandíbula el diastema es más corto que la serie premolo-molar; el mismo es marcadamente cóncavo dorsalmente y presenta la porción más baja por delante del dp4. En muy pocos ejemplares se observa un foramen mentoniano ubicado al nivel de la mitad anterior del dp4. La mmma se encuentra bien desarrollada y esta ubicada en la mitad superior de la mandíbula; es alargada y se extiende principalmente en la mitad posterior del dp4, como en A. minutissimus, y es poco oblicua en dirección ventral. La cresta masetérica se encuentra muy bien desarrollada y se continúa con el borde posterior de la mmma; esta cresta se encuentra bien proyectada lateralmente y se dispone en dirección postero-ventral (MACN A 237). La fosa masetérica es profunda en su porción anterior, como en A. pulchellus y los acarémidos. La fosa masetérica se encuentra limitada antero-dorsalmente por un surco poco desarrollado que se extiende desde la porción posterior de la muesca para el mmma hasta la base de la apófisis coronoides. La apófisis coronoides nace a nivel del borde posterior del m2; la misma se extiende postero-lateralmente delimitando una fosa retromolar lateral al m3. En la cara interna de la mandíbula se observa una sínfisis mandibular poco rugosa que se extiende hasta el borde posterior del m1; por delante del dp4 se observa un proceso mentoniano de tamaño mediano. Por detrás del proceso mentoniano la mandíbula se hace baja (Tabla 4.1a)

- Dientes inferiores. Los dp4 son más largos que anchos (Tabla 4.1b) (Fig. 4.1G) (MACN A 237). Presentan un metalofúlido I convexo anteriormente que une el protocónido labial y el metacónido lingual. Desde el borde posterior del protocónido se extiende el ectolófido, que es cóncavo lingualmente. Del borde postero-lingual del protocónido se extiende el metalofúlido II que suele estar reducido a simple spur como en $A$. minutissimus y algunos ejemplares de $A$. constans; esta cresta se dispone de forma oblicua en dirección postero-lingual. El mesolófido también tiene desarrollo variable: puede estar representado por una cresta que nace en el tercio posterior del ectolófido y toma contacto con el metacónido delimitando una cuenca anterior, como en A. constans, o puede estar reducido a una pequeña extensión del ectolófido, como en $A$. pulchellus (Fig. 4.1G). El hipolófido se extiende desde el punto donde se une el ectolófido y el 
brazo anterior del hipocónido; esta cresta es recta y alcanza el borde lingual del diente. El posterolófido es cóncavo anteriormente y, de la misma manera que el hipolófido, alcanza el borde lingual del diente. La anterofosétida es redondeada, poco profunda y puede estar unida al mesofléxido cuando el mesolófido esta reducido. El posterofléxido es poco más profundo y se cierra en individuos adultos. El hipofléxido es el más profundo de todos los fléxidos y es oblicuo en dirección posterior.

Los molares tienen tres crestas principales y una cuarta, segunda en posición, de desarrollo variable en los m1 y m2, pero ausente en el m3 (Fig. 4.1G). El metalofúlido I es recto y une el protocónido labial con el metacónido lingual; el metacónido se continúa posteriormente con el brazo posterior de metacónido, que se encuentra bien desarrollado incluso en el m3. Desde el borde posterior del protocónido se extiende el ectolófido que es bien oblicuo en dirección postero-lingual. En los m1 y en la mayor parte de los m2 disponibles puede observarse un metalofúlido II poco desarrollado o formando una pequeña extensión que nace del ectolófido, poco por detrás del protocónido. Lingualmente a dicha extensión se observa una cúspide accesoria que suele estar unida a una proyección posterior de la pared posterior del metalofúlido (Fig. 4.1G). El hipolófido y el posterolófido presentan una morfología semejante a la del dp4; se diferencian porque el extremo lingual del posterolófido se ubica muy cerca del entocónido, al igual que en A. minutissimus y A. pulchellus. El anterofléxido y el mesofléxido se unen delimitando un fléxido amplio; el posterofléxido es tan profundo como el fléxido anterior, aunque en individuos juveniles esta formando la posterofosétida. El hipofléxido es el más profundo de todos los fléxidos y es oblicuo posteriormente.

Los incisivos inferiores son comprimidos. La capa de esmalte anterior es gruesa; la cara anterior es lisa, con el borde lingual recto y el labial curvo. El diente es largo, se extiende por debajo de toda la rama horizontal de la mandíbula sobre el lado interno, prolongándose por detrás de la última muela, donde pasa al lado externo ascendiendo hacia la apófisis coronoides. 
Tabla 4.1a. Medidas mandibulares Acarechimys minutus (cm)

\begin{tabular}{lcl}
\hline MACN A 237 & AM2 & 0,448 \\
& AM3 & 0,300 \\
& & \\
MACN A 4062 & LDi & 0,484 \\
& AM1 & 0,400 \\
& AM2 & 0,592 \\
& AM3 & 0,324 \\
\hline
\end{tabular}

Tabla 4.1b. Medidas dentarias de Acarechimys minutus (mm)

\begin{tabular}{ccccc}
\hline & & LAP & AA & AP \\
\hline MACN A 237 & dp4-m3 & 6,20 & - & - \\
& dp4 & 1,66 & 1,10 & 1,30 \\
& m1 & 1,46 & 1,52 & 1,30 \\
& m2 & 1,66 & 1,70 & 1,54 \\
MACN A 4070 & m3 & 1,12 & 1,42 & 0,98 \\
& DP4-M3 & 6,96 & - & - \\
& DP4 & 1,66 & 1,90 & 1,90 \\
& M1 & 1,88 & 1,94 & 1,94 \\
MLP 15-410a & M2 & 1,88 & 2,00 & 2,00 \\
& M3 & 1,50 & 1,85 & 1,26 \\
& m1 & - & 1,46 & 1,52 \\
MLP 15-410b & m2 & 1,68 & 1,54 & 1,52 \\
& m3 & 1,56 & 1,48 & 1,08 \\
& M1 & 2,03 & 2,12 & 2,00 \\
& M2 & 2,02 & 2,30 & 2,24 \\
& M3 & 1,64 & 1,96 & 1,70 \\
\hline
\end{tabular}



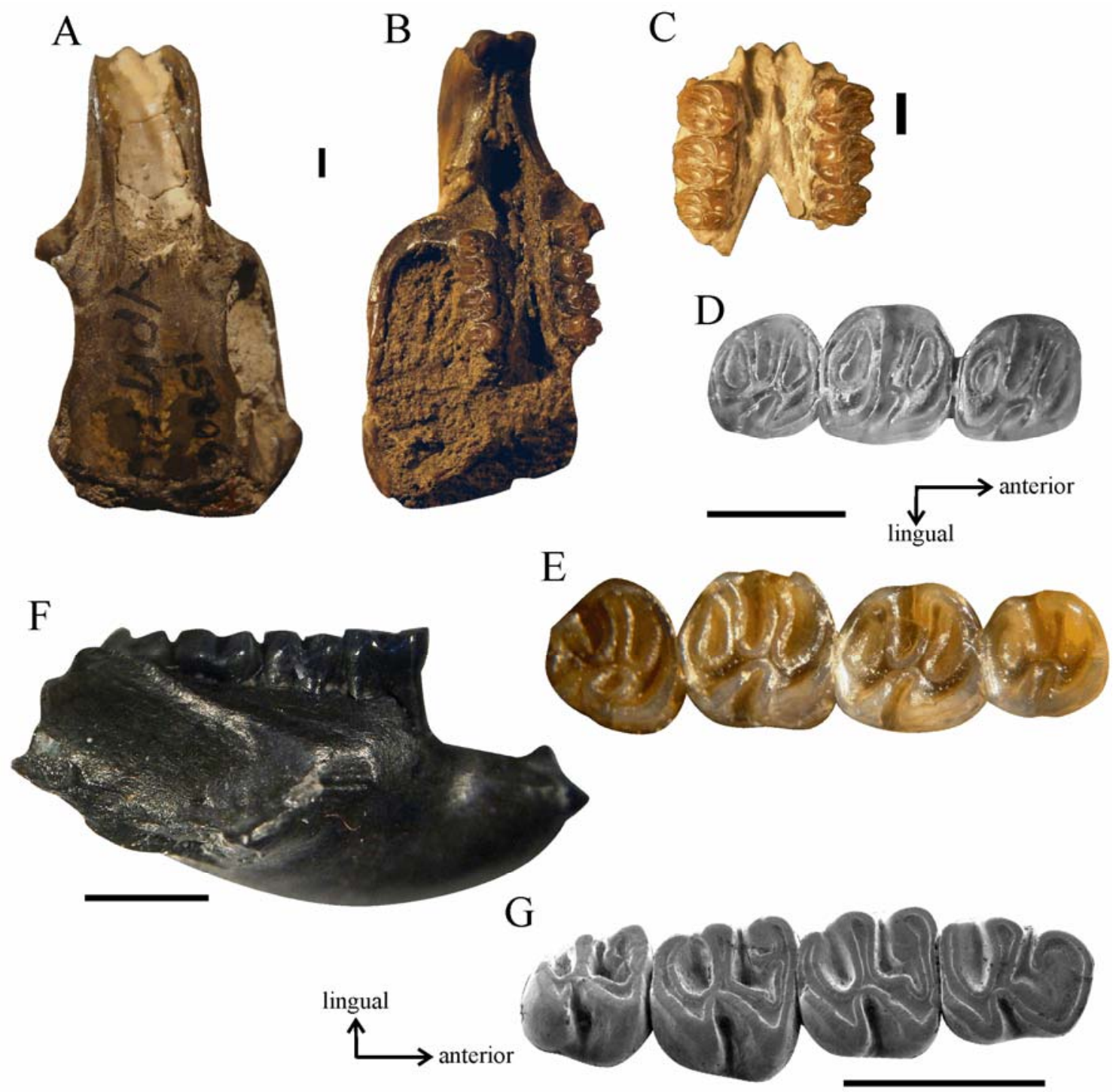

Figura 4.1. Acarechimys minutus. A-B. YPM PU 15806, cráneo incompleto. A:

Vista dorsal; B: vista ventral. C-D. MLP 15-410b, fragmento maxilar con M1-M3 izquierdo y derecho (Sintipo). C: vista ventral; D: M1-M3 derechos. E: YPM PU 15806, DP4-M3 derechos (invertido). F-G. MACN A 237, mandíbula derecha con dp4-m3 (sintipo); F: mandíbula en vista lateral; G: dp4-m3 derechos. Escala= $2 \mathrm{~mm}$ 
Acarechimys constans (Ameghino, 1887)

Holotipo: MLP 15-391, fragmento mandibular derecho con dp4-m3 e incisivo partido.

Material referido: (Ver Apéndice 1)

Distribución geográfica, estratigráfica y edad: barrancas del río Santa Cruz y Monte Observación, provincia de Santa Cruz; Fm Santa Cruz, Mioceno temprano cuspidal, “Edad Mamífero” Santacrucense.

Diagnosis modificada: especie un $22 \%$ más grande que A. minutus. Premolares inferiores con metalofúlido II de desarrollo variable: puede estar bien desarrollado o reducido a una pequeña extensión; mesolófido bien desarrollado a diferencia de $A$. minutus. En los molares inferiores el metalofúlido II generalmente bien desarrollado en el m1, mientras que en m2-m3 se encuentra reducido, a diferencia de A. minutus y $A$. minutissimus; presencia de cúspide accesoria de posición labial al metalofúlido II; en individuos juveniles el hipofléxido confluye con el posterofléxido. Incisivos inferiores no comprimidos y con la cara anterior curva a diferencia de las restantes especies del género. Mandíbula con la muesca para la inserción del tendón del M. masseter medialis pars anterior (mmma) poco desarrollada y ubicada a nivel del borde posterior del dp4mitad anterior del m1, como en A. pulchellus y a diferencia de A. minutus. A diferencia de las restantes especies del género la base de la apófisis coronoides nace a nivel del m3.

Comentarios: Como en la especie tratada anteriormente, la identificación del holotipo de A. constans se presta a confusión. Estudiando esta problemática se observó que MLP 15-391 coincide con la descripción original de Ameghino realizada en el año 1887 y con la descripción ampliada que realizó el mismo autor en el año 1889. En el MACN hay dos ejemplares rotulados como tipos de A. constans (MACN A 247 y MACN A 248a) y además están dibujados en el atlas de 1889. Todos estos ejemplares corresponderían al sintipo con el que Ameghino realizó la descripción original. Sin embargo, sólo MLP 15391 coincide con la descripción original por lo que se corresponde con el holotipo. Adicionalmente, cabe aclarar que Ameghino (1889) figuró como Stichomys constans (=Acarechimys constans) un fragmento de paladar con las dos hileras dentarias (MACN 
A 246) (Lámina VI, Fig. 8). Este ejemplar no pertenece a esta especie. B. Patterson asignó de manera informal dicho material a la especie Adelphomys candidus, idea con la que se coincide en este trabajo.

Descripción:- Dientes inferiores. El dp4 presenta el metalofúlido I bien desarrollado; el mismo es convexo anteriormente y une el protocónido con el metacónido. Desde el borde postero-lingual del protocónido se extiende el metalofúlido II que presenta distinto grado de desarrollo: puede estar bien desarrollado y dividir la anterofosétida en dos (MACN A 4064; MLP 15-391) (Fig. 4.2A-B), mientras que en otros ejemplares forma una cresta reducida que no alcanza el mesolófido (MACN A 247; MACN A 4075). Desde el borde posterior del protocónido se extiende el ectolófido que es bien cóncavo lingualmente. Cerca del extremo posterior del ectolófido nace el mesolófido que siempre se encuentra bien desarrollado, como en A. minutissimus; es algo cóncavo anteriormente y es oblicuo hacia delante alcanzando el metacónido (Fig. 4.2A-B). De esta manera queda delimitada una cuenca anterior, que está divida en dos en aquellos ejemplares donde el metalofúlido II está bien desarrollado (Fig. 4.2A-B). En el punto donde se unen el ectolófido con el brazo anterior del hipocónido nace el hipolófido. Esta cresta es recta y alcanza el borde lingual del diente. Posteriormente se observa un posterolófido que es cóncavo anteriormente y que alcanza el borde lingual del diente (Fig. 4.2A-B). La anterofosétida es redondeada y es la fosétida/ fléxido menos profunda de todas. El mesofléxido es angosto, mientras que el posterofléxido es el más amplio y profundo de los fléxidos/fosétidas linguales. El hipofléxido se orienta posteriormente y es el más profundo de todos.

En los molares inferiores el metalofúlido I es convexo anteriormente, como en A. pulchellus (Fig. 4.2A-B). Desde el borde posterior del protocónido se extiende el ectolófido que es oblicuo en dirección postero-lingual. En la mitad del largo del ectolófido nace el metalofúlido II. El m1 presenta un metalofúlido II corto, pero más desarrollado que en los restantes molares (Fig. 4.2A-B). Alineada labio-lingualmente con el extremo lingual del metalofúlido II se observa una cúspide accesoria, que es comprimida antero-posteriormente (Fig. 4.2A). Algunos ejemplares presentan en este diente una expansión que nace del borde posterior del metalofúlido I y que se dirige posteriormente hasta tomar contacto con la cúspide accesoria. El m2 presenta una morfología simplificada ya que el metalofúlido II se encuentra reducido (Fig. 4.2A-B), mientras que en el m3 esta cresta desapareció. La porción posterior de los molares es 
semejante a la del premolar con el hipolófido y posterolófido bien desarrollados (Fig. 4.2A-B). La única diferencia reside en que en individuos juveniles el hipofléxido confluye con el posterofléxido, ya que el brazo anterior del hipocónido no se une al extremo labial del hipolófido.

Los incisivos inferiores no son comprimidos. La cara esmaltada anterior es más delgada que en las restantes especies del género; es lisa y curva. El diente es largo, ya que pasa por debajo del m3 y termina lateralmente a este diente.

- Mandíbula. En la mandíbula el foramen mentoniano puede o no estar presente; en el caso que se encuentre presente, el mismo se ubica a nivel de la mitad anterior del dp4 o poco por delante de él (Fig. 4.2D). La muesca para la inserción del tendón del mmma se encuentra menos conspicua que en las restantes especies del género; es corta anteroposteriormente y se ubica en el límite entre el dp4-m1 (Fig. 4.2C-D), algo por detrás que en A. minutus y A. minutissimus, y como en A. pulchellus. La cresta masetérica se encuentra bien desarrollada y se continúa con el borde posterior de la mmma; se proyecta lateralmente y se dirige en dirección postero-ventral desde su origen. La fosa masetérica es tan profunda como en A. minutus, y, al igual que A. pulchellus, tiene una posición más posterior ya que su extremo anterior se ubica a nivel del m2 (Fig. 4.2D). El surco que limita la fosa masetérica antero-dorsalmente se encuentra poco desarrollado. La base de la apófisis coronoides nace a nivel del m3 (Fig. 4.2C-D) a diferencia de las restantes especies del género; la misma se extiende posterolateralmente delimitando una fosa retromolar esencialmente lateral al m3. En la cara interna de la mandíbula se observa una sínfisis mandibular poco rugosa que se extiende hasta el nivel del $\mathrm{m} 1$; por delante del dp4 se observa un proceso mentoniano poco desarrollado. 
Tabla 4.2. Medidas dentarias de Acarechimys constans (mm)

\begin{tabular}{ccccc}
\hline & & LAP & AA & AP \\
\hline MLP 15-391 & dp4-m3 & 8,74 & - & - \\
& $\mathrm{dp} 4$ & 2,28 & 1,42 & 1,68 \\
& $\mathrm{~m} 1$ & 2,02 & 1,98 & 1,96 \\
& $\mathrm{~m} 2$ & 2,08 & 2,00 & 1,98 \\
MACN A 247 & $\mathrm{m} 3$ & 1,74 & - & 1,64 \\
& $\mathrm{dp} 4-\mathrm{m} 2$ & 6,98 & - & - \\
& $\mathrm{dp} 4$ & 2,30 & 1,38 & 1,52 \\
MACN A 4075 & $\mathrm{m} 1$ & 2,22 & 2,06 & 1,90 \\
& $\mathrm{~m} 2$ & 2,24 & 2,06 & 1,98 \\
& $\mathrm{dp} 4-\mathrm{m} 1$ & 4,38 & - & - \\
& $\mathrm{dp} 4$ & 2,22 & 1,30 & 1,46 \\
& $\mathrm{~m} 1$ & 2,10 & 1,74 & 1,64 \\
\hline
\end{tabular}



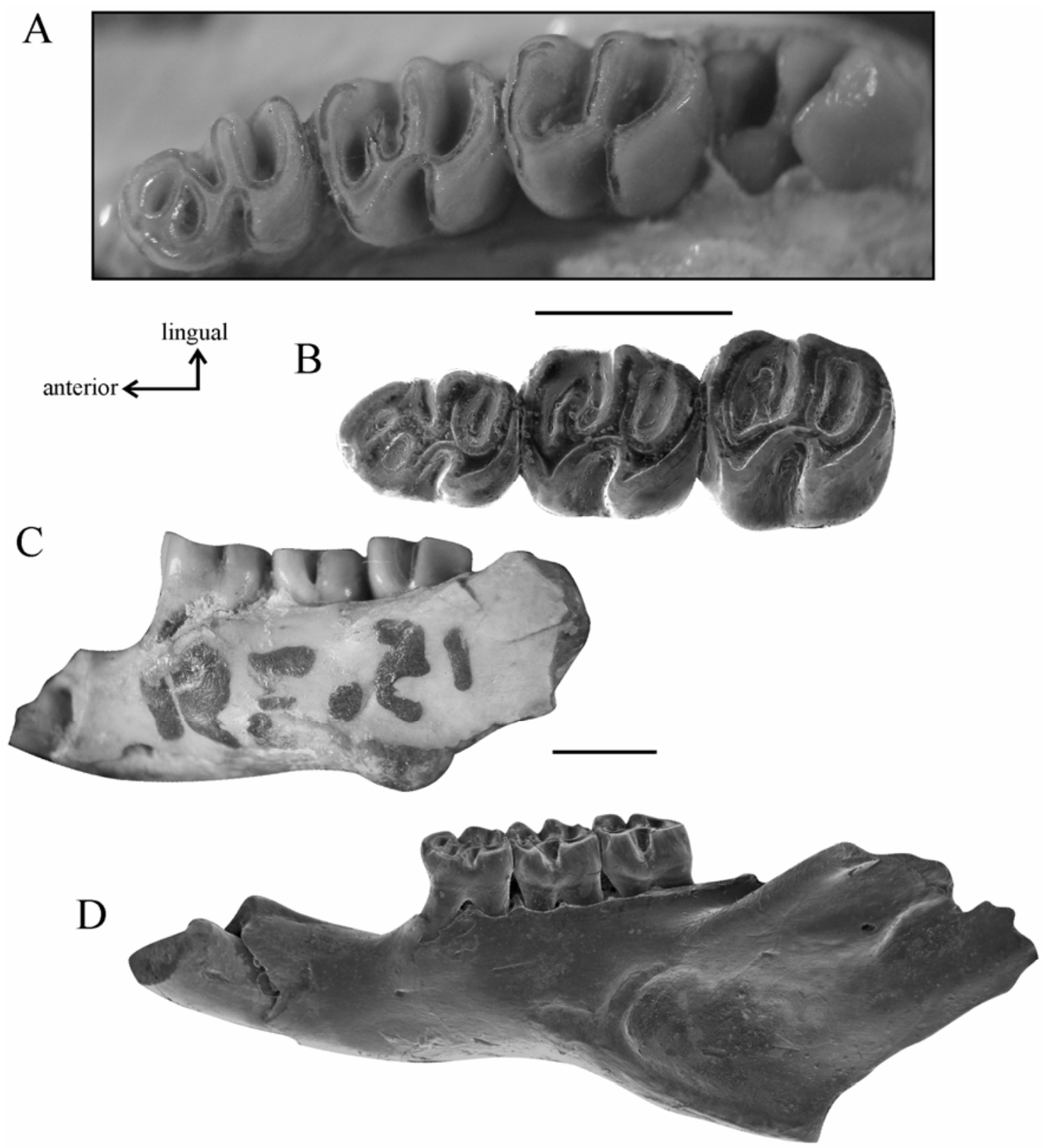

Figura 4.2. Acarechimys constans. A. MLP 15-391, dp4-m3 en vista oclusal (invertido) (holotipo). $B$. MACN A 4064, dp4-m2. C. MLP 15-391, fragmento mandibular en vista lateral (invertido) (holotipo). $D$. MACN A 4064, mandíbula en vista externa. Escala= $2 \mathrm{~mm}$ 
Acarechimys minutissimus (Ameghino, 1887)

Sinónimos: Stichomys diminutus Ameghino, 1891; Sciamys tenuissimus Ameghino, 1894. Estas sinonimias fueron propuestas por Patterson en Patterson y Wood (1982).

Sintipo: MACN A 256, Mandíbula izquierda casi completa con dp4-m3; MACN A 257, Mandíbula izquierda casi completa con dp4-m3; MACN A 258, mandíbula derecha con toda la dentadura; MLP 15-188, fragmento mandibular izquierdo con dp4-m3 e incisivo partido.

Tipos de los sinónimos: MACN A 4145, fragmento maxilar derecho con DP4 y MACN A 4146, fragmento mandíbula derecho con dp4 (S. tenuissimus); MACN A 4265, fragmento mandibular derecho con dp4-m1 (S. diminutus).

Material referido: (Ver Apéndice 1)

Distribución geográfica, estratigráfica y edad: niveles tentativamente asignados a la Formación Pinturas en Gobernador Gregores, Lago Cardiel, Portezuelo Sumich Norte, Toldos Sur, provincia de Santa Cruz, “Edad Pinturense?”. Niveles de la Fm Santa Cruz en Karaiken, provincia de Santa Cruz, Mioceno temprano cuspidal, "Edad Mamífero" Santacrucense. Barrancas del río Santa Cruz, Monte Observación, Yacimiento Dipilus y 10 millas al sur de Coy Inlet, provincia de Santa Cruz; Fm Santa Cruz, Mioceno temprano cuspidal, “Edad Mamífero” Santacrucense.

Diagnosis modificada: tamaño muy pequeño, 15\% menor que A. minutus. Premolares deciduos inferiores con metalofúlido II reducido y mesolófido bien desarrollado a diferencia de A. minutus. Molares inferiores con el metalofúlido II ausente en m1-m3, o reducido a una pequeña extensión del ectolófido en el $\mathrm{m} 1$; presencia de cúspide accesoria en la antero+mesofléxido de m1-m2 y sin brazo posterior del metacónido a diferencia de A. minutus. Incisivos inferiores de tamaño grande en relación al tamaño de la mandíbula en comparado con las restantes especies del género. Mandíbula con la muesca para la inserción del tendón del M. masseter medialis pars anterior (mmma) ubicada a nivel posterior del dp4-m1 como en A. minutus. 
Comentarios: al igual que en las dos especies descriptas anteriormente, la identificación del holotipo de A. minutissimus presta a confusión, ya que no se ha realizado hasta el momento una asignación de los ejemplares que siga los requerimientos impuestos por el Código de Nomenclatura Zoológico que acepte como válida a esta especie (lo mismo ocurre con todas las especies del género). Estudiando esta problemática se reconocieron algunos ejemplares que corresponderían al sintipo con el cual Ameghino realizó la descripción original y en la cual brinda detalles de dientes inferiores y mandíbula. En el MLP se encuentra depositado un fragmento mandibular con dp4-m3 (MLP 15-188) que fue recolectado por Carlos Ameghino en las barrancas del río Santa Cruz. Esta mandíbula coincide con la descripción original, que por cierto es muy vaga. Además, en el Museo Argentino de Ciencias Naturales se identificó el ejemplar MACN A 257 que se encuentra dibujado en el atlas de 1889 y coincide con la descripción original (figura 24, Lámina IV). Si nos basamos en el mismo supuesto de que los materiales figurados en el atlas tienen que ser los que estaban depositados en el MLP, se concluye que los materiales con los que Ameghino realizó la descripción original de Acarechimys minutissimus se encuentran depositados en las colecciones de Paleontología del MACN y del MLP y se opta por no elegir un Lectotipo.

\section{Descripción:}

- Cráneo. Se dispone de muy pocos fragmentos de cráneo preservados asignables a esta especie (MACN A 12683; YPM PU 15178). En la cara ventral del rostro se observan los forámenes incisivos muy bien desarrollados como en A. minutus, los cuales se continúan posteriormente con las crestas diastemales, que se extienden hasta el borde anterior de la porción interdentaria del paladar. La raíz ventral de la arcada cigomática nace poco por delante del DP4 y presenta el largo antero-posterior semejante al alto dorso-ventral. Al igual que en la especie tipo la tuberosidad masetérica se encuentra bien desarrollada; lateralmente a ella se observa una depresión para la inserción del músculo masetero lateral que es poco profunda. A diferencia de $A$. minutus, no se observa un foramen por detrás de la tuberosidad masetérica. En la cara dorsal de la raíz ventral de la arcada cigomática se observa un surco para el pasaje del nervio infraorbitario muy poco desarrollado.

- Dientes superiores. Al igual que en A. minutus, las hileras dentarias superiores se disponen de forma paralela y se encuentran inclinadas labialmente respecto al plano 
horizontal del cráneo. Dentro de la hilera dentaria el M2 es el diente de mayor tamaño, mientras que el DP4 y M3 son los más pequeños. La superficie oclusal presenta un aterrazamiento atenuado.

El DP4 es tetralofodonte y de contorno redondeado. A diferencia de la especie tipo, el anterolofo es más corto, recto y dispuesto de forma oblicua hacia delante. El protolofo nace en el punto donde se une el brazo posterior del protocono y el muro y a diferencia de A. minutus es recto, algo oblicuo anteriormente y en su extremo labial se encuentra el paracono. El muro es corto y se encuentra dirigido postero-lingualmente. El metalofo se extiende desde el punto donde se une el muro con el brazo anterior del hipocono hasta el metacono; al igual que el protolofo es cóncavo posteriormente, pero se diferencia en que es oblicuo posteriormente. El posterolofo es cóncavo anteriormente y se une al extremo labial del metalofo delimitando la posterofoseta. El paraflexo es el menos profundo de los flexos y es tan penetrante en la superficie oclusal como el mesoflexo, que es el flexo labial más profundo; la posterofoseta es la más penetrante en la superficie oclusal. El hipoflexo es el flexo menos penetrante en la superficie oclusal, pero es el más profundo de todos; es oblicuo anteriormente.

Los molares son semejantes al premolar. Se diferencian en que el paracono se encuentra mejor desarrollado que en la especie tipo y en que el área del protocono es más redondeada. En relación con los flexos, la diferencia con el premolar radica en que el hipoflexo es más amplio.

Los incisivos superiores son semejantes a los de la especie tipo; presentan sección oval. La capa de esmalte es gruesa. La cara esmaltada anterior es lisa, con el borde lingual recto y el labial curvo.

- Dientes inferiores. El dp4 presenta el metalofúlido I bien desarrollado; es convexo anteriormente y une el protocónido con el metacónido. Posteriormente, el metalofúlido II se encuentra reducido a una pequeña extensión, como en A. minutus y algunos ejemplares de A. constans (Fig. 4.3A-B). Desde el borde posterior del protocónido se extiende el ectolófido, que es cóncavo lingualmente. En su tercio posterior nace el mesolófido; esta cresta se encuentra bien desarrollada como en A. constans y generalmente toma contacto con el metacónido, delimitando una cuenca anterior redondeada (Fig. 4.3A-B). El hipolófido nace en el punto donde se une el ectolófido con el brazo anterior del hipocono; es recto y alcanza el borde lingual del diente. Posteriormente, del borde lingual del hipocónido se extiende el posterolófido que es cóncavo anteriormente y alcanza el borde lingual del diente (Fig. 4.3A-B). La 
anterofosétida es redondeada y poco profunda. El posterofléxido es algo más profundo y se cierra en individuos adultos; el mesofléxido es el más profundo de los fléxidos linguales y permanece abierto incluso en individuos adultos. El hipofléxido es el más profundo de todos los fléxidos y es oblicuo en dirección posterior. En los ejemplares provenientes de la Fm Pinturas el ectolófido pierde la conexión con el protocónido, de manera que el anterofléxido permanece abierto labialmente.

Los molares son trilofodontes, ya que el metalofúlido II está ausente o reducido a una pequeña extensión solamente en el m1 (Fig. 4.3A-B). El metalofúlido I suele ser recto y de disposición transversal, estando el protocónido y el metacónido alineados labio-lingualmente; sin embargo, en algunos ejemplares el metacónido puede tener una posición más anterior, por lo que el metalofúlido I es oblicuo anteriormente. Como consecuencia de la reducción del metalofúlido II el anterofléxido y mesofléxido confluyen, delimitando un gran fléxido anterior. En los m1-m2 puede observarse una cúspide accesoria en este fléxido anterior (Fig. 4.3A-B). El hipolófido y el posterolófido presentan una morfología semejante a la del dp4; se diferencian en que el extremo lingual del posterolófido se ubica muy cerca del entocónido al igual que en $A$. minutus y A. pulchellus. El posterofléxido es tan profundo como el fléxido anterior. El hipofléxido es el más profundo de todos los fléxidos y se orienta en dirección posterior.

Los incisivos inferiores son proporcionalmente grandes en relación al tamaño de la mandíbula. La capa de esmalte es gruesa. La cara esmaltada anterior es lisa, con el borde lingual recto y el labial curvo.

- Mandíbula. La mandíbula de A. minutissimus es robusta. Al igual que en las restantes especies del género el diastema es más corto que la serie premolo-molar y muy cóncavo dorsalmente. No hay un foramen mentoniano (Fig. 4.3C-D). La mmma se encuentra bien desarrollada; al igual que A. minutus es alargada antero-posteriormente, extendiéndose a lo largo del dp4 y la porción anterior del m1. La cresta masetérica se encuentra muy bien desarrollada y se continúa con el borde posterior de la mmma (Fig. 4.3C-D); esta cresta es muy protuberante y se dispone en dirección postero-ventral. La fosa masetérica es profunda en su porción anterior, más que en la especie tipo y semejante a los acarémidos (Fig. 4.3C-D). El surco que limita la fosa masetérica anterodorsalmente se encuentra poco desarrollado. La base de la apófisis coronoides nace a nivel del $\mathrm{m} 2$ como en $A$. minutus y A. pulchellus; la misma se extiende posterolateralmente delimitando una fosa retromolar lateral al m3. En la cara interna de la 
mandíbula se observa una sínfisis mandibular poco rugosa que se extiende hasta el nivel del m1; por delante del dp4 se observa un proceso mentoniano poco desarrollado.

Tabla 4.3a. Medidas mandibulares Acarechimys minutissimus (cm)

\begin{tabular}{lcl}
\hline MACN A 256 & LDi & 0,290 \\
& AM1 & 0,298 \\
& AM2 & 0,344 \\
& AM3 & 0,212 \\
& & \\
MACN A 258 & LDi & 0,292 \\
& AM1 & 0,262 \\
& AM2 & 0,348 \\
AM3 & 0,242 \\
\hline
\end{tabular}

Tabla 4.3b. Medidas dentarias de Acarechimys minutissimus (mm)

\begin{tabular}{ccccc}
\hline & & LAP & AA & AP \\
\hline MACN A 256 & dp4-m3 & 5,62 & - & - \\
& $\mathrm{dp} 4$ & 1,48 & 0,96 & 0,98 \\
& $\mathrm{~m} 1$ & 1,30 & 1,26 & 1,16 \\
& $\mathrm{~m} 2$ & 1,36 & 1,40 & 1,12 \\
\multirow{2}{*}{ MACN A 258 } & $\mathrm{m} 3$ & 1,10 & 1,06 & 0,98 \\
& $\mathrm{dp} 4-\mathrm{m} 3$ & 5,36 & - & - \\
& $\mathrm{dp} 4$ & 1,44 & 1,02 & 1,08 \\
& $\mathrm{~m} 1$ & 1,40 & 1,26 & 1,22 \\
& $\mathrm{~m} 2$ & 1,46 & 1,38 & 1,36 \\
& $\mathrm{~m} 3$ & 1,20 & 1,26 & 0,98 \\
& $\mathrm{dp} 4-\mathrm{m} 3$ & 5,42 & - & - \\
& $\mathrm{dp} 4$ & 1,48 & 1,04 & 1,14 \\
& $\mathrm{~m} 1$ & 1,44 & 1,28 & 1,26 \\
& $\mathrm{~m} 2$ & 1,42 & 1,38 & 1,40 \\
& $\mathrm{~m} 3$ & 1,24 & 1,22 & 1,04 \\
\hline
\end{tabular}




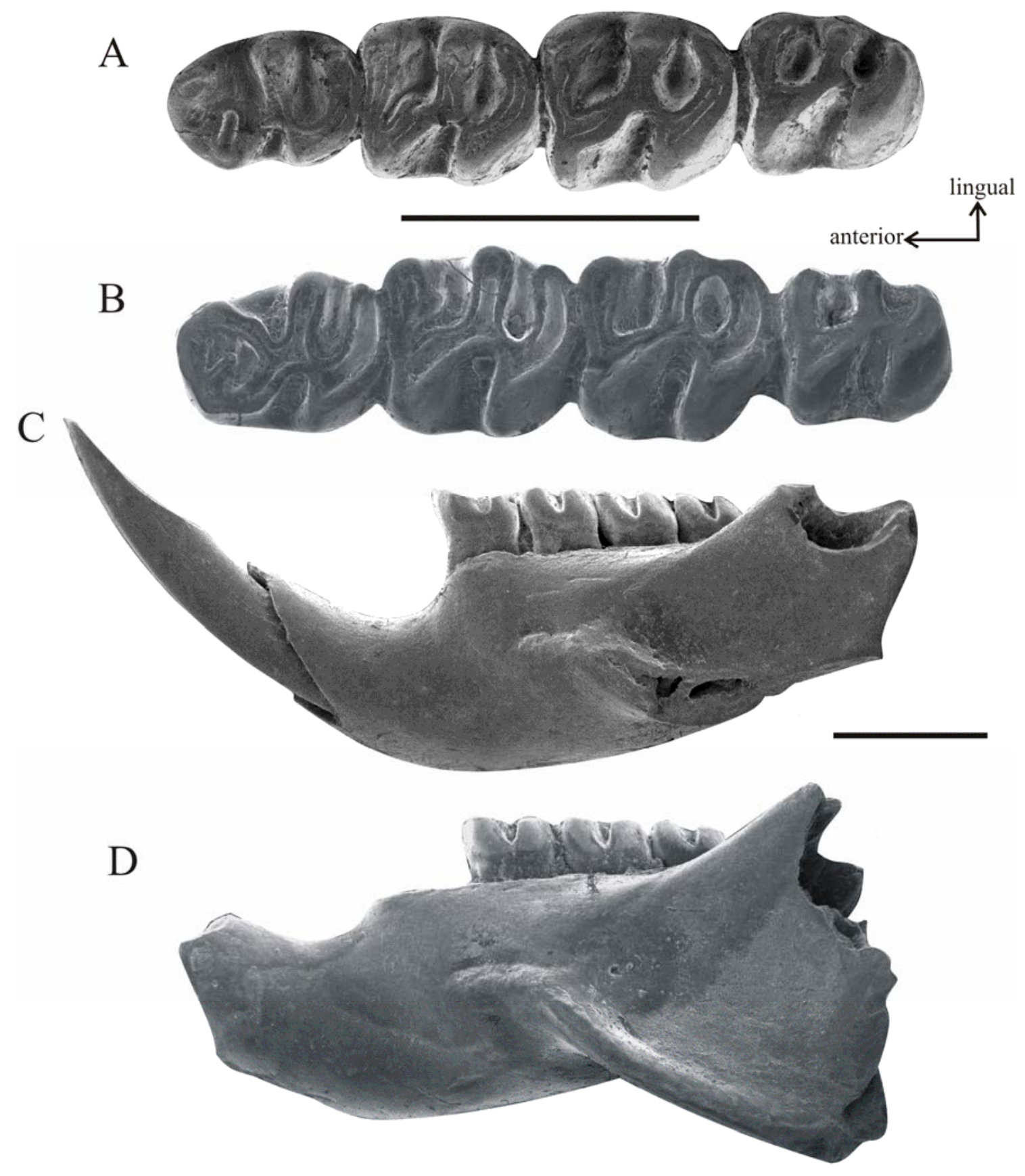

Figura 4.3. Acarechimys minutissimus. A: MACN A 256, dp4-m3 izquierdos (sintipo). B: MACN A 4076, vista oclusal de dp4-m3 (invertido). $C$ : MACN A 258, fragmento mandibular derecho con toda la dentadura (invertido) (sintipo). $D$ : MACN A 4093, fragmento mandibular izquierdo con m1-m3. Escala $=2 \mathrm{~mm}$ 
Acarechimys pulchellus (Ameghino, 1902)

Holotipo: MACN A 52-128, fragmento mandibular izquierdo con dp4-m3 e incisivo partido.

Material referido: (Ver Apéndice 1)

Procedencia geográfica, estratigráfica y edad: barranca sur del lago Colhue Huapi, provincia del Chubut; Fm Sarmiento, Miembro Colhué Huapi; Mioceno temprano, “Edad Mamífero” Colhuehuapense. Monte Observación, provincia de Santa Cruz; Fm Santa Cruz, Mioceno temprano cuspidal, “Edad Mamífero” Santacrucense.

Diagnosis ampliada: especie 25\% más grande que $A$. minutus. Premolares deciduos inferiores con metalofúlido II bien desarrollado y mesolófido reducido a diferencia de las restantes especies del género; $\mathrm{m} 1$ con el metalofúlido II de desarrollo variable, mientras que se encuentra reducido en m2-m3; presencia de cúspide accesoria y de brazo posterior del metacónido. Mandíbula sin foramen mentoniano y con la muesca para la inserción del tendón del M. masseter medialis pars anterior (mmma) ubicada a nivel posterior del dp4 y anterior del $\mathrm{m} 1$ como en $A$. constans y a diferencia de $A$. minutus.

Descripción:- Dientes inferiores. El dp4 es de menor tamaño en relación a los molares, comparado con las restantes especies del género (Tabla 4.4). Este diente presenta un metalofúlido I convexo anteriormente que une el protocónido labial y el metacónido lingual. Desde el borde posterior del protocónido se extiende el ectolófido, que es cóncavo lingualmente. Del borde postero-lingual del protocónido se extiende el metalofúlido II que se encuentra bien desarrollado y es oblicuo en dirección posterolingual como en A. minutissimus y A. constans (Fig. 4.4A). El está reducido a una extensión (Fig. 4.4A); en cualquiera de los dos casos, esta cresta se une al extremo del metalofúlido II y metalofúlido I delimitando una cuenca anterior. El hipolófido nace en el punto donde se une el ectolófido y el brazo anterior del hipocónido; esta cresta es recta, algo oblicua posteriormente y alcanza el borde lingual del diente. El posterolófido es cóncavo anteriormente y al igual que el hipolófido alcanza el borde lingual del diente (Fig. 4.4A). La anterofosétida es redondeada, poco profunda y se encuentra dividida en 
dos por el metalofúlido II (Fig. 4.4A). El mesofléxido y posterofléxido son más profundos. El hipofléxido es el más profundo de todos los fléxidos y es oblicuo en dirección posterior.

Los molares inferiores tienen tres crestas principales y una cuarta, segunda en posición de desarrollo variable (Fig. 4.4A). El metalofúlido I es convexo anteriormente, como en A. constans; esta cresta une el protocónido labial con el metacónido lingual. El metacónido se proyecta posteriormente formando un brazo posterior, el cual se encuentra bien desarrollado en todos los molares (Fig. 4.4A). El metalofúlido II se encuentra reducido en el m1-m3, aunque está mejor desarrollado en el m1 (Fig. 4.4A). Alineado labio-lingualmente al extremo posterior del brazo posterior del metacónido y el metalofúlido II se observa una cúspide accesoria, que también esta presente en el m3 (Fig. 4.4A). El hipolófido y posterolófido presentan desarrollo y morfología semejante a la del premolar. Como consecuencia de la reducción del metalofúlido II el anterofléxido y mesofléxido confluyen, delimitando un gran fléxido anterior que es tan profundo como el posterofléxido. El hipofléxido es el más profundo de todos y se dispone de forma oblicua en dirección posterior.

Los incisivos inferiores son robustos y algo comprimidos lateralmente. La capa de esmalte es gruesa. La cara esmaltada anterior es lisa, con el borde lingual recto y el labial curvo. El diente es largo, pasa por debajo del m3 en dirección externa y su extremo posterior se evidencia como un abultamiento en la mandíbula.

- Mandíbula. La mandíbula presenta un diastema corto y cóncavo, como en las restantes especies de Acarechimys. No hay un foramen mentoniano (Fig. 4.4B). La mmma se encuentra bien desarrollada; al igual que en A. constans tiene una posición posterior, entre el borde posterior del dp4 y la mitad anterior del m1 (Fig. 4.4B) y es alargada antero-posteriormente. La cresta masetérica esta bien desarrollada y se continúa con el borde posterior de la muesca (Fig. 4.4B); se encuentra bien proyectada lateralmente y se dirige en dirección postero-ventral desde sus orígenes. La fosa masetérica es algo más profunda que en A. constans, aunque menos que en A. minutissimus (Fig. 4.4B). Al igual que las restantes especies, el surco que limita la fosa masetérica anterodorsalmente no se encuentra bien desarrollado. La apófisis coronoides nace a nivel del m2 (Fig. 4.4B); se extiende postero-lateralmente delimitando una fosa retromolar esencialmente lateral al m3, que se extiende anteriormente hasta el m2. El borde anterior de la apófisis coronoides es recto y su extremo dorsal se ubica por encima de la hilera de dientes. Por detrás de la apófisis coronoides hay una escotadura mandibular 
larga antero-posteriormente y poco profunda. En la cara interna de la mandíbula se observa una sínfisis mandibular poco rugosa que se extiende hasta el nivel del dp4; a nivel del borde anterior del dp4 se observa un proceso mentoniano de tamaño mediano.

Comentarios: Protacaremys pulchellus fue creada por Ameghino en el año 1902. Vucetich et al. (2010b) incluyeron la especie Protacaremys pulchellus dentro del género Acarechimys, creando una nueva combinación: Acarechimys pulchellus. En dicho trabajo, los autores listaron una serie de caracteres que avalan dicho cambio sistemático (molares con aspecto menos columnar, trigónido mucho más corto, crestas más anchas y menos oblicuas que se encuentran separadas por fléxidos que se transforman en fosétidas con poco desgaste, y mesolófido reducido en m2-m3). En este análisis se asignan nuevos ejemplares que se encontraban rotulados en las colecciones del MACN como “Acarechimys sp.” (in Schedule).

Tabla 4.4. Medidas dentarias de Acarechimys pulchellus (mm)

\begin{tabular}{lcccc}
\hline & & LAP & AA & AP \\
\hline MACN A 52-128 & dp4-m3 & 7,96 & - & - \\
& dp4 & 1,88 & 1,38 & 1,44 \\
& $\mathrm{~m} 1$ & 1,90 & 1,96 & 1,68 \\
& $\mathrm{~m} 2$ & 1,91 & 2,02 & 1,98 \\
MACN A 4060 & $\mathrm{m} 3$ & 1,74 & 1,70 & 1,30 \\
& $\mathrm{dp} 4-\mathrm{m} 3$ & 8,98 & - & - \\
& $\mathrm{dp} 4$ & 2,30 & 1,46 & 1,50 \\
& $\mathrm{~m} 1$ & 2,12 & 1,96 & 1,84 \\
MACN A 4061 & $\mathrm{m} 2$ & 2,42 & 2,06 & 1,84 \\
& $\mathrm{~m} 3$ & 2,20 & 1,68 & 1,58 \\
& $\mathrm{dp} 4-\mathrm{m} 3$ & 7,98 & - & - \\
& $\mathrm{dp} 4$ & 2,08 & 1,36 & 1,52 \\
& $\mathrm{~m} 1$ & 2,00 & 1,84 & 1,66 \\
& $\mathrm{~m} 2$ & 2,02 & 2,00 & 1,84 \\
& $\mathrm{~m} 3$ & 1,78 & 1,68 & 1,40 \\
\hline
\end{tabular}



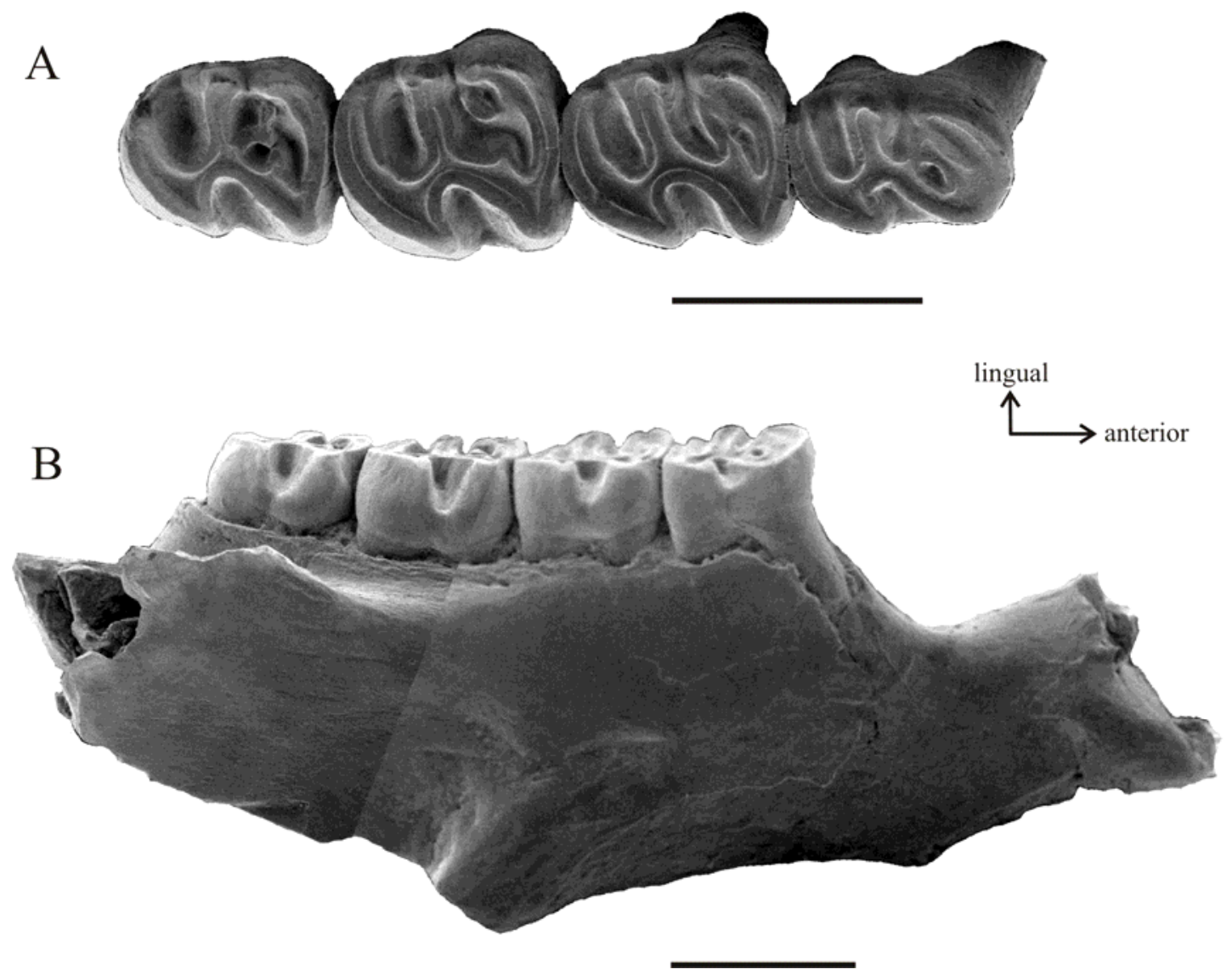

Figura 4.4. Acarechimys pulchellus. A-B. MACN A 52-128, mandíbula derecha con dp4-m3 e incisivo partido (holotipo); $A$ : dp4-m3 en vista oclusal; $B$ : mandíbula en vista externa. Escala= $2 \mathbf{m m}$ Imágenes tomadas de Vucetich et al. (2010b) 
Género “Acaremys” Ameghino, 1887

Especie tipo: Acaremys murinus Ameghino, 1887

Distribución geográfica y temporal: provincia del Chubut, Mioceno temprano "Edad Mamífero" Colhuehuapense; provincia de Santa Cruz, Mioceno temprano "Edad Pinturense” y Mioceno temprano cuspidal “Edad Mamífero” Santacrucense.

Diagnosis: Octodontoidea de tamaño pequeño a mediano. Dientes de coronas más altas que en Platypittamys y Galileomys, y más bajas que en Sciamys. Hipsodoncia unilateral presente, menos evidente que en Sciamys. Las cúspides se diferencian de las crestas solo en estados de desgaste casi nulos. Hileras dentarias paralelas, como en Sciamys principalis. Premolar superior con hipoflexo poco desarrollado, a diferencia de Sciamys, y con metalofo ausente o reducido. Premolar inferior con un fléxido en la cresta anterior que separa el protocónido del metacónido, menos desarrollado que en Galileomys, aunque más desarrollado que en Sciamys. En los molares inferiores el posterolófido es largo, a diferencia de Galileomys. Muesca para la inserción del tendón del M. masseter medialis pars anterior (mmma) bien desarrollada. La fosa masetérica mandibular es muy profunda anteriormente, a diferencia de Sciamys. En el cráneo la fosa masetérica es amplia y está limitada anteriormente por un reborde, los nasales presentan un foramen de homologías inciertas en la mitad de su largo antero-posterior; la rama vertical del cigoma es más delgada que en Sciamys, el proceso postorbital y la cresta sagital se encuentran bien desarrollados a diferencia de Sciamys.

Comentarios generales: como ocurre con numerosos materiales recolectados por C. Ameghino y descriptos por F. Ameghino en el año 1887, en muchos casos no se pudo identificar con certeza los ejemplares que conformaron el sintipo con los que trabajó el autor, ya que las primeras descripciones fueron muy vagas y no se numeraron los ejemplares ni se dio información de procedencia de la mayor parte de los mismos. Sin embargo, se realizó un estudio exhaustivo de los materiales recolectados por Ameghino y se investigó la información concerniente del tema [Patterson, 1952 (manuscrito inédito), Marshall, 1980; Fernicola, 2011] con el fin de identificar los materiales con los que Ameghino realizó las descripciones de los años 1887 y 1889. 
A pesar de que los resultados del análisis filogenético (Capítulo 5) demostraron que "Acaremys" no es un género monofilético tal como se lo reconocía hasta el momento, en este capítulo se listaran dentro de este género una nueva especie y las especies tradicionalmente asignadas a “Acaremys”. Esto se debe a que la intención es realizar una taxonomía alfa, no tomar decisiones taxonómicas formales. Sin embargo, la diagnosis del género se basa principalmente en la descripción de los caracteres presentes en la especie tipo y en las características que éste y las especies tradicionalmente asignadas a “Acaremys” comparten.

Acaremys murinus Ameghino, 1887

Sinonimia: Acaremys karaikensis Ameghino, 1891.

Sintipo: MACN A 266, mandíbula derecha con p4-m3 e incisivo partido; MLP 15-410, porción anterior de un cráneo con DP4-M1 e incisivos partidos.

Tipo del sinónimo: MACN A 1885, cráneo en mal estado de preservación con toda la dentadura.

Material referido: (Ver Apéndice 1)

Distribución geográfica, estratigráfica y edad: Gran Barranca, provincia del Chubut; Fm Sarmiento, Miembro Colhué Huapi, Mioceno temprano, "Edad Mamífero” Colhuehuapense; Los Toldos Sur, Gobernador Gregores, Lago Cardiel, provincia de Santa Cruz, Fm Pinturas?; Karaiken, provincia de Santa Cruz, Fm Santa Cruz?, "Edad Mamífero” Santacrucense?; barrancas del río Santa Cruz, Corrigen Aike, estancia Halliday, Monte León, 10 millas al sur de Coy Inlet provincia de Santa Cruz, Fm Santa Cruz, Mioceno temprano cuspidal, “Edad Mamífero” Santacrucense.

Diagnosis: roedor de tamaño semejante a “ $A$ ". tricarinatus. La parafoseta y la posterofoseta cerradas en individuos juveniles, mientras que en individuos seniles éstas desaparecen y los dientes adquieren forma de 8. Premolar inferior simple, con metalofúlido I, posterolófido, ectolófido bien desarrollados y metalofúlido II en distinto 
grado de desarrollo. En el cráneo, los procesos ascendentes de los premaxilares son más cortos que los nasales, a diferencia de Sciamys principalis.

Descripción:- Cráneo. Octodontoidea de tamaño pequeño a mediano. Los huesos nasales son más anchos en su porción anterior y se van angostando posteriormente; los mismos se extienden por detrás de los premaxilares, hasta la raíz dorsal de la arcada cigomática y hasta el nivel del M1. Los premaxilares ocupan la mitad anterior de la pared lateral del rostro; los procesos ascendentes del premaxilar ocupan gran parte de la porción dorsal del rostro (Fig. 4.5A), a diferencia de S. principalis, y son más cortos que los nasales, alcanzando el nivel del P4. La fosa masetérica incluye al alveolo del incisivo y se encuentra formada principalmente por el hueso maxilar y en menor medida por el hueso premaxilar; al igual que en Sciamys principalis, anteriormente se encuentra limitada por un reborde del premaxilar que se extiende desde el borde dorsal del rostro en dirección ventral (Fig. 4.5C). Los huesos frontales son angostos anteriormente y se ensanchan hacia atrás. La sutura del frontal con los nasales y premaxilares es muy crenulada. Posteriormente a la orbita, el frontal forma un pequeño proceso postorbitario; por detrás del mismo hay una pequeña constricción post-orbitaria (AMNH 9280). La raíz dorsal de la arcada cigomática se ubica a nivel del M1; se continúa con la rama vertical del cigoma que es grácil (a diferencia de Sciamys principalis, donde es robusta) y oblicua anteriormente (AMNH 9280) (Fig. 4.5C). La raíz ventral de la arcada cigomática nace por delante del P4 y su largo antero-posterior es similar al alto dorsoventral a diferencia de “Acaremys” sp. nov. En vista ventral, esta raíz se proyecta lateralmente, formando un arco que se continúa con la rama horizontal de la arcada cigomática. La tuberosidad masetérica (para la inserción del músculo masetero superficial) se encuentra bien desarrollada. En la cara dorsal de la raíz ventral de la arcada cigomática se observa un surco bien desarrollado para el pasaje del nervio infraorbitario.

El diastema en vista lateral es cóncavo en su porción anterior, mientras que su porción posterior es plana. En vista ventral, el diastema se va ensanchando posteriormente (Fig. 4.5B) (Tabla 4.5a), al igual que en las especies de Sciamys. Las fosas maxilares son muy profundas. Los forámenes incisivos se encuentran bien desarrollados y la sutura premaxilar-maxilar los intersecta aproximadamente en la mitad de su largo antero-posterior (Fig. 4.5B). Posteriormente, los forámenes incisivos se continúan con los rebordes diastemales que se extienden hasta el borde anterior de la porción interdentaria del paladar. Los forámenes palatinos posteriores son pequeños y se 
encuentran a nivel del P4-M1 (Fig. 4.5B). En la línea media de esta porción del paladar hay una quilla muy poco desarrollada. Posteriormente, las narinas abren a nivel del M3 o del límite entre M2-M3.

- Dientes superiores. Las hileras dentarias superiores son paralelas entre sí y se encuentran inclinadas labialmente respecto al plano horizontal del cráneo, como consecuencia de la hipsodoncia unilateral (Fig. 4.5B). Los molariformes son protohipsodontes bajos. En especímenes jóvenes las cúspides labiales en los dientes superiores se diferencian de las crestas; en algunos especímenes las cúspides linguales se encuentran comprimidas antero-posteriormente, dando el aspecto de ser acuminadas. Los P4/p4 son de menor tamaño que los molares (Tabla 4.5b); a medida que los dientes se van desgastando aumentan su diámetro labio-lingual.

El DP4 es tetralofodonte y es más largo que ancho (Tabla 4.5b) (Fig. 4.5D-E). El anterolofo es convexo anteriormente y alcanza el borde labial del diente; en la cara anterior del anterolofo, cerca del protocono, se observa un pequeño hundimiento, de manera semejante a lo que presenta Prospaniomys priscus. El protolofo es recto y de disposición oblicua anteriormente; en su extremo labial se une con el paracono (Fig. 4.5D-E). Ambas crestas permanecen separadas, incluso en estados de desgaste avanzados. En el ejemplar tipo la tercera cresta en posición se encuentra reducida y no alcanza el borde labial del diente (Fig. 4.5E); esto indica que se trata del mesolófulo, siendo la cuarta cresta en posición el metalofo+posterolofo. En los restantes ejemplares asignados a Acaremys murinus que presentan DP4 (MACN A 10092, PV SC 2588) la identidad de la tercera y cuarta cresta se encuentra enmascarada debido a que los dientes presentan mayor desgaste (Fig. 4.5D). El postero+metalofo se encuentra bien desarrollado; es cóncavo anteriormente y su extremo lingual se une con el metacono (Fig. 4.5D-E). El mesoflexo es el más amplio y profundo; mientras que el paraflexo y el posteroflexo/foseta son poco profundos. El hipoflexo es oblicuo anteriormente y poco penetrante en la superficie oclusal, aunque es el más profundo de los flexos.

El P4 tiene tres crestas bien desarrolladas y una cuarta, el metalofo, de desarrollo variable (Fig. 4.5F). La superficie oclusal es de contorno subcircular. El anterolofo es bajo, convexo anteriormente y no llega al borde labial del diente. El protolofo es la cresta mejor desarrollada; nace desde el protocono y puede extenderse labialmente de forma recta al eje antero-posterior del diente, o ser oblicuo posteriormente; en su extremo labial se observa el paracono, que es la cúspide mejor desarrollada (Fig. 4.5F). El metalofo puede estar ausente o reducido a una pequeña cresta que se une al 
posterolofo rápidamente con el desgaste. El protocono se encuentra mejor desarrollado que el hipocono, del cual está separado por un hipoflexo poco desarrollado, a diferencia de las especies de Sciamys. Los dos flexos labiales penetran hasta 3/4 de la superficie oclusal siendo, el flexo posterior considerablemente más amplio y profundo.

Los molares superiores son tetralofodontes y semejantes a los de las especies de Sciamys, de los que se diferencian por el menor grado de hipsodoncia. Con poco desgaste presentan contorno redondeado y crestas más delgadas que los flexos; a medida que aumenta el desgaste los dientes se hacen más anchos que largos. El anterolofo es largo y curvo, y desde estadíos tempranos de poco desgaste toma contacto con el paracono, delimitando una parafoseta poco profunda (Fig. 4.5D). El protolofo es la cresta mejor desarrollada; es recta y perpendicular al eje antero posterior del diente, y en su extremo labial se encuentra el paracono. El muro nace en el borde postero-lingual del protolofo y se dirige posteriormente en dirección postero-lingual. El metalofo nace en el punto donde se une el muro con el brazo anterior del hipocono; es recto y perpendicular al eje antero posterior del diente, y en su extremo labial se observa el metacono (Fig. 4.5D). El posterolofo es largo y cóncavo anteriormente; en individuos juveniles toma contacto con el metacono delimitando una posterofoseta poco profunda, como la parafoseta (Fig. 4.5D). Entre el hipocono y el posterolofo se observa una constricción que desaparece a medida que el diente adquiere mayor desgaste. La parafoseta y la posterofoseta desaparecen en individuos adultos, razón por la cual el diente adquiere forma de 8. El mesoflexo es el flexo labial más amplio y el más penetrante en la superficie oclusal; es recto y sólo desaparece en individuos seniles. El hipoflexo se opone al mesoflexo y penetra poco en la superficie oclusal; es oblicuo anteriormente y es el más profundo en la corona. A medida que los dientes presentan más desgaste el hipoflexo se vuelve menos penetrante y menos oblicuo; desaparece sólo en individuos muy seniles (AMNH 9280).

Los incisivos superiores son comprimidos (Fig. 4.5B). La capa de esmalte anterior es gruesa. La cara esmaltada anterior es lisa y presenta el borde lingual recto y el labial curvo. La superficie de desgaste es suavemente curva en vista lateral (Fig. 4.5C). Este diente es largo, ya que sobrepasa el borde posterior de la raíz inferior de la arcada cigomática.

- Mandíbula. La mandíbula presenta un diastema alargado y cóncavo dorsalmente (Fig. 4.5G-J); a diferencia de lo que se observa en las especies de Sciamys la concavidad se ubica a nivel de la mitad antero-posterior del diastema y no en la mitad posterior. Hay 
un foramen mentoniano muy bien desarrollado a nivel del punto más bajo del diastema. La mmma es alargada y recta antero-posteriormente y se ubica a nivel del borde posterior del p4 y la mitad anterior del m1. Ventralmente la muesca se encuentra limitada por un reborde que sobresale lateralmente de la pared de la mandíbula y que se continua con la cresta masetérica, la cual está muy bien desarrollada y se dirige posteroventralmente desde sus orígenes (Fig. 4.5G, I). La cresta masetérica sobresale lateralmente del cuerpo mandibular; esta característica es evidente cuando se observa la mandíbula en vista dorsal. La fosa masetérica es muy profunda anteriormente (Fig. 4.5G, I), como en las especies de Galileomys. El surco que limita la fosa masetérica antero-dorsalmente no se encuentra bien desarrollado; en su lugar se observa un reborde que se extiende desde el borde posterior de la muesca hasta la base de la apófisis coronoides (Fig. 4.5G, I). Este reborde, la cresta masetérica y la profundidad de la porción anterior de la fosa masetérica dan a la mandíbula un aspecto robusto, característico de los acarémidos. La apófisis coronoides nace a nivel del m2 o límite m2-m3 y se extiende en dirección postero-lateral delimitando una fosa retromolar pequeña y esencialmente lateral a la hilera dentaria. El foramen mandibular se encuentra bien desarrollado y se ubica en la rama ascendente, a mitad de camino entre la base de la apófisis y el cóndilo mandibular. En la cara interna de la mandíbula se observa la sínfisis mandibular poco rugosa que se extiende posteriormente hasta el nivel del m1 (Fig. 4.5H, J), como en las especies de Sciamys. Por delante del p4, se observa el proceso mentoniano bien desarrollado (Fig. 4.5I-J). La mandíbula es excavada debajo de la hilera de dientes y presenta numerosos forámenes accesorios. Por detrás de la quilla mentoniana la mandíbula se hace muy baja (Tabla 4.5a).

- Dientes inferiores. Los molariformes inferiores presentan tamaños semejantes en sí, siendo el m2 algo mayor que los restantes dientes (Tabla 4.5b) (Fig. 4.5I, L). En dientes que no presentan desgaste es posible observar las cúspides diferenciadas de las crestas.

El dp4 es de morfología semejante a la que se observa en Sciamys principalis y distinta de la de Galileomys eurygnathus. El metalofúlido I forma la cara anterior del diente; esta cresta es muy cóncava posteriormente y se une con el protocónido y con el metacónido delimitando una estructura en forma de C; la misma está cerrada posteriormente por el mesolófido, delimitando la anterofosétida. Desde el borde anterior del mesolófido nace una cresta que es recta y se dirige en dirección anterior, por lo que la anterofosétida queda dividida en dos. Del extremo postero-labial del protocónido, el ectolófido se extiende en dirección posterior. El hipolófido se extiende desde el extremo 
posterior del ectolófido; esta cresta es recta y su extremo lingual se fusiona con el entocónido. En estados de desgaste nulos se observa que el hipolófido todavía no se ha unido con el brazo anterior del hipocónido. El posterolófido se extiende desde el hipocónido; es cóncavo anteriormente y alcanza el borde lingual del diente. El mesofléxido es el fléxido más amplio, profundo, y menos penetrante de los fléxidos linguales; el posterofléxido es bien penetrante en la superficie oclusal. El hipofléxido es más profundo que el mesofléxido y es oblicuo posteriormente.

El p4 es simple, semejante al de Platypittamys brachyodon. El borde anterior del diente está formado por el metalofúlido I, que conecta el protocónido con el metacónido; estas dos cúspides se encuentran alineadas labio-lingualmente, a diferencia de lo que ocurre en “A.” tricarinatus y Platypittamys brachyodon. En individuos juveniles y adultos se observa un pequeño fléxido en la cara anterior del metalofúlido I (Fig. 4.5K-L). Desde el borde posterior del protocónido se extiende el ectolófido que se dirige postero-lingualmente y se une al posterolófido en su mitad labio-lingual. En algunos ejemplares puede observarse un metalofúlido II de desarrollo variable: en algunos especímenes se une al metalofúlido I definiendo una fosétida anterior (MACN A 4128; MACN PV SC 2585), en otros se dirige postero-lingualmente (Fig. 4.5K) y en otros puede estar sumamente reducido a una pequeña extensión del ectolófido (Fig. 4.5L). El posterolófido delimita el borde posterior del diente; es cóncavo anteriormente y conecta el hipocónido con el entocónido. En algunos ejemplares (MACN A 266; MMP $114 \mathrm{M}$ ) se observa una pequeña cúspide en el borde antero-lingual del posterolófido (Fig. 4.5K-L).

Los molares inferiores son tetralofodontes y semejantes a los de las especies de Sciamys, pero de coronas más bajas (Fig. 4.5K-L). El metalofúlido I es recto y une al protocónido con el metacónido. Del extremo posterior del protocónido nace un ectolófido que es bien oblicuo en dirección postero-lingual. En la mitad del largo del ectolófido nace el metalofúlido II, el cual se dirige antero-lingualmente hasta tomar contacto con el borde postero-labial del metacónido (Fig. 4.5K-L). De esta manera queda delimitada una anterofosétida poco profunda. En MACN A 4246 esta fosétida se encuentra divida en dos por una cresta que la atraviesa en sentido antero-posterior, de la misma manera que ocurre en Platypittamys brachyodon y en varios molares de Galileomys antelucanus y Sciamys principalis. El hipolófido nace en el punto donde se une el ectolófido con el brazo anterior del hipocónido (Fig. 4.5IK-L); es recto y alcanza el borde lingual del diente, donde se une al entocónido. El posterolófido es largo y 
cóncavo anteriormente; la porción labial de esta cresta es casi recta y paralela a la pared anterior del hipofléxido, y en la mitad de su largo se observa un evidente punto de inflexión donde la cresta se hace curva y oblicua antero-labialmente. El mesofléxido es el fléxido lingual más amplio y profundo. La anterofosétida se forma rápidamente en individuos juveniles y desaparece en individuos adultos, mientras que el posterofléxido es angosto en vista oclusal y menos profundo que el mesofléxido. El hipofléxido es el más penetrante de todos en la corona y es oblicuo posteriormente en individuos jóvenes, mientras que en ejemplares adultos se hace transversal al eje antero-posterior del diente. En ningún momento desaparecen todas las estructuras de la superficie oclusal, rasgo asociado a la baja altura de la corona y que lo diferencia de las especies de Sciamys.

Los incisivos inferiores son comprimidos. La cara esmaltada anterior es lisa, forma un ángulo recto en su borde lingual, mientras que el borde labial es curvo. La capa de esmalte se expande exterior e interiormente hasta la mitad del espesor del diente. En vista lateral, la superficie de desgaste tiene una suave curvatura (Fig. 4.5I-J). El diente se extiende por debajo de la hilera dentaria, sobre el lado interno, prolongándose por detrás de la última muela, donde pasa al lado externo, ascendiendo hasta la apófisis coronoides.

Comentarios: Ameghino (1891) diferenció la especie Acaremys karaikensis de Acaremys murinus por el mayor tamaño del cráneo, aunque con las hileras dentarias del mismo tamaño en ambas especies. Esta característica puede observarse claramente en el ejemplar tipo de A. karaikensis (MACN A 1885), el cual se encuentra bastante deteriorado y deformado. Sin embargo, en colecciones realizadas con posterioridad se encontraron ejemplares asignables a este género con tamaños intermedios entre estas especies (Scott, 1905). Scott (1905) planteó que la separación de A. murinus y A. karaikensis sobre la base del tamaño del cráneo no constituía un criterio válido para separar ambos taxones; sin embargo, expuso que la validez de ambas especies es evidente ya que $A$. karaikensis tiene incisivos más angostos que A. murinus y un rostro ancho en su porción posterior que se angosta hacia adelante. En esta revisión se pudo observar que los incisivos de los ejemplares asignados a Acaremys son variables y por lo tanto su morfología no representa una característica diagnóstica; en todos los ejemplares asignados a Acaremys y Sciamys el rostro es muy ancho en su porción posterior y se angosta hacia delante. Por ello, teniendo en cuenta que la determinación de especies sobre la base del tamaño dentario y óseo no suele ser un criterio exacto, y no 
encontrando otras diferencias que justifiquen la separación de las dos especies, se interpreta aquí Acaremys karaikensis como sinónimo junior de Acaremys murinus.

Scott (1905) interpretó que los ejemplares asignados a A. messor representaban, en realidad, ejemplares más grandes y robustos de A. murinus razón por la cual el autor sinonimizó ambas especies. Sin embargo, sobre la base del grado de hipsodoncia y la morfología mandibular en este trabajo A. messor fue sinonimizado con Sciamys principalis (Ver revisión de Sciamys).

El lectotipo de Acaremys murinus (MLP 15-410) fue designado por Patterson (1952) en un manuscrito no publicado que se encuentra depositado en el Dto. Científico Paleontología de Vertebrados del MLP; este ejemplar concuerda con la descripción de Ameghino de 1887 y 1889, pero sólo en parte ya que no tiene mandíbula asociada. Por otro lado, en el MACN hay una mandíbula con p4-m3 que concuerda con las descripciones de 1887 y 1889 y podría haber sido parte del sintipo (MACN A 266) (Fernicola, 2011). De modo que ambos ejemplares quedan definidos como parte del sintipo. 
Tabla 4.5a. Medidas craneanas y mandibulares Acaremys murinus (cm)

\begin{tabular}{lcl}
\hline MACN A 1885 & AAD & 0,646 \\
& AAP & 0,346 \\
& APD & 0,940 \\
& HCA & 0,798 \\
& LDS & 1,332 \\
& & \\
MMP 114M & LDi & 0,582 \\
& AM1 & 0,458 \\
& AM2 & 0,558 \\
& AM3 & 0,344 \\
\hline
\end{tabular}

Tabla 4.5b. Medidas dentarias de Acaremys murinus (mm)

\begin{tabular}{ccccc}
\hline & & LAP & AA & AP \\
\hline MACN A 266 & p4-m3 & 7,34 & - & - \\
& p4 & 1,68 & 1,44 & 1,70 \\
& m1 & 1,82 & 1,88 & 1,98 \\
& m2 & 1,98 & 2,24 & 2,02 \\
& m3 & 1,86 & 1,98 & 1,68 \\
MACN A 1885 (Holotipo de & P4-M3 & 7,24 & - & - \\
A. karaikensis) & & & & \\
& P4 & 1,76 & 2,28 & 2,18 \\
& M1 & 1,78 & 2,32 & 2,26 \\
MACN A 10092 & M2 & 1,98 & 2,44 & 2,20 \\
& M3 & 1,72 & 2,26 & 1,86 \\
& DP4 & 2,30 & 2,02 & 1,96 \\
MLP 15-410 & M1 & 1,92 & 2,26 & 2,16 \\
& M2 & 1,98 & 2,24 & 2,28 \\
MMP 114M & DP4 & 2,28 & 1,82 & 1,82 \\
& M1 & 1,70 & 1,90 & 1,90 \\
& p4-m3 & 7,14 & - & - \\
& p4 & 1,58 & 1,44 & 1,78 \\
& m1 & 1,88 & 1,92 & 1,84 \\
& m2 & 1,98 & 2,12 & 2,08 \\
& m3 & 1,70 & 1,90 & 1,56 \\
\hline
\end{tabular}



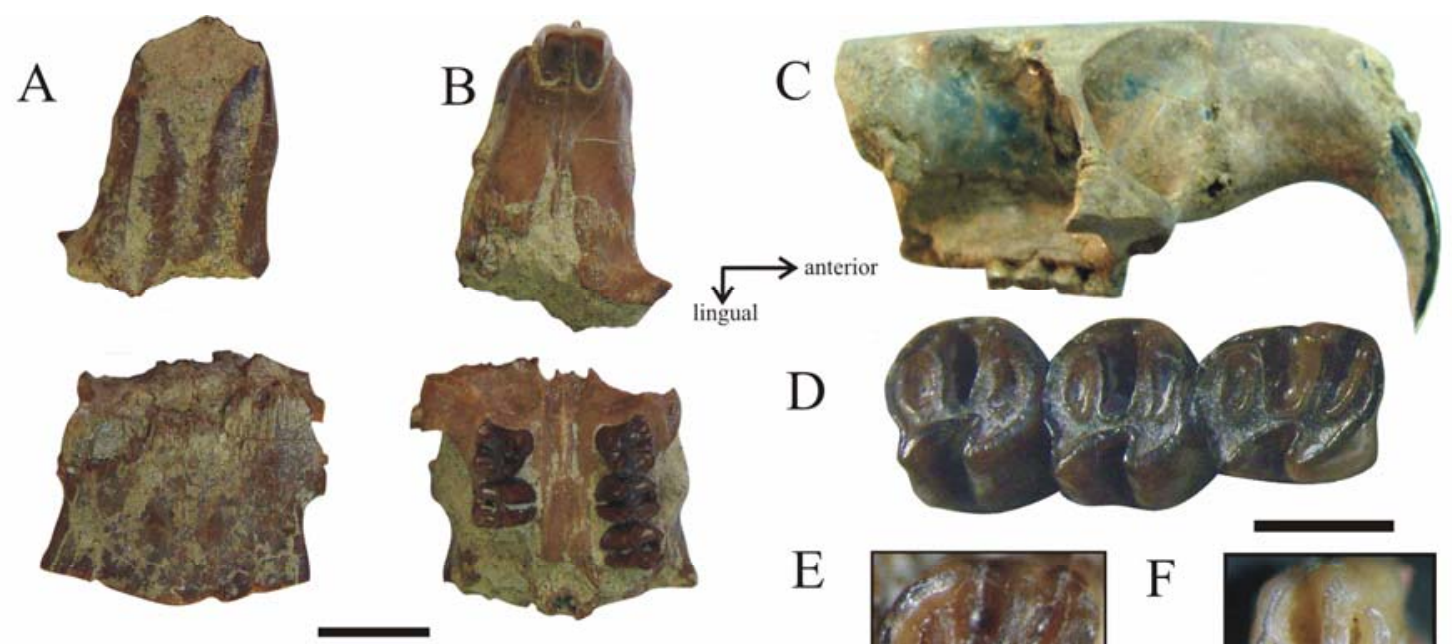

E
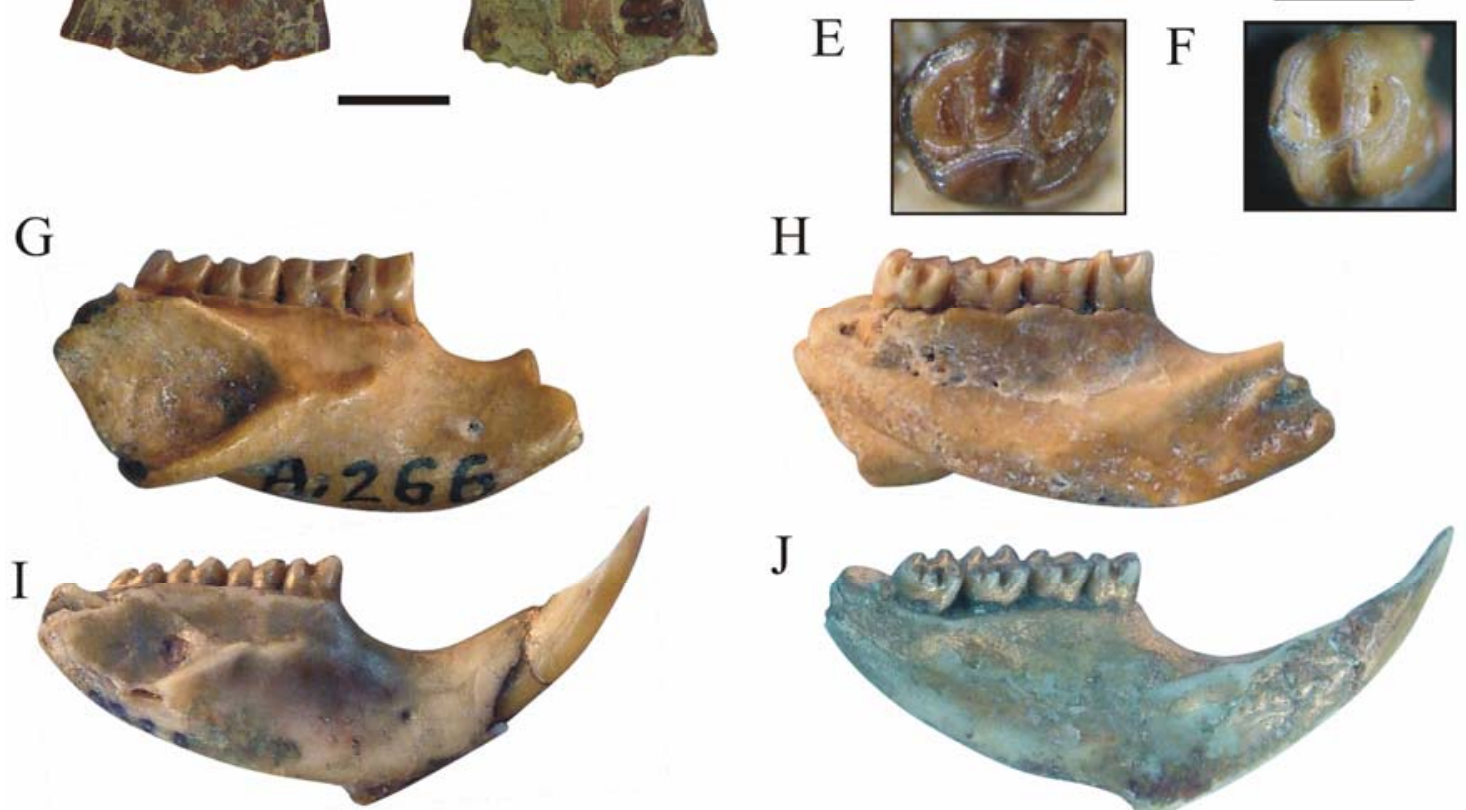

$\mathrm{H}$
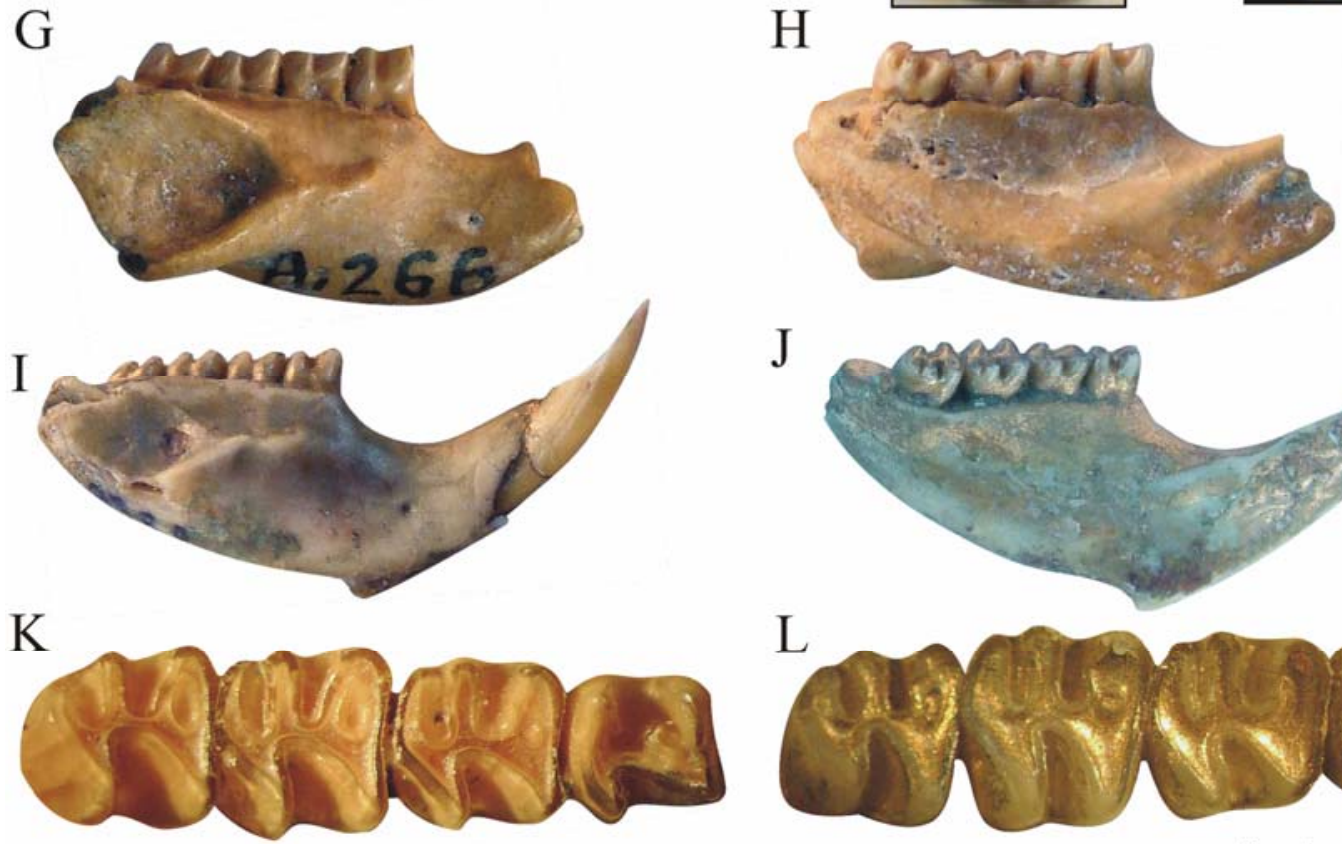

$\mathrm{J}$

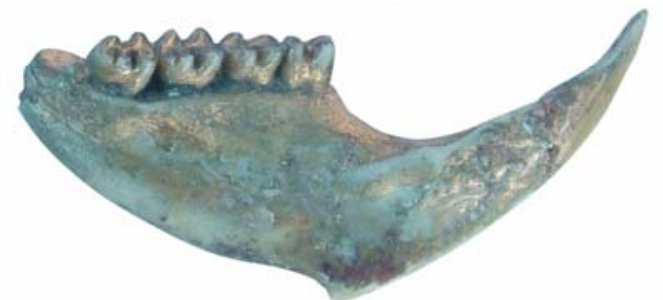

$\mathrm{L}$

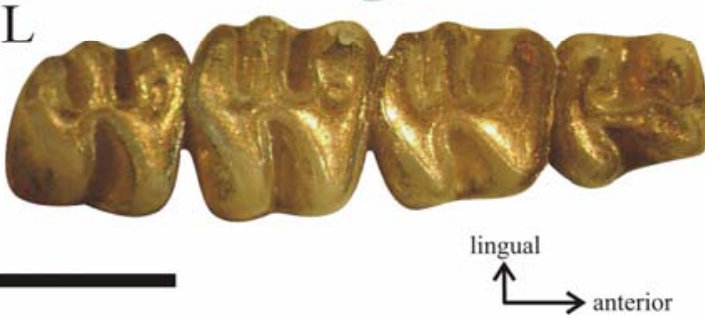

Figura 4.5. Acaremys murinus. A-B. MACN A 10092, cráneo parcialmente preservado con DP4-M1 derechos y DP4-M2 izquierdos; $A$ : vista dorsal; $B$ : vista ventral; $C$ : AMNH 9280, cráneo con toda la dentadura. $D$ : MACN A 10092, DP4-M2 (invertido). $E$ : DP4 derecho de MLP 15-410 (sintipo). $F$ : MACN PV SC 2588, P4 (invertido). $G-H$. MACN A 266, fragmento mandibular derecho con p4-m3 (sintipo); $G$ : vista externa; $H$ : vista interna (invertida). $I-J$. MMP 114, fragmento mandibular izquierdo con p4-m3; $I$ : vista externa (invertida); $J$ : vista interna p4-m3. K: MACN A 266, p4-m3. $L:$ MMP 114, p4-m3 (invertida). Escala $=5 \mathrm{~mm}$ 
Acaremys major Scott, 1905

Holotipo: YPM PU 15366, cráneo incompleto y deformado con los incisivos y las dos hileras dentarias completas.

Material referido: (Ver Apéndice 1)

Procedencia geográfica, estratigráfica y edad: Killik Aike de la provincia de Santa Cruz; Fm Santa Cruz; Mioceno inferior tardío, “Edad Mamífero” Santacrucense.

Diagnosis: octodontoideo de tamaño grande, aproximadamente 15\% más grande que Acaremys murinus. Dentro de la hilera dentaria P4 y M1 son más pequeños que M2 y M3, a diferencia de A. murinus donde M1 y M2 son más grandes. Hipo y posterolofo del M3 acortados labio-lingualmente. Incisivos pequeños en relación al tamaño craneano. Rostro más ancho anteriormente que A. murinus.

Descripción: Esta especie se diferencia de Acaremys murinus por su tamaño considerablemente mayor.

El cráneo es muy alargado. El rostro es robusto, y como es usual los nasales ocupan casi todo el dorso del rostro, son anchos en su porción anterior y se angostan posteriormente. El rostro es más ancho posteriormente, sin embargo, en su porción anterior es ancha en comparación con Acaremys murinus y las especies de Sciamys (Fig. 4.6A). El diastema es cóncavo en vista lateral (Fig. 4.6B). La raíz ventral de la arcada cigomática nace por delante del P4. En la porción posterior del cráneo se observa la cresta sagital. No es posible describir con mayor detalle el cráneo, ya que el mismo no se encuentra bien preservado.

Las hileras dentarias son paralelas como en Acaremys murinus y Sciamys principalis (Fig. 4.6A). Los dientes de los dos ejemplares asignados a esta especie presentan mucho desgaste, por lo que la superficie oclusal se encuentra totalmente simplificada en el P4, en el M1 queda un pequeño vestigio de hipoflexo, mientras que en el M2 se observa lo que queda de un mesoflexo poco penetrante en la superficie oclusal y un hipoflexo aún menos penetrante y de disposición oblicua anteriormente (Fig. 4.6C). El M3 presenta el clásico acortamiento labio-lingual de la porción posterior, pero a diferencia de los restantes taxones estudiados este acortamiento no está dado por 
la posición labial del hipocono respecto del protocono, sino que se debe al acortamiento del hipolofo y del posterolofo (Fig. 4.6C). En este diente se observan vestigios del mesoflexo y del posteroflexo que son igualmente penetrantes; el hipoflexo es menos penetrante que el mesoflexo y al igual que en el M2 es de disposición oblicua anteriormente.

Los incisivos son comprimidos. La cara esmaltada anterior es lisa y, como es usual, el borde interno es recto mientras que el externo es curvo. En vista lateral la superficie de desgaste es suavemente curva (Fig. 4.6B).

Comentarios: Más arriba se indicó en reiteradas ocasiones que el tamaño de los ejemplares no es un buen criterio a tener en cuenta a la hora de discriminar especies. Sin embargo, el tamaño de los ejemplares de $A$. major es tan grande que no cabe duda que representa una especie distinta. Los ejemplares adultos y seniles asignados a A. murinus no alcanzan semejante tamaño. A pesar de que los dientes de A. major presentan mucho desgaste, es posible determinar que es un acarémido sobre la base de la morfología craneana y dentaria. Su inclusión dentro del género Acaremys fue propuesta por Scott (1905) por la presencia de una cresta sagital en el cráneo y porque, a pesar de tratarse de individuos seniles, hay vestigios de estructuras en las superficies oclusales de casi todos los molariformes, que indica que éstos eran de corona comparativamente más baja que en las especies de Sciamys. A. major no fue incluido dentro del análisis filogenético del capítulo 5 como consecuencia del escaso material preservado y del estado de preservación del mismo. Sin embargo, se lo considera una especie de Acaremys por las características mencionadas anteriormente. 

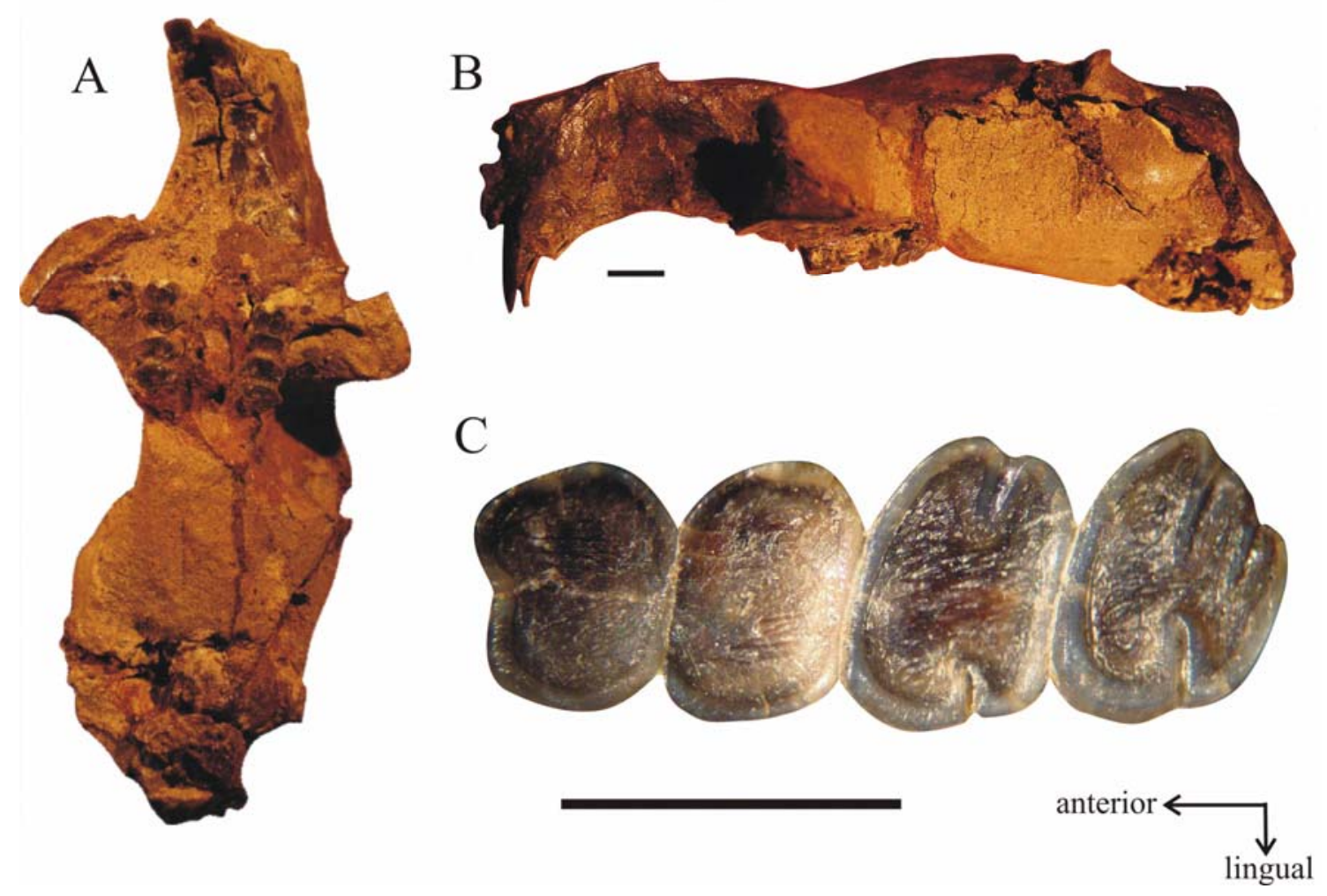

Figura 4.6. Acaremys major. A-C. YPM PU 15366, cráneo parcialmente preservado con toda la dentición (holotipo). $A$ : vista ventral; $B$ : vista lateral (invertido); $C$ : P4-M3 izquierdos. Escala= $5 \mathrm{~mm}$ 
“Acaremys” sp. nov.

Holotipo: MACN A 10095, cráneo casi completo con toda la dentadura.

Material referido: (Ver Apéndice 1)

Distribución geográfica, estratigráfica y edad: La Cueva, Killik Aike, provincia de Santa Cruz, Fm Santa Cruz, Mioceno temprano cuspidal, "Edad Mamífero" Santacrucense.

Diagnosis: especie de tamaño similar a Acaremys murinus. Premolar superior trilofodonte, donde el protolofo presenta una conexión muy delgada con el protocono. Molares con una cúspide accesoria en el protolofo e hipocono de posición labial respecto del protocono; M3 con el protolofo con una conexión muy delgada con el protocono, como en el P4. Cráneo sin surco para el pasaje del nervio infraorbitario y raíz ventral de la arcada cigomática larga antero-posteriormente y muy delgada dorsoventralmente, a diferencia de Acaremys murinus.

\section{Descripción:}

- Cráneo. El cráneo es relativamente largo y bajo (Tabla 4.7a). Los huesos nasales son anchos en su porción anterior y se van ahusando posteriormente, aunque no se preserva la porción posterior de los nasales en el ejemplar tipo (Fig. 4.7A); el borde anterior de los nasales es romo. La fosa masetérica es semejante a la de A. murinus y S. principalis: incluye al alveolo del incisivo y se encuentra limitada anteriormente por un reborde del premaxilar muy bien desarrollado (Fig. 4.7B); el premaxilar, al igual que A. murinus, participa en menor medida de la fosa masetérica en comparación con S. principalis. La sutura premaxilar-maxilar es crenulada en todo su recorrido; en la cara lateral del rostro esta sutura se dirige ventralmente de forma oblicua hacia atrás y luego, en la cara ventral del rostro, se extiende por el diastema a nivel de la mitad del largo de los forámenes incisivos (Fig. 4.7C). En vista lateral el diastema es cóncavo en su porción anterior y posteriormente se va haciendo plano, como en las restantes especies de Acaremys y Sciamys. Los huesos frontales se ensanchan hacia atrás; posteriormente a la orbita el frontal forma un proceso postorbitario bien desarrollado, más que en $A$. murinus (Fig. 4.7A); por detrás de ellos se observa una constricción post-orbitaria poco 
desarrollada. Los frontales limitan con los huesos parietales a través de una sutura recta y poco cóncava. Los parietales alcanzan el borde posterior del cráneo; anteriormente son algo globosos y posteriormente se aplanan y forman una cresta sagital bien desarrollada (Fig. 4.7A-B). La raíz ventral de la arcada cigomática nace apenas por delante del P4; ésta es muy extendida antero-posteriormente y deprimida dorsoventralmente y en su cara dorsal no se observa un surco para el pasaje del nervio infraorbitario, a diferencia de lo que se observa en A. murinus. En vista ventral, esta raíz se proyecta lateralmente, formando un arco que se continúa con la rama horizontal de la arcada cigomática (Fig. 4.7C). La tuberosidad masetérica es poco profunda. Lateralmente la depresión para la inserción del músculo masetero lateral es poco profunda y se extiende posteriormente hasta la unión maxilar-yugal. La rama horizontal es relativamente alta, con una pequeña apófisis paraorbitaria que se encuentra formada por el yugal y por una pequeña porción del escamoso (Fig. 4.7B); la sutura yugalescamoso es alargada antero-posteriormente y oblicua. La fosa yugal ocupa casi todo el alto de la rama, es larga y poco profunda. El escamoso forma la porción posterior de la rama horizontal de la arcada cigomática.

La bula timpánica se encuentra formada por el ectotimpánico y es de tamaño pequeño (Fig. 4.7C) (Tabla 4.7a), semejante a la de Sciamys principalis y los equímidos actuales Echimys y Kannabateomys. El MAE se ubica aproximadamente en el centro del eje antero-posterior de la bula, y algo dorsal a la mitad dorso-ventral de la misma; es grande, de contorno subcircular y se encuentra limitado por un pequeño reborde anteroventral. Por debajo del MAE se observa un foramen accesorio bien desarrollado. El seno epitimpánico y el seno hipotimpánico no se encuentran hipertrofiados. En vista ventral la bula auditiva es de forma casi ovalada, siendo la porción anterior la más ancha (Fig. 4.7C). El extremo antero-interno de la bula presenta una pequeña protuberancia. En la pared medial de la bula, cerca del contacto con el basioccipital, hay un foramen de homologías inciertas bien desarrollado.

La región occipital no se encuentra bien preservada en ningún ejemplar; sin embargo, se observa que es baja.

Al igual que en $A$. murinus en vista ventral el diastema es corto y se ensancha hacia atrás (Fig. 4.7C) (Tabla 4.7a). Los forámenes incisivos se encuentran bien desarrollados; la sutura premaxilar-maxilar los intersecta en la mitad de su largo anteroposterior. Posteriormente se continúan con los rebordes diastemales que se extienden hasta la porción interdentaria del paladar, como en A. murinus. Los forámenes palatinos 
posteriores también se encuentran poco desarrollados, pero a diferencia de A. murinus se encuentran a nivel del M1. En la línea media de esta porción del paladar hay una quilla muy poco desarrollada. Posteriormente, las narinas abren a nivel del M3, delimitando una fosa mesopterigoidea triangular (Fig. 4.7C). Dentro de la fosa mesopterigoidea, a nivel de los huesos preesfenoides y basiesfenoides se observan las vacuidades esfenopalatinas; éstas están bien desarrolladas y son de forma ovoide. No es posible distinguir la sutura entre el basiesfenoides y el basioccipital. Posteriormente en el basioccipital, y entre las bulas auditivas, se observa una quilla media bien desarrollada.

- Dientes superiores. El P4 es trilofondonte (Fig. 4.7D). El anterolofo es corto y no alcanza el borde labial del diente, como en A. murinus; en la pared anterior del área del protocono, se observa un pequeño hundimiento, algo semejante a lo que ocurre en Platypittamys brachyodon (Wood 1949). El protolofo es la cresta mejor desarrollada; su unión con el protocono es débil (Fig. 4.7D). El hipocono es pequeño y el hipoflexo se encuentra poco desarrollado, como en A. murinus (Fig. 4.7D).

Los molares son semejantes a los de A. murinus, aunque se diferencian en que presentan una cúspide accesoria en el protolofo bien desarrollada que se ubica en la mitad del largo labio-lingual de la cresta (Fig. 4.7D); además, el hipocono tiene una posición labial respecto del protocono. En MACN A 10095 se observa que en el P4 y M3 el protolofo se extiende desde el paracono en dirección lingual, pero no llega a tomar contacto con el muro ni con el protocono (Fig. 4.7D); en el M3 de YPM PU 15872 se observa una morfología semejante.

Comentarios: los ejemplares aquí asignados a “Acaremys” sp. nov. fueron asignados por Ameghino (in Schedule) y Scott (1905) a Acaremys murinus. Sin embargo, las diferencias en los caracteres craneanos (ausencia de surco para el pasaje del nervio infraorbitario, morfología de la raíz ventral de la arcada cigomática) y dentarios (morfología de protolofo en dientes con poco desgaste, cúspide accesoria en el protolofo) justifican la separación a nivel específico de estos ejemplares de los de $A$. murinus. Este nuevo taxón se incluyó aquí como una especie de Acaremys y no de Sciamys porque presenta una cresta sagital bien desarrollada (Fig. 4.7A), P4 trilofodonte y con el hipoflexo poco desarrollado; además este taxón se diferencia de Galileomys en la mayor altura de las coronas. Sin embargo, los resultados del análisis filogenético 
(Capítulo 5) no soportaron la inclusión de esta nueva especies dentro del género Acaremys, razón por la cual se lo escribe entre comillas.

Tabla 4.7a. Medidas craneanas “Acaremys” sp. nov. (cm)

\begin{tabular}{lcc}
\hline MACN A 10095 & AAD & 0,548 \\
\hline AAP & 0,366 \\
AC & 1,992 \\
AMB & 0,699 \\
APD & 1,036 \\
APP & 0,362 \\
HCA & 1,280 \\
HCP & 1,020 \\
LAC & 2,192 \\
LCB & 4,394 \\
LDS & 1,452 \\
LMB & 0,968 \\
LP & 2,134 \\
\hline
\end{tabular}

Tabla 4.7b. Medidas dentarias de “Acaremys" sp. nov. (mm)

\begin{tabular}{ccccc}
\hline & & LAP & AA & AP \\
\hline MACN A 10095 & P4-M3 & 7,27 & - & - \\
& P4 & 1,55 & 2,20 & 1,68 \\
& M1 & 1,96 & 2,40 & 2,26 \\
& M2 & 1,94 & 2,28 & 2,20 \\
& M3 & 1,82 & 2,22 & 1,42 \\
\hline
\end{tabular}




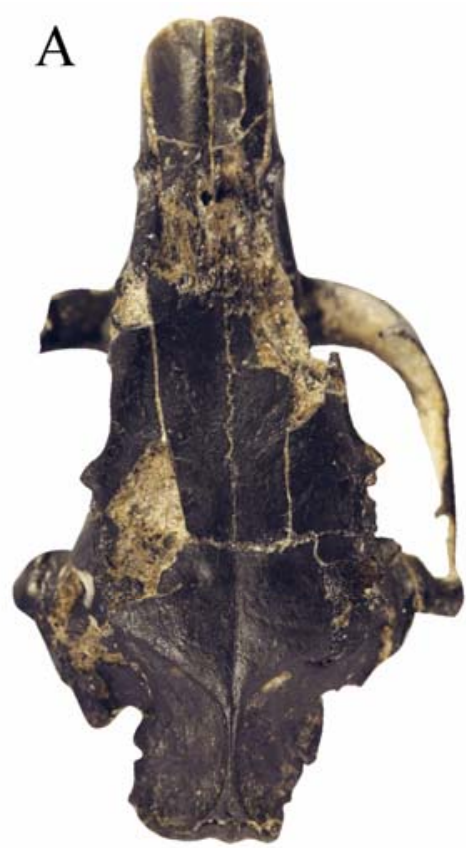

B

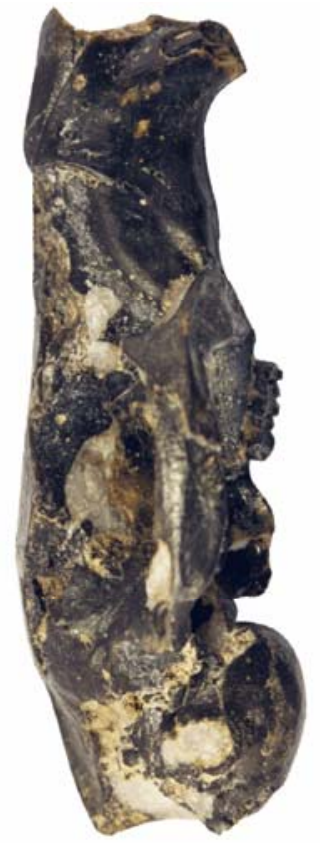

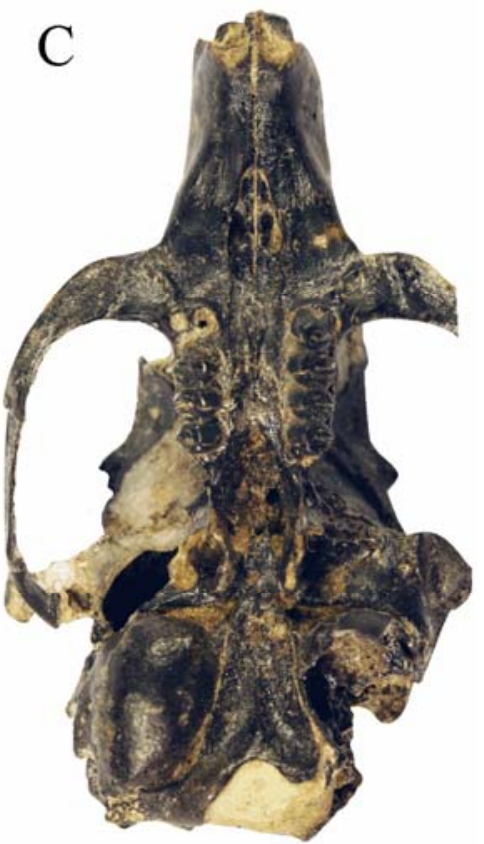

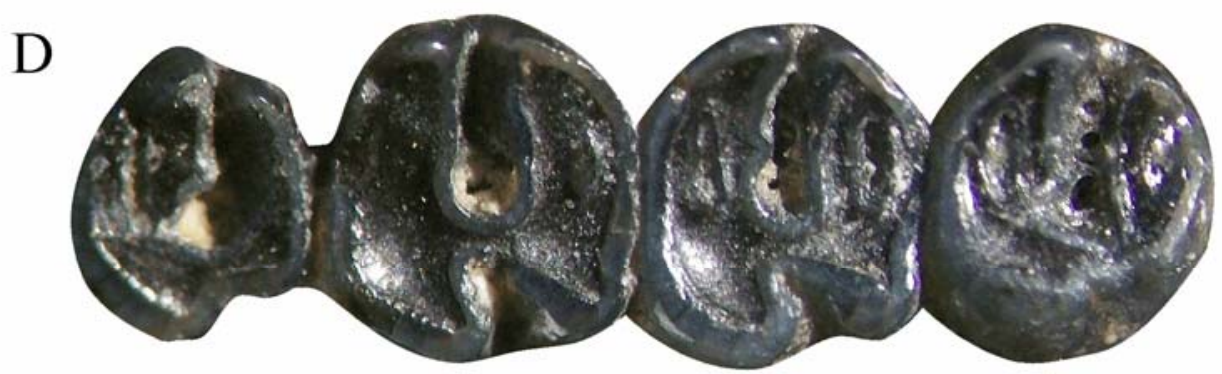

anterior

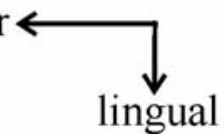

Figura 4.7. “Acaremys” sp. nov. A-C. MACN A 10095, cráneo casi completo con toda la dentición (holotipo). $A$ : Vista dorsal; $B$ : Vista lateral; $C$ : Vista ventral; $D$ : P4-M3 izquierdos. Escala $=\mathbf{5 m m}$ 
“Acaremys” tricarinatus Ameghino, 1894

Holotipo: MACN A 4113, mandíbula con ramas izquierda y derecha unidas a nivel de la sínfisis, con p4-m3 de ambos lados.

Material referido: sólo el ejemplar tipo.

Procedencia geográfica, estratigráfica y edad: Monte Observación, provincia de Santa Cruz, Fm Santa Cruz, Mioceno temprano cuspidal, "Edad Mamífero" Santacrucense.

Diagnosis: roedor de tamaño semejante a A. murinus. Premolar inferior con un fléxido adicional en la cara labial que separa el metalofúlido I del protocónido; metacónido de posición anterior respecto del protocónido; hipolófido presente a diferencia de Acaremys murinus e hipofléxido poco desarrollado. Molares inferiores con el metalofúlido II ausente en el m1 y reducido en el m2-m3. En la mandíbula, la muesca para la inserción del tendón del $M$. masseter medialis pars anterior (mmma) no es continua con la cresta masetérica a diferencia de Acaremys murinus.

\section{Descripción:}

- Dientes inferiores. Los dientes son mesodontes, de coronas más altas que A. murinus (Tabla 5.1).

El p4 presenta una morfología particular: el metalofúlido I se extiende desde el metacónido y se dirige en dirección labial; a diferencia de lo que ocurre en las restantes especies de Acaremys y en Sciamys, su extremo labial no toma contacto con el protocónido, sino que se encuentra separado de él por un fléxido adicional. Este fléxido es bien profundo y confluye con el anterofléxido aislando al metalofúlido I de las restantes estructuras oclusales (Fig. 4.8A). El metacónido es anterior al protocónido. Desde borde posterior del protocónido se extienden dos crestas (Fig. 4.8A): bien oblicuo en dirección postero-lingual se observa el metalofúlido II corto, mientras que desde su borde posterior y de disposición menos oblicua se extiende el ectolófido. Posteriormente, el ectolófido se une al posterolófido, que delimita posteriormente el diente. En el punto donde se unen el ectolófido y el posterolófido nace el hipolófido, que presenta desarrollo semejante al de las especies de Sciamys; se dirige en dirección 
antero-lingual y se une lingualmente al entocónido (Fig. 4.8A). El posterolófido se une labialmente al hipocónido y no alcanza el borde lingual del diente. El mesofléxido es el fléxido más penetrante y profundo de los fléxidos linguales; el anterofléxido y posterofléxido son igualmente profundos, aunque el posterofléxido es muy poco penetrante en la superficie oclusal. El hipofléxido es el más profundo de todos los fléxidos.

Los molares presentan tres crestas bien desarrolladas y una cuarta, segunda en posición, de desarrollo variable: ausente en el m1, reducida en m2 y m3 (Fig. 4.8A). El área donde se ubican las cúspides es bien redondeada, a diferencia de lo que ocurre en Acaremys murinus y Sciamys principalis. El metalofúlido I es recto y a diferencia de lo que ocurre en el premolar, une el protocónido con el metacónido. Desde el borde posterior del protocónido se extiende el ectolófido que es bien oblicuo en dirección postero-lingual (Fig. 4.8A). El hipolófido nace en el punto donde se une el ectolófido y el pequeño brazo anterior del hipocónido; esta cresta es recta y alcanza el borde lingual del diente, donde se une al entocónido. El posterolófido es cóncavo anteriormente y su extremo lingual termina muy cerca del entocónido. A diferencia de lo que ocurre en el premolar, en los molares no hay fléxidos accesorios, y el anterofléxido confluye con el mesofléxido en el $\mathrm{m} 1$, mientras que en los $\mathrm{m} 2$ y $\mathrm{m} 3$ se observa una pequeña anterofosétida (Fig. 4.8A).

Los incisivos inferiores son comprimidos lateralmente. La cara esmaltada anterior es lisa, forma un ángulo recto en su borde lingual, mientras que el borde labial es curvo. Este diente es largo, pasa por debajo del m3 y su extremo posterior se evidencia como abultamiento en la cara externa de la mandíbula.

- Mandíbula. La mandíbula presenta un diastema poco profundo (Fig. 4.8B); el foramen mentoniano se encuentra bien desarrollado y se ubica poco por detrás del punto más bajo del diastema. La mmma se encuentra bien desarrollada; es profunda, alargada antero-posteriormente y se ubica a nivel del p4-m1 (Fig. 4.8B), como Acaremys murinus y en Sciamys. Posteriormente, la cresta masetérica es discontinua respecto de la muesca; esta cresta se encuentra bien desarrollada y se orienta ventralmente desde sus orígenes. La fosa masetérica es bien profunda anteriormente (Fig. 4.8B), como en Acaremys murinus y Galileomys. El surco que limita la fosa masetérica anterodorsalmente se encuentra poco desarrollado. La apófisis coronoides nace a nivel del m3 y se extiende lateralmente, delimitando una fosa retromolar pequeña y principalmente 
lateral a la hilera dentaria. El foramen mandibular es grande y se ubica dorsalmente a la base de la apófisis coronoides.

Comentarios: Scott (1905) puso en duda la validez de esta especie y propuso que podría tratarse de un ejemplar juvenil de A. murinus. En este trabajo no se apoya esta propuesta debido a que existen ejemplares juveniles de A. murinus que no presentan la morfología dentaria de “A.” tricarinatus. Patterson (1952) en su manuscrito inédito sinonimizó a “A.” tricarinatus con S. principalis.

Hay ejemplares asignados aquí a Sciamys principalis provenientes de Monte León, Santa Cruz, (MACN PV SC2314, MACN PV SC 2419) que poseen una morfología del premolar semejante a la de “A.” tricarinatus y que podrían ser referidos a esta especie; sin embargo, en esos ejemplares el fléxido adicional se ubica en la cara antero-labial del diente, no en el lado labial, y los m1 de esos ejemplares presentan metalofúlido II. Por otro lado, los dientes de “A.” tricarinatus son de coronas más altas que las de A. murinus, presentando un grado de hipsodoncia semejante a los de Sciamys principalis (Ver tabla 5.1, índices de hipsodoncia). Teniendo en cuenta que el grado de hipsodoncia fue uno de los criterios (junto con la morfología mandibular) utilizado en este análisis para diferenciar Acaremys murinus de Sciamys es posible que "A." tricarinatus no represente una especie de Acaremys; quizás tampoco se trate de una especie de Sciamys, ya que presenta un patrón de reducción del metalofúlido II distinto. Estas hipótesis fueron puestas a prueba en el análisis filogenético del capítulo 5. Los resultados indicaron que “A.” tricarinatus es un acarémido sin relaciones directas con Acaremys murinus ni con Sciamys principalis.

Tabla 4.8. Medidas dentarias de “Acaremys” tricarinatus (mm)

\begin{tabular}{ccccc}
\hline & & LAP & AA & AP \\
\hline MACN A 4113 & p4-m3 & 8,1 & - & - \\
& p4 & 1,96 & 1,64 & 1,80 \\
& m1 & 2,06 & 2,06 & 2,00 \\
& m2 & 2,08 & 2,16 & 1,98 \\
& m3 & 2,00 & 1,92 & 1,52 \\
\hline
\end{tabular}


A

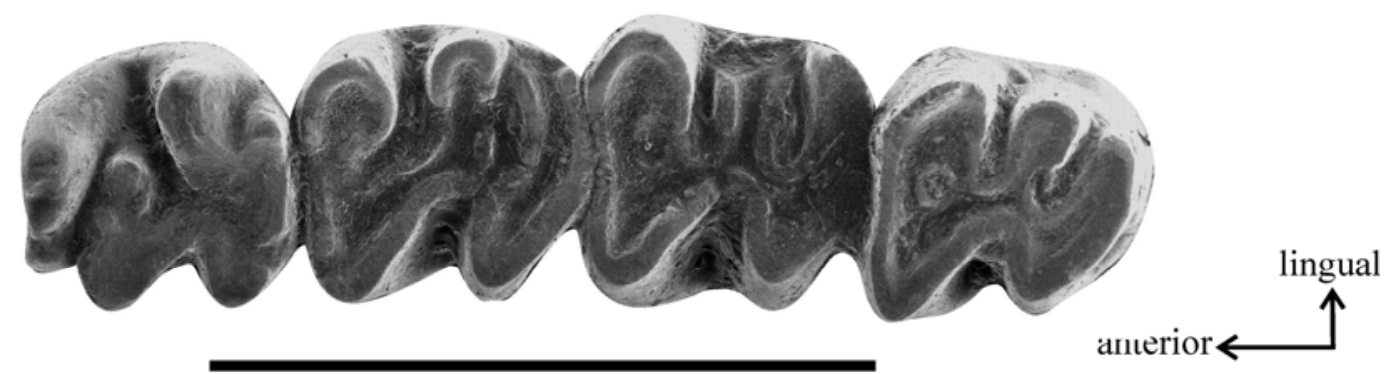

B



Figura 4.8. “Acaremys" tricarinatus. $A-B$. MACN A 4113, ambas hemimandíbulas unidas con toda la dentadura (holotipo); $A$ : p4-m3; $B$ : mandíbula en vista externa. Escala= $5 \mathrm{~mm}$ 
Género Caviocricetus Vucetich y Verzi, 1996

Especie tipo: Caviocricetus lucasi Vucetich y Verzi, 1996

Distribución geográfica y temporal: provincias del Chubut y Neuquén, "Edad Mamífero” Colhuehuapense, Mioceno temprano.

Diagnosis original: tamaño menor que Deseadomys arambourgi y más grande que Acarechimys minutissimus. El dp4 presenta el borde anterior con una gran abertura en forma de “v”. Superficie oclusal aterrazada con el paracono y metacono, y metacónido y entocónido más altos que el resto del diente, excepto en individuos seniles. Molares inferiores con una cúspide, más baja que los lofos, por detrás del metalofúlido I; fléxido antero-lingual notablemente más ancho que en Acarechimys. Anterolofo más corto que el protolofo, proporcionalmente más corto que en Acarechimys; mesolófulo más corto que el protolofo y unido a la cara anterior del metalofo, cerca del extremo labial. Dientes superiores generalmente más largos que anchos.

Caviocricetus lucasi Vucetich y Verzi, 1996

Holotipo: MPEF PV 505, fragmento maxilar izquierdo con DP4-M3.

Material referido: (Ver Apéndice 1)

Distribución geográfica, estratigráfica y edad: Bryn Gwyn, provincia del Chubut; Fm Sarmiento, Miembro Trelew; Sierra del Portezuelo Norte, provincia del Neuquén. Fm Cerro Bandera; “Edad Mamífero” Colhuehuapense, Mioceno temprano.

Diagnosis: la misma que para el género.

Descripción: la descripción original de Caviocricetus lucasi realizada por Vucetich y Verzi (1996) se mantiene vigente debido a su claridad y exactitud. Sin embargo, a continuación se destacan algunos rasgos de Caviocricetus lucasi que no fueron analizados previamente. En esta revisión se estudiaron los materiales depositados en el 
MPEF y ejemplares inéditos depositados en la colección de paleontología de vertebrados del MACN (Ver Apéndice 1).

- Cráneo. No se han hallado fragmentos de cráneo más completos que los descriptos por Vucetich y Verzi (1996), razón por la cual el mismo se encuentra representado únicamente por pequeños fragmentos de maxilar.

El borde posterior de la raíz ventral de la arcada cigomática nace por delante del hipoflexo/mesoflexo del DP4; esta raíz es tan larga como ancha. En la cara ventral de la raíz ventral de la arcada cigomática la tuberosidad masetérica es profunda y en algunos ejemplares (MACN PV CH1999 (en parte), MACN PV CH2001, MACN PV CH2002, MPEF-PV 1416-1), por detrás de ella se observa un foramen de homologías inciertas (este foramen también se encuentra presente en algunos ejemplares de Prospaniomys priscus y Protacaremys prior). En la cara dorsal de esta raíz no hay un surco diferenciado para el pasaje del nervio infraorbitario. La sutura maxilo-palatinos se encuentra a nivel del borde anterior del M1 (MPEF-PV 1416-1).

- Dientes superiores. El hipoflexo es amplio y en forma de semicírculo en el DP4 y en los molares se va haciendo gradualmente más oblicuo en sentido anterior (Fig. 4.9A). En individuos juveniles la porción anterior de los molares es tan ancha como la porción posterior, mientras que en individuos adultos la porción anterior es considerablemente más ancha que la posterior (Tabla 4.9).

En los premolares el paracono es más grande que el metacono. El mesolófulo en general es corto y no contacta el borde lingual del metacono [MACN PV CH1997 (en parte), MACN PV CH1999 (en parte), MACN PV CH2000, MACN PV CH2002], mientras que en los molares esta característica es menos frecuente [MACN PV CH2001 (en parte), MACN PV CH2002] (Fig. 4.9B). En el DP4 y M1 de MPEF-PV 1416-1 y en el DP4 de MPEF-PV 1416-13, inmediatamente por detrás del extremo lingual del mesolófulo se observa una pequeña extensión a modo de spur que es oblicua posteriormente. En individuos seniles no desaparecen todas las estructuras de la superficie oclusal (MACN PV CH1996); los flexos/fosetas labiales son igualmente profundos, mientras que el hipoflexo es un poco más profundo.

- Mandíbula. La mmma se ubica a nivel de la porción posterior del dp4 y anterior del $\mathrm{m} 1$, en la mitad de la altura de la mandíbula (Fig. 5.9C). La fosa masetérica es poco profunda. El proceso mentoniano es conspicuo y se ubica a nivel del límite anterior del dp4 (Fig. 5.9C). En la cara interna de la mandíbula se observa que la sínfisis mandibular es poco rugosa y se extiende hasta el límite anterior del dp4 (Fig. 5.9D). 
- Dientes inferiores. En todos los dientes inferiores se observan pequeños rebordes a manera de cíngulos en las caras anterior y posterior, acompañados de suaves concavidades en las paredes, al igual que en Prospaniomys priscus.

En algunos premolares (MACN PV CH1990) el protocónido no está unido al ectolófido, o la unión es débil. El metacónido es redondeado en algunos ejemplares, o alargado y oblicuo como el protocónido [MACN PV CH1990 (en parte)].

En los molares inferiores el metacónido y el entocónido son anteriores al protocónido e hipocónido respectivamente (Fig. 5.9E). El posterolófido presenta un engrosamiento lingual al hipocónido que correspondería al hipoconúlido, una cúspide que no suele ser diferenciable en otros caviomorfos. En individuos seniles (MACN PV CH1988, MACN PV CH1995) las superficies oclusales se hacen planas, aunque las crestas siguen siendo delgadas y los flexos amplios; en estos individuos los dientes siguen siendo más largos que anchos (Tabla 4.9).

Comentarios: Vucetich y Verzi (1996) plantearon la posibilidad de que la cuarta cresta en posición pudiera representar el posterolofo o la fusión del posterolofo con el metalofo. En esta revisión se apoya la segunda propuesta, ya que como bien explican los autores en individuos jóvenes esta cresta está formada por una porción lingual y otra labial (que con el desgaste se ponen en contacto y forman la cuarta cresta en posición (Fig. 4.9A-B). Además, los autores plantearon la posibilidad de que la pequeña extensión lingual del brazo posterior del protocónido en el m1 y m2, descripta como spur, representaría un vestigio de la segunda cresta en posición, y que esta correspondería al metalófido (metalofúlido II aquí) o al mesolófido. Aquí se interpreta que esta estructura corresponde al metalofúlido II, por estar topográficamente más relacionada al protocónido que al ectolófido (Fig. 5.9E). 
Tabla 4.9. Medidas dentarias de Caviocricetus lucasi (mm)

\begin{tabular}{lcccc}
\hline & & LAP & AA & AP \\
\hline MACN PV CH1988 & dp4 & 1,30 & - & - \\
& m1 & 1,52 & 1,32 & 1,46 \\
& m2 & 1,70 & 1,66 & 1,68 \\
MACN PV CH1988 & DP4 & 1,28 & 1,26 & 1,26 \\
& M1 & 1,54 & 1,58 & 1,52 \\
\multirow{3}{*}{ MACN PV CH1996 } & M2 & 1,64 & 1,72 & 1,68 \\
& DP4 & 1,28 & 1,30 & 1,24 \\
MACN PV CH2006 & M1 & 1,48 & 1,58 & 1,44 \\
& M2 & 1,64 & 1,86 & 1,62 \\
& dp4 & 1,52 & 0,98 & 1,10 \\
& m1 & 1,48 & 1,38 & 1,36 \\
& $\mathrm{~m} 2$ & 1,49 & 1,52 & 1,42 \\
\hline
\end{tabular}



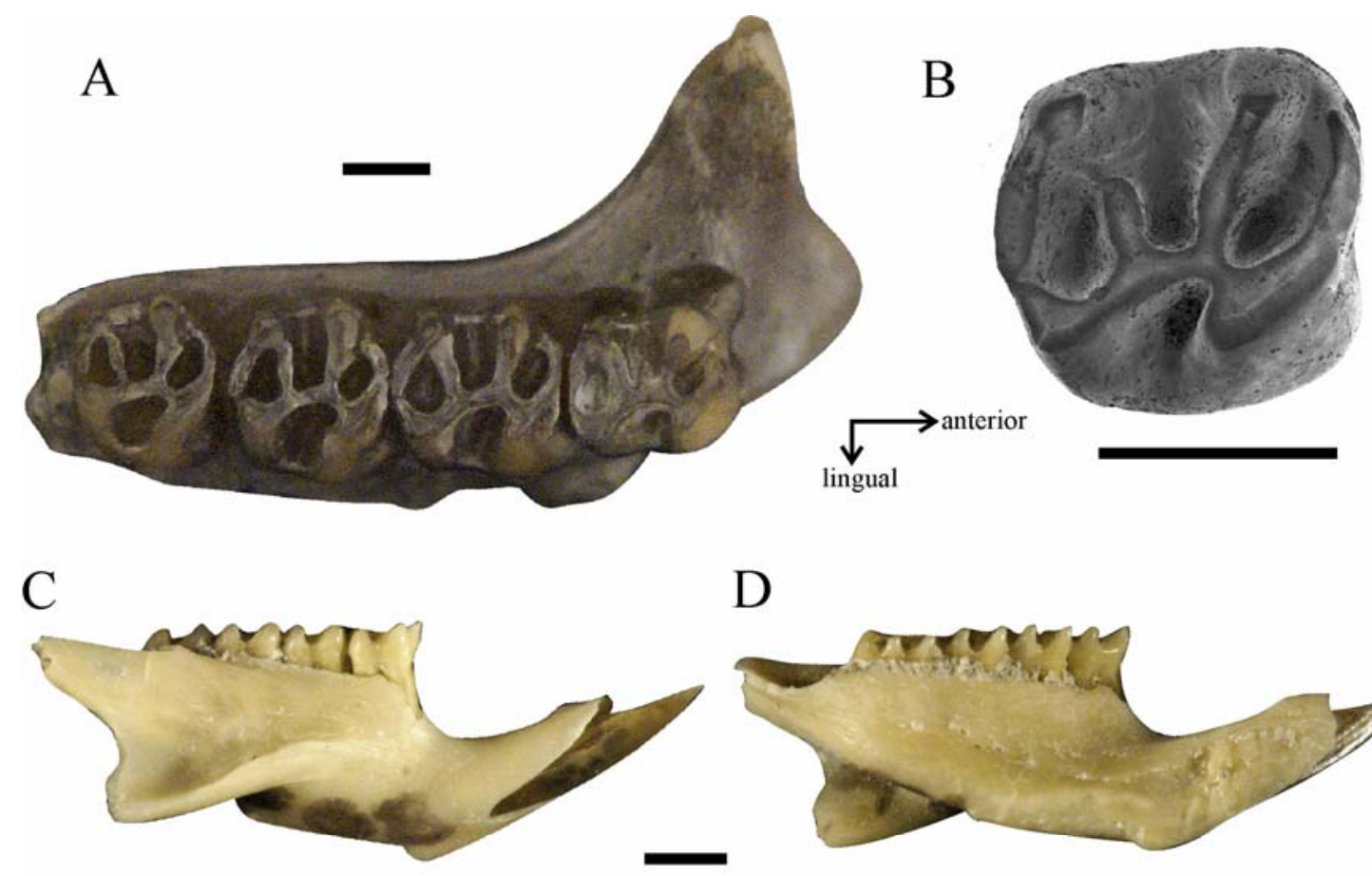

D

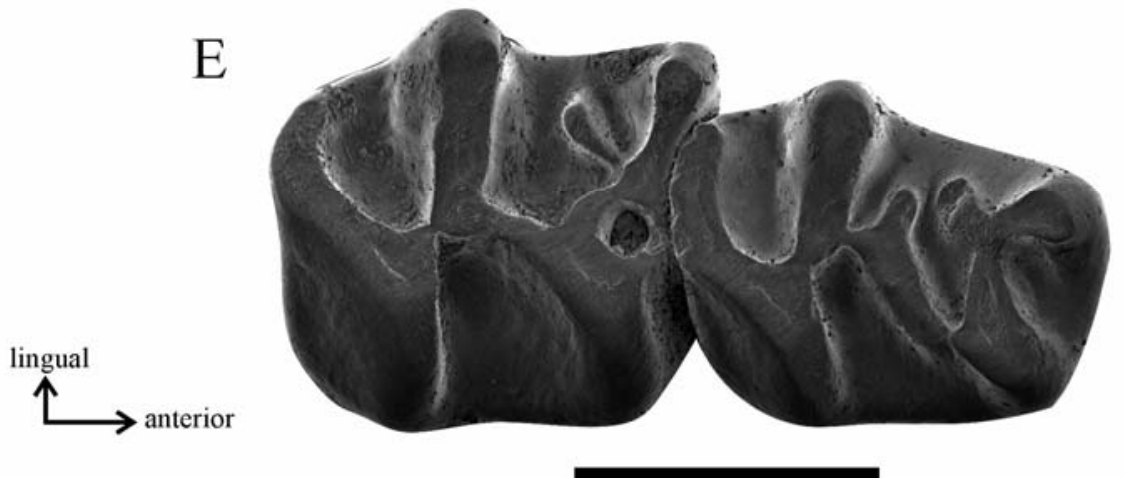

Figura 4.9. Caviocricetus lucasi. A: MPEF 505, fragmento maxilar derecho con DP4-M3 (holotipo). $B$ : PVPH 454, molar superior derecho proveniente de Cerro Bandera. $C$ - $D$. MPEF 510, mandíbula derecha con toda la dentición; $C$ : vista externa (invertida); $D$ : vista interna. $E$ : MACN CH 1990, fragmento mandibular derecho con dp4-m1. Escala= 1mm. Figura C extraída de Kramarz et al., 2005 
Género Galileomys Vucetich y Kramarz, 2003

Especie tipo: Galileomys antelucanus Vucetich y Kramarz, 2003

Distribución geográfica y temporal: provincia del Chubut, Mioceno temprano, "Edad Mamífero" Colhuehuapense; provincia de Santa Cruz, Mioceno temprano "Edad Pinturense”; provincia del Neuquén, Mioceno medio, “Edad Colloncurense”.

Diagnosis ampliada: Octodontoidea de tamaño pequeño. Dientes braquidontes y aterrazados, a diferencia de Acaremys y Sciamys; las cúspides labiales de los dientes superiores y las cúspides linguales de los dientes inferiores son más voluminosas, gruesas y altas que sus correspondientes crestas. Premolar superior con hipoflexo moderadamente desarrollado, menos que en Sciamys y como en Acaremys. Paracono de posición labial respecto al metacono y más voluminoso que éste, como en Platypittamys. Premolar inferior con un fléxido en la cresta anterior que separa el protocónido del metacónido, como en Sallamys, Deseadomys y Asteromys. El metalofúlido II y el posterolófido no alcanzan el borde lingual de los molares inferiores, a diferencia de Acaremys y Sciamys. La muesca para la inserción del tendón del $M$. masseter medialis pars anterior (mmma) se encuentra menos desarrollada que en Sciamys, y Acaremys, y mejor desarrollada que en Platypittamys. La fosa masetérica mandibular es muy profunda anteriormente, a diferencia de Sciamys.

Comentarios: la diagnosis original del género Galileomys Vucetich y Kramarz, 2003 incluye la descripción de la hipsodoncia comparada con la de Platypittamys Wood, 1949. Cabe destacar que al menos G. antelucanus y G. eurygnathus presentan un grado de hipsodoncia semejante al de Platypittamys. Por otro lado, los autores propusieron que los premolares superiores de Galileomys no presentan un hipoflexo bien desarrollado. Sin embargo, del estudio de los materiales asignados a Galileomys y la observación de nuevos materiales asignados a Galileomys antelucanus, demuestran que en los premolares definitivos el hipoflexo se encuentra moderadamente desarrollado, como en Acaremys.

En el análisis filogenético del capítulo 5 la monofilia del género Galileomys se recupera cuando se excluye del análisis a G.? colloncurensis. Sin embargo, esta especie se reconoce a través de dientes aislados que presentan mucho desgaste. Por ello, y hasta 
que se cuente con nuevos materiales asignados a G.? colloncurensis que apoyen o rechacen esta propuesta, se decidió incluir a G.? colloncurensis dentro del género Galileomys con dudas, apoyando la propuesta de Vucetich y Kramarz (2003).

Galileomys antelucanus Vucetich y Kramarz, 2003

Holotipo: MLP 82-V-2-105, fragmento mandibular izquierdo con p4-m2 e incisivo.

Material referido: (Ver Apéndice 1)

Distribución geográfica, estratigráfica y edad: Gran Barranca, provincia del Chubut, Fm Sarmiento, Miembro Colhué Huapi, Mioceno temprano, “Edad Mamífero” Colhuehuapense.

Diagnosis ampliada: molares con metalofúlido II parcialmente reducido; extensión posterior del metalofúlido I y cúspide accesoria en el antero+mesofléxido presentes. Premolares inferiores sin cúspides y/o crestas accesorias. Premolares superiores con tres o cuatro lofos. Paracono más voluminoso que en G. eurygnathus y G.? colloncurensis. Incisivos inferiores más delgados que en G. eurygnathus, con cara anterior lisa. Mandíbula más grácil y baja que en G. eurygnathus. Foramen mentoniano muy bien desarrollado y alineado con la porción más baja del diastema y el proceso mentoniano, a diferencia de G. eurygnathus en el que tiene una posición más anterior. Muesca para la inserción del tendón del M. masseter medialis pars anterior (mmma) menos desarrollada que en G. eurygnathus.

Descripción: la descripción original de Galileomys antelucanus realizada por Vucetich y Kramarz (2003) se mantiene vigente debido a su claridad y exactitud. Sin embargo, a continuación se destacan algunos rasgos de Galileomys antelucanus que no fueron analizados previamente.

MPEF-PV 5683a es el primer fragmento de maxilar asignado a G. antelucanus. La raíz ventral de la arcada cigomática nace poco por delante del P4 y su borde posterior se encuentra alineado con el borde anterior del premolar. La pequeña porción de raíz cigomática preservada es curva y baja dorso-ventralmente. La tuberosidad masetérica y la fosa para la inserción del músculo masetérico lateral se encuentran 
pobremente desarrolladas. En la cara dorsal de la raíz ventral de la arcada cigomática se observa un surco para el pasaje del nervio infraorbitario bien desarrollado, semejante al de G. eurygnathus.

Los premolares superiores pueden ser trilofodontes (Fig. 4.10A) o tetralofodontes. El protolofo es siempre la cresta mejor desarrollada de todas, mientras que el anterolofo y posterolofo se encuentran menos desarrollados y no alcanzan el borde labial del diente. En los premolares tetralofodontes se observa una cuarta cresta, tercera en posición, generalmente poco desarrollada, que se une al posterolofo rápidamente delimitando la posterofoseta. En individuos sin desgaste en sus dientes se observa que el muro está formado por una porción anterior y por una posterior que contactan con algo de desgaste (MPEF-PV 6937). El protocono se encuentra bien desarrollado, mientras que el hipocono es más pequeño y de posición labial respecto al protocono (Fig. 4.10A). El paracono es siempre la cúspide mejor desarrollada, como en Platypittamys brachyodon. El hipoflexo se encuentra moderadamente desarrollado (Fig. 4.10A); más que en Platypittamys brachyodon y Deseadomys arambourgi, aunque menos que en los molares de G. antelucanus. Este flexo es el menos penetrante de todos, puede ser oblicuo anteriormente o casi transversal al eje antero-posterior del diente. Los flexos labiales penetran casi 2/3 de la corona. En algunos ejemplares el paraflexo es el más amplio (MPEF-PV 5683a, MPEF PV-6003) (Fig. 4.10A), mientras que en otros lo es el mesoflexo (MPEF-PV 6007).

En los molares superiores el paracono también está muy bien desarrollado, más que en las restantes especies del género (Fig. 4.10B).

La mandíbula presenta el diastema largo y poco profundo (Fig. 4.10D-G). El foramen mentoniano está muy bien desarrollado y se ubica en la mitad del largo anteroposterior del diastema, alineado ventralmente con el proceso mentoniano. Este proceso se encuentra bien desarrollado (Fig. 4.10D, F). La mmma es alargada y se ubica a nivel del p4-m1 (Fig. 4.10D, F) y ésta mejor desarrollada que en Platypittamys brachyodon, aunque considerablemente menos que en G. eurygnathus. En el ejemplar tipo y en MPEF-PV 7557a la porción posterior de la misma es oblicua dorsalmente (Fig. 4.10D), mientras que en MPEF-PV 6008 y en MPEF-PV 5998 es oblicua ventralmente (Fig. 4.10F). El surco que limita la fosa masetérica antero-dorsalmente se encuentra poco desarrollado. La cresta masetérica está bien desarrollada y se inclina posteriormente en un ángulo algo menor que $45^{\circ}$ con respecto al eje antero-posterior de la mandíbula. La apófisis coronoides nace a nivel del borde posterior del m2 (MLP 82-V-2-105, MPEF 
PV 6008) (Fig. 4.10F), o a nivel del borde anterior del m3 (MPEF-PV 5988) y se extiende lateralmente, delimitando una fosa retromolar pequeña y principalmente lateral a la hilera dentaria. El foramen mandibular está muy bien desarrollado y tiene una posición alta en la rama ascendente de la mandíbula, relativamente cerca del cóndilo mandibular. En la cara interna de la mandíbula se observa que la sínfisis mandibular es poco rugosa y se extiende hasta el nivel de la mitad anterior del p4, algo por detrás del proceso mandibular (Fig. 4.10E, G).

Comentarios: en la descripción original de Galileomys antelucanus Vucetich y Kramarz (2003) señalaron que la parafoseta y la posterofoseta son casi tan profundas como el mesoflexo, razón por la cual en individuos adultos los dientes no llegan a adquirir la típica forma de 8 . Sin embargo, del estudio de estos ejemplares se observa que el mesoflexo es algo más profundo que la parafoseta y la posterofoseta, por lo que en individuos seniles los molares superiores adquirirían la forma de 8; esta última aseveración es especulativa y se basa en la profundidad de los flexos/fosetas de individuos juveniles, ya que no se dispone de ningún ejemplar con los molares lo suficientemente gastados. A diferencia de Sciamys y Acaremys, esta morfología se evidenciaría sólo en ejemplares seniles. Por otro lado, los Vucetich y Kramarz (2003) señalaron que el proceso mentoniano de la mandíbula es pequeño. Sin embargo, en MPEF PV-6008 y MPEF-PV 7557a puede observarse que el mismo se encuentra bien desarrollado (Fig. 4.10D-G).

Tabla 4.10aMedidas craneanas Galileomys antelucanus (cm)

\begin{tabular}{ccc}
\hline MLP 82-V-2-105 & LDi & 0,570 \\
& AM1 & 0,420 \\
& & \\
MPEF-PV 6008 & AM1 & 0,498 \\
& AM2 & 0,536 \\
& AM3 & 0,382 \\
\hline
\end{tabular}


Tabla 4.10b Medidas dentarias de Galileomys antelucanus (mm)

\begin{tabular}{ccccc}
\hline & & LAP & AA & AP \\
\hline MACN A 52-145 & $\mathrm{m} 1$ & 1,90 & 1,55 & 1,30 \\
& $\mathrm{~m} 2$ & 1,95 & 1,70 & 1,20 \\
MLP 82-V-2-105 & $\mathrm{p} 4$ & 1,61 & 1,31 & 1,61 \\
& $\mathrm{~m} 1$ & 1,99 & 2,03 & 1,81 \\
& $\mathrm{~m} 2$ & 1,99 & 2,06 & 1,69 \\
MPEF-PV 6008 & $\mathrm{i}$ & 4,80 & 1,13 & - \\
& $\mathrm{p} 4$ & 1,76 & 1,43 & 1,84 \\
& $\mathrm{~m} 1$ & 2,06 & 2,06 & 2,19 \\
& $\mathrm{~m} 2$ & 2,10 & 2,21 & 2,13 \\
\hline
\end{tabular}

A

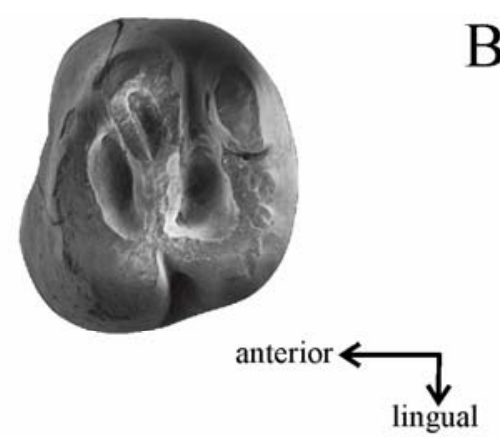

B

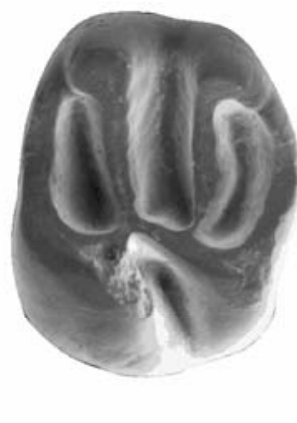

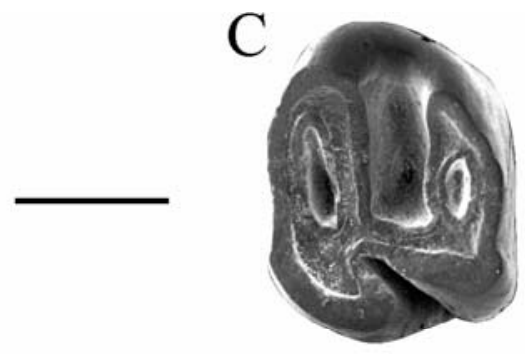
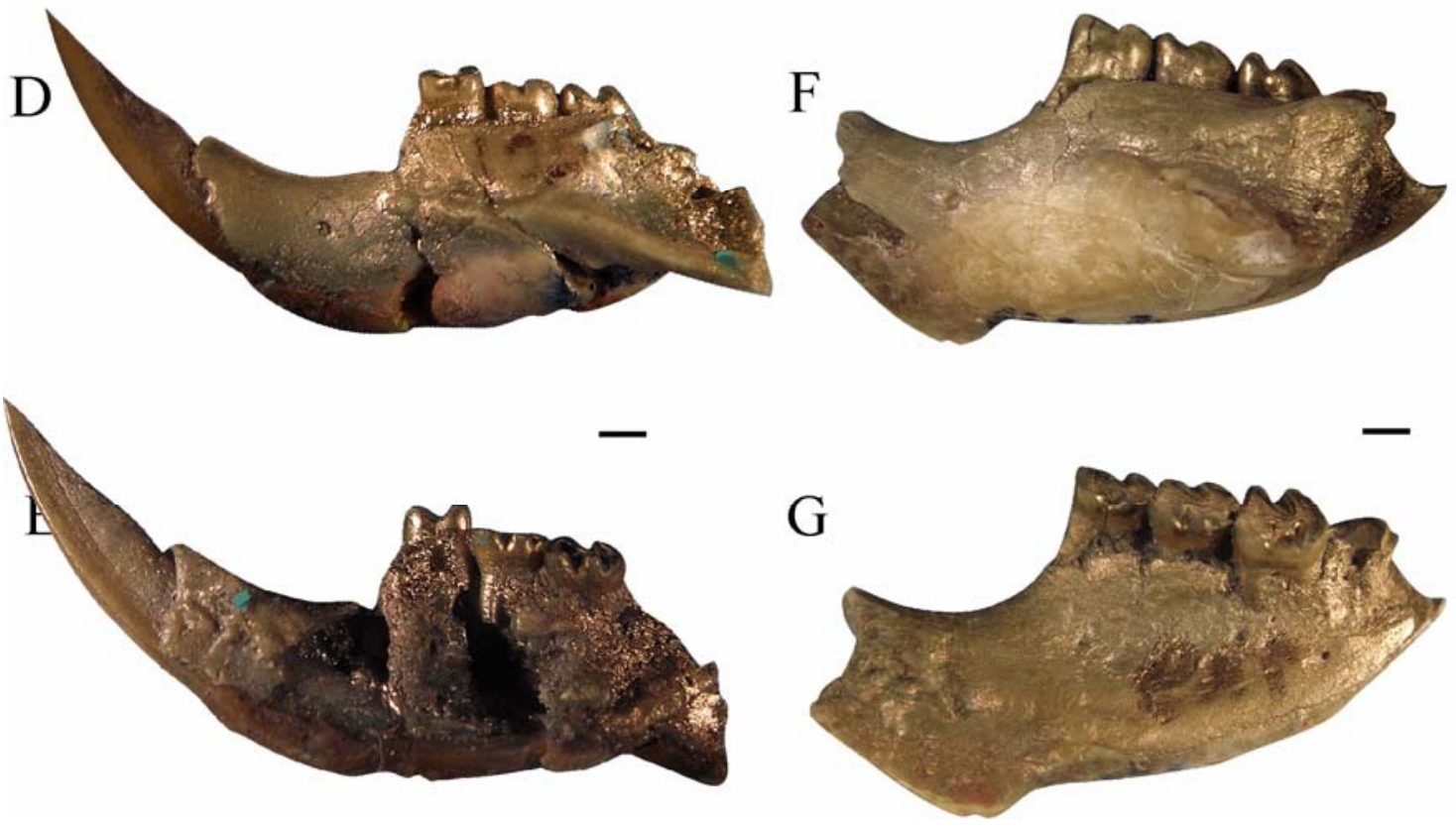

Figura 4.10. Galileomys antelucanus. A: MPEF-PV 6003, P4 derecho (invertida). B: MPEF-PV 6000, M1 ó M2 izquierdo. C: MPEF-PV 5995, M3 derecho. $D-E$. MLP 82-V-2-105 (holotipo); $D$ : mandíbula vista externa; $E$ : mandíbula vista interna (invertido). $F-G$. MPEF-PV 6008, mandíbula izquierda con p4-m2; $F$ : mandíbula vista externa; $G$ : mandíbula vista interna (invertida). Escala= 1mm. $A, B, C$ fueron tomadas de Vucetich y Kramarz (2003) 
Galileomys? colloncurensis Vucetich y Kramarz, 2003

Holotipo: MLP 91-IX-1-107a, m3 izquierdo.

Material referido: (Ver Apéndice 1)

Distribución geográfica, estratigráfica y edad: provincia del Neuquén, Fm Collón Curá, Mioceno medio, “Edad Colloncurense”.

Diagnosis original (Vucetich y Kramarz, 2003): dientes más grandes y más hipsodontes que G. antelucanus; molares inferiores con el metalofúlido II mucho más reducido. Molares superiores labialmente más cortos que lingualmente. Flexos y fléxidos más angostos que en G. antelucanus.

Comentarios: la descripción original de Galileomys? colloncurensis realizada por Vucetich y Kramarz (2003) se mantiene vigente debido a la precisión con la que los autores evaluaron los escasos caracteres observables. Como aclararon Vucetich y Kramarz, el material asignado a esta especie es muy fragmentario y se limita a dientes aislados que presentan mucho desgaste (Fig. 4.11A-D). Por ello, y hasta no encontrar ejemplares adicionales que brinden mayor información, se decidió mantener el estatus sistemático tentativo de esta especie, tal como se propuso originalmente.

En la descripción original, Vucetich y Kramarz (2003) describieron que los molares superiores de G.? colloncurensis adquieren una forma de 8. Como no se han encontrado molares superiores de individuos juveniles, hasta el momento se sabe que G.? colloncurensis adquiere esta morfología en ejemplares adultos. Sin embargo, en $G$. antelucanus los molares superiores de individuos adultos también adquieren forma de 8 (Fig. 4.11D), razón por la cual esta característica fue eliminada de la diagnosis original de G.? colloncurensis. 

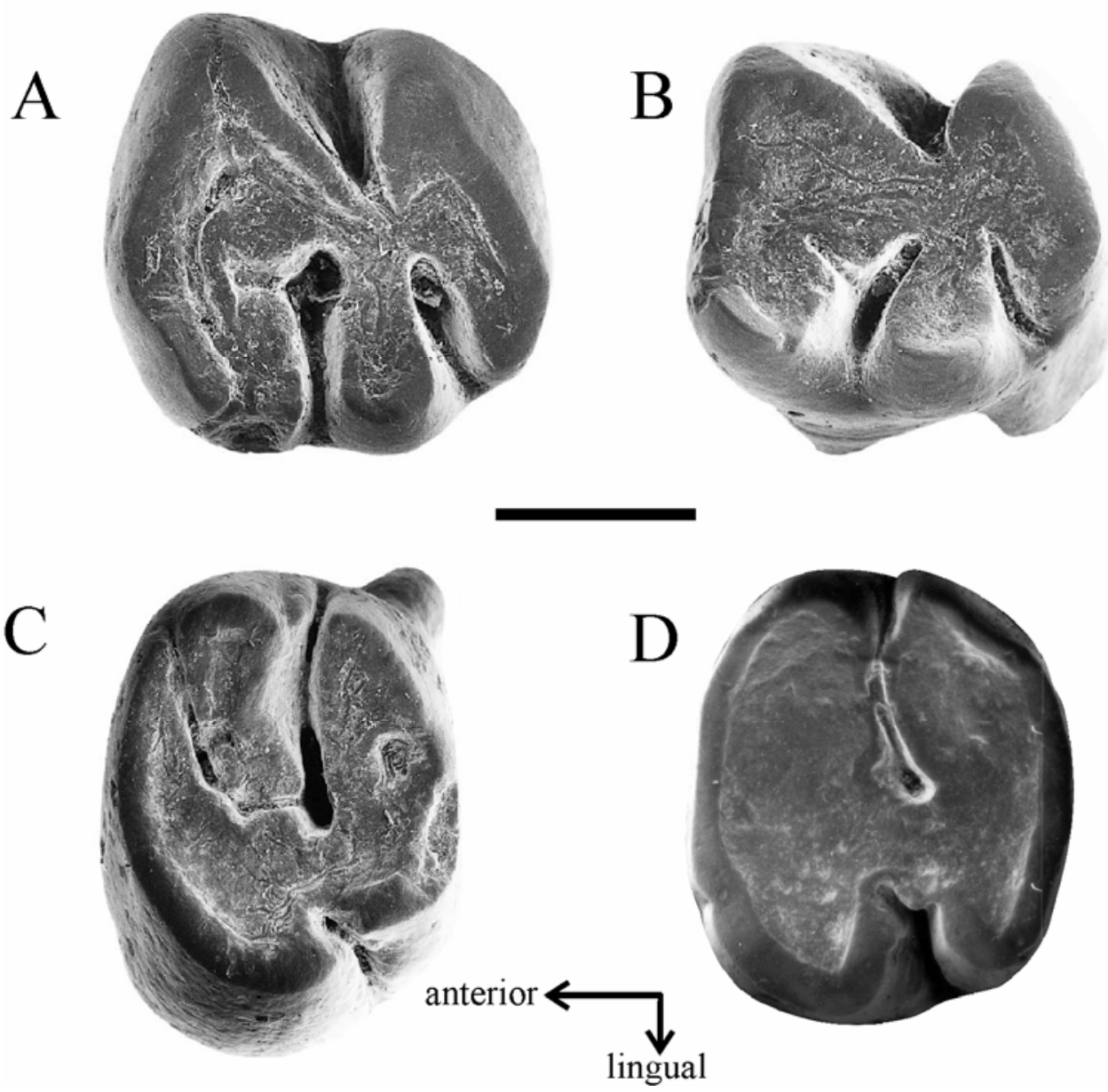

Figura 4.11. Galileomys? colloncurensis. A: MLP 91-IX-1-107b, m1 o m2 (invertido). B: MLP 91-IX1-107a, m3 izquierdo (holotipo). $C$ : MLP 91-IX-1-106a, P4 izquierdo. $D$ : MLP 91-IX-1-106b, M1 o M2 izquierdo. Escala= 1mm. Todas las figuras fueron tomadas de Vucetich y Kramarz (2003) 
Galileomys eurygnathus Kramarz, 2004

Holotipo: MACN PV SC2163, mandíbula izquierda casi completa con p4-m2 e incisivo partido.

Material referido: (Ver Apéndice 1)

Distribución geográfica, estratigráfica y edad: provincia de Santa Cruz, Fm Pinturas; Mioceno temprano, “Edad Pinturense”.

Diagnosis ampliada: dientes similares en morfología y tamaño a G. antelucanus. Molares inferiores con metalofúlido II de desarrollo variable y extensión posterior del metalofúlido I y cúspide accesoria de desarrollo variable. Premolares inferiores con cúspides y/o crestas accesorias. Paracono menos voluminoso que G. antelucanus. Incisivos inferiores más anchos que en la especie tipo, con la cara anterior ligeramente carenada. Mandíbula más robusta y alta que en G. antelucanus; sínfisis más larga y menos cóncava que en la especie tipo. Foramen mentoniano ubicado anteriormente, a diferencia de G. antelucanus donde tiene una posición más posterior. Muesca para la inserción del tendón del M. masseter medialis pars anterior (mmma) mejor desarrollada que en G. antelucanus y separada de la cresta masetérica, a diferencia de la especie tipo.

Descripción: la descripción original de Galileomys eurygnathus realizada por Kramarz (2004) se mantiene vigente debido a su claridad y exactitud. Sin embargo, a continuación se destacan algunos rasgos que no fueron analizados previamente.

Del cráneo se registran sólo unos pocos ejemplares que preservan pequeñas porciones de maxilar. La raíz ventral de la arcada cigomática nace algo por delante del P4, al igual que en la especie tipo. La tuberosidad masetérica se encuentra poco desarrollada y está bordeada posteriormente por un surco poco profundo. En la cara dorsal de la raíz ventral de la arcada cigomática se observa el surco para el pasaje del nervio infraorbitario; éste se encuentra bien desarrollado como en la especie tipo, aunque menos que en las especies de Sciamys y Acaremys.

Los molares superiores presentan una leve hipsodoncia unilateral y presentan las cúspides aterrazadas (Fig. 4.12A). En individuos seniles los molares adquieren forma de 8, ya que el mesoflexo y el hipoflexo son los flexos más profundos; al igual que en la 
especie tipo, esta morfología se adquiere sólo en individuos seniles. En los molares superiores el paracono es de posición labial respecto al metacono como en la especie tipo, pero esta cúspide es menos voluminosa (Fig. 4.12B). El anterolofo es algo más largo que el de G. antelucanus (Fig. 4.12B).

La mandíbula de G. eurygnathus presenta la sínfisis mandibular menos cóncava que en G. antelucanus y la mmma profunda y ubicada a nivel del límite entre p4-m1 (Fig. 4.12C); es corta antero-posteriormente y en algunos ejemplares es muy oblicua. La cresta masetérica nace a nivel de la mitad anterior del $\mathrm{m} 2$ y es independiente de la muesca (Fig. 4.12F). A diferencia de la especie tipo, el surco que limita la fosa masetérica ántero-dorsalmente se encuentra poco desarrollado. La apófisis coronoides nace a nivel del borde posterior del m2; la misma se encuentra muy reducida (MACN PV2077) y se extiende lateralmente desde sus orígenes delimitando una fosa retromolar pequeña y lateral a la hilera dentaria. El foramen mandibular tiene una posición alta, cerca del cóndilo mandibular, al igual que en la especie tipo.

Los p4 son algo más complejos que los de la especie tipo, ya que presentan estructuras accesorias, como por ejemplo cúspides o crestas (Fig. 4.12D-F). Contrariamente a lo que se observa en la especie tipo, el metalofúlido II presenta un desarrollo variable y puede estar formando una pequeña extensión del ectolófido (MACN PV SC2035; MACN PV SC2834), o puede formar una cresta conspicua. El metalofúlido II se encuentra algo más reducido que en la especie tipo en MACN PV SC2035, MACN PV SC2834.

Comentarios: en la descripción original de Galileomys eurygnathus Kramarz (2004) caracterizó a los incisivos inferiores como con cara anterior plana. Dentro del material referido a esta especie no hay ningún ejemplar que preserve este diente entero; el más completo se preserva anteriormente hasta el nivel del diastema (MACN PV SC2162, MACN PV SC2163). A ese nivel los incisivos presentan una sección con la cara lingual recta y la labial curva. Sin embargo, es necesario contar con un incisivo completo para caracterizar con certeza la cara anterior, ya que posteriormente la misma puede cambiar de morfología. 
Tabla 4.12. Medidas dentarias de Galileomys eurygnathus (mm)

\begin{tabular}{lrrrr}
\hline & & LAP & AA & AP \\
\hline MACN PV SC2030 & $\mathrm{p} 4$ & 1,70 & 1,60 & 1,60 \\
& $\mathrm{~m} 1$ & 2,00 & 2,00 & 1,60 \\
MACN PV SC2032 & $\mathrm{m} 2$ & 2,05 & 2,05 & 1,75 \\
MACN PV SC 2033 & $\mathrm{p} 4$ & 1,55 & 1,30 & 1,55 \\
MACN PV SC2163 & $\mathrm{p} 4$ & 1,60 & 1,60 & 1,90 \\
& $\mathrm{p} 4$ & 1,80 & 1,50 & 1,80 \\
MACN PV SC2166 & $\mathrm{m} 1$ & 2,05 & 1,90 & 1,80 \\
& $\mathrm{~m} 2$ & 2,10 & 2,15 & 1,85 \\
MACN PV SC2537 & $\mathrm{dp} 4$ & 2,30 & 1,10 & 1,50 \\
& $\mathrm{~m} 1$ & 1,80 & 1,50 & 1,90 \\
& $\mathrm{p} 4$ & 1,85 & 1,45 & 1,65 \\
& $\mathrm{~m} 1$ & 2,00 & 1,85 & 1,65 \\
MACN PV SC3557 & $\mathrm{m} 2$ & 2,15 & 2,05 & 1,80 \\
& $\mathrm{~m} 3$ & 1,95 & 1,80 & 1,65 \\
& $\mathrm{p} 4$ & 1,55 & 1,40 & 1,35 \\
& $\mathrm{~m} 1$ & 1,95 & 1,85 & 1,65 \\
& $\mathrm{~m} 2$ & 2,00 & - & 1,75 \\
\hline
\end{tabular}



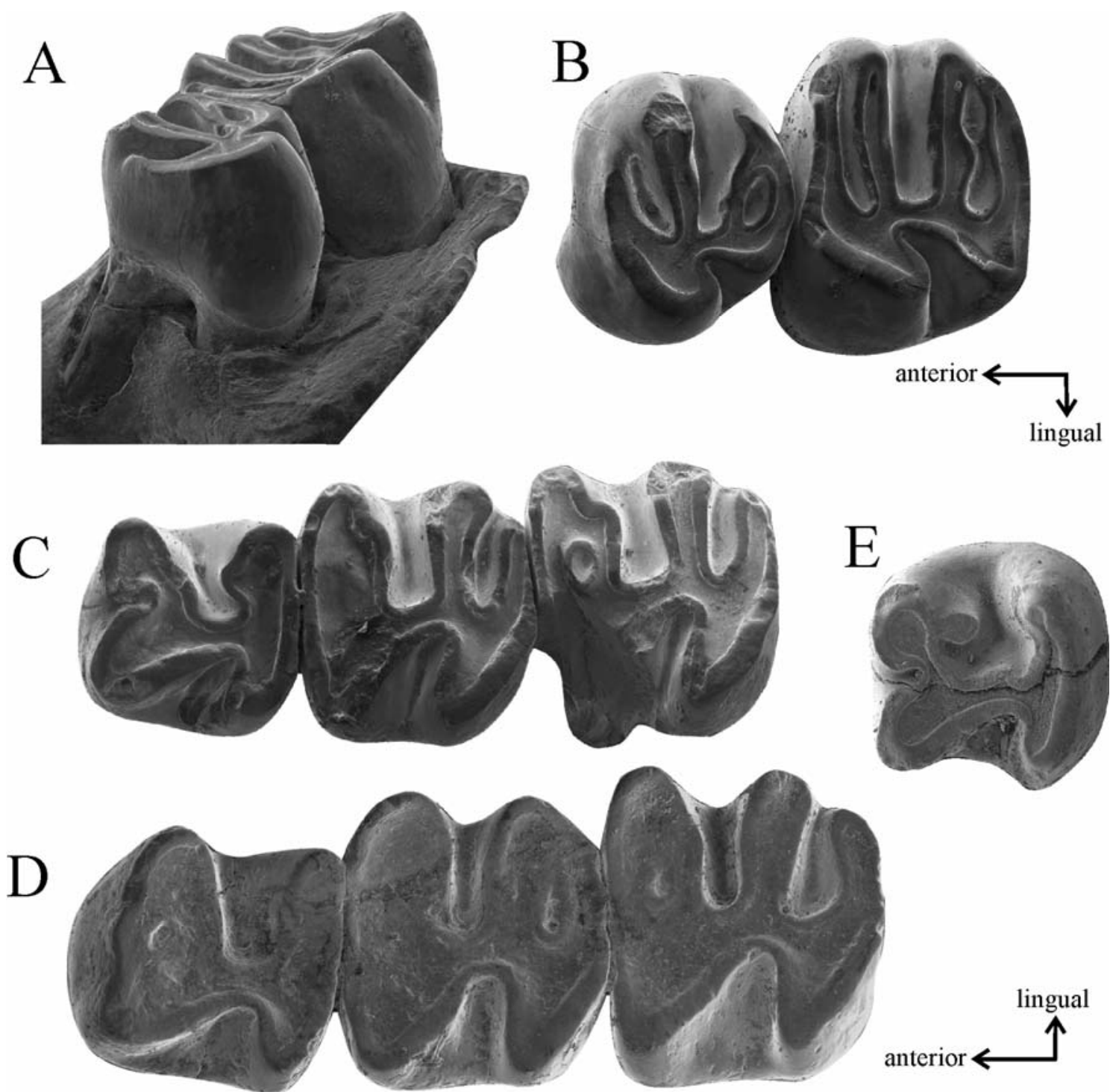

Figura 4.12. Galileomys eurygnathus. A-B. MACN PV SC2858, fragmento maxilar izquierdo con P4M1. A: vista antero-lingual; $B$ : vista oclusal. $C$ : MACN PV SC3557, fragmento mandibular derecho con p4-m2 (invertido). Vista oclusal. $D$ : MACN PV SC2030, fragmento mandibular izquierdo con p4-m2. E: MACN PV SC2033, p4 derecho (invertido). F: MACN PV SC2077, mandíbula derecha con $\mathrm{m} 1-\mathrm{m} 2$ e incisivo partido. Vista oclusal. Escala $=5 \mathrm{~mm}$ 
Migraveramus Patterson y Wood, 1982

Especie tipo: Migraveramus beatus Patterson y Wood, 1982

Distribución geográfica y temporal: Bolivia, Oligoceno tardío "Edad Mamífero" Deseadense.

Diagnosis modificada: molares inferiores mesodontes, con algo de hipsodoncia unilateral, a diferencia de Platypittamys. Superficies oclusales casi planas. Crestas bien desarrolladas. Reemplazo normal del premolar de leche. Los p4-m2 tetralofodontes, con crestas perpendiculares al eje antero-posterior del diente; m1-m2 con brazo posterior del metacónido, extensión posterior del metalofúlido I y posterolófido largo. Incisivos inferiores no comprimidos y con la cara anterior curva, a diferencia de Platypittamys. Proceso angular separándose del cuerpo mandibular a nivel de la mitad del m2. Foramen mentoniano muy bien desarrollado y ubicado por delante del p4 como en Galileomys; el mismo abre anterior y ventralmente.

Comentarios: en la diagnosis original del género Patterson y Wood (1982) describieron “an anteroposterior crest crossing lingual part of the anterofossetid”; esta estructura se interpreta aquí como una extensión posterior del metalofúlido I. Además, describieron al incisivo inferior como un diente con cara anterior plana; sin embargo, el holotipo YPM PU 21948 presenta la cara anterior curva.

Sobre la base de la morfología dentaria y bajo el supuesto que los Octodontidae representaban el grupo de roedores caviomorfos más primitivo, los autores ubicaron a Migraveramus dentro de la familia Octodontidae. En esta revisión el género se considera como un Octodontoidea incertae sedis cuyas relaciones con otros Octodontoidea serán evaluadas en un análisis filogenético (Ver capítulo 5: Análisis Filogenético).

Migraveramus beatus Patterson y Wood, 1982

Holotipo: YPM PU 21948, fragmento mandibular derecho con p4-m2

Material referido: sólo el holotipo. 
Procedencia geográfica, estratigráfica y edad: parte baja de los estratos de Salla, cuenca de Salla- Luribay, Bolivia; Oligoceno tardío, “Edad Mamífero” Deseadense.

Diagnosis: la misma que para el género.

Descripción ampliada: la descripción original de Migraveramus beatus provista por Patterson y Wood (1982) sigue vigente en varios aspectos. No obstante, a continuación se destacan algunos rasgos que no fueron evaluados originalmente. Además, se redescribe la dentición debido a las numerosas diferencias en cuanto a la interpretación de las estructuras dentarias respecto de la descripción original.

Es un roedor de tamaño medio, semejante a Sciamys principalis. En la mandíbula se observa un foramen mentoniano muy bien desarrollado, ubicado por delante del p4 y poco por detrás de la parte más baja del diastema (Fig. 4.13A). La mmma se encuentra muy poco desarrollada, es algo oblicua postero-ventralmente y está ubicada por debajo del m1. La cresta masetérica nace posteriormente y de forma continua con la muesca (Fig. 4.13A); sólo una pequeña porción anterior de la cresta masetérica se encuentra preservada; sin embargo, se observa que está bien desarrollada y que se dirige postero-ventralmente en un ángulo aproximado de $45^{\circ}$ con respecto al eje antero-posterior de la mandíbula. La base de la apófisis coronoides nace a nivel del límite entre m2-m3. La cara interna de la mandíbula no se encuentra bien conservada (Fig. 4.13B), razón por la cual no es posible describirla.

Dentro de la hilera dentaria el m2 es algo más grande que el m1, mientras que el p4 es algo más pequeño (Tabla 4.13) (Fig. 4.13C). Los molariformes presentan coronas más altas que Acaremys murinus (aproximadamente un 5\% más altas) y poco más bajas que Sciamys principalis (entre un 45 y un 55\% más bajas). El borde labial de los dientes es apenas más alto que el lingual, por lo que las superficies oclusales son casi planas. Las cúspides no se diferencian de sus respectivas crestas (Fig. 4.13C).

El p4 es tetralofodonte. El protocónido tiene una posición lingual respecto del hipocónido y el metacónido una posición algo más labial respecto del entocónido, por lo que la porción anterior del premolar es más angosta que la porción posterior (Fig. 4.13C). El metalofúlido I conecta el borde anterior del protocónido con el metacónido y es cóncavo posteriormente. El metalofúlido II está bien desarrollado, es cóncavo hacia adelante y no alcanza el borde lingual del diente; se extiende labialmente desde el protocónido y su extremo lingual se encuentra engrosado en una estructura que podría 
corresponderse con una cúspide de relaciones inciertas. El ectolófido presenta forma de s y se orienta postero-lingualmente. El hipolófido nace en el punto donde se une el ectolófido y el brazo anterior del hipocónido; esta cresta es recta y alcanza el área del entocónido en el borde lingual del diente (Fig. 4.13C). El posterolófido forma el borde posterior del diente; es largo y algo cóncavo hacia adelante. Concordando con lo que propusieron Wood y Patterson (1982), se observa un engrosamiento en el posterolófido, de posición lingual al hipocónido, que correspondería al hipoconúlido. De los fléxidos linguales el mesofléxido es el más amplio, penetrante y profundo. El anterofléxido y el metafléxido son igualmente profundos y penetrantes. El hipofléxido es oblicuo posteriormente y el más amplio de todos los fléxidos.

Los molares también son tetralofodontes. Se diferencian del premolar en que el protocónido y el metacónido se encuentran alineados labial y lingualmente con el hipocónido y entocónido respectivamente (Fig. 4.13C). Por otro lado, el metacónido presenta su brazo posterior muy largo y se curva en dirección labial, tomando contacto con la extensión posterior del metalofúlido I. Estas dos estructuras se ponen en contacto con el metalofúlido II delimitando una anterofosétida, que se encuentra divida en dos (Fig. 4.13C). Esta estructura es la que Patterson y Wood (1982) denominaron "anteroposterior crestlet of varying prominence, arising from the anterolophid and reaching the lingual tip of the metalophid".

El único incisivo preservado se encuentra partido a nivel del p4; el mismo no es comprimido siendo la cara anterior más ancha que la posterior. La cara esmaltada anterior es delgada, curva y lisa. El incisivo es largo ya que su base se encuentra por detrás del alvéolo del m3.

Comentarios: en la descripción original de Migraveramus beatus Wood y Patterson describieron la presencia de un anterocónido en el metalofúlido I del p4; sin embargo, esta cúspide no es evidente en el ejemplar preservado. También señalaron que "the posterolophid shows indications of there having been a hypoconulid"; no queda claro si los autores se refieren a todos los molariformes o a alguno en particular, pero esta condición fue corroborada sólo en el p4, donde se observa un abultamiento que podría indicar su presencia. 
Migraveramus cf. Migraveramus beatus

Holotipo: UF 114876, fragmento mandibular izquierdo con m1-m2

Procedencia estratigráfica, geográfica y edad: niveles de Branisella, Tapial Pampa este camp \#2, cuenca de Salla- Luribay, Bolivia; Oligoceno tardío, "Edad Mamífero” Deseadense.

UF 114876: este ejemplar es una mandíbula izquierda con m2-m3 perteneciente a un ejemplar adulto. La mandíbula se encuentra pobremente preservada (Fig. 4.13D-E). Este ejemplar se asigna a Migraveramus ya que presenta molares tetralofodontes; posterolófido largo; metalofúlido II, brazo posterior del metacónido y extensión posterior del metalofúlido I bien desarrollados, molariformes con los bordes labiales algo más alto que los linguales y superficies oclusales bien planas.

A diferencia del holotipo de $M$. beatus, UF 114876 es aproximadamente 20\% más pequeño (Tabla 4.13), presenta una extensión anterior del metalofúlido II, el brazo posterior del metacónido se encuentra más desarrollado y el posterolófido es considerablemente más largo, razón por la cual la posterofosétida se encuentra casi cerrada lingualmente (Fig. 4.13F). Adicionalmente, UF 114876 presenta la superficie externa de esmalte muy irregular, especialmente en el área del hipofléxido y la anterofosétida (Fig. 4.13F). UF 114876 presenta coronas más bajas que el ejemplar tipo, característica que puede deberse al mayor grado de desgaste de los dientes.

Las semejanzas y diferencias observadas entre UF 114876 y YPM PU 21948 sugieren que UF 114876 podría corresponderse con un nuevo ejemplar de Migraveramus.

Tabla 4.13. Medidas dentarias de Migraveramus beatus y Migraveramus cf. M. beatus (mm)

\begin{tabular}{ccccc}
\hline & & LAP & AA & AP \\
\hline YPM PU 21948 & $\mathrm{p} 4$ & 2,09 & 1,55 & 1,92 \\
& $\mathrm{~m} 1$ & 2,25 & 1,84 & 1,78 \\
& $\mathrm{~m} 2$ & 2,35 & 2,17 & 1,93 \\
UF 114876 & $\mathrm{m} 1$ & 1,78 & 1,48 & 1,8 \\
& $\mathrm{~m} 2$ & 1,86 & 1,73 & 1,77 \\
\hline
\end{tabular}



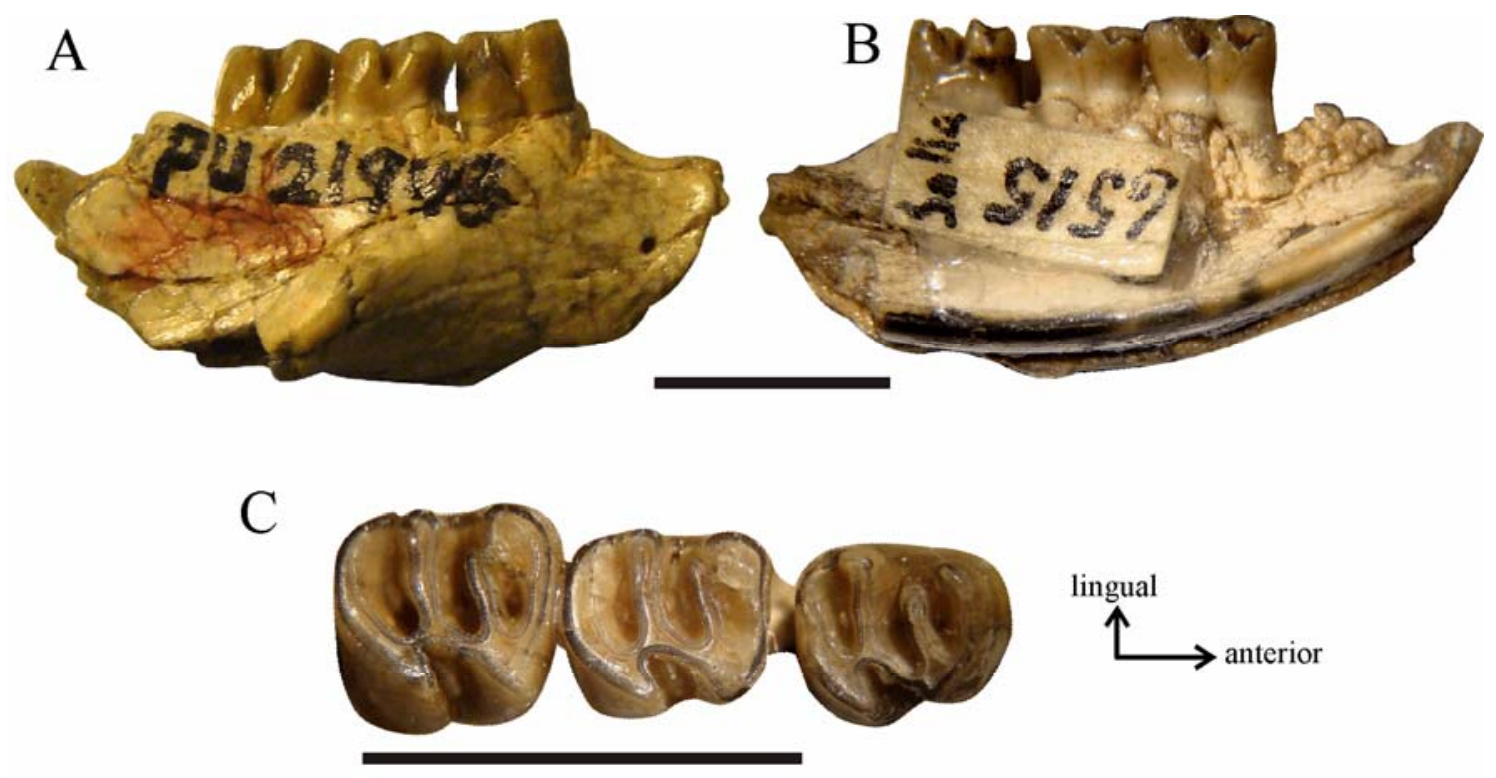

$\mathrm{D}$

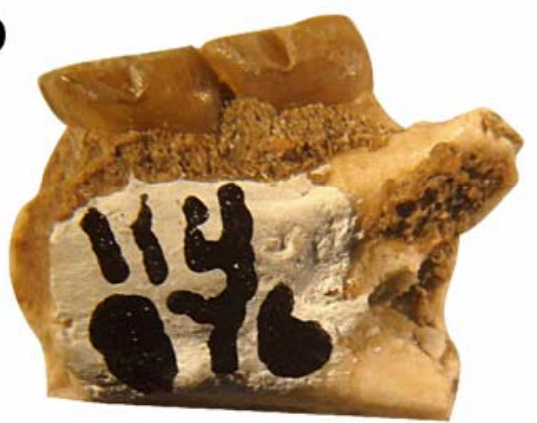

$\mathrm{E}$

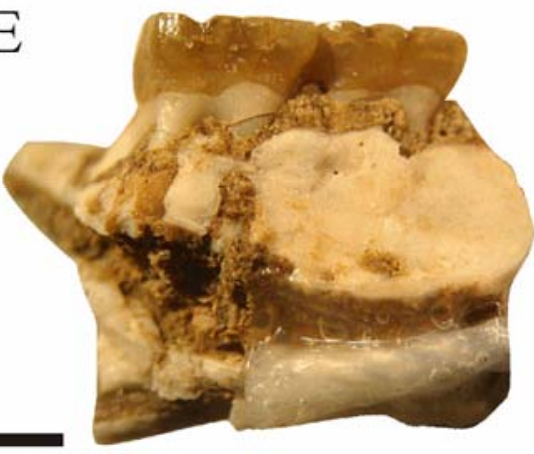

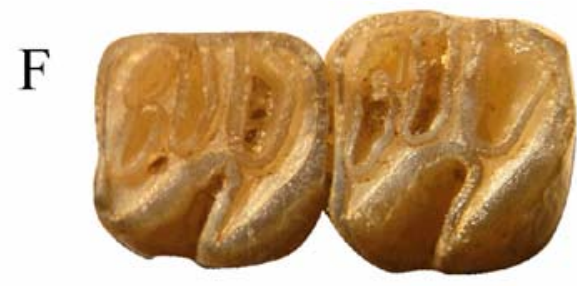

Figura 4.13. A-C. Migraveramus beatus, YPM PU 21948, fragmento mandibular derecho con p4-m2 (holotipo). $A$ : vista externa de la mandíbula $B$ : vista interna de la mandíbula; $C$ : vista oclusal de la dentición. $D-F$. Migraveramus cf. M. beatus, UF 114876, fragmento mandibular izquierdo con m2m3. $D$ : vista externa de la mandíbula $E$ : vista interna de la mandíbula; $F$ : vista oclusal de la dentición. Escala $=5 \mathrm{~mm}$ 
Género Platypittamys Wood, 1949

Especie tipo: Platypittamys brachyodon Wood, 1949

Distribución geográfica y temporal: provincia del Chubut, Oligoceno tardío, "Edad Mamífero” Deseadense.

Diagnosis modificada: octodontoideo de tamaño pequeño. Dientes braquiodontes y aterrazados, a diferencia de Migraveramus. Dientes superiores con leve hipsodoncia unilateral. Reemplazo normal de los premolares de leche. Cúspides diferenciadas de sus respectivas crestas. P4 trilofodonte y sin hipoflexo desarrollado, a diferencia de Sciamys. Paracono más voluminoso que metacono. Premolar inferior con metalofúlido II presente, a diferencia de Galileomys. Molares inferiores con brazo posterior de metacónido y extensión posterior del metalofúlido I. Incisivos superiores e inferiores más comprimidos que en Acaremys, con la cara esmaltada anterior lisa y curva.

Comentarios: en la diagnosis original del género, Wood (1949) consideró a Platypittamys como un acarémido. Sin embargo, el status sistemático de este taxón es controvertido (Wood y Patterson, 1959; Vucetich y Kramarz, 2003; Carvalho y Salles, 2004; Arnal y Kramarz, 2009; Arnal et al., 2010), razón por la cual en esta revisión se considera a Platypittamys como un Octodontoidea, cuyas relaciones fueron puestas a prueba en el análisis filogenético del capítulo 5. Por otro lado, Wood mencionó que "the masseter had not yet begun to pass through the infraorbital foramen", ya que describió un foramen infraorbitario pequeño en Platypittamys; sin embargo, esta característica no pudo ser evaluada como consecuencia del aplastamiento craneano.

Platypittamys brachyodon Wood, 1949

Holotipo: AMNH 29600, esqueleto con cráneo y mandíbula muy comprimidos.

Material referido: (Ver Apéndice 1) 
Distribución geográfica, estratigráfica y edad: Scarrit Pocket (Rinconada de los López), provincia del Chubut. Oligoceno tardío, “Edad Mamífero” Deseadense.

Diagnosis modificada: la misma que para el género.

Descripción ampliada: la descripción original de Platypittamys Wood, 1949 es extensiva y detallada y se realizó sobre la base de la reconstrucción del esqueleto. No obstante, numerosas características no pudieron ser observadas (debido a la preservación del material) y por ello, muchas de ellas no fueron evaluadas (Ver comentarios más abajo). En esta revisión se destacan rasgos que no fueron evaluados por Wood (1949). En cuanto a la descripción de los dientes, las principales diferencias entre la descripción original y la presentada aquí se basan en la diferente interpretación de las homologías de las estructuras oclusales.

- Cráneo. En el margen dorso-lateral del rostro se observa un reborde bien desarrollado (Fig. 4.14A). Aproximadamente en la mitad del largo antero-posterior del reborde se observa una proyección que se dirige ventralmente de manera semejante a lo que se observa en Acaremys y Sciamys; esta proyección podría representar el extremo anterior de la fosa masetérica. En la cara ventral del rostro los forámenes incisivos parecen haber estado bien desarrollados (AMNH 29601). La raíz ventral de la arcada cigomática nace poco por delante del P4 (Fig. 4.14A); es corta antero-posteriormente y muy curva, con la concavidad en dirección posterior. En la cara ventral del la raíz ventral de la arcada cigomática, la tuberosidad masetérica se encuentra moderadamente desarrollada; la superficie de inserción del tendón para el músculo masetero lateral es poco profunda y se extiende lateralmente hasta el punto donde termina la curvatura de la raíz ventral de la arcada cigomática. Las narinas abren a nivel del M2, delimitando una fosa mesopterigoidea de contorno triangular.

- Dientes superiores. En los molariformes superiores las cúspides labiales se diferencian claramente de las crestas, las cuales son delgadas y están separadas por flexos amplios. El M2 es el diente de mayor tamaño, mientras que el P4 es el más pequeño. La capa de esmalte que rodea a los molariformes superiores es gruesa, especialmente en la mitad lingual de los dientes.

El P4 es un diente simple, trilofodonte y es de contorno subcircular (Fig. 4.14BC). El borde anterior del diente lo forma el anterolofo, que no alcanza el borde labial; esta cresta se extiende desde el borde anterior del protocono, del cual se encuentra 
separada por una pequeña constricción. Posteriormente se encuentra el protolofo, que es la cresta más conspicua (Fig. 4.14B-C); es recta, se extiende desde el protocono y labialmente se une a un paracono muy voluminoso (AMNH 29600). El borde posterior del diente lo forma el posterolofo, que es cóncavo anteriormente y es más largo que el anterolofo. Esta cresta se extiende desde un área del hipocono, que es muy pequeña, y de la cual se encuentra separada por una pequeña constricción, hasta el borde externo del diente. El hipoflexo no esta presente, sino que lo que se observa es una pequeña constricción que penetra desde el borde postero-lingual del diente, que podría estar representando un esbozo de hipoflexo (Fig. 4.14B-C). Labialmente se observan dos flexos: el anterior es pequeño y poco profundo, mientras que el posterior es muy amplio y profundo.

Los molares superiores son tetralofodontes y de contorno cuadrangular. El paracono es más voluminoso que el metacono (Fig. 4.14C). El anterolofo es cóncavo posteriormente y no alcanza el borde labial del diente. El protolofo también es cóncavo posteriormente y se une labialmente al paracono. Desde el extremo postero-lingual del protolofo se extiende el muro en dirección postero-lingual. El metalofo nace en el punto donde se unen el muro y el brazo anterior del hipocono, y se dirige labialmente hasta el metacono. El posterolofo se extiende desde el borde posterior del hipocono y es cóncavo anteriormente; se extiende labialmente hacia el metacono, al cual se une ya en individuos juveniles. El M3 se diferencia del resto de los molares por presentar el talón reducido (Fig. 4.14C); el hipocono es labial respecto al protocono, por lo cual el metalofo y posterolofo son notablemente más cortos que en el M1 y M2. El hipoflexo es bien penetrante y oblicuo anteriormente en todos los molares; es el más profundo de los flexos. De los flexos labiales el mesoflexo es el más amplio y profundo, mientras que el paraflexo y la posterofoseta son los más penetrantes y angostos.

Los incisivos superiores son muy comprimidos. La cara esmaltada anterior es curva y lisa. Lateralmente la superficie de desgaste presenta forma de J (Fig. 4.14A).

- Mandíbula. En la mandíbula, la muesca para el tendón del mmma está muy poco desarrollada y se ubica por debajo del p4 en dirección oblicua postero-ventralmente (Fig. 4.14D). La misma se une de forma continua con la cresta masetérica, la cual es oblicua postero-ventralmente en un ángulo menor de $45^{\circ}$ con respecto al eje anteroposterior de la mandíbula (AMNH 29601). Otros rasgos de la mandíbula estarían fuertemente afectados por deformación post-mortem (Ver comentarios más abajo). 
- Dientes inferiores. Dientes braquiodontes y aterrazados, donde las cúspides linguales se distinguen claramente de las crestas (Fig. 4.14F-G).

El p4 es de contorno rectangular, siendo el eje mayor el antero-posterior. En AMNH 29600 el metalofúlido I en completo. En AMNH 29601 el borde anterior del diente tiene un fléxido/fosétida que separa el protocónido y el metacónido, como en los acarémidos y otros octodontoideos, chinchilloideos y cavioideos. Del borde posterolingual del protocónido se extiende el metalofúlido II que, como es usual, no alcanza el borde lingual del diente. Posteriormente el protocónido se continúa con el ectolófido, que es recto y de disposición oblicua en dirección postero-lingual. El ectolófido se prolonga hacia atrás hasta contactar con el posterolófido cerca de su punto medio. El posterolófido es algo convexo anteriormente y une el hipocónido con el entocónido. El hipofléxido es amplio y oblicuo posteriormente. Labialmente, el anterofléxido es pequeño y redondeado (AMNH 29600), mientras que en individuos adultos se forma una anterofosétida (AMNH 29601). El posterofléxido es el más amplio de todos.

Los molares inferiores son tetralofodontes. El metalofúlido I es recto y une el protocónido con el metacónido; posteriormente al metacónido se extiende el brazo posterior del metacónido (ausente sólo en el m2 de AMNH 29601). Cerca del extremo lingual del metalofúlido I nace la extensión posterior del metalofúlido I. Del borde posterior del protocónido nace el metalofúlido II; esta cresta toma contacto con el brazo posterior del metacónido y/o con la pequeña cresta del metalofúlido I, delimitando un lóbulo anterior. El ectolófido se extiende desde el protocónido en dirección posterolingual hasta su unión con el brazo anterior del hipocónido. En este punto nace el hipolófido, que es recto y se une lingualmente al entocónido. El posterolófido es corto y cóncavo anteriormente. El hipofléxido es el más amplio, penetrante y profundo de todos los fléxidos; es oblicuo posteriormente. La anterofosétida se forma ya en individuos juveniles y generalmente se encuentra divida en dos por la pequeña cresta descripta anteriormente; debido al grado de desgaste esta estructura no puede observarse en AMNH 29601 (o quizás porque no haya estado presente). El mesofléxido es el más amplio de los fléxidos linguales, y es tan penetrante como el posterofléxido, con la diferencia que este último forma una posterofosétida en individuos adultos (m2 de AMNH 29601).

Los incisivos inferiores son marcadamente comprimidos. La cara anterior es curva y lisa. La cavidad pulpar es muy comprimida y larga. Lateralmente, la superficie 
de desgaste es poco curva. Son largos, ya que su base se extiende algo posteriormente al m3.

Comentarios: Si bien Wood (1949) describió numerosos caracteres para Platypittamys, varios de ellos no fueron considerados en el presente estudio. Estos caracteres que no fueron evaluados se diferencian en 2 tipos:

1) Caracteres que no fueron evaluados debido a que no fueron incluidos en el análisis filogenético: éstos involucran los caracteres post-craneanos, que no fueron analizados aquí ya que esta revisión incluye sólo características craneanas y mandibulares, por ser éstas las únicas que se pueden evaluar en la mayoría de los octodontoideos fósiles.

2) Caracteres que no fueron evaluados debido a que no pudieron ser corroborados en los materiales estudiados:

- En la descripción original Wood describió un foramen infraorbitario de tamaño pequeño. Sin embargo, los ejemplares presentan un grado de aplastamiento tal que hace imposible determinar el verdadero tamaño de este foramen.

- El autor describió la forma y tamaño de los huesos de la porción posterior del techo craneano y de la región occipital; sin embargo, en AMNH 29601 no fue posible observar esta porción del cráneo, mientras que en AMNH 29600 la porción dorsoposterior del cráneo se encuentra muy pobremente preservada.

- Wood describió el hueso interparietal, argumentando que sus suturas eran claramente observables. Sin embargo, no fue posible identificar dichas suturas en el análisis de AMNH 29600 debido al estado de preservación del material.

- El proceso mentoniano de la mandíbula no se encuentra preservado en ninguno de los dos ejemplares estudiados; por ello no es posible observar el "small mental process of the mandible at the posterior end of the symphysis” que describió Wood (1949).

- El AMNH 29601 sufrió la pérdida de su premolar inferior en el trascurso de los años; actualmente se observan dos molares (m1-m2) en la mandíbula derecha, mientras que en la descripción original la misma mandíbula presentaba p4-m2.

- Wood (1949) describió la mandíbula de Platypittamys como “long and slender, apparently, at least a slight inflection of the angle, which extends well to the rear ...”. Sin embargo, en AMNH 29600 la forma actual de la hemimandíbula es muy probablemente consecuencia de la deformación mencionada anteriormente (Fig. 4.14E) y podrían encontrarse alteradas respecto de su estado original. 
Otros caracteres pudieron ser positivamente observados en los materiales descriptos por Wood (1949), pero aquí son reinterpretados:

- En AMNH 29600 se observa una pequeña constricción por detrás de la orbita que podría representar una pequeña constricción postorbitaria, que no fue descripta por Wood.

- Para los molares superiores Wood (1949) propuso que el muro representaría el brazo anterior del hipocono; aquí se interpreta que el brazo anterior del hipocono se extiende desde el hipocono hasta la base del metalofo, y por lo tanto es un elemento distinto del muro.

- Wood (1949) señaló que en el ectolófido del p4 hay una expansión que podría corresponderse con las primeras etapas de desarrollo del mesocónido. En el estudio de AMNH 29600 y AMNH 29601 no se observó dicha expansión, ni ninguna otra estructura que sugiera la presencia de un mesocónido. Además, el autor interpretó que la última cresta en posición del premolar sería el hipolófido; sin embargo, sobre la base de la interpretación de las homologías primarias de este estudio, se considera que la cresta posterior del p4 es un posterolófido. 


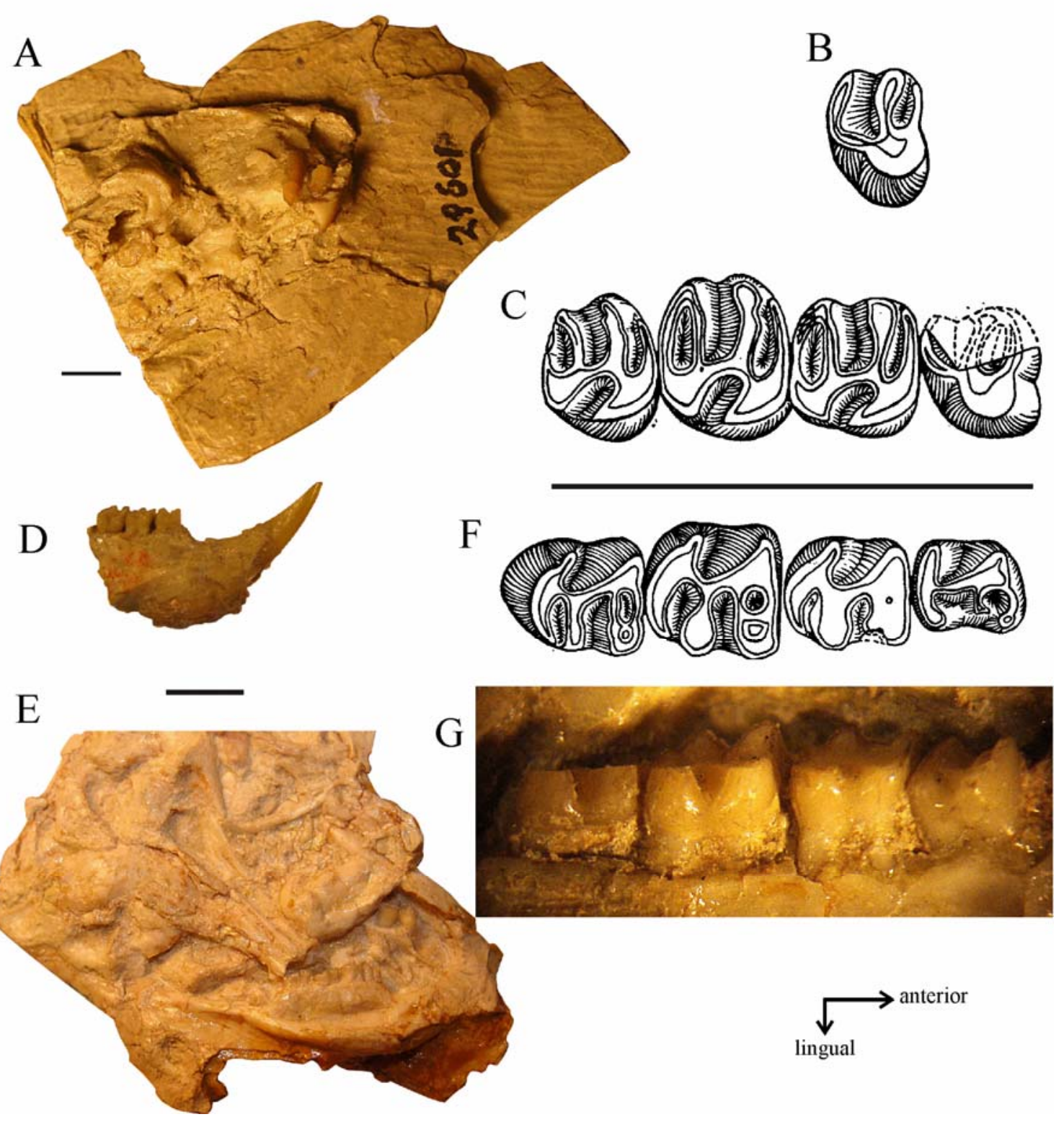

Figura 4.14. Platypittamys brachyodon. A: AMNH 29601, fragmento de cráneo en laja; $B$ : AMNH 29600, P4. $C$ - $D$. AMNH 29601; $C$ : P4 -M3 izquierdos en vista oclusal (invertido); $D$ : Vista externa de fragmento mandibular derecho con p4-m2 e incisivo. $E-G$. AMNH 29600 (holotipo); $E$ : laja con hemimandíbula en vista interna; $F$ : p4-m3 izquierdos en vista oclusal (invertido); $G$ p4-m3 izquierdos en vista labial (invertido). $B, C$ y $F$ fueron tomados de Wood (1949). Escala $5 \mathrm{~mm}$ 
Género Plesiacarechimys Vucetich y Vieytes, 2006

Especie tipo: Plesiacarechimys koenigswaldi Vucetich y Vieytes, 2006

Distribución geográfica y temporal: provincia de Río Negro, Mioceno medio "Edad Colloncurense”.

Diagnosis modificada: Octodontoidea de tamaño mediano, aproximadamente $50 \%$ más grande que la especie más grande de Acarechimys. Dientes de corona baja, con algo de hipsodoncia unilateral en los superiores; lofodonte, aunque las cúspides se diferencian en individuos juveniles. Molares superiores pentalofodontes con el metalofo pobremente desarrollado. Mesolófulo orientado hacia el metacono, fusionándose a él con poco desgaste. Paracono y metacono más altos que el resto del diente y paracono más grande que el metacono. Dientes inferiores tetralofodontes con el metalofúlido II bien desarrollado o reducido, aunque siempre bien desarrollado en el m1 y más bajo, y mejor desarrollado que en la especie más grande de Acarechimys. Metacónido y entocónido más altos que el resto del diente; entocónido expandido anteroposteriormente o sólo expandido anteriormente.

Comentarios: en la diagnosis original Vucetich y Vieytes indicaron que los dientes eran braquiodontes; sin embargo, sobre la base de la definición de grado de hipsodoncia utilizado en este análisis se propone que los dientes de Plesiacarechimys son mesodontes por lo que en la diagnosis el término "braquiodontes" fue reemplazado por “dientes de corona baja” (no se reemplaza por el término "mesodonte” ya que quizás en futuros análisis bajo una definición de hipsodoncia distinta, los molariformes de Plesiacarechimys se definen como braquiodontes nuevamente).

Plesiacarechimys koenigswaldi Vucetich y Vieytes, 2006

Holotipo: MLP 91-V-1-55, fragmento de cráneo con DP4-M2 izquierdo y fragmento de mandíbula izquierda con dp4-m2.

Material referido: (Ver Apéndice 1) 
Distribución geográfica, estratigráfica y edad: estancia Cerro San Antonio, Pilcaniyeu Viejo, provincia de Río Negro; Fm Collón Curá, “Edad Colloncurense”.

Diagnosis ampliada: la misma que para el género.

Descripción: la descripción original de Plesiacarechimys koenigswaldi realizada por Vucetich y Vieytes (2006) se mantiene vigente debido a su claridad y exactitud. Sin embargo, a continuación se destacan algunos rasgos de Plesiacarechimys koenigswaldi que no fueron analizados previamente.

- Cráneo. El holotipo (cráneo mal preservado y aplastado) y MLP 92-V-10-1 representan los dos cráneos sobre los cuales se realizó la descripción. Algunas estructuras se describen de forma condicional, debido a la mala conservación de los ejemplares (Fig. 4.15A). El rostro es robusto y pareciera no ensancharse posteriormente, a diferencia del rostro de los acarémidos. Los forámenes incisivos parecieran ser largos y angostos y posteriormente no se continúan con surcos diastemales. No se distingue la sutura premaxilo-maxilar que los intersecta. En vista lateral se observa una fosa masetérica de forma subtriangular, con su vértice anterior más agudo que el posterior y profunda (MLP 92-V-10-1), semejante a la de Prospaniomys priscus. Las ramas ascendentes de los premaxilares ocupan la porción lateral del techo del rostro craneano. Las fosas maxilares parecerían ser profundas (MLP 92-V-10-1). La raíz ventral de la arcada cigomática parecería extenderse lateralmente a nivel de la mitad anterior del DP4; en la cara dorsal de la arcada cigomática hay un pequeño reborde que delimita el pasaje para el nervio infraorbitario (MLP 92-V-10-17). En la porción posterior del cráneo se observa la porción lateral de la bula timpánica izquierda que parecería presentar el seno epitimpánico y la porción lateral del seno hipotimpánico bien desarrollados; el MAE es grande y por debajo de él no se observa un foramen accesorio. - Dientes superiores. Plesiacarechimys representa el único octodontoideo del OligoMioceno que presenta dientes superiores pentalofodontes (Fig. 4.15B). El paracono es más grande que el metacono. El DP4 es poco más pequeño que los molares. En los molares el metalofo se encuentra reducido y aislado dentro de la posterofoseta en el M1 del holotipo, mientras que en el M2 sólo su extremo lingual contacta al posterolofo. En MLP 92-V-10-1 el metalofo se encuentra reducido en todos los molares (Fig. 4.15C).

Los incisivos superiores son poco comprimidos y presentan la cara de esmalte anterior fina, lisa y con el borde labial curvo mientras que el lingual es recto. 
- Mandíbula. No hay foramen mentoniano y hay un proceso mentoniano conspicuo a nivel de la porción más baja del diastema (MLP 91-V-1-30). La mmma es corta anteroposteriormente, es poco profunda y se ubica a nivel del límite entre el dp4-m1 (Fig. 4.15D). La cresta masetérica nace en el borde posterior de la mmma y se extiende postero-ventralmente. La fosa masetérica es poco profunda y su límite anterior se ubica a nivel del m1-m2; en su porción postero-dorsal hay un abultamiento que se corresponde con la base del incisivo (MLP 92-V-10-15). El cóndilo mandibular es convexo y redondeado, y la rama ascendente parecería ser bien alta (MLP 91-V-1-55).

- Dientes inferiores. La morfología dentaria es similar a la de A. pulchellus y $A$. constans, aunque se diferencia en que en Plesiacarechimys koenigswaldi las coronas son más redondeadas en vista lateral y las cúspides son más conspicuas.

En el dp4 el mesolófido puede ser largo y tomar contacto con el metacónido (MLP 91-V-1-19) (Fig. 4.15E) o puede estar reducido a una pequeña extensión lingual del ectolófido (MLP 91-V-1-42, MLP 91-V-1-55). En ambos casos se delimita un lóbulo anterior que está divido en dos fosétidas por el metalofúlido II.

En cuanto a los molares, Vucetich y Vieytes (2006) interpretaron en la descripción original que el metalofúlido II estaba formado por dos secciones (una extensión del protocónido y una extensión del metacónido), en esta revisión se considera que sólo la extensión lingual del protocónido corresponde al metalofúlido II, mientras que la porción lingual de la segunda cresta corresponde a una extensión labial muy desarrollada del brazo posterior del metacónido, (Fig. 4.15F). En MLP 91-V-1-31 el brazo posterior del metacónido es muy largo, se curva en dirección anterior y contacta con el borde posterior del metalofúlido I, de manera semejante a lo que ocurre en Migraveramus beatus. En cambio, a diferencia de esta especie, en los molares no hay una extensión posterior del metalofúlido I, sino que hay en una proyección anterior del metalofúlido II (MLP 91-V-1-19, MLP 91-V-1-55). El mesofléxido es más profundo que la anterofosétida y el posterofléxido/posterofosétida. 
Tabla 4.15. Medidas dentarias de Plesiacarechimys koenigswaldi (mm)

\begin{tabular}{lllll}
\hline & & LAP & AA & AP \\
\hline MLP 91-V1-55 & DP4 & 2,54 & 3,14 & 3,00 \\
& M1 & 2,78 & 3,08 & 3,08 \\
& M2 & 2,92 & 3,46 & 3,24 \\
& dp4 & 2,98 & 2,06 & 2,10 \\
& m1 & 3,00 & 2,80 & 2,62 \\
MLP 91-V-1-42 & m2 & 3,16 & 3,26 & 3,06 \\
& dp4 & 3,08 & 2,20 & 2,26 \\
& m1 & 3,08 & 2,70 & 2,58 \\
\hline
\end{tabular}
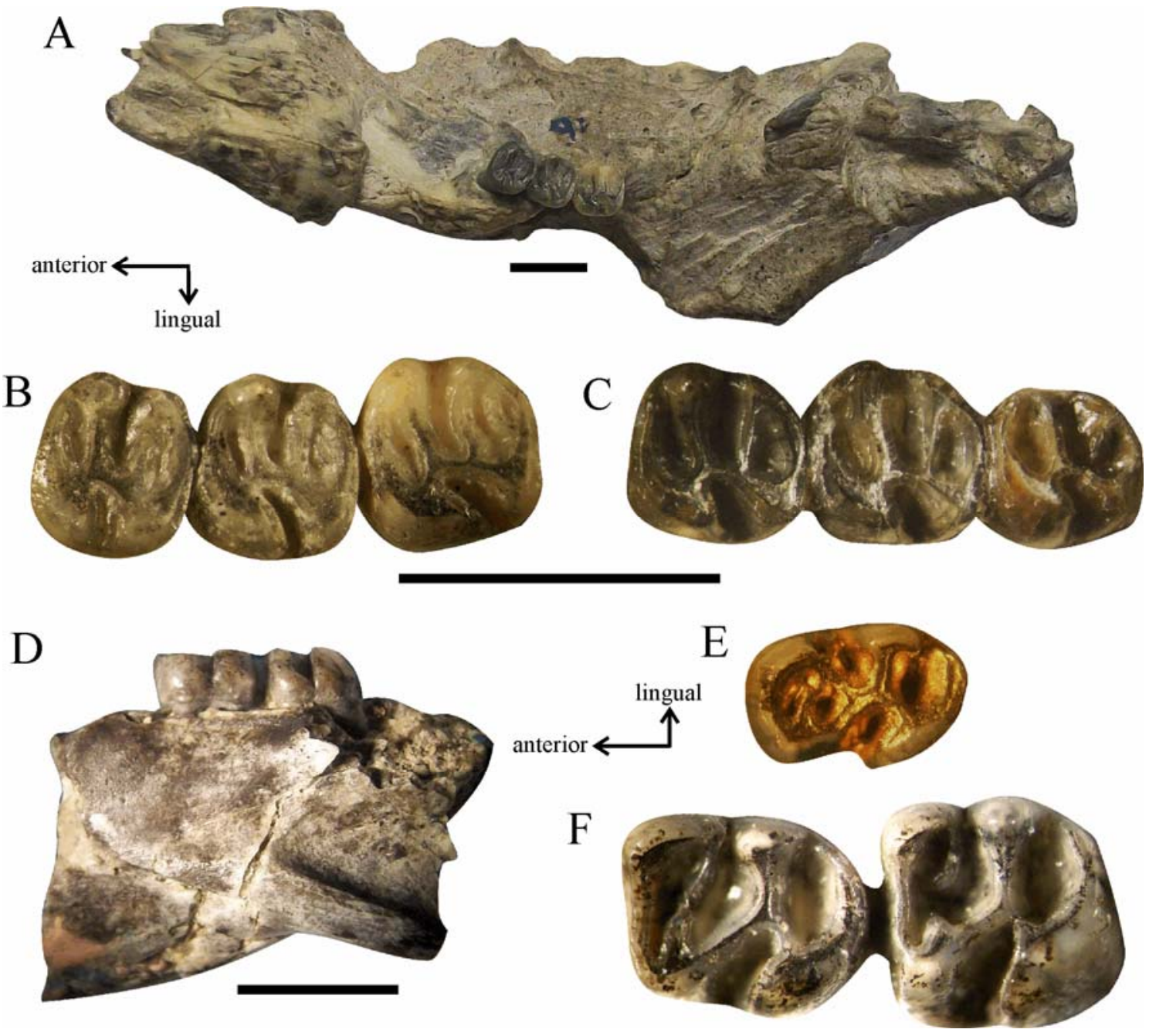

Figura 4.15. Plesiacarechimys koenigswaldi. A-B. MLP 91-V-1-55, cráneo con DP4-M2 derechos (holotipo); $A$ : cráneo en vista ventral; $B$ : DP4-M2 derechos; $C$ : MLP 92-V-10-1, M1-M3 izquierdos. $D$ : MLP 91-V-1-22, fragmento mandibular izquierdo con m1-m2. E: MLP 91-V-1-19, dp4 derecho. F: MLP 91-V-1-22, fragmento mandibular izquierdo con m1-m2. Escala 5mm 
Género Prospaniomys Ameghino, 1902

Especie tipo: Prospaniomys priscus Ameghino, 1902

Distribución geográfica y temporal: provincia del Chubut, Mioceno temprano "Edad Mamífero” Colhuehuapense.

Diagnosis ampliada: roedor de tamaño más grande que Protacaremys. Molares de coronas bajas y tetralofodontes, menos el m3 que es variable. Los superiores con el anterolofo separado del paracono a diferencia de Protacaremys y Acarechimys. Los inferiores con pequeños rebordes labiales a manera de cíngulos en las caras anterior y posterior, acompañados de suaves concavidades en las paredes; proyecciones labiales del protocónido e hipocónido acuminadas; metalofúlido II y posterolófido transversalmente más cortos que metalófulido I e hipolófido; metalofúlido II más largo en el $\mathrm{m} 2$ que en el $\mathrm{m} 1$; dp4 con cuatro crestas principales y metalofúlido II generalmente reducido, a diferencia de Protacaremys, Sciamys y Acaremys.

Prospaniomys priscus Ameghino, 1902

Sinonimia: Eoctodon crassiusculus Ameghino, 1904; Protoacaremys amplus Ameghino, 1904. Estas sinonimias fueron propuestas por Patterson en 1952 en un manuscrito no publicado.

Holotipo: MACN A 52-131, fragmento mandibular izquierdo con dp4-m1 e incisivo.

Tipos de los sinónimos: MACN A 52-139, fragmento mandibular derecho con toda la dentadura (P. amplus); MACN A 52-141, fragmento mandibular izquierdo con dp4-m1 (E. crassiusculus).

Material referido: (Ver Apéndice 1)

Distribución geográfica, estratigráfica y edad: Gran Barranca, provincia del Chubut, Fm Sarmiento, Miembro Colhué Huapi; Bryn Gwyn, provincia del Chubut, Fm 
Sarmiento, Mb Trelew; Valle Hermoso, provincia del Chubut, Fm Sarmiento; Sacanana, Fm Sarmiento. Mioceno temprano, “Edad Mamífero” Colhuehuapense.

Diagnosis ampliada: la misma que para el género.

Descripción ampliada y enmendada: Octodontoidea de tamaño pequeño, semejante a Acaremys y Sciamys pero más grande que Protacaremys.

- Cráneo. El cráneo es relativamente largo y bajo (Fig. 4.16A) (Tabla 4.16a). El techo craneano es plano y de bordes rectos y paralelos a nivel de los huesos nasales y frontales, mientras que a la altura de los parietales se ensancha. La bula timpánica es grande y redondeada en vista lateral.

Los huesos nasales son anchos y anteriormente ocupan casi toda la porción dorsal del rostro. Posteriormente se angostan entre los procesos ascendentes de los premaxilares, y alcanzan el nivel del DP4 y de la raíz dorsal de la arcada cigomática (Fig. 4.16B). Los premaxilares ocupan la mitad anterior de la pared lateral del rostro. La porción vertical de la sutura premaxilar-maxilar es ligeramente cóncava posteriormente. Los procesos ascendentes del premaxilar son tan largos como los nasales; se extienden a través de la cara dorso-lateral del rostro hasta la base de la raíz dorsal de la arcada cigomática. La fosa masetérica se encuentra bien desarrollada, y está formada principalmente en el hueso maxilar y secundariamente por el premaxilar; es profunda y de forma subtriangular, con su vértice anterior más agudo que el posterior (Fig. 4.16A). Dorsalmente se encuentra limitada por un pequeño reborde, mientras que ventralmente esta limitada por la tuberosidad de la base del incisivo.

Los frontales son relativamente angostos y planos. Su porción anterior no penetra entre los nasales y los premaxilares, y muy poco entre los premaxilares y los maxilares; las suturas con los nasales y premaxilares son muy crenuladas. La sutura con los parietales es algo cóncava hacia adelante y poco crenulada. El margen lateral de los frontales es recto y forma un reborde supraorbital prominente, que se continúa anteriormente con el borde posterior de la raíz dorsal de la arcada cigomática (Fig. 4.16A-B). Posteriormente, los rebordes supraorbitarios alcanzan un proceso postorbitario muy bien desarrollado; por detrás de los mismos los frontales se angostan abruptamente formando las constricciones postorbitarias muy bien desarrolladas (Fig. 4.16B). Por detrás de la constricción postorbitaria se observa una delgada línea temporal que se curva postero-ventralmente siguiendo el recorrido de la sutura parietal-escamoso. 
El foramen infraorbitario es grande, tan ancho como alto. La raíz dorsal de la arcada cigomática se ubica a nivel del DP4 y la porción posterior de los nasales y premaxilares (Fig. 4.16A). En la porción posterior de la raíz dorsal de la arcada cigomática se observa el hueso lagrimal, que es grande y se extiende ampliamente por la cara externa de la raíz; limita anterior y ventralmente con el hueso maxilar, alcanzando la rama vertical de la arcada cigomática. Dorsalmente limita con el frontal, extendiéndose por encima de la raíz dorsal de la arcada cigomática y formando una pequeña porción del techo craneano. Debido a su gran extensión, el lagrimal se encuentra muy cerca del borde posterior de los premaxilares. La rama vertical de la arcada cigomática se dispone de forma recta y es robusta, aunque su porción central se encuentra angostada (Fig. 4.16A). La raíz ventral de la arcada cigomática está ubicada a nivel del DP4, casi alineada verticalmente con la raíz dorsal de la arcada cigomática (Fig. 4.16A). En vista ventral, esta raíz se proyecta lateralmente, formando un arco que se continúa con la rama horizontal de la arcada cigomática (Fig. 4.16C). La tuberosidad masetérica es poco profunda y corta labio-lingualmente. Lateralmente la depresión para la inserción del músculo masetero lateral es poco profunda y se extiende hasta el nivel del M3. En la cara dorsal de la raíz ventral de la arcada cigomática hay un surco muy poco desarrollado para el pasaje del nervio infraorbitario. La rama horizontal del cigoma es recta y algo divergente en vista ventral, mientras que en vista lateral es baja y relativamente recta; la misma se encuentra formada principalmente por el hueso yugal, el cual se encuentra excluido de la rama vertical. La sutura yugal-maxilar es convexa hacia delante y se ubica poco por delante del borde anterior de la rama horizontal. La sutura yugal-escamosal es larga y casi horizontal. El proceso paraorbitario es de tamaño pequeño y se encuentra formado por el yugal y una pequeña porción del escamoso (Fig. 4.16A). La fosa yugal (para el origen del músculo masetero posterior) es corta, poco profunda y se encuentra expuesta ventralmente. La porción escamosa de la arcada cigomática es corta.

El borde anterior de la orbita es redondeado; posteriormente esta limitada por el proceso postorbitario del frontal y por el pequeño proceso paraorbitario del yugal (Fig. 4.16A). El escamoso se encuentra casi excluido de la pared posterior de la orbita. Su porción intraorbitaria posee un segmento anterior alto, cuya unión con la porción intraorbitaria del frontal es vertical y alcanza el borde posterior de la constricción postorbitaria. La porción extraorbitaria del escamoso es algo convexa. Por detrás de la raíz posterior de la arcada cigomática el escamoso se angosta notablemente entre el parietal 
y la bula auditiva (Fig. 4.16A); la sutura entre escamoso y parietal es elevada. La porción más posterior del escamoso, por detrás del MAE es todavía más angosta y oblicua postero-ventralmente (Fig. 4.16A).

En vista dorsal la región parietal es la más ancha del techo craneano. En su porción anterior los parietales son globosos, mientras que hacia atrás se aplanan. Se observan un par de líneas temporales que no contactan en la línea media del cráneo y delimitan un área sagital pobremente desarrollada (Fig. 4.16B). La sutura parietalsupraoccipital es sinuosa y muy crenulada en todo su recorrido. Entre la porción posterior del escamoso, la porción postero-lateral del parietal y el proceso lateral del supraoccipital se observa una osificación de forma subtriangular que se corresponde con la exposición dorsal del petroso (Fig. 4.16A-B). Esta estructura se encuentra asociada a un gran desarrollo de la bula timpánica.

La bula timpánica se encuentra formada por el ectotimpánico y es muy grande (Tabla 4.16a). Es alargada antero-posteriormente y se angosta hacia atrás, finalizando en el borde posterior del cráneo (Fig. 4.16C). El MAE se ubica aproximadamente en el centro del eje antero-posterior de la bula; es grande, de contorno subcircular y se encuentra limitado por un pequeño reborde antero-ventral (Fig. 4.16A). Hay un foramen accesorio bien desarrollado por debajo del MAE. El seno epitimpánico esta muy bien desarrollado y se ubica antero-dorsalmente al MAE (Fig. 4.16A). El seno hipotimpánico también se encuentra muy bien desarrollado e inflado, especialmente en su porción anterior (Fig. 4.16C). La bula contacta con el escamoso en la mayor parte de su longitud, a excepción de la porción anterior ubicada dorsalmente al seno epitimpánico, donde se encuentra el foramen postglenoideo; este foramen es bajo en altura y alargado antero posteriormente. Inmediatamente por detrás del MAE hay un pequeño foramen estilomastoideo. Posteriormente a este foramen se encuentra la apófisis mastoidea, que está formada por el ectotimpánico, es corta, robusta y algo oblicua posteriormente (Fig. 4.16A); nace en el borde postero-dorsal de la bula y termina a nivel del centro del MAE. En vista ventral, la bula posee forma de almendra, siendo anteriormente más ancha que en la porción posterior (Fig. 4.16C). La pared medial es más convexa que la pared externa. En la pared medial de la bula, cerca del contacto con el basioccipital, hay un foramen de homologías inciertas bien desarrollado.

La exposición mastoidea es de gran tamaño, se encuentra inflada y se fusiona con el borde posterior de la bula timpánica (Fig. 4.16A). Forma la porción posterolateral del cráneo y por ello se observa en vista lateral y en la vista posterior del cráneo. 
Dorsalmente se extiende por encima del margen dorsal del seno epitimpánico, penetrando entre lo que se interpreta como el proceso lateral del supraoccipital y el exooccipital, excluyendo a este último de formar parte de la pared lateral del cráneo (Fig. 4.16A).

La región occipital es baja y relativamente ancha. Como en otros caviomorfos adultos, los huesos occipitales se fusionan formando un solo hueso occipital; sin embargo, basioccipital, supraoccipital y exoccipitales se identifican teniendo en cuenta la posición de estos huesos en el cráneo. El foramen magnum es grande, más ancho que alto; aunque el único ejemplar que preserva esta región (MACN PV CH1913) se encuentra incompleto, la porción preservada del borde dorsal del foramen magnum indica que el mismo presentaba un contorno trapezoidal, más ancho dorsalmente que ventralmente. El supraoccipital se encuentra bien expandido, formando la parte más posterior del techo craneano; en esta región el hueso presenta unas pequeñas proyecciones orientadas anteriormente que penetran entre los parietales y la exposición dorsal del petroso. El proceso lateral del supraoccipital separa el escamoso de la exposición mastoidea (Fig. 4.16A); el mismo es angosto, corto y se extiende hasta el borde superior de la bula timpánica, como en los modernos octodóntidos. En vista occipital el cráneo posee una zona elevada media que podría corresponder a la cresta vertical. Los cóndilos occipitales están bien separados, son comprimidos y algo divergentes en dirección dorsal. Los procesos paraoccipitales se hallan adheridos en todo su recorrido a la pared posterior de las bulas; son cortos, divergentes en dirección ventral y están comprimidos antero-posteriormente.

El diastema es un poco más largo que la serie premolo-molar (Fig. 4.16C) (Tabla 4.16a). En vista lateral es casi recto y posee una posición más dorsal que la porción interdentaria del paladar. Las fosas maxilares son poco profundas. Los forámenes incisivos son grandes; su ancho ocupa más de la mitad del ancho del rostro y en el tercio anterior se angostan notablemente. La sutura premaxilar-maxilar intersecta a los forámenes incisivos en su porción anterior (Fig. 4.16C). Los forámenes incisivos se continúan posteriormente con unos surcos palatales bien desarrollados que se extienden por el paladar hasta el nivel de la mitad del M1; a nivel del DP4-M1 hay una pequeña quilla media en el paladar. Los forámenes palatinos posteriores son conspicuos y se ubican al nivel de la mitad del M1, en el extremo posterior de los surcos palatales. No es posible observar la sutura maxilo-palatino. Las narinas posteriores abren al nivel de la mitad anterior de los M2 y delimitan una fosa mesopterigoidea triangular (Fig. 4.16C). 
Como consecuencia, la porción interdentaria del paladar es muy corta anteroposteriormente y transversalmente más ancha que el ancho de los molares. Dentro de la fosa mesopterigoidea, a nivel de los huesos preesfenoides y basiesfenoides se encuentran las vacuidades palatinas; son grandes y de forma ovoide. Los pterigoideos se bifurcan posteriormente formando la cresta entopterigoidea medialmente y la cresta ectopterigoideo lateralmente, las cuales no parecen tomar contacto con las bulas. Estas crestas son robustas, cortas y delimitan una fosa pterigoidea pequeña. En ningún ejemplar preservado se observa la sutura entre el basiesfenoides y el basioccipital. El basioccipital es triangular y en su porción anterior presenta una pequeña quilla media. En los dos tercios posteriores entre la bula timpánica y el basioccipital hay una larga ranura que podría corresponderse, en parte, con los forámenes yugulares. El espacio que queda delimitado entre las dos bulas timpánicas es amplio, a pesar del gran tamaño de las mismas (Fig. 4.16C). En la base de cada cóndilo occipital se encuentran los forámenes hipoglosos que son redondeados y bien desarrollados.

- Dientes superiores. Las hileras dentarias superiores son poco extrovertidas, en un ángulo menor de $45^{\circ}$ con respecto al plano longitudinal del cráneo. Los molariformes son proporcionalmente grandes en comparación al tamaño del cráneo; son tetralofodontes, de coronas bajas y de tamaños similares, siendo el M2 ligeramente mayor (Fig. 4.16D-E) (Tabla 4.16b). Presentan una leve hipsodoncia unilateral, característica que desaparece en individuos con considerable desgaste en sus dientes. Las cúspides labiales, en especial el paracono, se diferencian de sus correspondientes crestas. Las crestas son angostas y se encuentran separadas por flexos o fosetas amplios y profundos. El primer molariforme de la serie dentaria presenta más desgaste que los restantes molares, por lo que se trata de un premolar de leche.

El DP4 es tetralofodonte. El anterolofo y el protolofo son rectos o ligeramente curvos, oblicuos hacia adelante y paralelos entre sí; labialmente ambas crestas permanecen separadas, incluso en estados de desgaste avanzados (Fig. 4.16D-E). El ángulo antero-lingual del diente es curvo. El anterolofo no alcanza el borde labial del diente. En esta cresta y de posición labial al protocono, se observa un engrosamiento que se evidencia en el parafexo (Fig. 4.16D); de posición lingual a este engrosamiento y en la cara anterior del anterolofo, cerca del protocono, se observa característicamente un pequeño hundimiento. El protolofo se extiende desde el punto donde se une el brazo posterior del protocono y el muro; está bien desarrollado y en su extremo labial se encuentra el paracono. El metalofo y el posterolofo alcanzan el borde labial del diente. 
En individuos juveniles se observa que el metacono esta unido al extremo labial del posterolofo; en individuos adultos el metalofo y el posterolofo se fusionan formando la posterofoseta, razón por la cual no es posible observar a qué cresta se encuentra unido el metacono (Fig. 4.16D-E). El paraflexo es el flexo más penetrante y nunca forma una parafoseta, mientras que el mesoflexo es el flexo labial más amplio y profundo; ambos son posteriormente oblicuos. La posterofoseta es la más superficial. El hipoflexo es poco penetrante y poco oblicuo; el mismo se angosta en individuos que presentan mucho desgaste en los dientes.

El M1 y el M2 se asemejan al DP4. Se diferencian en que el protocono es comprimido labio-lingualmente y oblicuo en individuos juveniles, mientras que en los adultos esta región se expande formando un ángulo antero-lingual ligeramente recto (Fig. 4.16D-E). El anterolofo es curvo. El protolofo es la cresta mejor desarrollada; a diferencia de lo que ocurre en el DP4, esta cresta presenta su porción lingual oblicua en dirección antero labial, alineada con el hipoflexo, mientras que la porción labial de la cresta se hace transversal al eje antero-posterior del diente (Fig. 4.15D-E). Esta morfología presenta distinto grado de desarrollo en los especímenes y es más evidente en los M1 y M2 que en el M3. El muro es oblicuo en dirección postero-lingual. El metalofo nace en el punto donde se une el muro con el brazo anterior del hipocono. A diferencia de lo que se observa en el DP4, el metacono se une a esta tercera cresta en posición. El posterolofo alcanza el borde labial del diente y con poco desgaste se une a la tercera cresta en posición delimitando la posterofoseta (Fig. 4.16D-E). Con relación con los flexos, la diferencia con el premolar radica en que el hipoflexo es amplio, poco penetrante en la superficie oclusal y más oblicuo anteriormente (Fig. 4.16D-E). El M3 se diferencia de los restantes molares por poseer la región posterior reducida; el hipocono es labial respecto al protocono, por lo cual el metalofo y posterolofo son notablemente más cortos que en el M1 y M2 (Fig. 4.16E).

Los incisivos superiores presentan una sección transversal pequeña (Fig. 4.15C); el borde lingual es recto, mientras que los restantes forman un semicírculo. La cara anterior es curva y lisa; son cortos, y su extremo radicular se ubica dorsalmente y poco por delante de la raíz ventral de la arcada cigomática. El extremo de ataque del diente se encuentra dirigido ventralmente (Fig. 4.16A).

- Mandíbula. El diastema es más corto que la serie premolo-molar, presenta la porción más profunda por delante del dp4 y hacia delante se hace gradualmente menos profundo (Fig. 4.16F-G). Hay un pequeño foramen mentoniano a nivel de la porción más baja del 
diastema, poco por delante del dp4 (MACN A 52-131; MACN A 52-134; MPEF 5664) o al nivel del borde anterior del dp4 (MPEF 7572); puede haber forámenes accesorios cerca del foramen mentoniano. La mmma se ubica a nivel del $\mathrm{m} 1 \mathrm{y}$ aproximadamente en la mitad de la altura de la mandíbula (Fig. 4.16F-G). La misma es casi tan larga como el m1 y poco profunda, aunque en algunos casos puede ser más corta anteroposteriormente. La cresta masetérica se continúa con el borde posterior de esta muesca (Fig. 4.16G); ésta se dispone de forma oblicua en dirección postero-ventral en un ángulo de $45^{\circ}$ con respecto al eje antero-posterior de la mandíbula. La fosa masetérica es poco profunda (Fig. 4.16G). El proceso coronoides nace a nivel de la mitad anterior del m3 y esta bien desarrollado; su cara anterior es convexa hacia delante y dorsalmente se extiende por arriba de la hilera dentaria (Fig. 4.16G). La fosa retromolar es amplia y esencialmente lateral al m3. Hay un foramen mandibular bien desarrollado por detrás del m3, en la base lingual del proceso coronoides. El cóndilo mandibular es ovalado; se ubica por debajo de la apófisis coronoides y levemente por encima de la seria molar (Fig. 4.16G). El proceso postcondíleo es amplio y saliente por detrás del cóndilo mandibular. El proceso angular es largo y termina posteriormente al proceso postcondíleo. En la cara interna de la mandíbula se observa una quilla mentoniana bien desarrollada y ubicada a nivel del foramen mentoniano. Por detrás de ella y hasta el borde posterior del m3, la rama horizontal de la mandíbula se hace cada vez más baja; esto puede ocurrir de forma abrupta (MPEF 5039) o ser una curvatura suave (MACN A 15-134). La sínfisis mandibular se extiende hasta el dp4 (MPEF 5039) o el borde anterior del m1 (MACN A 52-134). Distribuidos por toda la cara interna de la mandíbula se observan numerosos forámenes accesorios de distintos tamaños. La fosa histricognata es profunda.

- Dientes inferiores. Los molariformes inferiores no presentan hipsodoncia unilateral y sólo en unos pocos individuos juveniles se observa algo de aterrazamiento. Todos los dientes presentan tamaños similares, a excepción del dp4 que es más angosto y más largo que los molares (Fig. 4.16H) (Tabla 4.16b). Las cúspides son comprimidas anteroposteriormente, las crestas son delgadas y algo oblicuas posteriormente, y los flexos profundos (Fig. 4.16H). Los bordes anterior y posterior presentan pequeñas inflexiones, que hacia la base terminan en un reborde saliente a manera de cíngulo.

El dp4 tiene cuatro crestas principales y un metalófulido II generalmente reducido. El metalofúlido I nace del protocónido, es fuertemente cóncavo hacia atrás y lingualmente toma contacto con el metacónido; en su cara anterior suele observarse un 
engrosamiento comprimido labio-lingualmente, que corresponde al anterocónido (Fig. 4.16H). Desde el borde posterior del protocónido se extiende un largo ectolófido que se dirige posteriormente hasta el hipolófido; en su porción anterior esta cresta es cóncava lingualmente, mientras que por detrás del mesolófido se hace recta hacia atrás. En numerosos casos se observa un metalofúlido II que se extiende desde el protocónido en dirección postero-lingual; esta cresta puede alcanzar la mitad de la anterofosétida (MPEF 5039; MPEF 5664), puede apenas esbozarse en la anterofosétida (MPEF 6447; MPEF 7572) (Fig. 4.16H) o puede estar reducida (MACN A 52-131; MACN A 52135). La tercera cresta en posición es el mesolófido, está bien desarrollada y se extiende desde el ectolófido (Fig. 4.16H); es oblicua en sentido anterior y rápidamente toma contacto con el metacónido para formar una cuenca anterior; esta cuenca típicamente adquiere una forma de tipo “estrellada” como consecuencia de la morfología de las cúspides que la delimitan (Fig. 4.16H). La porción posterior del premolar, donde se encuentran el hipolófido y posterolófido está molarizada (Fig. 4.16H). El hipolófido es en general recto y transversal al eje antero-posterior del diente. El posterolófido es cóncavo hacia delante $\mathrm{y}$ es corto, no alcanza el borde lingual del diente. La anterofosétida se forma en estadios de desgaste nulos y no es profunda. El mesofléxido es el fléxido más amplio, profundo, y menos penetrante de los fléxidos linguales; el posterofléxido es bien penetrante en la superficie oclusal y se encuentra dirigido algo hacia adelante. El hipofléxido es más profundo que el mesofléxido y es oblicuo hacia atrás.

Los molares son tetralofodontes, aunque el m3 puede ser trilofodonte. Al igual que en el premolar, las cúspides son comprimidas antero-posteriormente, a excepción del metacónido que generalmente es alargado y oblicuo en dirección anterolabialposterolingual (Fig. 4.16H). En los m1-m3 el metalofúlido I es largo y algo cóncavo hacia atrás; el extremo lingual de la cresta es bien curvo debido a la disposición oblicua del metacónido. En la mayoría de los ejemplares se observa la presencia del brazo posterior del metacónido, el cual forma una estructura continua con el metalofúlido I y le da a esta cresta un aspecto bien curvo (Fig. 4.16H). El metalofúlido II se extiende desde un punto más posterior en comparación con el premolar y presenta un desarrollo variable: en el m1 puede llegar a alcanzar el borde postero-labial del metacónido delimitando una anterofosétida o puede no tomar contacto con esta cúspide; en el m2 esta cresta es más larga que en el m1, motivo por el que siempre toma contacto con el metacónido y delimita la anterofosétida (Fig. 4.16H); en el m3 el metalofúlido II puede 
estar bien desarrollado y contactar el metacónido delimitando una anterofosétida (MPEF 5664; MPEF 6447; MPEF 7574) (Fig. 4.16H), puede formar sólo un spur que nace del brazo posterior del protocónido (MACN A 52-139; MACN A 52-140), o puede estar ausente (MPEF 5627; MPEF 7572). En MACN A 52-134 el metalofúlido II forma sólo un spur, aunque lingualmente a él se observa una cúspide aislada en el medio del flexo anterior (anterofléxido+mesofléxido). El hipolófido y el posterolófido tienen la misma forma y disposición que en el premolar (Fig. 4.16H). El anterofléxido/anterofosétida es transversal al eje antero-posterior del diente y a diferencia de lo que ocurre en el premolar es considerablemente más pequeño; los dos fléxidos posteriores son oblicuos hacia delante. El mesofléxido es el más amplio y profundo de los fléxidos linguales, mientras que el posterofléxido es el más penetrante en la superficie oclusal. A diferencia del premolar, el hipofléxido tiene forma de herradura y es poco oblicuo posteriormente (Fig. 4.16H); es el fléxido más amplio y profundo de todos.

Los incisivos inferiores son comprimidos. La cara esmaltada es curva y lisa. El diente es largo y pasa por debajo del m3; su extremo posterior es observable como un abultamiento en la cara externa de la mandíbula.

Comentarios: Sólo una especie fue nominada, P. priscus Ameghino, 1902, pero algunos especímenes muestran molares superiores con metafoseta efímera y ángulo antero-lingual más curvo (MPEF 7574a), sugiriendo que podría tratarse de otra especie (Vucetich et al., 2010b). 
Tabla 4.15a. Medidas craneanas Prospaniomys priscus (cm)

\begin{tabular}{lcc}
\hline MACN PV CH1913 & AAD & 0,54 \\
& AC & 1,78 \\
& AMB & 0,75 \\
& APD & 0,78 \\
& HCA & 0,94 \\
& HCP & 1,17 \\
& LAC & 2,00 \\
& LCB & 4,84 \\
& LDS & 1,21 \\
& LMB & 1,35 \\
& LP & 1,89 \\
& LDi & 0,600 \\
MPEF-PV 5039 & AM1 & - \\
& AM2 & 0,590 \\
& AM3 & 0,300 \\
\hline
\end{tabular}

Tabla 4.15b. Medidas dentarias Prospaniomys priscus (mm)

\begin{tabular}{ccccc}
\hline & & LAP & AA & AP \\
\hline MACN A 52-131 & dp4 & 2,72 & - & - \\
& m1 & 2,68 & 2,26 & 2,28 \\
MACN PV CH1913 & DP4-M3 & 10,6 & - & - \\
& DP4 & 2,60 & 2,50 & 2,25 \\
& M1 & 2,65 & 2,65 & 2,45 \\
& M2 & 2,80 & 2,85 & 2,40 \\
MPEF-PV 5039 & M3 & 2,55 & 2,80 & 1,90 \\
& dp4-m3 & 10,21 & - & - \\
& dp4 & 2,48 & 1,50 & 1,74 \\
& m1 & 2,46 & 2,28 & 2,06 \\
& m2 & 2,85 & 2,46 & 2,44 \\
& m3 & 2,42 & 2,14 & 1,98 \\
\hline
\end{tabular}



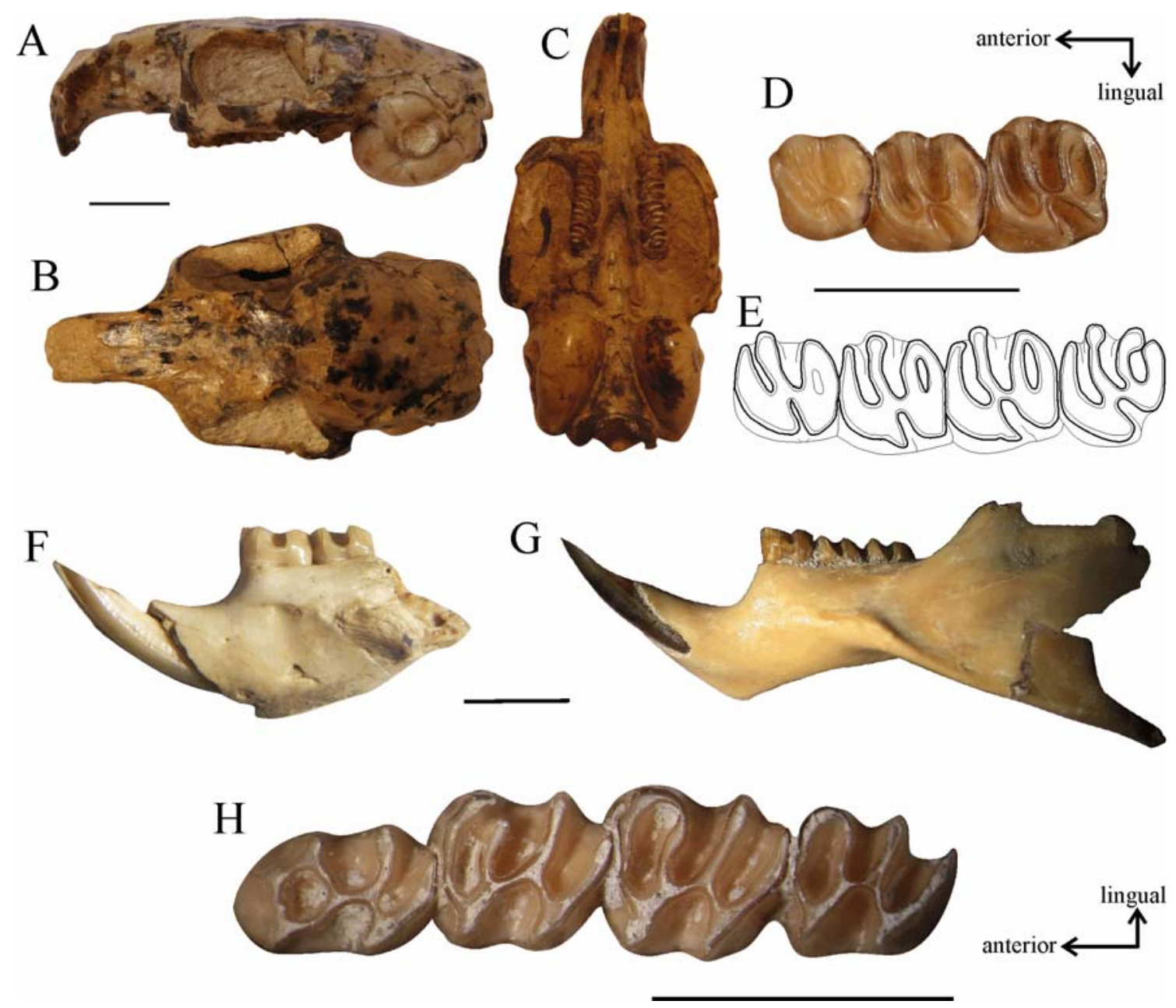

Figura 4.15. Prospaniomys priscus. A-C: MACN PV CH1913, cráneo casi completo con toda la dentadura; $A$. vista lateral; $B$. vista dorsal; $C$. vista ventral. DP4-M3. $D$ : MLP 82-V-2-32, fragmento maxilar derecho con DP4-M2 (invertido). E: MACN PV CH1913, esquema de DP4-M3. F: MACN A 52-131, fragmento mandibular izquierdo con dp4-m1 (holotipo). G: MPEF-PV 5039, mandíbula derecha casi completa con dp4-m3 (invertida). H: MPEF 6447, dp4-m3 derechos (invertido). 
Género Protacaremys Ameghino, 1902

Especie tipo: Protacaremys prior Ameghino, 1902

Distribución geográfica y temporal: provincia del Chubut, Mioceno temprano, "Edad Mamífero" Colhuehuapense; Provincia del Neuquén, Mioceno medio, "Edad Colloncurense”.

Diagnosis ampliada: roedor de tamaño más pequeño que Prospaniomys. Molares tetralofodontes, excepto el m3 que puede ser trilofodonte, de coronas más bajas que en Sciamys y más altas que en Prospaniomys, y con crestas levemente oblicuas. El m3 presenta tamaño similar al m2. En los molares superiores la parafoseta se cierra tempranamente en individuos juveniles, a diferencia de Acarechimys y Prospaniomys. Premolares inferiores con el metalofúlido II bien desarrollado, a diferencia de Prospaniomys. La mandíbula presenta el límite anterior de la fosa masetérica debajo del m1 y el surco que limita antero-dorsalmente la fosa masetérica muy desarrollado.

Comentarios: Ameghino (1902) erigió tres especies para este género: $P$. prior, $P$. avunculus y $P$. pulchellus. Sobre la base de la morfología dentaria Vucetich et al. (2010b) transfirieron a P. pulchellus al género Acarechimys, proponiendo la nueva combinación Acarechimys pulchellus. Esta hipótesis se pone a prueba en el análisis filogenético (Ver Capítulo 5).

Protacaremys prior Ameghino, 1902

Sinonimia: Archaeocardia mustersiana Ameghino, 1904; Acaremys preminutus Bordas, 1939; Eoctodon securiclatus Ameghino, 1902; Palaeocardia mater Ameghino, 1902.

Holotipo: MACN A 52-112b. Mandíbula derecha casi completa con dp4-m3 e incisivo.

Tipos de los sinónimos: MACN A 52-123, fragmento mandibular izquierdo con m1m3 (E. securiclatus); MACN A 52-125, fragmento mandibular izquierdo con m1-m3 (A. mustersiana); MACN A 52-130, fragmento mandibular derecho con m1-m2 ( $P$. 
mater); MACN A 11246, fragmento de maxilar derecho con DP4-M2 (A. preminutus). Estas sinonimias fueron propuestas por Patterson en un manuscrito inédito (1952) depositado en el MLP.

Material referido: (Ver Apéndice 1)

Distribución geográfica, estratigráfica y edad: Gran Barranca, provincia del Chubut, Fm Sarmiento, Miembro Colhué Huapi, Upper Fossil Zone; Bryn Gwyn, provincia del Chubut, Fm Sarmiento, Mb Trelew; Mioceno temprano "Edad Mamífero" Colhuehuapense.

Diagnosis modificada: Tamaño intermedio entre $P$. avunculus y "Protacaremys" sp. nov. Premolar inferior deciduo pentalofodonte, con las 5 crestas conspicuas, a diferencia de $P$. avunculus. Molares inferiores con el metalofúlido II bien desarrollado en m1-m2 y reducido en m3; hipofléxido amplio, en forma de semicírculo. Mandíbula con presencia variable de foramen mentoniano y fosa masetérica poco profunda.

\section{Descripción:}

- Cráneo. AMNH 29734 es el único ejemplar que preserva parcialmente el cráneo, el cual se encuentra en mal estado y aplastado dorso-ventralmente, razón que imposibilita una descripción detallada del mismo (Fig. 4.17A-C). En él se observa un rostro alargado y delgado, semejante al de Prospaniomys priscus. En la cara lateral del rostro la fosa masetérica no está bien desarrollada. En la cara ventral del mismo se observan unos forámenes incisivos bien desarrollados y delgados que se continúan posteriormente con los rebordes diastemales (Fig. 4.17A). La sutura premaxilar-maxilar intersecta los forámenes incisivos aproximadamente en la mitad de su largo. Por delante de los premolares las fosas maxilares están poco desarrolladas. La raíz ventral de la arcada cigomática nace por delante del DP4; en su cara ventral la tuberosidad masetérica se encuentra muy bien desarrollada. En la cara dorsal de la raíz ventral de la arcada cigomática no se observa un surco para el pasaje del nervio infraorbitario. En la porción posterior del cráneo sólo puede observarse la bula auditiva izquierda parcialmente preservada; a pesar de la preservación, la bula parecería ser grande y presentar un seno epitimpánico bien desarrollado. El MAE también parecería ser de gran tamaño y por 
detrás de él hay un foramen que correspondería con el foramen estilomastoideo (Fig. 4.17C).

- Dientes superiores. Cada hilera dentaria superior es labialmente cóncava y ambas son convergentes anteriormente (Fig. 4.17A). No se observa una diferencia de tamaño significativa de los molariformes dentro de las hileras dentarias. Los dientes son protohipsodontes bajos y presentan algo de hipsodoncia unilateral, característica que desaparece en individuos adultos. Las crestas son angostas, algo oblicuas anteriormente y se encuentran separadas por flexos o fosetas amplios y profundos (Fig. 4.17D).

El DP4 es redondeado. El anterolofo es curvo y alcanza el borde labial del diente. Lingualmente se une a un protocono redondeado. El protolofo se extiende desde el punto donde se une el brazo posterior del protocono y el muro; es recto y oblicuo anteriormente (Fig. 4.17D); en individuos juveniles, el anterolofo y el protolofo se unen delimitando la parafoseta. El muro es corto y paralelo al eje antero-posterior del diente. El metalofo y el posterolofo alcanzan el borde labial del diente y rápidamente toman contacto delimitando la posterofoseta (Fig. 4.17D). La parafoseta y la posterofoseta son de forma ovoide y son más penetrantes en la superficie oclusal que el mesoflexo; el mesoflexo es angosto y más profundo que las fosetas. El hipoflexo es oblicuo anteriormente, es el más profundo de los flexos y el menos penetrante en la superficie oclusal (Fig. 4.17D).

Los molares presentan una morfología semejante a la del premolar. Se diferencian en que presentan un contorno dentario menos redondeado, que está dado porque el protocono es alargado antero-posteriormente y oblicuo en individuos juveniles (Fig. 4.17D), mientras que en individuos adultos se hace paralelo al eje anteroposterior del diente. El M3 es de morfología redondeada igual que el premolar; presenta el hipocono de posición labial respecto del protocono, razón por la cual la porción posterior del diente se encuentra claramente acortada labio-lingualmente.

Los incisivos superiores se preservan sólo en AMNH 29734. Presentan sección transversal oval; la cara esmaltada anterior es curva y lisa. El extremo de ataque del diente se encuentra dirigido ventralmente (Fig. 4.17C).

- Mandíbula. El diastema es cóncavo y muy corto en relación a la hilera dentaria (Fig. 4.17E) (Tabla 4.17a-b). En el ejemplar tipo no se observa la presencia de foramen mentoniano; sin embargo, en algunos ejemplares asignados a esta especie puede observarse un pequeño foramen ubicado poco por delante del dp4 (MACN A 52-119, MACN A 52-121, MMP-122). La mmma se ubica a nivel del borde posterior del dp4 y 
borde anterior del m1, aproximadamente en la mitad de la altura de la mandíbula (Fig. 4.17E). La mmma es ovalada, poco profunda y algo oblicua ventralmente. La cresta masetérica se continúa con el borde posterior de la mmma y ésta se dispone de forma oblicua en dirección postero-ventral en un ángulo menor de $45^{\circ}$ con respecto al eje antero-posterior de la mandíbula. La fosa masetérica es muy poco profunda. El surco que limita antero-dorsalmente la fosa masetérica se encuentra bien desarrollado y se extiende desde el borde posterior de la mmma hasta la base anterior del proceso coronoides (Fig. 4.17D). El proceso coronoides nace a nivel de la mitad anterior del m3. La fosa retromolar es esencialmente posterior y algo lateral al m3. En la cara interna de la mandíbula se observa una quilla mentoniana bien desarrollada y ubicada a nivel de la porción anterior del dp4 (Fig. 4.17F). Por detrás de la quilla la mandíbula se hace considerablemente más baja (Tabla 4.17a).

- Dientes inferiores. Los dientes inferiores son tetralofodontes y presentan algo de aterrazamiento. Son cuadrangulares y presentan tamaños similares (Fig. 4.17G) (Tabla 4.17b).

El dp4 es pentalofodonte, más largo antero-posteriormente que ancho (Fig. 4.17G) (Tabla 4.17b). El metalofúlido I forma el borde anterior del diente; es cóncavo posteriormente y se extiende desde el protocónido hasta el metacónido. Del borde postero-lingual del protocónido se extiende el metalofúlido II. Esta cresta es recta, oblicua posteriormente y en individuos juveniles se une al margen postero-labial del metalofúlido I, delimitando una fosétida anterior (Fig. 4.17G). Del borde posterior del protocónido nace el ectolófido que se dirige en dirección postero-lingual. La tercera cresta en posición es el mesolófido. La misma se extiende desde el tercio posterior del ectolófido y no alcanza el borde lingual del diente (Fig. 4.17G); es recta y generalmente oblicua hacia delante, de manera que en algunos ejemplares puede tomar contacto con el metalofúlido II y así delimitar un lóbulo anterior en el premolar. En el punto donde se une el ectolófido y el brazo anterior del hipocónido nace el hipolófido, que es recto y alcanza el borde lingual del diente. El posterolófido es largo y cóncavo anteriormente. En el ejemplar tipo, puede observarse un engrosamiento del esmalte en el margen lingual del diente, opuesto al extremo lingual del mesolófido, que podría corresponder al mesostílido (Fig. 4.17G).

Los molares son tetralofodontes (Fig. 4.17G). El metalofúlido I es cóncavo posteriormente; nace de un protocónido algo comprimido antero-posteriormente y se extiende hasta el metacónido, que es comprimido labio-lingualmente y oblicuo. El 
metalofúlido II se extiende desde el ectolófido, bastante por detrás del protocónido (Fig. 4.17G). Al igual que en Prospaniomys priscus, esta cresta suele estar mejor desarrollada en el $\mathrm{m} 1$ que en el $\mathrm{m} 2$, mientras que en el $\mathrm{m} 3$ puede estar reducida a un pequeño spur lingual del ectolófido o ausente (Fig. 4.17G). El hipolófido nace del punto donde se une el ectolófido con el brazo anterior del hipocónido; se encuentra bien desarrollado y alcanza el borde lingual del diente. En algunos ejemplares (MPEF 5652, MPEF 6772, MPEF 6085) del borde antero-labial del hipolófido nace una pequeña proyección anterolingual en forma de spur; cuyas homologías son inciertas. El posterolófido es cóncavo anteriormente y largo; su extremo lingual llega casi hasta el extremo lingual del hipolófido. Los fléxidos/fosétidas linguales son semejantes a los del premolar. El hipofléxido se diferencia en que es considerablemente más amplio y presenta forma de herradura (Fig. 4.17G).

Los incisivos inferiores son poco comprimidos. La cara esmaltada anterior es gruesa y presenta una superficie externa lisa y curva; sólo en unos pocos ejemplares (MPEF 6092, MPEF 6054, MPEF 5646, MPEF 5652) se observa en su cara anterior un surco suavemente esbozado. El diente es largo, pasa por debajo del m3; su extremo posterior es observable como un abultamiento en la cara externa de la mandíbula. 
Tabla 4.17a. Medidas mandibulares Protacaremys prior (cm)

\begin{tabular}{ccc}
\hline MACN A 52-112b & LDi & 0,394 \\
& AM1 & 0,382 \\
& AM2 & 0,568 \\
& AM3 & 0,324 \\
& & \\
MLP 82-V-2-1 & LDi & 0,400 \\
& AM1 & 0,398 \\
& AM2 & 0,600 \\
& AM3 & 0,410 \\
\hline
\end{tabular}

Tabla 4.17b. Medidas dentarias de Protacaremys prior (mm)

\begin{tabular}{ccccc}
\hline & & LAP & AA & AP \\
\hline MACN 52-112b & dp4-m3 & 8,08 & - & - \\
& dp4 & 2,18 & 1,44 & 1,32 \\
& m1 & 2,02 & 1,88 & 1,72 \\
& m2 & 2,10 & 1,92 & 1,86 \\
& m3 & 1,78 & 1,84 & 1,50 \\
MACN 52-113 & DP4-M3 & 7,48 & - & - \\
& DP4 & 1,88 & 1,84 & 1,80 \\
& M1 & 2,00 & 1,93 & 1,92 \\
& M2 & 1,90 & 1,96 & 1,96 \\
MLP 82-V-2-1 & M3 & 1,70 & 1,80 & 1,28 \\
& dp4-m3 & 8,10 & - & - \\
& dp4 & 2,20 & 1,42 & 1,48 \\
& m1 & 1,92 & 1,68 & 1,70 \\
& m2 & 2,06 & 1,78 & 1,78 \\
MLP 85-VII-3-129 & m3 & 1,92 & 1,68 & 1,44 \\
& dp4-m3 & 7,74 & - & - \\
& dp4 & 2,08 & 1,40 & 1,50 \\
& m1 & 1,82 & 1,86 & 1,68 \\
& $\mathrm{~m} 2$ & 2,00 & 1,90 & 1,78 \\
& $\mathrm{~m} 3$ & 1,84 & 1,72 & 1,46 \\
\hline
\end{tabular}



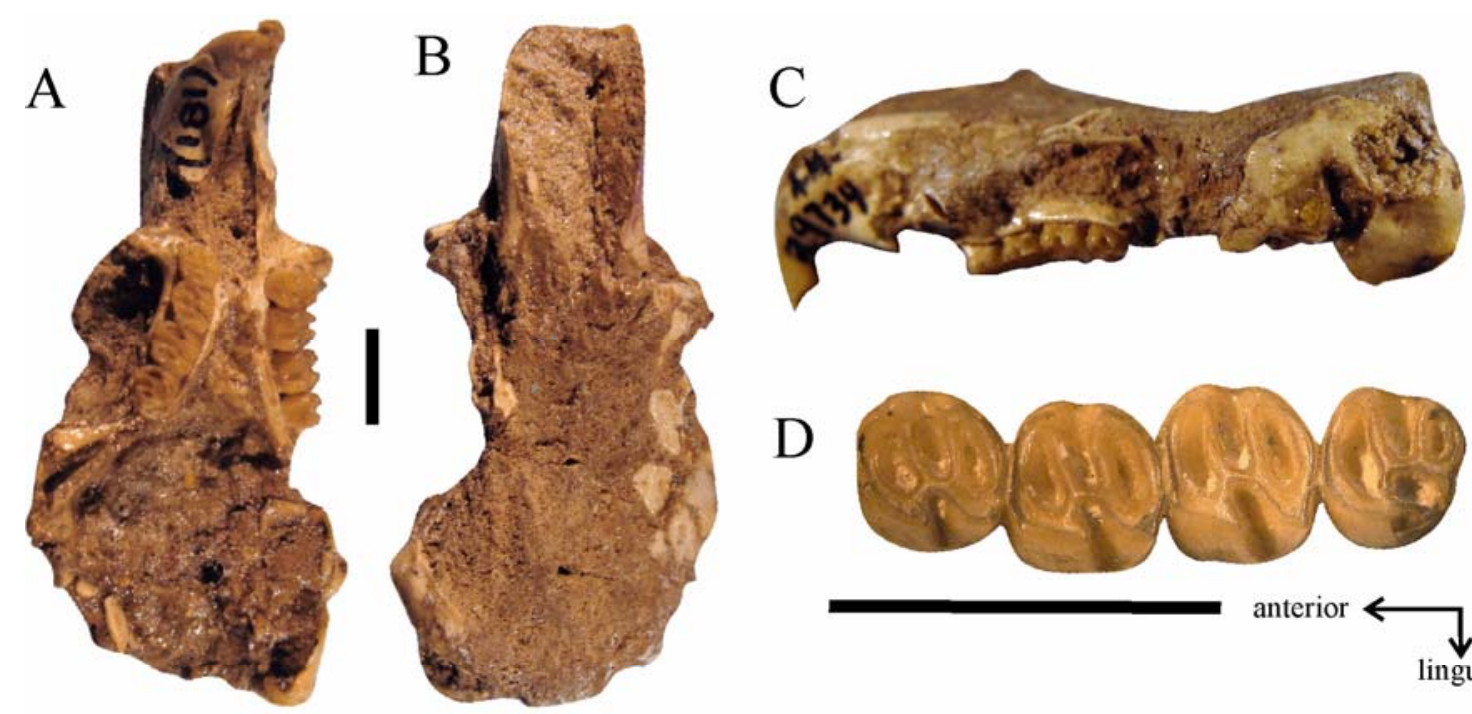

D
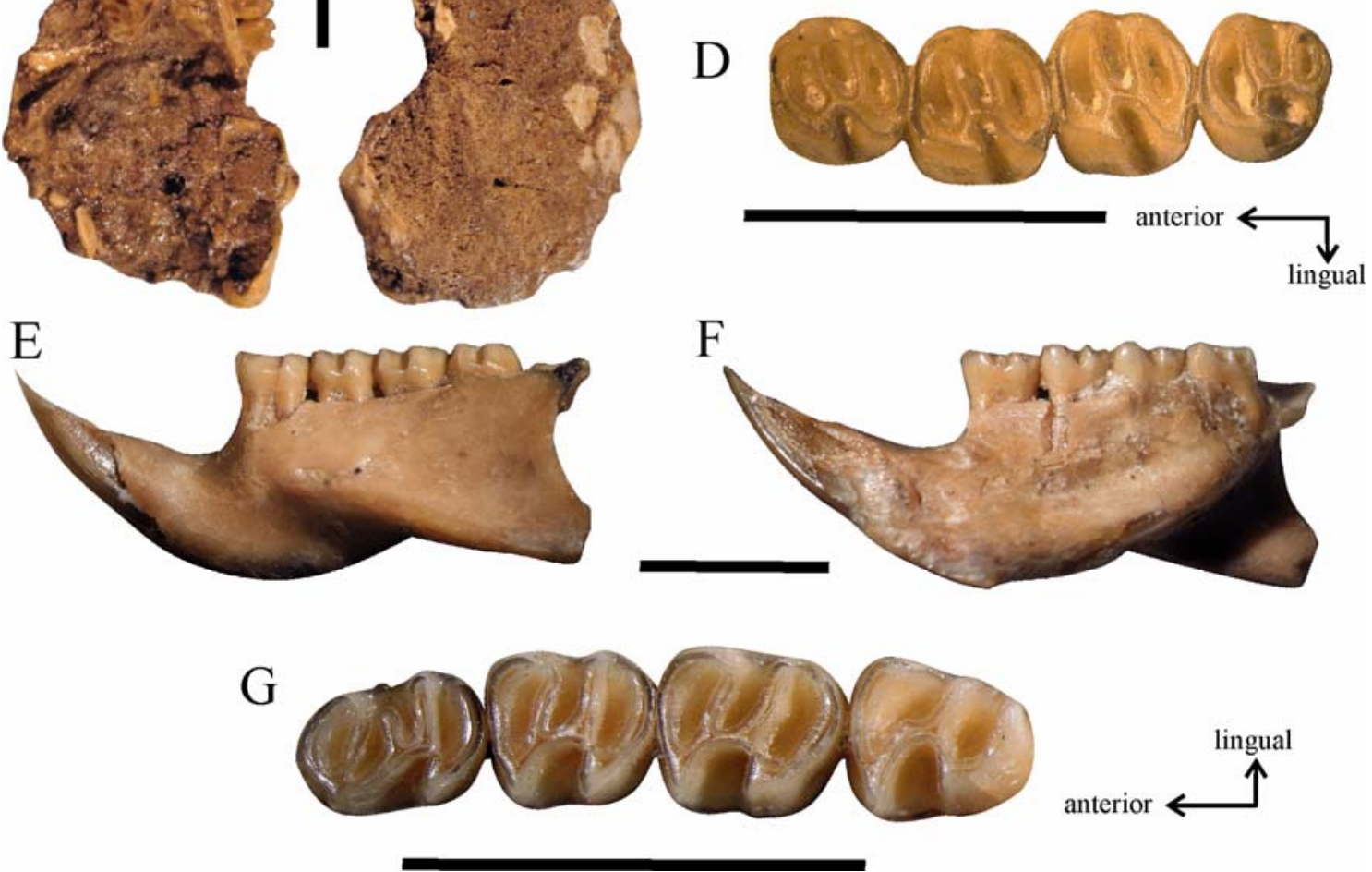

Figura 4.17. Protacaremys prior. A-C. AMNH 29734, cráneo parcialmente preservado. A: vista ventral; $B$ : vista dorsal; $C$ : vista lateral. $D$ : MACN A 52-113, DP4-M3. $E-G$. MACN A 112b, fragmento mandibular derecho (holotipo). $E$ : mandíbula en vista externa (invertido); $F$ : mandíbula en vista interna; $G$ : dp4-m3 (invertido). Escala $=5 \mathrm{~mm}$ 
Protacaremys avunculus Ameghino, 1902

Holotipo: MACN A 52-126, fragmento mandibular derecho con dp4-m3 e incisivo partido.

Material referido: (Ver Apéndice 1)

Distribución geográfica, estratigráfica y edad: Gran Barranca, provincia del Chubut, Fm Sarmiento, Miembro Colhué Huapi, Mioceno temprano, "Edad Mamífero" Colhuehuapense.

Diagnosis modificada: especie aproximadamente 15\% más pequeña que $P$. prior. Premolar inferior con mesolófido reducido a por una pequeña expansión lingual del ectolófido, a diferencia de la especie tipo. Metalofúlido II en m1-m2 más reducido que en $P$. prior. Metalofúlido II presente en el $\mathrm{m} 3$, a diferencia de $P$. prior. Hipofléxido más comprimido y oblicuo que en $P$. prior. Foramen mentoniano presente. La fosa masetérica es más profunda y la cresta masetérica es más prominente que en $P$. prior.

Descripción ampliada: Es la especie más pequeña del género (Tabla 4.18a y b).

- Cráneo. Del cráneo se preservan escasos fragmentos de maxilar. La raíz ventral de la arcada cigomática nace poco por delante del DP4 y en su cara dorsal no hay un canal para el pasaje del nervio infraorbitario, al igual que en $P$. prior.

- Dientes superiores. Los dientes superiores son semejantes a los de la especie tipo, aunque se diferencian en que la parafoseta se cierra algo más tarde con el desgaste.

- Mandíbula. La morfología mandibular es semejante a la de la especie tipo. Sin embargo, se diferencia en que presenta un pequeño foramen mentoniano a nivel del borde anterior del dp4, en la mitad inferior de la mandíbula (Fig. 4.18A), a diferencia de la especie tipo donde este foramen es de aparición variable. Este foramen está presente solo en alguno de los ejemplares referidos. Por otro lado, la mmma se ubica a nivel del límite entre dp4-m1 y es muy corta antero-posteriormente (Fig. 4.18A). El límite anterior de la cresta masetérica se ubica a nivel del límite entre el dp4-m1, más delante en comparación con la especie tipo. La configuración masetérica también varía respecto de $P$. prior ya que la fosa masetérica es un poco más profunda y porque la cresta 
masetérica se encuentra más expandida lateralmente. En la cara interna de la mandíbula la sínfisis mandibular se extiende hasta el dp4 (Fig. 4.18B).

- Dientes inferiores. El dp4 es pentalofodonte, pero se diferencia del de $P$. prior en que el extremo lingual del metalofúlido II se bifurca en una extensión corta que se dirige lingualmente y toma contacto con el metacónido, y otra porción que se dirige posterolabialmente y contacta el mesolófido (Fig. 4.18C); el mesolófido se encuentra representado por una extensión corta que nace del ectolófido (Fig. 4.18C). El dp4 de P. avunculus es semejante al de $P$. prior ya que ambos delimitan un lóbulo anterior que encierra una anterofosétida que se encuentra dividida en dos por el metalofúlido II. La porción posterior del diente es de aspecto molariforme ya que el hipolófido y el posterolófido presentan un desarrollo similar al de los molares, como en la especie tipo.

Los m1-m2 se caracterizan por presentar un metalofúlido II menos desarrollado en comparación con $P$. prior, aunque esta cresta se encuentra presente en el m3 (Fig. 4.18C). En el m3 la extensión posterior del metacónido es más larga que en las restantes especies del género y su extremo se curva labialmente, casi llegando a contactar el extremo labial del metalofúlido II. El hipofléxido se diferencia del de la especie tipo en que es más oblicuo posteriormente y no presenta forma de semicírculo.

Tabla 4.18a. Medidas mandibulares Protacaremys avunculus (cm)

\begin{tabular}{lll}
\hline MACN A 52-126 & AM1 & 0,310 \\
& AM2 & 0,452 \\
& AM3 & 0,330 \\
\hline
\end{tabular}

Tabla 4.18b. Medidas dentarias de Protacaremys avunculus (mm)

\begin{tabular}{ccccc}
\hline & & LAP & AA & AP \\
\hline MACN 52-117 & DP4 & 1,84 & 1,78 & 1,72 \\
MACN 52-126 & Dp4-m3 & 6,91 & - & - \\
& dp4 & 1,78 & 1,28 & 1,44 \\
& m1 & 1,66 & 1,64 & 1,60 \\
& m2 & 1,74 & 1,74 & 1,62 \\
& m3 & 1,73 & 1,58 & 1,48 \\
\hline
\end{tabular}


A $\quad$ B

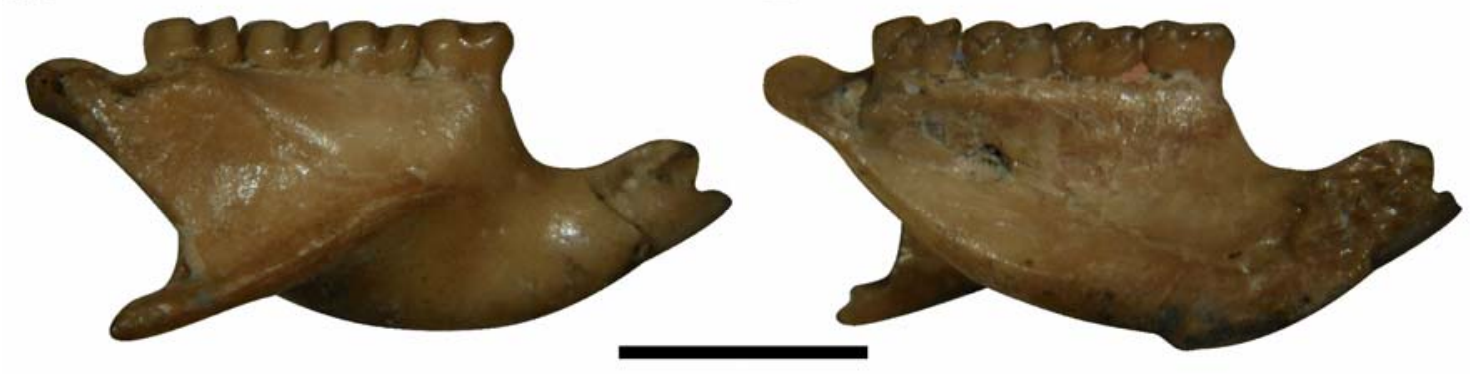

$\mathrm{C}$

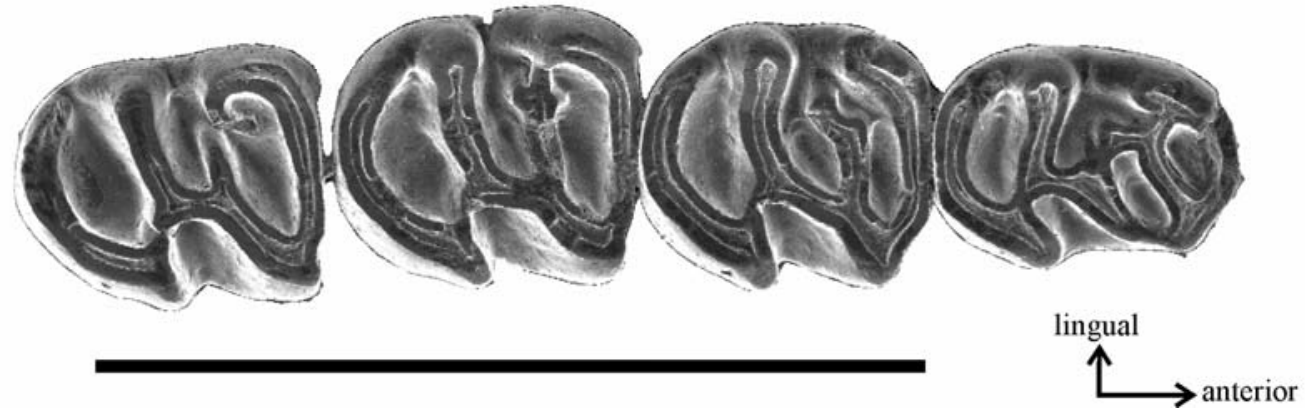

Figura 4.18. Protacaremys avunvulus. A-C. MACN A 52-126, fragmento mandibular derecho con dp4-m3 (holotipo). $A$ : mandíbula en vista externa; $B$ : mandíbula en vista interna (invertida); $C$ : dp4-m3. Escala $=5 \mathrm{~mm}$. $C$ fue tomada de Vucetich et al. (2010b) 
Protacaremys denisae Vucetich, Mazzoni y Pardiñas, 1993

Holotipo: MLP 91-IV-1-16, fragmento maxilar izquierdo con DP4-M2.

Material referido: (Ver Apéndice 1)

Distribución geográfica, estratigráfica y edad: Cañadón del Tordillo provincia del Neuquén, Formación Collón Curá, Mioceno medio, “Edad Colloncurense”.

Diagnosis original: tamaño similar a Protacaremys prior, pero con los molariformes de corona más alta, lo que determina fosetas más profundas y estrechas. Premolar inferior deciduo ligeramente más corto que en $P$. prior, con metalofúlido I y metalofúlido II unidos en su extremo labial formando un lóbulo anterior en forma de abanico.

Descripción ampliada: la descripción original de Vucetich et al. (1993) permanece vigente debido a su exactitud. Por otro lado, no se han recolectado nuevos materiales asignados a esta especie, por ello no se pueden evaluar caracteres adicionales.

Las principales diferencias respecto de la morfología dentaria están relacionadas al mayor grado de hipsodoncia que presenta esta especie (Fig. 4.19A-B). Los dientes superiores presentan algo de hipsodoncia unilateral y son notablemente más anchos en su porción anterior que la posterior (Tabla 4.19) (Fig. 4.19A). En la mandíbula la mmma se ubica a nivel del m1 y es muy poco conspicua; la cresta masetérica se continua con el borde posterior de la mmma y es notablemente más saliente que en $P$. avunculus (Fig. 4.19C).

Tabla 4.19. Medidas dentarias de Protacaremys denisae (mm)

\begin{tabular}{lcccc}
\hline & & LAP & AA & AP \\
\hline MLP 91-IV-1-16 & DP4 & 1,94 & 1,98 & 1,88 \\
& M1 & 1,98 & 2,02 & 1,92 \\
& M2 & 2,00 & 2,00 & 1,82 \\
MLP 91-IV-1-18 & m1 & 1,82 & - & - \\
& $\mathrm{m} 2$ & 1,98 & 1,88 & 1,80 \\
\hline
\end{tabular}


A

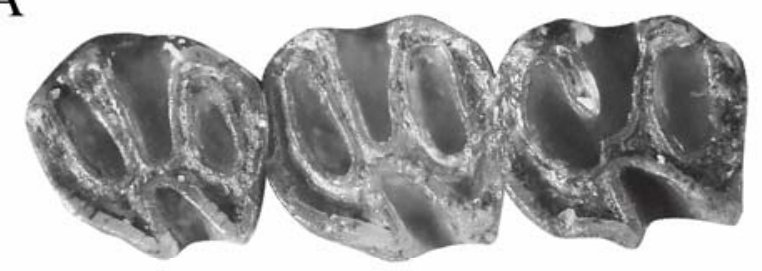

B

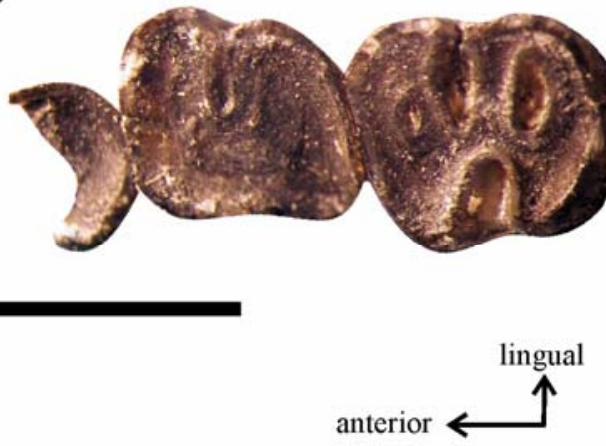

$\mathrm{C}$

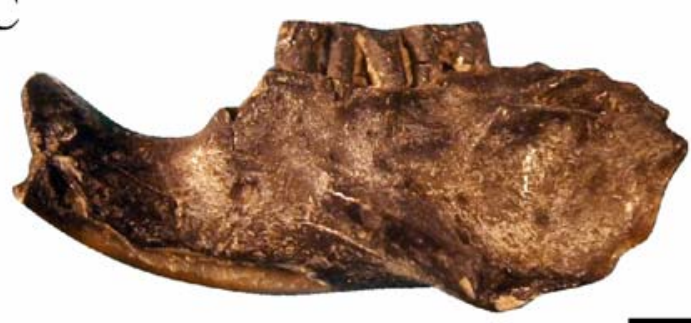

$\mathrm{D}$

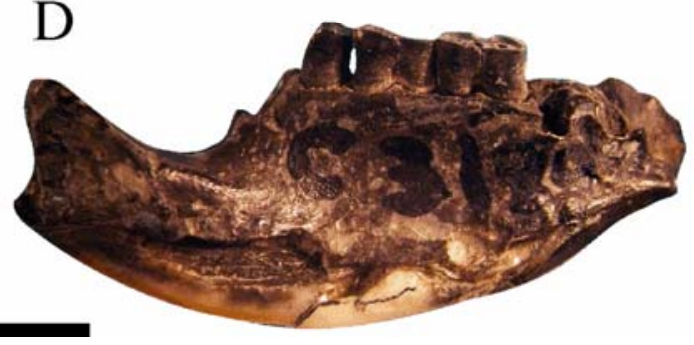

Figura 4.19. Protacaremys denisae. A: MLP 91-IV-1-16, fragmento maxilar izquierdo con DP4-M2 (holotipo). $B$-D. MLP 91-IV-1-18, fragmento mandibular derecho con m1-m2; B: m1-m2 (invertido); $C$ : mandíbula en vista externa; $D$ : mandíbula en vista interna. Escala $=5 \mathbf{m m}$ 
“Protacaremys” sp. nov.

Holotipo: AMNH 29740, fragmento mandibular izquierdo con dp4-m3.

Material referido: (Ver Apéndice 1)

Distribución geográfica, estratigráfica y edad: Gran Barranca, provincia del Chubut, Fm Sarmiento, Miembro Colhué Huapi, Mioceno temprano "Edad Mamífero" Colhuehuapense.

Diagnosis: especie aproximadamente $10 \%$ más grande que $P$. prior. Molariformes con crestas más gruesas y rectas que en $P$. prior y $P$. avunculus. El dp4 es pentalofodonte y el mesolófido alcanza el borde lingual del diente sin contactar el metacónido, a diferencia de las restantes especies del género. En los molares la anterofosétida se forma antes que la posterofosétida a diferencia de $P$. prior, como consecuencia de la mayor extensión lingual del metalofúlido II.

Descripción: Es la especie de Protacaremys de mayor tamaño. La misma se encuentra representada exclusivamente por dientes inferiores y por restos mandibulares.

- Mandíbula. Foramen mentoniano de mayor tamaño que en $P$. avunculus y ubicado por delante del dp4. El proceso mentoniano es grande y se ubica entre el foramen mentoniano y el dp4. La mmma se ubica a nivel del borde posterior del dp4 y m1 en una posición algo posterior que en $P$. prior y es más corta antero-posteriormente. La fosa masetérica es algo más profunda que la de P. prior, semejante a la de P. avunculus (Fig. 4.20A). La cresta masetérica es menos sobresaliente que la de P. avunculus. El surco que limita la fosa masetérica antero-dorsalmente es poco profundo (Fig. 4.20A). La apófisis coronoides nace a nivel del límite entre m2-m3 o a nivel del m3, razón por la cual la fosa retromolar es más externa que en las demás especies del género.

- Dientes inferiores. Los molariformes se caracterizan por presentar las crestas más gruesas y rectas que en las restantes especies del género (Fig. 4.20B).

En el dp4 de esta nueva especie las cinco crestas son rectas (Fig. 4.20B). El metalofúlido I es cóncavo posteriormente y conecta el protocónido con el metacónido. El metalofúlido II es recto y se extiende transversalmente al eje antero-posterior del diente desde el borde posterior del protocónido hasta el borde posterior del metacónido 
delimitando una fosétida anterior. El mesolófido es oblicuo anteriormente y, a diferencia de las restantes especies del género, alcanza el borde lingual del diente sin contactar el metacónido (Fig. 4.20B). La porción posterior del diente es de aspecto molariforme ya que el hipolófido y el posterolófido se presentan un desarrollo similar al de los molares, de igual manera que en las restantes especies del género.

En los molares el metalofúlido II alcanza el borde lingual del diente, de manera que tempranamente se forma la anterofosétida (Fig. 4.20B), más que en las restantes especie del género. En el m3 el metalofúlido II es largo y el metacónido está expandido, algo comprimido y tiene disposición oblicua (Fig. 4.20B).

Tabla 4.20. Medidas mandibulares y dentarias de “Protacaremys” sp. nov. (mm)

\begin{tabular}{ccccc}
\hline & & LAP & AA & AP \\
\hline MPEF 6423 & m1 & 2,20 & 1,94 & 1,88 \\
& AM1 & 4,24 & & \\
& AM2 & 5,00 & & \\
\hline
\end{tabular}

A
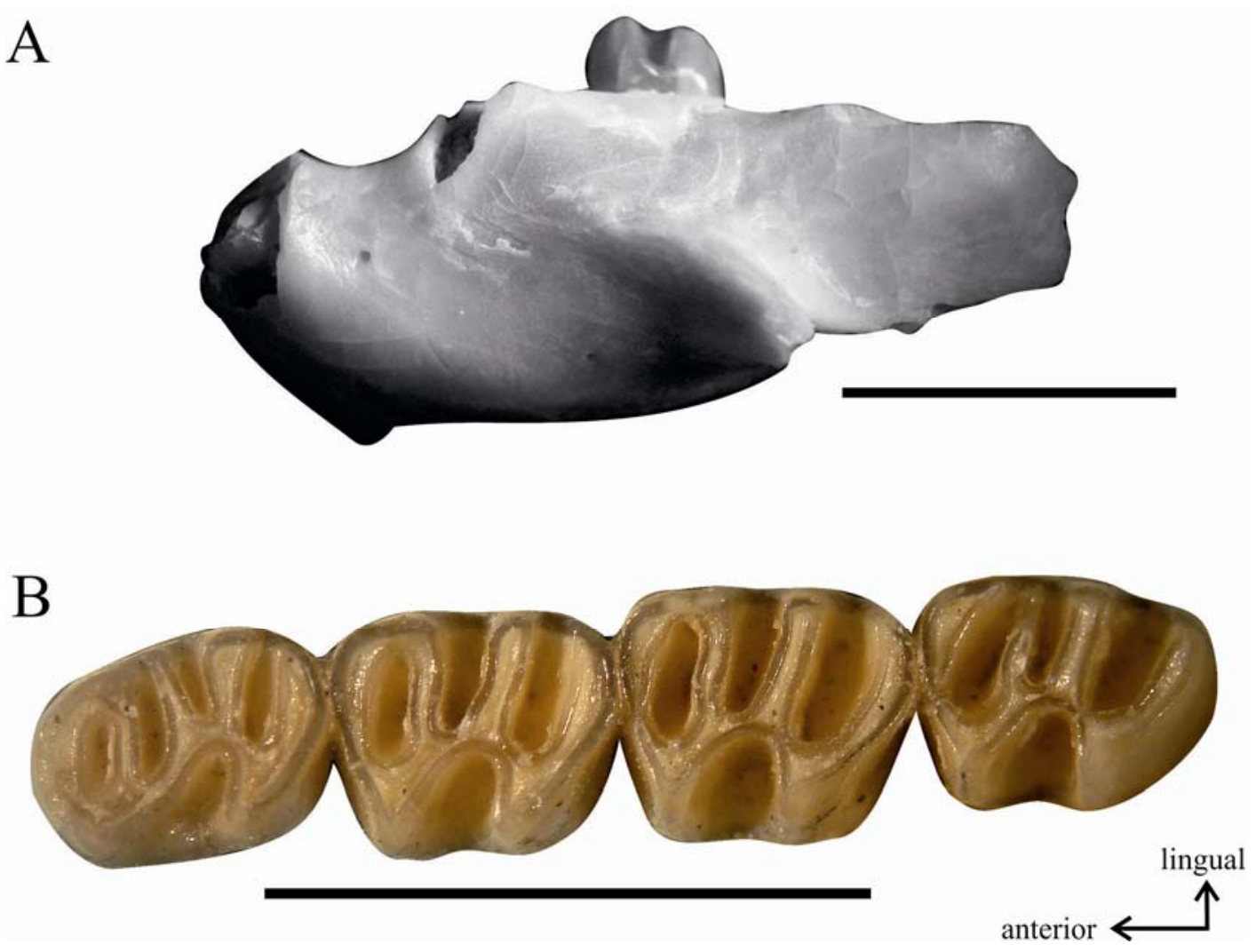

Figura 4.20. "Protacaremys" sp. nov. A: MPEF 6423, fragmento mandibular izquierdo con m1. $B$ : AMNH 29740, fragmento mandibular izquierdo con dp4-m3 (holotipo). Escala $=5 \mathrm{~mm}$ 
Género Sciamys Ameghino, 1887

Especie tipo: Sciamys principalis Ameghino, 1887

Distribución geográfica y temporal: provincia de Santa Cruz, Mioceno temprano, “Edad Pinturense” y “Edad Mamífero” Santacrucense.

Diagnosis modificada: Octodontoidea de tamaño mediano, semejante a “Acaremys” sp. nov. y Prospaniomys. Dientes de coronas más altas que en Galileomys y Acaremys. Hipsodoncia unilateral presente, más evidente que en Galileomys y Acaremys. Premolar superior definitivo con hipoflexo bien desarrollado, a diferencia de Galileomys y Acaremys, y metalofo mejor desarrollado que en Acaremys. Premolares inferiores de morfología más compleja que en Acaremys por la presencia de metalofúlido II e hipolófido; fléxido en el metalofúlido I que separa el protocónido del metacónido menos desarrollado que en Galileomys y Acaremys. En los molares inferiores el posterolófido es largo, al igual que en Acaremys y a diferencia de Galileomys. La muesca para la inserción del tendón del M. masseter medialis pars anterior (mmma) bien desarrollada, como en G. eurygnathus y Acaremys murinus. La fosa masetérica mandibular menos profunda anteriormente que en Galileomys y Acaremys. En el cráneo la fosa masetérica es amplia y se encuentra limitada anteriormente por un reborde y los nasales presentan un foramen accesorio en la mitad antero-posterior de los mismos, ambas estructuras compartidas con Acaremys; la rama vertical del cigoma más robusta que en Acaremys, y no hay proceso postorbital ni cresta sagital a diferencia de lo que ocurre en Acaremys.

Comentarios generales: como ya fue explicado para otros taxones, en muchos casos no se pudo identificar con certeza los ejemplares que conformaron el sintipo con los que trabajó Ameghino, ya que las primeras descripciones fueron muy vagas y no se numeraron los ejemplares ni se dio información de procedencia de la mayor parte de los mismos. Sin embargo, aquí se realizó un estudio exhaustivo de los materiales recolectados por Ameghino y se investigó la información concerniente al tema (Patterson, 1952 (manuscrito inédito), Marshall, 1980; Fernicola, 2011) con el fin de identificar los materiales con los que Ameghino realizó las descripciones del año 1887 y 1889. 
Sciamys principalis Ameghino, 1887

Sinonimia: Sciamys varians Ameghino, 1887; Acaremys messor Ameghino, 1889; Sciamys robustus Ameghino, 1894; Sciamys rostratus Scott, 1905.

Sintipo: MLP 15-146, rama mandibular izquierda con la porción infra-alveolar del incisivo y p4-m3 y MLP 15-349, p4-m3 izquierdos.

Tipos de los sinónimos: MLP 15-24, fragmento mandibular izquierdo con p4-m3 (S. varians); MACN A 4106, fragmento mandibular derecho con dp4-m2 (A. messor); MACN A 4144, fragmento mandibular derecho con p4 (S. robustus); YPM PU 15287, cráneo parcialmente preservado con las dos hileras dentarias y un fragmento mandibular derecho con $\mathrm{p} 4-\mathrm{m} 1$ (S. rostratus).

Material referido: (Ver Apéndice 1)

Distribución geográfica, estratigráfica y edad: Los Toldos Sur, Gobernador Gregores, Lago Cardiel, Loma de la Lluvia, provincia de Santa Cruz, Fm Pinturas?, Mioceno temprano, “Edad Pinturense”?; Karaiken, provincia de Santa Cruz, Mioceno temprano cuspidal?, "Edad Mamífero” Santacrucense?; barrancas del río Santa Cruz, Corriguen-Kaik, estancia La Angelina, estancia La Bajada, estancia La Costa, estancia Los Menucos (in Schedule), Killik Aike, lado sur del río Santa Cruz a 60 millas del lago Argentino, Monte Observación, Monte León, Yacimiento Dipilus, $10 \mathrm{mi}$ al sur de Coy Inlet, provincia de Santa Cruz, Formación Santa Cruz, Mioceno temprano cuspidal, “Edad Mamífero” Santacrucense.

Diagnosis modificada: Las cúspides no se diferencian de sus crestas, a diferencia de lo que ocurre en las especies de Acaremys, Galileomys y Sciamys latidens. La parafoseta y la posterofoseta se cierran en individuos juveniles y desaparecen en individuos adultos, de manera que tempranamente con el desgaste los dientes superiores adquieren forma de 8. Premolar superior tetralofodonte, con metalofo bien desarrollado. Hileras dentarias superiores paralelas, como en las especies de Acaremys. 


\section{Descripción:}

- Cráneo. El cráneo es relativamente largo y bajo. El techo craneano es plano y de bordes rectos y divergentes posteriormente a nivel de los huesos frontales, siendo la porción de los parietales la más ancha. Las bulas timpánicas se encuentran moderadamente desarrolladas.

Los huesos nasales son anchos anteriormente y se angostan en su porción posterior, extendiéndose hasta el nivel de la mitad anterior del M1 y el borde anterior de la raíz dorsal de la arcada cigomática (Fig. 4.21A); al igual que en Sciamys latidens y las especies de Acaremys se observa un foramen en cada borde externo de los nasales, en la mitad de su largo antero-posterior. Los premaxilares ocupan la mitad anterior de la pared lateral del rostro. La porción vertical de la sutura premaxilar-maxilar es poco crenulada y ligeramente cóncava posteriormente. Los procesos ascendentes del premaxilar son un poco más cortos que los nasales, llegando hasta el nivel del P4 (Fig. 4.21A); se extienden a través de la cara dorso-lateral del rostro hasta la mitad anterior de la raíz dorsal de la arcada cigomática. La fosa masetérica es semejante a la de las especies de Acaremys; es amplia, poco profunda y se encuentra limitada anteriormente por un reborde que se encuentra mejor desarrollado que en las especies de Acaremys (Fig. 4.21B). Este reborde anterior se encuentra menos desarrollado en individuos juveniles, mientras que en individuos adultos está bien desarrollado (MACN A 4115). La fosa masetérica está formada principalmente en el hueso maxilar, aunque debido a la extensión anterior de la fosa, el premaxilar forma gran parte de su borde anterior, a diferencia de lo que ocurre en otros octodontoideos. Los frontales son relativamente planos; presentan márgenes laterales angostos anteriormente, mientras que posteriormente se van haciendo más anchos; las suturas con los nasales y premaxilares son muy crenuladas. La sutura con los parietales es casi recta y poco crenulada. No hay un proceso post-orbitario bien desarrollado, a diferencia de las especies de Acaremys. Por detrás de los mismos, los frontales se angostan muy poco. La raíz dorsal de la arcada cigomática se ubica a nivel del borde posterior del P4 y la porción posterior de los nasales; esta raíz es ancha antero-posteriormente y en su porción posterior se observa el hueso lagrimal bien expuesto dorsalmente y formando una especie de escama (Fig. 4.21C). El lagrimal limita anterior y ventralmente con el maxilar, mientras que dorsalmente limita con el frontal. La rama vertical de la arcada cigomática es robusta a diferencia de las especies de Acaremys; es recta y se dispone de forma oblicua en dirección dorso-anterior ventro-posterior (Fig. 4.21C). La raíz ventral de la arcada 
cigomática está ubicada poco por delante del P4. En vista ventral, esta raíz se proyecta lateralmente, formando un arco que se continúa con la rama horizontal de la arcada cigomática. La tuberosidad masetérica (para la inserción del músculo masetero superficial) se encuentra bien desarrollada. Lateralmente, la depresión para la inserción del músculo masetero lateral es poco profunda. En la cara dorsal de la raíz ventral de la arcada cigomática el surco para el pasaje del nervio infraorbitario se encuentra bien desarrollado y está limitado lateralmente por un reborde alto, como en las especies de Acaremys. La rama horizontal del cigoma es algo divergente en vista ventral, mientras que en vista lateral es bien robusta y recta (Fig. 4.21C); la misma se encuentra formada principalmente por el hueso yugal, el cual se encuentra excluido de la rama vertical. La sutura yugal-maxilar es convexa anteriormente y se ubica poco por delante del borde anterior de la rama horizontal. La sutura yugal-escamosal es larga y cóncava dorsalmente. El proceso paraorbitario se encuentra poco desarrollado y esta formado por el yugal y el escamoso en iguales proporciones. La fosa yugal es larga anteroposteriormente, profunda y se encuentra expuesta en la mitad ventral de la rama horizontal. La porción escamosa de la arcada cigomática es corta.

El borde anterior de la orbita es de contorno rectangular; posteriormente la orbita esta limitada por el pequeño proceso paraorbitario. En algunos ejemplares (MACN A 11606) se observa el canal nasolacrimal que se origina en el extremo antero-dorsal de la cavidad orbitaria y se dirige antero-ventralmente, donde a nivel de la raíz ventral de la arcada cigomática se curva internamente hacia la cavidad nasal. En la porción intraorbitaria del frontal se puede observar un foramen (foramen frontal? sensu Wahlert, 1991) bien desarrollado, de contorno redondeado que se ubica casi en el límite dorsal de la órbita a nivel de la pequeña constricción post-orbitaria; antero-ventralmente a este foramen, en el frontal, se observa el foramen etmoidal que presenta forma ovalada. La porción extraorbitaria del escamoso es alta anteriormente y por detrás del borde posterior de la raíz posterior de la arcada cigomática el escamoso se angosta notablemente entre el parietal y la bula auditiva; la sutura entre escamoso y parietal es elevada. La porción más posterior del escamoso, por detrás del MAE se ensancha.

En vista dorsal la región parietal es la más ancha del techo craneano. En su porción anterior los parietales son anchos y globosos, mientras que hacia atrás se aplanan y angostan. No hay cresta sagital, a diferencia de Acaremys.

La bula timpánica está formada por el ectotimpánico y es pequeña. El MAE se ubica aproximadamente en el centro del eje antero-posterior de la bula; es grande, de 
contorno subcircular y se encuentra limitado por un reborde en forma de $\mathrm{u}$ abierto dorsalemente (Fig. 4.21C). Hay un foramen accesorio bien desarrollado por debajo del MAE. El seno epitimpánico se encuentra normalmente desarrollado. El seno hipotimpánico también se encuentra normalmente desarrollado. La bula contacta con el escamoso en la mayor parte de su longitud, a excepción de la porción anterior ubicada dorsalmente al seno epitimpánico, donde se encuentra el foramen postglenoideo; este foramen es ovalado, siendo el eje antero-posterior el mayor. En vista ventral, la bula posee forma arriñonada, siendo la pared medial más convexa que la pared externa.

El diastema es más largo que la serie premolo-molar. En vista lateral es cóncavo ventralmente en la porción anterior, mientras que posteriormente se hace casi recto; en vista ventral se observa que el diastema se ensancha considerablemente hacia atrás (Fig. 4.21D). La profundidad de la fosa maxilar es variable. Los forámenes incisivos se encuentran bien desarrollados; son muy anchos a nivel de la porción donde se ensancha el diastema. La sutura premaxo-maxilar intersecta a los forámenes incisivos en su porción anterior (Fig. 4.21D). Los surcos diastemales se encuentran poco desarrollados anteriormente y desaparecen por delante de los premolares, a diferencia de Acaremys murinus. Los forámenes palatinos posteriores se encuentran poco desarrollados y se ubican al nivel del límite entre P4-M1. La sutura maxilo-palatino presenta forma de V con el vértice ubicado a nivel de la mitad anterior de los M1. Las narinas posteriores abren al nivel de la mitad anterior del M3 o límite entre M2-M3 y delimitan una fosa mesopterigoidea triangular. El basioccipital es triangular.

- Dientes superiores. Las hileras dentarias superiores son paralelas entre sí y se encuentran inclinadas labialmente respecto del plano del paladar como consecuencia de la hipsodoncia unilateral (Fig. 4.21D). El P4 y el M3 son más pequeños que los M1 y M2. Los molares presentan coronas más altas que Acaremys murinus. En individuos jóvenes los dientes son largos antero-posteriormente, mientras que con mayor desgaste se hacen más anchos. Las cúspides no se diferencian de las crestas con las que están relacionadas.

Los DP4 son tetralofodontes, semejantes a los de las especies de Acaremys y Galileomys. Son más largos que anchos (Fig. 4.21E) (Tabla 3.21b). A diferencia de lo que ocurre en las especies de los demás géneros el hipocono tiene una posición lingual respecto del protocono. El anterolofo es cóncavo posteriormente y en individuos juveniles no alcanza el borde labial del diente (MACN PV SC 156), mientras que en individuos adultos sí (MACN PV SC 2378). El protolofo se encuentra bien 
desarrollado; es recto, oblicuo anteriormente y se une labialmente a un paracono poco diferenciado. Posteriormente, el muro es oblicuo lingualmente. La tercera y la cuarta cresta en posición se encuentran unidas al metacono en individuos juveniles, razón por la cual no es posible identificar las homologías de estas dos últimas crestas. En el borde posterior de la tercera cresta en posición de MACN PV SC 156 (Fig. 4.21E) se observan dos pequeñas proyecciones de homologías inciertas que se dirigen en dirección posterior en forma de V; en MACN PV SC 2378 se observa un pequeño abultamiento en ese mismo lugar. La posterofoseta es la más penetrante de las fosetas y la menos profunda; el mesoflexo es más amplio y profundo que el anteroflexo. El hipoflexo es oblicuo anteriormente, es poco penetrante y el más profundo de todos los flexos.

Los P4 son más complejos que los de Acaremys; presentan un contorno redondeado y son tetralofodontes, ya que tienen el metalofo bien desarrollado (Fig. 4.21F). El borde anterior del diente lo forma el anterolofo, que generalmente no alcanza el margen labial. El protolofo es la cresta mejor desarrollada; une el protocono con el paracono y es recta. Posteriormente se encuentra el muro, que es corto y recto. El metalofo se encuentra mejor desarrollado que en Acaremys (Fig. 4.21F); con poco desgaste se pone en contacto con el posterolofo delimitando una posterofoseta poco profunda que desaparece en individuos juveniles. De los flexos labiales el mesoflexo es el más amplio y profundo en la corona; paraflexo y mesoflexo penetran hasta la mitad de la superficie oclusal. La característica más notable, y que lo diferencia de las especies de Acaremys y de Platypittamys brachyodon, es el mayor desarrollo del área del hipocono y la consecuente diferenciación del hipoflexo, que se encuentra bien desarrollado y se opone al mesoflexo (Fig. 4.21F).

Los molares superiores son semejantes a los premolares. Son más anchos que largos (Tabla 4.21b). Se diferencian del premolar en que el metalofo se encuentra bien desarrollado y se une al metacono y al posterolofo en individuos juveniles (Fig. 4.21F). La parafoseta y la posterofoseta se forman en individuos con muy poco desgaste en sus dientes, mientras que en individuos con un poco más desgaste ambas fosetas se cierran y los molares adquieren forma de $\mathrm{H}$ debido a que los lóbulos son cortos ánteroposteriormente y transversalmente elongados (Fig. 4.21F). En individuos con moderado desgaste sólo quedan mesoflexo e hipoflexo enfrentados; el primero es bien penetrante en la superficie oclusal y transversal al eje antero-posterior del diente, mientras que el segundo es el más profundo de los flexos/fosetas y es poco oblicuo anteriormente. En individuos seniles el mesoflexo se cierra formando la mesofoseta, mientras que el 
hipoflexo siempre permanece abierto. El M3 se distingue porque el hipocono presenta una posición labial respecto del protocono; además el posteroflexo permanece abierto debido a que el posterolofo toma contacto con el metacono sólo en individuos adultos.

Los incisivos superiores son comprimidos y semejantes a los de las especies de Acaremys (Fig. 4.21D). La capa de esmalte es gruesa y la cara esmaltada anterior es lisa; el borde lingual forma un ángulo recto y el labial es más curvo y se expande hasta un tercio de su recorrido. La superficie de desgaste presenta una curvatura lateral que puede estar más o menos desarrollada. El extremo posterior del diente se ubica dorsalmente a la raíz ventral de la arcada cigomática.

- Mandíbula. El diastema es relativamente largo (tan largo como la distancia entre p4m2) y poco profundo. El foramen mentoniano se encuentra bien desarrollado y se ubica a nivel del punto más bajo del diastema o poco por delante de él (Fig. 4.21G). La mmma se encuentra muy bien desarrollada; es alargada antero-posteriormente y se ubica a nivel del p4-m1 y por arriba de la mitad de la altura de la mandíbula. La muesca se continúa postero-dorsalmente con un surco de desarrollo variable que se dirige hacia la base de la apófisis coronoides (Fig. 4.21G). La cresta masetérica se encuentra muy bien desarrollada y expandida lateralmente; es oblicua en dirección postero-ventral y su extremo anterior se continúa con el borde posterior de la mmma (Fig. 4.21G). La fosa masetérica es profunda, en especial su porción anterior, aunque algo menos que en las especies de Acaremys y Galileomys. El proceso coronoides nace a nivel del borde posterior del m2 y no se encuentra bien desarrollado (MACN A 244, MLP 63-XII-19132, MLP 63-XII-19-138); se extiende postero-lateralmente a la hilera dentaria, delimitando una fosa retromolar lateral al m3. El foramen mandibular se encuentra bien desarrollado y se ubica en la rama ascendente, a mitad de camino entre la base de la apófisis y el cóndilo mandibular. El cóndilo mandibular es de forma ovalada, siendo el eje antero-posterior el más largo, y se ubica al mismo nivel antero-posterior que la hilera dentaria; la mitad posterior del cóndilo es bien convexa dorsalmente. En la cara interna de la mandíbula se observa una sínfisis mandibular que se extiende posteriormente hasta el nivel del $\mathrm{m} 1$, como en Acaremys murinus; el proceso mentoniano se encuentra bien desarrollado y se ubica por delante del p4 y por detrás (Fig. 4.21G) o por debajo del foramen mentoniano. Por detrás de ella y hasta el borde posterior del m3, la rama horizontal de la mandíbula se hace abruptamente más baja. 
- Molares inferiores. Los molares inferiores presentan una hipsodoncia unilateral atenuada y, al igual que en los molares superiores, las cúspides no se individualizan en dientes que presentan poco desgaste.

El dp4 es semejante al de Acaremys murinus y distinto del que se conoce para Galileomys eurygnathus. Presenta cuatro crestas principales. MACN A 1871 y MACN PV SC 2782 son los dos ejemplares más juveniles y en ellos se puede apreciar la morfología particular de la porción anterior del diente, que luego cambia en individuos que presentan un poco más de desgaste. En ellos se observa que el metalofúlido I es fuertemente cóncavo hacia atrás y que se continúa posteriormente con un brazo posterior del metacónido muy bien desarrollado (Fig. 4.21H); el mesolófido se encuentra muy poco desarrollado y no está unido aún a la extensión posterior del metacónido; la extensión posterior del metacónido es curva y se dirige labialmente en dirección hacia el mesolófido, hasta un punto de inflexión donde se hace recto, se dirige hacia adelante y forma una extensión del brazo posterior del metacónido (Fig. 4.21H). El brazo posterior del metacónido puede atravesar la anterofosétida y tomar contacto con el borde posterior del metalofúlido I, de manera que el anterofléxido/anterofosétida se divide en dos; en MACN A 1871 y MACN PV SC 2782 se observa que el extremo lingual del mesolófido se continúa lingualmente mediante una cresta muy baja y muy poco desarrollada que en individuos con algo más de desgaste toma contacto con el brazo posterior del metacónido y delimita la anterofosétida. Desde el borde posterolabial del lóbulo anterior se extiende el ectolófido, que es corto y oblicuo en dirección postero-lingual. La porción posterior del premolar, donde se encuentran el hipolófido y el posterolófido está molarizada (Fig. 4.21H). El hipolófido nace en el punto donde se unen el ectolófido y el brazo anterior del hipocónido; es recto y alcanza el borde lingual del diente. El posterolófido es cóncavo hacia delante y es largo, ya que alcanza el borde lingual del diente. La anterofosétida se forma en estadios de desgaste muy bajos y es poco profunda (Fig. 4.21H). El mesofléxido es el fléxido más amplio, profundo, y menos penetrante de los fléxidos linguales; el posterofléxido es muy penetrante en la superficie oclusal y se encuentra dirigido en dirección labial. El hipofléxido es más profundo que el mesofléxido y es oblicuo posteriormente.

El p4 es semejante al de Platypittamys brachyodon, Deseadomys arambourgi y los restantes acarémidos, aunque más complejos en cuanto al número y desarrollo de los lófidos (Fig. 4.21I). Posee dos crestas principales: una anterior, el metalofúlido I, y otra posterior, el posterolófido, que se relacionan entre sí a través de un ectolófido poco 
oblicuo en sentido anterolabial-posterolingual. En la cara anterior del metalofúlido I puede haber un pequeño surco que desaparece pronto con el desgaste. El metacónido se encuentra alineado al protocónido o es posterior a él. El metalofúlido II se encuentra generalmente bien desarrollado y puede ser oblicuo anteriormente de manera que queda delimitada una fosétida anterior que desaparece con el desgaste, puede ser recto (MACN PV SC1694, MACN PV SC1990, MLP 15-349) (Fig. 4.21I) o puede ser oblicuo posteriormente y tomar contacto con estructuras ubicadas en la mitad posterior del diente (MACN PV SC2318, MACN PV SC2377, MACN PV SC2396). En algunos casos se observa un hipolófido semejante en desarrollo al de Deseadomys arambourgi que se encuentra separado del posterolófido por un posterofléxido poco penetrante en la corona (MACN PV SC2338, MACN PV SC2369, MACN PV SC2419).

Los molares inferiores son tetralofodontes y la superficie oclusal rápidamente se vuelve plana. El metalofúlido I une el protocónido y el metacónido que se encuentran alineados labio-lingualmente. El metalofúlido II se encuentra bien desarrollado y ya en individuos juveniles se une a la región del metacónido para delimitar una anterofosétida poco profunda que desaparece en individuos adultos (Fig. 4.21I). Como ocurre en otros Acaremyidae, la fosétida anterior del $\mathrm{m} 1 \mathrm{y}$ m2 puede encontrarse dividida en dos por una cresta longitudinal que se extiende desde el borde posterior del metalofúlido I hasta el metalofúlido II (MACN A 4112, MACN PV SC 2396, MLP 15-349, MLP 15-349, MLP 63-XII-19-139) (Fig. 4.21I). Desde el borde postero-labial del metalofúlido II se extiende en dirección postero-lingual un ectolófido corto. El hipolófido y el posterolófido presentan la misma disposición que en el dp4; sin embargo, se diferencian en que sus extremos linguales se encuentran próximos entre si de manera que delimitan la metafosétida en individuos adultos. Al igual que en las especies de Acaremys y a diferencia de lo que se observa en Platypittamys brachyodon y en las especies de Galileomys el posterolófido es largo y alcanza el margen lingual del diente (Fig. 4.21I). El mesofléxido es recto y es el más amplio y profundo de los fléxidos linguales y el menos penetrante en la superficie oclusal. El hipofléxido es el más amplio y es poco oblicuo posteriormente. En individuos adultos se forma la posterofosétida, mientras que en individuos seniles desaparecen estas dos estructuras, se forma la mesofosétida y permanece únicamente el hipofléxido.

Los incisivos inferiores son comprimidos lateralmente. Al igual que en los incisivos superiores la capa de esmalte es gruesa. La cara anterior presenta un reborde poco desarrollado en la línea media o algo externa. El borde lingual de esmalte forma un 
ángulo recto, mientras que el extremo labial se va curvando suavemente hasta expandirse hasta la mitad de la cara. La superficie de desgaste posee lateralmente una curvatura suave en todo su recorrido (Fig. 4.21G). El diente es largo, se extiende por debajo de toda la rama horizontal de la mandíbula sobre el lado interno, prolongándose por detrás de la última muela, donde pasa al lado externo ascendiendo hasta la apófisis coronoides.

Comentarios: las especies S. varians Ameghino, 1887 y S. robustus Ameghino, 1894 fueron diferenciadas de $S$. principalis por su menor y mayor tamaño respectivamente. Sin embargo, en colecciones realizadas con posterioridad se encontraron ejemplares asignados a este género que cubrieron los intervalos de tamaño intermedios existentes entre estas especies (Scott, 1905). Por otro lado, Ameghino en el año 1894 diagnosticó a S. robustus como con incisivos inferiores presentando la cara esmaltada anterior deprimida y con una fuerte arista longitudinal en su borde externo. Sin embargo, en el ejemplar designado como holotipo de esta especie (MACN A 4144) no se observa nada parecido a una fuerte arista, sino un pequeño reborde en la mitad externa de la cara anterior que bien podría corresponderse con el reborde que presentan los incisivos inferiores de Sciamys principalis. Al no existir otras características diagnósticas de estas dos especies que la diferencien de Sciamys principalis, las mismas se consideran aquí como sinónimos de S. principalis. Scott (1905) describió la especie S. rostratus, la cual presentaba características intermediarias entre $S$. principalis y $S$. varians; estas diferencias se expresaban en el tamaño relativo de la estructuras craneanas y de los incisivos. El ejemplar designado como holotipo de S. rostratus es YPM PU 15257 ([SIC]= YPM PU 15287) y representa un individuo adulto con la dentición simplificada por el desgaste, por lo cual no es posible observar características que puedan diferenciarlo de S. principalis; por ello no se justifica su diferenciación específica de Sciamys principalis. Esta propuesta es coincidente parcialmente con las notas inéditas que B. Patterson realizó en el año 1952; se diferencia de las mismas en que este autor incluyó dentro de Sciamys principalis a las especies “Acaremys" tricarinatus y A. karaikensis, y por otro lado no incluyó a S. robustus.

Por otro lado, cabe destacar la gran variabilidad en la morfología del p4 que se observa entre los ejemplares asignados a Sciamys principalis (Ver descripción del p4). La misma es considerada como variabilidad intraespecífica debido a que las restantes estructuras dentarias, mandibulares y craneanas son más “estables” morfológicamente; 
los ejemplares en donde se observan pequeñas variaciones en la morfología de algunas estructuras (e.g. foramen mentoniano poco por delante del punto más bajo del diastema o foramen mentoniano por debajo del punto más bajo del diastema), éstas no se encuentran asociadas a la variabilidad del p4. Por ello (y por el momento), se considera la existencia de dos especies del género Sciamys: S. principalis y S. latidens, que se describe más abajo.

Tabla 4.21a. Medidas craneanas y mandibulares Sciamys principalis $(\mathrm{cm})$

\begin{tabular}{lcl}
\hline MACN A 4114 & AAD & 0,542 \\
& AAP & 0,352 \\
& APD & 1,100 \\
& APP & 0,350 \\
& HCA & 1,052 \\
& LDS & 1,148 \\
& LP & 1,818 \\
& & \\
MACN A4115 & LDi & 0,622 \\
& AM1 & 0,520 \\
& AM2 & 0,636 \\
& AM3 & 0,398 \\
\hline
\end{tabular}

Tabla 4.21b. Medidas dentarias de Sciamys principalis (mm)

\begin{tabular}{ccccc}
\hline & & LAP & AA & AP \\
\hline MACN A 11606 & P4 & 1,72 & 2,32 & 2,08 \\
& M1 & 1,88 & 2,52 & 2,36 \\
& M2 & 1,88 & 2,56 & 2,22 \\
& M3 & 1,64 & 2,22 & 1,52 \\
MACN PV SC 156 & DP4 & 2,60 & 1,74 & 1,72 \\
MACN PV SC 1879 & P4 & 1,86 & 2,34 & 2,46 \\
& M1 & 2,08 & 2,52 & 2,46 \\
& M2 & 1,96 & 2,60 & 2,60 \\
MACN PV SC 2378 & M3 & 1,80 & 2,30 & 1,88 \\
MACN PV SC 1984 & DP4 & 2,22 & 1,86 & 1,88 \\
& dp4 & 2,62 & 1,42 & 1,82 \\
MACN PV SC 2372 & m1 & 2,04 & 1,98 & 1,88 \\
& m2 & 1,90 & 2,02 & 1,90 \\
& dp4 & 2,82 & 1,52 & 1,70 \\
MACN PV SC 2377 & m1 & 2,20 & 2,42 & 2,22 \\
& m2 & 2,10 & 2,60 & 2,42 \\
& p4 & 1,70 & 1,60 & 1,96 \\
& $\mathrm{~m} 1$ & 1,88 & 1,98 & 2,04 \\
& $\mathrm{~m} 2$ & 2,00 & 2,12 & 2,14 \\
& $\mathrm{~m} 3$ & 1,62 & 1,80 & 1,62 \\
\hline
\end{tabular}



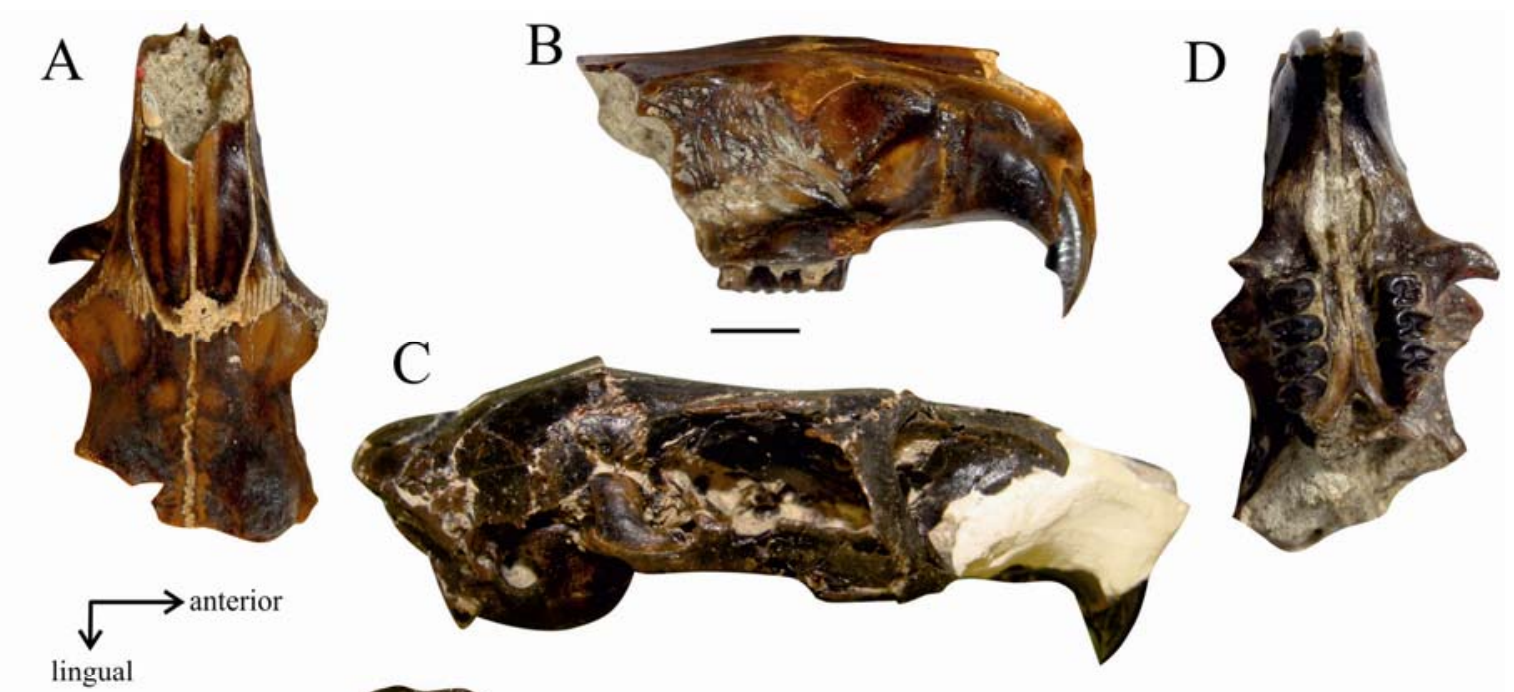

$\mathrm{E}$
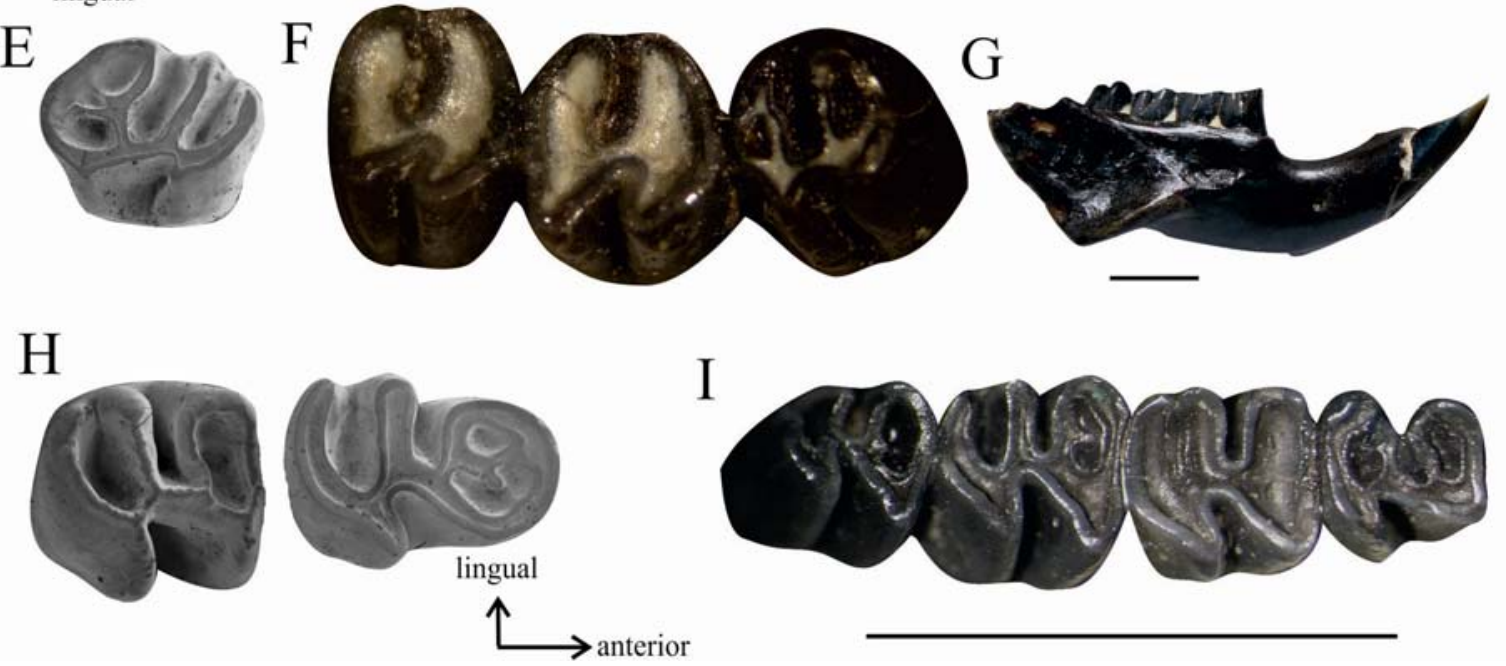

Figura 4.21. Sciamys principalis. $A, B$ y $D$. MACN A 11606, cráneo parcialmente preservado con toda la dentadura; $A$ : Vista dorsal; $B$ : Vista lateral (invertido); D: Vista ventral. $C$ : vista lateral del AMNH, cráneo casi completo con toda la dentadura (invertido). E: MACN PV SC 156, DP4 derecho. F: YPM PU 15089, P4-M2. G: MACN A 4114, mandíbula con p4-m3. H: MACN PV SC2394, fragmento mandibular derecho con dp4-m1. I: MLP 15-349, p4-m3 izquierdos (invertido) (sintipo). Escala $=5 \mathrm{~mm}$ 


\section{Sciamys latidens Scott, 1905}

Holotipo: YPM PU 15944, cráneo parcialmente preservado con toda la dentadura, fragmento mandibular izquierdo con toda la dentadura y parte del post-cráneo.

Material referido: sólo el holotipo.

Procedencia geográfica, estratigráfica y edad: Killik Aike, provincia de Santa Cruz; Formación Santa Cruz, Mioceno temprano cuspidal, “Edad Mamífero” Santacrucense.

Diagnosis modificada: rostro robusto y ancho, donde el premaxilar forma gran parte de su cara dorsal; hileras dentarias convergentes hacia atrás, a diferencia de S. principalis y las especies de Acaremys; expansiones internas del maxilar en los forámenes incisivos. Cúspides diferenciadas y crestas gruesas, a diferencia de S. principalis. El p4 presenta la porción posterior del diente molarizada, a diferencia de lo que ocurre en $S$. principalis, como consecuencia del desarrollo del hipolófido.

Descripción ampliada: la descripción original de Scott (1905) es detallada y destaca las características diagnósticas que diferencian a esta especie de Sciamys principalis. Sin embargo, a continuación se detallan algunos caracteres que no fueron evaluados previamente.

- Cráneo. El rostro de esta especie se diferencia de la de los restantes Sciamys y Acaremys murinus en que la fosa masetérica no se encuentra limitada anteriormente por un reborde bien delimitado; por el contario, esta estructura es más pequeña y su límite ventral está dado por la tuberosidad del incisivo (Fig. 4.22A). La raíz ventral de la arcada cigomática nace poco por delante del P4. En la cara ventral del rostro, se observan unos forámenes incisivos bien desarrollados, como en las restantes especies de Sciamys y las de Acaremys; en la mitad posterior de los mismos se observan un par de expansiones del maxilar, de extremos redondeados, que nacen desde el borde lateral de los forámenes y se extienden internamente, aunque sin contactar en la línea media (Fig. 4.22B); esta estructura no se observó en otros taxones estudiados. La sutura premaxilomaxilar intersecta a los forámenes incisivos en su mitad anterior. En su mitad posterior los forámenes incisivos se encuentran delimitados lateralmente por los rebordes incisivos, los cuales no se encuentran bien desarrollados en la porción posterior del 
diastema. Las narinas posteriores abren a nivel de los M3 delimitando una fosa mesopterigoidea triangular (Fig. 4.22B). En la cara dorsal del cráneo los frontales presentan los procesos post-orbitarios expandidos lateralmente y de contorno redondeado. Posteriormente a ellos, se observa unas pequeñas constricciones postorbitarias (Fig. 4.22C).

- Dientes superiores. Los dientes son de corona alta, semejante a lo que se observa en Sciamys principalis. Presentan una leve hipsodoncia unilateral. Las cúspides son más abultadas que las crestas (Fig. 4.22D).

El P4 es tetralofodonte, con el metalofo bien desarrollado, como Sciamys principalis (Fig. 4.22D). Presenta un contorno subcircular y es del mismo tamaño que el M3. El anterolofo y el protolofo por un lado y el metalofo y posterolofo por el otro están unidos en individuos juveniles para delimitar una parafoseta y posterofoseta subiguales. El hipoflexo es muy poco penetrante en la superficie oclusal, a diferencia de Sciamys principalis y es oblicuo anteriormente.

En los M1-M2 la posterofoseta se cierra y desaparece antes que la parafoseta. En el M1 se preservaron solamente mesoflexo e hipoflexo enfrentados, mientras que en el M2 se observa el paraflexo y la posterofoseta (Fig. 4.22D). Como es usual el M3 se caracteriza por presentar el hipocono de posición labial respecto del protocono y porque el posteroflexo permanece abierto postero-labialmente (Fig. 4.22D).

- Mandíbula. La mandíbula presenta un foramen mentoniano bien desarrollado ubicado poco por delante de la porción más baja del diastema, al igual que Sciamys principalis (Fig. 4.22E). Posteriormente la mmma esta bien desarrollada y se ubica entre el p4-m1. La cresta masetérica también se encuentra bien desarrollada y se extiende posteroventralmente respecto al plano horizontal de la mandíbula. La fosa masetérica es profunda anteriormente. La apófisis coronoides nace a nivel del m2.

- Dientes inferiores. Al igual que los molariformes superiores, los inferiores presentan crestas gruesas y cúspides voluminosas, en especial el metacónido.

El p4 presenta el metalofúlido I bien desarrollado que une el protocónido y el metacónido; no se observa un surco que separe ambas crestas, pero esto puede deberse al grado de desgaste que presentan los dientes. Del extremo posterior del protocónido nace el ectolófido que es oblicuo postero-lingualmente como en el p4 de los restantes acarémidos. Del borde posterior del ectolófido nace el metalofúlido II, que se encuentra bien desarrollado; es oblicuo anteriormente y se pone en contacto con el metacónido delimitando una anterofosétida. Se diferencia del p4 de Sciamys principalis y de las 
especies de Acaremys en que presenta el hipolófido bien desarrollado, que nace desde el ectolófido. El borde posterior del diente lo forma el posterolófido, que alcanza el borde lingual del diente.

Los molares son tetralofodontes y con la morfología general de los acarémidos. El metacónido es de posición más anterior que el protocónido, por lo que el metalofúlido I es oblicuo antero-lingualmente/postero-labialmente. En el $\mathrm{m} 1$ se observan el mesoflexo y posteroflexo poco penetrantes en la superficie oclusal y el hipofléxido bien penetrante y oblicuo posteriormente. En el m2 se observan además una pequeña anterofosétida. El m3 se caracteriza por presentar un posterolófido corto y porque el extremo lingual del metalofúlido II es oblicuo posteriormente, característica que no se observa en los restantes taxones estudiados.

Comentarios: los dibujos de Sciamys latidens del trabajo de Scott (1905) (Lámina LXVII, figuras 1, 2 y 3) muestran un cráneo considerablemente más completo que como se encontraba cuando pude estudiarlo en el año 2008, como consecuencia no se pudieron estudiar numerosas estructuras craneanas. 


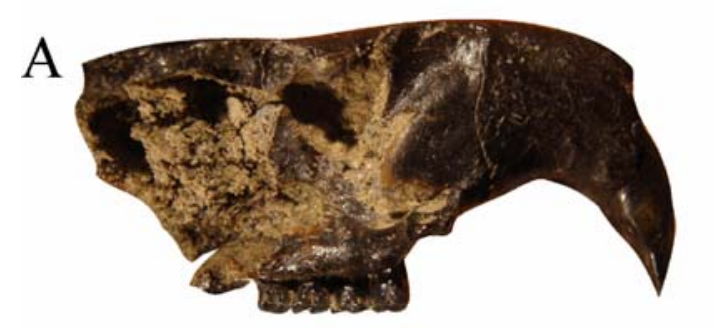

D
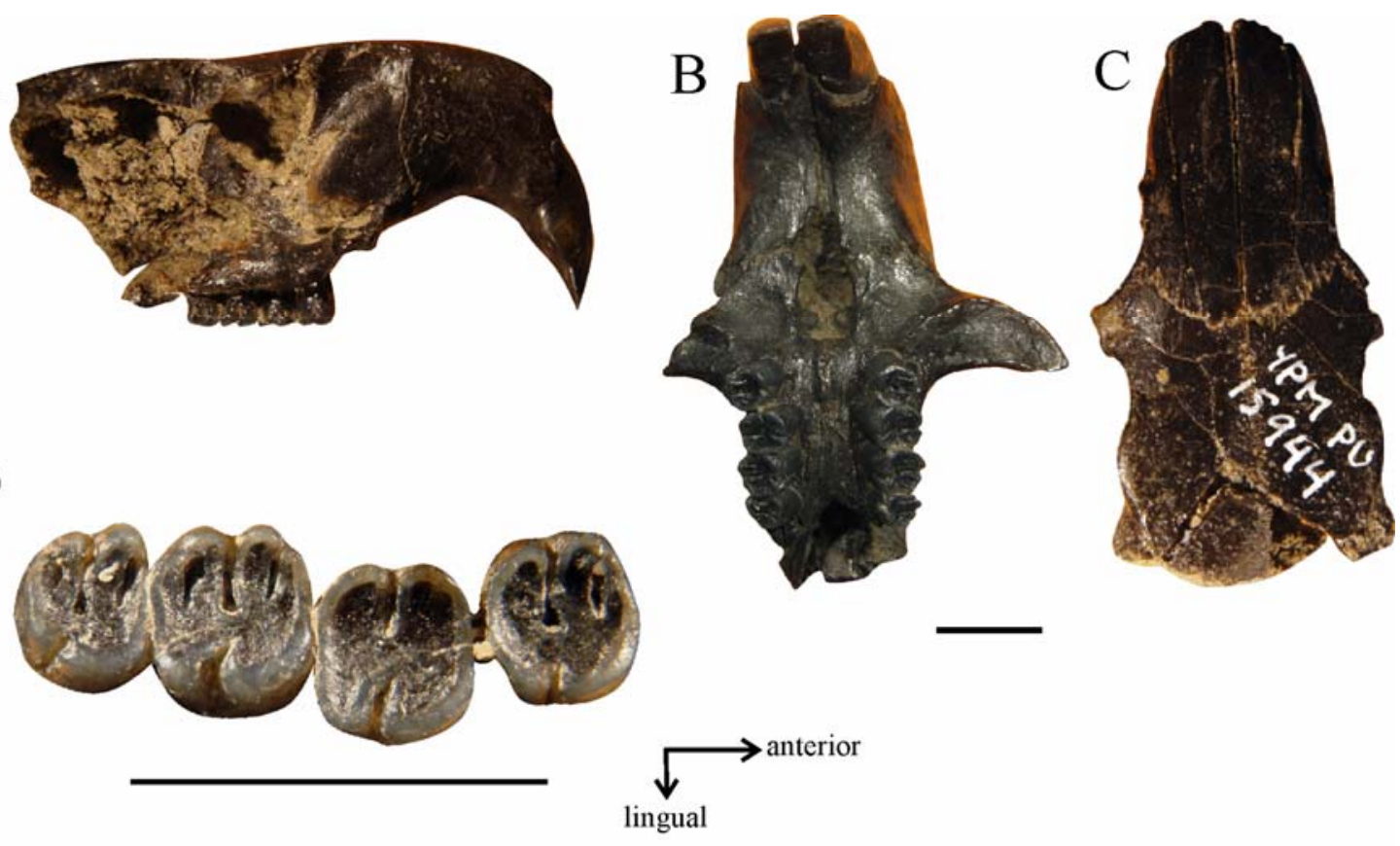

$\mathrm{E}$
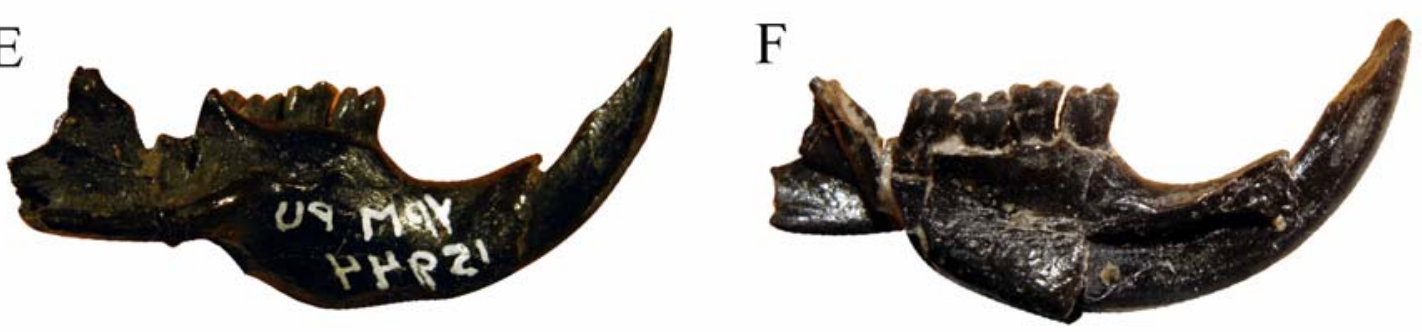

Figura 4.22. Sciamys latidens. A-F. YPM PU 15944, cráneo parcialmente preservado con toda la dentadura y fragmento mandibular izquierdo con p4-m3 (holotipo); $A$ : Cráneo en vista lateral; $B$ :

Cráneo en vista ventral; $C$ : Cráneo en vista dorsal; $D$ : P4-M3 derecho; $E$ : Mandíbula en vista externa (invertida); F: Mandíbula en vista interna. Escala $=5 \mathrm{~mm}$ 
CAPÍTULO 5

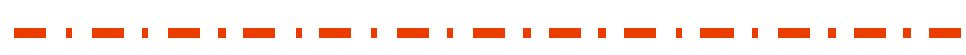

ANÁLISIS

FILOGENÉTICO 


\subsection{Antecedentes}

Los primeros trabajos en los que se estudiaron las relaciones filogenéticas de los Octodontoidea del Oligoceno tardío-Mioceno medio y cuyos resultados se expresaron en diagramas de tipo árbol no aplicaron la metodología cladística, sino que se realizaron sobre la base de la comparación morfológica de caracteres (Ameghino, 1889; Wood, 1949; Wood y Patterson, 1959; Patterson y Wood, 1982). Paralelamente numerosas contribuciones (cuyos resultados no fueron diagramados en árboles) propusieron relaciones de parentesco entre estos roedores (e. g. Landry, 1957; Patterson y Pascual, 1972; Reig, 1986, 1989; Verzi, 2002; Vucetich y Vieytes, 2006). En las últimas dos décadas hubo un incremento en el número de trabajos que aplicaron la metodología cladística para resolver las relaciones de los Caviomorfos en general (Kramarz, 2001; Pérez, 2010), y octodontoideos en particular (Verzi, 2001; Vucetich y Kramarz, 2003; Carvalho y Salles, 2004; Verzi, 2008; Olivares, 2009). De la misma manera, en los últimos años se incrementaron los estudios que utilizaron caracteres moleculares para realizar reconstrucciones filogenéticas (Huchon et al., 2000; Huchon y Douzery, 2001; Salazar-Bravo J. et al., 2001; Honeycutt et al., 2003).

Los primeros esquemas de tipo árbol que propusieron relaciones entre los caviomorfos fueron los que realizó Ameghino en el año 1889 (Fig. 5.1).

Ameghino (1887) agrupó a las especies de los géneros Acaremys, Sciamys, Steiromys y Sphingurus dentro de la familia Cercolabidae (Fig. 5.1). Posteriormente, en el año 1902 Ameghino incluyó dentro de Acaremyinae a Acaremys, Sciamys y Protacaremys, todos ellos relacionados con los eretizóntidos. Paralelamente, Ameghino (1887) agrupó a las especies de los géneros Adelphomys, Stichomys, Spaniomys y formas hoy agrupadas en otras superfamilias de caviomofos dentro de la familia Echinomyidae, la cual se encontraba relacionada al origen de los Octodontidae (Fig. 5.1). En el año 1902 Ameghino incluyó dentro de esta familia el género Prospaniomys. 


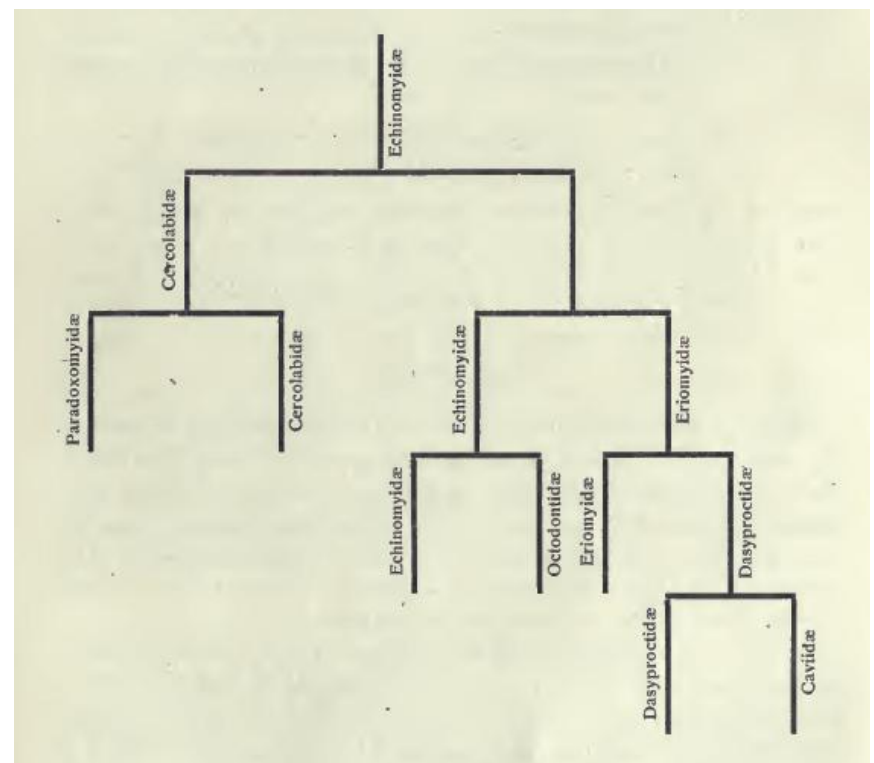

Fig. 5.1. Sucesión y descendencia de los grandes grupos de roedores sudamericanos sensu Ameghino, 1889

Sobre la base de la morfología dentaria y las adaptaciones post-craneanas, Wood (1949) interpretó que Platypittamys era el caviomorfo más primitivo conocido hasta ese momento. El autor entendía que los rasgos generalizados presentes en este taxón constituían una fuente importante de información para dilucidar el origen y relaciones filogenéticas de los roedores caviomorfos. Así fue como propuso que los acarémidos no debían incluirse dentro de los Erethizontoidea, a diferencia de lo que había planteado Ameghino (1902), sino que representarían el stock basal a partir del cual se habrían diferenciado los Octodontoidea, Chinchilloidea y Caviodea.

Landry (1957) realizó una revisión de los histricognatos. En la clasificación que el autor propuso, los acareminos (Platypittamys, "Eoctodon", Sciamys y Acaremys) se encontraban más estrechamente relacionados con los puerco-espines sudamericanos que con los restantes caviomorfos, por lo que los incluyó dentro de la superfamilia Erethizontoidea. Sobre la base de las similitudes dentarias, Landry propuso que los Echimyidae también podrían incluirse dentro de Erethizontoidea. El concepto que Landry tenía de Octodontoidea era particular; el autor apoyaba la hipótesis de que los octodóntidos derivaban de equímidos o myocastóridos, por lo que en este grupo incluyó a formas hipsodontes generalmente incluidas en los Myocastoridae, Cuniculidae, Eumegamyidae, Neopiblemidae, Dinomyidae y Octodontidae. 
Más tarde, Wood y Patterson (1959) estudiaron la fauna de roedores deseadenses de Patagonia y propusieron hipótesis filogenéticas para las distintas familias de roedores caviomorfos (Figs. 5.2. y 5.3). Sobre la base del análisis de un gran número de ejemplares fósiles concluyeron que los acarémidos se relacionaban con los Octodontidae, y propusieron reemplazar el término "Acaremyidae" por el de “Octodontidae primitivos". Estos autores determinaron que los integrantes de la superfamilia Octodontoidea del Oligoceno tardío-Mioceno temprano presentaban una morfología molar semejante entre sí, y que entre el Deseadense y el Colhuehuapense comenzaron a diferenciarse los dos linajes principales de octodontoideos modernos: el de los equímidos y el de los octodóntidos. Así fue como incluyeron a los octodontoideos del Oligoceno-Mioceno dentro de alguna de las dos familias.

Adicionalmente, como se observa en la figura 5.3 los autores relacionaron a Protacaremys con los Echimyidae a diferencia de la propuesta previa de Ameghino.

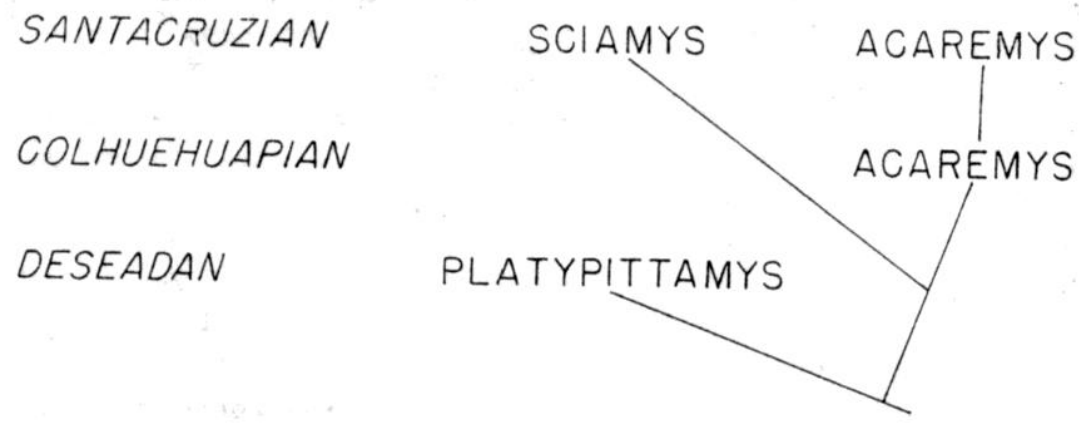

Fig. 5.2. Hipótesis filogenética de los Octodontidae del Oligoceno- Mioceno temprano sensu Wood y Patterson, 1959

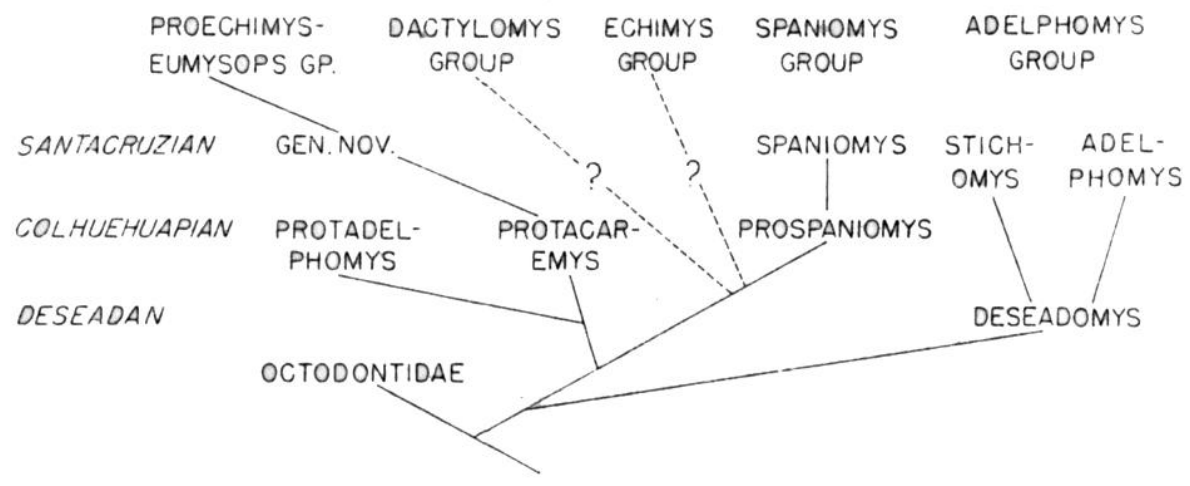

Fig. 5.3. Hipótesis filogenética de los Echimyidae del Oligoceno- Mioceno temprano sensu Wood y Patterson, 1959 
En el año 1967, Pascual propuso que Sciamys era un antecesor de los Octodontidae vivientes y que Acarechimys era el ancestro de equímidos fósiles como Eumysops Ameghino, 1888 y Chasichimys Pascual, 1967.

En 1982 Patterson y Wood estudiaron los roedores fósiles del Oligoceno tardío de Bolivia, así como también las relaciones entre ellos y los restantes caviomorfos. Respecto a las relaciones entre los octodontoideos, los resultados fueron concordantes con los que habían propuesto en 1959 (Fig. 5.4). Asimismo, propusieron que los Octodontidae (Platypittamys y Migraveramus) retenían una morfología dentaria generalizada para todos los Caviomorpha, con la posible excepción de los Erethizontoidea.

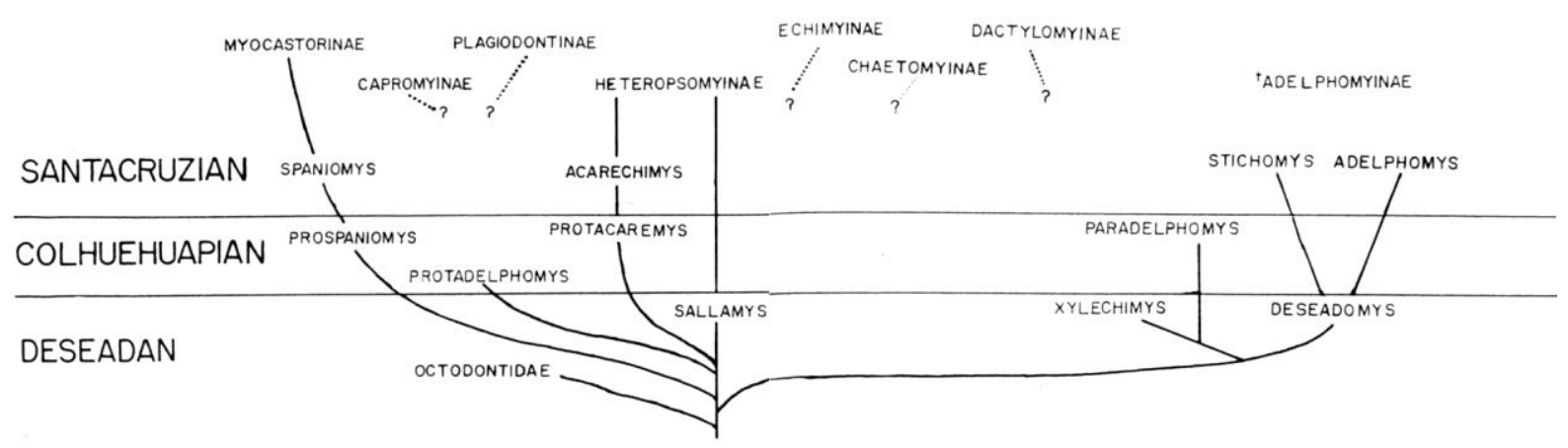

Fig. 5.4. Hipótesis filogenética de los Echimyidae tempranos y su posible relación con las formas vivientes sensu Patterson y Wood, 1982

Vucetich y Verzi (1991) propusieron nuevas agrupaciones para los octodontoideos fósiles y los Echimyidae vivientes. Dentro de Echimyinae los autores agruparon a varias especies vivientes de Echimyinae y a Protacaremys, Deseadomys, Xylechimys, Platypittamys y Acarechimys, mientras que dentro de Dactylomyinae incluyeron a Stichomys, Adelphomys y Spaniomys.

En un trabajo realizado en el año 1996, Vucetich y Verzi describieron Caviocricetus lucasi, al que no relacionaron con ninguna de las formas conocidas de octodontoideos fósiles, sino que lo describieron como un Octodontoidea incertae sedis. De esta manera, en este trabajo se refleja la idea de romper con la visión tradicional que proponía que las formas fósiles estaban relacionadas con los Octodontidae y Echimyidae vivientes. 
Verzi (2002) propuso a Acarechimys como un posible taxón basal de Octodontidae, aunque sin una justificación explícita para esta propuesta.

Vucetich y Kramarz (2003) realizaron uno de los primeros análisis filogenéticos en base a caracteres morfológicos dentarios y mandibulares con roedores octodontoideos utilizando la metodología cladística (Fig. 5.5). Uno de los resultados más destacados fue que se corroboró la monofilia de Acaremyidae, donde se incluyeron los géneros Sciamys, Acaremys y Galileomys. Los autores propusieron que esta familia representaba un linaje independiente de octodontoideos (ColhuehuapenseColloncurense) que se extinguió sin dejar descendientes. Además, propusieron la existencia de linajes de octodontoideos que podrían no tener relación directa con las formas modernas y que los taxones incluidos dentro de Echimyidae (Deseadomys, Protacaremys, Massoiamys, Stichomys y Eumysops) no conformarían un grupo monofilético, mientras que los taxones incluidos dentro de Octodontidae (Chasichimys, Chasicomys y Octomys) sí. Esta propuesta rechazaba las ideas previas de Wood y Patterson (1959) y Patterson y Wood (1982) de una diferenciación temprana de los octodontoideos en Octodontidae y Echimyidae.

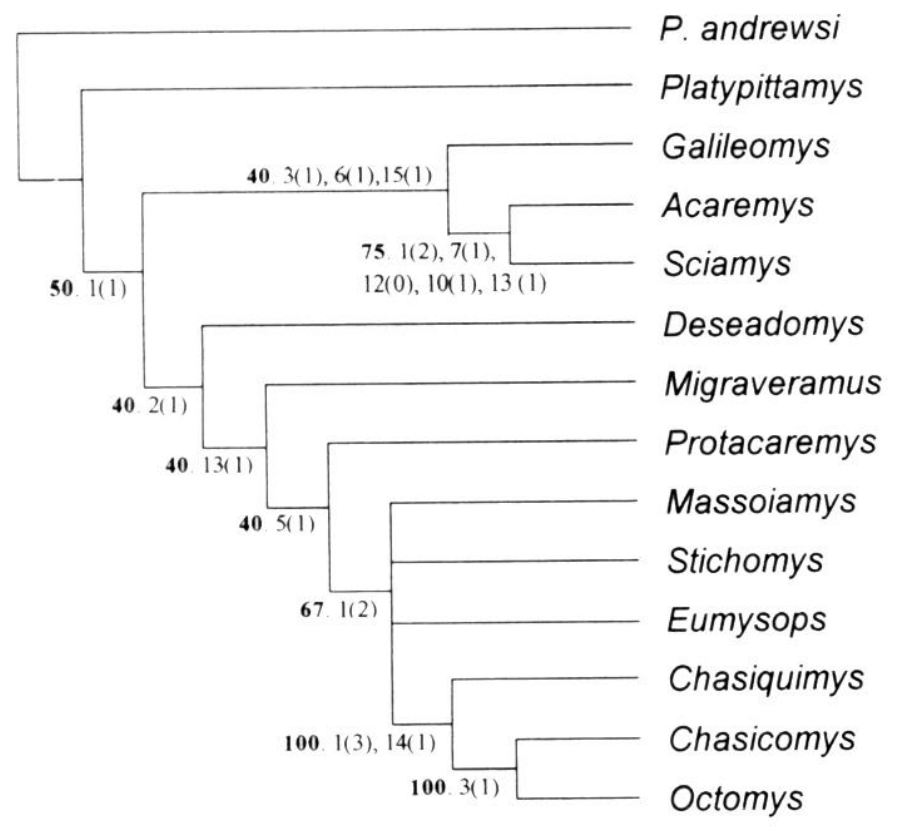

Fig. 5.5. Hipótesis filogenética propuesta por Vucetich y Kramarz (2003)

Carvalho y Salles (2004) realizaron un estudio filogenético en base a caracteres morfológicos dentarios, mandibulares y craneanos donde incluyeron una gran cantidad 
de octodontoideos fósiles y equímidos actuales. Los resultados (Fig. 5.6) indicaron que las formas vivientes de Echimyidae se relacionan entre sí en grupos definidos, mientras que los octodontoideos fósiles no presentan relaciones claras entre sí y se agrupan en politomías entre las formas vivientes de Echimyidae (Fig. 5.6). Los autores aclararon que los resultados son tentativos, ya que la matriz analizada presentaba una gran cantidad de datos faltantes.

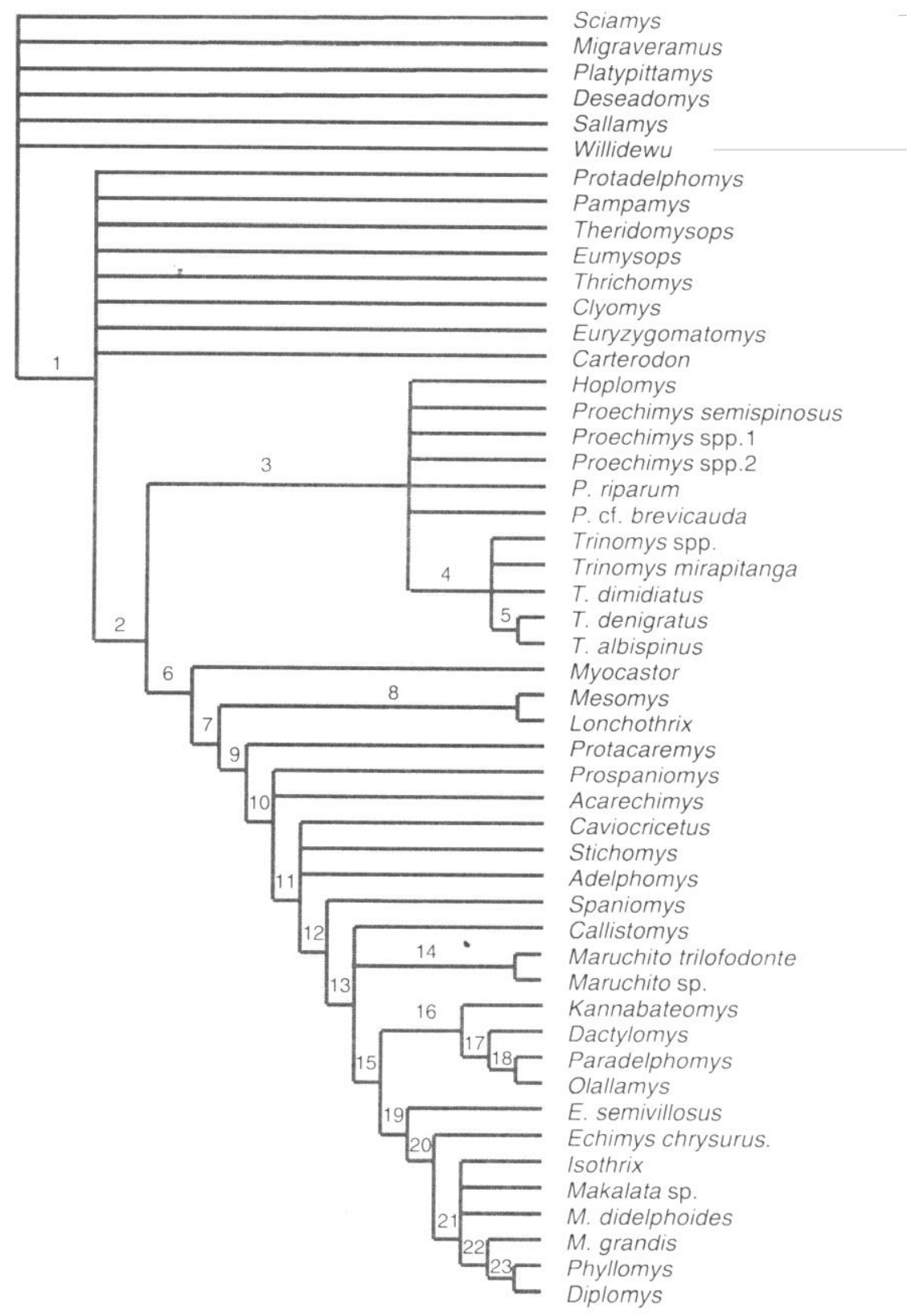

Fig. 5.6. Hipótesis filogenética propuesta por Carvalho y Salles (2004) 
En ese mismo año Frailey y Campbell (2004) describieron lo que consideraban la fauna más antigua de roedores sudamericanos. En la discusión de los resultados los autores propusieron que los Octodontidae evolucionaron a partir de un antecesor más estrechamente relacionado a los Echimyidae que a los Acaremyidae.

En un trabajo donde no se realizó un análisis cladístico, pero sí se propusieron relaciones entre octodontoideos, Vucetich y Vieytes (2006) erigieron el género Plesiacarechimys. Sobre la base de la morfología dentaria y la microestructura del esmalte, concluyeron que Plesiacarechimys podría estar relacionado a Acarechimys, o podría representar un linaje evolutivo diferente dentro de la superfamilia. También defendieron la propuesta de una evolución temprana de octodontoideos compleja, ya que sobre la base de la microestructura del esmalte de los incisivos, Plesiacarechimys sería un octodontoideo basal, y una línea filética diferente de Caviocricetus por un lado, y Sallamys-Protadelphomys- Willidevu por otro.

\subsection{Análisis filogenético}

El objetivo de este análisis es estudiar las relaciones filogenéticas de la mayor parte de los Octodontoidea del Oligoceno tardío-Mioceno medio asignados a la superfamilia Octodontoidea y las relaciones entre éstos con los modernos Octodontidae. Con los resultados obtenidos se intentará aportar al esclarecimiento de patrones evolutivos tempranos de los octodontoideos, así como al origen y antigüedad de la familia Octodontidae.

El análisis filogenético se realizó siguiendo los principios metodológicos del cladismo (Hennig, 1968; Farris, 1983). Esta metodología propone que los taxones se relacionan a través de caracteres derivados compartidos (sinapomorfías) y que los organismos se agrupan naturalmente en grupos monofiléticos. El cladismo utiliza el criterio de máxima parsimonia para establecer las homologías entre los distintos caracteres de los taxones, con el fin de esclarecer ancestralidad común (Farris, 1983; Kitching et al., 1998). El principio de máxima parsimonia sostiene que cuando existen dos o más hipótesis se debe escoger aquella más simple y que posea menor cantidad de inferencias ad hoc (Farris, 1983; Kitching et al., 1998). 


\subsubsection{Taxones incluidos en el análisis}

En el análisis filogenético se incluyeron 39 taxones de nivel especie. Veintiséis corresponden a octodontoideos del Oligoceno tardío-Mioceno medio. Fueron incluidos seis taxones referidos a la familia Octodontidae, tres de los cuales representan taxones extintos, mientras que tres son formas vivientes. Además, fueron incluidos dos taxones vivientes clasificados en la familia Echimyidae.

\section{- Grupo externo:}

Como grupo externo se incluyeron las especies Metaphiomys beadnelli Osborn, 1908 del Oligoceno temprano de África y Phiomys andrewsi Osborn, 1908 del Eoceno tardío-Oligoceno temprano de África (Ver Apéndice 2); con esta última especie se enraizaron los diferentes árboles. Estas dos especies se incluyen dentro de los "Phiomorpha", que es considerado por la mayor parte de las propuestas evolutivas como el grupo hermano o como el stem group de Caviomorpha (Patterson y Wood, 1982; Wood, 1985; Martin, 1994; Nedbal et al., 1994; Marivaux et al., 2001; Mouchaty et al., 2001; Marivaux et al., 2004; Huchon et al., 2007; Blanga-Kanfi et al., 2009; Antoine et al. 2011). El concepto de Phiomys andrewsi y Metaphiomys beadnelli que se utilizó en este análisis es el de Holroyd (1994), quien realizó una revisión exhaustiva de estos roedores africanos. El concepto de Phiomys andrewsi utilizado por Wood (1968) consideraba a esta especie como una agrupación de especímenes morfológicamente distintos que no poseían características propias definidas.

Además, se incluyeron las especies de eretizontoideos extintos Eosteiromys homogenidens y Steiromys detentus del Mioceno temprano de Patagonia ("Edades Mamífero" Colhuehuapense y Santacrucense respectivamente) y el moderno Coendou como grupos externos (Ver Apéndices 2 y 3). Los eretizontoideos son considerados por algunos autores como el grupo hermano del resto de los caviomorfos (Wood y Patterson, 1959; Woods, 1972; Patterson y Wood, 1982; Huchon et al., 1999; Candela, 1999). La elección de los eretizontoideos sirvió para poner a prueba la monofilia de Octodontoidea, aunque de forma parcial ya que en este análisis no están representados la totalidad de los taxones incluidos dentro de la superfamilia Octodontoidea y tampoco se incluyeron representantes de las restantes superfamilias de caviomorfos (Caviodea y Chinchilloidea). 


\section{- Grupo interno:}

En este análisis se incluyeron veintiséis taxones extintos incluidos dentro de Octodontoidea, representando la mayor parte de los octodontoideos del lapso temporal Oligoceno tardío-Mioceno medio (Ver Apéndice 1). Con el objetivo de evaluar las posibles relaciones de estos taxones con los modernos Octodontidae, se incluyeron en este análisis 3 taxones de Octodontidae extintos. Pithanotomys columnaris Ameghino, 1887b (del Plioceno temprano-Pleistoceno del oeste y centro de Argentina) fue elegida debido a que es considerada como un Octodontidae fósil estrechamente relacionado con las formas actuales de Octodontidae (Reig, 1989; Verzi et al., 2002). También se incluyeron Plataeomys brevis Rovereto, 1914, del Plioceno temprano del noroeste de Argentina, y Neophanomys biplicatus Rovereto, 1914, del Mioceno tardío-Plioceno temprano; esta última fue relacionada al moderno Octodontomys gliroides y al linaje miocénico de Chasichimys Pascual, 1967 (Verzi et al., 1999). Dentro de las formas modernas de Octodontidae se incluyeron las especies Octomys mimax, Tympanoctomys barrerae y Octodontomys gliroides. Esta última es una especie de relaciones inciertas dentro de la familia Octodontidae (George y Weir, 1972; Rossi et al., 1990; Gallardo, 1992; Gallardo y Kirsch, 2001; Verzi y Carrin Iglesias, 1999; Verzi et al., 1999), aunque sobre la base de la morfología craneana y dentaria generalizada es considerado el miembro más primitivo de Octodontidae vivientes (Verzi, 2001, 2002).

Los Echimyidae modernos incluidos fueron Kannabateomys amblyonyx $\mathrm{y}$ Echimys sp. Los taxones actuales fueron seleccionados por la disponibilidad del material cráneo-dentario (Apéndice 3).

\subsubsection{Descripción de los caracteres incluidos en el análisis}

En este análisis se estudiaron 116 caracteres en total. Cuarenta son caracteres craneanos, 19 mandibulares y 57 dentarios. De ellos, 18 caracteres fueron tomados de la bibliografía, 13 fueron modificados de la bibliografía y 95 representan caracteres nuevos. Los caracteres que fueron tomados de la bibliografía se indican con el autor y año del trabajo entre paréntesis. Con $*$ se marcan aquellos caracteres con alguna modificación respecto a la publicación original (adición o extracción de estados de carácter, cambios pequeños en la enunciación de los mismo, etc.).

Las homologías de las estructuras dentarias se basaron en homologías primarias (de Pinna, 1991); las mismas se establecen según los criterios de correspondencia, 
similitud y topografía. Ésta es la etapa previa al reconocimiento de las homologías secundarias o sinapomorfías (de Pinna, 1991) que se reconocen a posteriori del análisis cladístico y que presentan un valor filogenético.

La matriz de caracteres resultante se muestra en el Apéndice 4.

\section{- Caracteres dentarios}

1) Grado de hipsodoncia: braquiodonte (0), mesodonte (1), protohipsodonte (2), euhipsodonte (3).

Se define sobre la base un índice de hipsodoncia (ih) dado por la relación entre la altura de la corona y el largo antero-posterior de la misma en el m1 ó m2 (Janis, 1988). El alto de la corona se midió desde la base de la corona del lado labial hasta el ápice del protocónido. El largo antero-posterior de la corona se midió en la superficie oclusal y no en la base o a una altura media de la corona, ya que de esta manera se pueden utilizar dientes incluido en una serie dentaria. Las medidas se toman en dientes sin desgaste. En aquellos taxones de los que no se conocen ejemplares sin desgaste, las medidas se toman en el ejemplar que presenta el menor desgaste disponible. Los estados se definieron de la siguiente manera (Ver tabla 5.1.):

Braquiodonte: ih menor que 0,5. Dientes son de corona baja. Mesodonte: ih entre 0,5 y 1. Las raíces están diferenciadas ya en individuos juveniles. Protohipsodonte alto: ih mayor que 1 y son dientes que forman raíces recién en estadíos adultos. Euhipsodonte: dientes de corona muy alta, sin raíces.

2) Grosor de las crestas en vista oclusal: más angostas que los flexos/idos (0), iguales o más gruesas que los flexos/idos (1).

El grosor de las crestas y flexos/idos se evaluó en la mitad del largo labio-lingual de los mismos. Como en general todas las crestas son delgadas en estados nulos de desgaste, el grosor de las mismas es evaluado en individuos con estados de desgaste relativamente avanzados. En taxones donde no se puedan identificar las crestas (octodóntidos modernos) esta característica no puede ser evaluada y se codifica como

$(-)$.

3) Presencia de DP3: presencia (0), ausencia (1). 
4) Premolares deciduos: reemplazo normal (0), retención (1).

Para codificar este estado de carácter en los Octodontidae modernos se siguió la propuesta de Verzi (1994), quien indicó que estos taxones retienen los premolares de leche.

5) Largo relativo de la hilera de dientes yugales (DP4/4-M3/3 o P4/4-M3/3) respecto del tamaño de la porción anterior del cráneo.

El largo relativo de la hilera dentaria se midió a través de un índice que se calculó dividiendo el largo de la porción anterior del cráneo (L) por el largo de la hilera de dientes yugales (LHD). El largo de la porción anterior del cráneo se interpreta como la distancia desde el borde posterior del alvéolo de los incisivos hasta el borde posterior del M3. Estos índices (Ver tabla 5.2) fueron introducidos en el TNT para su evaluación como datos cuantitativos (Ver sección 5.2.3.3).

6) Posición de las hileras dentarias respecto del eje sagital del cráneo: paralelas (0), poco convergentes (1), muy convergentes (2).

7) Orientación de las hileras dentarias: rectas (0), labialmente cóncavas (1).

8) Superficie oclusal: aterrazada (0), no aterrazada (1).

Este carácter se evalúa en molariformes superiores de individuos juveniles, ya que en individuos adultos el aterrazamiento puede verse muy atenuado por efecto del desgaste dentario. La definición de aterrazamiento corresponde a la de Vucetich y Verzi (1996). Un diente aterrazado sin desgaste presenta las cúspides labiales, en especial el paracono, mucho más desarrollado en altura que las restantes cúspides; además, el anterolofo y el posterolofo son notablemente más bajos que las restantes crestas.

En algunos taxones puede observarse lo que pareciera ser un aterrazamiento mucho menos evidente, que no esta dado por la morfología del diente, sino que se forma por efecto de la oclusión durante la masticación (Prospaniomys, Protacaremys, Acaremys, etc.); a este tipo de "aterrazamiento" se la codifica como estado 1.

9) Hipsodoncia unilateral: conspicua (0), atenuada (1), ausente (2). 
Hipsodoncia asimétrica donde el crecimiento en altura de la corona de los molares superiores se da más rápido en el borde lingual del diente en relación con el labial (Jaeger J.-J., 1989). Esta característica se evalúa en los molares superiores y se encuentra asociada a la inclinación del plano oclusal de las hileras dentarias superiores con respecto al plano de la porción interdentaria del paladar, de manera que las superficies oclusales se orientan externamente.

10) Diferenciación de las cúspides labiales de sus respectivas crestas en dientes superiores: si (0), no (1).

Este carácter se evalúa en individuos juveniles. Se considera que las cúspides se diferencian de las crestas cuando en individuos juveniles se observa un engrosamiento terminal, redondeado y de mayor altura que las crestas. En individuos adultos las cúspides suelen perder la individualización ya que se incorporan a las crestas; sin embargo, en estos ejemplares se sigue observando un engrosamiento correspondiente a las cúspides.

11) Mesolófulo en el DP4: presente (0), ausente (1).

12) Metalofo en el DP4 (Antoine et al., 2011)*: presente y unido lingualmente al brazo anterior del hipocono (0), presente y unido lingualmente al posterolofo (1), fusionado al posterolofo (2).

13) Tamaño del P4 respecto del M1 (Marivaux et al., 2004)*: P4 >ó = M1 (0), P4 $<$ M1 (1).

Marivaux et al. (2004) describieron cuatro estados para este carácter (P4 >ó = M1, P4 < M1, P4 diminuto y P4 ausente); sin embargo, los dos últimos estados de carácter no se encuentran representados en los taxones incluidos en este análisis filogenético, por lo que fueron eliminados. Marivaux et al. no explicaron cómo tomaron las medidas, pero aquí el tamaño se evalúa multiplicando el largo antero-posterior del diente por el ancho a nivel del hipoflexo.

14) Metalofo en el P4: presente (0), ausente (1). 
15) Base del hipocono en el P4: labial al protocono (0), alineado con el protocono $(1)$.

16) Hipoflexo en el P4: ausente (0), incipiente (1), poco desarrollado (2), bien desarrollado (3).

En aquellos taxones donde sólo se observa un pequeño hundimiento en el borde lingual del diente se considera que el hipoflexo se encuentra ausente cuando el hipocono no es conspicuo (Platypittamys) o incipiente cuando el hipocono es conspicuo (Deseadomys). En aquellos casos donde el hipoflexo está presente, pero menos desarrollado que en los molares, se considera que él se encuentra poco desarrollado (Galileomys, Acaremys); en aquellos taxones donde el hipoflexo esta tan desarrollado como en los molares se considera que esta bien desarrollado (Sciamys, eretizóntidos).

17) Proporción largo/ancho de los molares superiores (Marivaux et al., 2004)*: largo mayor que ancho (0), largo = que ancho (1), largo menor que ancho (2).

Las medidas se tomaron en los M1-M2 de individuos juveniles. El ancho se midió en la base de los dientes a nivel del hipoflexo, mientras que el largo se calculó en la superficie oclusal. De esta manera el ancho es una medida fija que no varía con el desgaste; debido a que el largo sí puede variar dependiendo del estado de desgaste, esta medida se evaluó en individuos con estados de desgaste comparables.

18) Secuencia de cierre de los flexos labiales en M1-M2: todos los flexos persistentes (0), posterofoseta cierra antes que la parafoseta (1), para y posterofosetas cierran simultáneamente (2).

Esta característica se evalúa en los M1-M2 de ejemplares juveniles/adultos jóvenes.

19) Forma del ángulo antero-lingual en M1-M3: redondeado (0), formando un ángulo obtuso (1), formando un ángulo recto (2).

Esta característica se evalúa en ejemplares juveniles, ya que la morfología del área del protocono varía según el estado de desgaste del diente. 
20) Base del hipocono en M1-M2: labial al protocono (0), alineado labialmente con el protocono (1).

21) Desarrollo del paracono en M1-M3: más grande que el metacono (0), de igual tamaño que el metacono (1).

El paracono se considera más grande que el metacono cuando se observa una diferencia importante en el volumen de ambas cúspides. Este carácter es inaplicable en aquellos taxones donde no se diferencian las cúspides.

22) Oblicuidad de las crestas en M1-M3: transversales al eje antero-posterior del diente (0), oblicuas en dirección anterolabial-posterolingual (1).

Se considera que las crestas son oblicuas hacia delante cuando todas son oblicuas. Se tienen en cuenta todas las crestas debido a que el protolofo siempre tiene algún grado de oblicuidad, aún cuando las restantes crestas puedan ser transversales.

23) Largo del anterolofo en M1-M3: corto, no llega al mismo nivel que el paracono (0) largo, llega al mismo nivel que el paracono (1).

En los octodóntidos no es posible evaluar este carácter.

24) Forma del anterolofo en M1-M3: convexo hacia delante (0), recto (1).

25) Mesolófulo en M1-M3: presente (0), ausente (1).

26) Metalofo en M1-M3 (Marivaux et al., 2004)*: presente y unido lingualmente al brazo anterior del hipocono (0), presente y unido lingualmente al posterolofo (1), fusionado al posterolofo y formando parte de la cresta posterior (2).

27) Orientación del hipoflexo en M1-M3: oblicuo anteriormente (0), poco oblicuo anteriormente u orientado transversalmente al eje antero posterior del diente (1).

28) Incisivos superiores: comprimidos lateralmente (0), no comprimidos lateralmente (1). 
Se consideran comprimidos cuando el diámetro antero-posterior del diente es por lo menos una vez y media el ancho (Ver tabla 5.3).

29) Presencia de un surco en la cara anterior de los incisivos superiores: sin surco (0), con un surco moderado (1).

30) Superficie de desgaste en los incisivos superiores: desgaste en forma de J o L (0), desgaste plano (1).

Con este carácter se diferencia aquellos taxones que tienen la superficie de desgaste con algún grado de convexidad de aquellos donde la superficie de desgaste es plana, o casi plana.

31) Anterocónido en el dp4 (Marivaux et al., 2004)*: presente (0), ausente (1).

32) Posición del metacónido (o área del metacónido) respecto al protocónido (o área del protocónido) en el dp4: anterior (0), alineado (1), posterior (2).

33) Metalófulido I en el dp4: presente (0), ausente (1).

En los octodóntidos euhipsodontes se consideró que la pared anterior de los molariformes la delimita el metalofúlido I, por ello esta cresta se codificó como presente en los mismos.

34) Metalófulido II en el dp4: conspicuo (0), reducido (1), ausente (2).

35) Mesolófido en el dp4: conspicuo (0), corto (1), pequeño (2), ausente (3).

El mesolófido se codifica como corto cuando forma una cresta que no alcanza el borde labial del diente; en cambio, se codifica como pequeño cuando esta formando un spur o pequeña extensión del ectolófido.

36) Fléxido adicional en la cara labial del dp4: presente (0), ausente (1). 
37) Posición del metacónido respecto al protocónido en el p4: anterior (0), alineado transversalmente (1), posterior (2).

38) Fléxido en la pared del metalofúlido I en el p4: conspicuo (0), poco desarrollado (1); ausente (2).

39) Metalofúlido II en el p4: ausente (0), poco desarrollado (1), conspicuo (2).

Se considera que el metalofúlido II se encuentra poco desarrollado cuando se observa como una pequeña extensión del ectolófido. En Phiomys andrewsi este carácter no pudo ser evaluado y se codificó como (?) debido a que la morfología peculiar del p4 no permitió una identificación certera de las crestas en la mitad anterior del diente.

40) Hipolófido en el p4 (Marivaux et al., 2004): ausente (0), presente (1).

41) Talónido en el p4 (Marivaux et al., 2004)*: subigual (0), más ancho que el trigónido (1).

Marivaux et al. (2004) describieron cuatro estados para este carácter (angosto, menor o igual que el trigónido, poco más ancho que el trigónido y mucho más ancho que el trigónido). Sin embrago, en este trabajo se reconocieron dos estados que son los que se encuentran representados en los taxones incluidos en este análisis.

42) Posición del metacónido (o área del metacónido) respecto al protocónido (o área del protocónido) en m1-m3: anterior (0), alineado (1), posterior (2).

En las especies euhipsodontes no es posible diferenciar las cúspides; sin embargo, las mismas se encuentran en las que aquí se llaman áreas del protocónido y metacónido que son sobre las cuales se evalúa la alineación o no de las mismas.

43) Desarrollo del metalofúlido II en m1-m2: bien desarrollado (0), reducido (1), ausente (2).

Se asume que la segunda cresta en posición de un molar inferior tetralofodonte es el metalofúlido II. Hay que tener en cuenta que el metalofúlido II en general no alcanza el borde lingual del diente, salvo contadas excepciones donde el mismo se encuentra alargado; teniendo en cuenta esta condición se considera como bien 
desarrollado (estado 0) cuando alcanza por lo menos 3/4 partes del ancho de la superficie oclusal. Se considera reducido cuando la cresta está presente pero no alcanza $3 / 4$ partes de la superficie oclusal. No se tiene en cuenta el $\mathrm{m} 3$ ya que es el diente más variable y suele presentar un número menor de crestas que los $\mathrm{m} 1$ y $\mathrm{m} 2$ (e.g. Spaniomys, Prospaniomys, Deseadomys).

44) Posición del entocónido respecto del hipocónido en m1-m3: alineado transversalmente (0), anterior (1).

En las especies euhipsodontes se utilizó el mismo criterio que en el carácter 42 para evaluar este carácter.

45) Extensión del posterolófido en m1-m2: corto (0), largo (1).

46) Hipoconúlido en m1-m3: individualizado (0), no individualizado (1).

47) Extensión posterior del metalofúlido I en m1-m2: presente (0), ausente (1).

La extensión posterior del metalofúlido I es una cresta que nace en la pared posterior del metalofúlido I y que atraviesa la anterofosétida antero-posteriormente.

48) Cúspide accesoria posterior al metalofúlido I y anterior al hipolófido en m1m2: presente (0), ausente (1).

Para que este carácter se codifique como presente tiene que estar representado en al menos el $\mathrm{m} 1$ o el $\mathrm{m} 2$ de un ejemplar. Esto se debe a que dentro de una hilera dentaria puede faltar el $\mathrm{m} 1$ o $\mathrm{m} 2$, o porque en el $\mathrm{m} 1$ pueden no observarse las estructuras dentarias como consecuencia del mayor desgaste de este diente respecto del $\mathrm{m} 2$.

49) Brazo posterior del metacónido en m1-m2: presente (0), ausente (1).

50) Oblicuidad de las crestas en los dientes inferiores: transversales al eje anteroposterior del diente (0), oblicuas en dirección anterolabial-posterolingual (1). 
Se considera que las crestas son oblicuas hacia atrás cuando todas son oblicuas. Este carácter no se encuentra asociado al carácter 22.

51) Orientación del hipofléxido en m1-m3: oblicuo hacia atrás, opuesto al metafléxido o al hipolófido (0), transverso, opuesto al mesofléxido (1) oblicuo hacia adelante, opuesto al anterofléxido (2).

52) Tamaño del $\mathbf{m} 3$ con respecto al $\mathbf{m} 2: \mathrm{m} 3<\mathrm{m} 2(0), \mathrm{m} 3<<\mathrm{m} 2(1), \mathrm{m} 3=\mathrm{m} 2(2)$. Se considera que el m3 es mucho más pequeño que el m2 (estado de carácter 1) cuando es aproximadamente la mitad del tamaño del m2.

53) Microestructura del esmalte de los incisivos inferiores: IPM paralela a las HSB (0), IPM en ángulo agudo respecto de las HSB (45) (1), IPM en ángulo sub-recto respecto de las $\mathrm{HSB}\left(>\mathrm{a} 60^{\circ}\right.$ ) (2), IPM en ángulo recto respecto de las HSB (3).

Se incorporó la microestructura del esmalte de los incisivos inferiores ya que esta característica fue estudiada en un mayor número de taxones en relación a la microestructura del esmalte de los incisivos superiores. Los datos de la microestructura del esmalte fueron tomados de Martin (1992), Vucetich y Vieytes (2006) y discutidos con la Dra. Carolina Vieytes.

54) Incisivos inferiores: comprimidos lateralmente (0), no comprimidos lateralmente (1).

Se consideran comprimidos cuando el alto del diente es por lo menos una vez y media el ancho. El alto del diente se mide como la distancia desde la tangente de la curvatura del diente en su cara externa hasta el mismo punto en la cara interna del diente. El ancho del diente es el ancho de la cara esmaltada del incisivo. No es redundante con la misma característica que en los superiores (e.g. Acaremys). (Ver tabla $5.4)$.

55) Cara anterior de los incisivos inferiores: curva (0), con el borde lingual recto y el labial curvo (1), plana (2). 
Se codificó como curva cuando toda la cara anterior es curva. Se codificó como plana cuando los dos lados son en ángulo recto. Se evalúa en individuos que no sean muy juveniles y cerca del ápice.

56) Longitud de los incisivos inferiores: largos, pasan por debajo del $\mathrm{m} 3$ (0), su base llega hasta el m3 (1), no alcanzan el m3 (2).

\section{- Características craneanas}

57) Extensión posterior de los premaxilares en relación a los nasales (Kramarz, 2001): más cortos (0), iguales (1), más largos (2).

58) Penetración de los frontales entre los nasales y los premaxilares (Kramarz, 2001): no (0), si (1).

59) Forma de los huesos nasales (Wible et al., 2005)*: márgenes laterales paralelos (0), márgenes laterales más anchos anteriormente (1).

Wible et al. (2005) describen tres estados de carácter (anchos anteriormente, casi paralelos y anchos posteriormente); sin embargo, en este trabajo se descartó el estado "anchos posteriormente" ya que no se encontraba representado en ninguno de los taxones analizados.

60) Incisivo incluido en la fosa masetérica rostral: no (0), si (1).

Cuando la tuberosidad del incisivo forma el límite inferior de la fosa masetérica rostral se considera como incisivo excluido de la fosa masetérica rostral.

61) Relación largo/ancho del rostro (Candela, 2000)*.

El largo del rostro se mide desde el borde posterior del alveolo de los incisivos hasta el borde anterior del alveolo del premolar. El ancho del rostro se calcula a nivel del borde anterior de la raíz ventral de la arcada cigomática. Estos valores fueron introducidos en el TNT para su evaluación como datos cuantitativos (Ver tabla 5.5) (Ver sección 5.2.3.3). 
62) Forámenes incisivos: largos (0), cortos (1).

Los forámenes incisivos se consideran largos cuando su largo es igual o mayor a la mitad del largo del diastema.

63) Forámenes incisivos: estrechos (0), anchos (1).

Los forámenes incisivos se consideran anchos cuando su ancho alcanza la mitad del ancho del rostro.

64) Sutura premaxilo-maxilar que intersecta el foramen incisivo (Wahlert, 1985): ubicada en el borde posterior de los forámenes incisivos (0), ubicada aproximadamente en la mitad del largo de los forámenes incisivos (1).

65) Crestas diastemales por detrás de los forámenes incisivos: ausentes (0), presentes (1).

Las crestas diastemales son rebordes del paladar a nivel del diastema que suelen extenderse desde el borde posterior de los forámenes incisivos hasta la porción interdentaria del paladar. No debe confundirse esta estructura con los surcos palatales, que son los surcos que pueden aparecer entre las crestas diastemales.

66) Forma de los huesos frontales: anchos anteriormente y más angostos posteriormente (0), con márgenes laterales rectos (1), angostos anteriormente y más anchos posteriormente (2).

67) Proceso post-orbitario: ausente (0), presente (1).

68) Constitución del proceso post-orbitario: formado sólo por el frontal (0), formado por el frontal y parietal (1).

69) Constricción post-orbitaria: ausente (0), presente (1).

70) Posición de la raíz dorsal de la arcada cigomática (Kramarz, 2001)*: anterior al M1 (0), a nivel del M1 o entre M1-M2 (1). 
Kramarz (2001) describió tres estados para este carácter (anterior al nivel del $\mathrm{m} 1$, entre $\mathrm{m} 1$ y $\mathrm{m} 2$ y posterior al $\mathrm{m} 1$ ). En este trabajo el último de estos estados de carácter no se encontraba representado en ninguno de los taxones analizados, por lo que se eliminó. La posición de la raíz dorsal de la arcada cigomática se toma en punto medio del largo antero-posterior de la misma.

71) Exposición del hueso lagrimal en la rama vertical y/o raíz dorsal de la arcada cigomática: poco expuesto (0), bien expuesto (1).

Se considera que el lagrimal está poco expuesto en la rama vertical y/o raíz dorsal de la arcada cigomática cuando no abarca más de la mitad del ancho anteroposterior de las mismas. Cuando el lagrimal abarca más de la mitad del ancho anteroposterior de la rama vertical y/o raíz dorsal de la arcada cigomática se considera que está bien expuesto.

72) Raíz ventral de la arcada cigomática: diámetros antero-posterior y dorsoventral semejantes (0), diámetro antero-posterior es al menos el doble que el dorsoventral (1).

Como "raíz ventral de la arcada cigomática" se considera a la porción más proximal de la arcada (el área de inserción del músculo masetero superficial + la porción más proximal del área de origen del músculo masetero lateral) ya que son las porciones que se preservan en la mayor parte de los especímenes fósiles.

73) Posición de la raíz ventral de la arcada cigomática en relación al plano de la región interdentaria del paladar: al mismo nivel (0), rama inferior más dorsal (1).

Se considera que la raíz ventral de la arcada cigomática se encuentra al mismo nivel que la región interdentaria del paladar cuando ambas se encuentran en un mismo plano longitudinal o cuando la separación dorso-ventral entre ellas es muy pequeña.

74) Posición de la raíz dorsal de la arcada con respecto a la raíz inferior (Candela, 2000)*: alineada con la raíz inferior (0), por detrás de la raíz inferior (1).

Este carácter se diferencia del utilizado por Candela (2000), porque ella definió tres estados (raíz dorsal ubicada por detrás de la raíz ventral, raíz dorsal ubicada apenas 
por detrás de la raíz ventral, y raíz dorsal ubicada a nivel de la raíz ventral), mientras que en este trabajo se definieron sólo dos estados de carácter.

75) Canal para el pasaje del nervio infraorbitario en el piso del foramen infraorbitario: ausente (0), presente con un reborde lateral poco desarrollado (1), presente con un reborde lateral bien desarrollado (2).

Se considera como estado de carácter 1 cuando el reborde lateral forma apenas un levantamiento que limita el pasaje para el nervio infraorbitario lateralmente.

76) Proceso paraorbital en vista lateral (Verzi, 2001)*: formado por el yugal y el escamoso (0), formado sólo por el escamoso (1), formado sólo por el yugal (2), ausente (3).

A los tres estados de carácter reconocidos por Verzi (2001) se adiciona el estado ausente.

77) Profundidad de la fosa yugal: superficial (0), profunda (1), ausente (2).

Se considera que la fosa yugal es profunda cuando la pared de la misma se ubica en un punto evidentemente interno respecto de la pared lateral de la rama horizontal de la arcada cigomática (Echimys, Acarechimys, Sciamys). Por el contrario, cuando esta diferencia no es evidente se considera que la fosa yugal es superficial (Prospaniomys).

78) Altura de la fosa yugal: baja (0), alta (1).

La fosa yugal se considera alta cuando su altura alcanza al menos la mitad de la altura de la rama horizontal de la arcada cigomática.

79) Largo de la fosa yugal: corta (0), larga (1).

La fosa yugal se considera larga cuando su largo es igual o mayor que la mitad del largo de la rama horizontal de la arcada cigomática.

80) Posición del foramen etmoidal (Wahlert, 1991): a nivel del M3 (0), a nivel de la unión M2-M3 (1), a nivel de la mitad del M2 a la mitad del M1 (2). 
81) Foramen esfeno- palatino: foramen ubicado por delante del M1 (0), foramen ubicado a nivel del M1 (1), foramen ubicado por detrás del M1 (2), ranura ubicada a lo largo del DP4-M1 (3), ranura ubicada a lo largo de M1-M2 (4).

82) Forámenes palatinos posteriores: ubicados entre palatinos y maxilares a nivel del M1 (0), ubicados en los maxilares a nivel del M1 (1), ubicados en los maxilares a nivel del P4 (2).

Los forámenes palatinos posteriores son pares y generalmente son de mayor tamaño que los restantes forámenes que se encuentran en el paladar.

83) Forámenes palatinos posteriores: bien desarrollados (0), pequeños (1).

84) Posición de las narinas posteriores: abren a nivel del M3 (0), abren a nivel del M2 (1).

85) Vacuidades esfenopalatinas (Meng et al., 2003): ausente (0), presente (1).

86) Forámenes buccinador y masticatorio (Wahlert, 1991): separados (0), unidos en una única abertura (1).

87) Foramen oval (Wahlert, 1991): limitado por el aliesfenoides (0), limitado posteriormente por la bula auditiva (1).

88) Posición de los parietales en el techo craneano (Wahlert, 1991)*: alcanzan o están cerca del occipucio (0), retraídos y no están cerca del occipucio (1).

Wahlert (1991) reconoció tres estados para este carácter (parietal alcanza el occipucio, poco retraído del occipucio, no se encuentra cerca del occipucio). Sin embargo, en este trabajo se reconocieron sólo dos estados, ya que son los que se pudieron observar en los roedores incluidos en el análisis filogenético.

89) Extensión ventral del proceso lateral del supraoccipital (Kramarz, 2001): excede el borde dorsal de la bula (0), se extiende hasta el borde dorsal de la bula (1). 
90) Extensión dorsal de la exposición mastoidea (Kramarz, 2001): no excede el borde dorsal de la bula (0), excede el borde dorsal de la bula (1), mastoideo expuesto en el techo craneano (2).

Se considera el estado 2 sólo si el proceso mastoideo está expuesto en la porción dorsal del cráneo.

91) Exposición mastoidea en el occipucio: no (0), si (1).

Para que el mastoideo se considere expuesto en el occipucio debe encontrarse en el mismo nivel que los huesos occipitales. Los casos como Myocastor, Eumysops y los equímidos modernos, donde el mastoideo se ubica en otro plano respecto de los huesos occipitales, se toman como no expuestos.

92) Forma de la exposición mastoidea (Kramarz, 2001): cóncavo (0), plano (1), convexo (2).

93) Exposición dorsal del petroso: ausente (0), presente (1).

94) Desarrollo del seno epitimpánico (Kramarz, 2001): pequeño (0), bien desarrollado (1).

Kramarz (2001) no definió un seno epitimpánico pequeño y uno grande. Aquí se consideró que un seno epitimpánico pequeño no se evidencia como una estructura separada del resto de las estructuras de la bula timpánica. En cambio, se encuentra bien desarrollado cuando aumenta su tamaño y se distingue como una estructura separada del resto de las estructuras de la bula timpánica.

95) Receso hipotimpánico: pequeño (0), inflado (1), hipertrofiado (2).

Se considera que el receso hipotimpánico es pequeño en bulas pequeñas, como por ejemplo en la de los equímidos vivientes. Cuando se observan bulas de mayor tamaño en relación al tamaño del cráneo se consideran que están infladas (Octodontomys, Octomys), mientras que aquellas bulas que presentan un volumen extremadamente grande en relación al tamaño del cráneo se considera que están hipertrofiadas (Tympanoctomys). 
96) Foramen accesorio por debajo del MAE: ausente (0), presente y pequeño (1), presente y bien desarrollado (2).

97) Procesos paraoccipitales: ventralmente orientados, con el extremo libre y separado de la bulla y ventral a ella (0) ventralmente orientados, con el extremo adherido a la bula (1), cortos, lateralmente orientados y completamente unidos a la bula (2), cortos, ventralmente orientados y completamente unidos a la bula (3).

- Características mandibulares

98) Largo del diastema: más corto que la distancia de p4(dp4)-m1 (0), igual o más largo que la distancia de p4(dp4)-m1 (1).

(Ver tabla 5.6)

99) Foramen mentoniano: presente (0), ausente (1).

100) Posición del foramen mentoniano: anterior al nivel más bajo del diastema (0), al nivel del nivel más bajo del diastema o poco por detrás del mismo (1), por debajo del premolar (2).

Las mandíbulas se orientan de forma que la hilera dentaria se encuentre horizontal.

101) Posición del borde anterior de la muesca para el tendón del mmma: ubicada por delante del m1 (0), ubicada por debajo del m1 (1), ubicada por detrás del m1 (2).

102) Posición de la muesca para el tendón del mmma con respecto a la altura del cuerpo mandibular (Candela, 2000)*: por encima de la mitad de la altura mandibular (0), aproximadamente en la mitad de la altura mandibular (1).

Las mandíbulas se orientan de forma que la hilera dentaria se encuentre horizontal. Candela (2000) definió tres estados para este carácter (muy por encima de la mitad de altura mandibular, por encima de la mitad de la altura mandibular, en la mitad 
de la altura mandibular). En este trabajo los estados de carácter 0 y 1 de Candela se unificaron para definir el estado de carácter 0.

103) Origen de la cresta masetérica (Verzi, 2001): incluye la muesca para la inserción del tendón del músculo masetero medial (0), posterior a la muesca para la inserción del tendón del músculo masetero medial (1).

104) Orientación de la cresta masetérica: ventralmente dirigida desde sus orígenes (0), postero-ventralmente dirigida desde sus orígenes (1).

Las mandíbulas se orientan de forma que la hilera dentaria esté horizontal. La cresta masetérica se encuentra ventralmente dirigida cuando el ángulo que forma su porción más anterior con respecto al eje antero- posterior de la mandíbula es de $45^{\circ} \mathrm{o}$ mayor.

105) Surco antero-dorsal de la fosa masetérica: ausente (0), poco desarrollado (1), muy desarrollado (2).

Cuando el surco que limita la fosa masetérica antero-dorsalmente se encuentra bien desarrollado, se extiende desde el borde posterior de la muesca hasta la base de la apófisis coronoides y es profundo, al menos en su porción más ventral. El mismo puede ser poco profundo.

106) Profundidad de la porción anterior de la fosa masetérica (Candela, 2000): superficial, o incluso plana (0), moderadamente profunda (1), muy profunda (2).

La fosa masetérica corresponde a la porción de la mandíbula que se encuentra dorsal a la cresta masetérica. En este carácter se evalúa la porción anterior de la misma ya que es la que presenta las diferentes morfologías; en sus $2 / 3$ posteriores la fosa masetérica es generalmente superficial o plana.

107) Límite anterior de la fosa masetérica: posterior al m1 (0), debajo del m1 (1), por delante del m1 (2). 
108) Base del proceso coronoides: anterior al $\mathrm{m} 3$ (0), a nivel del $\mathrm{m} 3$ (1)

Cuando se encuentra en el límite entre el m2-m3 se codifica como estado 1.

109) Margen anterior del proceso coronoides (Pérez, 2010b): convexo (0), recto (1), cóncavo (2).

110) Escotadura mandibular: profunda (0), poco profunda o ausente (1).

La escotadura mandibular es el espacio que se ubica entre el proceso coronoides y el cóndilo mandibular.

111) Altura del extremo del proceso coronoides respecto de la posición del cóndilo mandibular (Pérez, 2010b): ubicado a la misma altura que el cóndilo (0), ubicado ventralmente al cóndilo (1).

112) Fosa retromolar (Candela, 2000): esencialmente posterior al $\mathrm{m} 3$ (0), posterolateral al m3 y algo extendida anteriormente (1).

113) Altura del cóndilo mandibular (Wible et al., 2005): más alto que la superficie oclusal (0), alto como la altura oclusal (1).

114) Proceso mentoniano: poco desarrollado (0), bien desarrollado (1).

El proceso mentoniano es la proyección ventral del extremo posterior de la sínfisis mandibular. Se considera que el proceso mentoniano está poco desarrollado cuando es una saliente muy suave o cuando directamente no se observa ninguna saliente.

115) Límite posterior de la sínfisis mandibular: anterior al p4/dp4 (0), a nivel del $\mathrm{p} 4 / \mathrm{dp} 4$ (1), posterior al p4/dp4 (2).

116) Desarrollo de la repisa pterigoidea (Candela, 2000): poco desarrollada (0), bien desarrollada (1), muy bien desarrollada (2). 
La repisa pterigoidea es la proyección ventro-lingual de la región póstero-ventral de la región angular.

\subsubsection{Tratamiento de los caracteres}

\subsubsection{Ordenamiento de los caracteres}

Todos los caracteres fueron tratados con peso $=1$. Veintiún caracteres fueron tratados como aditivos ya que contienen estados anidados o porque son caracteres multiestados donde uno de los estados es "ausente" (caracteres 1, 6, 9, 16, 19, 34, 35, $38,39,43,53,56,57,75,92,100,101,105,106,116,117)$. Los caracteres se pueden tratar como aditivos en aquellos casos donde se observa secuencia lógica de transformación; esto no implica que se asuma una direccionalidad en el cambio de los caracteres (polarización), o sea que no hay que conocer el estado ancestral de este carácter. Al no hacer aditivos aquellos caracteres donde se observa una secuencia lógica de transformación se estaría perdiendo información filogenética relevante del grupo.

\section{Secuencia lógica de transformación de algunos caracteres:}

- Carácter 1 (grado de hipsodoncia): para pasar del estado de carácter "braquiodonte" a "euhipsodonte", o a la inversa, es necesario que existan estados de carácter intermedios que sean "mesodonte" y "protohipsodonte".

- Carácter 6 (hileras dentarias): para pasar del estado de carácter "hileras dentarias paralelas" a "muy convergentes", o a la inversa, es necesario que exista un estado de carácter intermedio que sea "hileras dentarias poco convergentes".

- Carácter 9 (hipsodoncia unilateral): para pasar del estado de carácter "hipsodoncia unilateral conspicua" a "hipsodoncia unilateral ausente", o a la inversa, es necesario que exista un estado de carácter intermedio que sea "hipsodoncia unilateral atenuada".

- Carácter 16 (hipoflexo en el P4): para pasar del estado de carácter "hipoflexo bien desarrollado" a "hipoflexo ausente", o a la inversa, es necesario que existan estados de carácter intermedios que sean "incipiente" o "hipoflexo poco desarrollado".

- Carácter 19 (forma del ángulo antero-lingual en los molares superiores): para pasar del estado de carácter "ángulo antero-lingual redondeado" a "formando un ángulo recto", o a la inversa, es necesario que exista un estado de carácter intermedio que sea “ángulo antero-lingual oblicuo". 
- Carácter 34 (metalofúlido II en el dp4): para pasar del estado de carácter "metalofúlido II conspicuo" a "metalofúlido II ausente", o a la inversa, es necesario que exista un estado de carácter intermedio que sea "metalofúlido II reducido".

- Carácter 35 (mesolófido en el dp4): para pasar del estado de carácter "mesolófido conspicuo" a "mesolófido ausente", o a la inversa, es necesario que exista un estado de carácter intermedio que sea "mesolófido reducido".

-- Carácter 38 (fléxido en la pared del metalofúlido I en el p4): para pasar del estado de carácter "conspicuo" a "ausente", o a la inversa, es necesario que exista un estado de carácter intermedio que sea "poco desarrollado".

- Carácter 39 (metalofúlido II en el p4): para pasar del estado de carácter "conspicuo" a "ausente", o a la inversa, es necesario que exista un estado de carácter intermedio que sea "poco desarrollado".

- Carácter 43 (metalofúlido II en m1-m2): para pasar del estado de carácter "conspicuo" a "ausente", o a la inversa, es necesario que exista un estado de carácter intermedio que sea "reducido".

- Carácter 53 (microestructura del esmalte de los incisivos inferiores): para pasar del estado de carácter "IPM paralela a las HSB" a "IPM en ángulo recto respecto de las HSB", o a la inversa, es necesario que existan estados de carácter intermedio que sean "IPM en ángulo agudo respecto de las HSB (45)" y "IPM en ángulo sub-recto respecto de las $\operatorname{HSB}\left(>\mathrm{a} 60^{\circ}\right) "$

- Carácter 56 (longitud de los incisivos inferiores): para pasar del estado de carácter “incisivos pasan por debajo del m3" a "incisivos no alcanzan el m3", o a la inversa, es necesario que exista un estado de carácter intermedio que sea "base del incisivos llega hasta el m3".

- Carácter 57 (extensión posterior de los premaxilares en relación a los nasales): para pasar del estado de carácter "más cortos" a "más largos", o a la inversa, es necesario que exista un estado de carácter intermedio que sea "iguales".

- Carácter 75 (canal para el pasaje del nervio infraorbitario): para pasar del estado de carácter "ausente" a "presente con un reborde lateral bien desarrollado", o a la inversa, es necesario que exista un estado de carácter intermedio que sea "presente con un reborde lateral poco desarrollado". 
- Carácter 92 (forma de la exposición mastoidea): para pasar del estado de carácter "cóncavo" a "convexo", o a la inversa, es necesario que exista un estado de carácter intermedio que sea "plano".

- Carácter 100 (posición del foramen mentoniano): para pasar del estado de carácter "anterior al nivel más bajo del diastema" a "por debajo del premolar", o a la inversa, es necesario que exista un estado de carácter intermedio que sea "al nivel del nivel más bajo del diastema o poco por detrás del mismo".

- Carácter 101 (posición del borde anterior de la muesca para el tendón del mmma): para pasar del estado de carácter "ubicada por delante del m1" a "ubicada por detrás del m1", o a la inversa, es necesario que exista un estado de carácter intermedio que sea "ubicada por debajo del m1".

- Carácter 105 (surco antero-dorsal de la fosa masetérica): para pasar del estado de carácter "ausente" a "muy desarrollada", o a la inversa, es necesario que exista un estado de carácter intermedio que sea "poco desarrollada".

- Carácter 106 (profundidad anterior de la fosa masetérica): para pasar del estado de carácter "superficial, o incluso plana" a "muy profunda", o a la inversa, es necesario que exista un estado de carácter intermedio que sea "moderadamente profunda".

- Carácter 116 (límite posterior de la sínfisis mandibular): para pasar del estado de carácter "anterior al p4/dp4" a "posterior al p4/dp4", o a la inversa, es necesario que exista un estado de carácter intermedio que sea "a nivel del p4/dp4".

- Carácter 117 (desarrollo de la repisa pterigoidea): para pasar del estado de carácter "poco desarrollada" a "muy bien desarrollada", o a la inversa, es necesario que exista un estado de carácter intermedio que sea "bien desarrollada".

\subsubsection{Datos faltantes}

Los datos faltantes, pueden deberse a datos ausentes por distintas causas (material fósil incompleto) o datos inaplicables. Sea cual fuera el caso, los programas tratan a los dos tipos de datos faltantes de la misma manera (carácter ausente). Los datos inaplicables son aquellos caracteres que no tienen un equivalente topológico con el cual establecer una homología. Es importante tratar de disminuir el número de datos 
inaplicables, lo que puede solucionarse, por ejemplo, aumentándose el número de estados de carácter.

Los datos faltantes son considerados un problema en paleontología, ya que los fósiles suelen estar incompletos y esto puede expresarse en relaciones entre taxones difíciles de resolver, es decir en árboles consenso poco resueltos. Sin embargo, hay que tener presente que la falta de resolución puede deberse al conflicto entre caracteres y/o a datos faltantes (Kearney, 2002), por lo que no es necesario eliminar taxones ni caracteres conflictivos del análisis. Pol y Escapa (2009) desarrollaron un método, llamado Iterpcr, con el cual es posible identificar los taxones (o clados) conflictivos y así evaluar las causas subyacentes que producen la inestabilidad filogenética (datos faltantes, conflictos entre caracteres o ambas). Esta metodología se aplica al programa TNT y fue utilizada en este trabajo.

\subsubsection{Datos cuantitativos}

Algunos caracteres cuantitativos fueron ingresados en la matriz de datos morfológicos y analizados como tales, sin la necesidad de crear estados de carácter arbitrarios. Goloboff et al. (2006) propusieron la forma de tratar caracteres continuos con el programa TNT; estos tipos de caracteres son tratados preferentemente como aditivos, de manera que el programa puede aplicar la optimización de Farris (1970) y de Goloboff (1993) y analizarlos sin la necesidad de discretizar los estados de carácter arbitrariamente.

\subsubsection{Análisis cladístico:}

El programa utilizado para los análisis filogenéticos fue el TNT en su versión 1.1 (Goloboff et al., 2008). Como la cantidad de taxones incluidos en los análisis es grande $(\mathrm{N}>25)$ y los caracteres no son del todo congruentes, se realizó una búsqueda heurística de cálculo con el fin de hallar los árboles más parsimoniosos (los que requieran del menor número de pasos). Los análisis se realizaron con el algoritmo TBR (Tree Bisection Reconection) con 1000 replicaciones y salvando 10 árboles por replicación. Se realizaron 2 ciclos de TBR ya que en la primera corrida no se pudieron hallar todos los árboles más parsimoniosos. Del primer ciclo de TBR resultaron 289 árboles más parsimoniosos de 484 pasos $(\mathrm{CI}=0,342$ y $\mathrm{RI}=0$, 529); estas topologías se 
encontraron en 97 de las 357 réplicas. En el segundo ciclo de TBR se utilizaron los árboles guardados en la memoria y se encontraron 360 árboles más parsimoniosos de 484 pasos cada uno. El consenso estricto de todos los árboles obtenidos en este análisis se muestra en la figura 5.7:

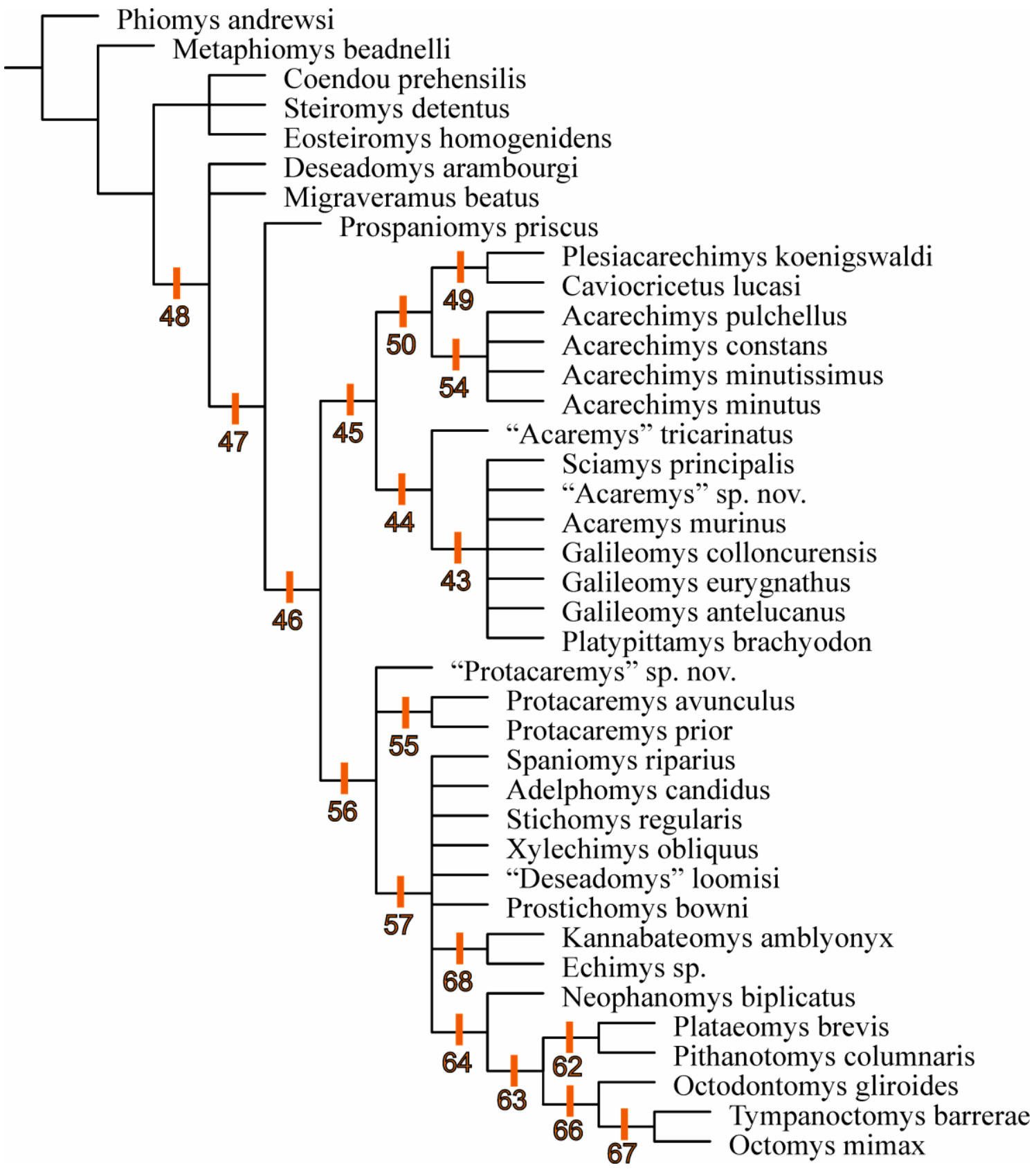

Fig. 5.7. Consenso estricto de 360 árboles más parsimoniosos de 484 pasos. En naranja se enumeran los nodos

En el cladograma consenso (Fig. 5.7) se observa que dentro de Octodontoidea Migraveramus beatus, Deseadomys arambourgi y Prospaniomys priscus presentan una posición basal dentro de la superfamilia. $P$. priscus representa el grupo hermano de una 
dicotomía que agrupa, por un lado, a las formas fósiles que han sido vinculadas al origen de los Octodontidae (Acaremyidae, Plesiacarechimys, Acarechimys) y a Caviocricetus lucasi, y por otro lado agrupa a las formas fósiles que han sido agrupadas dentro de la subfamilia "Adelphomyinae" junto con las formas modernas de Echimyidae y Octodontidae.

Los octodontoideos del Oligoceno tardío- Mioceno medio tradicionalmente vinculados a los modernos Octodontidae (Platypittamys, Migraveramus, Acaremys, Sciamys, Acarechimys) o cuya relación con éstos nunca ha sido testeada (e.g. Cavocricetus) no tienen relación directa con los representantes actuales de la familia Octodontidae. Por el contrario, los resultados sugieren que estos taxones conforman, junto con otros octodontoideos del Oligoceno tardío- Mioceno medio, un extenso stem group del clado constituido por los octodóntidos del Mioceno tardío- reciente, los equímidos vivientes incluidos en este análisis y los taxones fósiles tradicionalmente asignados a la familia Echimyidae (Wood y Patterson, 1959; Patterson y Pascual, 1971; Patterson y Wood, 1982; Vucetich y Verzi, 1991).

Patterson y Wood (1982) propusieron que Migraveramus beatus representaba un octodóntido ancestral de morfología dentaria similar a la de Platypittamys. Por otro lado, Wood y Patterson (1959) propusieron que las dos especies de Deseadomys representarían los antecesores de lo que ellos llamaron “Adelphomys group". En este análisis se concluye que Migraveramus beatus, junto con Deseadomys arambourgi, representan las líneas evolutivas más tempranamente divergentes dentro de la superfamilia que no dejaron descendientes (Fig. 5.7).

La posición filogenética y relaciones de Prospaniomys priscus obtenidas en este análisis también se oponen a la de las propuestas previas (Fig. 5.7). Ameghino (1902) interpretó a este taxón como ancestro directo de Spaniomys e incluyó ambos dentro de la familia Echinomyidae, en la que incluía taxones que hoy se agrupan en distintas superfamilias. Posteriormente, las propuestas sobre posición y relaciones de parentesco de Prospaniomys han ido cambiando, aunque siempre este taxón fue incluido dentro de la familia Echimyidae (Ameghino, 1904; Patterson y Pascual, 1968; Patterson y Wood, 1982; Kramarz, 2001, 2004; Vucetich et al., 2010b). Más recientemente, Arnal y Kramarz (2010) concluyeron que Prospaniomys presenta numerosos caracteres craneanos compartidos con los Octodontidae modernos, pudiendo representar una forma 
basal dentro de esta familia. De este análisis se desprende que Prospaniomys tiene una posición basal dentro de Octodontoidea en su conjunto, representando el grupo hermano de los restantes octodontoideos analizados excluyendo a Migraveramus beatus y Deseadomys arambourgi (nodo 47). Este nodo está sustentado por 2 sinapomorfías (Ver Apéndice 5). Por lo descripto anteriormente resulta novedosa la posición de Prospaniomys priscus y, además, refleja la evidente necesidad de seguir investigando las relaciones de este género en un contexto filogenético más amplio que el del presente análisis.

El siguiente nodo [nodo 46 (Fig. 5.7)] incluye a los restantes octodontoideos analizados, que en todos los árboles se agruparon en dos grandes clados; este nodo se encuentra sustentado por 5 sinapomorfías (incisivos inferiores comprimidos lateralmente, huesos nasales con márgenes laterales más anchos anteriormente, extensión ventral del proceso lateral del supraoccipital excede el borde dorsal de la bula timpánica, receso hipotimpánico pequeño y posición del borde anterior de la mmma ubicada por delante del m1). Uno de estos clados [nodo 45 (Fig. 5.7)] incluye la mayor cantidad de especies fósiles que han sido interpretadas como relacionadas con los Octodontidae modernos (Acarechimys, Sciamys, Acaremys y Platypittamys). Cuatro sinapomorfías sustentan este nodo (incisivos superiores comprimidos lateralmente, huesos frontales angostos anteriormente y más anchos posteriormente, canal para el pasaje del nervio infraorbitario limitado lateralmente por un reborde poco desarrollado y escotadura mandibular poco profunda o ausente). Dentro de este clado se observan dos agrupaciones: por un lado, se agrupan las especies de Acarechimys y Plesiacarechimys koenigswaldi + Caviocricetus lucasi (nodo 50), mientras que el nodo 44, sustentado por dos sinapomorfías (Ver Apéndice 5), agrupa a las especies asignadas a los Acaremyidae por Vucetich y Kramarz (2003), corroborando la monofilia de la familia. Sin embargo, dentro de este clado se encuentra anidado Platypittamys brachyodon (Fig. 5.7), considerado como un Acaremyidae por Wood (1949), pero excluido de esta familia por Vucetich y Kramarz (2003). En el análisis de la figura 5.7 los acarémidos forman una politomía que no pudo ser resuelta. Dentro del clado que queda delimitado en el nodo 49 (Fig. 5.7) se observa que Plesiacarechimys koenigswaldi y Caviocricetus lucasi se encuentran más relacionados entre sí que con cualquier otro octodontoideo conocido. Caviocricetus fue propuesto por Vucetich y Verzi (1996) como un octodontoideo incertae sedis. Por otro lado, Plesiacarechimys fue propuesto por Vucetich y Vieytes 
(2006) como un octodontoideo primitivo emparentado con Acarechimys, o representando un linaje independiente dentro de la superfamilia. Los resultados de este análisis apoyan en cierta forma la última de estas dos hipótesis propuestas por Vucetich y Vieytes. Las sinapomorfías que definen este clado corresponden con la presencia de mesolófulo en los molariformes superiores, metalofo fusionado al posterolofo en el DP4, microestructura del esmalte de los incisivos inferiores con la IPM en ángulo subrecto respecto de la HSB, mmma ubicada aproximadamente en la mitad de la altura mandibular y surco que limita la fosa masetérica antero-dorsalmente ausente.

Por otro lado, en el nodo 54 se corrobora la monofilia del género Acarechimys y se corrobora la propuesta de Vucetich et al. (2010b) quienes incluyeron a Protacaremys pulchellus Ameghino dentro de Acarechimys. Patterson y Wood (1982) no ubicaron explícitamente a las especies de Acarechimys en ninguna familia dentro de los octodontoideos, aunque las compararon con las del género Protacaremys (que era incluido dentro de los Echimyidae). Pascual (1967) consideró a Acarechimys como un equímido relacionado a la ancestralidad de Eumysops y Chasichimys. En la figura 5.7 se observa que las relaciones entre las distintas especies de Acarechimys no pudieron ser resueltas.

El segundo gran clado (nodo 56) está conformado por el clado de los equímidos vivientes incluidos en este análisis y el clado de los Octodontidae del Mioceno tardíoReciente. Junto con ellos se agrupan las formas fósiles tradicionalmente asignadas a la subfamilia "Adelphomyinae" (Wood y Patterson, 1959; Patterson y Pascual, 1968; Patterson y Wood, 1982; Vucetich y Verzi, 1991). Sin embargo, este análisis no permite esclarecer las relaciones de estos últimos. Las 4 sinapomorfías que sustentan este nodo corresponden con hileras dentarias superiores poco convergentes anteriormente, crestas en los molares superiores oblicuas en dirección anterolabial-posterolingual, mmma ubicada aproximadamente en la mitad de la altura mandibular y una porción anterior de la fosa masetérica poco profunda o incluso plana. Aunque no resulta posible precisar la posición de "Protacaremys" sp. nov. las dos especies nominales $P$. prior y $P$. avunculus se agrupan por compartir 2 sinapomorfías (Ver Apéndice 5). Ameghino (1902) describió a Protacaremys como antecesor del género Acaremys, aunque luego fue relacionado a los Echimyidae por Wood y Patterson (1959) y Patterson y Wood (1982), y más específicamente a los “Adelphomyinae” por Kramarz (2001). El resultado de este 
análisis indica que Protacaremys es la forma más basal de este clado, contradiciendo la propuesta de Ameghino, pero no justifica su inclusión dentro de los Echimyidae.

En el nodo 64 se agrupan los Octodontidae modernos. Las sinapomorfías que justifican esta agrupación son la presencia de dientes protohipsodontes y una mmma ubicada por encima de la mitad de la altura mandibular. Dentro de esta familia, Neophanomys biplicatus representa el taxón más basal; Plataeomys brevis y Pithanotomys columnaris se agrupan en un clado que es el grupo hermano de los octodóntidos vivientes (Fig. 5.7). Octodontomys gliroides representa el octodóntido viviente más basal, estando Tympanoctomys barrerae y Octomys mimax íntimamente relacionados.

Por lo tanto, más allá de los objetivos puntuales puestos a prueba en esta tesis, del análisis filogenético se desprenden una gran cantidad de resultados novedosos, muchos de los cuales se oponen a las interpretaciones previas.

Análisis con Iterpcr: Este es un método iterativo, desarrollado por Pol y Escapa (2009), que compara tripletes de taxones dentro de los árboles más parsimoniosos para detectar agrupamientos inestables (clados o ramas terminales). Posteriormente, en estos agrupamientos se estudia la optimización alternativa de caracteres con el fin de identificar aquellos caracteres responsables de la inestabilidad (por conflicto de caracteres) o los que puedan mejorar la resolución de las ramas si llegaran a escorearse (datos faltantes). Aplicando la metodología de Iterpcr se identificaron aquellos taxones cuyas relaciones dentro de los octodontoideos soportaban distintas posiciones y por lo tanto oscurecían las relaciones de los restantes octodontoideos (Ver apartado 5.2.3.2).

De este análisis surgió que "Deseadomys” loomisi, Galileomys? colloncurensis y las especies del género Acarechimys representan los taxones problemáticos. Esto puede deberse a la gran cantidad de datos faltantes que presentan (estos taxones se encuentran representados en general por restos muy fragmentarios). Además, en G.? colloncurensis los caracteres $1,2,8,9,14,16,20,21$ y 45 resultaron conflictivos ya que soportaban posiciones alternativas en los distintos árboles más parsimoniosos (generalmente se trata de caracteres polimórficos o datos faltantes), mientras que en " $D$." loomisi fueron los caracteres 2, 43, 45, 49, 55, 99, 106 y 107. Por lo tanto si se ignoran las posiciones de estos taxones el consenso se resuelve de la manera que se observa en la figura 5.8: 


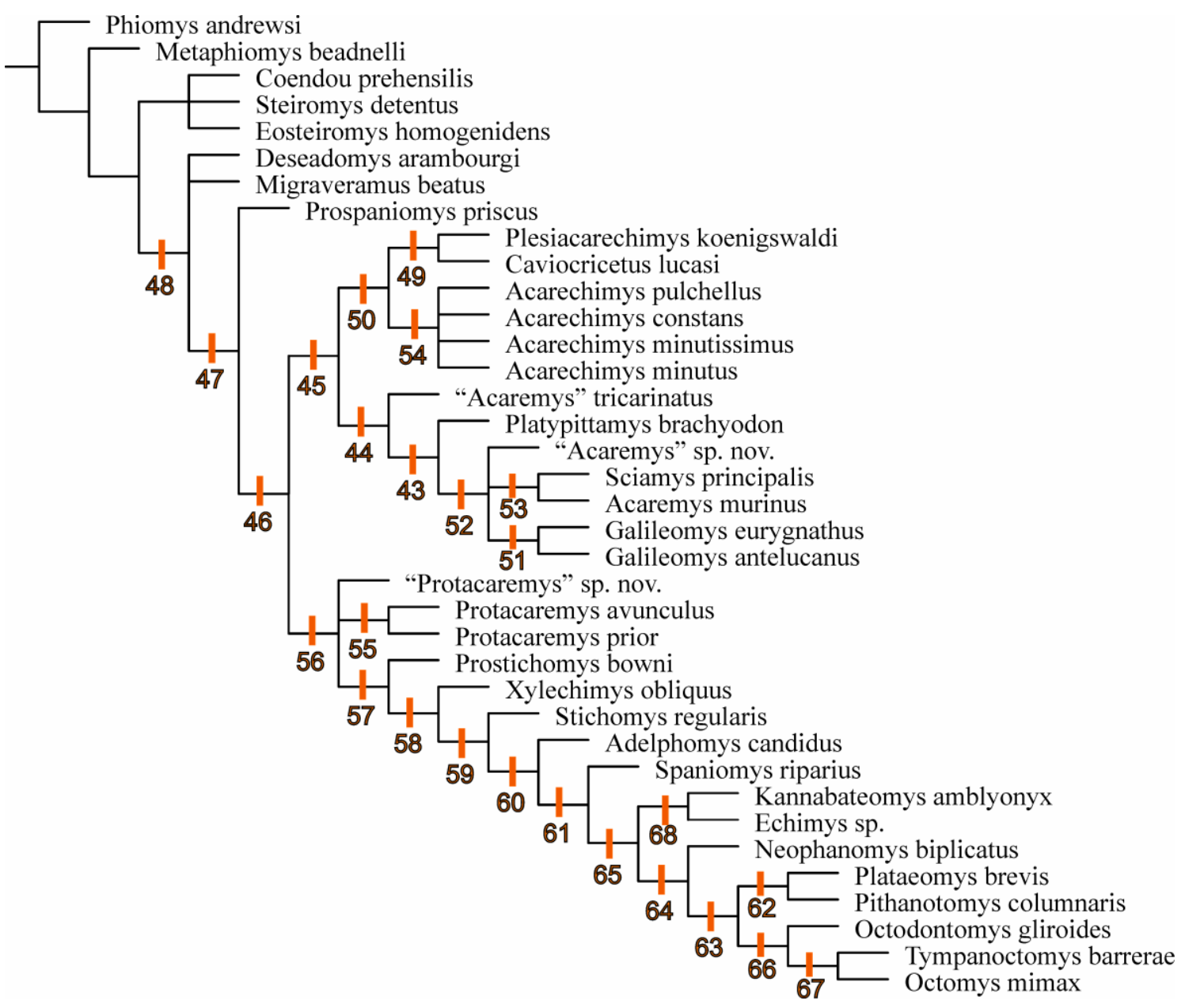

Fig. 5.8. Consenso estricto de 360 árboles más parsimoniosos de 484 pasos donde se ignora la posición de "D." loomisi y G.? colloncurensis. En naranja se enumeran los nodos

A pesar de que el clado que agrupa a las especies de Acarechimys se encuentra soportado, las relaciones entre las cuatro especies no pudieron resolverse (Fig. 5.8). Esto significa que las mismas son igualmente inestables, lo que normalmente se debe a la falta de información dentro del clado.

Ignorando la posición de G.? colloncurensis es posible determinar las relaciones internas dentro del clado de los Acaremyidae. Como resultado se observa que $G$. antelucanus y $G$. eurygnathus se encuentran íntimamente relacionados, al igual que Sciamys principalis y Acaremys murinus. Estos dos clados y "Acaremys" sp. nov. se unen en una politomía. El grupo hermano de estas formas es Platypittamys brachyodon y como el taxón más basal de la familia se reconoce a "Acaremys" tricarinatus.

Ignorando la posición de "Deseadomys" loomisi se resuelven las relaciones entre los taxones tradicionalmente agrupados en la subfamilia "Adelphomyinae". Éstos resultan ser sucesivos grupos hermanos del clado formado por los equímidos vivientes 
incluidos en este análisis y el clado de los Octodontidae, siendo Spaniomys riparius el más próximo a este nodo.

Uno de los resultados más destacables es la relación de las formas modernas de Echimyidae y Octodontidae dentro de la superfamilia. En todos los árboles se recuperaron las mismas relaciones: los Echimyidae y Octodontidae modernos se encuentran más estrechamente relacionados entre sí que con cualquier octodontoideo del Oligoceno-Mioceno medio, concordando con las propuestas de Vucetich y Kramarz (2003) y Arnal et al. (2010).

5.2.5 Soporte de ramas: el soporte de ramas de un grupo es el resultado de la interacción entre caracteres que favorecen esa agrupación y caracteres que la contradicen (Goloboff et al., 2003). En este estudio se utilizaron distintos métodos de soporte de ramas con el fin de evaluar la confianza de los datos obtenidos en el análisis cladístico y determinar cuán bien sustentados se encuentran los nodos en los árboles resultantes. Los métodos utilizados fueron el soporte de Bremer absoluto, Bootstrap standard y re-muestreo simétrico.

Cabe aclarar que los soportes fueron evaluados en los consensos donde se ignoró la posición de G. colloncurensis y "D." loomisi ya que anteriormente fueron identificados como taxones problemáticos; en general, taxones conflictivos y/o incompletos pueden reducir considerablemente el valor de los soportes.

5.2.5.1 Soporte de Bremer: El soporte de Bremer absoluto mide la cantidad de pasos extra necesarios para que un nodo no se recupere en el consenso estricto (Bremer 1988, 1994).

En la figura 5.9 se observan los valores de soporte de Bremer que, en líneas generales, son bajos. El nodo más basal que agrupa a Octodontoidea presenta un soporte de 1. Prospaniomys priscus y el nodo 46 (Fig. 5.7 y 5.8) que separa los dos grandes clados de octodontoideos presentan soportes de 2. El clado que agrupa a los Acaremyidae, Acarechimys, Plesiacarechimys y Caviocricetus presenta un soporte de 1; todos los nodos de este clado tienen soportes muy bajos, a excepción de los que agrupan a Sciamys-Acaremys y Plesiacarechimys-Caviocricetus que presentan soportes de 2. El nodo que agrupa al otro gran clado de octodontoideos [nodo 56 (Fig. 5.8 y 5.8)] también 
presenta un soporte de 1. Sin embargo dentro de este clado se encuentran los nodos mejor soportados dentro de la superfamilia: los nodos que agrupan a las dos especies de Protacaremys y el que agrupa a los equímidos vivientes tienen valores de 3, mientras que los nodos 57, 58, 65 (el que agrupa a las formas modernas de octodontoideos), 62 (octodóntidos fósiles) y 66 (octodóntidos vivientes) presentan soportes de 2.

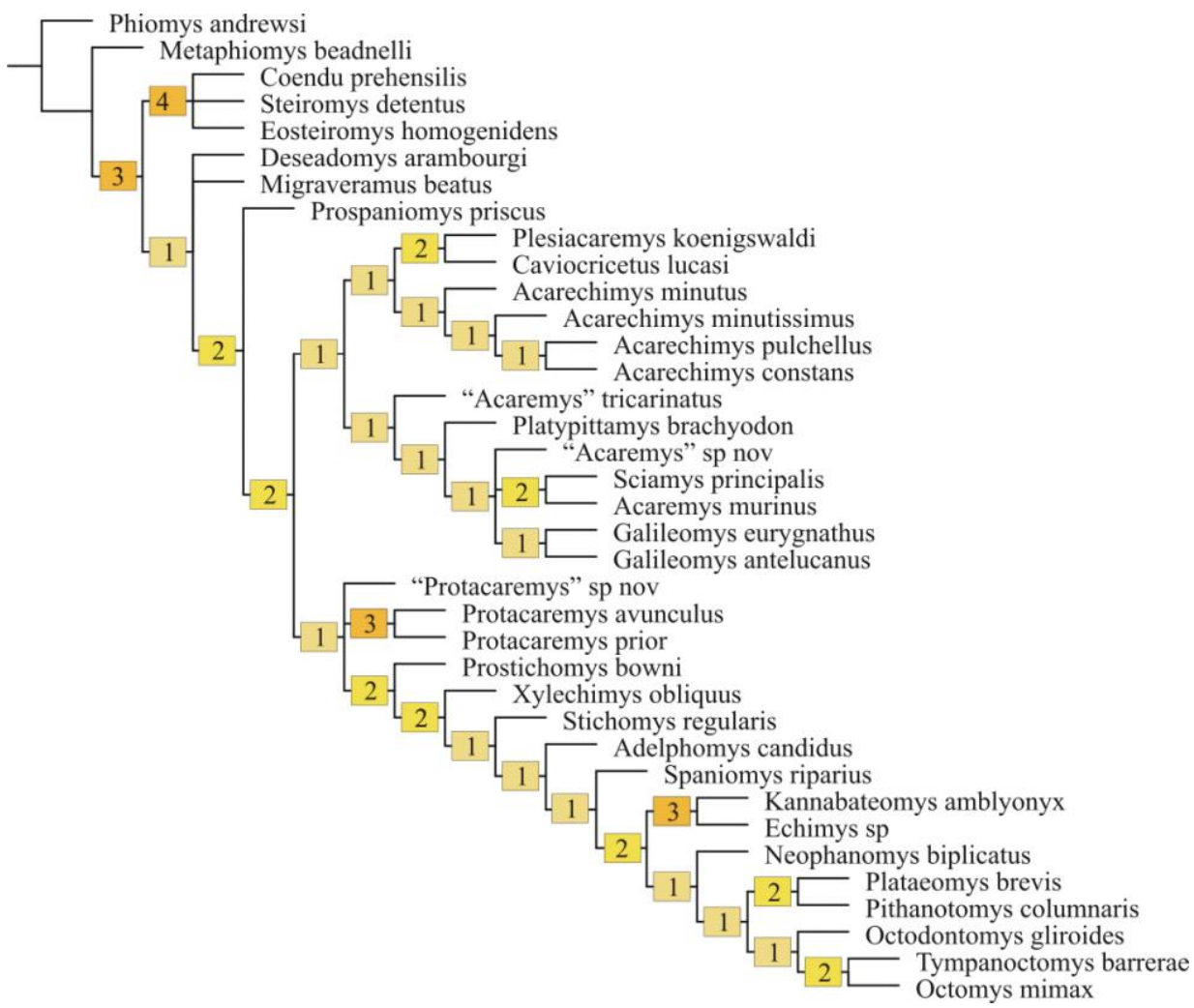

Fig. 5.9. Cladograma mostrando los valores de soporte de Bremer ignorando la posición de $G$. colloncurensis y "D." loomisi

5.2.5.2 Bootstrap standard: se lo reconoce como uno de los procedimientos de aleatorización para medir soportes de rama. Esta metodología mide la probabilidad de recuperar una agrupación dada una matriz determinada (Efron, 1979; Felsenstein, 1985); consiste en muestrear los caracteres de una matriz aleatoriamente con reemplazo, para formar matrices de igual tamaño (y con los mismos taxones) con algunos caracteres replicados y otros que desaparecen; esto se repitió 10000 veces. Así se calcularon los árboles óptimos de cada matriz y se evaluó el grado de conflicto entre ellos por medio de mediciones de frecuencia:

Frecuencias absolutas: obtienen los consensos de mayoría para todos los árboles generados. El valor de Bootstrap de una rama va a depender del porcentaje de veces que aparezca esa rama entre los árboles (cuanto mayor es el número de caracteres que 
apoyen una agrupación, mayor será la probabilidad de que la misma aparezca en los óptimos de cada matriz).

Diferencia de frecuencias (GC): mide la diferencia de frecuencia entre el grupo y su grupo contradictorio más frecuente.

Al igual que lo ocurrido para el soporte de Bremer, los nodos del consenso reducido tienen valores de soportes bajos. Los nodos más basales de Octodontoidea tienen los valores más bajos, mientras que los nodos que agrupan a Sciamys-Acaremys, las dos especies de Galileomys, Protacaremys y los nodos que agrupan a las formas modernas de Octodontidae y Echimyidae tienen los soportes más altos.

Sin embargo, hay que tener presente que el Bootstrap provee un soporte unilateral, ya que los grupos que se recuperan están indudablemente bien soportados, aunque la inversa no es cierta.

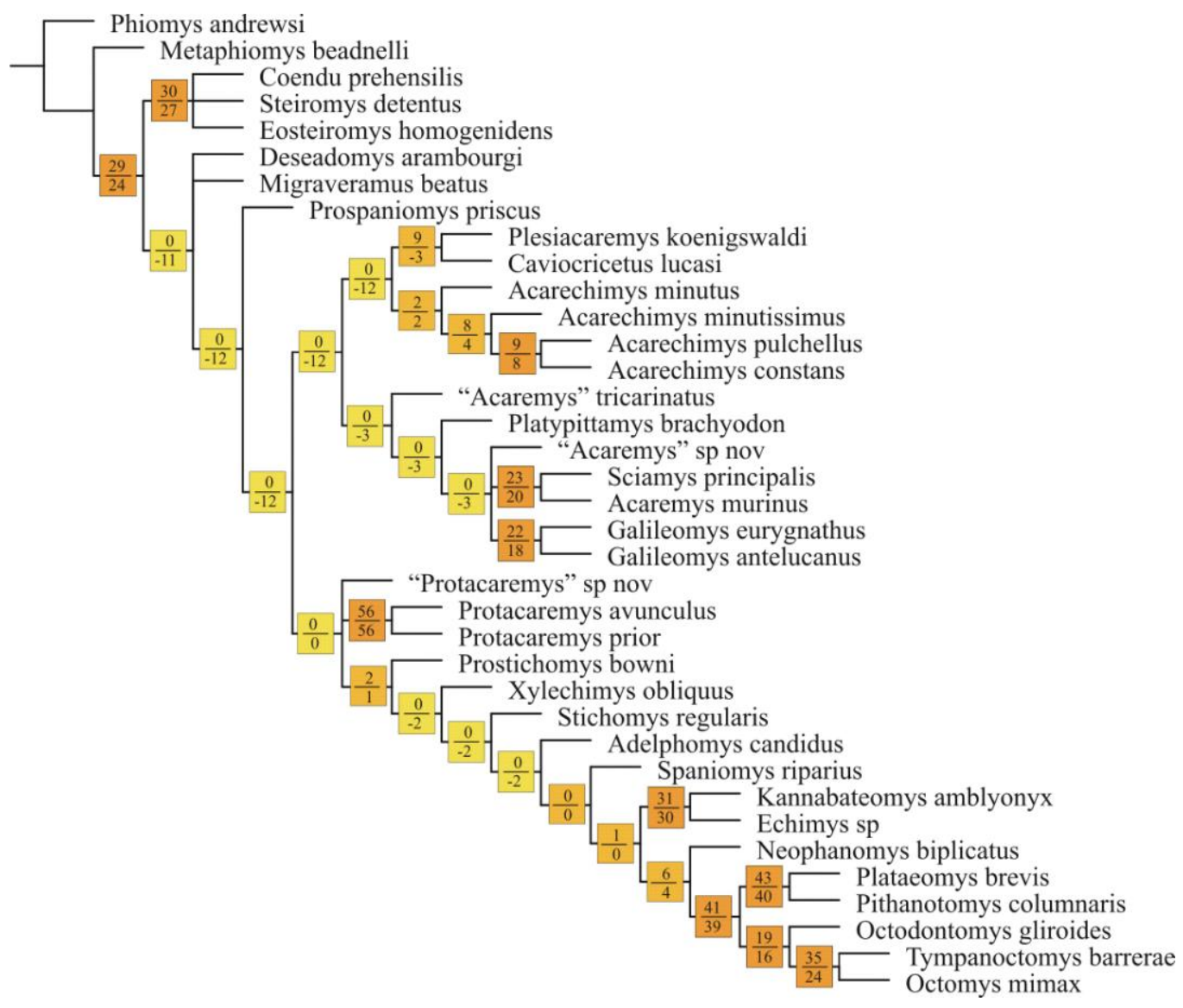

Fig. 5.10. Cladograma mostrando los valores de Bootstrap ignorando la posición de $\boldsymbol{G}$. colloncurensis y "D.".loomisi. Los valores superiores indican las frecuencias absolutas y los inferiores la diferencia de frecuencias (GC) 
5.2.5.3 Re-muestreo simétrico: en esta metodología, a diferencia del Bootstrap (y del Jacknife, que no fue calculado en este análisis), la medición de los soportes no se ve afectada por los pesos o costos de transformación de los caracteres y por los caracteres no informativos (Goloboff et al., 2003). En casos como el presente, donde el set de datos presenta caracteres aditivos y no aditivos, es recomendable usar esta metodología.

Al igual que el Bootstrap los resultados se expresan en frecuencias absolutas y diferencias de frecuencias (GC) entre el grupo y el grupo más contradictorio.

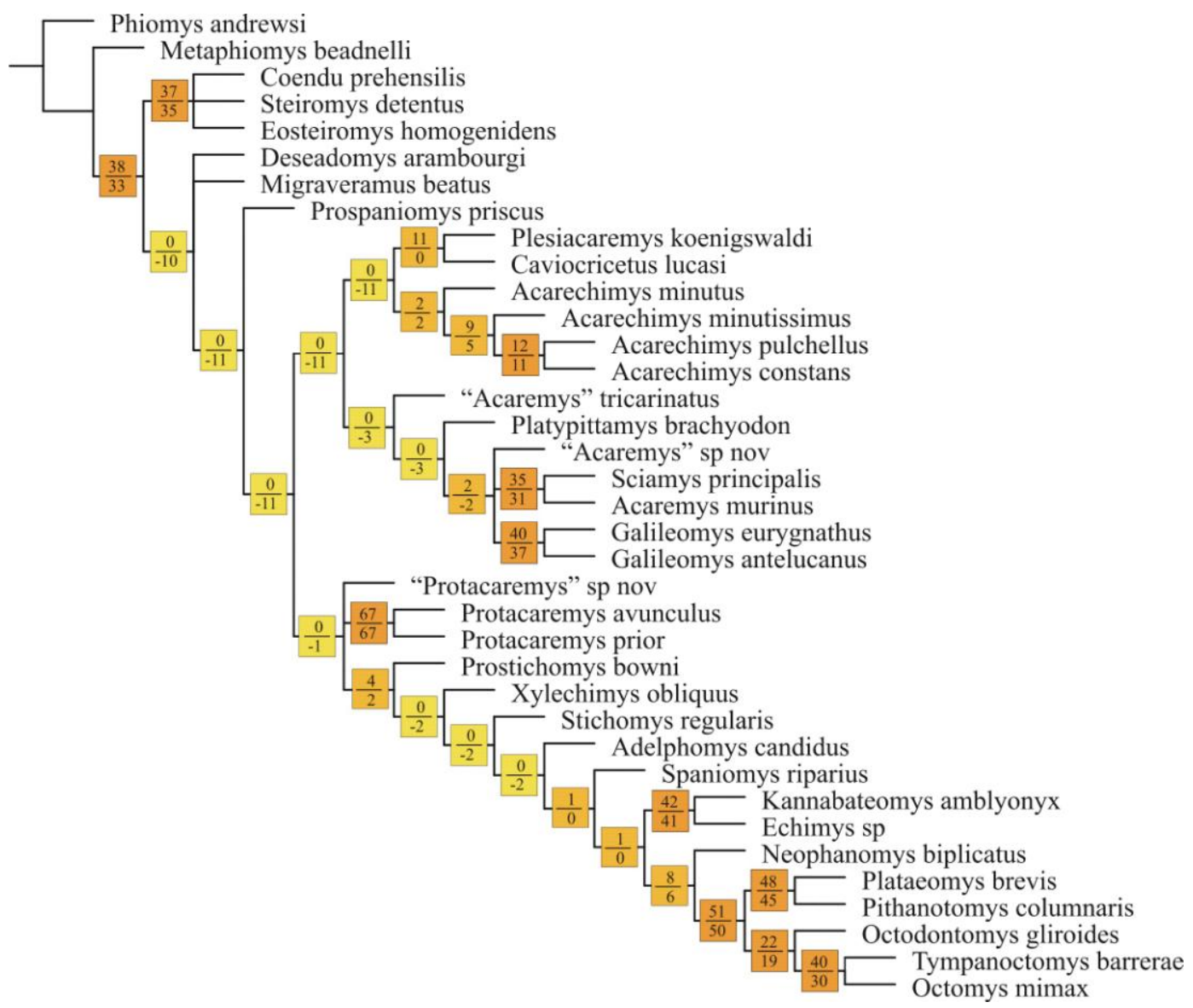

Fig. 5.11. Cladograma mostrando los valores de soporte de nodos según re-muestreo simétrico ignorando la posición de G. colloncurensis y "D." loomisi. Los valores superiores indican las frecuencias absolutas y los inferiores la diferencia de frecuencias (GC)

Al igual que los resultados obtenidos para las otras medidas de soportes, con el re-muestreo simétrico se observan valores bajos de soporte.

Los resultados obtenidos anteriormente concuerdan en presentar soportes generales bajos; sin embargo, las 3 metodologías coinciden en indicar cuáles son los nodos mejor soportados. Aplicando los tres métodos se observó que el soporte del nodo 
que agrupa a los octodontoideos presentaba valores muy bajos. En cambio, los valores de soporte de los nodos 47 y 48 (Fig. 5.7 y 5.8) fueron de los más altos utilizando soporte de Bremer, mientras que con Bootstrap standart y re-muestreo simétrico estos nodos presentaron soportes bajos. Estos valores de soporte bajos pueden estar expresando la presencia de una gran cantidad de caracteres homoplásicos, y, además, reflejan la evidente necesidad de seguir investigando las relaciones de los octodontoideos basales en un contexto filogenético más amplio.

Lo mismo ocurrió con los nodos 57 y 58 (Fig. 5.7 y 5.8). Sin embargo, las 3 metodologías coincidieron en que las agrupaciones formadas por PlesiacarechimysCaviocricetus, Sciamys-Acaremys, Protacaremys, equímidos vivientes y octodóntidos tienen los soportes más altos.

\subsubsection{Clasificación}

En este trabajo se tomaron escasas decisiones taxonómicas formales, como consecuencia de los bajos soportes que se encontraron en la mayor parte de los nodos; es necesario corroborar estos resultados en futuros análisis agregando información faltante o mayor cantidad de taxones y caracteres. Sin embargo, en la figura 5.12 se muestran los resultados obtenidos en cuanto a la recuperación de las familias tradicionalmente reconocidas de Octodontoidea.

Los resultados presentados anteriormente permiten corroborar la monofilia de la familia Acaremyidae representando una línea filética independiente y sin relación con los octodóntidos modernos, concordando con la propuesta de Vucetich y Kramarz (2003). Sin embargo, estos autores sólo incluyeron dentro de la familia a los géneros Galileomys, Acaremys y Sciamys. De acuerdo a los resultados de este análisis filogenético, Platypittamys se encuentra anidado dentro del clado que agrupa a los acarémidos, siendo "A." tricarinatus el acarémido de posición más basal. Teniendo en cuenta la semejanza en la morfología dentaria y craneana, numerosos autores han planteado la relación de Platypittamys con Acaremys y Sciamys, y su inclusión dentro de un mismo grupo (Wood (1949), Wood y Patterson (1949), Landry (1957), Patterson y Wood (1982)). Por lo expuesto anteriormente, se redefine aquí a Acaremyidae como el grupo que incluye al antecesor común más cercano de "Acaremys" tricarinatus y Acaremys murinus y todos sus descendientes (Fig. 5.12). 




Fig. 5.12. Consenso estricto mostrando las familias de Octodontoidea

Con respecto a la especie descripta como "Acaremys" sp. nov. en la revisión sistemática (Capítulo 4), su asignación al género Acaremys no se encuentra sustentada por los resultados del análisis filogenético, por lo que su inclusión a éste u otro género requiere estudios adicionales. Del mismo modo, tampoco se haya sustentada la asignación genérica de "Acaremys" tricarinatus, requiriendo la erección formal de un nuevo género para incluir a esta especie.

En este análisis se corroboró la monofilia de un clado integrado por las especies de Acarechimys más Plesiacarechimys koenigswaldi y Caviocricetus lucasi. Estos resultados son parcialmente coincidentes con la propuesta de Vucetich y Vieytes (2006) sobre la posible relación entre Plesiacarechimys y Acarechimys. En base a los 
resultados obtenidos en este análisis se propone entonces el nombre Acarechimyidae al nuevo taxón de rango familia integrado por las especies Acarechimys minutus, A. minutissimus, A. constans, A. pulchellus, Plesiacarechimys koenigswaldi y Caviocricetus lucasi, que representa el grupo hermano de la familia Acaremyidae. Estos resultados deberán ser puestos a prueba en futuros análisis más inclusivos con el fin de corroborar la existencia de esta agrupación e indagar las relaciones de la misma con los restantes linajes de octodontoideos.

Por otro lado, la subfamilia "Adelphomyinae" resultó ser parafilética, tal como propusieron Vucetich y Kramarz (2003), Carvalho y Salles (2004) y Arnal et al. (2010) en distintos análisis cladísticos. Además, se corroboró la monofilia del género Protacaremys, aunque la nueva especie "Protacaremys" sp. nov. debe ser referida a un nuevo género, ya que no se agrupa con $P$. prior ni $P$. avunculus. Se rechaza la monofilia del género Deseadomys, como consecuencia de que "D." loomisi resulta muy lejanamente emparentado a la especie tipo D. arambourgi (Fig. 5.7, 5.8 y 5.12).

Es interesante destacar que estos resultados sugieren que Echimyidae, en tanto incluya a las formas fósiles del Oligoceno-Mioceno medio, es un grupo parafilético, y posiblemente resulte necesaria una re-definición de dicho grupo.

\subsubsection{Evolución de los caracteres tradicionalmente utilizados para diferenciar Octodontidae y Echimyidae}

En este apartado se discute, a la luz de los resultados del análisis filogenético en el consenso donde no se aplicó iterpcr, la evolución de algunos de los caracteres que tradicionalmente han sido utilizados para diferenciar a los Octodontidae y Echimyidae fósiles (Wood y Patterson, 1959; Patterson y Wood, 1982; Verzi et al., 1994).

- $\quad$ Reemplazo de los premolares de leche (correspondiente al carácter 4 del análisis cladístico): Tradicionalmente la retención de los premolares de leche fue considerada como una característica de los Echimyidae post-deseadenses que los diferenciaba de los Octodontidae (Wood y Patterson, 1959; Patterson y Wood, 1982). Sin embargo, Verzi (1999) señaló que los Octodontidae vivientes también retienen los premolares de leche.

Los resultados de este análisis indican que el recambio normal de los premolares de leche es una condición plesiomórfica para los Octodontoidea. La condición derivada de este carácter (retención de los premolares de leche) es una sinapomorfía del nodo que 
agrupa a los octodontoideos (a excepción de Deseadomys arambourgi y Migraveramus beatus) (Fig. 5.13). No obstante, se observa una reversión de este carácter a una condición plesiomórfica en los Acaremyidae.

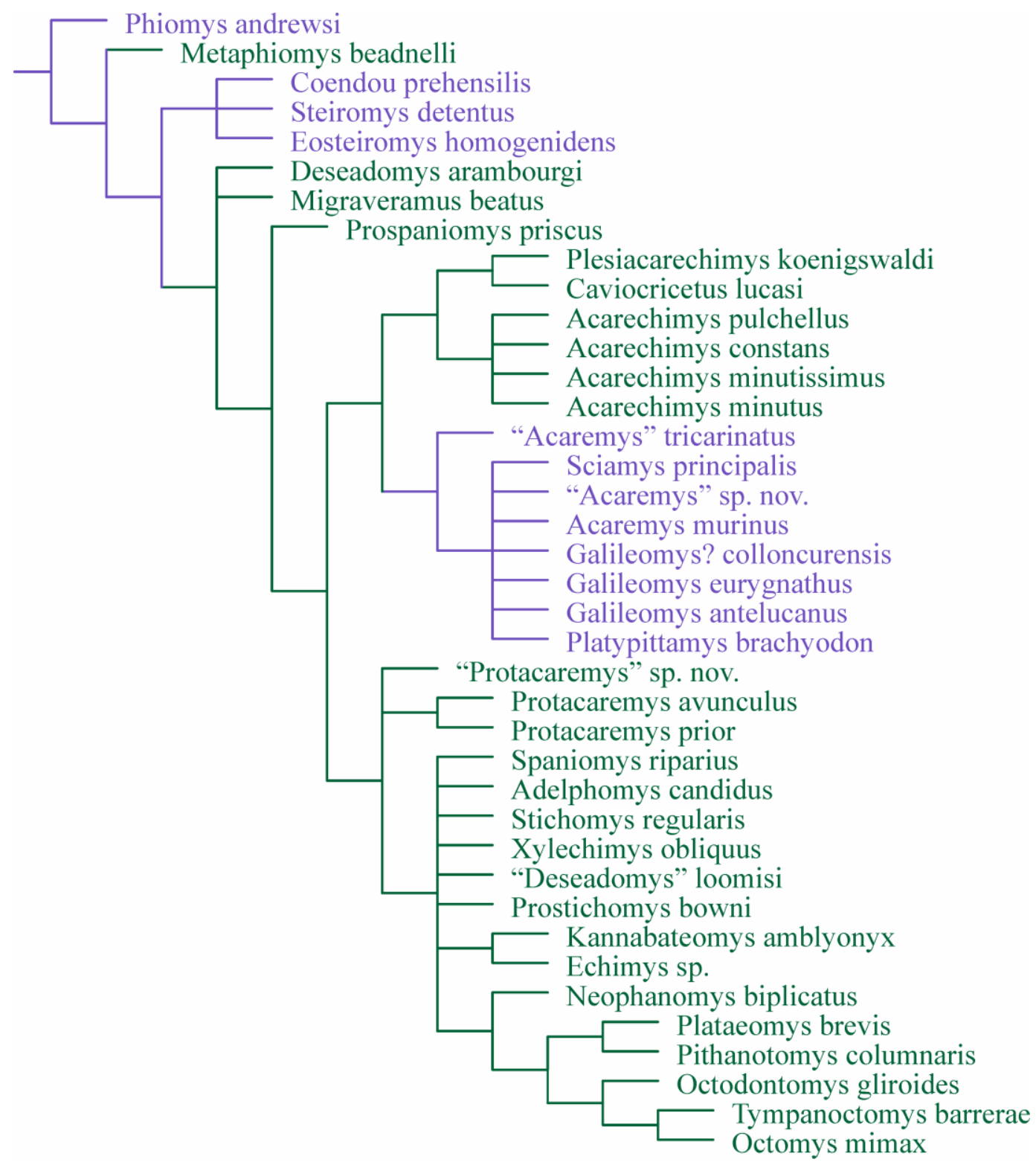

Fig. 5.13. Optimización del recambio de los premolares de leche. En azul se muestra el estado 0 (reemplazo normal) y en verde el estado de carácter 1 (retención de los premolares de leche)

Este carácter es de importancia desde el punto de vista evolutivo, pero resulta difícil comprender su reversión en los acarémidos ya que implica un costo evolutivo grande y sin una lógica explicable. En las figuras 5.7 y 5.8 se observa que la posición de Prospaniomys priscus es la responsable de que en los acarémidos se "requiera" una reversión como la propuesta. Adicionalmente, si se tiene en cuenta que los soportes de 
los nodos más basales de la superfamilia son muy bajos, no es difícil imaginar un escenario evolutivo donde los acarémidos presenten una posición más basal dentro de los octodontoideos y puedan haber estado menos relacionados a las formas que retienen los premolares deciduos.

Esta propuesta tendría que ponerse a prueba en un análisis donde se incluyan todos los octodontoideos conocidos que recambian normalmente los premolares (e.g. Sallamys, Protadelphomys y Willidevu). De cualquier manera, queda claro que este carácter es compartido tanto por los octodóntidos como por la mayoría de los taxones tradicionalmente clasificados como Echimyidae y no es informativo para la comprensión de la diferenciación de los octodóntidos.

- Oblicuidad de los lofos (correspondiente al carácter 22 del análisis cladístico): Wood y Patterson (1959) propusieron que los Echimyidae fósiles se caracterizaban por presentar crestas oblicuas al eje antero-posterior del diente, a diferencia de los Octodontidae que presentaban las crestas perpendiculares.

En la figura 5.14 se advierte que como condición plesiomórfica en los octodontoideos (y en los histricognatos en general) los lofos se disponen transversalmente al eje antero-posterior del diente, mientras que la oblicuidad de los mismos representa una sinapomorfía ambigua del nodo que agrupa a las especies fósiles tradicionalmente asignadas a Echimyidae y las formas modernas de Echimyidae y Octodontidae (Fig. 5.14). Sin embargo, dentro de este nodo esta condición se corroboró sólo para los octodontoideos fósiles tradicionalmente asociados a los Echimyidae y en el equímido viviente Kannabateomys, mientras que en los Octodontidae este carácter no pudo ser evaluado (mayormente debido a la extrema simplificación oclusal) y Echimys presenta una reversión hacia una condición plesiomórfica de este carácter (Fig. 5.14). 


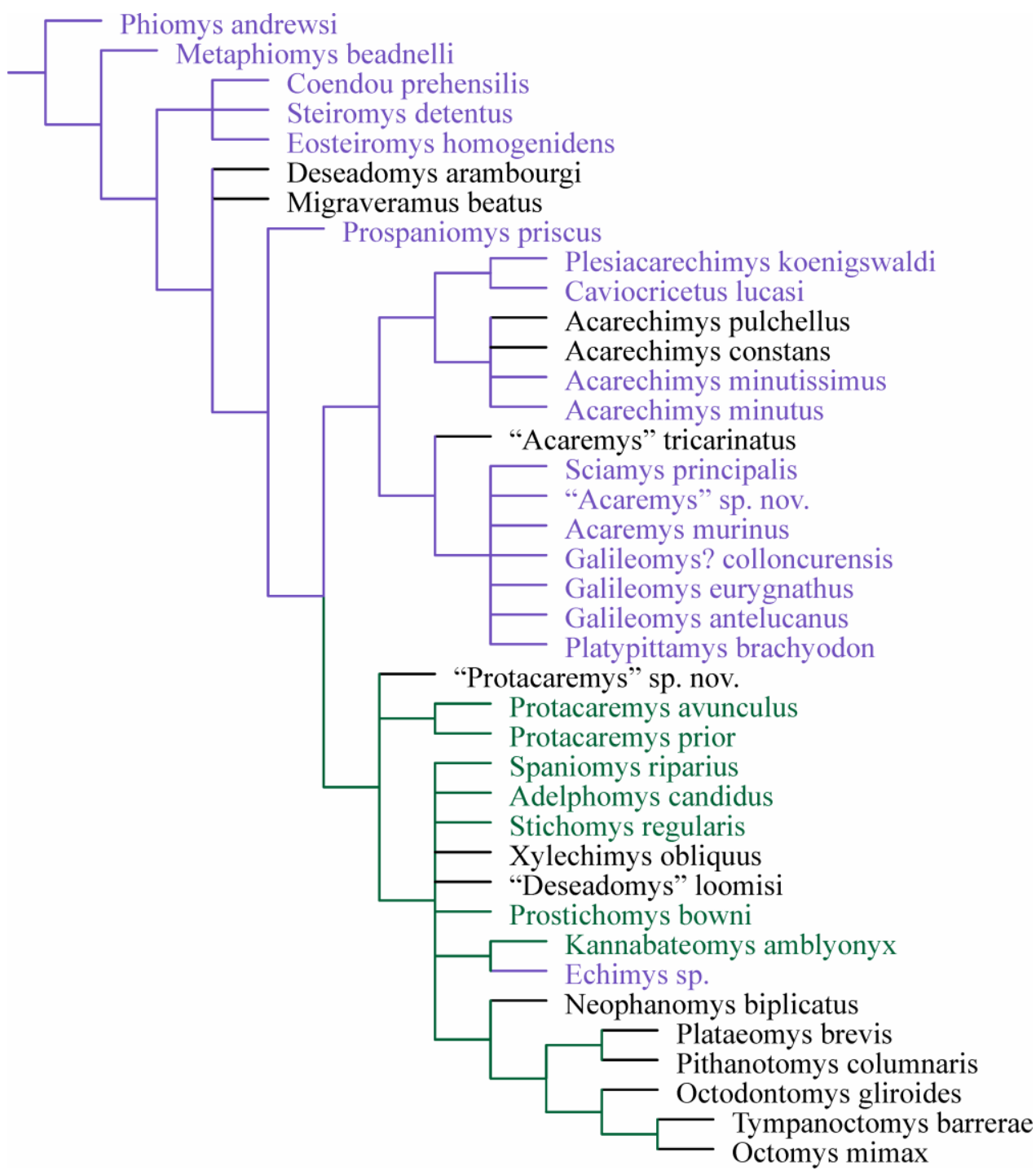

Fig. 5.14. Optimización de la oblicuidad de las crestas. En azul se muestra el estado de carácter 0 (crestas transversales) y en verde el estado de carácter 1 (crestas oblicuas al eje antero-posterior del diente)

- Tendencia a la reducción y pérdida del metalofúlido II (correspondiente al carácter 43 del análisis cladístico): Patterson y Wood (1982) consideraron que este carácter, junto con la retención de DP4/dp4, representaba una de las características más confiables para identificar a los Echimyidae fósiles. Sin embargo, en la figura 5.15 se muestra la distribución variable de este carácter dentro de Octodontoidea. Dentro los dos taxones más basales de la superfamilia, Migraveramus beatus presenta metalofúlido II bien desarrollado (estado de carácter 0), mientras que en Deseadomys arambourgi esta estructura presenta desarrollo variable (estado de carácter 1). Prospaniomys prior, Sciamys principalis, Acaremys murinus, Platypittamys brachyodon, "Protacaremys" sp. nov., las 2 especies de Protacaremys y Spaniomys riparius presentan metalofúlido II 
bien desarrollado. Por otro lado, los taxones incluidos en el nodo 50 (a excepción de $A$. minutissimus donde este carácter es polimórfico), "Acaremys" tricarinatus, Galileomys colloncurensis y Xylechimys obliquus presentan el metalofúlido II de desarrollo variable. El estado de carácter más derivado (metalofúlido II ausente) se observa en Adelphomys candidus, "D." loomisi y las dos especies de equímidos vivientes analizadas. Entre los octodóntidos, el carácter es polimórfico en Neophanomys biplicatus, mientras que en los restantes el carácter no pudo ser evaluado debido a la extrema simplificación oclusal.

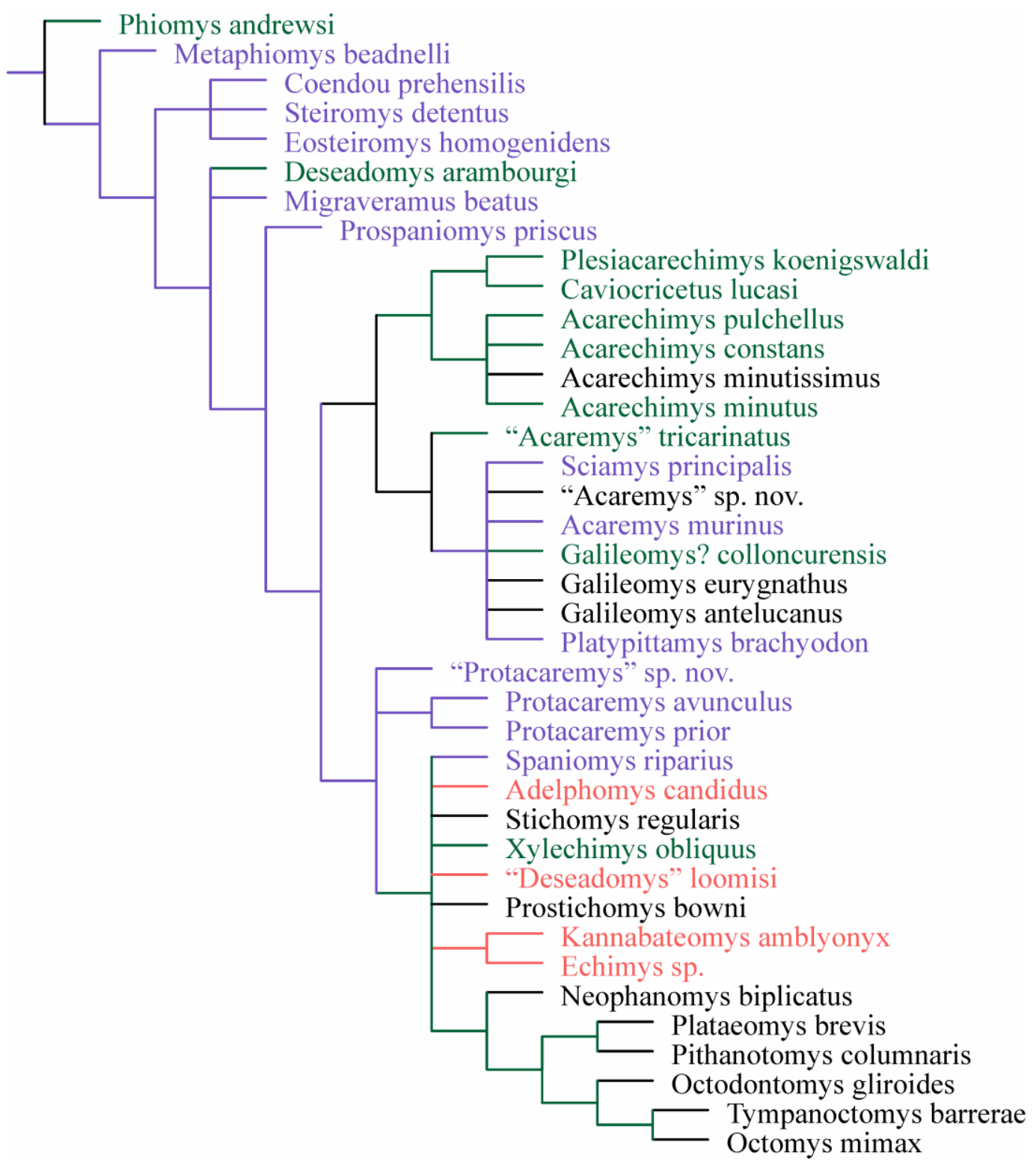

Fig. 5.15. Optimización del desarrollo del metalofúlido II en m1-m3. En azul se muestra el estado 0 (bien desarrollado), en verde el estado de carácter 1 (reducido) y en naranja el estado de carácter 2 (ausente) 
Además, es importante resaltar que la optimización del carácter en el nodo 66 (Fig. 5.8) es el estado 1 (metalofúlido II reducido), lo que permite interpretar que el ancestro hipotético de los octodóntidos y los equímidos modernos analizados habría tenido molares esencialmente trilofodontes, y por lo tanto ésta sería la condición a partir de la cual se habrían diferenciado los octodóntidos. Por lo tanto, se descarta que el grado de desarrollo del metalofúlido II presente relevancia para identificar la diferenciación temprana de los Octodontidae.

- Configuración masetérica de la mandíbula (correspondiente al carácter 103 del análisis cladístico): la discontinuidad entre la mmma y la cresta masetérica ha sido propuesta como una sinapomorfía de Octodontidae por Verzi et al. (1994) y Verzi (1999). 


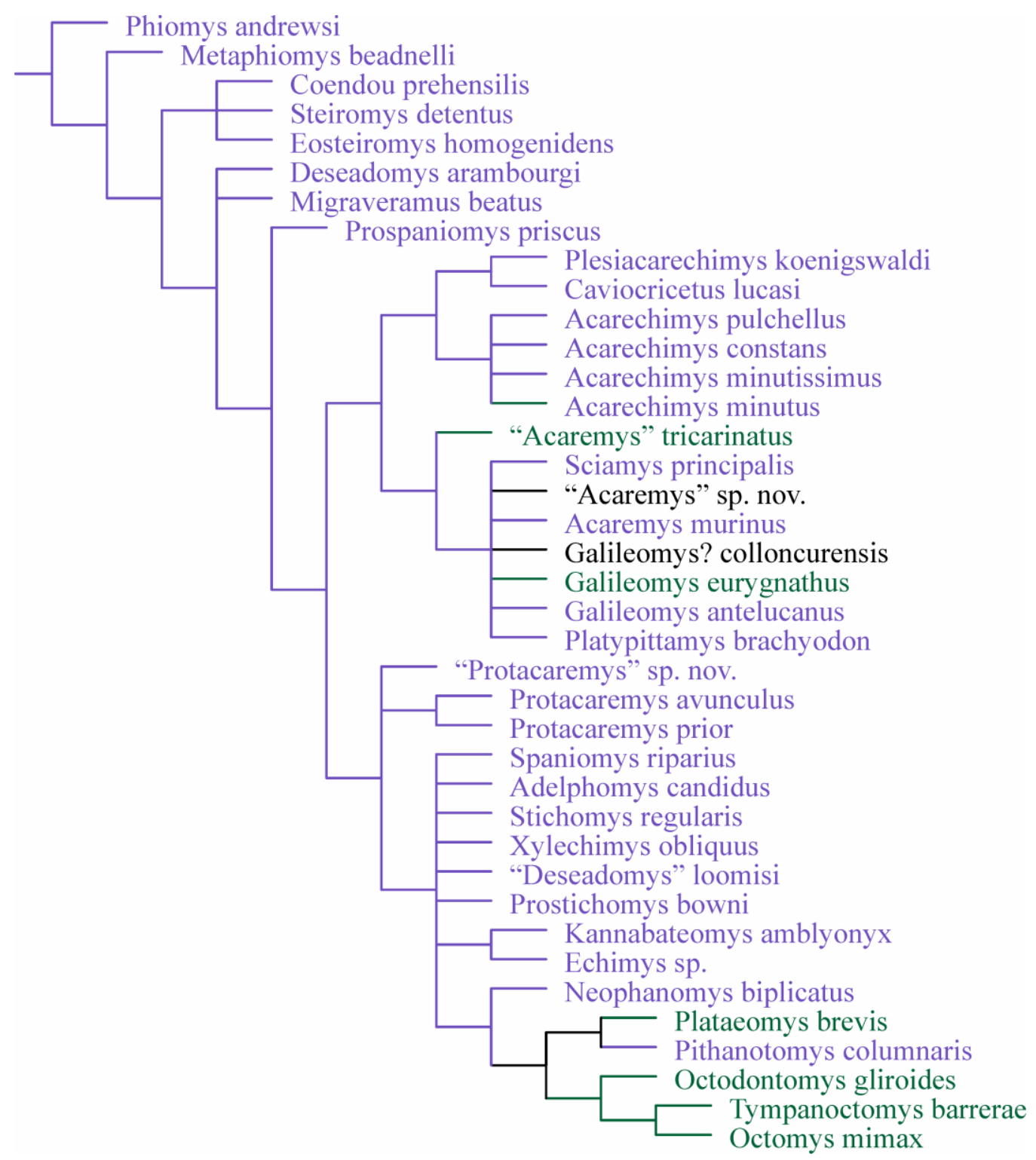

Fig. 5.16. Optimización de la configuración masetérica de la mandíbula. En azul se muestra el estado 0 (continuos) y en verde el estado de carácter 1 (discontinuo)

En la figura 5.16 se observa que la condición primitiva para los histricognatos es que la mmma y la cresta masetérica se dispongan de manera continua. Debido a que la condición derivada no se verifica en el octodóntido más tempranamente divergente (Neophanomys biplicatus), este carácter no resulta ser una sinapomorfía de Octodontidae (nodo 66), sino una sinapomorfía ambigua del nodo subsiguiente (nodo 65) o una sinapomorfía no ambigua del nodo que agrupa a los octodóntidos vivientes analizados (nodo 68). La presencia del estado derivado en los acarémidos "Acaremys" tricarinatus y Galileomys eurygnathus sería producto de sendas convergencias autapomórficas. Sin embargo, la ausencia del estado derivado en todos los 
octodontoideos conocidos tradicionalmente clasificados como equímidos sugiere que este carácter continúa siendo válido para caracterizar a los octodóntidos más avanzados. 
CAPÍTULO 6

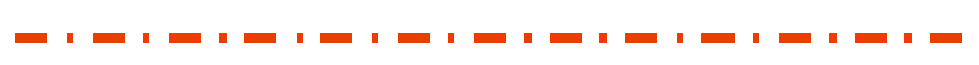

DIVERSIFICACIÓN

TEMPRANA

DE

OCTODONTOIDEA 


\subsection{Origen y Diversificación de Octodontoidea basales}

El registro fósil y las hipótesis filogenéticas se pueden unificar para formar las hipótesis filogenéticas calibradas paleontológicamente, donde se puede estudiar el tiempo y modo de evolución de un grupo, así como la divergencia y edad de divergencia de clados, tasas evolutivas e hiatos del registro fósil (Norell, 1992; Pol y Norell, 2006). A partir de las reconstrucciones filogenéticas calibradas paleontológicamente se pueden identificar los linajes fantasmas, que llevan este nombre debido a que no son identificados en el registro, sino que su existencia se deduce de la estructura del árbol filogenético. De esta manera se evaluará, en parte, la historia de los linajes de octodontoideos teniendo en cuenta la aparición/desaparición y diversificación de los mismos.

\section{$\underline{\text { Radiaciones de Octodontoidea: }}$}

Clásicamente se ha postulado que la historia evolutiva temprana de los octodontoideos había estado caracterizada por un evento simple de diferenciación muy basal de las familias Echimyidae y Octodontidae (Ameghino, 1889, 1902, 1904; Wood, 1949; Wood y Patterson, 1959; Patterson y Wood, 1982). Con el descubrimiento de una mayor cantidad de taxones fósiles se estableció la idea de una evolución temprana mucho más compleja, aunque se seguía manteniendo el concepto general de una dicotomía Octodontidae-Echimyidae (Pascual, 1967; Vucetich y Verzi, 1991; Vucetich et al., 1999; Verzi, 2002). Los resultados del análisis filogenético realizado en este trabajo rechazan esas propuestas, y plantean una historia evolutiva temprana compleja de la superfamilia que dio origen a sucesivos linajes de octodontoideos que no dejaron descendientes modernos, coincidiendo parcialmente con las propuestas de Reig (1989), Vucetich y Kramarz (2003) y Vucetich y Vieytes (2006). 


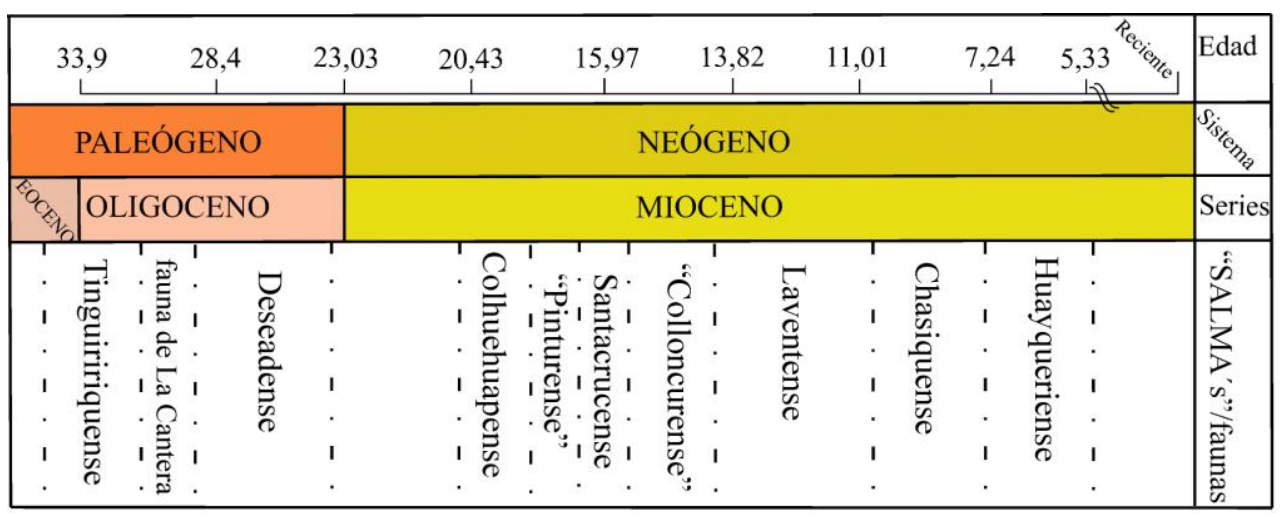

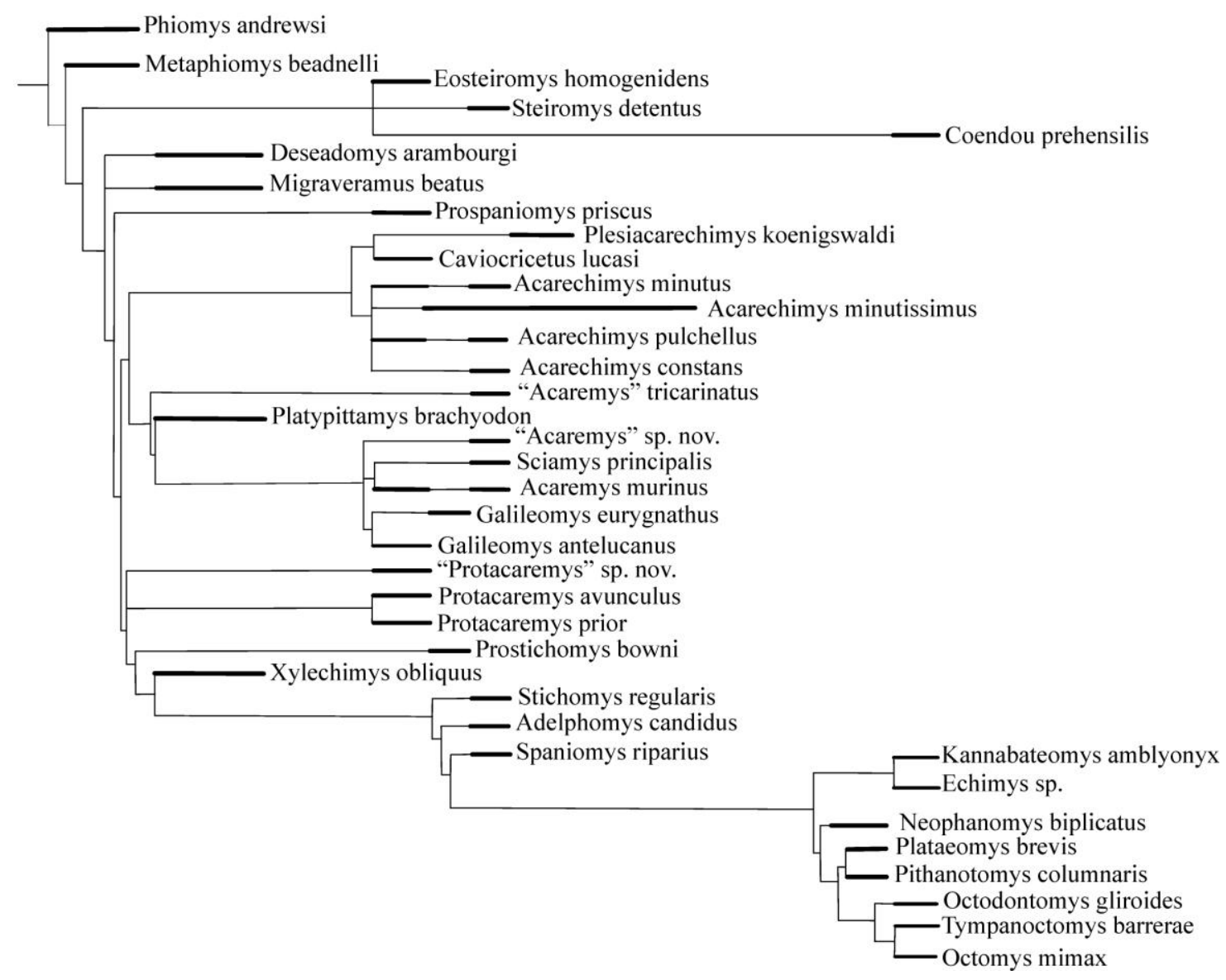

Fig. 6.1. Hipótesis filogenética calibrada paleontológicamente mostrando la evolución de Octodontoidea, linajes fantasmas y radiaciones dentro de la superfamilia. Las líneas gruesas indican el registro de cada especie, mientras que las delgadas indican los linajes fantasmas

Del presente análisis se interpreta que:

- $\quad$ En el Deseadense ya están establecidos los principales linajes de Octodontoidea que dominaron durante el Mioceno temprano y medio. De ello se deduce la ocurrencia de una radiación en tiempos anteriores al Deseadense. La misma puede haber ocurrido durante el Oligoceno temprano, época donde están registrados sin dudas los primeros octodontoideos (La Cantera, Santa Rosa). Para esta época se reconocen más linajes 
fantasmas que linajes registrados, aunque hay que aclarar que el registro de octodontoideos es bastante pobre, a pesar de la diversidad conocida.

Los taxones que se encuentran representados en el Deseadense no se encuentran estrechamente relacionados entre sí, sino que corresponden a distintos linajes tempranamente diferenciados. De estos taxones sólo algunos corresponden a linajes de octodontoideos representados en edades más tardías (Platypittamys brachyodon y Xylechimys obliquus), mientras que de los otros no se conocen descendientes aún (Deseadomys arambougi y Migraveramus beatus).

- En el Colhuehuapense se observa un incremento importante de taxones registrados, asociado con una mayor variedad de tipos morfológicos, aunque es posible que esto se deba en gran parte a que los esfuerzos de prospección en sedimentos del Mioceno temprano han sido más intensos que para depósitos de otras edades. Esta mayor diversidad está conformada por taxones que aparecen como sobrevivientes de linajes diferenciados en tiempos pre-Deseadenses (i.e. Prospaniomys priscus, "A." tricarinatus, las especies de Protacaremys), junto con los Acarechimyidae y los Acaremyidae más derivados. Estos dos últimos grupos podrían haber radiado en tiempos pre-Colhuehapenses, constituyendo un segundo evento de diversificación dentro de los Octodontoidea. Esta segunda radiación se caracteriza por la existencia de numerosos eventos cladogenéticos menores que habrían dado origen a las especies de Acarechimys, Sciamys y Acaremys que caracterizan la "Edad Mamífero" Santacrucense. Otros taxones típicamente santacrucences tradicionalmente clasificados como "Adelphomyinae" (i.e. Stichomys, Adelphomys) y Spaniomys también parecen haberse diferenciado en este segundo evento de diversificación. Hacia la "Edad Mamífero" Santacrucense se observa la supervivencia de algunas especies colhuehuapenses junto con la aparición de nuevas especies que testimonian un recambio de tipos morfológicos dentarios. Estos nuevos tipos morfológicos se caracterizan por presentar coronas comparativamente más altas, sin cúspides evidentes y crestas más anchas. Estos cambios habrían ocurrido convergentemente en acarémidos, acarequímidos y en las especies de Adelphomys, Stichomys y Spaniomys. En estos últimos, además, se verifica una mayor tendencia a la oblicuidad de las crestas, conformando un patrón dentario semejante, y probablemente homólogo, al que caracteriza a algunos equímidos vivientes. Estos cambios estructurales coinciden con la incipiente aridización patagónica inferida para esta época (Barreda y Palazzesi, 2007; Palazzesi y Barreda, 2007). 
- En el Mioceno medio los octodontoideos disminuyen dramáticamente en diversidad. No se puede descartar, como ocurre en la Edad Deseadense, que un menor registro de octodontoideos colloncurenses de deba al insuficiente esfuerzo de prospección. Los únicos taxones conocidos (Galileomys? colloncurensis, Plesiacarechimys koenigswaldi, Protacaremys denisae, Maruchito trilofodonte Vucetich et al., 1993, Massoiamys obliquus Vucetich, 1978, Ricardomys longidens Walton, 1990, Acarechimys sp. y Stichomys?) corresponderían a linajes supervivientes del segundo evento de radiación.

- En el Mioceno tardío (Chasiquense-Huayqueriense) se considera extinguida la mayor parte de los linajes de octodontoideos, y se registran sin dudas los primeros representantes de la familia Octodontidae (Verzi, 1999; Verzi, 2002), lo que indica que hubo una tercera radiación en tiempos pre-Chasiquenses. Se estima que esta radiación debe haber ocurrido a finales del Mioceno medio principios del Mioceno tardío (Vucetich et al., 1999), época para la que se registran numerosos eventos climáticos y una gran actividad tectónica, que resultaron en la modificación de los ambientes del sur de Sudamérica, haciéndolos cada vez más áridos (Pascual y Ortiz-Jaureguizar, 1990; Vucetich et al., 1999; Ortiz-Jaureguizar y Cladera, 2006; Barreda y Palazzesi, 2007; Palazzesi y Barreda, 2007). Concordantemente, la novedad evolutiva más destacada en los Octodontidae es un aumento notorio en la altura de la corona y la consecuente simplificación dentaria (Verzi, 1999). Otros grupos de caviomorfos (e.g. Cavioidea, Dinomyidae) también muestran radiaciones evolutivas de gran escala para este período (Vucetich et al., 1999; Pérez, 2010b). El registro de esta época, restringido mayormente a centro y norte de Argentina, es rico en octodontoideos, aunque éstos presentan una composición muy distinta a la de edades anteriores. Son variados los octodóntidos indudables y aparecen linajes nuevos o al menos no identificados previamente, como los miocastorinos, "eumysopinos" y abrocómidos.

Tradicionalmente, se propuso que los Octodontidae se habrían diferenciado en latitudes altas del continente, asociados al marcado deterioro climático ocurrido en esta región a partir del Mioceno tardío (Pascual, 1967; Reig, 1986; Verzi, 1999). Esta hipótesis clásica supone que los Octodontidae se diferenciaron en latitudes altas a partir de ancestros que estaban en latitudes altas (evolución in situ). Asumiendo esta propuesta, se esperaría encontrar formas fósiles en el registro de edades "Colloncurense"-Laventense con un patrón dentario que "pre-anuncie" al que 
caracteriza a los octodóntidos modernos (i.e. dientes con tendencia a la euhipsodoncia, molares inferiores trilofodontes o con el metalofúlido II reducido y que presenten la tendencia a adquirir forma de 8). Sin embargo, la falta de registro de estos supuestos morfotipos ancestrales en latitudes altas podría indicar que los Octodontidae se habrían originado a partir de ancestros en latitudes bajas (donde casi no tenemos registro para el Mioceno temprano y medio, salvo La Venta, en Colombia y Quebrada Honda, en Bolivia), y que recién en el Mioceno tardío invadieron latitudes altas, tal vez asociados a un desmejoramiento climático.

Sea cual fuese el caso, al igual que lo que ocurre para los octodontoideos basales, queda evidenciado un hiato en el registro de formas fósiles relacionadas al origen de la familia Octodontidae que se extendería por lo menos hasta antes del Santacrucense. La hipótesis de Pascual (1967) de que Acarechimys podría ser el ancestro de los Octodontidae, no es apoyada por los resultados del presente análisis.

Por último, con el descubrimiento reciente de nuevas faunas de roedores preDeseadenses [La Cantera (Patagonia) Oligoceno temprano, Santa Rosa (Perú) Eoceno tardío-Oligoceno temprano? y la nueva fauna proveniente de la amazonia peruana de edad Eoceno medio] se abren nuevas perspectivas para re-evaluar el origen, el tiempo y modo de evolución de los más tempranos caviomorfos en general y en este caso de los octodontoideos en especial. Recientemente, Antoine et al. (2011) dieron a conocer la fauna de roedores más antigua de Sudamérica. Del análisis filogenético de estos autores [Antoine et al., 2011, Fig. 3(a)], aunque ellos no lo dicen en el texto, se deduce que los Octodontoidea divergieron al menos en el Eoceno medio, antes que las restantes superfamilias de caviomorfos. Esta propuesta lleva aparejado el problema de la existencia de un hiato temporal de casi 10 millones de años entre la supuesta diferenciación de Octodontoidea y los primeros octodontoideos reconocidos por Frailey y Campbell (2004) y Vucetich et al. (2010a). Sin embargo, este nuevo marco evolutivo, en el que los octodontoideos se habrían diferenciado muy antiguamente (Eoceno medio?), permite una mejor comprensión de la diversidad de líneas evolutivas reconocidas para el Oligoceno tardío en Patagonia y Bolivia. Los 10 millones de años que transcurrieron desde la diferenciación de Octodontoidea en latitudes bajas de Sudamérica hasta su aparición en el registro son suficientes para que este grupo de roedores primitivamente pentalofodontes se dispersara a latitudes más altas y originara la variedad de tipos morfológicos tetralofodontes que se reconocen para el Deseadense. 


\subsection{La evolución dentaria de Acaremyidae}

Como ya se explicó en el capítulo 5, se corroboró la monofilia de la familia Acaremyidae. En este apartado se evaluará la evolución de los caracteres dentarios dentro de esta familia teniendo en cuenta los resultados del análisis filogenético. El ancestro de los acarémidos adquirió un recambio normal de los premolares de leche y una profundización de la porción anterior de la fosa masetérica, características que diagnostican a los Acaremyidae. Esta familia se diferenció a partir de ancestros que presentaban dientes mesodontes, premolares superiores definitivos simplificados (sin metalofo) y cúspides diferenciadas. El linaje más tempranamente divergente es el de "Acaremys" tricarinatus, que se caracteriza por presentar un fléxido adicional en el borde antero-labial del p4. En el linaje que dio origen a este taxón se verificó un aumento en la hipsodoncia y un engrosamiento en el diámetro transversal de las crestas respecto de los flexos (estados de carácter convergentes con Sciamys principalis). El siguiente nodo (nodo 43, figura 6.2) está caracterizado por la desaparición del hipolófido en el p4 y por el advenimiento de una extensión posterior del metalofúlido I en los molares inferiores. Dentro de los caviomorfos aquí analizados, la ausencia de hipolófido en el p4 se observa sólo en los acarémidos; sin embargo, en S. principalis y G. eurygnathus esta cresta puede reaparecer, de modo que el carácter revierte a la condición ancestral de la superfamilia. En cambio, se corrobora la múltiple aparición de una extensión posterior del metalofúlido I en los molares inferiores en otros octodontoideos (i.e. M. beatus, Xylechimys obliquus, Plesiacarechimys koenigswaldi y de manera variable en Acarechimys minutus, A. minutissimus y A. constans). Platypittamys brachyodon representa el siguiente linaje en diferenciarse. Este taxón se caracteriza por presentar una reducción extrema del hipoflexo del P4 y el p4 con el talónido subigual respecto del trigónido. Además, se deduce una reversión a la condición ancestral en el grado de hipsodoncia y el aterrazamiento en los molares y en la forma de la cara anterior (curva) en los incisivos inferiores. Por otro lado, los molares superiores se tornaron cuadrangulares, con el hipocono de posición labial al protocono (característica compartida convergentemente con "Acaremys" sp. nov.), y el paracono de mayor tamaño que el metacono (característica compartida convergentemente con $G$. antelucanus, G.? colloncurensis, A. minutissimus y P. koenigswaldi). En el siguiente nodo (nodo 52, figura 6.2) se verifica un mayor desarrollo del hipoflexo en el P4, mientras que en los molares superiores la antero y la posterofoseta se cierran simultáneamente de modo que los taxones más hipsodontes ( $S$. principalis) adquieren 
una morfología molar en forma de 8. En los premolares inferiores se observa una reversión a la condición ancestral para caviomorfos, donde el metacónido y el protocónido se encuentran alineados, y además, se desarrolla un fléxido que separa el metacónido del protocónido que es conspicuo en las especies de Galileomys, menos evidente en $A$. murinus, mientras que en $S$. principalis puede estar reducido o ausente. Un fléxido similar habría evolucionado convergentemente en Deseadomys arambourgi. A partir del nodo 52 (Fig. 6.2) algunas de las relaciones internas de los acarémidos no pudieron resolverse por completo, y por lo tanto tampoco la evolución de algunos caracteres. "Acaremys" sp. nov. se caracteriza por presentar una cúspide accesoria en el protolofo y porque el hipocono es de posición labial al protocono en los molares superiores (estado de carácter convergente con P. brachyodon). En S. principalis y A. murinus se evidencia un alargamiento del anterolofo en los molares superiores (estado de carácter convergente con G. eurygnathus) y la reducción del metalofúlido II en los dp4. Además de las características ya señaladas, $S$. principalis desarrolló un hipoflexo en el P4 más penetrante, una mayor hipsodoncia unilateral (estado de carácter convergente con G. antelucanus, G. eurygnathus y Caviocricetus lucasi) y cúspides no individualizadas (estado de carácter convergente con M. beatus y D. arambourgi y con el nodo 57 que agrupa a los "adelfominos" y a las formas vivientes). La diferenciación del metalofo y la alineación del hipocono con el protocono en el P4 son reversiones a la condición primitiva en el contexto de los caviomorfos aquí analizados. Además, Sciamys principalis presenta en la mandíbula la porción anterior de la fosa masetérica poco profunda a diferencia de los restantes acarémidos. En cambio, en el linaje que dio origen a $A$. murinus se observa una tendencia a la reducción del tamaño del m3 respecto del m2 (estado de carácter convergente con los octodóntidos vivientes, aunque menos evidente). En G. antelucanus y G. eurygnathus se acentúo el desarrollo del fléxido en el p4 que separa el protocónido y el metacónido; asimismo se observa una reversión en el grado de hipsodoncia a una condición braquiodonte y a una superficie oclusal aterrazada. En G. antelucanus hubo un aumento del tamaño del paracono respecto del metacono, al igual que en $P$. brachyodon, A. minutissimus y $P$. koenigswaldi. 


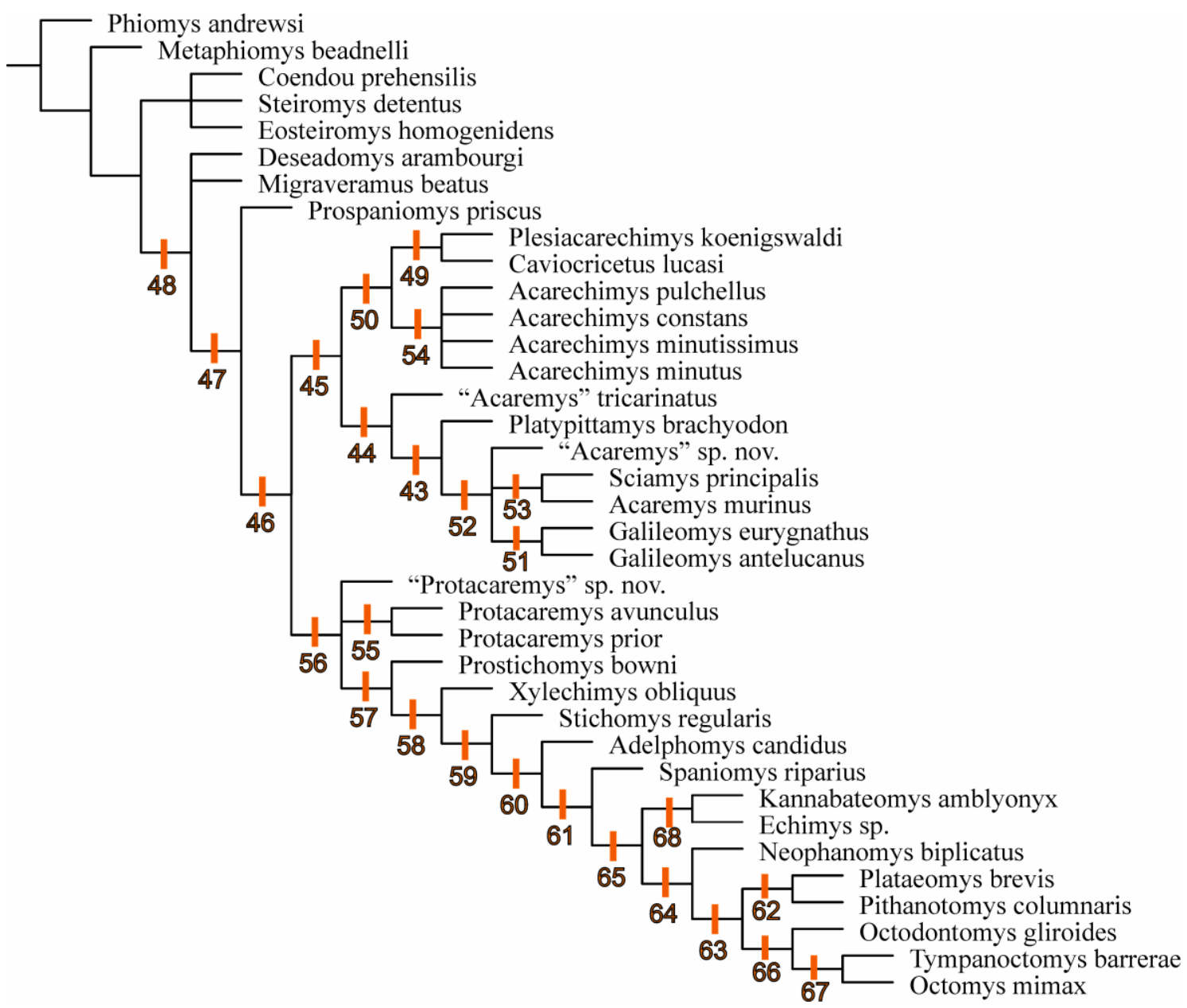

Fig. 6.2. Consenso estricto aplicando iterpcr de 360 árboles más parsimoniosos de 484 pasos. En naranja se enumeran los nodos

\subsection{La evolución dentaria de Acarechimyidae}

De manera semejante al apartado anterior, aquí se evaluará la evolución de los caracteres dentarios dentro del clado aquí nominado como familia Acarechimyidae, teniendo en cuenta los resultados del análisis filogenético. Esta familia se diferenció a partir de ancestros con dientes mesodontes y dientes superiores e inferiores tetralofodontes. Desde sus orígenes hubo una dicotomía por la cual se diferenciaron dos linajes. En uno de ellos, definido en el nodo 49 (Fig. 6.2), se verificó la reversión al estado ancestral para caviomorfos del desarrollo del mesolófulo en los dientes superiores y el desarrollo del metalofo en el DP4 (este último estado de carácter convergente sólo con A. murinus). Además, en este grupo la IPM no se dispone en ángulo recto respecto de los prismas como es característico en los octodontoideos, sino que evolucionó, o permaneció en una disposición primitiva, donde la IPM se dispone en ángulo sub-recto respecto de los prismas. En el linaje que dio origen a Plesiacarechimys koenigswaldi se observa el engrosamiento del paracono respecto del metacono (estado 
de carácter convergente con A. minutissimus, P. brachyodon y G. antelucanus) y el anterolofo en los molares pasa de ser anteriormente convexo a ser recto (estado de carácter convergente con $P$. priscus y G. eurygnathus). En cambio, en la línea evolutiva que dio origen a Caviocricetus lucasi se revirtió el grado de hipsodoncia y el aterrazamiento, se deduce la desaparición del metalofúlido I en los dp4, el corrimiento del metacónido a una posición anterior respecto del protocónido y el desarrollo del hipoconúlido en los molares inferiores a un estado ancestral comparable al de los fiomorfos. Además, se corroboró un aumento de la hipsodoncia unilateral, un alargamiento de los molares superiores, que pasan de ser más anchos que largos a ser más largos que anchos, un acortamiento del posterolófido (características compartidas convergentemente con P. brachyodon, G. antelucanus, G. eurygnathus y P. priscus) y la desaparición del brazo posterior del metacónido en los molares inferiores (características compartidas convergentemente con A. minutissimus, A. constans, nodo 52 у D. arambourgi).

Por otro lado, el clado definido en el nodo 54 (=Acarechimys) (Fig. 6.2) está caracterizado por el cambio de un ángulo antero-lingual obtuso en lo molares superiores a uno redondeado. Las relaciones entre las distintas especies de Acarechimys no pudieron ser resueltas.

\subsection{La evolución dentaria de "Adelphomyinae"}

Aquí se evaluará la evolución de los caracteres dentarios dentro del clado definido en el nodo 56 (Fig. 6.2), teniendo en cuenta los resultados del análisis filogenético. Los taxones fósiles del Oligoceno tardío-Mioceno temprano incluidos en este nodo fueron tradicionalmente agrupados dentro la subfamilia de equímidos "Adelphomyinae". Aunque los resultados del análisis filogenético indican que no son un grupo natural, se evaluará la evolución de los caracteres dentarios debido a que los "adelfominos" representan el stem group de las formas modernas de Echimyidae y Octodontidae.

Los integrantes del clado definido en el nodo 56 (Fig. 6.2) se diferenciaron a partir de ancestros que presentaban dientes mesodontes, molares superiores e inferiores tetralofodontes, con las crestas transversales al eje antero-posterior del diente y las hileras dentarias superiores paralelas una respecto de la otra. Los representantes más basales de este nodo presentan algunas de sus relaciones internas no resueltas. En el linaje que dio origen a "Protacaremys" sp. nov. se verificó un corrimiento anterior del 
metacónido respecto del protocónido en los molares inferiores, de modo que hay una reversión hacia el estado ancestral comparable al presente en los fiomorfos. En el nodo 55 (Fig. 6.2) se observa un aumento del tamaño del $\mathrm{m} 3$ respecto del $\mathrm{m} 2$, estado de carácter que evolucionó convergentemente en Stichomys regularis. En el nodo 57 (Fig. 6.2) se verificó el engrosamiento de las crestas respecto de los fléxidos (característica compartida convergentemente con Sciamys principalis y "Acaremys" tricarinatus), la pérdida de individualización de las cúspides (característica compartida convergentemente con los dos octodontoideos más basales y S. principalis), los dientes se vuelven cuadrangulares (característica compartida convergentemente con Platypittamys brachyodon), la porción antero-lingual de los molares superiores pasa de formar un ángulo obtuso a uno recto, se reduce el tamaño del mesolófido en el dp4 y los incisivos se hacen más cortos llegando su raíz hasta el m3. El primer linaje en diferenciarse de este nodo es el de Prostichomys bowni, donde se verificó la reversión al estado basal de Octodontoidea de incisivos de cara anterior curva y un corrimiento del metacónido que se ubica posteriormente respecto del protocónido. En el nodo 58 se verifica el acortamiento del posterolófido en los molares inferiores, característica compartida con algunos acarémidos, $C$. lucasi y $P$. priscus. El linaje más tempranamente divergente de ese nodo es Xylechimys obliquus donde se evidencia el desarrollo de una extensión posterior del metalofúlido I. En el nodo 59 se corrobora la desaparición del brazo posterior del metacónido en los molares inferiores, característica compartida convergentemente con los acarémidos incluidos en el nodo 52, A. constans, A. minutissimus, $C$. lucasi y D. arambourgi. El linaje más tempranamente divergente es el de Stichomys regularis donde se verifica un aumento del tamaño del m3 (estado de carácter compartido con las especies de Protacaremys y P. columnaris) y una cara anterior de los incisivos inferiores curva, característica compartida convergentemente con P. bowni, K. amblyox y O. gliroides). A nivel del nodo 60 (Fig. 6.2) se observa que los molares superiores se hacen más largos que anchos y también se verifica el alargamiento del anterolofo (característica compartida convergentemente con $P$. prior). El linaje que dio origen a Adelphomys candidus es el primero en divergir y en él se observa una aproximación anterior de las hileras dentarias (característica compartida convergentemente con $P$. prior y el nodo 62), hipocono labial al protocono, la reducción del metalofúlido II en los dp4, la reversión a un estado ancestral para los octodontoideos de un incisivo inferior no comprimido lateralmente (característica además compartida con el nodo 63 y Echimys) y la cara anterior de los incisivos planos (característica 
compartida con el nodo 62 y T. barrerae). A nivel del nodo 65 (Fig. 6.2) se evidencia el cambio en los molares superiores de un borde antero-lingual recto a uno redondeado. En el linaje que dio origen a Spaniomys riparius se corrobora la posición anterior del metacónido respecto del protocónido en los dientes inferiores, la reversión al estado primitivo para octodontoideos del desarrollo del metalofúlido II en los molares inferiores (estado de carácter compartido convergentemente además con las especies de Protacaremys). A partir del nodo 65 se diferencian las formas modernas de Echimyidae incluidas en el análisis y Octodontidae (Fig. 6.2). En este punto los principales cambios que afectaron a los ancestros de estas formas no ocurrieron en los dientes, sino en el cráneo y en la mandíbula (concordando con la propuesta de Arnal y Kramarz, 2010); en este linaje se desarrollaron forámenes palatinos posteriores pequeños y sínfisis mandibulares poco rugosas. En el nodo 68 (Fig. 6.2) se agrupan los equímidos aquí analizados, que se caracterizan por presentar el hipofléxido de los molares inferiores oblicuo hacia delante. Además, se caracterizan por presentar cambios en algunas estructuras craneanas [raíz dorsal de la arcada cigomática ubicada anteriormente al M1 (al igual que en los octodontoideos basales), forámenes esfeno-palatinos ubicados en los maxilares a nivel del M1, narinas posteriores abriendo a nivel del M3 (al igual que en $P$. columnaris), desaparición de las vacuidades esfeno-palatinas, acortamiento del diastema mandibular revirtiendo al estado ancestral de los caviomorfos, límite anterior de la fosa masetérica ubicada a nivel del m1 (característica convergente con las dos especies de Protacaremys y el nodo 69) y la base del proceso coronoides ubicado por delante del m3]. En el nodo 64 se agrupan los Octodontidae, que se caracterizan por el incremento en la altura de la corona y por la ubicación en la mitad dorsal de la mandíbula de la mmma, esta última característica revirtiendo al estado ancestral de Octodontoidea. Neophanomys biplicatus no presenta autapomorfías conocidas, de modo que representa estructuralmente el ancestro del linaje evolutivo que dio origen a los restantes Octodontidae. En el nodo 63 se corrobora un aumento aún mayor del grado de hipsodoncia, de modo que los taxones incluidos presentan dientes euhipsodontes; además, se deduce la adquisición de incisivos no comprimidos (revirtiendo al estado ancestral de los octodontoideos). A partir de este nodo se infiere la primera dicotomía dentro de los octodóntidos. Una de las líneas dio origen a los octodóntidae fósiles Plataeomys brevis y Pithanotomys columnaris, donde se observa una convergencia anterior de las hileras dentarias superiores. Además, en el cráneo se observa un cambio hacia una morfología donde la raíz ventral de la arcada cigomática presenta diámetros 
antero-posterior y dorso-ventral semejantes y a nivel mandibular se corrobora la presencia de una fosa retromolar esencialmente posterior al $\mathrm{m} 3$. En el linaje que dio origen a $P$. brevis los molares superiores son cuadrangulares, mientras que en el de $P$. columnaris siguen siendo más largos que anchos. En el linaje que dio origen a $P$. columnaris hay un engrosamiento del m3. La otra línea dio origen a los octodóntidos vivientes aquí analizados, que se caracterizan por una reducción extrema del m3 y del desarrollo del seno epitimpánico en la región auditiva del cráneo (estado de carácter compartido convergentemente con $P$. priscus) y por la ausencia del proceso postorbitario en el cráneo. 
CAPÍTULO 7

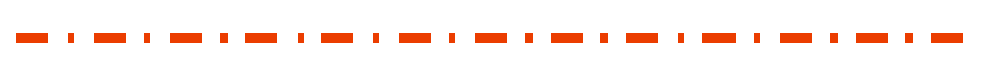

\section{CONCLUSIONES}


Conclusiones taxonómicas:

$\checkmark$ De la revisión sistemática realizada en este trabajo resultaron 20 taxones de nivel especie válidos (Acarechimys minutus, A. minutissimus, A. constans, A. pulchellus, Acaremys murinus, A. major, "A". tricarinatus, Caviocricetus lucasi, Galileomys antelucanus, G.? colloncurensis, G. eurygnathus, Migraveramus beautus, Platypittamys brachyodon, Plesiacarechimys koenigswaldi, Prospaniomys priscus, Protacaremys prior, P. avunculus, P. denisae, Sciamys principalis y S. latidens) y 2 especies nuevas, informalmente descriptas como "Acaremys" sp. nov. y "Protacaremys" sp. nov.

$\checkmark \quad$ Las especies Sciamys varians Ameghino, S. rostratus Ameghino, S. robustus y Acaremys messor Ameghino son sinónimos de Sciamys principalis Ameghino.

La especie Acaremys karaikensis es sinónimo de Acaremys murinus.

Las especies Eoctodon crassiusculus y Protacaremys amplus son sinónimos de Prospaniomys priscus.

Las especies Acaremys preminutus, Archaeocardia mustersiana, Eoctodon securiclatus y Palaeocardia mater son sinónimos de Protacaremys prior.

Conclusiones filogenéticas: del análisis cladístico se desprende que:

$\checkmark \quad$ Los octodontoideos del Oligoceno tardío-Mioceno medio tradicionalmente vinculados a los modernos Octodontidae (Platypittamys, Migraveramus, Acaremys, Sciamys, Acarechimys) no tienen relación directa con los representantes actuales de la familia Octodontidae. Contrariamente, estos taxones conforman el stem group del clado constituido por los octodóntidos del Mioceno tardío-reciente, los equímidos vivientes incluidos en este análisis y los taxones fósiles tradicionalmente asignados a la familia Echimyidae (e.g. Adelphomys, Stichomys, Spaniomys). 
Los Echimyidae y Octodontidae modernos se encuentran más estrechamente relacionados entre sí que con los octodontoideos del Oligoceno tardío-Mioceno medio.

$\checkmark \quad$ Se corroboró la monofilia de la familia Acaremyidae, que representa un linaje independiente de octodontoideos. Dentro de esta familia se incluyen las especies Platypittamys brachyodon, Acaremys murinus, Acaremys major, "Acaremys" tricarinatus, "Acaremys" sp. nov., Galileomys antelucanus, G. eurygnathus, G.? colloncurensis, Sciamys principalis y S. latidens.

$\checkmark \quad$ Se reconoció una nueva familia, informalmente aquí denominada Acarechimyidae, que incluye las especies de Acarechimys, Plesiacarechimys koenigswaldi y Caviocricetus lucasi, y representa el grupo hermano de Acaremyidae.

$\checkmark \quad$ Se corrobora la parafilia de "Adelphomyinae". Las formas tradicionalmente incluidas dentro de esta subfamilia conforman el stem group de las formas modernas de Echimyidae y Octodontidae.

$\checkmark \quad$ Los resultados de los análisis filogenéticos no sustentan las asignaciones genéricas de "Acaremys" sp. nov., "Protacaremys" sp. nov., "Acaremys" tricarinatus y "Deseadomys" loomisi.

$\checkmark \quad$ Los resultados del análisis filogenético calibrado geocronológicamente plantean una historia evolutiva temprana compleja de la superfamilia, que dio origen a sucesivos linajes de octodontoideos que no dejaron descendientes modernos. A través de este estudio se detectaron al menos 3 pulsos de diversificación:

- El primero ocurrido en tiempos pre-Deseadenses (Oligoceno temprano?), ya que en el Oligoceno tardío están establecidos los principales linajes de Octodontoidea que dominaron durante el Mioceno temprano y medio.

- El segundo evento de diversificación ocurrió en tiempos pre-Colhuehuapenses, e implicó la diferenciación de Acarechimyidae y los Acaremyidae más derivados. Como consecuencia, en el Colhuehuapense se registran taxones que aparecen como sobrevivientes de linajes diferenciados en tiempos pre-Deseadenses junto con representantes de nuevos linajes diferenciados en épocas pre-Colhuehuapenses. Hacia la 
"Edad Mamífero" Santacrucense, se observa la supervivencia de algunas especies colhuehuapenses junto con la aparición de nuevos taxones. Estos últimos testimonian un recambio de tipos morfológicos dentarios hacia dientes de coronas más altas y superficies oclusales simplificadas, hecho que coincide con la incipiente aridización patagónica inferida para esta época.

Del estudio de la evolución de los caracteres dentarios de Acaremyidae, Acarechimyidae, "Adelphomyinae" y Octodontidae se desprende que una gran cantidad de ellos pueden entenderse evolutivamente como producto de reversiones y paralelismos entre los distintos linajes de octodontoideos, resultando en un patrón en forma de mosaico que ha dificultado históricamente la compresión de las relaciones filogenéticas entre estos roedores. También se podría interpretar como consecuencia de un registro fósil muy fragmentario.

A pesar de los avances obtenidos en este trabajo, es necesario estudiar las relaciones de los octodontoideos y sus patrones evolutivos en un estudio más exhaustivo y con un muestro taxonómico más amplio, donde se incluyan la totalidad de los taxones de la superfamilia. 


\section{BIBLIOGRAFÍA}

Ameghino, F. 1887. Enumeración sistemática de las especies de mamíferos fósiles coleccionadas por Carlos Ameghino en los terrenos eocenos de la Patagonia austral. Boletín del Museo de La Plata 1: 1-26.

Ameghino, F. 1889. Contribución al conocimiento de los mamíferos fósiles de la República Argentina. Actas de la Academia Nacional de Ciencias en Córdoba 6: 1-1027, Atlas: 198.

Ameghino, F. 1891. Nuevos restos de mamíferos fósiles descubiertos por Carlos Ameghino en el Eoceno inferior de la Patagonia austral. Especies nuevas, adiciones y correcciones. Revista Argentina de Historia Natural 1: 289-328.

Ameghino, F. 1894. Enumération synoptique des espéces des mammiferes fósiles des formations éocenes de Patagonie. Boletín de la Academia Nacional de Ciencias de Córdoba 13: 259-452.

Ameghino, F. 1895. Première contribution à la connaissance de la faune mammalogique des couches à Pyrotherium. Boletín del Instituto Geográfico Argentino 15: 603-660.

Ameghino, F. 1897. Mamíferos Cretáceos de la Argentina. Segunda contribución al conocimiento de la fauna mastológica de las capas con restos de Pyrotherium. Boletín del Instituto Geográfico Argentino 18: 406-429, 431-521.

Ameghino, F. 1902. Première contribution à la connaissance de la faune mammalogique des couches à Colpodon. Boletín de la Academia Nacional de Ciencias de Córdoba 17: 71138.

Ameghino, F. 1904. Paleontología Argentina: relaciones filogenéticas y geográficas. Publicación de la Universidad Nacional de La Plata, Facultad de Ciencias FísicoMatemáticas 2: 1-79.

Ameghino, F. 1906. Les Formations sédimentaires du Crétacé supérieur et du Tertiaire de Patagonie avec un parallèle entre leurs faunes mammalogiques et celles de l'ancien continent. Anales del Museo Nacional de Historia Natural de Buenos Aires 15: 1-568.

Antoine, P.-O. ; Marivaux, L.; Croft, D. A.; Billet, G.; Ganerod, M.; Grégory Fanjat, C.; Rousse, S.; Gismondi, S. 2011. Middle Eocene rodents from Peruvian Amazonia reveal the pattern and timing of caviomorph origins and biogeography. Proceedings of the Royal Society B (doi: 10.1098/rspb.2011.1732) 
Arnal, M. y Kramarz, A. G. 2009. Adición al conocimiento y consideraciones filogenéticas de Prospaniomys Ameghino (Rodentia, Caviomorpha, Octodontoidea). Ameghiniana 46(4): 9R.

Arnal, M.; Kramarz, A. G. 2010. First complete skull of an octodontoid (Rodentia, Caviomorpha) from the early Miocene of South America and its bearing in the early evolution of Octodontoidea. Geobios 44: 435-444.

Arnal, M., Kramarz, A. G. y Vucetich, M. G. 2010. Un nuevo roedor Colhuehuapense (Mioceno temprano) de Patagonia y consideraciones preliminares sobre la evolución de la superfamilia Octodontoidea. X Congreso Argentino de Paleontología y Bioestratigrafía y VII Congreso Latinoaméricano de Paleontología, La Plata, Argentina Libro de resúmenes: 132-133.

Barreda, V.; Palazzesi, L. 2007. Patagonian Vegetation turnovers during the Paleogene-Early Neogene: origin of Arid-adapted floras. The botanical Review 73: 31-50.

Barrio, C.; Carlini, A. A.; Goin F. J. 1989. Litogénesis y antigüedad de la Formación Chichinales de Paso Cordoba (Río Negro, Argentina). IV Congreso Argentino de Paleontología y Bioestratigrafía (Mendoza), Actas 4: 149-156.

Bellosi, E. S. 2010. Physical stratigraphy of the Sarmiento Formation (middle Eocene- lower Miocene) at Gran Barranca, central Patagonia. En: The Paleontology of Gran Barranca: Evolution and Environmental Change trough the Middle Cenozoic of Patagonia. (Eds. Madden R. H. Carlini A. A., Vucetich M. G., y Kay R. F). Cambridge University Press, pps 19-31.

Blanga-Kanfi, S.; Miranda, H.; Penn, O.; Pupko, T.; DeBry, R. W.; Huchon, D. 2009. Rodent phylogeny revised: analysis of six nuclear genes from all major rodent clades. BMC Evolutionary Biology 9: 71.

Bowdich, T. E. 1821. An analysis of the natural classifications of Mammalia for the use of students and travelers. Smith pps. 115. París.

Bondesio, P.; Rabassa, J.; Pascual, R.; Vucetich, M. G.; Scillato-Yané, G. J. 1980. La Formación Collón-Curá de Pilcaniyeu viejo y sus alrededores (Río Negro, República Argentina). Su antigüedad y las condiciones ambientales según su distribución, su litogénesis y sus vertebrados. Actas II Congreso Argentino de Paleontología y Bioestratigrafía y I Congreso Latinoamericano de Paleontología 3: 85-99.

Bordas, A. F. 1939. Diagnosis sobre algunos mamíferos de las capas con Colpodon. Physis 16: 413-433. 
Bown, T. M.; Larriestra, C. N.; Powers, D. W. 1988. Análisis Paleoambiental de la formación Pinturas (Mioceno Inferior), Provincia de Santa Cruz. Segunda Reunión Argentina de Sedimentología, Actas 1: 31-35.

Bown, T. M.; Larriestra, C. N. 1990. Sedimentary paleoenvironments of fossil platyrrhine localities, Miocene Pinturas Formation, Santa Cruz province, Argentina. Journal of Human Evolution 19: 87-119.

Bown, T. M.; Fleagle J. G. 1993. Systematics, bioestratigraphy and dental evolution of the Palaeothentidae, Later Oligocene to Early-Middle Miocene (Deseadan-Santacrucian) Caenolestoid Marsupials of South America. Supp. Journal of Paleontology 67: 1-76.

Bremer, K. 1988. The limits of amino acid sequence data in angiosperm phylogenetic reconstruction. Evolution 42: 795-803.

Bremer, K. 1994. Branch support and tree stability. Cladistics 10: 295-304.

Bryant, J. D., Mc Kenna, M. C. 1995. Cranial anatomy and phylogenetic position of Tsaganomys altaicus (Mammalia, Rodentia) from the Hsanda Gol Formation (Oligocene), Mongolia. American Museum Novitates 3156: 1-42.

Butler, P. M. 1985. Homologies of molar cusps and crests and their bearing of rodent phylogeny. En: Evolutionary Relationships among rodents. A multidisciplinary Analysis. (Eds. Luckett W. P. y Hartenberger J.-L.). Plenum Press: 381-401.

Campbell, K. E.; Frailey, C. D.; Romero-Pittman L. 2004. The Paleogene Santa Rosa Local Fauna of Amazonian Perú: Geographic and Geological Setting. En: The Paleogene Mammalian Fauna of Santa Rosa, Amazonian Peru. (Ed. Campbell K. E.). Natural History Museum of Los Angeles County, Sciences Series N40, pps 3-14.

Candela, A. M. 1999. The evolution of the molar pattern of the Erethizontidae (Rodentia, Hystricognathi) and the validity of Parasteiromys Ameghino, 1904. Palaeovertebrata 28: 53-73.

Candela, A. M. 2000. Los Erethizontidae (Rodentia, Hystricognathi) fósiles de Argentina. Sistemática e historia evolutiva y biogeográfica. Tesis doctoral inédita, Facultad de Ciencias Naturales y Museo, La Plata. Universidad Nacional de La Plata.

Candela, A. M. 2002. Lower deciduous tooth homologies in Erethizontidae (Rodentia, Hystricognathi): Evolutionary significance. Acta Paleontologica Polonica 47: 717-723.

Candela, A. M. 2005. Los roedores del "Mesopotamiense" (Mioceno tardío, Formación Ituzaingó) de la provincia de Entre Ríos (Argentina). Insugeo 14: 37-48. 
Campbell, K. E. 2004. The Paleogene Santa Rosa Local Fauna: Introduction. En: The Paleogene Mammalian Fauna of Santa Rosa, Amazonian Peru. (Ed. Campbell K. E.). Natural History Museum of Los Angeles County, Sciences Series N40, pps 1-2.

Carlini, A. A.; Scillato-Yané, G. J.; Vizcaino, S. 1993. Un Myrmecophagidae (Vermilingua) del Mioceno de Cerro Boleadoras (Santa Cruz, Argentina). Ameghiniana 30: 102.

Carvalho, G.; Salles, L. 2004. Relationships among extant and fossil echimyids (Rodentia, Hystricognathi). Zoological Journal of the Linnean Society 142: 445-477.

Castellanos, A. 1937. Ameghino y la antigüedad del hombre sudamericano. Asociación Cultural de Conferencia, Rosario (Argentina), Ciclo de Carácter General 2: 47-192.

Comité Argentino de Estratigrafía 1992. Código Argentino de Estratigrafía. Asociación Geológica Argentina, serie B, vol. 20 64pps.

Contreras, L. C.; Torres Mura, J. C.; Spotorno, A. E.; Catzeflis, F. M. 1993. Morphological variation of the glans penis of South American octodontid and abrocomid rodents. Journal of Mammalogy 74: 926-935.

Contreras, L. C.; Torres Mura, J. C.; Spotorno, A. E.; Walker, L. I. 1994. Chromosomes of Octomys mimax and Octodontomys gliroides and relationships of octodontid rodents. Journal of Mammalogy 75: 768-774.

Chaffee, R. G. 1952. The Deseadan vertebrate fauna of the Scarrit Pocket, Patagonia. Bulletin of the American Museum of Natural History 98: 503-562.

Croft, D. A. 2007. The middle Miocene (Laventan) Quebrada Honda fauna, southern Bolivia, and a description of its notoungulates. Paleontology 50: 277-303.

Croft, D. A.; Flynn, J. J.; Wyss, A. R. 2004. Notoungulata and Liptopterna of the early Miocene Chucal fauna, Northern Chile. Fieldiana, Geology new series 50: 1-52.

de Pinna, M. C. 1991. Concepts and test of homology in the cladistic paradigma. Cladistics 7: 367-394.

Efron, B. 1979. Boostrao methods: another look at the jacknife. Annals of Statistics 7 : 1-26.

Ellerman, J. R. 1940. The families and genera of living rodents. British Museum of Natural History Vol. 1 y 2. London.

Emmons, L. H. 1997. Neotropical Rainforest Mammals. A field guide. The University of Chicago Press, pps 1-281.

Farris, J. S. 1970. Methods for computing Wagner trees. Systematic Zoology 19: 83-92.

Farris, J. S. 1983. The logical basis of phylogenetic analysis. En: Advances in cladistics. (Eds. Platnick, N. L. y Funk, V. A.) Columbia University Press, pps 7-36. 
Felsenstein, J. 1985. Confidence limits on phylogenies: an approach using the boostrap. Evolution 39: 783-791.

Fernicola, J. C. 2011. Implicancias del conflicto Ameghino-Moreno sobre la colección de mamíferos fósiles realizada por Carlos Ameghino en su primera exploración al río Santa Cruz, Argentina. Revista del Museo Argentino de Ciencias Naturales 13 (1): 41-57.

Fleagle, J. G.; Bown, T. M. 1983. New primate fossils from Late Oligocene (Colhuehuapian) localities of Chubut province, Argentina. Folia Primatologica 41: 240-266.

Fleagle, J. G.; Bown, T. M.; Swisher, C.; Buckley, G. 1995. Age of the Pinturas and Santa Cruz Formations. Actas del VI Congreso Argentino de Paleontología y Bioestratigrafía 129-135.

Flynn, J. L.; Jacobs, L. L.; Cheema, I. U. 1986. Baluchimyinae, a new Ctenodactyloid rodent subfamily from the Miocene of Baluchistan. American Museum Novitates 2841: 1-58.

Flynn, J. J.; Swisher; C. C. 1995. Cenozoic South American Land Mammal Ages: correlation to global geochronologies. Geochronology Time Scales and Global Stratigraphic Correlation. SEPM Special Publication 54: 317-333.

Flynn, J. J.; Novacek, M. J.; Dodson, H. E.; Frassinetti, D.; McKenna, M. C.; Norell, M. A.; Sears, K. E.; Swisher III, C. C.; Wyss, A. R. 2002. A new fossil assemblage from the southern Chilean Andes: implications for geology, geochronology, and tectonics. Journal of South American Earth Sciences 15: 285-302.

Flynn, J. J.; Charrier, R.; Croft, D. A.; Gans, P. B.; Herriott, T. M.; Wertheim, J. A.; Wyss, A. R. 2008. Chronologic implications of new Miocene mammals from the Cura-Mallín and Trapa Trapa Formations, Laguna del Laja area, south central Chile. Journal of South American Earth Sciences 26: 412-423.

Frailey, C. D.; Campbell, K. E. 2004. Paleogene Rodents from Amazonian Peru: The Santa Rosa Local Fauna. En: The Paleogene Mammalian Fauna of Santa Rosa, Amazonian Peru. (Ed. Campbell K. E.). Natural History Museum of Los Angeles County, Sciences Series $\mathrm{N}^{\circ} 40$, pps 71-130.

Frenguelli, J. 1930. Nomenclatura estratigráfica patagónica. Annales de la Sociedad de Ciencia de Santa Fe 3: 1-117.

Galewski, T.; Mauffrey, J.-F. ; Leite, Y. L. R.; Patton, J. L.; Douzery, E. J. P. 2005. Ecomorphological diversification among South American spiny rats (Rodentia, Echimyidae): a phylogenetic and chronological approach. Molecular Phylogenetics and Evolution 34: 601-615. 
Gallardo, M. H. 1992. Karyotipic evolutionin octodontid rodents based on C-band analysis. Journal of Mammalogy 73: 89-98.

Gallardo, M. H.; Kirsch, A. W. 2001. Molecular relationships among Octodontidae (Mammalia: Rodentia: Caviomorpha). Journal of Mammalian Evolution 8: 73-89.

George, W. ; Weir, B. J. 1972. The chromosomes of some octodontids with special reference to Octodontomys (Rodentia, Hystricomorpha). Chromosoma 37: 53-62.

Glanz, W. E.; Anderson, S. 1990. Notes on Bolivian Mammals. 7. A new species of Abrocoma (Rodentia) and relationships of the Abrocomidae. American Museum Novitates 2991: 1-32.

Goin, F. J.; Candela, A. M. 2004. New Paleogene marsupials from the Amazon Basin of Eastern Perú. En: The Paleogene Mammalian Fauna of Santa Rosa, Amazonian Peru. (Ed. Campbell K. E.). Natural History Museum of Los Angeles County, Sciences Series $\mathrm{N}^{\circ} 40$, pps 15-70.

Goloboff, P. A.; Mattoni, C. I.; Quinteros A. S. 2006. Continous characters analyzed as such. Cladistics 22: 589-601.

Goloboff, P. A.; Farris, J.S.; Källersjö, M.; Oxelman, B.; Ramírez, M.; Szumik, C. 2003. Improvements to resampling measures of group support. Cladistics 19: 324-332.

Goloboff, P. A.; Farris, J.S.; Nixon, K. C. 2008. TNT, a free program for phylogenetics analysis. Cladistics 24: 774-786.

Guerrero, J. 1997. Stratigraphy, Sedimentary environments, and the Miocene uplift of the Colombian Andes. En: Vertebrate Paleontology in the Neotropics: The Miocene fauna of La Venta, Colombia. (Eds. Kay, R. F., Madden, R. H., Cifelli, R. H. y Flynn, J. J). Smithsonian Institution Press, pps 15-59.

Hennig, W. H. 1969. Elementos de una sistemática filogenética. Editorial Universitaria de Buenos Aires, $353 \mathrm{pp}$.

Hoffstetter, R. 1968. Un gisement de mammifères deseadiens (Oligocene inferieur) en Bolivie. Comptes Rendus Academies des Sciences, Paris 267 D: 1095-1097.

Hoffstetter, R. 1975. El origen de los Caviomorpha y el problema de los Hystricognathi (Rodentia). Actas del primer Congreso Argentino de Paleontología y Bioestratigrafía, Tucumán, Argentina 2: 505-528.

Hoffstetter, R.; Lavocat, R. 1970. Decouverte dans le Deseadien de Bolivie de genres pentalophodontes appuyant les affinites africaines des Rongeurs Caviomorphes. Comptes Rendus des Seances de l'Academie des Sciences, Paris, (serie D) 271: 172175. 
Holroyd, P. A. 1994. An examination of dispersal origins for Fayum Mammalia. Tesis Doctoral inédita, Department of biological Anthropology and Anatomy, Graduate School of Duke University.

Honeycutt, R. L.; Rowe, D. L.; Gallardo, M. H. 2003. Molecular systematics of the South American caviomorph rodents: relationships among species and genera in the family Octodontidae. Molecular Phylogenetics and Evolution 26: 476-489.

Huchon, D.; Douzery, E. J. P. 2001. From the old World to the New World: a molecular chronicle of the phylogeny and biogeography of Hystricognath rodents. Molecular Phylogenetics and Evolution 20: 238-251.

Huchon, D.; Catzeflis, M. F.; Douzery, J. P. 1999. Molecular evolution of the nuclear von Willebrand factor gene in Mammals and the phylogeny of rodents. Molecular Biology and Evolution 16: 577-589.

Huchon, D.; Catzeflis, M. F.; Douzery J. P. 2000. Variance of molecular datings, evolution of rodents and the phylogenetic affinities between Ctenodactylidae and Hystricognathi. Proceedings of the Royal Society of London 267: 393-402.

Huchon, D.; Chevret, P.; Jordan, U.; Kilpatrick, C.; Ranwez, V.; Enkins, P.; Brosius, J. ; Schmitz, J. 2007. Multiple molecular evidences for a living mammalian fossil. PNAS (doi: 10.1073pnas.0701289104).

International Comission on Stratigraphy 2009. International Stratigraphic Chart.

Jackson, J. E.; Branch, L. C.; Villareal, D. 1996. Lagostomus maximus. Mammalian Species 543: 1-6.

Jaeger, J.-J. 1989. L'evolution de la pentalophodontiechez les rongeurs Caviomorphes (Mammalia, Rodentia). Geobios, mémoire spécial 12: 235-244.

Janis, C. M. 1988. An estimation of tooth volume and hypsodonty indices in Ungulate Mammals, and the correlation of these factors with dietary preference. Memoires du museum National d' Historie Naturelle. Serie C 53: 367-387.

Kay, R; MacFadden, B. J.; Madden, R. H.; Sandeman, H.; Anaya, F. 1998. Revised age of the Salla Beds, Bolivia, and its bearing on the age of the Deseadan South American land mammal "Age". Journal of Vertebrate Paleontology 18: 189-199.

Kearney, M. 2002. Fragmentary taxa, Missing data, and ambiguity: mistaken assumptions and conclusions. Sust. Biology 51: 369-381.

Kitching, I. J.; Forey, P. L.; Humphries, C. J.; Williams, D. L. 1998. Cladistics. The Theory and practice of parsimony analysis. $2^{\circ}$ Edition, Systematics Association Publication. Oxfford University Press, New York. 
Kraglievich, L. 1930a. Diagnosis osteológico-dentaria de los géneros vivientes de la subfamilia Caviinae. Anales del Museo Nacional de Historia Natural de Buenos Aires 36: 59-95.

Kraglievich, L. 1930b. La Formación Friaseana del río Frías, río Fénix, Laguna Blanca, etc., y su fauna de mamíferos. Physis 10: 127-161.

Kraglievich, L. 1932. Nuevos apuntes para la geología y paleontología uruguayas. Anales del Museo de Historia Natural de Montevideo 3: 257-321.

Kraglievich, L. 1934. La antigüedad pliocena de las faunas de Monte Hermoso y Chapadmalal, deducidas de la comparación con las que le procedieron y sucedieron. Imprenta El Siglo Ilustrado, pps. 1-136.

Kraglievich, J. L. 1965. Speciation Phyletique dans les rongeurs fossiles du genre Eumysops Ameghino (Echimyidae, Heteropsomyinae). Extrait de Mammalia 29: 258-267.

Kramarz, A. G. 2001a. Un Nuevo roedor Adelphomyinae (Hystricognathi, Echimyidae) del Mioceno Medio-Inferior de Patagonia, Argentina. Ameghiniana 38: 163-168.

Kramarz, A. G. 2001b. Revision of the Family Cephalomyidae (Rodentia, Caviomorpha) and new cephalomids from the early Miocene of Patagonia. Palaeovertebrata 30: 51-88.

Kramarz, A. G. 2004. Octodontoids and erethizontoids (Rodentia, Hystricognathi) from the Pinturas Formation, Early- Middle Miocene of Patagonia, Argentina. Ameghiniana 41: 199-216.

Kramarz, A. G. 2005. Hystricognath rodents from the Pinturas Formation, Early-Middle Miocene of Patagonia, biostratigraphic and paleoenvironmental implications. Journal of South American Erath Sciences 18: 199-212.

Kramarz, A. G.; Bellosi, E. S. 2005. Hystricognath rodents from the Pinturas Formation, Early- Middle Miocene of Patagonia, biostratigraphic and paleoenviromental implications. Journal of South American Earth Sciences 18: 199-212.

Kramarz, A. G.; Garrido, A.; Forasiepi, A.; Bond, M.; Tambussi, C. 2005.

Estratigrafía y vertebrados (Aves y Mamíferos) de la Fm Cerro Bandera, Mioceno temprano de la Provincia del Neuquén, Argentina. Revista Geológica de Chile 32: 273291.

Kramarz, A. G.; Vucetich, M. G.; Carlini, A. A.; Ciancio, M. R.; Abello, M. A.; Deschamps, M. C.; Gelfo, J. N. 2010. A new mammal fauna at the top of the Gran Barranca sequence and its biochronological significance. En: The Paleontology of Gran Barranca: Evolution and Environmental Change trough the Middle Cenozoic of Patagonia. (Eds 
Madden R. H., Carlini A. A., Vucetich M. G., y Kay R. F.) Cambridge University Press: 260-273.

Landry, S. O. Jr 1957. The interrelationships of the New and Old World Hystricomorph rodents. University of California Press Berkeley and California 56: 1-118.

Landry, S. O. 1999. A proposal for a new classification and nomenclature for the Glires (Lagomorpha and Rodentia). Mitteilungen aus dem Museum für Naturkunde in Berlin Reihe 75 2: 283-316.

Lavocat, R. 1976. Rongeurs caviomorphes de L’Oligocene de Bolivie. II. Rongeurs de Bassin Deseadien de Salla-Luribay. Palaeovertebrata 7: 15-90.

Leanza, H. A.; Hugo, C. A.1997. Hoja Geológica 3969-III -Picún Leufú, provincias del Neuquén y Río Negro. Instituto de Geología y Recursos Naturales, SEGEMAR, Boletín 218: 1-135. Buenos Aires.

Leite, Y. L.; Patton, J. L. 2002. Evolution of South American spiny rats (Rodentia, Echimyidae): the star-phylogeny hypothesis revisited. Molecular Phylogenetics and Evolution 25: 455-464

Loomis, F. B. 1914. The Deseado formation of Patagonia. Amherst, Massachussetts, Amherst Colleague, pps 1-232.

López, G. M.; Vucetich, M. G.; Carlini, A. A.; Bond, M.; Pérez, M. E.; Ciancio, M. R.; Pérez, D. J.; Arnal, M.; Olivares, A. I. 2010. New Miocene Mammal assemblages from Neogene Manantiales Basin, Cordillera Frontal, San Juan, Argentina. En: Cenozoic Geology of the Central Andes of Argentina (Eds. Salfity J. A. and Marquillas R. A.) Special Paper of the Geological Society of America: 211-226.

MacFadden, B. J.; Campbell, K. E.; Cifelli, R. L.; Siles, O.; Jhonson, N. M.; Naeser, C. W.; Zeiler, P. K. 1985. Magnetic polarity stratigraphy and mammalian fauna of Deseadan (Late Oligocene) Salla beds of Northern of Bolivia. Journal of Geology 93: 223-250.

Madden, R. H.; Guerrero, J.; Kay, R. F.; Flynn, J. J.; Swisher, C. C.; Walton, A. H. 1997. The Laventan Stage and Age. En: Vertebrate Paleontology in the Neotropics: The Miocene Fauna of La Venta, Colombia (Eds Kay, R. F.; Madden, R. H.; Cifelli, R. H. y Flynn, J. J.) Smithsonian Institution Press, Washington D. C. pps 499-519.

Mares, M. A.; Ojeda, R. A. 1982. Patterns of diversity and adaptation in South American Hystricognath rodents. En: Mammalian Biology in South America (Eds. Mares M. A y Genoways H.) Special Publication Pymatuning Laboratory of Ecology 6: 393-432. 
Marivaux, L. ; Vianey-Liaud, M. ; Welcomme, J.-L. ; Jaeger, J.-J. 2001. The role of Asia in the origin and diversification of histricognathous rodents. Zoologica Scripta 31: 225239.

Marivaux, L.; Welcomme, J.-L. 2003. New Diatomyid and Baluchimyine rodents from the Oligocene of Pakistan (Bugti Hills, Balochistan): systematic and paleobiogeographic implications. Journal of Vertebrate Paleontology 23: 420-434.

Marivaux, L.; Vianey-Liaud, M. ; Jaeger, J.-J. 2004. High-level phylogeny of early Tertiary rodents: dental evidence. Zoological Journal of the Linnean Society 142: 105-134.

Marshall L. G. 1976. Fossil localities for santacrucian (early Miocene) Mammals, Santa Cruz province, southern Patagonia, Argentina. Journal of Paleontology 50: 1129-1142.

Marshall, L. G. 1980. Systematics of the south american marsupial family Caenolestidae. Fieldiana Geology 5: 1-145.

Marshall, L. G.; Pascual, R. 1977. Nuevos marsupials Caenolestidae del "Piso Notohippidiense" (SW de Santa Cruz, Patagonia) de Ameghino. Sus aportaciones a la cronología y evolución de las comunidades de mamíferos sudamericanos. Publicaciones del Museo Municipal de Ciencias Naturales de Mar del Plata "Lorenzo Scaglia" 2: 91 122.

Marshall, L. G.; Hoffstetter, R.; Pascual, R. 1983. Mammals and stratigraphy: geochronology of the continental mammal-bearing Tertiary of South America. Palaeovertebrata 1-93.

Marshall, L. G.; Cifelli, R. L.; Drake, R. E.; Curtis, G. H. 1986a. Vertebrate paleontology, geology, and geochronology of the Tapera de López and Scarritt Pocket, Chubut province, Argentina. Journal of Paleontolgy 60: 920-951.

Marshall, L. G.; Drake, R. R.; Curtis, G. H.; Butler, R. F.; Glanagan, K. M.; Naeser, C. W. 1986b. Geochronology of the type Santacrucian (middle Tertiary) land mammal age, Patagonia, Argentina. Journal of Geology 94: 449-457.

Martin, T. 1992. Schmelzmuster in den Incisiven Alt- und Neuweltlicher hystricognather Nagetiere. Palaeovertebrata, Mémoires Extraordinalles: 1-168.

Martin, T. 1994. African origin of caviomorph rodents is indicated by incisor enamel microstructure. Paleobiology 20: 5-13.

Mendía, J. E.; Bayarsky, A. 1981. Estratigrafía del Terciario en el Valle inferior del río Chubut. Actas del VIII Congreso Geológico Argentino 3: 593-606.

Meng, J.; Yaoming, H.; Chuankui, L. 2003. The osteology of Rhombomylus (Mammalia, Glires): implications for phylogeny and evolution of Glires. Bulletin of the American Museum of Natural History 275: 1-247. 
Mones, A. 1982. An equivocal nomenclature: what means hypsodonty?. Palaeöntologische Zeitschrift 56: 107-111.

Mones, A.; Ubilla, M. 1978. La edad Deseadense (Oligoceno inferior) de la Formación Fray Bentos y su contenido paleontológico, con especial referencia a la presencia de Proborhyaena cf. gigantea Ameghino (Marsupialia, Borhyaenidae) en el Uruguay. Nota preliminar. Comunicaciones paleontológicas del Museo de Historia Natural de Montevideo 1: 151-158.

Mones, A.; Castiglioni, 1979. Addition to the knowledge on fossil rodents of Uruguay (Mammalia, Rodentia). Palaeöntologische Zeitschrift 53: 77-87.

Montalvo, C. I.; Cardonatto, M. C.; Visconti, G.; Verzi, D. H.; Vucetich, M. G. 1996. Vertebrados de la Formación Cerro Azul (Mioceno tardío) del Valle de Quehué, provincia de La Pampa, Argentina. Actas VI Jornadas Pampeanas de Ciencias Naturales, Coprocna: 159-165.

Mouchaty, S. K. ; Catzeflis, F. ; Janke, A. ; Arnason, U. 2001. Molecular evidence of an African Phiomorpha- South American caviomorpha clade and support for Hystricognathi based on the complete Mitochondrial genome of the cane rat (Thryonomys swinderianus). Molecular Phylogenetics and Evolution 18: 127-135.

Nedbal, M. A.; Allard, M. W.; Honeycutt, R. L. 1994. Molecular Systematics of Hystricognath rodents: evidence from the Mitichondrial 12S rRNA gene. Molecular Phylogenetics and Evolution 3: 206-220.

Norell, M. A. 1992. Taxic origin and temporal diversity: the effect of phylogeny (Eds Novaceck and Wheeler) Columbia University, pp. 89-118.

Nowak, R. M. 1991. Walker's Mammals of the World, $5^{\text {th }}$ ed. Maryland, Johns Hopkins University Press.

Olivares, A. I. 2009. Anatomía, Sistemática y evolución de los roedores caviomorfos sudamericanos del género Eumysops Ameghino (Rodentia, Echimyidae). Tesis Doctoral inédita, Facultad de Ciencias Naturales y Museo de La Plata. Universidad Nacional de La Plata.

Ortiz Jaureguizar, E; Cladera, G. A. 2006. Paleoenvironmental evolution of southern South America during the Cenozoic. Journal of Arid Environments 66: 498-532.

Palazzesi, L.; Barreda, V. 2007. Major vegetation trends in the Tertiary of Patagonia (Argentina): a qualitative Paleoclimatic approach based on palynological evidence. Flora 202: 328-337. 
Parera, A. 2002. Los mamíferos de Argentina y la región Austral de Sudamérica. El Ateneo, Buenos Aires, Argentina, 443 pps.

Pascual, R; Ortega Hinojosa, E. J.; Gondar, D.; Tonni, E. 1965. Las edades del cenozoico mamalífero de la Argentina, con especial atención en aquellas del territorio Bonaerense. Anales de la Comisión de Investigaciones de Ciencias de Buenos Aires 6: 165-193.

Pascual, R. 1967. Los roedores Octodontoidea (Caviomorpha) de la Formación Arroyo Chasicó (Plioceno inferior) de la Provincia de Buenos Aires. Revista de Museo de La Plata (Paleontología) 5: 259-282.

Pascual, R; Odreman Rivas, O. E. 1971. Evolución de las comunidades de vertebrados del Terciario Argentino. Los aspectos paleozoogeográficos y paleoclimáticos asociados. Ameghiniana 7: 372-412.

Pascual, R.; Ortiz Jaureguizar, E. 1990. Evolving climates and mammal faunas in the Cenozoic South America. Journal of Human Evolution 19: 23-60.

Patterson, 1952. Manuscrito inédito depositado en el MLP.

Patterson, B.; Pascual R. 1968. New echimyids rodents from the Oligocene of Patagonia and a synopsis of the Family. Breviora 301: 1-14.

Patterson, B.; Pascual, R. 1972. The fossil Mammal fauna of South America. En: Evolution, Mammals and Southern continents (Eds Keast A., Erk F. C. y Glass B.) State University of New York Press, pp. 247-309.

Patterson, B.; Marshall, L. G. 1978. The Deseadan, early Oligocene, Marsupialia of South America. Fieldiana Geology 41: 37-100.

Patterson, B.; Wood, A. E. 1982. Rodents from the Deseadan Oligocene of Bolivia and the relationships of the Caviomorpha. Bulletin of Museum of Comparative Zoology, Harvard 149: 371-543.

Pérez, M. E. 2010a. A new rodent (Cavioidea, Hystricognathi) from the middle Miocene of Patagonia, mandibular homologies, and the origin of the crown group Caviodea sensu stricto. Journal of Vertebrate Paleontology 30: 1848- 1859.

Pérez, M. E. 2010b. Sistemática, ecología y bioestratigrafía de Eocardiidae (Rodentia, Hystrocognathi, Cavioidea) del Mioceno temprano y medio de Patagonia. Tesis Doctoral inédita, Facultad de Ciencias Naturales y Museo de La Plata. Universidad Nacional de La Plata.

Pol, D.; Escapa, I. H. 2009. Unstable taxa in cladistic analysis: identification and the assessment of relevant characters. Clasdistics 25: 1-13. 
Pol, D.; Norell, M. A. 2006. Uncertainty in the age of fossils and the stratigraphic fit to phylogenies. Systematic Biology 55: 512-521.

Ré, G. H.; Bellosi, E. S.; Heizler, M.; Vilas, J. F.; Madden, R. H.; Carlini, A. A.; Kay, R. F.; Vucetich, M. G. 2010. A geochronology for the Sarmiento Formation at Gran Barranca. En: The Paleontology of Gran Barranca: Evolution and Environmental Change trough the Middle Cenozoic of Patagonia. (Eds Madden R. H., Carlini A. A., Vucetich M. G., y Kay R. F.) Cambridge University Press, pps 46-58.

Reguero, M. A; 1998. El problema de las relaciones sistemáticas y filogenéticas de los Typotheria (Mammalia, Notoungulata): análisis de los taxones de Patagonia de la Edad Mamífero Deseadense (Oligoceno). Tesis Doctoral inédita, Facultad de Ciencias Exactas y Naturales. Universidad Nacional de Buenos Aires.

Reguero, M. A; Prevosti, F. J. 2010. Rodent-like notoungulates (Typotheria) from Gran Barranca, Chubut province, Argentina: phylogeny and systematics. En: The Paleontology of Gran Barranca: Evolution and Environmental Change trough the Middle Cenozoic of Patagonia. (Eds Madden R. H., Carlini A. A., Vucetich M. G., y Kay R. F.) Cambridge University Press, pps 152- 169.

Reig, O. A. 1981. Teoría del origen y desarrollo de la fauna de mamíferos de América del Sur. Monographie Naturae. Museo de Ciencias Naturales de Mar del Plata "Lorenzo Scaglia” 1: 1-116.

Reig, O. A. 1986. Diversity pattern and differentiation of High Andean rodents. En: High Altitude Tropical Biogeography. (Eds Vuilleumier F. y Monasterio M.) Oxford University Press, pps 404-439.

Reig, O. A. 1989. Karyotypic repatterning as one triggering factor in cases of explosive speciation. En: Evolutionary biology of transient unstable populations. (Ed Fontdevila A.) Springer-Verlag, Berlin: 246-289.

Rieppel, O. 1994. Homology, topology, and typology: the history of modern debates. En: Homology: the hierarchical Basis of Comparative Biology (Ed. Hall, B. K.). Academic Press, San Diego: 55-75.

Rossi, M. S.; Reig, O. E.; Zorzopulos J. 1990. Evidence for rolling-circle replication in a major satellite DNA from the South American rodents of the genus Ctenomys. Molecular Biology and Evolution 7: 340-350.

Roth, S. 1898. Apuntes sobre la geología y paleontología en los territorios del Río Negro y Neuquén. Revista del Museo de La Plata 9: 143-196. 
Roth, S. 1908. Beitrag zur Gliederung der Sedimentablagerungen in Patagonien und der Pampasregion. Neues Jahrbuch für Mineralogie, Geologie und Paläontologie 26: 92150.

Roth, S. 1920. Investigaciones geológicas de la llanura pampeana. Revista del Museo de La Plata 25: 135-342.

Rovereto, C. 1914. Los estratos Araucanos y sus fósiles. Anales del Museo de Historia Natural de Buenos Aires 25: 1-250.

Rusconi, C. 1933. Nuevos restos de monos fósiles del Terciario antiguo de Patagonia. Anales de la Sociedad Científica Argentina 116: 286-289.

Salazar-Bravo, J.; Dragoo, J. w.; Tinnin, D. S.; Yates, T. L. 2001. Phylogeny and evolution of the Neotropical rodent genus Calomys: inferences from mitochondrial DNA sequence data. Molecular Phylogenetics and Evolution 20: 173-184.

Scillato-Yané ; G. H.; Carlini, A. A.; Vizcaino, S. 1993. Los Xenarthra (Mammalia, Edentata) del Mioceno medio de Patagonia. Ameghiniana 30: 352.

Scott, W. B. 1905. Mammalia of the Santa Cruz beds. En: Reports of the Princeton University Expeditions to Patagonia 1896-1899. Parte III, Glires 39: 348-487.

Shockey, B. J.; Hitz, R.; Bond M. 2004. Paleogene Notoungulates from the Amazon Basin of Peru. En: The Paleogene Mammalian Fauna of Santa Rosa, Amazonian Peru. (Ed. Campbell K. E.). Natural History Museum of Los Angeles County, Sciences Series $\mathrm{N}^{\circ} 40$, pps 61-70.

Simpson, G. G. 1935. Early and middle Tertiary geology of the Gaiman region, Chubut, Argentina. American Museum Novitates 775: 1-29.

Simpson, G. G. 1940. Review of the mammal bearing Tertiary of South America. Proceedings of the American Philosophical Society 86: 403-404.

Simpson, G. G. 1941. How we knew where to dig?. En: Through hell and high water. Pps205-209.

Simpson, G. G. 1945. The principles of classification and a classification of mammals. Bulletin of the American Museum of Natural History 85: 350pps.

Simpson, G. G. 1948. The beginning of the age of mammals in South America. Bulletin of the American Museum of Natural History 91: 1-232.

Soria, M. F.; Alvarenga, H. 1989. Nuevos restos de mamíferos de la Cuenca de Taubaté, Estado de Sao Paulo, Brasil. Anales de la Academia Brasilera de Ciencias 61:157-175. 
Spalletti, L. A.; Mazzoni, M. M. 1979. Estratigrafía de la Formación Sarmiento en la barranca sur del lago Colhue Huapi, provincial del Chubut. Revista de la Asociación Geológica Argentina 34: 271-281.

Spotorno, A. E.; Valladares, J. P.; Marin, J. C.; Palma, R. E.; Zuleta, C. A. 2004. Molecular divergence and phylogenetic relationships of chinchillids (Rodentia, Chinchillidae). Journal of Mammalogy 85: 384-388.

Tauber, A. A. 1994. Estratigrafía y vertebrados fósiles de la Formación Santa Cruz (Mioceno Inferior) de la costa atlántica entre las rías del Coyle y de Río Gallegos, Provincia de Santa Cruz, República Argentina. Tesis Doctoral inédita, Facultad de Ciencias Exactas, Físicas y Naturales. Universidad Nacional de Córdoba.

Tauber, A. A. 1997. Bioestratigrafía de la Formación Santa Cruz (Mioceno Inferior) en el extremo sudeste de la Patagonia. Ameghiniana 34: 413-426.

Tullberg, T. 1899. Über das System der Nagertiere: eine phylogenetische Studie. Nova Acta Regiae Societatis Scientiarium Upsaliensis 3: 1-514.

Ugarte, F. R. E. 1956. El Grupo de Río Zeballos en el flanco occidental de la Meseta Buenos Aires (provincia de Santa Cruz). Revista de la Asociación Geológica Argentina 11: 202216.

Van der Klaauw, C. J. 1931. The auditory bulla in some fossil mammals with a general introduction on this region of the skull. Bulletin of the American Museum of Natural History 62: 1-352.

Verzi, D. H. 1999. The dental evidence on the differentiation of the ctenomyine rodents (Caviomorpha, Octodontidae, Ctenomyinae). Acta Theriologica 44: 263-282.

Verzi, D. H. 2001. Phylogenetic position of Abalosia and the evolution of the extant Octodontinae (Rodentia, Caviomorpha, Octodontidae) Acta Theriologica 46: 243-268.

Verzi, D. H. 2002. Patrones de evolución morfológica en Ctenomyinae (Rodentia, Octodontidae). Mastozoología Neotropical 9: 309-328.

Verzi, D. H. 2008. Phylogeny and adaptive diversity of rodents of the family Ctenomyidae (Caviomorpha): delimiting lineages and genera I the fossil record. Journal of Zoology 274: 386-394.

Verzi, D. H.; Carrín Iglesias, M. 1999. Revisión de las afinidades de un primitivo Octodontidae (Rodentia, Caviomorpha) del Plioceno de Argentina. Boletín de la Real Sociedad Española de Historia Natural 94: 99-104. 
Verzi, D. H.; Montalvo, C. I.; Vucetich, M. G. 1991. Nuevos restos de Xenodontomys simpsoni Kraglievich y la sistemática de los más antiguos Ctenomyinae (Rodentia, Octodontidae). Ameghiniana 28: 325-331.

Verzi, D. H.; Vucetich, M. G.; Montalvo, C. I. 1994. Octodontid-like Echimyidae (Rodentia): an Upper Miocene episode in the radiation of the Family. Palaeovertebrata 23: 199-210.

Verzi, D.H.; Montalvo, C. I.; Vucetich, M. G. 1999. Afinidades y significado evolutivo de Neophanomys biplicatus (Rodentia, Octodontidae) del Mioceno tardío- Plioceno temprano de Argentina. Ameghiniana 36: 83-90.

Verzi, D. H.; Tonni, E. P.; Scaglia, O. A.; San Cristobal, J. O. 2002. The fossil record of the desert adapted South American rodent Tympanoctomys (Rodentia, Octodontidae). Paleoenvironmental and biogeographic significance. Palaeogeography, Palaeoclimatology, Palaeoecology 179: 149-158.

Voss, R.; Angermann, R. 1997. Revisionary notes on Neotropical Porcupines (Rodentia, Erethizontidae). I Type material described by Olfers (1818) and Kuhl (1820) in the Berlin Zoological Museum. American Museum Novitates 3214: 1-44.

Vucetich, M. G. 1978. El primer Octodontidae (Rodentia, Caviomorpha) registrado en sedimentos de la Edad Friasense (Mioceno tardío). Ameghiniana 13: 331.

Vucetich, M. G. 1984. Los roedores de la edad Friasense (Mioceno medio) de Patagonia. Tesis Doctoral inédita, Facultad de Ciencias Naturales y Museo de La Plata. Universidad Nacional de La Plata.

Vucetich, M. G. 1994. La fauna de roedores de la Formación Cerro Boleadoras (Mioceno Inferior?) en la provincia de Santa Cruz (Argentina). Acta Geológica Leopoldensia 39: 365-374.

Vucetich, M. G.; Bond, M. 1984. Un nuevo Octodontoidea (Rodentia, Caviomorpha) del Oligoceno tardío de la provincia de Chubut (Argentina). Ameghiniana 21: 105-114.

Vucetich, M. G.; Verzi, D.H. 1991. Un nuevo Echimyidae (Rodentia, Hystricognathi) de la Edad Colhuehuapense de Patagonia y consideraciones sobre la sistemática de la familia. Ameghiniana 28: 67-74.

Vucetich, M. G.; Verzi, D. H. 1992. Las homologías en los diseños oclusales de los roedores Caviomorpha: un modelo alternativo. Mastozoología Neotropical 1: 61-72.

Vucetich, M. G.; Verzi, D.H. 1994. The presence of Protadelphomys (Rodentia, Echimyidae) in the Colhuehuapian of the South Barracas of lake Colhue Huapi (Chubut). Ameghiniana 31: 93-94. 
Vucetich, M. G.; Verzi, D.H. 1996. A peculiar octodontoid (Rodentia, Caviomorpha) with terraced molars from the Lower Miocene of Patagonia (Argentina). Journal of Vertebrate Paleontology 16: 297-302.

Vucetich, M. G.; Ribeiro, A. M. 2003. A new and primitive rodent from the Tremembé Formation (Late Oligocene) of Brazil, with comments on the morphology of the lower premolars of Caviomorph rodents. Revista Brasileira de Paleontología 5: 73-82.

Vucetich, M. G.; Kramarz, G. A. 2003. New Miocene rodents from Patagonia (Argentina) and their bearing on the early radiation of the Octodontoids (Hystricognathi). Journal of Vertebrate Paleontology 23: 435-444.

Vucetich, M. G.; Vieytes, E. C. 2006. A middle Miocene primitive octodontoid rodent and its bearing on the early evolutionary history of the Octodontoidea. Palaeontolographica Abteilung 277: 81-91.

Vucetich, M. G.; Verzi, D.H.; Dozo, M T. 1992. El "status" sistemático de Gaimanomys alwinea (Rodentia, caviomorpha, Echimyidae). Ameghiniana 29: 85-85.

Vucetich, M. G.; Mazzoni, M. M.; Pardiñas, J. F. 1993. Los roedores de la Formación Collón Curá (Mioceno Medio), y la Ignimbrita Pilcaniyeu. Cañadón del Tordillo, Neuquén. Ameghiniana 30: 361-381.

Vucetich, M. G.; Souza Cunha, F. L.; Ferraz d Alvarenga, H. M. 1993. Un roedor Caviomorpha de la Formación Tremembé (Cuenca de Taubaté), Estado de Sao Paulo, Brasil. Anales de la Academia Brasilera de Ciencias 65: 247-251.

Vucetich, M. G.; Verzi, D.H.; Hartenberger, J.-L. 1999. Review and analysis of the radiation of the South American Hystricognathi (Mammalia, Rodentia). Comptes Rendus Académie des Sciendes Paris, Sciences de la terre et des planetes 329: 763-769.

Vucetich, M. G. ; Vieytes, E. C. ; Pérez, M. E. ; Carlini, A. A. 2010a. The rodents from La Cantera and the early evolution of caviomorph in South America. En: The Paleontology of Gran Barranca: Evolution and Environmental Change trough the Middle Cenozoic of Patagonia. (Eds Madden R. H., Carlini A. A., Vucetich M. G., y Kay R. F.) Cambridge University Press, pps 189-201.

Vucetich, M. G.; Kramarz, A. G.; Candela, A. M. 2010b. Colhuehuapian rodents from Gran Barranca and other Patagonian localities: the state of the art. En: The Paleontology of Gran Barranca: Evolution and Environmental Change trough the Middle Cenozoic of Patagonia. (Eds Madden R. H., Carlini A. A., Vucetich M. G., y Kay R. F.) Cambridge University Press, pps 206- 219. 
Wahlert, J. H. 1983. Relationships of the Florentiamyidae (Rodentia, Geomyoidea) based on cranial and dental morphology. American Museum Novitates 2769: 1-23.

Wahlert, J. H. 1985. Cranial foramina of rodents. En: Evolutionary relationships among rodents. A multidisciplinary analysis. (Eds Luckett W. P. y Hartenberger J.-L.). Plenum Press, New York, pps 311-331.

Wahlert, J. H. 1991. The Harrymyinae, a new Heteromyid Subfamily (Rodentia, Geomorpha), based on cranial and dental morphology of Harrymys Munthe, 1988. American Museum Novitates 3013: 1-23.

Walton, A. 1990. Rodents. En: Vertebrate paleontology in the Neotropic. The Miocene fauna of La Venta (Eds. Kay R. F., Madden R. H., Cifelli R. L. y Flynn J. J.). Smithsonian Institution Press, Washington: 392-409.

Walton, A. 1997. Rodents. En: Vertebrate Paleontology in the Neotropics: The Miocene fauna of La Venta, Colombia. (Eds. Kay, R. F., Madden, R. H., Cifelli, R. H. y Flynn J. J). Smithsonian Institution Press, pps 499-519.

Waterhouse, G. E. 1839. Observations on the Rodentia, with a view to point out the groups, as indicated by the structure of the crania in this order of Mammals. Magazine of Natural History 3: 90-96.

Wible, J. R.; Wang Yuanqing, Li Chuankui; Dawson, M. R. 2005. Cranial anatomy and relationships of a new Ctenodactyloid (Mammalia, Rodentia) from the early Eocene of Hubei province, China. Annals of Carnegie Museum 74: 91-150.

Wood, A. E. 1949. A new Oligocene rodent genus from Patagonia. American Museum Novitates 1435: 1-54.

Wood, A. E. 1955. A revised classification of the rodents. Journal of Mammalogy 36: 165187.

Wood, A. E. 1968. Early Cenozoic Mammalian Faunas, Fayum Province, Egypt. Part II: The African Oligocene Rodentia. Bulletin of the Peabody Museum of Natural History 28: 23-105.

Wood, A. E. 1985. Northern waif primates and rodents. En: The great America biotic interchange. (Eds. Stehli F. G. y Webb S. D.). Plenum Press, New York, pps 267-282.

Wood, A. E.; Patterson, B. 1959. The rodents of the Deseadan Oligocene of Patagonia and the beginnings of South American rodent evolution. Bulletin Museum of Comparative Zoology 120: 281-428. 
Woods, C. A. 1972. Comparative myology of jaw, hyoid and pectoral appendicular regions of New and Old World hystricomorph rodents. Bulletin of the American Museum of Natural History 147: 115-198.

Woods, C. A. 1984. Hystricognath rodents. En: Orders and Families of recent mammals of the World. (Eds. Anderson S. y Jones Jr. J. K.). Wiley, Ney York, pps 389-446.

Woods, C. A.; Howland, E. B. 1979. Adaptative radiation of capromyid rodents: anatomy of the masticatory apparatus. Journal of Mammalogy 60: 95-116.

Woods, C. A.; Hermanson, J. W. 1985. Myology of Hystricognath rodents: an analysis of form, function and phylogeny. En: Evolutionary relationships among rodents. A multidisciplinary analysis. (Eds. Luckett W. P. y Hartenberger J.-L.) Plenum Press, New York: 515-547.

Woods, C. A.; Kilpatrick, C. W. 2005. Infraorder Hystricognathi Brandt, 1855. En: Mammal species of the World (Eds. Wilson, D. E. y Reeder, D. M.). Johns Hopkins University Press, pps. 1538-1600. 


\section{APÉNDICE 1. Listado de octodontoideos fósiles vinculados al origen de los Octodontidae}

\begin{tabular}{|c|c|c|c|c|}
\hline ESPECIMEN & MATERIAL & DESCRIPCIÓN & LOCALIDAD & $\begin{array}{l}\text { PROCEDENCIA } \\
\text { ESTRATIGRÁFICA } \\
\text { Y CRONOLÓGICA }\end{array}$ \\
\hline $\begin{array}{l}\text { Acaremys murinus } \\
\text { (Sintipo) }\end{array}$ & MLP 15-410 & $\begin{array}{l}\text { Porción anterior de cráneo } \\
\text { con DP4-M1 izquierdo y } \\
\text { derecho e incisivos partidos }\end{array}$ & Santa Cruz & $\begin{array}{l}\text { Fm Santa Cruz, } \\
\text { Mioceno temprano } \\
\text { superior }\end{array}$ \\
\hline Acaremys murinus & AMNH 9280 & $\begin{array}{l}\text { Cráneo casi completo con } \\
\text { toda la dentadura }\end{array}$ & Patagonia & $\begin{array}{l}\text { Fm Santa Cruz, } \\
\text { Mioceno temprano } \\
\text { superior }\end{array}$ \\
\hline Acaremys murinus & MACN A 249 & $\begin{array}{l}\text { Mandíbula izquierda con } \\
\text { p4-m3 }\end{array}$ & Santa Cruz & $\begin{array}{l}\text { Fm Santa Cruz, } \\
\text { Mioceno temprano } \\
\text { superior }\end{array}$ \\
\hline $\begin{array}{l}\text { Acaremys murinus } \\
\text { (Sintipo) }\end{array}$ & MACN A 266 & $\begin{array}{l}\text { Mandíbula derecha casi } \\
\text { completa con toda la } \\
\text { dentadura. Incisivo partido }\end{array}$ & Santa Cruz & $\begin{array}{l}\text { Fm Santa Cruz, } \\
\text { Mioceno temprano } \\
\text { superior }\end{array}$ \\
\hline Acaremys murinus & MACN A 1879 & $\begin{array}{l}\text { Rama mandibular derecha } \\
\text { casi completa con p4-m } 2 \text { e } \\
\text { incisivo }\end{array}$ & Santa Cruz & $\begin{array}{l}\text { Fm Santa Cruz, } \\
\text { Mioceno temprano } \\
\text { superior }\end{array}$ \\
\hline Acaremys murinus & MACN A 1885 & $\begin{array}{l}\text { Cráneo casi completo mal } \\
\text { preservado, con toda la } \\
\text { dentadura }\end{array}$ & Santa Cruz & $\begin{array}{l}\text { Fm Santa Cruz, } \\
\text { Mioceno temprano } \\
\text { superior }\end{array}$ \\
\hline Acaremys murinus & MACN A 1899 & $\begin{array}{l}\text { Mandíbula derecha casi } \\
\text { completa con p4-m3 e } \\
\text { incisivo partido }\end{array}$ & Santa Cruz & $\begin{array}{l}\text { Fm Santa Cruz, } \\
\text { Mioceno temprano } \\
\text { superior }\end{array}$ \\
\hline Acaremys murinus & MACN A 1900 & $\begin{array}{l}\text { Fragmento mandibular } \\
\text { derecho con p4-m3 e } \\
\text { incisivo partido }\end{array}$ & Santa Cruz & $\begin{array}{l}\text { Fm Santa Cruz, } \\
\text { Mioceno temprano } \\
\text { superior }\end{array}$ \\
\hline Acaremys murinus & MACN A 4112 & $\begin{array}{l}\text { Fragmento mandibular } \\
\text { izquierdo con } \mathrm{p} 4-\mathrm{m} 3 \mathrm{e} \\
\text { incisivo partido }\end{array}$ & Santa Cruz & $\begin{array}{l}\text { Fm Santa Cruz, } \\
\text { Mioceno temprano } \\
\text { superior }\end{array}$ \\
\hline $\begin{array}{l}\text { "Acaremys" tricarinatus } \\
\text { (Holotipo) }\end{array}$ & MACN A 4113 & $\begin{array}{l}\text { Ramas mandibulares } \\
\text { izquierda y derecha } \\
\text { parcialmente preservadas y } \\
\text { unidas; con toda la } \\
\text { dentadura y los incisivos }\end{array}$ & $\begin{array}{l}\text { Monte } \\
\text { Observación, Santa } \\
\text { Cruz }\end{array}$ & $\begin{array}{l}\text { Fm Santa Cruz, } \\
\text { Mioceno temprano } \\
\text { superior }\end{array}$ \\
\hline Acaremys murinus & MACN A 4120 & $\begin{array}{l}\text { Mandíbula derecha con } \\
\text { incisivo en el alveolo y p4- } \\
\text { m3 }\end{array}$ & Santa Cruz & $\begin{array}{l}\text { Fm Santa Cruz, } \\
\text { Mioceno temprano } \\
\text { superior }\end{array}$ \\
\hline Acaremys murinus & MACN A 4128 & $\begin{array}{l}\text { Mandíbula derecha casi } \\
\text { completa con toda la } \\
\text { dentadura. Incisivo partido }\end{array}$ & Santa Cruz & $\begin{array}{l}\text { Fm Santa Cruz, } \\
\text { Mioceno temprano } \\
\text { superior }\end{array}$ \\
\hline Acaremys murinus & MACN A 4133 & $\begin{array}{l}\text { Mandíbula derecha casi } \\
\text { completa con toda la } \\
\text { dentadura. Incisivo partido }\end{array}$ & Santa Cruz & $\begin{array}{l}\text { Fm Santa Cruz, } \\
\text { Mioceno temprano } \\
\text { superior }\end{array}$ \\
\hline Acaremys murinus & MACN A 4143 & $\begin{array}{l}\text { Cráneo mal preservado con } \\
\text { P4-M1 izquierdo y M1-M3 } \\
\text { derecho }\end{array}$ & $\begin{array}{l}\text { Corrigen Aike, } \\
\text { Santa Cruz }\end{array}$ & $\begin{array}{l}\text { Fm Santa Cruz, } \\
\text { Mioceno temprano } \\
\text { superior }\end{array}$ \\
\hline Acaremys murinus & MACN A 4246 & $\begin{array}{l}\text { Fragmento mandibular } \\
\text { izquierdo con dp4-m1 }\end{array}$ & Santa Cruz & $\begin{array}{l}\text { Fm Santa Cruz, } \\
\text { Mioceno temprano } \\
\text { superior }\end{array}$ \\
\hline
\end{tabular}


Acaremys murinus

"Acaremys" sp. nov.

Acaremys murinus

"Acaremys" sp. nov.

(Holotipo)

Acaremys murinus

Acaremys murinus

Acaremys murinus

Acaremys murinus

Acaremys murinus

Acaremys murinus

Acaremys murinus

Acaremys murinus

Acaremys murinus

Acaremys murinus

Acaremys murinus

(en parte)

Acaremys murinus?

Acaremys murinus

Acaremys murinus

Acaremys murinus
MACN A 10091

(en parte)

MACN A 10091

(en parte)

MACN A 10092

MACN A 10095

MACN A 12167 (52- m1-m2 145)

MACN A 12682

MACN PV SC1694

MACN PV SC1831 Fragmento mandibular izquierdo $\mathrm{p} 4-\mathrm{m} 2$

MACN PV SC2339 Fragmento mandibular izquierdo con $\mathrm{p} 4-\mathrm{m} 2 \mathrm{e}$ incisivo partido

MACN PV SC2347 Fragmento mandibular izquierdo con $\mathrm{p} 4-\mathrm{m} 2 \mathrm{e}$ incisivo partido

MACN PV SC2410 Fragmento mandibular derecho con $\mathrm{m} 1-\mathrm{m} 2$

MACN Pv SC2585 Mandíbula izquierda casi completa con $\mathrm{p} 4-\mathrm{m} 2$

MACN Pv SC2586

MACN Pv SC2587

MACN Pv SC2588

MACN PV SC4046

Fragmento maxilar derecho con P4-M2

MACN PV SC4047

2 molariformes aislados

MACN PV SC4050 Fragmento mandibular derecho con $\mathrm{m} 2$

MACN PV SC4051 6 molariformes
Santa Cruz

Santa Cruz

Santa Cruz

La Cueva, Santa

Cruz

Monte

Observación, Santa

Cruz

Monte

Observación, Santa

Cruz

Monte León, Santa

Cruz

Monte León, Santa

Cruz

Monte León, Santa

Cruz

Toldos Sur, Santa

Cruz

Toldos Sur, Santa

Cruz

Toldos Sur, Santa

Cruz

Toldos Sur, Santa

Cruz

Gobernador

Gregores, Santa

Cruz

Gobernador

Gregores, Santa

Cruz

Gobernador

Gregores, Santa

Cruz

Gobernador

Gregores, Santa

Cruz
Fm Santa Cruz, Mioceno temprano superior

Fm Santa Cruz, Mioceno temprano superior

Fm Santa Cruz, Mioceno temprano superior

Fm Santa Cruz, Mioceno temprano superior

Fm Sarmiento, Mioceno temprano inferior

Fm Santa Cruz Mioceno temprano superior

Fm Santa Cruz, Mioceno temprano superior

Fm Santa Cruz, Mioceno temprano superior

Fm Santa Cruz, Mioceno temprano superior

Fm Santa Cruz,

Mioceno temprano superior

Fm Pinturas,

Mioceno inferior medio

Fm Pinturas,

Mioceno inferior medio

Fm Pinturas,

Mioceno inferior medio

Fm Pinturas,

Mioceno inferior medio

Fm Pinturas,

Mioceno inferior medio

Fm Pinturas, Mioceno inferior medio

Fm Pinturas, Mioceno inferior medio

Fm. Pinturas, Mioceno inferior medio 
Acaremys murinus

Acaremys murinus

Acaremys murinus

Acaremys murinus

Acaremys sp.

Acaremys sp.

Acaremys murinus

Acaremys murinus

Acaremys major

(Holotipo)

Acaremys major

“Acaremys" sp. nov.

Acaremys murinus

Acarechimys minutus (Sintipo) MACN A 237

Acarechimys minutus

(Sintipo)

Acarechimys minutus?

Acarechimys minutus

Acarechimys minutus
YPM PU 15872

YPM PU 15895

MACN A 4065

MACN PV SC4077

MACN PV SC4078

MACN PV SC4082

MACN PV SC4099

MLP 82-XII-1/3

MLP 84-III-8-43

MMP 114 M

YPM PU 15281

YPM PU 15366

YPM PU 15413

MACN A 4062

MACN A 4070
Fragmento maxilar izquierdo con P4-M2

Fragmento mandibular derecho con m1-m3

Fragmento mandibular izquierdo con m1-m3

Fragmento mandibular izquierdo con dp4

Mandíbula derecha con p4$\mathrm{m} 2$, fragmento mandibular derecho con $\mathrm{p} 4-\mathrm{m} 2 \mathrm{e}$ incisivo y fragmento mandibular izquierdo con m1-m3

Fragmento mandibular derecho con toda la dentadura

Mandíbula izquierda casi completa con toda la dentadura

Fragmento mandibular derecho con toda la dentadura

Cráneo casi completo con la dentadura; mal preservado

Fragmento de cráneo

2 ramas maxilares con M1M3?

Porción anterior del cráneo con M2 0 M3 derecho; en mal estado

Fragmento mandibular derecho con dp4-m3 e incisivo partido Fragmento mandibular derecho con dp4-m3 e incisivo partido Mandíbula izquierda casi completa con dp4-m3 e incisivo partido

Mandíbula izquierda casi completa con dp4 (partido)$\mathrm{m} 2$

Fragmento de maxilar izquierdo con DP4-M3
Lago Cardiel,

Santa Cruz

Lago Cardiel,

Santa Cruz

Lago Cardiel,

Santa Cruz

Karaiken, Santa

Cruz

Santa Cruz

Ea. La Bajada

Barrancas del Sur del Lago Colhué

Huapi, Chubut

10 millas al sur de

Coy Inlet, Santa

Cruz

Killik Aike, Santa

Cruz

Killik Aike, Santa Cruz

Killik Aike, Santa Cruz

Estancia Halliday

Barrancas del río

Santa Cruz, Santa

Cruz

Barrancas del río

Santa Cruz, Santa

Cruz

Monte

Observación, Santa

Cruz

Monte

Observación, Santa

Cruz

Shehuen, Santa

Cruz
Fm. Pinturas, Mioceno inferior medio

Fm. Pinturas, Mioceno inferior medio

Fm. Pinturas, Mioceno inferior medio

Fm Santa Cruz? Mioceno inferior

Fm Santa Cruz, Mioceno temprano superior

Fm Santa Cruz Mioceno temprano superior

Fm Sarmiento, Mioceno temprano

Fm Santa Cruz, Mioceno temprano superior

Fm Santa Cruz, Mioceno temprano superior

Fm Santa Cruz, Mioceno temprano superior

Fm Santa Cruz, Mioceno temprano superior

Fm Santa Cruz, Mioceno temprano superior

Fm Santa Cruz, Mioceno temprano superior

Fm Santa Cruz, Mioceno temprano superior

Fm Santa Cuz, Mioceno temprano superior

Fm Santa Cuz, Mioceno temprano superior

Fm Santa Cuz, Mioceno temprano superior 
Acarechimys minutus

MACN A 4071

Acarechimys minutus

MACN A 4263

Acarechimys minutus

MACN A 4264

Acarechimys minutus

(Sintipo)

MLP 15-410a

Acarechimys minutus

(Sintipo)

Acarechimys minutus

YPM PU 15806

Acarechimys minutissimus

(Sintipo)

Acarechimys minutissimus

(Sintipo)

Acarechimys minutissimus

(Sintipo)

Acarechimys minutissimus

Acarechimys minutissimus

MACN A 1895

Acarechimys minutissimus

MACN A 1896

Acarechimys minutissimus

MACN A 1897

Acarechimys minutissimus?

MACN A 1898

Acarechimys minutissimus

MACN A 4072

Acarechimys minutissimus

MACN A 4073

Acarechimys minutissimus

MACN A 4076
Mandíbula derecha casi completa con toda la dentadura

Fragmento mandibular izquierdo con dp4-m2

Fragmento mandibular izquierdo con dp4

Fragmento mandibular izquierdo con m1-m3

Fragmento de paladar con M1-M3 izquierdo y M1-M3 derechos

Cráneo casi completo con la dentadura

Mandíbula izquierda casi completa con dp4-m3 e incisivo partido

Fragmento mandibular izquierdo con dp4-m3 e incisivo

Mandíbula derecha casi completa con toda la dentadura

Fragmento mandibular izquierdo con dp4-m3

Fragmento mandibular izquierdo con $\mathrm{m} 1$ e incisivo partido

Fragmento mandibular izquierdo con dp4-m3 e incisivo partido

Fragmento mandibular derecho con m1-m2

Fragmento mandibular izquierdo con m1-m3

Fragmento mandibular derecho con dp4-m2 y fragmento mandibular derecho con dp4-m3 Fragmento mandibular izquierdo con dp4-m2 e incisivo partido

Mandíbula derecha casi completa con toda la
Shehuen, Santa

Cruz

Shehuen, Santa

Cruz

Shehuen, Santa

Cruz

Barrancas del río

Santa Cruz, Santa

Cruz

Barrancas del río

Santa Cruz, Santa

Cruz

Killik Aike, Santa Cruz

Barrancas del río Santa Cruz, Santa Cruz

Barrancas del río Santa Cruz, Santa Cruz

Barrancas del río Santa Cruz, Santa Cruz

Monte

Observación, Santa

Cruz

Monte

Observación, Santa

Cruz

Santa Cruz
Fm Santa Cuz, Mioceno temprano superior

Fm Santa Cuz, Mioceno temprano superior

Fm Santa Cuz,

Mioceno temprano superior

Fm Santa Cuz, Mioceno temprano superior

Fm Santa Cuz, Mioceno temprano superior

Fm Santa Cuz, Mioceno temprano superior

Fm Santa Cruz, Mioceno temprano superior

Fm Santa Cruz, Mioceno temprano superior

Fm Santa Cruz, Mioceno temprano superior

Fm Santa Cruz, Mioceno temprano superior

Fm Santa Cruz, Mioceno temprano superior

Fm Santa Cruz, Mioceno temprano superior

Fm Santa Cruz, Mioceno temprano superior

Fm Santa Cruz, Mioceno temprano superior Fm Santa Cruz, Mioceno temprano superior

Fm Santa Cruz, Mioceno temprano superior

Fm Santa Cruz Mioceno temprano 
Acarechimys minutissimus

MACN A 4077

Acarechimys minutissimus

Acarechimys minutissimus

MACN A 4079

Acarechimys minutissimus

Acarechimys minutissimus

MACN A 4081

Acarechimys minutissimus

MACN A 4082

Acarechimys minutissimus

Acarechimys minutissimus

Acarechimys minutissimus

Acarechimys minutissimus

Acarechimys minutissimus

Acarechimys minutissimus

Acarechimys minutissimus

Acarechimys minutissimus

Acarechimys minutissimus

MACN A 4091

Acarechimys minutissimus

MACN A 4092

Acarechimys minutissimus

MACN A 4084

MACN A 4085

MACN A 4086

MACN A 4087

MACN A 4088

MACN A 4089

MACN A 4090

MACN A 4093 dentadura

Mandíbula izquierda casi completa con m1-m3 e incisivo

Mandíbula derecha casi completa con dp4-m3

Mandíbula derecha casi completa con m1-m3 e incisivo

Mandíbula derecha casi completa con dp4-m3

Mandíbula derecha casi completa con dp4-m1

Fragmento mandibular derecho con dp4-m3

Fragmento de mandíbula izquierda con dp4-m2
Mandíbula derecha casi completa con m1-m3 e incisivo

Fragmento mandibular izquierdo con dp4-m1 e incisivo

Mandíbula derecha casi completa con dp4-m2 e incisivo

Mandíbula izquierda incisivo derecho con incisivo y adherido a la cara Mandíbula izquierda casi competa con m1-m2 y diente adherido a la cara Fragmento mandibular derecho con dp4-m2 e Fragmento mandibular izquierdo con m1-m3

Rama mandibular izquierda con m1-m3

Mandíbula izquierda casi completa con m1-m3
Fragmento mandibular superior

Santa Cruz

Fm Santa Cruz, Mioceno temprano superior

Santa Cruz

Fm Santa Cruz, Mioceno temprano superior

Santa Cruz

Fm Santa Cruz, Mioceno temprano superior

Santa Cruz

Santa Cruz

Santa Cruz

Santa Cruz

Santa Cruz

Santa Cruz

Santa Cruz

Santa Cruz

Santa Cruz

Santa Cruz

Santa Cruz

Santa Cruz

Santa Cruz

Santa Cruz
Fm Santa Cruz Mioceno temprano superior

Fm Santa Cruz, Mioceno temprano superior

Fm Santa Cruz, Mioceno temprano superior

Fm Santa Cruz, Mioceno temprano superior Mioceno temprano superior

Fm Santa Cruz, Mioceno temprano superior

Fm Santa Cruz, Mioceno temprano superior

Fm Santa Cruz, Mioceno temprano superior

Fm Santa Cruz, Mioceno temprano superior Fm Santa Cruz, Mioceno temprano superior

Fm Santa Cruz, Mioceno temprano superior

Fm Santa Cruz Mioceno temprano superior

Fm Santa Cruz, Mioceno temprano superior

Fm Santa Cruz, Mioceno temprano superior
Fm Santa Cruz, 
Acarechimys minutissimus

MACN A 4094

Acarechimys minutissimus

MACN A 4145

Acarechimys minutissimus

MACN A 4146

Acarechimys minutissimus

MACN A 4265

Acarechimys minutissimus

MACN A 4266

Acarechimys minutissimus

MACN A 12683

Acarechimys minutissimus

MACN A 10093

Acarechimys minutissimus

Acarechimys minutissimus

Acarechimys minutissimus

Acarechimys minutissimus

Acarechimys minutissimus

Acarechimys minutissimus

Acarechimys minutissimus

Acarechimys minutissimus (Sintipo)

Acarechimys minutissimus

Acarechimys constans

Acarechimys constans

Acarechimys constans?

MACN A 4058

Acarechimys constans

MLP 15-188

YPM PU 15178

MACN A 247

MACN A 248a?

MACN A 4064
Mandíbula derecha casi completa con dp4-m2 e incisivo

Fragmento de maxilar derecho con dp4

Fragmento mandibular izquierdo con dp4 y fragmento mandibular derecho con $\mathrm{m} 2$ dp4-m1 derechos

Fragmento mandibular derecho con dp4-m1

Mandíbula derecha con dp4$\mathrm{m} 2$ e incisivo; fragmento maxilar derecho con DP4-

M2

Fragmento mandibular derecho con dp4-m2

MACN PV SC2158

MACN PV SC2589

MACN PV SC2590

MACN PV SC4045

MACN PV SC4091

MACN PV SC4092

MACN PV SC4098
Fragmento mandibular Fragmento mandibular derecho con dp4-m2

Fragmento maxilar derecho con DP4-M1

Fragmento mandibular derecho con m1-m3

Fragmento mandibular izquierdo con dp4-m1 Fragmento mandibular izquierdo con m1-m2 Fragmento mandibular derecho con dp4-m1

Fragmento mandibular izquierdo con dp4-m3 e incisivo partido

Cráneo parcialmente preservado con DP4-M2 derecho y DP4-M1 izquierdo; incisivo en plástico

Rama mandibular izquierda parcialmente preservada con $\mathrm{m} 1-\mathrm{m} 2$

Rama mandibular derecha parcialmente preservada con dp4-m2 e incisivo partido Mandíbula derecha casi completa con dp4-m1

Mandíbula izquierda casi completa con dp4-m2 e derecho con dp4 e incisivo
Santa Cruz

Monte

Observación, Santa

Cruz

Monte

Observación, Santa

Cruz

Monte

Observación, Santa

Cruz

Monte

Observación, Santa

Cruz

yacimiento Dipilus 1897-98, Santa

Cruz

Portezuelo Sumich

Norte, Santa Cruz

Toldos Sur, Santa

Cruz

Toldos Sur, Santa

Cruz

Gobernador

Gregores, Santa

Cruz

Lago Cardiel,

Santa Cruz

Lago Cardiel,

Santa Cruz

Karaiken, Santa

Cruz

Barrancas del río

Santa Cruz, Santa

Cruz

10 millas al sur de

Coy Inlet, Santa

Cruz

Barrancas del río

Santa Cruz, Santa

Cruz

Barrancas del río

Santa Cruz, Santa

Cruz

Monte

Observación, Santa

Cruz

Monte

Observación, Santa
Fm Santa Cruz, Mioceno temprano superior

Fm Santa Cruz, Mioceno temprano superior

Fm Santa Cruz,

Mioceno temprano superior

Fm Santa Cruz,

Mioceno temprano superior

Fm Santa Cruz,

Mioceno temprano superior

Fm Santa Cruz,

Mioceno temprano superior

Fm Santa Cruz, Mioceno temprano superior

Fm Pinturas,

Mioceno temprano

Fm Pinturas,

Mioceno temprano

Fm Pinturas,

Mioceno temprano

Fm Pinturas,

Mioceno temprano

Fm Pinturas,

Mioceno temprano

Fm Pinturas,

Mioceno temprano

Fm Santa Cruz?

Mioceno temprano superior

Fm Santa Cruz, Mioceno temprano superior

Fm Santa Cruz, Mioceno temprano superior

Fm Santa Cruz, Mioceno temprano superior Fm Santa Cruz, Mioceno temprano 
Acarechimys constans

Acarechimys constans

Acarechimys constans

(Lectotipo)

Acarechimys constans

Acarechimys constans

Acarechimys constans

Acarechimys sp.

Acarechimys pulchellus

(Holotipo)

Acarechimys pulchellus

Acarechimys pulchellus

Acarechimys pulchellus

Acarechimys pulchellus

Acarechimys pulchellus

Acarechimys pulchellus

Acarechimys pulchellus

Acarechimys sp.

Acaremyidae
MACN A 4074

MACN A 4075

MLP 15-391

MLP 15-391a

MLP 15-391b

MLP 15-391c

MLP 91-IV-1-15

MACN A 52-128

MACN A 1878

MACN A 4060

MACN A 4061

MACN A 4067

MACN A 4068

MACN A 4074

MACN A 4263

MPEF-PV 1417

MACN 10091

(en parte) incisivo partido

Fragmento mandibular izquierdo con dp4-m1 e incisivo partido

Mandíbula derecha casi completa con dp4-m1 e incisivo partido

Fragmento mandibular derecho con dp4-m3 e incisivo partido

Cruz

Monte

Observación, Santa

Cruz

Monte

Observación, Santa

Cruz

Barrancas del río Santa Cruz, Santa

Cruz

Mandíbula derecha con dp4$\mathrm{m} 2$

Barrancas del río Santa Cruz, Santa Cruz

Mandíbula derecha con m1m3

Barrancas del río

Santa Cruz, Santa

Cruz

Mandíbula izquierda con incisivo roto y dp4-m1

Fragmento mandibular izquierdo con m1-m2 Rama mandibular izquierda con toda la dentadura

Mandíbula derecha casi completa con dp4-m2 e incisivo

Mandíbula izquierda casi completa con toda la dentadura

Mandíbula derecha casi completa con toda la dentadura; incisivo partido

Mandíbula izquierda casi completa con dp4-m3

Fragmento mandibular derecho con dp4-m3

Fragmento mandibular izquierdo con dp4-m1 e incisivo partido Fragmento mandibular izquierdo con dp4-m2

Molariforme inferior aislado

8 dientes aislados y 1 fragmento maxilar con P4M1 de acarémido; 5 dientes aislados de Spaniomys
Barrancas del río

Santa Cruz, Santa

Cruz

Cañadón del

Tordillo, Neuquén

Barranca sur del

Lago Colhue

Huapí, Chubut

Monte

Observación, Santa

Cruz

Monte

Observación, Santa

Cruz

Monte

Observación, Santa

Cruz

Monte

Observación, Santa

Cruz

Monte

Observación, Santa

Cruz

Shehuen

Bryn Gwyn, Chubut

Santa Cruz
Santa Cruz superior

Fm Santa Cruz, Mioceno temprano superior

Fm Santa Cruz, Mioceno temprano superior

Fm Santa Cruz, Mioceno temprano superior

Fm Santa Cruz, Mioceno temprano superior

Fm Santa Cruz, Mioceno temprano superior

Fm Santa Cruz, Mioceno temprano superior

Fm Collón Curá,

Mioceno medio

Fm Sarmiento, Mb

Colhue Huapi,

Mioceno temprano

Fm Santa Cruz, Mioceno temprano superior

Fm Santa Cruz, Mioceno temprano superior

Fm Santa Cruz, Mioceno temprano superior

Fm Santa Cruz, Mioceno temprano superior

Fm Santa Cruz, Mioceno temprano superior

Fm Santa Cruz,

Mioceno temprano superior

Fm Santa Cruz, Mioceno temprano superior

Fm Sarmiento, Mioceno temprano inferior

Fm Santa Cruz, Mioceno temprano superior 
Acaremyidae

MACN A 255

Acaremyidae

MACN A 4128

Acaremyidae

MACN A 4133

Acaremyidae

MPEF-PV 5673b

Acaremyidae

MPEF-PV 5889

Caviocricetus lucasi

Caviocricetus lucasi

Caviocricetus lucasi

Caviocricetus lucasi

Caviocricetus lucasi

Caviocricetus lucasi

Caviocricetus lucasi

Caviocricetus lucasi

Caviocricetus lucasi

Caviocricetus lucasi

Caviocricetus lucasi

Caviocricetus lucasi

Caviocricetus lucasi

Caviocricetus lucasi
Rama mandibular izquierda Santa Cruz incompleta con dp4-m3 e incisivo partido

Rama mandibular derecha casi completa con toda la dentadura; incisivo partido

rama mandibular derecha con toda la dentadura

Molar superior aislado

p4 aislado

MACN PV CH1989

$2 \mathrm{dp} 4$ aislados

MACN PV CH1990

8 fragmentos mandibulares con dp4-m1

MACN PV CH1991 10 fragmentos mandibulares con $\mathrm{m} 1$

MACN PV CH1992 Fragmento mandibular derecho con dp4

MACN PV CH1993 6 fragmentos de mandíbula con 1 molariforme aislado

MACN PV CH1994 1 molar inferior aislado

MACN PV CH1995 20 fragmentos de mandíbula con $\mathrm{m} 1-\mathrm{m} 2$

MACN PV CH1996

Fragmento maxilar izquierdo con DP4-M2

MACN PV CH1997 13 fragmentos de maxilar con DP4-M1

MACN PV CH1998 15 fragmentos de maxilar izquierdo con DP4-M1

MACN PV CH1999 14 fragmentos de maxilar izquierdo con DP4

MACN PV CH2000 5 fragmentos de maxilar con DP4

MACN PV CH2001 5 fragmentos de maxilar con M1

MACN PV CH2002 2 fragmentos de maxilar con 2 molariformes
Bryn Gwyn,

Chubut

Santa Cruz

Santa Cruz

Gran Barranca, Chubut

Gran Barranca, Chubut

Bryn Gwyn, Chubut

Bryn Gwyn, Chubut

Bryn Gwyn, Chubut

Bryn Gwyn, Chubut

Bryn Gwyn, Chubut

Bryn Gwyn, Chubut

Bryn Gwyn, Chubut

Bryn Gwyn, Chubut

Bryn Gwyn, Chubut

Bryn Gwyn, Chubut

Bryn Gwyn, Chubut

Bryn Gwyn, Chubut

Bryn Gwyn, Chubut
Fm Santa Cruz, Mioceno temprano superior

Fm Santa Cruz, Mioceno temprano superior

Fm Santa Cruz, Mioceno temprano superior

Fm Sarmiento, Mb

Colhue Huapi, Mioceno inferior temprano

Fm Sarmiento, Mb

Colhue Huepi, Mioceno inferior temprano

Fm Sarmiento, $\mathrm{Mb}$

Trelew, Mioceno temprano inferior Fm Sarmiento, Mb Trelew, Mioceno temprano inferior Fm Sarmiento, $\mathrm{Mb}$ Trelew, Mioceno temprano inferior Fm Sarmiento, Mb Trelew, Mioceno temprano inferior Fm Sarmiento, Mb Trelew, Mioceno temprano inferior Fm Sarmiento, Mb Trelew, Mioceno temprano inferior Fm Sarmiento, Mb Trelew, Mioceno temprano inferior Fm Sarmiento, Mb Trelew, Mioceno temprano inferior Fm Sarmiento, Mb Trelew, Mioceno temprano inferior Fm Sarmiento, Mb Trelew, Mioceno temprano inferior Fm Sarmiento, Mb Trelew, Mioceno temprano inferior Fm Sarmiento, Mb Trelew, Mioceno temprano inferior Fm Sarmiento, Mb Trelew, Mioceno temprano inferior Fm Sarmiento, Mb Trelew, Mioceno 
Caviocricetus lucasi

Caviocricetus lucasi

Caviocricetus lucasi

Caviocricetus lucasi

Caviocricetus lucasi

Caviocricetus lucasi

Caviocricetus lucasi

Caviocricetus lucasi

(Holotipo)

Caviocricetus lucasi

Caviocricetus lucasi

Caviocricetus lucasi

Caviocricetus lucasi

Caviocricetus lucasi

Caviocricetus lucasi

Caviocricetus lucasi

Caviocricetus lucasi

Caviocricetus lucasi

Caviocricetus lucasi

Caviocricetus lucasi

Caviocricetus lucasi
MACN PV CH2003

MACN PV CH2004

MACN PV CH2005

MACN PV CH2006

MACN PV CH2007

MACN PV SC2591

MPEF-PV 503

MPEF-PV 505

MPEF-PV 506

MPEF-PV 516

MPEF-PV 518

MPEF-PV 5049

MPEF-PV 5080

MPEF-PV 5082

MPEF-PV 5095

MPEF-PV 5105

MPEF-PV 5111

MPEF-PV 5113

MPEF-PV 5115

MPEF-PV 1416-1
1 fragmento maxilar con 2 molariformes

Bryn Gwyn, Chubut

Bryn Gwyn, Chubut aislados

3 fragmentos maxilar con un molariforme

Bryn Gwyn, Chubut

Fragmento mandibular con dp4-m2

Bryn Gwyn, Chubut

Fragmento mandibular derecho con $\mathrm{m} 2$

Bryn Gwyn, Chubut

Fragmento maxilar con DP4-M1

Fragmento mandibular derecho con dp4-m1

Fragmento maxilar derecho con DP4- M3

Fragmento maxilar izquierdo con DP4-M2

Mandíbula derecha casi completa con dp4-m3

Mandíbula izquierda casi completa con dp4-m3 en incisivo partido Fragmento de mandíbula derecha con dp4-me e incisivo

Mandíbula derecha casi completa con toda la dentadura

Mandíbula izquierda casi completa con dp4-m3 en incisivo partido

Mandíbula izquierda casi completa con toda la dentadura

Mandíbula derecha casi completa con dp4-m3 e incisivo partido

Fragmento maxilar derecho con DP4- M3

Fragmento maxilar derecho con M1-M3

Fragmento mandibular izquierdo con incisivo y sin molariformes

Fragmento maxilar izquierdo con DP4-M3 temprano inferior Fm Sarmiento, $\mathrm{Mb}$ Trelew, Mioceno temprano inferior Fm Sarmiento, $\mathrm{Mb}$ Trelew, Mioceno temprano inferior Fm Sarmiento, Mb Trelew, Mioceno temprano inferior Fm Sarmiento, Mb Trelew, Mioceno temprano inferior Fm Sarmiento, $\mathrm{Mb}$ Trelew, Mioceno temprano inferior Fm Sarmiento, $\mathrm{Mb}$ Trelew, Mioceno temprano inferior Fm Sarmiento, Mb Trelew, Mioceno temprano inferior Fm Sarmiento, Mb Trelew, Mioceno temprano inferior Fm Sarmiento, $\mathrm{Mb}$ Trelew, Mioceno temprano inferior Fm Sarmiento, Mb Trelew, Mioceno temprano inferior Fm Sarmiento, Mb Trelew, Mioceno temprano inferior Fm Sarmiento, Mb Trelew, Mioceno temprano inferior Fm Sarmiento, $\mathrm{Mb}$ Trelew, Mioceno temprano inferior Fm Sarmiento, Mb Trelew, Mioceno temprano inferior Fm Sarmiento, Mb Trelew, Mioceno temprano inferior Fm Sarmiento, Mb Trelew, Mioceno temprano inferior Fm Sarmiento, $\mathrm{Mb}$ Trelew, Mioceno temprano inferior Fm Sarmiento, $\mathrm{Mb}$ Trelew, Mioceno temprano inferior Fm Sarmiento, Mb Trelew, Mioceno temprano inferior Fm Sarmiento, Mb Trelew, Mioceno 
Caviocricetus lucasi

Caviocricetus lucasi

Caviocricetus lucasi

Caviocricetus lucasi

Caviocricetus lucasi

Caviocricetus lucasi

Galileomys antelucanus (Holotipo)

Galileomys antelucanus

Galileomys antelucanus

Galileomys antelucanus?

Galileomys antelucanus

Galileomys antelucanus

Galileomys antelucanus

Galileomys antelucanus

Galileomys antelucanus
MPEF-PV 1416-2

MPEF-PV 1416-6

MPEF-PV 1416-7

MPEF-PV 1416-9

MPEF-PV 1416-13

MPEF-PV 1416-16

MLP 82-V-2-105

MACN A 52-145

MPEF-PV 5683a

MPEF-PV 5986

MPEF-PV 5988

MPEF-PV 5990

MPEF-PV 5991

MPEF-PV 5992

MPEF-PV 5993
M1 en un pequeño

fragmento maxilar y 2

incisivos aislados

Fragmento mandibular derecho con dp4-m1 e incisivo roto, fragmento maxilar izquierdo con DP4M2, dp1-m1 izquierdos y 1 molar inferior izquierdo aislado

Fragmento mandibular izquierdo con dp4-m2 e incisivo

Fragmento maxilar derecho con DP4- M3

Fragmento mandibular derecho con dp4-m2 e incisivo

Fragmento maxilar derecho con DP4- M3

Mandíbula derecha casi completa con p4-m2 e incisivo

m1-m2 derechos en una pequeña porción de mandíbula

Fragmento maxilar derecho con $\mathrm{P} 4$

Mandíbula derecha casi completa con p4-m2 e incisivo partido

Mandíbula derecha casi completa con m1-m2

p4 derecho

M1ó M2 izquierdo

m1 ó m2 izquierdo

m1 ó m2 izquierdo
Bryn Gwyn,

Chubut

Bryn Gwyn, Chubut

Bryn Gwyn, Chubut

Bryn Gwyn, Chubut

Bryn Gwyn, Chubut

Bryn Gwyn, Chubut

Barranca sur del lago Colhué Huapí, Chubut

Barranca sur del lago Colhué Huapí?, Chubut

Gran Barranca, Chubut

Gran Barranca, Chubut

Gran Barranca, Chubut

Gran Barranca, Chubut

Gran Barranca, Chubut

Gran Barranca, Chubut

Gran Barranca, Chubut temprano inferior Fm Sarmiento, Mb Trelew, Mioceno temprano inferior

Fm Sarmiento, Mb Trelew, Mioceno temprano inferior

Fm Sarmiento, Mb Trelew, Mioceno temprano inferior Fm Sarmiento, Mb Trelew, Mioceno temprano inferior Fm Sarmiento, Mb Trelew, Mioceno temprano inferior Fm Sarmiento, Mb Trelew, Mioceno temprano inferior Fm Sarmiento, Mb. Colhue Huapi, Mioceno inferior temprano Fm Sarmiento, Mb. Colhue Huapi, Mioceno inferior temprano Fm Sarmiento, Mb. Colhue Huapi, Mioceno inferior temprano

Fm Sarmiento, Mb. Colhue Huapi, Mioceno inferior temprano

Fm Sarmiento, Mb.

Colhue Huapi, Mioceno inferior temprano

Fm Sarmiento, Mb.

Colhue Huapi, Mioceno inferior temprano

Fm Sarmiento, Mb.

Colhue Huapi, Mioceno inferior temprano

Fm Sarmiento, Mb.

Colhue Huapi, Mioceno inferior temprano Fm Sarmiento, Mb. Colhue Huapi, Mioceno inferior temprano 


\begin{abstract}
Galileomys antelucanus
\end{abstract}
Galileomys antelucanus

Galileomys antelucanus

Galileomys antelucanus

Galileomys antelucanus

Galileomys antelucanus

Galileomys antelucanus

Galileomys antelucanus

Galileomys antelucanus

Galileomys antelucanus

Galileomys antelucanus

Galileomys antelucanus

Galileomys antelucanus

Galileomys antelucanus

Galileomys antelucanus
MPEF-PV 5994

MPEF-PV 5995

MPEF-PV 5997

MPEF-PV 5998

MPEF-PV 5999

MPEF-PV 6000

MPEF-PV 6001

MPEF-PV 6002

MPEF-PV 6003

MPEF-PV 6004

MPEF-PV 6005

MPEF-PV 6006

MPEF-PV 6007

MPEF-PV 6008

MPEF-PV 6009
P4 derecho

M3 derecho

p4 izquierdo

Fragmento mandibular izquierdo con $\mathrm{m} 1$

m1 ó m2 izquierdo

M1ó M2 izquierdo

M1ó M2 derecho

M3 derecho

P4 derecho

M1ó M2 derecho

m1 ó m2 derecho

m1 ó m2 derecho

P4 derecho

Fragmento mandibular izquierdo con $\mathrm{p} 4-\mathrm{m} 2 \mathrm{e}$ incisivo partido

Fragmento de p4 izquierdo
Gran Barranca, Chubut

Gran Barranca, Chubut

Gran Barranca, Chubut

Gran Barranca, Chubut

Gran Barranca, Chubut

Gran Barranca, Chubut

Gran Barranca, Chubut

Gran Barranca, Chubut

Gran Barranca, Chubut

Gran Barranca, Chubut

Gran Barranca, Chubut

Gran Barranca, Chubut

Gran Barranca, Chubut

Gran Barranca, Chubut

Gran Barranca, Chubut
Fm Sarmiento, Mb.

Colhue Huapi, Mioceno inferior temprano

Fm Sarmiento, Mb.

Colhue Huapi, Mioceno inferior temprano

Fm Sarmiento, Mb.

Colhue Huapi, Mioceno inferior temprano

Fm Sarmiento, Mb.

Colhue Huapi, Mioceno inferior temprano

Fm Sarmiento, Mb.

Colhue Huapi,

Mioceno inferior temprano

Fm Sarmiento, Mb.

Colhue Huapi,

Mioceno inferior temprano

Fm Sarmiento, Mb.

Colhue Huapi,

Mioceno inferior temprano

Fm Sarmiento, Mb.

Colhue Huapi,

Mioceno inferior temprano

Fm Sarmiento, Mb.

Colhue Huapi,

Mioceno inferior temprano

Fm Sarmiento, Mb.

Colhue Huapi,

Mioceno inferior temprano

Fm Sarmiento, Mb.

Colhue Huapi,

Mioceno inferior temprano

Fm Sarmiento, Mb.

Colhue Huapi,

Mioceno inferior temprano

Fm Sarmiento, Mb.

Colhue Huapi,

Mioceno inferior temprano

Fm Sarmiento, Mb.

Colhue Huapi,

Mioceno inferior temprano

Fm Sarmiento, Mb.

Colhue Huapi,

Mioceno inferior temprano 
Galileomys antelucanus

Galileomys antelucanus

Galileomys antelucanus

Galileomys antelucanus

Galileomys antelucanus

Galileomys antelucanus

Galileomys antelucanus

Galileomys antelucanus

Galileomys antelucanus

Galileomys antelucanus

Galileomys antelucanus

Galileomys antelucanus

Galileomys? colloncurensis

Galileomys? colloncurensis

Galileomys? colloncurensis

Galileomys? colloncurensis

Galileomys? colloncurensis

Galileomys? colloncurensis

(Holotipo)
MPEF-PV 6010

m1 ó m2 izquierdo

MPEF-PV 6011

P4 izquierdo

MPEF-PV 6012

P4 derecho

MPEF-PV 6013

M1ó M2 izquierdo

MPEF-PV 6014

M1ó M2 izquierdo

MPEF-PV 6015

M1ó M2 derecho partido

MPEF-PV 6016

m3 derecho

MPEF-PV 6092b

p4 aislado

MPEF-PV 6937

P4 izquierdo aislado

MPEF-PV 6938a

Molar inferior aislado

MPEF-PV 6967a,b,c 3 molares inferiores aislados

MPEF-PV 7557a

MPL 91-IX-1-8

MLP 91-IX-1-35a

MLP 91-IX-1-106a

MLP 91-IX-1-106b

MLP 91-IX-1-106c

MLP 91-IX-1-107a
Mandíbula izquierda casi completa con p4-m2

Fragmento de paladar con M1-M2

m1 ó m2 aislado

P4 izquierdo aislado

M1 o M2 izquierdo aislado

M1 o M2 derecho aislado

m3 izquierdo
Gran Barranca, Chubut

Gran Barranca, Chubut

Gran Barranca, Chubut

Gran Barranca, Chubut

Gran Barranca, Chubut

Gran Barranca, Chubut

Gran Barranca, Chubut

Gran Barranca, Chubut

Gran Barranca, Chubut

Gran Barranca, Chubut

Gran Barranca, Chubut

Gran Barranca, Chubut

Cañadón del Tordillo, Neuquén Cañadón del Tordillo, Neuquén Cañadón del

Tordillo, Neuquén Cañadón del

Tordillo, Neuquén Cañadón del

Tordillo, Neuquén

Cañadón del Tordillo, Neuquén
Fm Sarmiento, Mb.

Colhue Huapi, Mioceno inferior temprano

Fm Sarmiento, Mb.

Colhue Huapi, Mioceno inferior temprano

Fm Sarmiento, Mb.

Colhue Huapi,

Mioceno inferior temprano

Fm Sarmiento, Mb.

Colhue Huapi,

Mioceno inferior temprano

Fm Sarmiento, Mb.

Colhue Huapi,

Mioceno inferior temprano

Fm Sarmiento, Mb.

Colhue Huapi,

Mioceno inferior temprano

Fm Sarmiento, Mb.

Colhue Huapi,

Mioceno inferior temprano

Fm Sarmiento, Mb.

Colhue Huapi,

Mioceno inferior temprano

Fm Sarmiento, Mb

Colhue Huapi,

Mioceno inferior temprano

Fm Sarmiento, Mb

Colhue Huapi,

Mioceno inferior temprano

Fm Sarmiento, Mb.

Colhue Huapi,

Mioceno inferior

temprano

Fm Sarmiento, Mb.

Colhue Huapi,

Mioceno inferior temprano

Fm Collón Curá,

Mioceno medio

Fm Collón Curá,

Mioceno medio

Fm Collón Curá,

Mioceno medio

Fm Collón Curá,

Mioceno medio

Fm Collón Curá,

Mioceno medio

Fm Collón Curá,

Mioceno medio 
Galileomys? colloncurensis

Galileomys? colloncurensis

Galileomys? colloncurensis

Galileomys? colloncurensis

Galileomys? colloncurensis

Galileomys? colloncurensis

Galileomys eurygnathus

Galileomys eurygnathus

Galileomys eurygnathus

Galileomys eurygnathus

Galileomys eurygnathus

Galileomys eurygnathus

Galileomys eurygnathus

Galileomys eurygnathus

Galileomys eurygnathus

Galileomys eurygnathus

Galileomys eurygnathus

Galileomys eurygnathus

Galileomys eurygnathus

Galileomys eurygnathus

Galileomys eurygnathus

Galileomys eurygnathus
MLP 91-IX-1-107b

MLP 91-IX-1-199a

MLP 91-IX-1-199b

MLP 91-IX-1-200a

MLP 91-IX-1-200b

MLP 91-IX-1-200c

MACN PV SC2029

MACN PV SC2030

MACN PV SC2031

MACN PV SC2032

MACN PV SC2033

MACN PV SC2035

MACN PV SC2036

MACN PV SC2077

MACN PV SC2078

MACN PV SC2079

MACN PV SC2108

MACN PV SC2109

MACN PV SC2110

p4 izquierdo aislado

MACN PV SC2111 1 molar inferior derecho aislado

MACN PV SC2112 DP4 izquierdo aislado

MACN PV SC2161 1 molar superior derecho aislado
Cañadón del

Tordillo, Neuquén

Cañadón del

Tordillo, Neuquén

Cañadón del

Tordillo, Neuquén

Cañadón del

Tordillo, Neuquén

Cañadón del

Tordillo, Neuquén

Cañadón del

Tordillo, Neuquén

Río Pinturas,

Portezuelo Sumich

Sur, Santa Cruz

Río Pinturas,

Portezuelo Sumich

Sur, Santa Cruz

Río Pinturas,

Portezuelo Sumich

Sur, Santa Cruz

Río Pinturas,

Portezuelo Sumich

Sur, Santa Cruz

Río Pinturas,

Portezuelo Sumich

Sur, Santa Cruz

Río Pinturas,

Portezuelo Sumich

Sur, Santa Cruz

Río Pinturas,

Portezuelo Sumich

Sur, Santa Cruz

Río Pinturas, Ea.

La Caldera, Santa

Cruz

Río Pinturas, Ea. El

Carmen, Santa

Cruz

Río Pinturas, Ea. El

Carmen, Santa

Cruz

Río Pinturas, Ea. El

Carmen, Santa

Cruz

Río Pinturas, Ea. E

Carmen, Santa

Cruz

Río Pinturas, Ea. El

Carmen, Santa

Cruz

Río Pinturas, Ea. El

Carmen, Santa

Cruz

Río Pinturas, Ea. El

Carmen, Santa

Cruz

Río Pinturas,

Portezuelo Sumich

Norte, Santa Cruz
Fm Collón Curá,

Mioceno medio

Fm Collón Curá,

Mioceno medio

Fm Collón Curá,

Mioceno medio

Fm Collón Curá,

Mioceno medio

Fm Collón Curá,

Mioceno medio

Fm Collón Curá,

Mioceno medio

Fm Pinturas,

Mioceno inferior

Fm Pinturas,

Mioceno inferior

Fm Pinturas,

Mioceno inferior

Fm Pinturas,

Mioceno inferior

Fm Pinturas,

Mioceno inferior

Fm Pinturas,

Mioceno inferior

Fm Pinturas,

Mioceno inferior

Fm Pinturas,

Mioceno inferior

Fm Pinturas,

Mioceno inferior

Fm Pinturas,

Mioceno inferior

Fm Pinturas,

Mioceno inferior

Fm Pinturas,

Mioceno inferior

Fm Pinturas,

Mioceno inferior

Fm Pinturas,

Mioceno inferior

Fm Pinturas,

Mioceno inferior

Fm Pinturas,

Mioceno inferior 


\section{Galileomys eurygnathus}

Galileomys eurygnathus (Holotipo)

Galileomys eurygnathus

Galileomys eurygnathus

Galileomys eurygnathus

Galileomys eurygnathus

Galileomys eurygnathus?

Galileomys eurygnathus?

Galileomys eurygnathus

Galileomys eurygnathus

Galileomys eurygnathus

Galileomys eurygnathus

Galileomys eurygnathus

Galileomys eurygnathus

Galileomys eurygnathus

Galileomys eurygnathus

Galileomys eurygnathus

Galileomys eurygnathus

Galileomys eurygnathus

Galileomys eurygnathus
MACN PV SC2163

MACN PV SC2164

MACN PV SC2165

MACN PV SC2166

MACN PV SC2167

MACN PV SC2169

1 molar inferior derecho aislado

MACN PV SC2170 1 molar inferior derecho aislado

MACN PV SC2171 1 molar inferior derecho aislado

MACN PV SC2172 1 molar superior derecho y 1 molar superior izquierdo aislados

MACN PV SC2173 1 molar superior izquierdo aislado

MACN PV SC2427 Fragmento mandibular derecho con $\mathrm{m} 1$ (partido)-m2 e incisivo roto

MACN PV SC2537 Fragmento mandibular derecho con $\mathrm{p} 4-\mathrm{m} 3$

MACN PV SC2834 m1-m2 derechos aislados

MACN PV SC2835 2 molares superiores izquierdos aislados y 1 fragmento de DP4

MACN PV SC2836 1 molar inferior derecho aislado y 1 molar inferior izquierdo aislado

MACN PV SC2857 Fragmento mandibular izquierdo con $\mathrm{m} 2$

MACN PV SC2858 Fragmento maxilar izquierdo con P4-M1

MACN PV SC2859 M3 derecho aislado

MACN PV SC3557 Fragmento mandibular derecho con $\mathrm{p} 4-\mathrm{m} 2$
Río Pinturas,

Portezuelo Sumich

Norte

Río Pinturas,

Portezuelo Sumich

Norte

Río Pinturas,

Portezuelo Sumich

Norte

Río Pinturas,

Portezuelo Sumich

Norte

Río Pinturas,

Portezuelo Sumich

Norte

Río Pinturas,

Portezuelo Sumich

Norte

Río Pinturas,

Portezuelo Sumich

Norte

Río Pinturas,

Portezuelo Sumich

Norte

Río Pinturas,

Portezuelo Sumich

Norte

Río Pinturas,

Portezuelo Sumich

Norte

Río Pinturas,

Portezuelo Sumich

Norte

Río Pinturas, Cerro de los monos,

Santa Cruz

Río Pinturas, Ea.

Los Toldos, Santa

Cruz

Río Pinturas, Ea.

Los Toldos, Santa

Cruz

Río Pinturas, Ea.

Los Toldos, Santa Cruz

Río Pinturas, Loma de la lluvia, Santa

Cruz

Río Pinturas, Loma de la lluvia, Santa Cruz

Río Pinturas, Loma de la lluvia, Santa

Cruz

Río Pinturas, Loma de la lluvia, Santa Cruz

Río Pinturas,

Portezuelo Sumich Norte, Santa Cruz
Fm Pinturas,

Mioceno inferior

Fm Pinturas,

Mioceno inferior

Fm Pinturas,

Mioceno inferior

Fm Pinturas,

Mioceno inferior

Fm Pinturas,

Mioceno inferior

Fm Pinturas,

Mioceno inferior

Fm Pinturas,

Mioceno inferior

Fm Pinturas,

Mioceno inferior

Fm Pinturas,

Mioceno inferior

Fm Pinturas,

Mioceno inferior

Fm Pinturas,

Mioceno inferior

Fm Pinturas,

Mioceno inferior

Fm Pinturas,

Mioceno inferior

Fm Pinturas,

Mioceno inferior

Fm Pinturas,

Mioceno inferior

Fm Pinturas,

Mioceno inferior

Fm Pinturas,

Mioceno inferior

Fm Pinturas,

Mioceno inferior

Fm Pinturas,

Mioceno inferior

Fm Pinturas,

Mioceno inferior 


\begin{abstract}
Galileomys eurygnathus
\end{abstract}
Galileomys eurygnathus

Galileomys eurygnathus

Migraveramus beatus

(Holotipo)

Migraveramus $c f$. $M$. beatus

Platypittamys brachyodon

(Holotipo)

Platypittamys brachyodon

Platypittamys brachyodon

Plesiacarechimys

koenigswaldi

Plesiacarechimys $c f$.

koenigswaldi

Plesiacarechimys

koenigswaldi

Plesiacarechimys

koenigswaldi

Plesiacarechimys

koenigswaldi

Plesiacarechimys

koenigswaldi

Plesiacarechimys

koenigswaldi

Plesiacarechimys

koenigswaldi

Plesiacarechimys

koenigswaldi

Plesiacarechimys

koenigswaldi

Plesiacarechimys

koenigswaldi

Plesiacarechimys

koenigswaldi

(Holotipo)

Plesiacarechimys

koenigswaldi
MACN PV SC3976

YPM PU 21948

UF 114876

AMNH 29.600

AMNH 29.601

AMNH 29.602

dp4 derecho aislado

p4 derecho aislado

1 molar superior derecho aislado

Fragmento mandibular derecho con P4-M2

Fragmento mandibular izquierdo con m1-m2

Esqueleto con cráneo y mandíbula

Esqueleto parcialmente preservado con cráneo Esqueleto parcialmente preservado sin cráneo Fragmento mandibular izquierdo con m1-m3

MLP 91-V-1-4

MLP 91-V-1-7

MLP 91-V-1-13

MLP 91-V-1-16

MLP 91-V-1-19

MLP 91-V-1-22

MLP 91-V-1-30

MLP 91-V-1-31

MLP 91-V-1-42

MLP 91-V-1-44

MLP 91-V-1-55

MLP 92-V-10-1
Fragmento mandibular izquierdo con $\mathrm{m} 1$ (partido)$\mathrm{m} 2$

Fragmento mandibular izquierdo con $\mathrm{m} 1$

Fragmento mandibular izquierdo con m1-m3

Fragmento de mandíbula derecha con $\mathrm{m} 2$

dp4-m1 izquierdos

Fragmento mandibular izquierdo con m1-m3

Fragmento mandibular izquierdo con m1-m2

Fragmento mandibular derecho con m1-m2

Fragmento mandibular derecho con dp4-m1

Fragmento mandibular izquierdo con m1-m2

Fragmento de cráneo con DP4-M2 izquierdo y fragmento de mandíbula izquierda con dp4-m2 Fragmento anterior de cráneo con M1-M3
Río Pinturas, Portezuelo Sumich Norte, Santa Cruz

Río Pinturas, Ea.

Ana María. Loma

de las Ranas, Santa

Cruz

Río Pinturas, Ea.

Ana María. Loma

de las Ranas, Santa

Cruz

Cuenca de Salla-

Luribay, Bolivia

Cuenca de Salla-

Luribay, Bolivia

Scarrit Pocket,

Chubut

Scarrit Pocket,

Chubut

Scarrit Pocket,

Chubut

Estancia El Criado, Pilcaniyeu Viejo,

Río Negro

Estancia El Criado,

Pilcaniyeu Viejo,

Río Negro

Estancia El Criado,

Pilcaniyeu Viejo,

Río Negro

Estancia El Criado,

Pilcaniyeu Viejo,

Río Negro

Estancia El Criado, Fm Collón Curá, Pilcaniyeu Viejo,

Río Negro

Estancia El Criado,

Pilcaniyeu Viejo,

Río Negro

Estancia El Criado, Fm Collón Curá, Pilcaniyeu Viejo, Mioceno medio

Río Negro

Estancia El Criado, Fm Collón Curá, Pilcaniyeu Viejo, Mioceno medio

Río Negro

Estancia El Criado, Fm Collón Curá, Pilcaniyeu Viejo, Mioceno medio

Río Negro

Estancia El Criado, Fm Collón Curá, Pilcaniyeu Viejo, Mioceno medio

Río Negro

Estancia El Criado, Fm Collón Curá, Pilcaniyeu Viejo, Mioceno medio

Río Negro

Estancia El Criado, Fm Collón Curá, Pilcaniyeu Viejo, Mioceno medio

Río Negro

Estancia El Criado, Fm Collón Curá, Pilcaniyeu Viejo, Mioceno medio 
Plesiacarechimys cf.

koenigswaldi

Plesiacarechimys

koenigswaldi

Plesiacarechimys

koenigswaldi

Prospaniomys priscus

(Holotipo)

Prospaniomys priscus

Prospaniomys priscus

Prospaniomys priscus

Prospaniomys priscus

Prospaniomys priscus

Prospaniomys priscus

Prospaniomys priscus

Prospaniomys priscus

Prospaniomys priscus

Prospaniomys priscus

Prospaniomys priscus

Prospaniomys priscus

Prospaniomys priscus

Prospaniomys sp.
MLP 92-V-10-14

MLP 92-V-10-15

MLP 92-V-10-17

MACN A 52-131

MACN A 52-132

MACN A 52-133

MACN A 52-134

MACN A 52-135

MACN A 52-136

MACN A 52-137

MACN A 52-138

MACN A 52-139

MACN A 52- 140

MACN A 52- 141

MACN A 52- 142

MACN PV CH1913

MLP 82-V-2-32

MPEF-PV 1418 izquierdo y ambos incisivos partidos

Fragmento mandibular derecho con m1-m2

fragmento mandibular derecho con m1-m3

Fragmento maxilar izquierdo con DP4-M1

Mandíbula izquierda casi completa con dp4-m1 e incisivo

Fragmento maxilar derecho con DP4-M1

Fragmento maxilar izquierdo con DP4-M1

Porción anterior de una mandíbula derecha con dp4$\mathrm{m} 1$ e incisivo

Fragmento mandibular derecho con dp4-m1

Fragmento mandibular derecho con m1-m2

Fragmento mandibular izquierdo con $\mathrm{m} 1$

2 dp4 aislados

Mandíbula derecha casi completa con dp4-m1 e incisivo roto

Mandíbula izquierda casi completa con dp4-m3 e incisivo roto

Mandíbula derecha casi completa con m1-m2 e incisivo roto

DP4 aislado

Cráneo completa con toda la dentadura

Fragmento maxilar derecho con DP4-M2

Fragmento mandibular derecho con m1-m2
Pampa de Gan Gan, Chubut

Río Negro

Estancia El Criado, Fm Collón Curá, Pilcaniyeu Viejo, Mioceno medio

Río Negro

Estancia El Criado, Fm Collón Curá, Pilcaniyeu Viejo, Mioceno medio

Río Negro

Estancia El Criado, Fm Collón Curá, Pilcaniyeu Viejo, Mioceno me

Río Negro

Chubut

Fm Sarmiento, Mioceno temprano inferior

Fm Sarmiento, Mioceno temprano inferior

Fm Sarmiento, Mioceno temprano inferior

Fm Sarmiento, Mioceno temprano inferior

Fm Sarmiento, Mioceno temprano inferior

Fm Sarmiento, Mioceno temprano inferior

Fm Sarmiento, Mioceno temprano inferior

Fm Sarmiento, Mioceno temprano inferior

Fm Sarmiento, Mioceno temprano inferior

Fm Sarmiento, Mioceno temprano inferior

Fm Sarmiento, Mioceno temprano inferior

Fm Sarmiento, Mioceno temprano inferior

Fm Sarmiento, Mioceno temprano inferior

Fm Sarmiento, Mioceno temprano inferior

Bryn Gwyn, Chubut 
Prospaniomys sp.

Prospaniomys sp.

Prospaniomys priscus

Prospaniomys priscus

Prospaniomys sp.

Prospaniomys priscus

Prospaniomys priscus?

Prospaniomys priscus

Prospaniomys priscus

Prospaniomys priscus

Prospaniomys priscus

Prospaniomys priscus

Prospaniomys priscus

Prospaniomys priscus?

Prospaniomys priscus
MPEF-PV 5664

MPEF-PV 1574

MPEF-PV 1575

MPEF-PV 5039

MPEF-PV 5558

MPEF-PV 5620

MPEF-PV 5621

MPEF-PV 5624

MPEF-PV 5647

MPEF-PV 5648

MPEF-PV 5649

MPEF-PV 5653

MPEF-PV 5659

MPEF-PV 5660

MPEF-PV 5665
Fragmento maxilar izquierdo con DP4-M3

Fragmento mandibular izquierdo con m1-m3

Fragmento mandibular izquierdo con dp4-m1 e incisivo partido

Mandíbula derecha casi completa con dp4-m3 e incisivo partido

Mandíbula derecha casi completa con m1-m3 e incisivo partido

Fragmento mandibular izquierda con dp4-m2 e incisivo partido

Mandíbula derecha con toda

2 fragmentos de una mandíbula con incisivo y m2, y 1 fragmento maxilar aislado

Fragmento maxilar derecho aislado izquierdo con M1-M3

Fragmento maxilar izquierdo con DP4 y molar superior aislado

Porción anterior de mandíbula derecha con incisivo y $1 \mathrm{dp} 4$ m3 y molar inferior Fragmento mandibular izquierdo con dp4-m3

Fragmento mandibular izquierdo con dp4-m1
Fragmento maxilar
Valle Hermoso

Valle Hermoso

Bryn Gwyn, Chubut

Gran Barranca, Chubut

Gran Barranca, Chubut

Gran Barranca, Chubut

Gran Barranca, Chubut

Gran Barranca, Chubut

Gran Barranca, Chubut

Gran Barranca, Chubut

Gran Barranca, Chubut

Gran Barranca, Chubut

Gran Barranca, Chubut

Gran Barranca, Chubut

Gran Barranca, Chubut temprano inferior Fm Sarmiento, Mioceno temprano inferior

Fm Sarmiento, Mioceno temprano inferior

Fm Sarmiento, Mb Trelew, Mioceno temprano inferior Fm Sarmiento, Mb Colhue Huapi, Mioceno temprano inferior

Fm Sarmiento, Mb Colhue Huapi, Mioceno temprano inferior

Fm Sarmiento, Mb

Colhue Huapi,

Mioceno temprano inferior

Fm Sarmiento, Mb

Colhue Huapi,

Mioceno temprano inferior

Fm Sarmiento, Mb

Colhue Huapi,

Mioceno temprano inferior

Fm Sarmiento, Mb

Colhue Huapi,

Mioceno temprano inferior

Fm Sarmiento, Mb

Colhue Huapi,

Mioceno temprano inferior

Fm Sarmiento, Mb

Colhue Huapi,

Mioceno temprano inferior

Fm Sarmiento, Mb

Colhue Huapi,

Mioceno temprano inferior

Fm Sarmiento, Mb

Colhue Huapi,

Mioceno temprano inferior

Fm Sarmiento, Mb

Colhue Huapi,

Mioceno temprano inferior

Fm Sarmiento, Mb

Colhue Huapi,

Mioceno temprano 
Prospaniomys priscus

Prospaniomys priscus

Prospaniomys sp

Prospaniomys priscus

Prospaniomys priscus

Prospaniomys priscus

Prospaniomys priscus

Prospaniomys priscus

Prospaniomys priscus

Prospaniomys priscus

Prospaniomys priscus

Prospaniomys priscus

Prospaniomys priscus

Prospaniomys priscus

Prospaniomys priscus
MPEF-PV 5668

MPEF-PV 5672

1 molar superior izquierdo y $1 \mathrm{~m} 2$ derecho aislados

Fragmento mandibular izquierdo con m1-m3

MPEF-PV 5883

MPEF-PV 5886

MPEF-PV 5887

MPEF-PV 5892

MPEF-PV 5893

MPEF-PV 5894

MPEF-PV 5987

MPEF-PV 5989

MPEF-PV 6043a

MPEF-PV 6045

MPEF-PV 6069

MPEF-PV 6071
5 molares superiores aislados

6 molares superiores aislados

3 dp4 y 1 molar inferior aislados

Fragmento maxilar derecho con 1 molariforme y 2 molares superiores aislados

Fragmento maxilar izquierdo con DP4-M1 y fragmento maxilar derecho con DP4-M1

$3 \mathrm{~m} 3$ aislados

Fragmento mandibular derecho con 1 molar

Fragmento maxilar derecho con DP4-M2

1 fragmento mandibular derecho con m2-m3, 1 fragmento mandibular izquierdo con 2 molariformes partidos y 1 dp4 derecho aislado 4 molares superiores aislados

Fragmento maxilar derecho con DP4-M1

Fragmento maxilar derecho
Gran Barranca, Chubut

Gran Barranca, Chubut

Gran Barranca, Chubut

Gran Barranca, Chubut

Gran Barranca, Chubut

Gran Barranca, Chubut

Gran Barranca, Chubut

Gran Barranca, Chubut

Gran Barranca, Chubut

Gran Barranca, Chubut

Gran Barranca, Chubut

Gran Barranca, Chubut

Gran Barranca, Chubut

Gran Barranca, Chubut

Gran Barranca, inferior

Fm Sarmiento, Mb

Colhue Huapi,

Mioceno temprano inferior

Fm Sarmiento, Mb

Colhue Huapi,

Mioceno temprano inferior

Fm Sarmiento, $\mathrm{Mb}$

Colhue Huapi,

Mioceno temprano inferior

Fm Sarmiento, Mb

Colhue Huapi,

Mioceno temprano inferior

Fm Sarmiento, Mb

Colhue Huapi,

Mioceno temprano inferior

Fm Sarmiento, Mb

Colhue Huapi,

Mioceno temprano inferior

Fm Sarmiento, Mb

Colhue Huapi,

Mioceno temprano inferior

Fm Sarmiento, Mb

Colhue Huapi,

Mioceno temprano inferior

Fm Sarmiento, Mb

Colhue Huapi,

Mioceno temprano inferior

Fm Sarmiento, Mb

Colhue Huapi,

Mioceno temprano inferior

Fm Sarmiento, Mb

Colhue Huapi,

Mioceno temprano inferior

Fm Sarmiento, Mb

Colhue Huapi,

Mioceno temprano inferior

Fm Sarmiento, Mb

Colhue Huapi, Mioceno temprano inferior

Fm Sarmiento, Mb Colhue Huapi, Mioceno temprano inferior

Fm Sarmiento, Mb 
con DP4-M1

MPEF-PV 6089a

Prospaniomys priscus

Prospaniomys sp.

Prospaniomys priscus

Prospaniomys priscus

Prospaniomys priscus

Prospaniomys priscus

Prospaniomys priscus

Prospaniomys priscus

Prospaniomys priscus

Prospaniomys priscus

Prospaniomys priscus

Prospaniomys priscus

Prospaniomys priscus

Prospaniomys priscus
MPEF-PV 6089b

MPEF-PV 6095

MPEF-PV 6345

MPEF-PV 6446

MPEF-PV 6447

MPEF-PV 6501

MPEF-PV 6527

MPEF-PV 6540

MPEF-PV 6750

MPEF-PV 6769

MPEF-PV 6771

MPEF-PV 6773

MPEF-PV 6774
Fragmento maxilar izquierdo con DP4-M1 y 1 molar superior izquierdo aislado

Fragmento maxilar izquierdo con DP4-M1, 1 molar superior izquierdo aislado y 1 molar inferior derecho aislado Fragmento maxilar izquierdo con DP4-M3

Fragmento maxilar derecho con DP4-M1 y dp4-m3 izquierdos

Fragmento mandibular derecho con m1-m3

Mandíbula derecha casi completa con dp4-m3

DP4 izquierdo aislado

Fragmento mandibular izquierdo con m1-m2

Fragmentos de mandíbula, incisivo y 2 molariformes en un bloque de sedimento

DP4 aislado

Fragmento mandibular derecho (partido) con dp4m3

Fragmento mandibular izquierdo con dp4-m1

Fragmento mandibular izquierdo con m2-m3

Fragmento maxilar derecho con 3 molariformes
Chubut

Gran Barranca, Chubut

Gran Barranca, Chubut

Gran Barranca, Chubut

Gran Barranca, Chubut

Gran Barranca, Chubut

Gran Barranca, Chubut

Gran Barranca, Chubut

Gran Barranca, Chubut

Gran Barranca, Chubut

Gran Barranca, Chubut

Gran Barranca, Chubut

Gran Barranca, Chubut

Gran Barranca, Chubut

Gran Barranca, Chubut
Colhue Huapi, Mioceno temprano inferior

Fm Sarmiento, Mb Colhue Huapi, Mioceno temprano inferior

Fm Sarmiento, Mb Colhue Huapi, Mioceno temprano inferior

Fm Sarmiento, Mb Colhue Huapi, Mioceno temprano inferior

Fm Sarmiento, Mb

Colhue Huapi,

Mioceno temprano inferior

Fm Sarmiento, Mb

Colhue Huapi,

Mioceno temprano inferior

Fm Sarmiento, Mb

Colhue Huapi,

Mioceno temprano inferior

Fm Sarmiento, Mb

Colhue Huapi,

Mioceno temprano inferior

Fm Sarmiento, Mb

Colhue Huapi,

Mioceno temprano inferior

Fm Sarmiento, Mb

Colhue Huapi,

Mioceno temprano inferior

Fm Sarmiento, Mb

Colhue Huapi,

Mioceno temprano inferior

Fm Sarmiento, Mb

Colhue Huapi,

Mioceno temprano inferior

Fm Sarmiento, Mb

Colhue Huapi,

Mioceno temprano inferior

Fm Sarmiento, Mb

Colhue Huapi,

Mioceno temprano inferior

Fm Sarmiento, Mb

Colhue Huapi,

Mioceno temprano inferior 
Prospaniomys priscus

Prospaniomys priscus

Prospaniomys priscus

Prospaniomys priscus

Prospaniomys priscus

Prospaniomys priscus

Prospaniomys priscus

Prospaniomys priscus

Prospaniomys priscus?

Prospaniomys priscus

Prospaniomys priscus

Prospaniomys priscus?

Prospaniomys priscus

Prospaniomys priscus

Prospaniomys priscus
MPEF-PV 7510

MPEF-PV 6805

MPEF-PV 6830 (en parte)

MPEF-PV 6830a

MPEF-PV 6831

MPEF-PV 6832 (en parte)

MPEF-PV 6833

MPEF-PV 6904b

MPEF-PV 6909

MPEF-PV 6934b

MPEF-PV 6969 (en parte)

MPEF-PV 6979

MPEF-PV 7516

MPEF-PV 7563

MPEF-PV 7566a
Fragmento maxilar derecho con DP4-M2

6 molariformes aislados no asociados

DP4 izquierdo aislado

Fragmento maxilar izquierdo con DP4-M1

Fragmento maxilar izquierdo con DP4-M1

Fragmento maxilar derecho con DP4- y M1 partido

Fragmento mandibular derecho con m1-m2 y 1 molar superior derecho aislado

Mandíbula derecha casi completa con toda la dentadura

1 molar superior izquierdo aislado

Fragmento mandibular derecho con dp4-m3

Mandíbula sin dientes y 1 molar inferior aislado

Fragmento mandibular derecho con $\mathrm{m} 2$

Mandíbula izquierda casi completa con toda la dentadura

Fragmento maxilar izquierdo con DP4-M1
Gran Barranca, Chubut

Gran Barranca, Chubut

Gran Barranca, Chubut

Gran Barranca, Chubut

Gran Barranca, Chubut

Gran Barranca, Chubut

Gran Barranca, Chubut

Gran Barranca, Chubut

Gran Barranca, Chubut

Gran Barranca, Chubut

Gran Barranca, Chubut

Gran Barranca, Chubut

Gran Barranca, Chubut

Gran Barranca, Chubut

Gran Barranca, Chubut
Fm Sarmiento, Mb Colhue Huapi, Mioceno temprano inferior

Fm Sarmiento, Mb Colhue Huapi, Mioceno temprano inferior

Fm Sarmiento, Mb

Colhue Huapi,

Mioceno temprano inferior

Fm Sarmiento, Mb

Colhue Huapi,

Mioceno temprano inferior

Fm Sarmiento, Mb

Colhue Huapi,

Mioceno temprano inferior

Fm Sarmiento, Mb

Colhue Huapi,

Mioceno temprano inferior

Fm Sarmiento, Mb

Colhue Huapi,

Mioceno temprano inferior

Fm Sarmiento, Mb

Colhue Huapi,

Mioceno temprano inferior

Fm Sarmiento, Mb

Colhue Huapi,

Mioceno temprano inferior

Fm Sarmiento, Mb

Colhue Huapi,

Mioceno temprano inferior

Fm Sarmiento, Mb

Colhue Huapi,

Mioceno temprano inferior

Fm Sarmiento, $\mathrm{Mb}$

Colhue Huapi,

Mioceno temprano inferior

Fm Sarmiento, Mb

Colhue Huapi,

Mioceno temprano inferior

Fm Sarmiento, $\mathrm{Mb}$

Colhue Huapi,

Mioceno temprano inferior

Fm Sarmiento, Mb

Colhue Huapi,

Mioceno temprano inferior 
Prospaniomys priscus

MPEF-PV 7568

Prospaniomys priscus

MPEF-PV 7572

"Protacaremys" sp. nov. (Holotipo)

Protacaremys prior

AMNH 29734

Protacaremys prior

Protacaremys prior

(Holotipo)

Protacaremys prior

Protacaremys prior

Protacaremys prior

Protacaremys prior

Protacaremys avunculus

MACN A 52-117

Protacaremys prior

Protacaremys prior

Protacaremys prior

Protacaremys prior

Protacaremys prior

Protacaremys prior

MACN A 52-123

Protacaremys avunculus

MACN A 52-124

Protacaremys prior

MACNA 52-113

MACN A 52-114

MACN A 52-115

MACN A 52-116

MACN A 15-118

MACN A 52-119

MACN A 52-120

MACN A 52-121

MACN A 52-122

MACN A 52-125
Fragmento maxilar derecho con DP4-M1

Gran Barranca, Chubut

Mandíbula izquierda casi completa con toda la dentadura

Fragmento mandibular izquierdo con dp4-m3

Cráneo parcialmente preservado con las 2 hileras dentarias

Fragmento maxilar derecho con DP4-M2

MACN A 52-112b
Mandíbula derecha casi completa con toda la dentadura

Fragmento maxilar izquierdo con DP4-M3

2 molares aislados

Fragmento maxilar derecho con DP4-M1

Fragmento maxilar izquierdo con DP4-M1

Fragmento maxilar izquierdo con DP4

Fragmento maxilar izquierdo con DP4

Fragmento mandibular derecho con dp4 (partido)$\mathrm{m} 2$

Fragmento mandibular derecho con $\mathrm{m} 1$ (partido) y $\mathrm{m} 2$

Fragmento mandibular derecho con dp4 e incisivo

2 molariformes inferiores derechos aislados

Fragmento mandibular izquierdo con m1-m3 y un fragmento de maxilar izquierdo con M1

Fragmento maxilar izquierdo con DP4-M1

Fragmento mandibular
Gran Barranca, Chubut

Gran Barranca, Chubut

Barranca sur del Lago Colhue Huapi, Chubut Bryn Gwyn, Chubut

Colhue Huapi?, Chubut

Colhue Huapi?, Chubut

Colhue Huapi?, Chubut

Colhue Huapi?, Chubut

Colhue Huapi?, Chubut

Colhue Huapi?, Chubut

Colhue Huapi?, Chubut

Barranca sur del lago Colhue Huapi?, Chubut

Barranca sur del lago Colhue Huapi?, Chubut Barranca sur del lago Colhue Huapi?, Chubut Barranca sur del lago Colhue Huapi?, Chubut

Barranca sur del lago Colhue Barranca sur del Huapi?, Chubut
Fm Sarmiento, Mb Colhue Huapi, Mioceno temprano inferior

Fm Sarmiento, Mb

Colhue Huapi,

Mioceno temprano inferior

Fm Sarmiento, Mb

Colhue Huapi,

Mioceno temprano

Fm Sarmiento, Mb

Colhue Huapi,

Mioceno temprano

Fm Sarmiento, Mb

Trelew, Mioceno temprano

Fm Sarmiento, Mb

Colhue Huapi,

Mioceno temprano

Fm Sarmiento, Mb

Colhue Huapi?,

Mioceno temprano

Fm Sarmiento, Mb

Colhue Huapi,

Mioceno temprano

Fm Sarmiento, Mb

Colhue Huapi,

Mioceno temprano

Fm Sarmiento, Mb

Colhue Huapi,

Mioceno temprano

Fm Sarmiento, Mb

Colhue Huapi,

Mioceno temprano

Fm Sarmiento, Mb

Colhue Huapi,

Mioceno temprano

Fm Sarmiento, Mb

Colhue Huapi,

Mioceno temprano

Fm Sarmiento, Mb

Colhue Huapi,

Mioceno temprano

Fm Sarmiento, Mb

Colhue Huapi,

Mioceno temprano

Fm Sarmiento, Mb

Colhue Huapi,

Mioceno temprano

Fm Sarmiento, Mb

Colhue Huapi,

Mioceno temprano

Fm Sarmiento, Mb

Colhue Huapi,

Mioceno temprano

Fm Sarmiento, Mb 
Protacaremys avunculus (Holotipo)

Protacaremys prior

Protacaremys prior

Protacaremys prior

Protacaremys denisae (Holotipo)

Protacaremys denisae

Protacaremys denisae

Protacaremys prior

Protacaremys denisae

Protacaremys denisae

Protacaremys denisae

Protacaremys prior?

Protacaremys prior

Protacaremys avunculus

Protacaremys

Protacaremys?

Protacaremys avunculus

Protacaremys sp.

Protacaremys prior
MPEF-PV 5683

MACN A 52-126

MACN A 52-130

MLP 82-V-2-1

MLP 85-VII-3-129

MLP 91-IV-1-16

MLP 91-IV-1-18

MLP 91-IV-1-20

MLP 92-X-10-24

AR 91-51a

AR 91-51b

AR 91-51c

MMP 116

MMP 122

MPEF-PV 5619

MPEF-PV 5652

MPEF-PV 5655

MPEF-PV 5685

MPEF-PV 5686 izquierdo con m1-m3

Mandíbula derecha casi completa con toda la dentadura

Fragmento mandibular derecho con m1-m2

Mandíbula izquierda con toda la dentadura

Fragmento mandibular derecho con toda la dentadura

Fragmento de paladar izquierdo con DP4-M2

Fragmento mandibular con parte del DP4 y m1-m2

Fragmento mandibular derecho con m2-m3 e incisivo partido

3 fragmentos de mandíbula y 2 maxilares con DP4-M3

Fragmento de paladar con M1-M2

Fragmento de paladar con DP4-M1

fragmento mandibular con dp4-m1

Fragmento mandibular derecho con m1-m3 Fragmento mandibular izquierdo con dp4-m1 Fragmento maxilar izquierdo con DP4-M1

Fragmento mandibular derecho con dp4-m1 e incisivo

Fragmento mandibular izquierdo con dp4-m2

Fragmento maxilar derecho con DP4-M1 y molar superior aislado

Fragmento maxilar derecho con DP4-M2

Fragmento mandibular derecho con $\mathrm{m} 2$, dp4 derecho aislado, molar lago Colhue

Huapi?, Chubut

Barranca sur del

lago Colhue

Huapi?, Chubut

Barranca sur del

lago Colhue

Huapi?, Chubut

Barranca sur del

lago Colhue Huapi,

Chubut

Barranca sur del

lago Colhue Huapi,

Chubut

Cañadón del

Tordillo, provincia

del Neuquén

Cañadón del

Tordillo, provincia

del Neuquén

Cañadón del

Tordillo, provincia

del Neuquén

Puesto Almendra,

Chubut

Cañadón del

Tordillo de la

provincia del

Neuquén

Cañadón del

Tordillo de la

provincia del

Neuquén

Cañadón del

Tordillo de la

provincia del

Neuquén

Gran Barranca,

Chubut

Gran Barranca,

Chubut

Gran Barranca,

Chubut

Gran Barranca, Chubut

Gran Barranca, Chubut

Gran Barranca, Chubut
Colhue Huapi,

Mioceno temprano

Fm Sarmiento, Mb

Colhue Huapi,

Mioceno temprano

Fm Sarmiento, Mb

Colhue Huapi,

Mioceno temprano

Fm Sarmiento, Mb

Colhue Huapi,

Mioceno temprano

Fm Sarmiento, Mb

Colhue Huapi,

Mioceno temprano

Fm Collón Cura

Mioceno medio

Fm Collón Cura,

Mioceno medio

Fm Collón Cura,

Mioceno medio

Fm Sarmiento, Mb

Colhue Huapi,

Mioceno temprano

Fm Collón Cura,

Mioceno medio

Fm Collón Cura Mioceno medio

Fm Collón Cura, Mioceno medio

Fm Sarmiento, Mb

Colhue Huapi,

Mioceno temprano

Fm Sarmiento, Mb

Colhue Huapi,

Mioceno temprano

Fm Sarmiento, Mb

Colhue Huapi,

Mioceno temprano

Fm Sarmiento, Mb

Colhue Huapi,

Mioceno temprano

Fm Sarmiento, Mb

Colhue Huapi,

Mioceno temprano

Fm Sarmiento, Mb

Colhue Huapi,

Mioceno temprano 
Protacaremys?

Protacaremys sp.

"Protacaremys" sp. nov.?

Protacaremys prior

"Protacaremys" sp. nov.

Protacaremys prior

Protacaremys sp.

Protacaremys avunculus

"Protacaremys" sp. nov.

Protacaremys prior

Protacaremys prior

Protacaremys prior

"Protacaremys" sp. nov.

Protacaremys prior

"Protacaremys" sp. nov.

Protacaremys avunculus

Protacaremys prior

Protacaremys prior
MPEF-PV 6427

MPEF-PV 6747

MPEF-PV 5888

MPEF-PV 5890

MPEF-PV 5895 (en parte)

MPEF-PV 5896

MPEF-PV 6036

MPEF-PV 6041

MPEF-PV 6042

MPEF-PV 6044

MPEF-PV 6054

MPEF-PV 6055

MPEF-PV 6057

MPEF-PV 6082

MPEF-PV 6089b

MPEF-PV 6092

MPEF-PV 6423

MPEF-PV 6748 inferior derecho aislado y

fragmento mandibular

izquierdo con dp4-m1

5 molares superiores aislados

$2 \mathrm{~m} 3$ aislados

Fragmento mandibular con

1 molariforme y 5 molariformes inferiores aislados

2 dp4

Fragmento mandibular izquierdo con m2-m3 y fragmento mandibular con $\mathrm{m} 1-\mathrm{m} 2$

2 molares inferiores izquierdos y $1 \mathrm{dp} 4$ izquierdos aislados

Fragmento mandibular izquierdo con incisivo partido y dp4 aislado Fragmento maxilar derecho con DP4-M1

Fragmento de mandíbula izquierda mal preservada con $\mathrm{m} 2$, incisivo y molar aislado

Bochoncito con fragmentos maxilares y molariformes

1 molar superior derecho aislado

Fragmento mandibular izquierdo con dp4-m2

Fragmento mandibular izquierdo con m2-m3

1 dp4 izquierdo, 1 molar derecho inferior y 1 molar superior derecho aislados Fragmento mandibular izquierdo con $\mathrm{m} 1 \mathrm{e}$ incisivo partido

Fragmento mandibular izquierdo con $\mathrm{m} 2$ e incisivo partido

Fragmento maxilar izquierdo con DP4-M2

Fragmento maxilar derecho con DP4-M2
Gran Barranca, Chubut

Gran Barranca, Chubut

Gran Barranca, Chubut

Gran Barranca, Chubut

Gran Barranca, Chubut

Gran Barranca, Chubut

Gran Barranca, Chubut

Gran Barranca, Chubut

Gran Barranca, Chubut

Gran Barranca, Chubut

Gran Barranca, Chubut

Gran Barranca, Chubut

Gran Barranca, Chubut

Gran Barranca, Chubut

Gran Barranca, Chubut

Gran Barranca, Chubut

Gran Barranca, Chubut

Gran Barranca, Chubut
Fm Sarmiento, Mb

Colhue Huapi, Mioceno temprano Fm Sarmiento, Mb Colhue Huapi, Mioceno temprano Fm Sarmiento, Mb Colhue Huapi, Mioceno temprano

Fm Sarmiento, Mb Colhue Huapi, Mioceno temprano Fm Sarmiento, Mb Colhue Huapi, Mioceno temprano

Fm Sarmiento, Mb Colhue Huapi, Mioceno temprano

Fm Sarmiento, Mb Colhue Huapi, Mioceno temprano Fm Sarmiento, Mb Colhue Huapi, Mioceno temprano Fm Sarmiento, Mb Colhue Huapi, Mioceno temprano

Fm Sarmiento, Mb Colhue Huapi, Mioceno temprano Fm Sarmiento, Mb Colhue Huapi, Mioceno temprano Fm Sarmiento, Mb Colhue Huapi, Mioceno temprano Fm Sarmiento, Mb Colhue Huapi, Mioceno temprano Fm Sarmiento, Mb Colhue Huapi, Mioceno temprano Fm Sarmiento, Mb Colhue Huapi, Mioceno temprano Fm Sarmiento, Mb Colhue Huapi, Mioceno temprano Fm Sarmiento, Mb Colhue Huapi, Mioceno temprano Fm Sarmiento, Mb Colhue Huapi, 
"Protacaremys" sp. nov.

MPEF-PV 6770

Protacaremys prior

Protacaremys prior

Protacaremys prior

Protacaremys prior

Protacaremys prior

Sciamys principalis

Sciamys principalis

Sciamys principalis

Sciamys principalis

Sciamys principalis

Sciamys principalis

Sciamys principalis

Sciamys principalis

Sciamys principalis

Sciamys principalis

Sciamys principalis

Sciamys principalis

Sciamys principalis

Sciamys principalis
MPEF-PV 6772

Fragmento mandibular izquierdo con m2-m3 e incisivo partido

Fragmento mandibular derecho con dp4-m2 e incisivo partido

MPEF-PV 6804

MPEF-PV 6894

MPEF-PV 6904a

MPEF-PV 7468

MACN A 244

MACN A 245

MACN A 248b

MACN A 250

MACN A 255

MACN A 265

MACN A 1871

MACN A 1872

MACN A 1886

MACN A 1887

MACN A 1888

MACN A 1901

MACN A 1903

MACN A 1904
Fragmento mandibular derecho con dp4-m2 e incisivo partido

1 molar superior derecho y 1 molar superiores izquierdo aislados

Fragmento mandibular izquierdo con m2-m3 y 1 molar superior izquierdo aislado

Fragmento maxilar izquierdo con DP4-M1

Mandíbula derecha casi completa con m1-m3 e incisivo, mandíbula izquierda casi completa con $\mathrm{m} 1-\mathrm{m} 2$ e incisivo

Fragmento mandibular derecho con $\mathrm{p} 4-\mathrm{m} 3 \mathrm{e}$ incisivo partido Fragmento mandibular izquierdo con dp4-m1

Mandíbula derecha con incisivo y $\mathrm{m} 1-\mathrm{m} 3$

Mandíbula izquierda con p4-m3

Rama mandibular derecha con dp4-m3 e incisivo roto

Fragmento mandibular izquierdo con incisivo partido y dp4-m1

Mandíbula izquierda con dp4-m1

Mandíbula izquierda con incisivo partido y $\mathrm{m} 2-\mathrm{m} 3$ Mandíbula izquierda con incisivo partido y $\mathrm{m} 2$ Fragmento mandibular derecho con incisivo partido y $\mathrm{m} 1-\mathrm{m} 3$

Mandíbula derecha con p4- Santa Cruz $\mathrm{m} 2$

Mandíbula izquierda con incisivo partido y m1-m3

Mandíbula izquierda con
Gran Barranca, Chubut

Gran Barranca, Chubut

Gran Barranca, Chubut

Gran Barranca, Chubut

Gran Barranca, Chubut

Gran Barranca, Chubut

Santa Cruz

Santa Cruz

Santa Cruz

Santa Cruz

Santa Cruz

Santa Cruz

Santa Cruz

Santa Cruz

Santa Cruz

Santa Cruz
Mioceno temprano Fm Sarmiento, Mb Colhue Huapi, Mioceno temprano Fm Sarmiento, Mb Colhue Huapi, Mioceno temprano Fm Sarmiento, Mb Colhue Huapi, Mioceno temprano Fm Sarmiento, Mb Colhue Huapi, Mioceno temprano Fm Sarmiento, Mb Colhue Huapi, Mioceno temprano

Fm Sarmiento, Mb Colhue Huapi, Mioceno temprano Fm Santa Cruz, Mioceno temprano superior

Fm Santa Cruz, Mioceno temprano superior

Fm Santa Cruz, Mioceno temprano superior

Fm Santa Cruz, Mioceno temprano superior

Fm Santa Cruz, Mioceno temprano superior

Fm Santa Cruz, Mioceno temprano superior

Fm Santa Cruz, Mioceno temprano superior

Fm Santa Cruz, Mioceno temprano superior

Fm Santa Cruz, Mioceno temprano superior

Fm Santa Cruz, Mioceno temprano superior Fm Santa Cruz, 
Sciamys principalis

Sciamys principalis

Sciamys principalis

Sciamys principalis?

Sciamys principalis

Sciamys principalis

Sciamys principalis

Sciamys principalis

Sciamys principalis?

Sciamys principalis

Sciamys principalis

Sciamys principalis

Sciamys principalis

Sciamys principalis

Sciamys principalis

Sciamys principalis

Sciamys principalis

Sciamys principalis

Sciamys principalis
MACN A 4057

MACN A 4059

MACN A 4063

MACN A 4066a

MACN A 4105

MACN A 4106

MACN A 4107

MACN A 4108

MACN A 4109

MACN A 4110

MACN A 4111

MACN A 4114

MACN A 4115

MACN A 4118

MACN A 4119

MACN A 4121

MACN A 4122

MACN A 4123

MACN A 4125 incisivo partido y p4-m3

Fragmento mandibular derecho con p4-m3 e incisivo partido

Fragmento mandibular derecho con dp4-m2

Mandíbula izquierda casi completa con dp4-m1

Dos molares superiores y un molariforme superior suelto

Paladar con ambas hileras dentarias

Fragmento mandibular dercho con dp4-m2 e incisivo partido Mandíbula izquierda con incisivo en el alveolo y p4$\mathrm{m} 1$

Mandíbula derecha con incisivo partido y $\mathrm{p} 4-\mathrm{m} 3$

Mandíbula derecha con incisivo partido y $\mathrm{p} 4-\mathrm{m} 3$

Fragmento mandibular izquierdo con incisivo partido y $\mathrm{p} 4-\mathrm{m} 3$

Mandíbula derecha con incisivo partido y $\mathrm{p} 4-\mathrm{m} 3$

Cráneo casi completo con toda la dentadura

2 ramas mandibulares asociadas casi completas

Ambas hemimandíbulas fusionadas con incisivo derecho y p4-m3 derechos Mandíbula izquierda con incisivo en el alveolo y m1$\mathrm{m} 2$

Mandíbula derecha con incisivo y $\mathrm{p} 4-\mathrm{m} 2$

Mandíbula derecha con incisivo partido y $\mathrm{p} 4-\mathrm{m} 3$

Fragmento mandibular izquierdo con p4-m3 e incisivo partido Mandíbula derecha con incisivo y $\mathrm{p} 4-\mathrm{m} 3$
Monte

Observación, Santa

Cruz

Monte

Observación, Santa

Cruz

Monte

Observación, Santa

Cruz

Monte

Observación, Santa

Cruz

Santa Cruz

Barrancas del río

Santa Cruz, Santa

Cruz

Santa Cruz

Santa Cruz

Santa Cruz

Santa Cruz

Santa Cruz

Monte

Observación, Santa

Cruz

Monte

Observación, Santa

Cruz

Karaiken, Santa

Cruz

Santa Cruz

Santa Cruz

Santa Cruz

Santa Cruz

Santa Cruz
Mioceno temprano superior

Fm Santa Cruz,

Mioceno temprano superior

Fm Santa Cruz, Mioceno temprano superior

Fm Santa Cruz,

Mioceno temprano superior

Fm Santa Cruz,

Mioceno temprano superior

Fm Santa Cruz,

Mioceno temprano superior

Fm Santa Cruz,

Mioceno temprano superior

Fm Santa Cruz,

Mioceno temprano superior

Fm Santa Cruz,

Mioceno temprano superior

Fm Santa Cruz,

Mioceno temprano superior

Fm Santa Cruz,

Mioceno temprano superior

Fm Santa Cruz,

Mioceno temprano superior

Fm Santa Cruz,

Mioceno temprano superior

Fm Santa Cruz,

Mioceno temprano superior

Fm Santa Cruz,

Mioceno temprano superior

Fm Santa Cruz,

Mioceno temprano superior

Fm Santa Cruz,

Mioceno temprano superior

Fm Santa Cruz,

Mioceno temprano superior

Fm Santa Cruz, Mioceno temprano superior

Fm Santa Cruz,

Mioceno temprano superior 
Sciamys principalis

Sciamys principales

MACN A 4127

Sciamys principalis

Sciamys principalis

MACN A 4130

Sciamys principalis

MACN A 4131

Sciamys principalis

Sciamys principalis

Sciamys principalis

Sciamys principalis

Sciamys principalis

Sciamys principalis

Sciamys principalis

Sciamys principalis

Sciamys robustus

Sciamys principalis

Sciamys principalis

Sciamys principalis

Sciamys principalis

Sciamys principalis

Sciamys principalis

MACN A 4132

MACN A 4134

MACN A 4135

MACN A 4136

MACN A 4137

MACN A 4138

MACN A 4141

MACN A 4142

MACN A 4144

MACN A 10088
MACN A 4129

Mandíbula izquierda con incisivo en el alveolo y p4m3

Fragmento mandibular izquierdo con $\mathrm{p} 4-\mathrm{m} 3$

Mandíbula izquierda con incisivo partido y $\mathrm{p} 4-\mathrm{m} 3$

Mandíbula derecha con incisivo y $\mathrm{p} 4-\mathrm{m} 3$

Mandíbula derecha con incisivo en el alveolo y p4m3

MACN A 11606

MACN PV SC156

MACN PV SC176

MACN PV SC1603

MACN PV SC1633
Mandíbula derecha con incisivo en el alveolo y p4m3

Fragmento maxilar izquierdo con M1-M3

Paladar con M1-M2 derechos y M2 izquierdo

Fragmento maxilar izquierdo con P4-M2

Fragmento maxilar izquierdo con M1-M3

Fragmento maxilar izquierdo con P4-M2

Fragmento maxilar izquierdo con P4-M1

Porción anterior de un cráneo con P4-M3 e incisivo izquierdo y M1 e incisivo derecho partidos

Fragmento mandibular derecho con $\mathrm{p} 4$ e incisivo partido

Mandíbula derecha casi completa

Cráneo con ambos incisivos e hileras dentarias completas DP4 derecho aislado

Fragmento maxilar derecho con p4-m1

$\mathrm{m} 1$ o m2 izquierdo aislado

1 molariforme superior izquierdo aislado
Santa Cruz

Santa Cruz

Santa Cruz

Santa Cruz

Santa Cruz

Santa Cruz

Santa Cruz

Santa Cruz

Santa Cruz

Santa Cruz

Santa Cruz

Santa Cruz

Santa Cruz

Santa Cruz

Monte

Observación, Santa

Cruz

Monte

Observación, Santa
Fm Santa Cruz, Mioceno temprano superior

Fm Santa Cruz, Mioceno temprano superior

Fm Santa Cruz, Mioceno temprano superior

Fm Santa Cruz, Mioceno temprano superior

Fm Santa Cruz,

Mioceno temprano superior

Fm Santa Cruz,

Mioceno temprano superior

Fm Santa Cruz,

Mioceno temprano superior

Fm Santa Cruz, Mioceno temprano superior

Fm Santa Cruz,

Mioceno temprano superior

Fm Santa Cruz,

Mioceno temprano superior

Fm Santa Cruz,

Mioceno temprano superior

Fm Santa Cruz,

Mioceno temprano superior

Fm Santa Cruz,

Mioceno temprano superior

Fm Santa Cruz, Mioceno temprano superior

Fm Santa Cruz,

Mioceno temprano superior

Fm Santa Cruz,

Mioceno temprano superior

Fm Santa Cruz,

Mioceno temprano superior

Fm Santa Cruz,

Mioceno temprano superior

Fm Santa Cruz,

Mioceno temprano superior

Fm Santa Cruz,

Mioceno temprano 
Sciamys principalis

Sciamys principalis

Sciamys principalis

Sciamys principalis

Sciamys principalis

Sciamys principalis

Sciamys principalis

Sciamys principalis?

Sciamys principalis

Sciamys principalis

Sciamys principalis

Sciamys principalis

Sciamys principalis

Sciamys principalis

Sciamys principalis

Sciamys principalis

Sciamys principalis

Sciamys principalis

Sciamys principalis
MACN PV SC1649 M3 derecho aislado

MACN PV SC1667

MACN PV SC1686

MACN PV SC1701

MACN PV SC1704

MACN PV SC1726

MACN PV SC1742 p4-m2 derechos

MACN PV SC1749 Fragmento mandibular derecha con $\mathrm{p} 4-\mathrm{m} 3 \mathrm{e}$ incisivo roto

MACN PV SC1768 Mandíbula derecha casi completa con $\mathrm{p} 4-\mathrm{m} 2 \mathrm{e}$ incisivo partido

MACN PV SC1769 Mandíbula derecha casi completa con dp4-m1

MACN PV SC1795 1 molariforme superior derecho aislado

MACN PV SC1818 1 molar inferior izquierdo aislado

MACN PV SC1863 m1 ó m2 derecho aislado

MACN PV SC1876 Fragmento de mandíbula izquierda con $\mathrm{p} 4-\mathrm{m} 2$

MACN PV SC1879 Fragmento maxilar con P4M3 izquierdos

MACN PV SC1907 Fragmento maxilar derecho con P4-M1

MACN PV SC1927 P4 derecho aislado

MACN PV SC1984 Mandíbula derecha casi completa con dp4-m2 e incisivo

MACN PV SC1988
Cruz

Monte

Observación, Santa

Cruz

Monte

Observación, Santa

Cruz

Monte

Observación, Santa

Cruz

Monte

Observación, Santa

Cruz

Monte

Observación, Santa

Cruz

Monte

Observación, Santa

Cruz

Monte

Observación, Santa

Cruz

Monte

Observación, Santa

Cruz

Monte

Observación, Santa

Cruz

Monte

Observación, Santa

Cruz

Monte

Observación, Santa

Cruz

Monte

Observación, Santa

Cruz

Monte

Observación, Santa

Cruz

Monte

Observación, Santa

Cruz

Monte

Observación, Santa

Cruz

Monte

Observación, Santa

Cruz

Monte

Observación, Santa

Cruz

Monte

Observación, Santa

Cruz

\section{Monte}

Observación, Santa Cruz superior

Fm Santa Cruz,

Mioceno temprano superior

Fm Santa Cruz,

Mioceno temprano superior

Fm Santa Cruz,

Mioceno temprano superior

Fm Santa Cruz,

Mioceno temprano superior

Fm Santa Cruz,

Mioceno temprano superior

Fm Santa Cruz,

Mioceno temprano superior

Fm Santa Cruz,

Mioceno temprano superior

Fm Santa Cruz,

Mioceno temprano superior

Fm Santa Cruz,

Mioceno temprano superior

Fm Santa Cruz,

Mioceno temprano superior

Fm Santa Cruz,

Mioceno temprano superior

Fm Santa Cruz,

Mioceno temprano superior

Fm Santa Cruz,

Mioceno temprano superior

Fm Santa Cruz,

Mioceno temprano superior

Fm Santa Cruz,

Mioceno temprano superior

Fm Santa Cruz,

Mioceno temprano superior

Fm Santa Cruz,

Mioceno temprano superior

Fm Santa Cruz,

Mioceno temprano superior

Fm Santa Cruz, izquierdo con m1-m2 incisivo partido
Mioceno temprano superior 
Sciamys principalis

Sciamys principalis

Sciamys principalis

Sciamys principalis

Sciamys principalis

Sciamys principalis

Sciamys principalis

Sciamys principalis

Sciamys principalis

Sciamys principalis?

Sciamys principalis

Sciamys principalis

Sciamys principalis

Sciamys principalis

Sciamys principalis?

Sciamys principalis

Sciamys principalis

Sciamys principalis

Sciamys principalis
MACN PV SC1990

Fragmento mandibular izquierdo con $\mathrm{p} 4-\mathrm{m} 2 \mathrm{e}$ incisivo partido

MACN PV SC1992 Fragmento mandibular izquierdo con $\mathrm{p} 4-\mathrm{m} 2 \mathrm{e}$ incisivo partido

MACN PV SC1994 Fragmento mandibular derecho con m1-m2 e incisivo partido

MACN PV SC1995 1 molariforme inferior izquierdo aislado

MACN PV SC2206 Fragmento maxilar derecho con P4-M2

MACN PV SC2272 DP4 derecho aislado

MACN PV SC2294 P4 derecho aislado

MACN PV SC2305 Fragmento mandibular izquierdo con $\mathrm{p} 4-\mathrm{m} 2 \mathrm{e}$ incisivo partido

MACN PV SC2314 Mandíbula derecha casi completa con $\mathrm{p} 4-\mathrm{m} 3 \mathrm{e}$ incisivo partido

MACN PV SC2315 Mandíbula izquierda casi completa con $\mathrm{p} 4-\mathrm{m} 3 \mathrm{e}$ incisivo partido

MACN PV SC2316 Mandíbula izquierda casi completa con toda la dentadura

MACN PV SC2318 Fragmento mandibular derecho con $\mathrm{p} 4 \mathrm{e}$ incisivo partido

MACN PV SC2321 Fragmento maxilar (en parte)

MACN PV SC2320 izquierdo con M1-M3

Fragmento mandibular izquierdo con $\mathrm{m} 2-\mathrm{m} 3 \mathrm{e}$ incisivo partido

MACN PV SC2323 Fragmento mandibular derecho con 2 molariformes rotos

MACN PV SC2327 Fragmento mandibular izquierdo con $\mathrm{m} 1-\mathrm{m} 3 \mathrm{e}$ incisivo partido

MACN PV SC2328 Fragmento mandibular derecho con $\mathrm{p} 4-\mathrm{m} 1$

MACN PV SC2334 Fragmento mandibular izquierdo con dp4

MACN PV SC2341 Fragmento maxilar izquierdo con P4-M2
Monte

Observación, Santa

Cruz

Monte

Observación, Santa

Cruz

Monte

Observación, Santa

Cruz

Monte

Observación, Santa

Cruz

Monte León, Santa

Cruz

Monte

Observación, Santa

Cruz

Monte León, Santa

Cruz

Monte León, Santa

Cruz

Monte León, Santa

Cruz

Monte León, Santa

Cruz

Monte León, Santa

Cruz

Monte León, Santa

Cruz

Monte León, Santa

Cruz

Monte León, Santa

Cruz

Monte León, Santa

Cruz

Monte León, Santa Cruz

Monte León, Santa Cruz
Fm Santa Cruz, Mioceno temprano superior

Fm Santa Cruz, Mioceno temprano superior

Fm Santa Cruz, Mioceno temprano superior

Fm Santa Cruz, Mioceno temprano superior

Fm Santa Cruz, Mioceno temprano superior Fm Santa Cruz, Mioceno temprano superior

Fm Santa Cruz, Mioceno temprano superior

Fm Santa Cruz, Mioceno temprano superior

Fm Santa Cruz, Mioceno temprano superior

Fm Santa Cruz, Mioceno temprano superior

Fm Santa Cruz, Mioceno temprano superior

Fm Santa Cruz, Mioceno temprano superior

Fm Santa Cruz, Mioceno temprano superior

Fm Santa Cruz, Mioceno temprano superior

Fm Santa Cruz, Mioceno temprano superior

Fm Santa Cruz, Mioceno temprano superior

Fm Santa Cruz, Mioceno temprano superior Fm Santa Cruz, Mioceno temprano superior

Fm Santa Cruz, Mioceno temprano superior 
Sciamys principalis

Sciamys principalis

Sciamys principalis

Sciamys principalis

Sciamys principalis

Sciamys principalis

Sciamys principalis

Sciamys principalis

Sciamys principalis?

Sciamys principalis

Sciamys principalis

Sciamys principalis

Sciamys principalis?

Sciamys principalis

Sciamys principalis

Sciamys principalis

Sciamys principalis

Sciamys principalis

Sciamys principalis

Sciamys principalis

Sciamys principalis
MACN PV SC2349 p4-m1 derechos

MACN PV SC2351

MACN PV SC2368

MACN PV SC2369

MACN PV SC2370

MACN PV SC2371

MACN PV SC2372

MACN PV SC2373

MACN PV SC2375

MACN PV SC2376

MACN PV SC2377

MACN PV SC2378

MACN PV SC2393

MACN PV SC2394

MACN PV SC2396

MACN PV SC2405

MACN PV SC2408

MACN PV SC2409

MACN PV SC2419

MACN PV SC2586

MACN PV SC2588
Fragmento mandibular izquierdo con 1 molariforme

Fragmento mandibular izquierdo con m1-m3 e incisivo partido

Mandíbula derecha casi completa con p4-m3 e incisivo partido Fragmento mandibular derecho con m1-m2 e incisivo partido Fragmento mandibular derecho con dp4-m1 e incisivo partido Fragmento mandibular derecho con dp4-m2

Mandíbula izquierda casi completa con m1-m3 e incisivo partido

Fragmento mandibular izquierdo con $\mathrm{p} 4-\mathrm{m} 2 \mathrm{e}$ incisivo partido Fragmento mandibular derecho con dp4

Mandíbula derecha casi completa con la dentadura supernumeraria

Fragmento maxilar izquierdo con DP4

Fragmento mandibular derecho con $\mathrm{p} 4-\mathrm{m} 3$

Fragmento mandibular derecho con dp4-m1 e incisivo partido Mandíbula izquierda casi completa con p4-m3 e incisivo partido Fragmento mandibular izquierdo con $\mathrm{p} 4-\mathrm{m} 2 \mathrm{e}$ incisivo partido Fragmento mandibular izquierdo con m1-m3 e incisivo partido

Fragmento mandibular izquierdo con dp4-m1 e incisivo partido

Fragmento mandibular izquierdo con p4-m3 e incisivo roto Fragmento mandibular derecho con p4-m2 36 molariformes aislados
Monte León, Santa Cruz

Monte León, Santa

Cruz

Monte León, Santa

Cruz

Monte León, Santa

Cruz

Monte León, Santa Cruz

Monte León, Santa Cruz

Monte León, Santa Cruz

Monte León, Santa Cruz

Monte León, Santa Cruz

Monte León, Santa Cruz

Monte León, Santa Cruz

Monte León, Santa Cruz

Monte León, Santa Cruz

Monte León, Santa Cruz

Monte León, Santa Cruz

Monte León, Santa Cruz

Monte León, Santa Cruz

Monte León, Santa Cruz

Monte León, Santa Cruz

Toldos Sur, Santa

Cruz

Toldos Sur, Santa
Fm Santa Cruz, Mioceno temprano superior

Fm Santa Cruz, Mioceno temprano superior

Fm Santa Cruz, Mioceno temprano superior

Fm Santa Cruz, Mioceno temprano superior

Fm Santa Cruz, Mioceno temprano superior

Fm Santa Cruz Mioceno temprano superior

Fm Santa Cruz, Mioceno temprano superior

Fm Santa Cruz, Mioceno temprano superior

Fm Santa Cruz, Mioceno temprano superior

Fm Santa Cruz Mioceno temprano superior

Fm Santa Cruz, Mioceno temprano superior

Fm Santa Cruz, Mioceno temprano superior

Fm Santa Cruz, Mioceno temprano superior

Fm Santa Cruz, Mioceno temprano superior

Fm Santa Cruz, Mioceno temprano superior

Fm Santa Cruz, Mioceno temprano superior

Fm Santa Cruz, Mioceno temprano superior

Fm Santa Cruz, Mioceno temprano superior

Fm Santa Cruz, Mioceno temprano superior Fm. Pinturas, Mioceno temprano Fm. Pinturas, 
Sciamys principalis

Sciamys principalis

Sciamys principalis

Sciamys principalis

Sciamys principalis

Sciamys principalis

Sciamys principalis

Sciamys principalis

Sciamys principalis

Sciamys principalis

Sciamys principalis

Sciamys principalis

Sciamys principalis

Sciamys principalis

Sciamys principalis

Sciamys principalis

Sciamys principalis

Sciamys principalis

Sciamys principalis (en parte)

MACN PV SC2621 m1 ó m2 derecho aislado

MACN PV SC2624 dp4 derecho aislado

MACN PV SC2626 m1 ó m2 derecho aislado

MACN PV SC2660 Fragmento mandibular

izquierdo con $\mathrm{p} 4-\mathrm{m} 3$

MACN PV SC2697 m1 ó m2 derecho aislado

MACN PV SC2712 m1 ó m2 izquierdo aislado

MACN PV SC2723 Mandíbula derecha casi

completa con p4-m3 e

incisivo partido

MACN PV SC2773 Mandíbula izquierda casi

completa con $\mathrm{p} 4-\mathrm{m} 3 \mathrm{e}$

incisivo partido

MACN PV SC2777 Fragmento mandibular

izquierdo con $\mathrm{p} 4-\mathrm{m} 3 \mathrm{e}$

incisivo partido

MACN PV SC2782 Fragmento mandibular

izquierdo con dp4-m2 e

incisivo partido

MACN PV SC2792 m1-m2 izquierdos

MACN PV SC31174

MACN PV SC311710

MLP 15-23

MLP 15-24

MLP 15-25

MLP 15-146

MLP 15-218

MLP 15-197
Cruz

Monte

Observación, Santa

Cruz

Monte

Observación, Santa

Cruz

Monte

Observación, Santa

Cruz

Monte

Observación, Santa

Cruz

Monte

Observación, Santa

Cruz

Monte

Observación, Santa

Cruz

Monte

Observación, Santa

Cruz

Monte León, Santa

Cruz

Monte León, Santa

Cruz

Monte León, Santa

Cruz

Monte León, Santa

Cruz

Monte

Observación, Santa

Cruz

Monte

Observación, Santa

Cruz

Barrancas del río

Santa Cruz, Santa

Cruz

Barrancas del río

Santa Cruz, Santa

Cruz

Barrancas del río

Santa Cruz, Santa

Cruz

Barrancas del río

Santa Cruz, Santa

Cruz

Barrancas del río

Santa Cruz, Santa

Cruz

Barrancas del río

Santa Cruz, Santa

Cruz
Mioceno temprano

Fm Santa Cruz,

Mioceno temprano superior

Fm Santa Cruz,

Mioceno temprano superior

Fm Santa Cruz,

Mioceno temprano superior

Fm Santa Cruz,

Mioceno temprano superior

Fm Santa Cruz,

Mioceno temprano superior

Fm Santa Cruz,

Mioceno temprano superior

Fm Santa Cruz,

Mioceno temprano superior

Fm Santa Cruz,

Mioceno temprano superior

Fm Santa Cruz,

Mioceno temprano superior

Fm Santa Cruz,

Mioceno temprano superior

Fm Santa Cruz,

Mioceno temprano superior

Fm Santa Cruz,

Mioceno temprano superior

Fm Santa Cruz, Mioceno temprano superior

Fm Santa Cruz, Mioceno temprano superior

Fm Santa Cruz,

Mioceno temprano superior

Fm Santa Cruz,

Mioceno temprano superior

Fm Santa Cruz,

Mioceno temprano superior

Fm Santa Cruz,

Mioceno temprano superior

Fm Santa Cruz,

Mioceno temprano superior 
Sciamys principalis

MLP 15-222

Sciamys principalis

MLP 15-225

Sciamys principalis

MLP 15-347

Sciamys principalis

Sciamys principalis

Sciamys principalis

Sciamys principalis

Sciamys principalis

Sciamys principalis

Sciamys principalis

Sciamys?

Sciamys principalis

Sciamys principalis?

Sciamys principalis

Sciamys principalis

Sciamys principalis

Sciamys principalis

Sciamys principalis

Sciamys principalis

Sciamys principalis
MLP 15-349

MLP 15-352

MLP 15-390

MLP 15-391d

MLP 15-393

MLP 63-XII-19-126

MLP 63-XII-19-127

MLP 63-XII-19-128

MLP 63-XII-19-129

MLP 63-XII-19-130

MLP 63-XII-19-131

MLP 63-XII-19-132

MLP 63-XII-19-133

MLP 63-XII-19-134

MLP 63-XII-19-135

MLP 63-XII-19-136

Fragmento mandibular derecha $\mathrm{m} 1-\mathrm{m} 2$

MLP 63-XII-19-137 Mandíbula izquierda casi

Mandíbula izquierda cas completa con $\mathrm{p} 4-\mathrm{m} 3 \mathrm{e}$ incisivo roto

Fragmento de mandíbula izquierda con dp4-m2 e incisivo roto

Fragmento mandibular izquierdo con m1-m2 e incisivo roto

Fragmento de mandíbula derecha con dp4 y m2, y fragmento maxilar con 2 molariformes

Fragmento de mandíbula izquierda con dp4-m2 e incisivo roto

Fragmento mandibular derecho con $\mathrm{p} 4-\mathrm{m} 3 \mathrm{e}$ incisivo partido

Mandíbula derecha casi completa con la dentadura supernumeraria

Fragmento mandibular derecho con m1-m2 e incisivo partido

Fragmento mandibular izquierdo con $\mathrm{p} 4-\mathrm{m} 2 \mathrm{e}$ incisivo partido

Fragmento mandibular derecho con $\mathrm{p} 4-\mathrm{m} 3 \mathrm{e}$ incisivo partido

Fragmento mandibular

Fragmento mandibular izquierdo con $\mathrm{p} 4-\mathrm{m} 3$

Fragmento mandibular izquierdo con m1-m3 e incisivo partido Fragmento mandibular derecho con m1-m3

Fragmento mandibular izquierdo con $\mathrm{p} 4-\mathrm{m} 2$
Barrancas del río

Santa Cruz, Santa

Cruz

derechos

Fragmento mandibular derecho con m1-m2

Fragmento mandibular izquierdo con m1-m2 derecho con p4 (partido)-m3
Barrancas del río

Santa Cruz, Santa

Cruz

Barrancas del río

Santa Cruz, Santa

Cruz

Barrancas del río

Santa Cruz, Santa

Cruz

Barrancas del río

Santa Cruz, Santa

Cruz

Barrancas del río

Santa Cruz, Santa

Cruz

"curso inferior del río Santa Cruz",

Santa Cruz

Santa Cruz

Barrancas del río Santa Cruz, Santa

Barrancas del río Santa Cruz, Santa

Barrancas del río

Santa Cruz, Santa

Barrancas del río

Santa Cruz, Santa

Barrancas del río

Santa Cruz, Santa

Barrancas del río

Santa Cruz, Santa

Barrancas del río

Santa Cruz, Santa

Barrancas del río

Santa Cruz, Santa

Barrancas del río

Santa Cruz, Santa

Barrancas del río

Santa Cruz, Santa

Barrancas del río

Santa Cruz, Santa

Barrancas del río
Fm Santa Cruz, Mioceno temprano superior

Fm Santa Cruz, Mioceno temprano superior

Fm Santa Cruz, Mioceno temprano superior

Fm Santa Cruz,

Mioceno temprano superior

Fm Santa Cruz,

Mioceno temprano superior

Fm Santa Cruz,

Mioceno temprano superior

Fm Santa Cruz, Mioceno temprano superior

Fm Santa Cruz, Mioceno temprano superior

Fm Santa Cruz, Mioceno temprano superior

Fm Santa Cruz, Mioceno temprano superior

Fm Santa Cruz,

Mioceno temprano superior

Fm Santa Cruz,

Mioceno temprano superior

Fm Santa Cruz, Mioceno temprano superior

Fm Santa Cruz, Mioceno temprano superior

Fm Santa Cruz, Mioceno temprano superior

Fm Santa Cruz,

Mioceno temprano superior

Fm Santa Cruz, Mioceno temprano superior

Fm Santa Cruz, Mioceno temprano superior

Fm Santa Cruz, Mioceno temprano superior

Fm Santa Cruz, 
Sciamys principalis

Sciamys principalis

Sciamys principalis?

Sciamys principalis

Sciamys principalis

Sciamys principalis

Sciamys principalis

Sciamys principalis

Sciamys principalis

Sciamys?

Sciamys principalis?

Sciamys principalis?

Sciamys principalis

Sciamys principalis

Sciamys principalis

Sciamys principalis

Sciamys principalis

Sciamys principalis
MLP 63-XII-19-138

MLP 63-XII-19-139

MLP 63-XII-19-141

MLP 63-XII-19-142

MLP 82-XII-1-1

MLP 82-XII-1-2

MLP 82-XII-1-3

MLP 82-XII-1-15

MLP 82-XII-1-17

MLP 84-III-8-43

MPM-PV (PLC-NT08-16)

MPM-PV(CB-RK08-04)

YPM PU 15089

YPM PU 15168

YPM PU 15287

YPM PU 15575

YPM PU 15623

YPM PU 15624 completa con m1-m3 e incisivo partido

Fragmento mandibular izquierdo con $\mathrm{p} 4-\mathrm{m} 3$

Mandíbula izquierda casi completa con p4-m2

Fragmento mandibular izquierdo con $\mathrm{p} 4-\mathrm{m} 2$

Fragmento mandibular derecho con p4-m1

Fragmento mandibular derecho con $\mathrm{p} 4-\mathrm{m} 2$

Fragmento mandibular izquierdo con p4(partido)m3

Fragmento mandibular derecho con $\mathrm{p} 4-\mathrm{m} 2$

Fragmento mandibular derecho con dp4-m1

Fragmento mandibular con 2 molariformes

Mandíbula izquierda cas completa con $\mathrm{p} 4-\mathrm{m} 2 \mathrm{e}$ incisivo

Porción anterior del cráneo con M1 de ambos lados y los 2 incisivos

Porción anterior del cráneo con P4 izquierdo y los 2 incisivos DP4-M2 derechos

Fragmento de cráneo, mandíbula izquierda con p4m3 y post cráneo

fragmentario

Cráneo parcialmente preservado con las dos hileras dentarias y un fragmento mandibular derecho con $\mathrm{p} 4-\mathrm{m} 1$

Cráneo con P4-M3 derechos

Fragmento de cráneo con P4-M3 derechos y P4-M1 izquierdos y fragmento mandibular izquierdo con p4

2 incisivos unidos y
Santa Cruz, Santa

Barrancas del río

Santa Cruz, Santa

Barrancas del río

Santa Cruz, Santa

Barrancas del río

Santa Cruz, Santa

Barrancas del río

Santa Cruz, Santa

Santa Cruz

Santa Cruz

Santa Cruz

Santa Cruz

Santa Cruz

Ea. La Bajada Santa Cruz

NF

NF

Lado sur del río Santa Cruz a 60 millas del lago,

Santa Cruz

$10 \mathrm{mi}$ al sur de Coy

Inlet, Santa Cruz

10 mi al sur de Coy

Inlet, Santa Cruz

Killik Aike, Santa Cruz

Killik Aike, Santa Cruz

10 mi al sur de Coy
Mioceno temprano superior Fm Santa Cruz, Mioceno temprano superior

Fm Santa Cruz, Mioceno temprano superior

Fm Santa Cruz, Mioceno temprano superior

Fm Santa Cruz, Mioceno temprano superior

Fm Santa Cruz, Mioceno temprano superior

Fm Santa Cruz, Mioceno temprano superior

Fm Santa Cruz Mioceno temprano superior

Fm Santa Cruz, Mioceno temprano superior

Fm Santa Cruz, Mioceno temprano superior

Fm Santa Cruz, Mioceno temprano superior

Fm Santa Cruz,

Mioceno temprano superior

Fm Santa Cruz,

Mioceno temprano superior

Fm Santa Cruz, Mioceno temprano superior

Fm Santa Cruz, Mioceno temprano superior

Fm Santa Cruz, Mioceno temprano superior

Fm Santa Cruz, Mioceno temprano superior Fm Santa Cruz, Mioceno temprano superior

Fm Santa Cruz, 
Sciamys latidens

Octodontoidea indet.

Octodontoidea indet.

Octodontoidea indet.

Octodontoidea indet.

Octodontoidea indet.

MPEF-PV 6101

Octodontoidea indet.

MACN A 4069

MPEF PV-5624

MLP 15-26 fragmentos de post-cráneo

YPM PU 15944

MACN A 52- 127

MACN PV SC2428
Cráneo parcialmente preservado, fragmento mandibular derecho y resto de post-cráneo fragmentario Fragmento mandibular derecho con dp4-m1 e incisivo partido

Rama mandibular derecha con $\mathrm{dp} 4 \mathrm{y} \mathrm{m} 1$ roto e incisivo

Fragmento de mandíbula derecha sin dientes

2 DP4

Bochón con fragmentos maxilares y 1 molariformes indistinguibles

Fragmento mandibular derecho con 2 molariformes rotos
Inlet, Santa Cruz

Killik Aike, Santa

Cruz

Barranca sur del

Lago Colhue

Huapi?, Chubut

Monte

Observación, Santa

Cruz

Río Pinturas. Cerro

de los monos,

Santa Cruz

Gran Barranca,

Chubut

Gran Barranca,

Chubut

Barrancas del Río

Santa Cruz, Santa

Cruz
Mioceno temprano superior Fm Santa Cruz, Mioceno temprano superior

Fm Sarmiento, $\mathrm{Mb}$ Colhue Huapi, Mioceno temprano Fm Santa Cruz, Mioceno temprano superior

Fm Pinturas, Mioceno inferior

Fm Sarmiento, Mb Colhue Huapi, Mioceno temprano Fm Sarmiento, Mb Colhue Huapi, Mioceno temprano Fm Santa Cruz, Mioceno temprano superior 


\section{APÉNDICE 2. Listado de roedores fósiles incluidos en el análisis cladístico}

\begin{tabular}{|c|c|c|c|}
\hline ESPECIMEN & MATERIAL & DESCRIPCIÓN & $\begin{array}{l}\text { PROCEDENCIA ESTRATIGRÁFICA } \\
\text { Y CRONOLÓGICA }\end{array}$ \\
\hline Adelphomys candidus & MACN A 241 & $\begin{array}{l}\text { Mandíbula izquierda } \\
\text { con dp4-m3 }\end{array}$ & $\begin{array}{l}\text { Fm Santa Cruz (Mioceno temprano). } \\
\text { Santa Cruz, Argentina }\end{array}$ \\
\hline Adelphomys candidus & MACN A 243 & $\begin{array}{l}\text { Mandíbula derecha con } \\
\text { dp4-m2 }\end{array}$ & $\begin{array}{l}\text { Fm Santa Cruz (Mioceno temprano). } \\
\text { Santa Cruz, Argentina }\end{array}$ \\
\hline Adelphomys candidus & MACN A 246 & $\begin{array}{l}\text { Paladar con DP4-M2 de } \\
\text { ambos lados }\end{array}$ & $\begin{array}{l}\text { Fm Santa Cruz (Mioceno temprano). } \\
\text { Santa Cruz, Argentina }\end{array}$ \\
\hline Adelphomys candidus & MACN A 1919 & $\begin{array}{l}\text { Mandíbula derecha con } \\
\text { dp4-m2 }\end{array}$ & $\begin{array}{l}\text { Fm Santa Cruz (Mioceno temprano). } \\
\text { Santa Cruz, Argentina }\end{array}$ \\
\hline Adelphomys candidus & MACN A 1923 & $\begin{array}{l}\text { Mandíbula izquierda } \\
\text { con } \mathrm{m} 1-\mathrm{m} 3\end{array}$ & $\begin{array}{l}\text { Fm Santa Cruz (Mioceno temprano). } \\
\text { Santa Cruz, Argentina }\end{array}$ \\
\hline Deseadomys arambourgi & MNHN 1903-3-1 & $\begin{array}{l}\text { Mandíbula derecha con } \\
\text { p4-m3 e incisivo }\end{array}$ & $\begin{array}{l}\text { Fm Sarmiento (Oligoceno tardío). } \\
\text { Santa Cruz, Argentina }\end{array}$ \\
\hline Deseadomys arambourgi & ACM 3163 & P4-M2 & $\begin{array}{l}\text { Fm Sarmiento (Oligoceno tardío). } \\
\text { Chubut, Argentina }\end{array}$ \\
\hline Deseadomys arambourgi & ACM 3071 & M3 & $\begin{array}{l}\text { Fm Sarmiento (Oligoceno tardío). } \\
\text { Chubut, Argentina }\end{array}$ \\
\hline Deseadomys arambourgi & MPEF PV 594 & P4 derecho & \\
\hline "Deseadomys" loomisi & ACM 3087 & $\begin{array}{l}\text { Mandíbula derecha con } \\
\text { m1-m2 }\end{array}$ & $\begin{array}{l}\text { Fm Sarmiento (Oligoceno tardío). } \\
\text { Chubut, Argentina }\end{array}$ \\
\hline Eosteiromys homogenidens & MACN A 52-165 & $\begin{array}{l}\text { Cráneo con P4-M3 } \\
\text { derechos y M1-M2 } \\
\text { izquierdos }\end{array}$ & $\begin{array}{l}\text { Fm Sarmiento (Mioceno temprano). } \\
\text { Chubut, Argentina }\end{array}$ \\
\hline Eosteiromys homogenidens & MACN A 52-166 & $\begin{array}{l}\text { Mandíbula izquierda } \\
\text { con p4-m2 }\end{array}$ & $\begin{array}{l}\text { Fm Sarmiento (Mioceno temprano). } \\
\text { Chubut, Argentina }\end{array}$ \\
\hline Eosteiromys homogenidens & MACN A 52-169 & $\begin{array}{l}\text { Molar inferior derecho } \\
\text { aislado }\end{array}$ & $\begin{array}{l}\text { Fm Sarmiento (Mioceno temprano). } \\
\text { Chubut, Argentina }\end{array}$ \\
\hline Metaphiomys beadnelli & AMNH 13273 & $\begin{array}{l}\text { Mandíbula izquierda } \\
\text { con } \mathrm{m} 1-\mathrm{m} 2\end{array}$ & $\begin{array}{l}\text { Secuencia superior de la Fm Jebel } \\
\text { Qatrani (Oligoceno temprano). Egipto }\end{array}$ \\
\hline Metaphiomys beadnelli & $\mathrm{AMNH}$ & & $\begin{array}{l}\text { Secuencia superior de la Fm Jebel } \\
\text { Qatrani (Oligoceno temprano). Egipto }\end{array}$ \\
\hline Phiomys andrewsi & AMNH 13275 & $\begin{array}{l}\text { Mandíbula derecha con } \\
\text { p4-m3 }\end{array}$ & $\begin{array}{l}\text { Fm Jebel Qatrani, Quarry B (Eoceno } \\
\text { tardío-Oligoceno temprano). Egipto }\end{array}$ \\
\hline Phiomys andrewsi & DPC 6034 & $\begin{array}{l}\text { Maxilar izquierdo con } \\
\text { P4-M2 }\end{array}$ & $\begin{array}{l}\text { Fm Jebel Qatrani, Quarry E (Eoceno } \\
\text { tardío-Oligoceno temprano). Egipto }\end{array}$ \\
\hline Neophanomys biplicatus & MACN A 8253 & $\begin{array}{l}\text { Mandíbula izquierda } \\
\text { con dp4-m2 }\end{array}$ & $\begin{array}{l}\text { Andalhualá, Catamarca, Argentina. } \\
\text { Araucanense }\end{array}$ \\
\hline Neophanomys biplicatus & MACN A 8565 & $\begin{array}{l}\text { Mandíbula derecha con } \\
\text { dp4-m2 }\end{array}$ & $\begin{array}{l}\text { Fm Araucana. Huayqeurías, Mendoza, } \\
\text { Argentina }\end{array}$ \\
\hline Pithanotomys orthorhynchus & MACN PV 264 & $\begin{array}{l}\text { Mandíbula derecha con } \\
\text { m1-m3 }\end{array}$ & $\begin{array}{l}\text { Fm Chapadmalal (Plioceno). Buenos } \\
\text { Aires, Argentina }\end{array}$ \\
\hline Pithanotomys columnaris & MACN PV 7331 & $\begin{array}{l}\text { Cráneo con toda la } \\
\text { dentadura }\end{array}$ & $\begin{array}{l}\text { Fm Araucana. Monte Hermoso, Buenos } \\
\text { Aires, Argentina }\end{array}$ \\
\hline Pithanotomys columnaris & MACN PV 7332 & $\begin{array}{l}\text { Cráneo con toda la } \\
\text { dentadura }\end{array}$ & $\begin{array}{l}\text { Fm Araucana. Monte Hermoso, Buenos } \\
\text { Aires, Argentina }\end{array}$ \\
\hline Pithanotomys columnaris & MACN PV 8562 & $\begin{array}{l}\text { Mandíbula izquierda } \\
\text { con dp4-m3 }\end{array}$ & $\begin{array}{l}\text { Fm Araucana. Huayqeurías, Mendoza, } \\
\text { Argentina }\end{array}$ \\
\hline Pithanotomys sp. & MACN PV 10969 & $\begin{array}{l}\text { Mandíbula derecha con } \\
\text { dp4-m1 }\end{array}$ & Miramar, Buenos Aires, Argentina \\
\hline Plataeomys brevis & MACN A 2376 & $\begin{array}{l}\text { Fragmento de paladar } \\
\text { con las } 2 \text { hileras } \\
\text { dentarias }\end{array}$ & $\begin{array}{l}\text { Andalhualá, Catamarca, Argentina. } \\
\text { Araucanense }\end{array}$ \\
\hline Plataeomys sp. & MACN A 7342 & $\begin{array}{l}\text { Fragmento mandibular } \\
\text { izquierdo con dp4-m3 }\end{array}$ & $\begin{array}{l}\text { Fm Araucana. Monte Hermoso, Buenos } \\
\text { Aires, Argentina }\end{array}$ \\
\hline Plataeomys sp. & MACN A 8298 & Mandíbula derecha con & Andalhualá, Catamarca, Argentina. \\
\hline
\end{tabular}




\section{Plataeomys brevis \\ Plataeomys brevis \\ Plataeomys sp. \\ Plataeomys sp. \\ Prostichomys bowni \\ Prostichomys bowni \\ Prostichomys bowni \\ Prostichomys bowni \\ Prostichomys bowni \\ Prostichomys bowni \\ Prostichomys bowni \\ Prostichomys bowni \\ Prostichomys bowni}

Prostichomys bowni

Prostichomys bowni

Spaniomys riparius

Spaniomys riparius

Spaniomys riparius

Spaniomys riparius

Spaniomys riparius

Spaniomys riparius

Spaniomys riparius

Spaniomys riparius

Spaniomys riparius

Spaniomys riparius

Steiromys detentus

Steiromys detentus

Steiromys detentus
MACN A 8374

MACN A 8375

MACN A 8387

MACN A 8391

MACN PV SC 3509

MACN PV SC 3856

MACN PV SC 3857

MACN PV SC 3859

MACN PV SC 3860

MACN PV SC 3861

MACN PV SC 3862

MACN PV SC 3863

MACN PV SC 3864

MACN PV SC 3922

MACN PV SC 3923

MACN A 263

MACN A 264

MACN A 4184

MACN A 4185

MACN A 4282

MACN A 4284

MACN A 4285

MACN A 4286

MACN A 4292

MACN A 4299

MACN A 5

MACN A 6

MACN A 10 dp4-m3

Cráneo con las 2 hileras dentarias

Cráneo con DP4-M3

derechos y DP4-M1

izquierdo

Mandíbula izquierda

con dp4-m3

Mandíbula izquierda

con dp4-m3

Cráneo con DP4-M2

derechos e izquierdos

Mandíbula izquierda

con dp4-m3

Mandíbula izquierda

con dp4-m2

Paladar con M1-M3 de

ambos lados

Maxilar derecho con

DP4-M2

Maxilar izquierdo con

DP4-M3

Mandíbula izquierda

con dp4-m2

Mandíbula derecha con dp4-m3

Paladar con DP4-M3

derechos y M1-M3

izquierdos

Cráneo con DP4-M3 de ambos lados

Cráneo con M1-M3

derechos y M2-M3

izquierdos

Mandíbula izquierda

con dp4-m3

Mandíbula derecha con

m1-m2

Cráneo con DP4-M3

izquierdos y DP4-M2

derechos

Cráneo con DP4-M2 de ambos lados

Mandíbula derecha con dp4-m2

Mandíbula derecha con

dp4-m2

Mandíbula derecha con dp4-m3

Mandíbula derecha con

dp4-m3

Mandíbula izquierda con dp4-m2

Mandíbula derecha con dp4-m3

Mandíbula izquierda con p4-m3

Cráneo con ambos P4
Araucanense

Andalhualá, Catamarca, Argentina. Araucanense

Andalhualá, Catamarca, Argentina. Araucanense

Andalhualá, Catamarca, Argentina. Araucanense

Andalhualá, Catamarca, Argentina. Araucanense

Fm Pinturas (Mioceno temprano).

Santa Cruz, Argentina

Fm Pinturas (Mioceno temprano).

Santa Cruz, Argentina

Fm Pinturas (Mioceno temprano).

Santa Cruz, Argentina

Fm Pinturas (Mioceno temprano).

Santa Cruz, Argentina

Fm Pinturas (Mioceno temprano).

Santa Cruz, Argentina

Fm Pinturas (Mioceno temprano).

Santa Cruz, Argentina

Fm Pinturas (Mioceno temprano).

Santa Cruz, Argentina

Fm Pinturas (Mioceno temprano).

Santa Cruz, Argentina

Fm Pinturas (Mioceno temprano).

Santa Cruz, Argentina

Fm Pinturas (Mioceno temprano).

Santa Cruz, Argentina

Fm Pinturas (Mioceno temprano).

Santa Cruz, Argentina

Fm Santa Cruz (Mioceno temprano). Santa Cruz, Argentina

Fm Santa Cruz (Mioceno temprano). Santa Cruz, Argentina

Fm Santa Cruz (Mioceno temprano). Santa Cruz, Argentina

Fm Santa Cruz (Mioceno temprano). Santa Cruz, Argentina

Fm Santa Cruz (Mioceno temprano). Santa Cruz, Argentina

Fm Santa Cruz (Mioceno temprano). Santa Cruz, Argentina

Fm Santa Cruz (Mioceno temprano). Santa Cruz, Argentina

Fm Santa Cruz (Mioceno temprano). Santa Cruz, Argentina

Fm Santa Cruz (Mioceno temprano). Santa Cruz, Argentina

Fm Santa Cruz (Mioceno temprano). Santa Cruz, Argentina

Fm Santa Cruz (Mioceno temprano).

Santa Cruz, Argentina

Fm Santa Cruz (Mioceno temprano). Santa Cruz, Argentina

Fm Santa Cruz (Mioceno temprano). 
Steiromys detentus

MACN A 4154

Steiromys detentus

MACN A 4155

Steiromys detentus

Steiromys detentus

Steiromys detentus

Steiromys detentus

Stichomys regularis

Stichomys regularis

Stichomys regularis

Stichomys regularis

Stichomys regularis

Stichomys regularis

Stichomys regularis

Stichomys regularis

Stichomys regularis

Stichomys regularis

Xylechimys obliquus
MACN A 4156

MACN A 4159

MACN A 10046

MACN A 10774

MACN A $\sin n^{\circ}$

AMNH 9.512

MACN A 239

MACN A 240

MACN A 4198

MACN A 4200

MACN A 4206

MACN A 4207

MACN 4269

YPM PU 15423

MLP 59-II-26-81
Mandíbula derecha con m1-m2

Mandíbula izquierda con m1-m2 y parte del $\mathrm{m} 3$

Fragmento mandibular derecho con m1-m3 Mandíbula izquierda con p4-m2

Cráneo P4 izquierdo y

P4-M2 derechos

Mandíbula izquierda con m1-m3

Paladar con DP4-M3 de ambos lados

Cráneo con DP4-M3

derechos y DP4-M1

izquierdos

Mandíbula derecha con dp4-m2

Mandíbula derecha con dp4-m3

Mandíbula izquierda con dp4-m2

Mandíbula izquierda con dp4-m2

Mandíbula izquierda con dp4 (roto)-m3

Mandíbula derecha con dp4-m3

Paladar con DP4-M3 izquierdo y DP4-M1 derechos

Fragmento mandibular izquierdo con dp4-m3 Mandíbula derecha con m1-m3
Santa Cruz, Argentina

Fm Santa Cruz (Mioceno temprano). Santa Cruz, Argentina

Fm Santa Cruz (Mioceno temprano).

Santa Cruz, Argentina

Fm Santa Cruz (Mioceno temprano). Santa Cruz, Argentina

Fm Santa Cruz (Mioceno temprano). Santa Cruz, Argentina

Fm Santa Cruz (Mioceno temprano). Santa Cruz, Argentina

Fm Santa Cruz (Mioceno temprano). Santa Cruz, Argentina

Fm Santa Cruz (Mioceno temprano). Santa Cruz, Argentina

Fm Santa Cruz (Mioceno temprano). Santa Cruz, Argentina

Fm Santa Cruz (Mioceno temprano). Santa Cruz, Argentina

Fm Santa Cruz (Mioceno temprano). Santa Cruz, Argentina

Fm Santa Cruz (Mioceno temprano). Santa Cruz, Argentina Fm Santa Cruz (Mioceno temprano). Santa Cruz, Argentina Fm Santa Cruz (Mioceno temprano). Santa Cruz, Argentina Fm Santa Cruz (Mioceno temprano). Santa Cruz, Argentina Fm Santa Cruz (Mioceno temprano). Santa Cruz, Argentina

Fm Santa Cruz (Mioceno temprano), Killik Aike, Santa Cruz, Argentina Fm Sarmiento, Deseadense (Oligoceno tardío). Chubut, Argentina 


\section{APÉNDICE 3. Listado de roedores vivientes incluidos en el análisis cladístico}

\begin{tabular}{|c|c|c|c|}
\hline ESPECIMEN & MATERIAL & DESCRIPCIÓN & $\begin{array}{l}\text { PROCEDENCIA } \\
\text { GEOGRÁFICA }\end{array}$ \\
\hline Coendou sp. & MACN ma 25-22 & esqueleto & Paraguay \\
\hline Coendou sp. & MACN ma 54-3 & Cráneo con mandíbula & Misiones, Argentina \\
\hline Coendou sp. & MACN ma 31.237 & Cráneo con mandíbula & Misiones, Argentina \\
\hline Coendou sp. & MACN ma 40.201 & Cráneo con mandíbula & Misiones, Argentina \\
\hline Coendou sp. & MACN ma 50.275 & Cráneo con mandíbula & \\
\hline Coendou sp. & MACN ma 50.278 & Cráneo con mandíbula & Bolivia \\
\hline Echimys sp. & MACN ma 3.28 & Cráneo con mandíbula & Brasil \\
\hline Echimys sp. & MACN ma 31.158 & Cráneo con mandíbula & Ea. Condor \\
\hline Echimys sp. & MACN ma 31.160 & Cráneo con mandíbula & Ecuador \\
\hline Kannabateomys amblyox & MACN ma 51.37 & Cráneo con mandíbula & Misiones, Argentina \\
\hline Octodontomys gliroides & MACN ma 27.94 & Cráneo con mandíbula & Jujuy, Argentina \\
\hline Octodontomys gliroides & MACN ma 3056 & Cráneo con mandíbula & \\
\hline Octodontomys gliroides & MACN ma 17834 & Cráneo con mandíbula & Jujuy, Argentina \\
\hline Octodontomys gliroides & MACN ma 17835 & Cráneo con mandíbula & Jujuy, Argentina \\
\hline Octodontomys gliroides & MACN ma 17836 & Cráneo con mandíbula & Jujuy, Argentina \\
\hline Octodontomys gliroides & MACN ma 17837 & Cráneo con mandíbula & Jujuy, Argentina \\
\hline Octomys mimax & MACN ma 13765 & Cráneo con mandíbula & San Juan, Argentina \\
\hline Tympanoctomys barrerae & MACN ma 39-944 & Cráneo con mandíbula & Mendoza, Argentina \\
\hline Tympanoctomys barrerae & MACN ma 39-946 & Cráneo con mandíbula & \\
\hline Tympanoctomys barrerae & MACN ma 39-949 & Cráneo con mandíbula & Mendoza, Argentina \\
\hline
\end{tabular}




\section{APÉNDICE 4. Matriz de caracteres}

\begin{tabular}{|c|c|c|c|c|c|c|c|c|c|c|c|c|c|c|c|c|c|c|c|c|c|c|c|c|c|c|c|c|c|}
\hline & & & & & & & & & 10 & & & & & & & & & & 20 & & & & & & & & & & 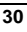 \\
\hline Phiomys andrewsi & 0 & 0 & 1 & 0 & $?$ & $?$ & 0 & 2 & 0 & $?$ & $?$ & 1 & 0 & 0 & 1 & 2 & 1 & 0 & 1 & 1 & 0 & 0 & 0 & 0 & 1 & 0 & $?$ & $?$ & $?$ \\
\hline Metaphiomys beadnelli & 0 & 0 & 0 & 1 & $?$ & $?$ & 0 & 1 & 0 & 0 & 1 & $?$ & $?$ & $?$ & ? & 2 & 1 & 1 & 1 & 1 & 0 & 0 & 1 & 0 & 1 & 0 & $?$ & $?$ & $?$ \\
\hline Steiromys detentus & 1 & 0 & 1 & 0 & 0 & $?$ & 1 & 1 & 0 & 0 & 1 & 0 & [01] & 1 & 3 & 2 & 2 & 1 & 0 & 1 & 0 & 1 & 0 & 0 & 1 & 0 & 1 & 0 & 1 \\
\hline Coendou prehensilis & 1 & 0 & 1 & 0 & 1 & 0 & 1 & 1 & 0 & 0 & 1 & 0 & 0 & 1 & 3 & 2 & 1 & 1 & 1 & 0 & 0 & 0 & 0 & 0 & 1 & 0 & 0 & 0 & 0 \\
\hline Migraveramus beatus & 1 & 0 & 1 & 0 & $?$ & $?$ & 1 & $?$ & 1 & $?$ & $?$ & $?$ & $?$ & $?$ & $?$ & $?$ & $?$ & $?$ & ? & - & $?$ & ? & $?$ & $?$ & $?$ & ? & $?$ & $?$ & $?$ \\
\hline Caviocricetus lucasi & 0 & 0 & 1 & 1 & $?$ & $?$ & 0 & 0 & 0 & 0 & 2 & $?$ & $?$ & $?$ & $?$ & 0 & 1 & 1 & 1 & 1 & 0 & 0 & 0 & 0 & 2 & 0 & $?$ & $?$ & $?$ \\
\hline Galileomys antelucanus & 0 & 0 & 1 & 0 & ? & $?$ & 0 & 0 & 0 & ? & ? & 1 & [01] & [01] & 2 & 2 & 2 & 1 & 1 & 0 & 0 & 0 & 0 & 1 & 0 & 0 & ? & ? & ? \\
\hline Galileomys eurygnathus & 0 & 0 & 1 & 0 & ? & $?$ & 0 & 0 & 0 & 1 & 0 & 1 & [01] & 0 & 2 & 2 & 2 & 1 & 1 & 1 & 0 & 1 & 1 & 1 & 0 & 0 & ? & ? & ? \\
\hline "Acaremys" tricarinatus & 2 & 1 & ? & 0 & ? & $?$ & 1 & ? & 0 & ? & ? & ? & $?$ & $?$ & ? & ? & $?$ & $?$ & ? & ? & $?$ & ? & ? & ? & $?$ & ? & ? & ? & ? \\
\hline Sciamys principalis & 2 & 1 & 1 & 0 & 0 & 0 & 1 & 0 & 1 & ? & ? & 1 & 0 & 1 & 3 & 2 & 2 & [01] & 1 & 1 & 0 & 1 & 0 & 1 & 0 & 0 & 0 & 0 & 0 \\
\hline Acarechimys minutus & 1 & 0 & 1 & 1 & 0 & 0 & 1 & 1 & 0 & 1 & 0 & $?$ & $?$ & $?$ & $?$ & 2 & 1 & 0 & 1 & 1 & 0 & 0 & 0 & 1 & 0 & 0 & 0 & 0 & 0 \\
\hline Acarechimys minutissimus & 1 & 0 & 1 & 1 & 0 & 0 & 1 & 1 & 0 & 1 & 0 & ? & ? & $?$ & ? & 2 & 1 & 0 & 1 & 0 & 0 & 0 & 0 & 1 & 0 & 0 & 0 & 0 & 0 \\
\hline Acarechimys constans & 1 & 0 & 1 & 1 & ? & $?$ & 1 & 1 & 0 & ? & ? & ? & $?$ & $?$ & ? & ? & $?$ & $?$ & ? & ? & $?$ & ? & $?$ & ? & $?$ & ? & ? & ? & ? \\
\hline Acarechimys pulchellus & 1 & 0 & 1 & 1 & ? & $?$ & 1 & 1 & 0 & ? & ? & ? & ? & $?$ & ? & ? & $?$ & $?$ & ? & ? & $?$ & ? & ? & ? & $?$ & ? & ? & ? & ? \\
\hline Protacaremys prior & 1 & 0 & 1 & 1 & 2 & 1 & 1 & 1 & 0 & 1 & 0 & $?$ & $?$ & $?$ & $?$ & 2 & 1 & 1 & 1 & 1 & 1 & 1 & 1 & 1 & 0 & 0 & $?$ & 0 & 0 \\
\hline Protacaremys avunculus & 1 & 0 & 1 & 1 & ? & $?$ & 1 & 1 & 0 & 1 & 0 & ? & $?$ & $?$ & ? & 2 & 1 & 1 & 1 & 1 & 1 & 0 & 1 & 1 & 0 & 0 & $?$ & ? & ? \\
\hline Xylechimys obliquus & 1 & 1 & $?$ & $?$ & $?$ & $?$ & 1 & $?$ & 1 & $?$ & $?$ & $?$ & $?$ & $?$ & $?$ & $?$ & $?$ & $?$ & $?$ & - & $?$ & ? & $?$ & $?$ & $?$ & ? & $?$ & $?$ & $?$ \\
\hline Stichomys regularis & 1 & 1 & 1 & 1 & 1 & 0 & 1 & 1 & 1 & 1 & 0 & $?$ & $?$ & $?$ & ? & 1 & 1 & 2 & 1 & - & 1 & 0 & 1 & 1 & 0 & 1 & $?$ & $?$ & $?$ \\
\hline Adelphomys candidus & 1 & 1 & 1 & 1 & 2 & 0 & 1 & 1 & 1 & $r$ & 0 & ? & ? & $?$ & ? & 0 & 1 & 2 & 0 & - & 1 & 1 & 1 & 1 & 0 & 1 & ? & ? & ? \\
\hline Spaniomys riparius & 1 & 1 & 1 & 1 & 0 & 0 & 1 & 1 & 1 & 1 & 0 & ? & $?$ & $?$ & ? & 0 & 1 & 0 & 1 & - & 1 & 1 & [01] & 1 & 0 & 1 & 1 & 0 & ? \\
\hline Plesiacarechimys koenigswaldi & 1 & 0 & 1 & 1 & ? & $?$ & 1 & 1 & 0 & 0 & 2 & ? & ? & $?$ & ? & 2 & 1 & 1 & $r$ & 0 & 0 & 0 & 1 & 0 & [12] & 0 & 0 & 0 & ? \\
\hline Pithanotomys columnaris & 3 & - & 1 & 1 & 2 & 0 & 1 & 2 & 1 & ? & ? & ? & $?$ & $?$ & ? & 0 & - & 0 & 1 & - & - & - & 0 & ? & $?$ & 1 & 1 & 0 & 0 \\
\hline Plataeomys brevis & 3 & - & 1 & 1 & 2 & 0 & 1 & 2 & 1 & $?$ & ? & ? & ? & $?$ & ? & 1 & - & 0 & 1 & - & - & - & 0 & ? & $?$ & 1 & 1 & 0 & 0 \\
\hline Neophanomys biplicatus & 2 & 1 & 1 & 1 & $?$ & $?$ & 1 & $?$ & 1 & $?$ & $?$ & $?$ & $?$ & $?$ & ? & $?$ & $?$ & $?$ & $?$ & $?$ & $?$ & $?$ & $?$ & $?$ & $?$ & $?$ & $?$ & $?$ & $?$ \\
\hline Octodontomys gliroides & 3 & - & 1 & 1 & 0 & 1 & 1 & 2 & 1 & ? & ? & ? & $?$ & $?$ & ? & 0 & - & 0 & 1 & - & - & - & 0 & ? & $?$ & 1 & 0 & 0 & 0 \\
\hline Octomys mimax & 3 & - & 1 & 1 & 0 & 0 & 1 & 2 & 1 & ? & ? & ? & $?$ & $?$ & ? & 0 & - & 0 & 1 & - & - & - & 0 & ? & $?$ & 1 & 0 & 0 & 0 \\
\hline Tympanoctomys barrerae & 3 & - & 1 & 1 & 0 & 1 & 1 & 2 & 1 & ? & ? & ? & ? & $?$ & ? & 2 & - & 0 & 1 & - & - & - & 0 & ? & $?$ & 1 & 1 & 0 & 0 \\
\hline Echimys sp. & 1 & 1 & 1 & 1 & 0 & 1 & 1 & 1 & 1 & 1 & 0 & ? & $?$ & $?$ & ? & 0 & 0 & 0 & 1 & - & 0 & 1 & 1 & 1 & 0 & 1 & 0 & 1 & 0 \\
\hline Kannabateomys amblyonyx & 0 & 1 & 1 & 1 & 1 & 0 & 1 & 1 & 1 & 1 & 0 & ? & $?$ & $?$ & ? & 2 & 0 & 0 & 1 & - & 1 & 1 & 1 & 1 & 0 & 1 & 1 & 0 & 0 \\
\hline
\end{tabular}




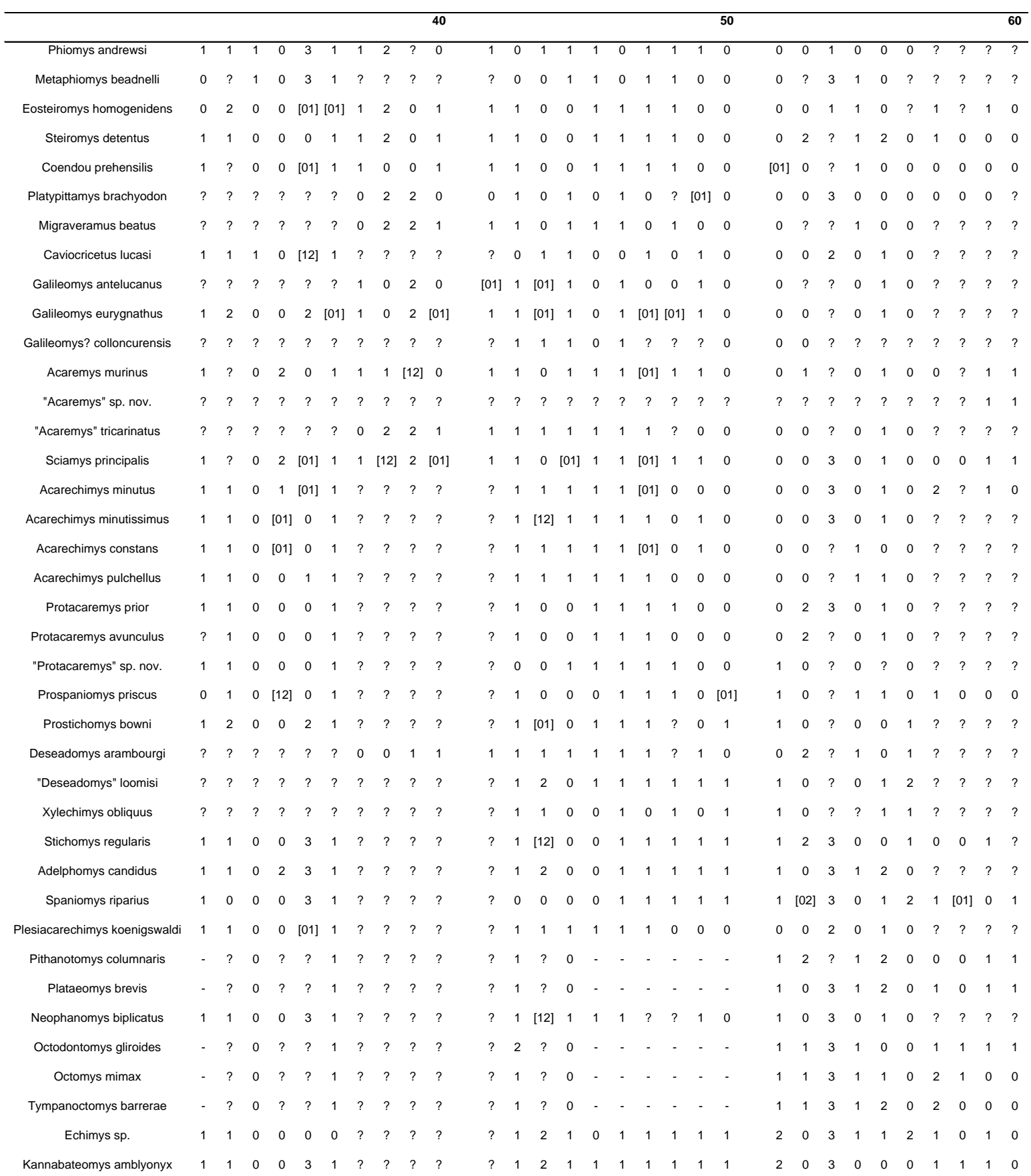




\begin{tabular}{|c|c|c|c|c|c|c|c|c|c|c|c|c|c|c|c|c|c|c|c|c|c|c|c|c|c|c|c|c|c|c|}
\hline & & & & & & & & & & 70 & & & & & & & & & & 80 & & & & & & & & & & 90 \\
\hline Metaphiomys beadnelli & ? & ? & ? & ? & ? & ? & ? & $?$ & ? & ? & 0 & 0 & ? & ? & ? & $?$ & ? & ? & ? & $?$ & ? & ? & $?$ & ? & $?$ & ? & ? & ? & ? & $?$ \\
\hline Steiromys detentus & ? & 0 & 1 & 1 & 0 & 1 & ? & 1 & 1 & ? & 0 & 0 & 1 & 0 & ? & $?$ & ? & ? & 0 & 4 & ? & ? & 1 & ? & $?$ & 0 & 1 & 1 & ? & ? \\
\hline Coendou prehensilis & 1 & 0 & 0 & 1 & 0 & 1 & 1 & 0 & 0 & 0 & 0 & 0 & 0 & 0 & 3 & 2 & - & - & 1 & 4 & 1 & 0 & [01] & 1 & 0 & 1 & 0 & 1 & 0 & 0 \\
\hline Migraveramus beatus & $?$ & $?$ & $?$ & $?$ & $?$ & $?$ & $?$ & $?$ & $?$ & $?$ & $?$ & $?$ & $?$ & $?$ & $?$ & $?$ & $?$ & $?$ & $?$ & $?$ & $?$ & $?$ & $?$ & $?$ & $?$ & $?$ & $?$ & $?$ & $?$ & $?$ \\
\hline Caviocricetus lucasi & ? & ? & ? & ? & ? & ? & ? & $?$ & ? & ? & 0 & 0 & ? & 0 & ? & $?$ & ? & ? & ? & ? & ? & ? & $?$ & ? & $?$ & ? & ? & ? & ? & $?$ \\
\hline Galileomys antelucanus & $?$ & $?$ & $?$ & $?$ & $?$ & $?$ & $?$ & $?$ & $?$ & $?$ & 0 & $?$ & $?$ & 1 & $?$ & $?$ & $?$ & $?$ & $?$ & $?$ & $?$ & $?$ & $?$ & $?$ & $?$ & $?$ & $?$ & $?$ & $?$ & ? \\
\hline Galileomys eurygnathus & $?$ & $?$ & $?$ & $?$ & $?$ & $?$ & $?$ & $?$ & $?$ & ? & $?$ & $?$ & $?$ & 1 & $?$ & $?$ & $?$ & $?$ & $?$ & ? & $?$ & $?$ & $?$ & $?$ & $?$ & $?$ & $?$ & $?$ & $?$ & $?$ \\
\hline "Acaremys" tricarinatus & $?$ & $?$ & $?$ & $?$ & $?$ & $?$ & $?$ & $?$ & $?$ & $?$ & $?$ & $?$ & $?$ & $?$ & ? & $?$ & $?$ & $?$ & $?$ & $?$ & $?$ & $?$ & $?$ & $?$ & $?$ & $?$ & $?$ & $?$ & $?$ & $?$ \\
\hline Sciamys principalis & 1 & 0 & 1 & 1 & 2 & 0 & - & 1 & 0 & 1 & 0 & 0 & 1 & 2 & 0 & 0 & 0 & 1 & $?$ & ? & 2 & 1 & 0 & $?$ & $?$ & $?$ & $?$ & 0 & $?$ & $?$ \\
\hline Acarechimys minutus & ? & ? & 1 & 1 & 2 & ? & ? & $?$ & 0 & ? & 0 & 0 & 1 & 1 & 0 & 1 & 1 & 1 & ? & $?$ & 1 & 0 & 1 & ? & $?$ & ? & ? & ? & ? & $?$ \\
\hline Acarechimys minutissimus & ? & ? & ? & 1 & ? & ? & ? & $?$ & ? & ? & 0 & 0 & ? & 1 & ? & $?$ & ? & ? & ? & $?$ & ? & ? & $?$ & ? & $?$ & ? & ? & ? & ? & $?$ \\
\hline Acarechimys constans & ? & ? & ? & ? & ? & ? & ? & ? & ? & ? & ? & ? & ? & ? & ? & $?$ & ? & ? & ? & ? & ? & ? & $?$ & ? & $?$ & ? & ? & ? & ? & $?$ \\
\hline Acarechimys pulchellus & $?$ & $?$ & $?$ & $?$ & $?$ & $?$ & $?$ & $?$ & $?$ & $?$ & $?$ & $?$ & ? & ? & ? & $?$ & ? & ? & ? & $?$ & ? & ? & $?$ & ? & $?$ & ? & ? & ? & ? & $?$ \\
\hline Protacaremys prior & ? & 0 & ? & ? & ? & ? & ? & $?$ & ? & $?$ & 0 & 0 & ? & 0 & ? & $?$ & ? & ? & ? & : & ? & ? & $?$ & ? & $?$ & ? & ? & ? & ? & ? \\
\hline Protacaremys avunculus & ? & ? & ? & ? & ? & ? & ? & $?$ & ? & $r^{\prime}$ & 0 & 0 & ? & 0 & ? & $?$ & ? & ? & ? & . & ? & ? & $?$ & ? & $?$ & ? & ? & ? & ? & $?$ \\
\hline Stichomys regularis & $?$ & 0 & 1 & 1 & 1 & 1 & 0 & 1 & $?$ & $?$ & 0 & 0 & $?$ & 0 & $?$ & $?$ & $?$ & $?$ & $?$ & ? & 1 & 0 & 1 & $?$ & $?$ & $?$ & $?$ & $?$ & $?$ & $?$ \\
\hline Adelphomys candidus & ? & ? & ? & ? & ? & ? & ? & $?$ & ? & . & ? & ? & ? & 0 & ? & $?$ & ? & ? & ? & ? & 1 & 0 & 1 & ? & $?$ & ? & ? & ? & ? & ? \\
\hline Spaniomys riparius & 1 & 0 & 1 & 1 & 1 & 1 & 0 & 1 & 1 & ? & 1 & 1 & 1 & 1 & ? & $?$ & ? & ? & 1 & ? & 1 & 0 & 1 & ? & $?$ & ? & ? & ? & ? & ? \\
\hline Plesiacarechimys koenigswaldi & ? & ? & ? & 0 & ? & ? & ? & $?$ & ? & ? & ? & 1 & ? & 1 & ? & $?$ & ? & ? & ? & ? & ? & ? & $?$ & ? & $?$ & ? & ? & ? & ? & ? \\
\hline Pithanotomys columnaris & 1 & 1 & 1 & 0 & 2 & 1 & 0 & 1 & 1 & 0 & 0 & 1 & 1 & 0 & ? & $?$ & ? & ? & ? & ? & ? & ? & 0 & ? & $?$ & ? & ? & ? & ? & ? \\
\hline Plataeomys brevis & 0 & 0 & 0 & 0 & 2 & ? & ? & $?$ & 1 & ? & 0 & 0 & 1 & 0 & ? & $?$ & ? & ? & ? & ? & ? & ? & 1 & ? & $?$ & ? & ? & ? & ? & ? \\
\hline Neophanomys biplicatus & ? & ? & ? & ? & ? & ? & ? & $?$ & ? & $?$ & ? & ? & ? & ? & ? & $?$ & ? & ? & ? & ? & ? & ? & $?$ & ? & $?$ & ? & ? & ? & ? & ? \\
\hline Octodontomys gliroides & 1 & 0 & 1 & 1 & 2 & 0 & - & 1 & 1 & 0 & 1 & 1 & 1 & 2 & 0 & 0 & 1 & 1 & 2 & 4 & 2 & 1 & 1 & 1 & 1 & 0 & 1 & 0 & 1 & 1 \\
\hline Octomys mimax & 1 & 0 & 0 & 0 & 2 & 0 & - & 1 & 1 & 0 & 0 & 0 & 1 & 2 & 2 & 1 & 1 & 1 & 2 & 3 & 1 & 1 & 1 & 1 & 1 & 0 & 1 & 1 & 1 & 1 \\
\hline Tympanoctomys barrerae & 1 & 0 & 0 & 0 & 2 & 0 & - & 0 & 1 & 0 & 1 & 1 & 1 & 0 & 1 & 1 & 1 & 1 & 2 & 3 & 0 & 0 & 1 & 1 & $?$ & 1 & 1 & 1 & 2 & 1 \\
\hline Echimys sp. & 1 & 0 & 1 & 1 & 2 & 0 & - & 0 & 0 & 0 & 1 & 0 & 1 & 0 & 0 & 1 & 1 & 1 & 2 & 1 & 1 & 1 & 0 & 0 & 1 & 0 & 0 & 0 & 1 & 0 \\
\hline Kannabateomys amblyonyx & 1 & 0 & 0 & 1 & 1 & 1 & 0 & 1 & 0 & 0 & 1 & 1 & 1 & 0 & 0 & 1 & 1 & 1 & 2 & 1 & 1 & 1 & 0 & 0 & 0 & 0 & 0 & 0 & 1 & 0 \\
\hline
\end{tabular}




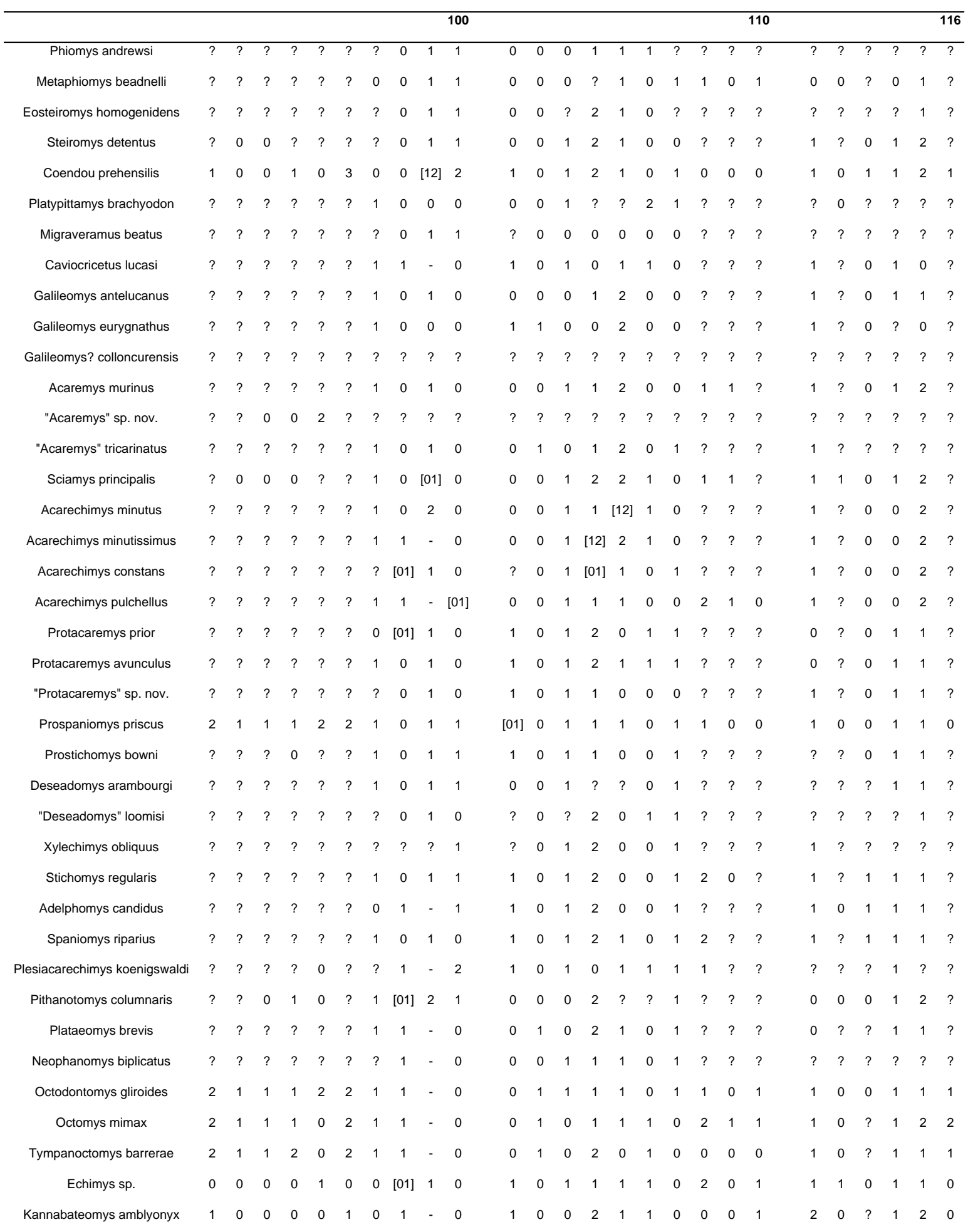




\section{APÉNDICE 5. Sinapomorfías de los nodos del consenso}

Nodo 42:

- Carácter 1 (grado de hipsodoncia): braquiodonte $\rightarrow$ mesodonte

- Carácter 8 (superficie oclusal): aterrazada $\rightarrow$ no aterrazada

- Carácter 33 (metalofúlido I en el dp4): ausente $\rightarrow$ presente

- Carácter 35 (mesolófido en el dp4): ausente $\rightarrow$ conspicuo

- Carácter 42 (Posición del metacónido respecto al protocónido en m1-m3): anterior $\rightarrow$ alineado

- Carácter 46 (hipoconúlido en m1-m3): individualizado $\rightarrow$ no individualizado

- Carácter 104 (orientación de la cresta masetérica): ventralmente dirigida desde sus orígenes $\rightarrow$ posteroventralmente dirigida desde sus orígenes.

\section{Nodo 43:}

- Carácter 40 (hipolófido en el p4): presente $\rightarrow$ ausente

- Carácter 47 (extensión posterior del metalofúlido I en m1-m2): ausente $\rightarrow$ presente

Nodo 44:

- Carácter 4 (premolares deciduos): retención $\rightarrow$ reemplazo normal

- Carácter 106 (profundidad de la porción anterior de la fosa masetérica): moderadamente profunda $\rightarrow$ muy profunda

Nodo 45:

- Carácter 28 (incisivos superiores): no comprimidos lateralmente $\rightarrow$ comprimidos lateralmente

- Carácter 66 (forma de los huesos frontales): con márgenes laterales rectos $\rightarrow$ angostos anteriormente y más anchos posteriormente

- Carácter 75 (canal para el pasaje del nervio infraorbitario en el piso del foramen infraorbitario): ausente $\rightarrow$ presente con un reborde lateral poco desarrollado

- Carácter 110 (escotadura mandibular): profunda $\rightarrow$ poco profunda o ausente

Nodo 46:

- Carácter 53 (largo relativo de la hilera de dientes yugales respecto del tamaño de la porción anterior del cráneo): $2.160 \rightarrow$ 2.260-2.380

- Carácter 54 (incisivos inferiores): no comprimidos lateralmente $\rightarrow$ comprimidos lateralmente

- Carácter 59 (Forma de los huesos nasales): márgenes laterales paralelos $\rightarrow$ márgenes laterales más anchos anteriormente

- Carácter 89 (Extensión ventral del proceso lateral del supraoccipital): se extiende hasta el borde dorsal de la bula $\rightarrow$ excede el borde dorsal de la bula

- Carácter 95 (Receso hipotimpánico): inflado $\rightarrow$ pequeño

- Carácter 101 (posición del borde anterior de la muesca para el tendón del mmma): ubicada por debajo del $\mathrm{m} 1 \rightarrow$ ubicada por delante del $\mathrm{m} 1$ 
Nodo 47:

- Carácter 4 (premolares deciduos): reemplazo normal $\rightarrow$ retención

- Carácter 55 (cara anterior de los incisivos inferiores): curva $\rightarrow$ con el borde lingual recto y el labial curvo

Nodo 48:

- Carácter 14 (metalofo en el P4): presente $\rightarrow$ ausente

- Carácter 25 (mesolófulo en M1-M3): presente $\rightarrow$ ausente

- Carácter 26 (metalofo en M1-M3): presente y unido lingualmente al posterolofo $\rightarrow$ presente y unido lingualmente al brazo anterior del hipocono

- Carácter 37 (posición del metacónido respecto al protocónido en el p4): alineado transversalmente $\rightarrow$ anterior

- Carácter 98 (largo del diastema): más corto que la distancia de p4(dp4)-m1 $\rightarrow$ igual o más largo que la distancia de p4(dp4)-m1

Nodo 49:

- Carácter 11 (mesolófulo en el DP4): ausente $\rightarrow$ presente

- Carácter 12 (metalofo en el DP4): presente y unido lingualmente al brazo anterior del hipocono $\rightarrow$ fusionado al posterolofo

- Carácter 25 (mesolófulo en M1-M3): ausente $\rightarrow$ presente

- Carácter 26 (metalofo en M1-M3): presente y unido lingualmente al brazo anterior del hipocono $\rightarrow$ fusionado al posterolofo

- Carácter 53 (microestructura del esmalte de los incisivos inferiores): IPM en ángulo recto respecto de las HSB $\rightarrow$ IPM en ángulo sub-recto respecto de las HSB

- Carácter 102 (posición de la mmma respecto a la altura del cuerpo mandibular): por encima de la mitad de la altura mandibular $\rightarrow$ aproximadamente en la mitad de la altura mandibular

- Carácter 105 (surco antero-dorsal de la fosa masetérica): poco desarrollado $\rightarrow$ ausente

Nodo 50:

- Carácter 99 (foramen mentoniano): presente $\rightarrow$ ausente

Nodo 51:

- Carácter 1 (grado de hipsodoncia): mesodonte $\rightarrow$ braquiodonte

- Carácter 8 (superficie oclusal aterrazada): ausente $\rightarrow$ presente

- Carácter 9 (hipsodoncia unilateral): atenuada $\rightarrow$ presente

- Carácter 38 (fléxido en la pared del metalofúlido I en el p4): poco desarrollado $\rightarrow$ presente

- Carácter 103 (orientación de la cresta masetérica): postero-ventralmente dirigida desde sus orígenes $\rightarrow$ ventralmente dirigida desde sus orígenes

\section{Nodo 52:}


- Carácter 16 (hipoflexo en el P4): incipiente $\rightarrow$ poco desarrollado

- Carácter 18 (secuencia de cierre de los flexos labiales): posterofoseta cierra antes que la parafoseta $\rightarrow$ para y posterofosetas cierran simultáneamente

- Carácter 37 (posición del metacónido respecto al protocónido): anterior $\rightarrow$ alineado trasversalmente

- Carácter 38 (fléxido en la pared anterior del metalofúlido I en el p4): ausente $\rightarrow$ poco desarrollado

- Carácter 53 (largo relativo de la hilera de dientes yugales respecto del tamaño de la porción anterior del cráneo): $2.750 \rightarrow$ 2.900-2.930

- Carácter 84 (posición de las narinas posteriores): abren a nivel del M2 $\rightarrow$ abren a nivel del M3

- Carácter 108 (base del proceso coronoides): a nivel del m3 $\rightarrow$ anterior al m3

\section{Nodo 53:}

- Carácter 23 (largo del anterolofo en M1-M3): corto $\rightarrow$ largo

- Carácter 34 (metalofúlido II en el dp4): presente $\rightarrow$ ausente

- Carácter 75 (canal para el pasaje del nervio infraorbitario en el piso del foramen infraorbitario): presente con el reborde lateral poco desarrollado $\rightarrow$ presente con el reborde lateral bien desarrollado

- Carácter 83 (forámenes palatinos posteriores): bien desarrollados $\rightarrow$ pequeños

- Carácter 116 (desarrollo de la repisa pterigoidea): bien desarrollada $\rightarrow$ muy bien desarrollada

Nodo 54:

- Carácter 19 (forma del ángulo antero-lingual en M1-M3): formando un ángulo obtuso $\rightarrow$ redondeado

- Carácter 115 (límite posterior de la sínfisis mandibular): a nivel del p4/dp4 $\rightarrow$ anterior al p4/dp4

- Carácter 116 (desarrollo de la repisa pterigoidea): bien desarrollada $\rightarrow$ muy bien desarrollada

\section{Nodo 55:}

- Carácter 52 (tamaño del $\mathrm{m} 3$ con respecto al $\mathrm{m} 2$ ): $\mathrm{m} 3<\mathrm{m} 2 \rightarrow \mathrm{m} 3=\mathrm{m} 2$

- Carácter 105 (surco antero-dorsal de la fosa masetérica): poco desarrollado $\rightarrow$ muy desarrollado

- Carácter 107 (límite anterior de la fosa masetérica): posterior al $\mathrm{m} 1 \rightarrow$ debajo de $\mathrm{m} 1$

- Carácter 112 (fosa retromolar): postero-lateral al m3 y algo extendida anteriormente $\rightarrow$ esencialmente posterior al $\mathrm{m} 3$

Nodo 56:

- Carácter 6 (posición de las hileras dentarias respecto del eje sagital del cráneo): paralelas $\rightarrow$ poco convergentes

- Carácter 22 (oblicuidad de las crestas en M1-M3): transversales al eje antero-posterior del diente $\rightarrow$ oblicuas en dirección anterolabial-posterolingual

- Carácter 102 (posición de la mmma respecto a la altura del cuerpo mandibular): por encima de la mitad de la altura mandibular $\rightarrow$ aproximadamente en la mitad de la altura mandibular

- Carácter 106 (profundidad de la porción anterior de la fosa masetérica): moderadamente profunda $\rightarrow$ superficial, o incluso plana 
Nodo 57:

- Carácter 2 (grosor de las crestas en vista oclusal): más angostas que los flexos/idos $\rightarrow$ iguales o más gruesas que los flexos/idos

- Carácter 10 (diferenciación de las cúspides labiales de sus respectivas crestas en dientes superiores): si $\rightarrow$ no

- Carácter 17 (proporción largo/ancho de los molares superiores): largo menor que ancho $\rightarrow$ largo $=$ que ancho

- Carácter 19 (forma del ángulo antero-lingual en M1-M3): formando un ángulo obtuso $\rightarrow$ formando un ángulo recto

- Carácter 35 (mesolófido en el dp4): presente $\rightarrow$ pequeño

- Carácter 50 (oblicuidad de las crestas en m1-m3): transversales al eje antero-posterior del diente $\rightarrow$ oblicuas en dirección anterolabial-posterolingual

- Carácter 56 (longitud de los incisivos inferiores): largos, pasan por debajo del m3 $\rightarrow$ su base llega hasta el m3

- Carácter 101 (posición del borde anterior de la mmma): ubicada por delante del $\mathrm{m} 1 \rightarrow$ ubicada por debajo del $\mathrm{m} 1$

Nodo 58:

- Carácter 45 (extensión del posterolófido en m1-m2): largo $\rightarrow$ corto

- Carácter 105 (surco antero-dorsal de la fosa masetérica): poco desarrollado $\rightarrow$ muy desarrollado

Nodo 59:

- Carácter 49 (brazo posterior del metacónido en m1-m2): presente $\rightarrow$ ausente

\section{Nodo 60:}

- Carácter 17 (proporción largo/ancho de los molares superiores): largo = que ancho $\rightarrow$ largo mayor que ancho

- Carácter 23 (largo del anterolofo en M1-M3): corto, no llega al mismo nivel que el paracono $\rightarrow$ largo, llega al mismo nivel que el paracono

Nodo 61:

- Carácter 19 (forma del ángulo antero-lingual en M1-M3): formando un ángulo recto $\rightarrow$ redondeado

- Carácter 101 (posición del borde anterior de la mmma): ubicada por debajo del $\mathrm{m} 1 \rightarrow$ ubicada por delante del $\mathrm{m} 1$

- Carácter 105 (profundidad de la porción anterior de la fosa masetérica): superficial, o incluso plana $\rightarrow$ moderadamente profunda

Nodo 62:

- Carácter 6 (hileras dentarias): paralelas/ poco convergentes $\rightarrow$ muy convergentes 
- Carácter 55 (cara anterior de los incisivos inferiores): con el borde lingual recto y el labial curvo $\rightarrow$ plana

- Carácter 72 (raíz ventral de la arcada cigomática): diámetro antero-posterior es la menos el doble que el dorso-ventral $\rightarrow$ diámetros antero-posterior y dorso-ventral semejantes

- Carácter 112 (fosa retromolar): posterolateral al m3 y algo extendida anteriormente $\rightarrow$ esencialmente posterior al $\mathrm{m} 3$

Nodo 63:

- Carácter 1 (grado de hipsodoncia): hipsodonte alto $\rightarrow$ euhipsodonte

- Carácter 54 (incisivos inferiores): comprimidos lateralmente $\rightarrow$ no comprimidos lateralmente

\section{Nodo 64:}

- Carácter 1 (grado de hipsodoncia): mesodonte $\rightarrow$ protohipsodonte

- Carácter 102 (posición de la mmma respecto a la altura del cuerpo mandibular): aproximadamente en la mitad de la altura mandibular $\rightarrow$ por encima de la mitad de la altura mandibular

\section{Nodo 65:}

- Carácter 83 (forámenes palatinos posteriores): bien desarrollados $\rightarrow$ pequeños

- Carácter 114 (proceso mentoniano): bien desarrollado $\rightarrow$ poco desarrollado

Nodo 66:

- Carácter 5 (largo relativo de la hilera de dientes yugales respecto del tamaño de la porción anterior del cráneo): $0.260-2.330 \rightarrow 2.400-2.460$

- Carácter 67 (proceso post-orbitario): presente $\rightarrow$ ausente

- Carácter 94 (desarrollo del seno epitimpánico): pequeño $\rightarrow$ bien desarrollado

\section{Nodo 67:}

- Carácter 57 (extensión posterior de los premaxilares en relación a los nasales): iguales $\rightarrow$ más largos

- Carácter 59 (forma de los huesos nasales): márgenes laterales más anchos anteriormente $\rightarrow$ márgenes laterales paralelos

- Carácter 64 (sutura premaxilar-maxilar que intersecta el foramen incisivo): ubicada aproximadamente en la mitad del largo de los forámenes incisivos $\rightarrow$ ubicada en el borde posterior de los forámenes incisivos

- Carácter 81 (foramen esfeno-palatino): ranura ubicada a lo largo de M1-M2 $\rightarrow$ ranura ubicada a lo largo de DP4-M1

- Carácter 89 (extensión ventral del proceso lateral del supraoccipital): excede el borde dorsal de la bula $\rightarrow$ se extiende hasta el borde dorsal de la bula

- Carácter107 (límite anterior de la fosa masetérica): posterior al m1 $\rightarrow$ debajo del m1

- Carácter 108 (base del proceso coronoides): a nivel del $\mathrm{m} 3 \rightarrow$ anterior al $\mathrm{m} 3$ 
TABLA 5.1. Índices de hipsodoncia

\begin{tabular}{|c|c|c|c|c|c|}
\hline TAXÓN & EJEMPLAR & & ALTO & LARGO & $\begin{array}{l}\text { IH (Largo/ } \\
\text { ancho) }\end{array}$ \\
\hline \multirow[t]{4}{*}{ Acaremys murinus } & MACN A 266 & $\mathrm{~m} 1$ & 1,05 & 1,80 & 0,583 \\
\hline & & $\mathrm{m} 2$ & 1,15 & 1,90 & 0,605 \\
\hline & MACN A 1879 & $\mathrm{~m} 1$ & 1,65 & 2,15 & 0,767 \\
\hline & & $\mathrm{m} 2$ & 1,40 & 2,20 & 0,636 \\
\hline \multirow{2}{*}{ "Acaremys" tricarinatus } & MACN A 4113 & $\mathrm{~m} 1$ & 1,98 & 2,00 & 0,990 \\
\hline & & $\mathrm{m} 2$ & 2,22 & 2,00 & 1,110 \\
\hline \multirow{2}{*}{ Acarechimys minutissimus } & MACN A 1894 & $\mathrm{~m} 1$ & 0,76 & 1,28 & 0,593 \\
\hline & & $\mathrm{m} 2$ & 1,04 & 1,30 & 0,800 \\
\hline \multirow[t]{3}{*}{ Acarechimys constans } & MACN A 247 & $\mathrm{~m} 1$ & 1,24 & 2,04 & 0,608 \\
\hline & MLP 15-391 & $\mathrm{m} 1$ & 1,30 & 2,02 & 0,644 \\
\hline & & $\mathrm{m} 2$ & 1,46 & 2,08 & 0,702 \\
\hline \multirow[t]{2}{*}{ Acarechimys pulchellus } & MACN A s $/ n^{\circ}$ & $\mathrm{m} 1$ & 0,96 & 1,94 & 0,495 \\
\hline & & $\mathrm{m} 2$ & 1,10 & 2,04 & 0,530 \\
\hline \multirow[t]{4}{*}{ Adelphomys candidus } & MACN A 241 & $\mathrm{~m} 1$ & 2,28 & 3,62 & 0,63 \\
\hline & & $\mathrm{m} 2$ & 2,62 & 3,60 & 0,73 \\
\hline & MACN A 243 & $\mathrm{~m} 2$ & 3,05 & 3,55 & 0,859 \\
\hline & MACN A 1922 & $\mathrm{~m} 1$ & 2,46 & 3,06 & 0,803 \\
\hline \multirow[t]{2}{*}{ Coendou sp. } & MACN ma 54-3 & $\mathrm{m} 1$ & 1,92 & 3,96 & 0,484 \\
\hline & & $\mathrm{m} 2$ & 2,08 & 4,00 & 0,520 \\
\hline "Deseadomys" loomisi & ACM 3087 & $\mathrm{~m} 1$ & 1,50 & 2,46 & 0,609 \\
\hline \multirow{2}{*}{ Echimys sp. } & MACN ma 31.158 & $\mathrm{~m} 1$ & 1,60 & 2,66 & 0,601 \\
\hline & & $\mathrm{m} 2$ & 1,94 & 2,96 & 0,655 \\
\hline \multirow[t]{2}{*}{ Eosteiromys homogenidens } & MACN A 52-166 & $\mathrm{m} 1$ & 1,70 & 4,70 & 0,361 \\
\hline & MACN A 52-170 & m1 ó m2 & 2,80 & 4,38 & 0,64 \\
\hline Migraveramus beatus & YPM PU 21948 & $\mathrm{~m} 1$ & 1,45 & 2,25 & 0,640 \\
\hline \multirow[t]{3}{*}{ Plesiacarechimys koenigwaldi } & MLP 91-V-1-4 & $\mathrm{m} 2$ & 1,24 & 2,82 & 0,440 \\
\hline & MLP 91-V-1-22 & $\mathrm{m} 1$ & 1,68 & 2,98 & 0,57 \\
\hline & & $\mathrm{m} 2$ & 1,98 & 2,66 & 0,744 \\
\hline \multirow[t]{3}{*}{ Prospaniomys priscus } & MACN A 52-131 & $\mathrm{m} 1$ & 1,46 & 2,76 & 0,520 \\
\hline & MPEF PV-5039 & $\mathrm{m} 1$ & 1,46 & 2,50 & 0,528 \\
\hline & & $\mathrm{m} 2$ & 1,50 & 2,80 & 0,535 \\
\hline \multirow[t]{2}{*}{ Protacaremys prior } & MACN A 52-112b & $\mathrm{m} 1$ & 1,06 & 1,80 & 0,588 \\
\hline & & $\mathrm{m} 2$ & 1,08 & 1,94 & 0,556 \\
\hline \multirow[t]{2}{*}{ Protacaremys avunculus } & MACN A 52-126 & $\mathrm{m} 1$ & 0,92 & 1,66 & 0,554 \\
\hline & & $\mathrm{m} 2$ & 0,94 & 1,70 & 0,552 \\
\hline "Protacaremys" sp. nov. & MACN A 52-123 & $\mathrm{m} 1$ & 1,48 & 2,12 & 0,698 \\
\hline \multirow{3}{*}{ Prostichomys bowni } & MACN PV SC 3856 & $\mathrm{~m} 1$ & 1,62 & 2,48 & 0,653 \\
\hline & & $\mathrm{m} 2$ & 1,70 & 2,60 & 0,653 \\
\hline & MACN PV SC 3862 & $\mathrm{~m} 1$ & 1,80 & 2,60 & 0,692 \\
\hline \multirow[t]{3}{*}{ Sciamys principalis } & MACN A 4107 & $\mathrm{~m} 1$ & 2,00 & 2,20 & 0,909 \\
\hline & MACN PV SC2588 & $\mathrm{m} 1$ ó m2 & 0,22 & 0,196 & 1,132 \\
\hline & MACN PV SC2588 & $\mathrm{m} 1$ ó m2 & 0,23 & 0,198 & 1,161 \\
\hline \multirow[t]{5}{*}{ Spaniomys riparius } & MACN A 263 & $\mathrm{~m} 1$ & 1,48 & 2,88 & 0,513 \\
\hline & MACN A 4282 & $\mathrm{~m} 1$ & 1,64 & 2,80 & 0,585 \\
\hline & & $\mathrm{m} 2$ & 2,02 & 2,98 & 0,677 \\
\hline & MACN A 4259 & $\mathrm{~m} 1$ & 1,18 & 2,82 & 0,418 \\
\hline & & $\mathrm{m} 2$ & 1,60 & 3,00 & 0,533 \\
\hline Spaniomys modestus & MACN A 251 & $\mathrm{~m} 1$ & 0,85 & 2,20 & 0,386 \\
\hline \multirow[t]{3}{*}{ Steiromys detentus } & MACN A 10774 & $\mathrm{~m} 1$ & 2,40 & 4,40 & 0,545 \\
\hline & & $\mathrm{m} 2$ & 2,60 & 4,40 & 0,591 \\
\hline & MACN A 4154 & $\mathrm{~m} 1$ & 2,70 & 4,50 & 0,600 \\
\hline
\end{tabular}


Stichomys regularis

Xilechimys obliquus m2

MACN A 4214

MLP 59-II-26-81 $\mathrm{m} 1$

$\mathrm{m} 2$

$\mathrm{m} 1$

$\mathrm{m} 2$

$\begin{array}{lll}2,6 & 3,90 & 0,660 \\ 2,20 & 3,70 & 0,594 \\ - & 4,05 & - \\ 1,46 & 2,90 & 0,503 \\ 1,48 & 2,94 & 0,503\end{array}$


TABLA 5.2. Tamaño relativo de las hileras dentarias

\begin{tabular}{lllll}
\hline TAXÓN & EJEMPLAR & L & LDH & \\
\hline "Acaremys" sp. nov. & MACN A 10095 & 2,586 & 0,794 & 3,26 \\
Eosteromys homogenidens & MACN A 52-165 & 4,374 & 1,998 & 2,19 \\
Pithanotomys columnaris & MACN 7331 & 3,462 & 1,576 & 2,19 \\
& MACN 7332 & 3,798 & 1,638 & 2,32 \\
Plataeomys brevis & MACN PV 8374 & 2,230 & 0,985 & 2,26 \\
Platypittamys brachyodon & AMNH 29601 & 4,400 & 1,600 & 2,75 \\
Prospaniomys priscus & MACN PV CH1913 & 2,658 & 1,128 & 2,36 \\
Protacaremys prior & AMNH 29734 & 10,708 & 4,500 & 2,38 \\
Sciamys principalis & MACN A 4114 & 2,382 & 0,812 & 2,93 \\
& MACN 11606 & 2,220 & 0,766 & 2,90 \\
Spaniomys riparius & MACN A 4184 & 2,804 & 1,20 & 2,33 \\
Steiromys detentus & MLP 15-17 & 8,108 & 3,756 & 2,16 \\
Stichomys regularis & AMNH 9.512 & 5,170 & 2,460 & 2,10 \\
& & & & \\
Coendou sp. & MACN Ma 54-3 & 3,082 & 1,538 & 2,00 \\
Echimys sp. & MACN Ma 31.158 & 2,810 & 1,266 & 2,22 \\
Kannabateomys amblyox & MACN Ma 51.37 & 2,852 & 1,524 & 1,87 \\
Octodontomys gliroides & MACN Ma 27.94 & 1,956 & 0,794 & 2,46 \\
Octomys mimax & MACN Ma 13765 & 2,278 & 0,844 & 2,70 \\
Tmpanoctomys barrerae & MACN Ma 39-946 & 1,368 & 0,570 & 2,40 \\
\hline
\end{tabular}


TABLA 5.3. Incisivos superiores

\begin{tabular}{llll}
\hline TAXÓN & EJEMPLAR & DIÁMETRO A-P & ANCHO \\
\hline Acaremys murinus & MACN A 10092 & 0,250 & 0,126 \\
Eosteiromys homogenidens & MACN A 52-165 & 0,502 & 0,398 \\
Plataeomys brevis & MACN PV 8375 & 0,246 & 0,218 \\
Pithanotomys columnaris & MACN PV 7332 & 0,436 & 0,404 \\
Plesiacarechimys koenigswaldi & MLP 92-V-10-1 & 0,386 & 0,146 \\
Prospaniomys priscus & MACN PV CH1913 & 0,180 & 0,172 \\
Spaniomys riparius & MACN A 4185 & 0,188 & 0,140 \\
Sciamys principalis & MACN A 4114 & 0,262 & 0,138 \\
Steiromys detentus & MACN A 10046 & 0,440 & 0,360 \\
& & & \\
Coendou sp. & MACN Ma 54-3 & 0,364 & 0,228 \\
Echimys sp. & MACN Ma 31.158 & 0,266 & 0,160 \\
Kannabateomys amblyox & MACN Ma 51.37 & 0,260 & 0,214 \\
Octodontomys gliroides & MACN Ma 27.94 & 0,254 & 0,168 \\
Octomys mimax & MACN Ma 13765 & 0,238 & 0,148 \\
Tympanoctomys barrerae & MACN Ma 39-946 & 0,168 & 0,130 \\
\hline
\end{tabular}




\section{TABLA 5.4. Incisivos inferiores}

\begin{tabular}{llcl}
\hline TAXÓN & EJEMPLAR & DIÁMETRO A-P & ANCHO \\
\hline Acaremys murinus & MMP 114M & 0,20 & 0,10 \\
“Acaremys" tricarinatus & MACN A 4113 & 0,20 & 0,11 \\
Acarechimys constans & MLP 15-391 & 0,16 & 0,14 \\
Acarechimys minutissimus & MACN A 258 & 0,12 & 0,08 \\
Acarechimys pulchellus & MACN A 4060 & 0,16 & 0,15 \\
Adelphomys candidus & MACN A 241 & 0,44 & 0,23 \\
Eosteiromys homogenidens & MACN A 52-166 & 0,40 & 0,35 \\
Pithanotomys columnaris & MACN PV 262 & 0,37 & 0,35 \\
Prospaniomys priscus & MACN A 52-131 & 0,17 & 0,12 \\
Prostichomys bowni & MACN PV SC 3856 & 0,19 & 0,12 \\
Protacaremys avunculus & MACN A 52-126 & 0,16 & 0,10 \\
Protacaremys prior & MACN A 52-112b & 0,17 & 0,11 \\
"Protacaremys" sp. nov. & MPEF PV-6054 & 1,52 & 0,10 \\
Sciamys principalis & MLP 15-349 & 0,21 & 0,13 \\
Spaniomys riparius & MACN A 4285 & 0,20 & 0,15 \\
& MACN A 4292 & 0,19 & 0,15 \\
Steiromys detentus & MACN A 10774 & 0,42 & 0,40 \\
Stichomys regularis & MACN A 4198 & 0,47 & 0,20 \\
& MACN A 4200 & 0,46 & 0,19 \\
Coendou sp. & MACN Ma 54-3 & 0,30 & \\
Echimys sp. & MACN Ma 31.158 & 0,21 & 0,25 \\
Kannabateomys amblyox & MACN Ma 51.37 & 0,30 & 0,16 \\
Octodontomys gliroides & MACN Ma 27.94 & 0,20 & 0,22 \\
Octomys mimax & MACN Ma 13765 & 0,21 & 0,16 \\
Tympanocetomys barrerae & MACN Ma 39-946 & 0,15 & 0,14 \\
\hline
\end{tabular}


TABLA 5.5. Relación largo/ancho del rostro

\begin{tabular}{lllll}
\hline TAXÓN & EJEMPLAR & LARGO & ANCHO & L/A \\
\hline Acaremys murinus & MACN A 10092 & 1,080 & 0,794 & 1,360 \\
“Acaremys" sp. nov. & MACN A 10095 & 1,300 & 1,020 & 1,274 \\
Eosteiromys homogenidens & MACN A 52-165 & 1,854 & 1,590 & 1,166 \\
Pithanotomys columnaris & MACN PV 7331 & 1,760 & 1,374 & 1,281 \\
& MACN PV 7332 & 1,756 & 1,346 & 1,310 \\
Plataeomys brevis & MACN PV 8375 & 1,124 & 0,910 & 1,235 \\
Prospaniomys priscus & MACN PV CH1913 & 1,208 & 0,798 & 1,513 \\
Prostichomys bowni & MACN PV SC 3509 & 1,090 & 0,790 & 1,379 \\
Sciamys principalis & MACN A 4114 & 1,158 & 0,982 & 1,179 \\
Spaniomys riparius & MACN A 4184 & 1,326 & 0,716 & 1,852 \\
& MACN A 4185 & 1,152 & 0,658 & 1,750 \\
Stichomys regularis & AMNH 9.512 & 2,678 & 1,600 & 1,673 \\
& & & & \\
Coendou sp. & MACN Ma 54-3 & 1,536 & 1,150 & 1,335 \\
Echimys sp. & MACN Ma 31.158 & 1,110 & 0,800 & 1,387 \\
Kannabateomys amblyox & MACN Ma 51.37 & 1,232 & 0,890 & 1,384 \\
Octodontomys gliroides & MACN Ma 27.94 & 1,088 & 0,838 & 1,298 \\
Octomys mimax & MACN Ma 13765 & 1,100 & 0,768 & 1,432 \\
Tympanoctomys barrerae & MACN Ma 39-946 & 0,800 & 0,596 & 1,342 \\
\hline
\end{tabular}


TABLA 5.6. Largo del diastema mandibular

\begin{tabular}{llll}
\hline TAXÓN & EJEMPLAR & $\begin{array}{l}\text { Largo } \\
\text { Diastema }\end{array}$ & $\mathrm{d} \mathrm{p} 4 / \mathrm{dp} 4-\mathrm{m} 1$ \\
\hline Acaremys murinus & MMP 114M & 0,582 & 0,364 \\
Acarechimys minutus & MACN A 4062 & 0,484 & 0,380 \\
Acarechimys minutissimus & MACN A 258 & 0,292 & 0,276 \\
Acarechimys pulchellus & MACN A 4060 & 0,430 & 0,446 \\
Adelphomys candidus & MACN A 241 & 0,528 & 0,701 \\
Deseadomys arambourgi & MNHN 1903-3-1 & 1,750 & 2,700 \\
Galileomys antelucanus & MLP 82-V-2-105 & 0,570 & 0,384 \\
Metaphiomys beadnelli & YPM 18222 & 1,436 & 1,700 \\
Pithanotomys columnaris & MACN PV 262 & 0,790 & 0,786 \\
Platypittamys brachyodon & AMNH 29601 & 1,220 & 0,776 \\
Prospaniomys priscus & MPEF PV-5039 & 0,600 & \\
Prostichomys bowni & MACN PV SC 3857 & 0,630 & 0,530 \\
Protacaremys avunculus & MACN A 52-126 & 0,394 & 0,338 \\
Protacaremys prior & MACN A 52-122b & 0,394 & 0,424 \\
Sciamys principalis & MACN A 4115 & 0,622 & 0,410 \\
Spaniomys riparius & MACN A 4285 & 0,844 & 0,540 \\
Stichomys regularis & MACN A 4207 & 0,754 & 0,658 \\
& & & \\
Coendou sp. & MACN Ma 54-3 & 0,636 & 0,658 \\
Echimys sp. & MACN Ma 31.158 & 0,658 & 1,240 \\
Kannabateomys amblyox & MACN Ma 51.37 & 0,628 & 0,796 \\
Octodontomys gliroides & MACN Ma 27.94 & 0,582 & 0,450 \\
Octomys gliroides & MACN Ma 13765 & 0,590 & 0,482 \\
Tympanoctomys barrerae & MACN Ma 39-946 & 0,458 & 0,322 \\
\hline & & & \\
\hline
\end{tabular}

